Semiotik der Verewigung

Markus Gut - 978-3-8467-6517-3 
Markus Gut - 978-3-8467-6517-3

Downloaded from Fink.de@4/26/2023 07:48:17AM via free access 
Markus Gut

\section{Semiotik der Verewigung}

Versuch einer Typologie anhand literarischer Texte um 1800

BRILL | WILHELM FINK 


\section{Publiziert mit Unterstützung des Schweizerischen Nationalfonds zur Förderung der wissenschaftlichen Forschung.}

\section{Die vorliegende Arbeit wurde von der Philosophischen Fakultät der Universität Zürich im Herbstsemester 2018 auf Antrag der Promotionskommission bestehend aus Prof. Dr. Daniel Müller Nielaba (hauptverantwortliche Betreuungsperson), Prof. Dr. Claudia Liebrand und Prof. Dr. Sabine Schneider als Dissertation angenommen.}

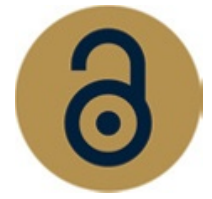

Dies ist ein Open-Access-Titel, der unter den Bedingungen der CC BY-NC-ND 4.o-Lizenz veröffentlicht wird. Diese erlaubt die nicht kommerzielle Nutzung, Verbreitung und Vervielfältigung in allen Medien, sofern keine Veränderungen vorgenommen werden und der/die ursprüngliche(n) Autor(en) und die Originalpublikation angegeben werden.

Weitere Informationen und den vollständigen Lizenztext finden Sie unter https://creativecommons.org/licenses/by-nc-nd/4.o/

Die Bedingungen der CC-Lizenz gelten nur für das Originalmaterial. Die Verwendung von Material aus anderen Quellen (gekennzeichnet durch eine Quellenangabe) wie Schaubilder, Abbildungen, Fotos und Textauszüge erfordert ggf. weitere Nutzungsgenehmigungen durch den jeweiligen Rechteinhaber.

DOI: https://doi.org/10.30965/9783846765173

Bibliografische Information der Deutschen Nationalbibliothek

Die Deutsche Nationalbibliothek verzeichnet diese Publikation in der Deutschen Nationalbibliografie; detaillierte bibliografische Daten sind im Internet über http://dnb.d-nb.de abrufbar.

(C) 2020 beim Autor. Verlegt durch Wilhelm Fink Verlag, ein Imprint der Brill-Gruppe

(Koninklijke Brill NV, Leiden, Niederlande; Brill USA Inc., Boston MA, USA; Brill Asia Pte Ltd, Singapore; Brill Deutschland GmbH, Paderborn, Deutschland)

www.fink.de

Der Wilhelm Fink Verlag behält sich das Recht vor, die Veröffentlichung vor unbefugter Nutzung zu schützen und die Verbreitung durch Sonderdrucke, anerkannte Fotokopien, Mikroformausgaben, Nachdrucke, Übersetzungen und sekundäre Informationsquellen, wie z. B. Abstraktions- und Indexierungsdienste einschließlich Datenbanken, zu genehmigen.

Anträge auf kommerzielle Verwertung, Verwendung von Teilen der Veröffentlichung und/oder Übersetzungen sind an den Wilhelm Fink Verlag zu richten.

Einbandabbildung: Orpheus und Eurydike im Durchgang des Römischen Hauses im Park an der Ilm in Weimar; ursprüngliche Wandmalerei von Heinrich Meyer, 1798; 2001-2002 rekonstruiert nach Entwürfen Meyers; Fotografie von Irmgard Thiel.

Einbandgestaltung: Evelyn Ziegler, München

Herstellung: Brill Deutschland GmbH, Paderborn

ISBN 978-3-7705-6517-7 (hardback)

ISBN 978-3-8467-6517-3 (e-book) 
meinen Eltern 
Markus Gut - 978-3-8467-6517-3

Downloaded from Fink.de@4/26/2023 07:48:17AM via free access 


\section{Inhalt}

I Einführung und erste historische Problematisierung $\ldots \ldots \ldots \ldots 1$

1. Problemherleitung und Fragestellung $\ldots \ldots \ldots \ldots \ldots \ldots \ldots . . \ldots 1$

2. Methode, Eingrenzung des Zeitbereichs, Textauswahl und

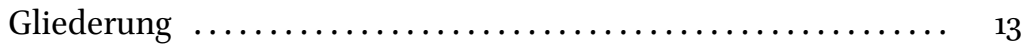

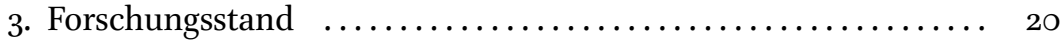

3.1 Hermeneutik-Posthermeneutik: Ewigkeitsbehauptung

gegenüber Schriftzeichen als Axiom der hermeneutischen

Tradition ............................. 21

3.2 Studien zu Eigenzeiten sowie Unendlichkeit und Ewigkeit . . 27

3.3 Aktuelle praktische Herausforderungen des langfristigen

Wissenserhalts - am Beispiel der RK\&M-Initiative

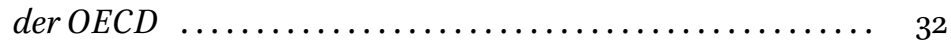

3.4 Einzelstudien $\ldots \ldots \ldots \ldots \ldots \ldots \ldots \ldots \ldots \ldots \ldots \ldots \ldots \ldots, 37$

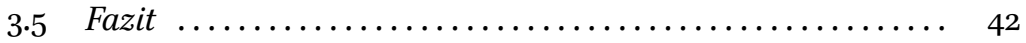

4. Historische Problematisierung der ,abendländischen`

Ewigkeitsbehauptungen gegenüber Schriftzeichen -

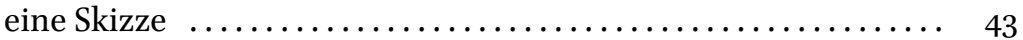

4.1 Schrift als dominantes Medium im Diskurs der Verewigung:

Buchreligionen und Schriftzentrismus ............ 45

4.2 Das Problem der selbsterfüllenden Prophezeiung ....... 53

4.3 Von der Aufklärung bis ins 21. Jahrhundert: Übertragung eines göttlichen Attributes $\ldots \ldots \ldots \ldots \ldots \ldots \ldots \ldots \ldots \ldots \ldots$

II Grundoperation Unendliche Aktualisation $\ldots \ldots \ldots \ldots \ldots \ldots \ldots 6$

1. Unteroperation Unendliche Lektüre $\ldots \ldots \ldots \ldots \ldots \ldots \ldots \ldots 62$

1.1 Lebens-Ansichten des Katers Murr ............... 62

1.1.1 Makroebene: unendlicher Anfang und unendliches Ende $\ldots \ldots \ldots \ldots \ldots \ldots \ldots \ldots . \ldots 6$

1.1.2 Mikroebene: Abgrenzungshinweise und ihre

Eigendynamik - Klammerbemerkungen, Absätze

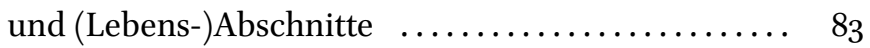

1.1.3 Zusammenführung der Ergebnisse $\ldots \ldots \ldots \ldots \ldots . \ldots 9$

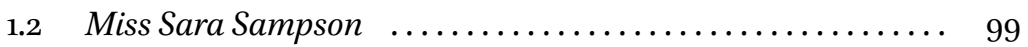

1.2.1 Tödliche Gedankenstriche des Mitleidens ....... 103

1.2.2 Anfang - Mitte - Mitte und die Verewigung im

Mitleid(en) ...................... 109 
2. Unteroperation Unendliches Verstummen $\ldots \ldots \ldots \ldots \ldots \ldots \ldots$

$2.1 \quad$ Der Spinnerin Nachtlied $\ldots \ldots \ldots \ldots \ldots \ldots \ldots \ldots \ldots \ldots \ldots$

2.1.1 Der Spinnerin Nachtlied und die poetologische

Metaphorik der mittelhochdeutschen Tagelieder .... 118

2.1.2 Nachtlied, Tagelied und Lessings Ästhetik des

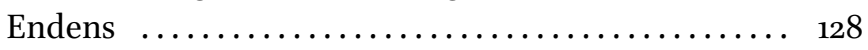

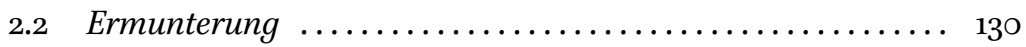

2.2.1 Zu Hans-Jost Freys Interpretation der Ode $\ldots . \ldots \ldots . \quad 131$

2.2.2 Strophen eins bis drei: verstummendes „Echo“ und antithetische Zeitstruktur $\ldots \ldots \ldots \ldots \ldots \ldots \ldots . .136$

2.2.3 Strophen vier bis sieben: Versuch einer selbsterfüllenden Prophezeiung $\ldots \ldots \ldots \ldots \ldots \ldots .141$

3. Historische Kontextualisierung der Grundoperation

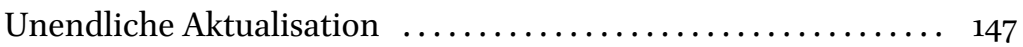

3.1 Unendliche Lektüre und unendliches Schreiben - mit einem

Exkurs zuJean Paul ......................... 148

3.2 Ästhetik des Endens: die Linie Lessing - Jean Paul -

Romantik ................................ 155

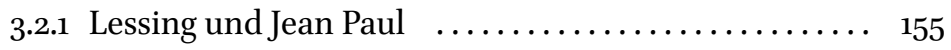

3.2.2 Lessing und die frühromantische

Fragmentästhetik ........................ 160

3.3 Der Herausgeber als Ewigkeitsgarant . ............... 165

3.4 Zusammenführung der Ergebnisse $\ldots . \ldots \ldots \ldots \ldots \ldots \ldots . . \ldots 9$

III Grundoperation Autonome Performative Produktion ........ 175

1. Unteroperation Poetische Performativität $\ldots \ldots \ldots \ldots \ldots \ldots \ldots . \quad 175$

1.1 Der Zauberlehrling ............................ 185

1.1.1 Ausgangspunkt der Argumentation $\ldots \ldots \ldots \ldots \ldots . \ldots 192$

1.1.2 Das (zu) dauerhafte Werk des Zauberlehrlings . .... 194

1.1.3 Die der Versuch zu verewigen rief, die Geister, /

Werd'n wir nun nicht los $\ldots \ldots \ldots \ldots \ldots \ldots \ldots \ldots, 198$

$1.2 \quad$ Wallenstein .................................. 205

1.2.1 Prolog (Abschnitte eins bis drei) $\quad \ldots . \ldots \ldots \ldots \ldots . \ldots 206$

1.2.2 Flüchtigkeit des Krieges und Überdauern des

Namens $\ldots \ldots \ldots \ldots \ldots \ldots \ldots \ldots \ldots \ldots \ldots \ldots . \ldots \ldots$

1.2.3 Überdauern im Textum: Wallensteins Tod und

Wallensteins Tod 


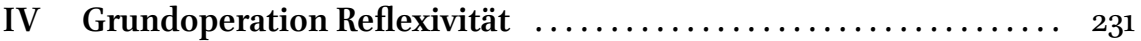

1. Unteroperation Autoreflexivität $\ldots \ldots \ldots \ldots \ldots \ldots \ldots \ldots \ldots . .233$

$1.1 \quad$ Heinrich von Ofterdingen (Höhlenszene) $\ldots \ldots \ldots \ldots \ldots \ldots 233$

1.1.1 „Zeichen“, „Ewigkeit", „Bild“ und Metabild ......... 238

1.1.2 Bilder sehen, Bilder lesen: Hermeneutik, Spiegelung und Iterabilität $\ldots \ldots \ldots \ldots \ldots \ldots \ldots \ldots \ldots \ldots \ldots \ldots \ldots \ldots$

1.1.3 „Ewigkeit“ und potenzierte Autoreflexivität $\ldots . \ldots . .252$

1.1.4 Zusammenfassung - mit einem kleinen Exkurs zu Wilhelm Meisters Lehrjahre $\ldots \ldots \ldots \ldots \ldots \ldots \ldots . \ldots 257$

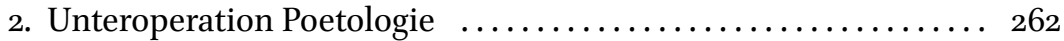

$2.1 \quad$ Der Phönix ............................... 262

2.1.1 Zum Topos des Phönix, zu Lessings

Fabel-Abhandlungen und der „Bestandheit der

$[$ Fabel-]Charaktere“ ......................... 265

2.1.2 Das Fabelwesen Phönix und das Wesen der Fabel ... 270

2.1.3 Unverortbares Verstehen und ewige „Bestandheit“ ... 273

$2.2 \quad$ Nänie .................................. 277

2.2.1 Ein Paradoxon, das selbst die Götter zum Weinen

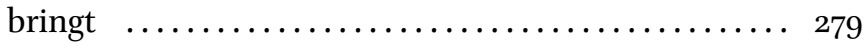

2.2.2 Göttlicher Trost? Poetologie als (Meta-)Operation zur Ewigkeitsattribuierung - mit einem Exkurs zu Ovids Orpheus und Eurydike $\ldots . \ldots \ldots \ldots \ldots \ldots . \ldots 284$

3. Historische Kontextualisierung der Grundoperation

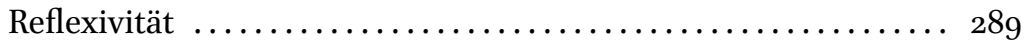

$3.1 \quad$ Reflexionsphilosophie .......................... 289

3.1.1 Die Metaphorik der philosophischen Reflexion und deren Eigendynamik $\ldots \ldots \ldots \ldots \ldots \ldots \ldots \ldots \ldots .291$

3.1.2 Philosophische (Auto-)Reflexion, Ewigkeit zweiter Ordnung und die Grundoperation Reflexivität .... 296

3.1.3 Philosophische (Auto-)Reflexion und deren Wechselwirkung mit den Operationen Autoreflexivität und Poetologie $\ldots . \ldots \ldots \ldots \ldots . \ldots 300$

3.2 Autonomieästhetik ........................... 302

3.2.1 Autonomie und Zeitlichkeit $\ldots \ldots \ldots \ldots \ldots \ldots \ldots . \ldots 304$

3.2.2 Reflexivität und Autonomieästhetik - mit einem Fabel-Exkurs 
3.3 Genieästhetik

3.3.1 Die Übertragung göttlicher Attribute auf das Genie und dessen Werk ....................... 319

3.3.2 Exemplarische Textstellen bei Herder, Goethe und E. T. A. Hoffmann $\quad \ldots \ldots \ldots \ldots \ldots \ldots \ldots \ldots \ldots, 3^{28}$

V Schlussteil

1. Zusammenführung der Ergebnisse $\ldots \ldots \ldots \ldots \ldots \ldots \ldots \ldots . \ldots \ldots \ldots$

1.1 Eine Typologie der Operationen zur Ewigkeitsattribuierung von Schriftzeichen ........................... 341

1.2 Eine Verortung der Operationen im historischen Kontext des 18. und frühen 19. Jahrhunderts 348

2. Ausblick unter weiterer Anknüpfung an bestehende Forschungsdiskurse ............................. 354

2.1 Zur Literatur- und Geistesgeschichte sowie zur Typologie $\ldots 354$

2.2 Zur Hermeneutik ............................ 362

2.3 Zur Literarizität sowie kritische Reflexion auf die vorliegende Arbeit und ihr Fachgebiet 366

\section{Semiotics of Eternalization. English General Survey} and Summary

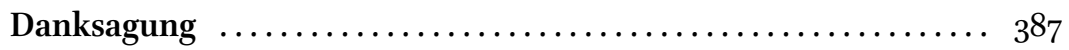

Literaturverzeichnis $\ldots \ldots \ldots \ldots \ldots \ldots \ldots \ldots \ldots \ldots \ldots \ldots \ldots \ldots \ldots \ldots$ 


\section{Einführung und erste historische Problematisierung}

\section{Problemherleitung und Fragestellung}

In der vorliegenden Monographie wird es darum gehen, sich aus literaturwissenschaftlich-semiotischer Perspektive mit der im ,abendländischen‘ Kulturraum präsenten Vorstellung auseinanderzusetzen, Schriftzeichen könnten Gedanken, Dinge oder Personen und deren Taten verewigen, also für alle Zeiten festhalten. Diese Vorstellung aber ist nicht eine, die nur etwa Grabinschriften oder dichterische Werke einschließt. Sie erstreckt sich ebenfalls auf wissenschaftliche Arbeiten. Eine Monographie, die sich wissenschaftlich mit dieser Vorstellung auseinandersetzt, hat folglich immer auch und von Anfang an kritisch zu hinterfragen, ob sie nicht bereits selbst darum bemüht ist, Verewigung anzustreben oder eigenes Überdauern $\mathrm{zu}$ behaupten. In diesem Sinne soll eine erste derartige Hinterfragung in den Gegenstand des vorliegenden Buches einführen - und zwar anhand der Widmung, wie sie in Dissertationsschriften üblich und auch diesem Kapitel vorangestellt ist.

Es ließe sich ganz grundsätzlich fragen, weshalb sich Widmungen - sei es im Falle belletristischer oder wissenschaftlicher Werke - bis in die ,bürgerliche', nicht aristokratisch-höfische Gesellschaft des 21. Jahrhunderts erhalten haben. ${ }^{1}$ Der adlige Geldgeber, dessen Erwähnung in einer Widmung einst notwendig war, wurde schon seit geraumer Zeit ersetzt, im Falle einer Dissertationsschrift im deutschen Sprachraum überwiegend durch staatliche Institutionen. Die Widmungen richten sich heute denn auch nicht mehr an die adlige Herrschaft, sondern haben sich auf die Familie - bei den Dissertationsschriften gemeinhin auf die Eltern - der jeweiligen Autorinnen und Autoren übertragen. In dieser Übertragung spiegelt sich der Aufstieg des (Bildungs-)Bürgertums, eines Bürgertums, das die moderne Universität seit dem ausgehenden 18. Jahrhundert trägt und zu dessen Konstitution die

1 Zum Form- und Funktionswandel der Buchwidmung in der Zeit von 1625 bis 1769 vgl. die entsprechende Monographie von Gabriele Schramm. Diese hält als ein wesentliches Element der Widmungspraxis vor allem des 17. Jahrhunderts fest, dass dem (zumeist adligen) Gönner durch die Widmung explizit oder implizit Nachruhm versprochen wird resp. Dichter darauf hoffen, dass potenzielle Gönner „wenigstens die ,Begiehr der Unsterbligkeit‘ in die Mäzenatenrolle treib[t]“" (Schramm 2003, S. 6o2, vgl. u. a. S. 6o1-605). 
Universität umgekehrt wesentlich beigetragen hat. Eine mögliche Antwort auf die Frage, weshalb sich Widmungen noch immer halten, wäre also in der Kombination einer langen Paratexttradition einerseits mit dem Zur-SchauStellen und Bekräftigen bürgerlichen Selbstbewusstseins andererseits zu finden. Ein Ansatz für eine weitere Antwort hingegen, eine Antwort, die zum Kern der vorliegenden Arbeit führt, findet sich bereits im alten Ägypten, so etwa in einer Weisheitslehre des 13. Jahrhunderts vor Christus, die mit ihrer vergleichenden Bezugnahme auf die Dauerhaftigkeit des Erzes an den berühmten Vers ${ }^{2}$ des Horaz erinnert: ${ }^{3}$

\author{
Jene weisen Schreiber \\ seit der Zeit, die nach den Göttern kam, \\ die verkündeten, was kommen werde, \\ deren Namen bleiben bestehen in Ewigkeit, \\ obwohl sie dahingegangen sind, \\ nachdem sie ihre Lebensspanne vollendet hatten, \\ und obwohl alle ihre Angehörigen vergessen sind. \\ Sie haben sich keine Pyramiden aus Erz, \\ keine Grabsteine aus Eisen errichtet; \\ Sie konnten auch keine Erben hinterlassen in Gestalt von Kindern, \\ die ihre Namen hätten lebendig erhalten können. \\ Vielmehr haben sie sich Erben geschaffen \\ in Gestalt von Büchern mit Lehren, die sie verfaßt haben. \\ [...] \\ Es wurden ihnen Tore an ihre (Grab-)Hallen gemacht - \\ nun sind sie zerfallen;
}

2 „Exegi monumentum aëre perennius“ / „Errichtet habe ich ein Monument, das Erz überdauert"; die Parallelen sind noch deutlicher, liest man über den ersten Vers der Ode hinaus: „das den majestätischen Bau der Pyramiden überragt, / welches nicht der nagende Regen noch der Nordwind zügellos / vermag zu zerstören oder unzählbar / der Jahre Folge und der Zeiten Flucht" (Horaz, Oden, III, 30 resp. Horaz 2015, S. 182 f.). Aber im Unterschied zu den zitierten altägyptischen Versen wird hier, freilich weitaus impliziter als in Ovids Nachwort der Metamorphosen (siehe unten Kapitel I.4.2), die selbstbewusste Ewigkeitsbehauptung auch reflektiert, hin auf die Abhängigkeit der Ode von Lesern, die der lateinischen Sprache mächtig sind: „Nicht gänzlich werde ich vergehen, ein großer Teil von mir / wird entgehen der Todesgöttin; unaufhörlich werde ich in der Nachwelt / wachsen im Ruhme jugendfrisch, solange auf das Kapitol / steigen wird mit der schweigenden Jungfrau der Priester“ (ebd.). Diese Lesergebundenheit ist geblieben (auch die Übersetzung ins Deutsche ist ein Zeugnis davon), selbst wenn Horaz' Ode das Ende der römischen Kulte und den Dienst der Vestalinnen bereits eineinhalbtausend Jahre überdauert hat.

3 Diese Parallele zu Horaz ist bereits anderen Forschern aufgefallen; vgl. dazu J. Assmann 1991, S. 173, Anm. 1; vgl. dazu ergänzend Börnchen 2006, S. 115-117; dieser verweist auch auf die Pyramidensimilitudo bzw. -metapher im Zusammenhang mit Tod, Grab und (Schrift-) Zeichen bei Hegel und Derrida. 
ihre Totenpriester sind fort, ihre Grabsteine mit Erde bedeckt, ihre Gräber vergessen.

Und doch wird ihr Name genannt, und zwar wegen der Bücher, die sie verfaßt haben, als sie noch lebten.

Gut ist die Erinnerung an ihren Verfasser

bis in alle Ewigkeit. ${ }^{4}$

Noch komprimierter findet sich dieser Ansatz bei Platon, der in seinem Symposion Diotima Folgendes in den Mund gelegt hat:

Und jeder würde sich wünschen, dass ihm eher solche Kinder geboren werden als die leiblichen, indem er voller Bewunderung auf Homer und Hesiod und die anderen vortrefflichen Dichter blickt, was für eigene Nachkommen sie hinterlassen haben, die ihnen unsterblichen Ruhm und ewiges Andenken gewähren, da sie selbst so (unvergänglich) sind. ${ }^{5}$

Nach Diotima wäre eine Dissertation für die Eltern des Autors oder der Autorin also so etwas wie der bessere Enkel, gezeugt von einem schlechteren, lediglich biologischen Kinde. ${ }^{6}$ Und dass diese biologischen Kinder - Schriftsteller, Dichterinnen, Wissenschaftler - Widmungen verfassen, läge nach ihr am Versuch, nicht nur sich, sondern auch seine Eltern mittels Schrift zu verewigen. Potenzielle Gründe für diesen Versuch gäbe es viele: von Dankbarkeit und Liebe und dem Wunsch, die Eltern an der eigenen vermeintlichen Unsterblichkeit teilnehmen zu lassen, über die Freude oder das schlechte Gewissen, ein nach Diotima ,besseres Kind geboren‘ zu haben als die Eltern, bis zu ,schlichtem‘ Pflichtgefühl gegenüber der Familie und/oder den Vorgaben der Textsorte. Damit ist das Feld aufgetan, von wo aus und wie man sich der in der abendländischen Kultur- und Geistesgeschichte seit Jahrtausenden präsenten Vorstellung, Schriftzeichen könnten Vergängliches verewigen, nähern könnte: Die möglichen Herangehensweisen reichen von der Geschichtswissenschaft über die Anthropologie bis hin zur Psychologie.

4 Papyrus Chester Beatty IV, verso 2.5-2.13, zitiert nach Brunner 1988, S. 224 f. Vgl. dazu u. a. Dorn 2009, S. 70-24; J. Assmann 2003, S. 46 f.; und ders. 1991, S. 173-178.

5 Platon, Symposion, S. 117.

$6 \mathrm{Zu}$ altgriechischen Vorstellungen zur Relation der beiden ,Kinder ${ }^{‘}$ mit der Unsterblichkeit ihrer jeweiligen ,Eltern' vgl. Svenbro 2005, S. 65-77. Bemerkenswert ist in diesem Zusammenhang auch die Nähe der lateinischen Wörter librî und lîberî (beide im Plural), wobei ersteres ,Bücher', letzteres ,Kinder‘ bedeuten kann. Da die Römer keine Längenzeichen verwendeten, ist der Unterschied schriftlich noch geringer, ,Bücher und ,Kinder fallen somit in der Schrift beinahe wortwörtlich zusammen. 
All diese unterschiedlichen Disziplinen hätten jedoch ein grundsätzliches Problem auf sprachlich-semiotischer Ebene zu berücksichtigen, das die weltweit frühsten heute bekannten, zum Teil umstrittenen Schriftzeugnisse (ca. 5300 v. Chr.) der sogenannten Donauzivilisation, ${ }^{7}$ auch alteuropäische Zivilisation genannt, ${ }^{8}$ ebenso betrifft wie antike Grabinschriften, heutige an Brücken befestigte Schlösschen mit den Namen resp. Initialen von Verliebten oder die Möglichkeit, einen Facebook-Account in den ,Gedenkzustand' und damit in einen virtuellen Grabstein zu verwandeln. ${ }^{9}$ Dieses Problem ist die Doppelung ${ }^{10}$ eines jeden sprachlichen Zeichens in eine materiale und eine intelligible Konstituente, die Ferdinand de Saussure mit signifiant (Signifikant) und signifié (Signifikat) benannt hat." ${ }^{11}$ Dieser Doppelung - die auch icons und indices und damit letztlich jedem Zeichen inhärent ist - entwächst die Bedingung, dass ein sprachliches Zeichen zu seiner Konstitution immer auf einen Rezipienten angewiesen ist, der die materiale Ebene des Zeichens mit der intelligiblen verbindet, um erst dann über jene intelligible Ebene zum Referenten, dem Gegenstand, auf den das Zeichen verweist, zu gelangen (vgl. ,semiotisches Dreieck ${ }^{c}$ ). Für Schriftzeichen im Speziellen heißt dies also, dass sie auf eine Leserin oder einen Leser ${ }^{12}$ angewiesen sind, wollen sie nicht bloße Kerbe in einem Stein, Druckerschwärze auf einem Blatt Papier, Kontrast auf einem Bildschirm usw. bleiben.

Diese grundsätzliche Lesergebundenheit eines Schriftzeichens resp. die an Rezipienten gebundene intelligible Seite von Zeichen im Allgemeinen ist denn auch bekanntlich die Basis für Zeichenmodelle, die dasjenige Saussures erweitern, indem sie den Kommunikationszusammenhang, in dem ein Zeichen im Zuge seiner Konstitution zwingend steht, miteinzubeziehen suchen. Für die vorliegende Untersuchung genügt es jedoch vorerst, das Modell Saussures jeweils im Hintergrund mitzubedenken. Komplexere Zeichenmodelle werden, wo notwendig, zu gegebener Zeit miteinbezogen, so etwa im Kapitel III

Vgl. Haarmann 2011, S. 20; und ders. 1991, S. 69-80.

Vgl. Haarmann 1991, S. 70.

Zur „Bedeutung der Virtualität für das Todesproblem“ vgl. Krüger 2004, S. 94-99.

10 Eine solche Dopplung gilt selbst dann, wenn man für eine Kultur wie die altägyptische eine Kultur der „unmittelbaren Signifikation“ annimmt, wo die Weltreferenz von Zeichen zugleich immer auch Gottesreferenz bedeutet haben soll (vgl. J. Assmann 1991, S. 88-90).

11 Eine sehr gute Auseinandersetzung mit Saussures Zeichentheorie im Zusammenhang mit der Schrift unter Einbezug von Derridas Phonozentrismuskritik am Genfer Linguisten, die an wesentlichen Stellen (auch durch inkorrekte bis verfälschte Zitate) ein falsches Bild von Saussures Thesen vermittelt, findet sich bei Stefan Börnchen (vgl. ders. 2006, S. 162-170).

12 Wenn im Folgenden vom ,Leser oder von ,Lesern` die Rede ist, sind Leserinnen selbstverständlich immer auch mitgemeint. 
zur poetischen Performativität, das einleitend eine Kombination von John L. Austins Sprechakttheorie mit Roman Jakobsons „poetischer Funktion“ vornimmt.

Wenn im Folgenden von ,Schriftzeichen' die Rede ist, so sind damit aufgrund des Fokus auf den abendländischen Kulturraum und wenn nicht explizit von anderen Schriftsystemen die Rede ist - bedeutungstragende Zeichen $^{13}$ der lateinischen Alphabetschrift gemeint; bei Verweisen auf altgriechische, hebräische oder arabische Texte ebenfalls Zeichen der betreffenden Alphabetschriften. Dies heißt jedoch nicht, dass die Erkenntnisse der vorliegenden Arbeit, insbesondere dort, wo sie semiotische Operationen beschreiben, grundsätzlich nicht auf andere Kulturräume und Schriftsysteme übertragbar wären. ${ }^{14}$

Das Problem, das die Dopplung eines jeden sprachlichen Zeichens in eine materiale und eine intelligible Konstituente für die Verewigung mittels Schriftzeichen mit sich bringt, ist bereits auf innersprachlicher Ebene - also selbst wenn man die Vergänglichkeit der Materialität von Schrift und Schriftträger außer Acht lässt - mindestens zweifacher Natur:

Erstens ist - die Kenntnis der Schrift und der verschriftlichten Sprache einmal vorausgesetzt - das Signifikat, das mentale Konzept, das das Zeichen in einem ersten Schritt ,weckt', unter verschiedenen Lesern nie exakt deckungsgleich. Je abstrakter die Semantik des Zeichens, je größer die individuellen, zeitlichen, kulturellen usw. Abweichungen ${ }^{15}$ zwischen dem Leser, seiner

13 Die kleinste Einheit ist dabei oft das einzelne Wort, es kann aber auch ein einzelnes verschriftlichtes Morphem, im Falle von Abkürzungen auch ein einzelner Buchstabe sein. Hinzutreten können, je nach Kontext, auch einzelne Satzzeichen, wie etwa der Gedankenstrich, die ebenfalls bedeutungstragend sein können; vgl. zu Letzterem etwa die Kapitel zu Miss Sara Sampson und den Lebens-Ansichten des Katers Murr. Dass die hier der Untersuchung unterworfenen Zeichen resp. Zeichengebilde bedeutungstragend sein müssen, ist vermeintlich selbsterklärend: Wo kein Inhalt transportiert wird, kann auch nichts dauerhaft festgehalten werden. Die Grenzen sind bei näherer Betrachtung jedoch nicht absolut trennscharf zu ziehen: So ließe sich selbst für einen einzelnen, isolierten Buchstaben der betreffenden Alphabetschriften sagen, er suche einen Lautwert dauerhaft festzuhalten; ein weiteres Problem stellen Schriftimitationen dar, deren Zeichen an sich nichts bedeuten, die in ihrer Verweisfunktion auf Schriftlichkeit, ihrer magischen Aufladung usw. (vgl. z. B. Hiller 2003, S. 36) jedoch durchaus bedeutungstragend sind.

14 Freilich würde eine solche Übertragung aber Ergänzungen (in beide Richtungen) und Einschränkungen mit sich bringen; vgl. dazu den betreffenden Ausblick in Kapitel 2.1 des Schlussteils.

15 Veränderungen, die den Sprachgebrauch einer ganzen Kommunikationsgemeinschaft betreffen, wie etwa Bedeutungswandel, sind dabei ebenfalls mitgemeint. Dass das Bewusstsein darum, dass jedes Wort resp. Morphem einem Bedeutungswandel unterworfen ist, erst im Verlauf des 18. Jahrhunderts entsteht, darauf hat Peter Szondi in seiner 
Lebenswelt und dem einstigen spezifischen Kommunikationszusammenhang des jeweiligen Zeichens, desto größer die Abweichung vom einstigen gedachten Signifikat des Verfassers des Zeichens und desto prekärer der Verweis auf den Referenten. ${ }^{16}$ Dies gilt bekanntlich bereits für eine wiederholte Lektüre der gleichen Schriftzeichen durch dieselbe Person, da deren jeweilige neue Lektüre, von den vorangegangen Lektüren beeinflusst, immer eine andere gewesen sein wird. ${ }^{17}$

Zweitens ist die Wiederholbarkeit der Aktualisation - im Falle der Schriftzeichen die Wiederholbarkeit der Lektüre - die Möglichkeitsbedingung eines jeden Zeichengebrauchs, wie bereits Jacques Derrida treffend festgestellt hat. ${ }^{18}$ Der Verfasser von Schriftzeichen, der zugleich deren erster Leser ist (sofern er nicht bloß im engsten Sinne abschreibt), hat keine Kontrolle mehr über deren Signifikat, sobald er die Zeichen niedergeschrieben hat - und dass eine solche Kontrolle nicht statthaben kann, ermöglicht ihm überhaupt erst den freien Gebrauch der von ihm verwendeten Zeichen usw. ${ }^{19}$

Die Ausgangslange ist also eine paradoxale: Auf der einen Seite findet sich die Vorstellung, Schriftzeichen könnten Gedanken, Dinge oder Personen und deren Taten verewigen. Auf der anderen Seite ist in semiotischer Hinsicht ein Schriftzeichen äußerst flüchtig: Es vermag im Zuge der Lektüre nie zweimal das exakt identische Signifikat zu wecken und wird, kaum gelesen, immer wieder nur noch (z. B.) schwarze Farbe auf weißem Papier gewesen sein; während auf rein biologisch-physikalischer Ebene sowohl der Leser als auch das Schrift- und Schriftträgermaterial - allesamt unabdingbar für die Konstitution von Schriftzeichen - nicht der Zeit enthoben, sondern Tod und Verfall unterworfen sind.

Mit der Feststellung dieses Paradoxons hat sich die Vorstellung, Schriftzeichen könnten Gedanken, Dinge oder Personen und deren Taten verewigen, als semiotisch falsch erwiesen. Konsequenterweise müsste man also eine Auseinandersetzung mit jener Vorstellung bereits hier wieder beenden oder auf eine rein historische Untersuchung des Auftretens derselben ausweichen. Oder aber man bleibt nicht einfach bei der Feststellung des Paradoxons stehen,

Auseinandersetzung mit Johann Martin Chladenius hingewiesen (Szondi 1975, insbesondere S. $76-78)$.

16 Vgl. dazu mit Blick auf die Hermeneutik und die Sehnsucht, in der jeweiligen Kommunikationssituation das ,treffende ' Wort zu finden - dabei auf Hans-Georg Gadamer eingehend -, Angehrn 2004, S. 126.

17 Vgl. dazu zusammenfassend ebd., S. 175-177; sowie den Einbezug des Begriffs der Iterabilität in Kapitel 1.1 des Schlussteils.

18 Vgl. Derrida 1999.

19 Vgl. ebd., u. a. S. $346-349$. 
sondern nimmt die intellektuell produktive Irritation an, die ein jedes Paradoxon bereithält. Genau Letzteres tut die vorliegende Arbeit. Und das führt nun - noch ehe ihre genaue Fragestellung zu nennen ist - zu einer ersten, für die Arbeit und das Vorbeugen von Missverständnissen zentralen begrifflichen Differenzierung: Im Folgenden wird nicht mehr von der „Vorstellung, Schriftzeichen könnten Gedanken, Dinge oder Personen und deren Taten verewigen“, die Rede sein, sondern präziser zum einen von der Ewigkeitsbehauptung gegenüber Schriftzeichen und zum anderen von der Ewigkeitsattribuierung von Schriftzeichen.

Mit Ewigkeitsbehauptung gegenüber Schriftzeichen sind jeweils all die Textstellen resp. Aussagen gemeint, die trotz der oben festgestellten Flüchtigkeit behaupten, Schriftzeichen könnten Gedanken, Dinge oder Personen und deren Taten für alle Zeiten festhalten und damit verewigen. Diese Behauptung kann implizit erfolgen oder explizit, die Grenzen sind dabei zum Teil fließend.

Implizite Ewigkeitsbehauptungen gegenüber Schriftzeichen begegnen einem auf Schritt und Tritt und reichen von den oben bereits erwähnten, in unseren Tagen an Brücken und Geländern festgemachten Schlösschen mit den Initialen von Verliebten über Goethes Rede zum Schäkespears Tag (vgl. Kapitel IV.3.3 zur Genieästhetik) bis hin zu Hans-Georg Gadamers Verwendung des „Klassischen“ (vgl. das Kapitel zum Forschungsstand). Implizite Ewigkeitsbehauptungen gegenüber Schriftzeichen müssen nicht zwingend allein auf sprachlicher Ebene erfolgen, oft werden sie auch kombiniert mit Elementen, die nicht direkt mündlichen oder schriftlichen Aussagen zuzuordnen sind, so etwa im Falle der institutionellen und architektonischen Elemente bei Archiven und Bibliotheken. Die vorliegende Arbeit hat sich jedoch auf die sprachliche Ebene zu beschränken.

Explizite Ewigkeitsbehauptungen gegenüber Schriftzeichen sind seltener, aber dennoch ebenfalls zahlreich anzutreffen, so z. B. in Schillers Prolog zu Wallensteins Lager (vgl. Kapitel III.1.2.1), im Zusammenhang mit der Forderung nach Pressefreiheit in Lessings Schrift Die Nachtigall im Ersten Beitrag von Zur Geschichte und Litteratur ${ }^{20}$ oder auch einer fiktiven Figur in den Mund

20 „Was Einmal [sic] gedruckt ist, gehört der ganzen Welt auf ewige Zeiten. Niemand hat das Recht, es zu vertilgen. Wenn er es tut, beleidiget er die Welt unendlich mehr, als sie der Verfasser des vertilgten Buches, von welcher Art es auch immer sei, kann beleidiget haben. Er stürzet sie vorsetzlich [sic] in Ungewissheit und Zweifel; er beraubt sie des einzigen Mittels, selbst zu sehen, selbst zu urteilen; er verlangt, auf eine eben so vermessene als lächerliche Art, dass sie ihm blindlings glauben, ihn blindlings für einen eben so ehrlichen als einsichtsvollen Mann halten soll“ (Lessing, Werke, Bd. 7, S. 449). 
gelegt wie in E. T. A. Hoffmanns Lebens-Ansichten des Katers Murr ${ }^{21}$ - oder etwa, wie bereits zitiert, in altägyptischen Texten, den Worten Diotimas in Platons Symposion und dem berühmten Vers aus Horaz' Ode. Das gilt auch für die ebenfalls schon im antiken Griechenland zu beobachtende umgekehrte Perspektive mit der freilich selben Behauptung: dass das Schreiben von der Sterblichkeit derer zeuge, die schreiben (im Gegensatz zu den griechischen Göttern, die als Unsterbliche das Schreiben nicht nötig haben). ${ }^{22}$ Zumindest bei ambitionierteren Autorinnen und Autoren finden sich in unmittelbarer Nähe von Textstellen mit Ewigkeitsbehauptungen oft auch Textstellen mit Ewigkeitsattribuierungen, was im Laufe des Hauptteils dieser Arbeit immer wieder zu beobachten sein wird.

Ewigkeitsattribuierung von Schriftzeichen bezeichnet die Versuche, in einer schriftlichen Äußerung innersprachliche Operationen zu verwenden, die darauf abzielen, die semiotische Flüchtigkeit von Schriftzeichen auszuschalten und dadurch das Signifikat resp. die Signifikate der jeweiligen schriftlichen Äußerung für alle Zeiten festzuhalten. Die oben festgestellte Flüchtigkeit von Schriftzeichen wird im Falle der Ewigkeitsattribuierung also nicht geleugnet resp. ignoriert wie bei der Ewigkeitsbehauptung, sondern es wird gerade in Auseinandersetzung mit dieser Flüchtigkeit versucht, ihr so weit wie möglich entgegenzuwirken, wofür in gewissen Fällen sogar die Flüchtigkeit selbst in Dienst genommen wird (vgl. Kapitel II.2 zur Unteroperation Unendliches Verstummen).

Im Falle des Begriffs Ewigkeitsattribuierung ist es notwendig, die beiden Bestandteile des Kompositums noch etwas genauer zu definieren: Das Bestimmungswort Ewigkeit wird hier - und das gilt auch für das Kompositum Ewigkeitsbehauptung - verwendet in Anlehnung an die in der Alltagssprache im Kontext von Verschriftlichung gebrauchte Bedeutung des Verbs verewigen. ${ }^{23}$ Es meint ein vom Zeitpunkt des jeweiligen Schreibaktes an end-

21 „Kann aber auch wohl einem hohen Genius jemals unbedeutendes begegnen? Alles, was er in seiner Knabenzeit unternahm oder nicht unternahm, ist von der höchsten Wichtigkeit, und verbreitet helles Licht über den tiefern Sinn, über die eigentliche Tendenz seiner unsterblichen Werke" (Hoffmann, Werke, Bd. ${ }_{5}$, S. 38). Diese Textstelle wird in Kapitel IV.3.3 noch genauer behandelt.

22 Vgl. Svenbro 2005, S. 142, inklusive Anm. 44.

23 „verb. ewig, unsterblich machen, mhd. verêwigen, sehr selten, zusammensetzung zu einfachem ewigen theil 3, 1204, dessen bedeutung ver nicht ändert" (Deutsches Wörterbuch von Jacob und Wilhelm Grimm, Bd. 25, Sp. 284 f.). Zum Verb ,ewigen‘: „perpetuare, perpetuis temporibus possidendum dare, perennem, immortalem reddere, mhd. êwigen“" (ebd., Bd. 3, Sp. 1204-1206). Um 1800 sind, im Gegensatz zu heute, noch beide Formen in Gebrauch, wie die im Deutschen Wörterbuch angeführten Zitate belegen. Das 
loses Fortdauern der verschriftlichten Inhalte resp. der Signifikate in der Zeit. Das Grundwort Attribuierung hingegen betont, dass diese ,Ewigkeit' nicht den Schriftzeichen wesenhaft inhärent ist, sondern ihnen dieses Attribut von außen zugeschrieben ${ }^{24}$ wird.

Freilich besitzt der Begriff Ewigkeit im abendländischen Kulturraum auch eine starke christlich-theologische Konnotation. Was die rein innersprachlichsemiotische Ebene der Versuche zur Ewigkeitsattribuierung von Schriftzeichen anbelangt, so sei dezidiert klargestellt, dass eine solche Konnotation hier nicht mitgemeint ist.

Dass diese Konnotation aber dann, wenn es um eine historische Kontextualisierung der Versuche zur Ewigkeitsattribuierung von Schriftzeichen geht, mitschwingt, ist durchaus erwünscht: Die Attribute des Ewigen und Unsterblichen wurden (und das gilt nicht nur für den abendländischen Kulturraum) über Jahrtausende hinweg den Göttern zugeordnet, schon lange vor der Dominanz des Christentums. Ebenso war der Schriftgebrauch in zahlreichen Kulturen lange Zeit eng mit dem priesterlich-sakralen Bereich verbunden oder diesem gar vorbehalten. So verortet man denn auch die weltweit ältesten bekannten (zum Teil umstrittenen) Schriftzeugnisse der sogenannten Donaukultur ausschließlich im Bereich des Sakralen. ${ }^{25}$ Noch weiter gehend ist mit Harald Haarmanns Universalgeschichte der Schrift festzuhalten:

[D]ie ersten Aufzeichnungen überlieferter Texte in den antiken Kultursprachen sind weder juridische Texte noch Chroniken, und in keiner der regionalen Schrifttraditionen stehen literarische Texte am Anfang. Die Motivationen, eine Schrift zu entwickeln und zu verwenden, sind nirgendwo weltlicher Art oder künstlerischer Natur. ${ }^{26}$

Jasper Svenbro vertritt angesichts des sehr frühen und breiten Auftretens der Alphabetschrift im antiken Griechenland zum Totengedenken die These, dass jene vielleicht ursprünglich eigens zu diesem Zweck aus dem Nahen Osten

Schweizerdeutsche Wörterbuch (Idiotikon), zugleich auch das detailreichste Wörterbuch für das Frühneuhochdeutsche, nennt zum Verb ,ewen' resp. ,êwigen' gar explizit die enge Verknüpfung des Verbes mit der Schrift: „dauerhaft machen (das Andenken durch Schrift)" (Schweizerdeutsches Wörterbuch, Bd., 1, Sp. 608 und 612).

24 ,Zugeschrieben' auch und gerade im wortwörtlichen Sinne.

25 Vgl. Haarmann 1991, S. 73.

26 Ebd., S. 70. 
übernommen wurde. ${ }^{27}$ Dieser archäologisch global ${ }^{28}$ beobachtete Ursprung der Schrift im Bereich des Sakralen scheint auch in zahlreichen mythologischreligiösen Überlieferungen zu den Erfindern der Schrift(en) nachzuwirken: Bei Platon z. B. ist es Theut (Thot), der die ägyptischen Hieroglyphen erfunden hat; bei Isidor von Sevilla ist es die Göttin Isis und für das Hebräische Moses; in gewissen islamisch geprägten Überlieferungen gilt Allah offenbar als ursprünglicher Erfinder der arabischen Schrift, während etwa christliche Legenden von Gott inspirierte Heilige und Missionare als Erfinder der gotischen, kyrillischen, armenischen und georgischen Alphabete betrachten. ${ }^{29}$ Trotz dieses archäologisch verbürgten und mythologisch-religiös aufgeladenen Ursprungs der Schrift ist aber - zumindest für den abendländischen Kulturraum - bis in die heutige Zeit generell folgende Tendenz zu beobachten: die Übertragung des den Göttern vorbehaltenen Attributs der Ewigkeit auf die Schrift, während parallel dazu die Schrift dort, wo sie hauptsächlich dem sakralen Kontext vorbehalten war, aus dem sie einst stammte, immer mehr von diesem unabhängig verwendet wird - eine Tendenz, die sich in der Zeit um 1800 verstärkt und dabei besonders sichtbar wird. ${ }^{30}$ (Näheres dazu folgt im letzten Kapitel der vorliegenden Einführung, das eine historische Problematisierung der Ewigkeitsbehauptungen gegenüber Schriftzeichen vornimmt.) Die Konnotation des verwendeten Begriffsteils Ewigkeits- mit dem Bereich des Sakralen im Allgemeinen und der christlich-jüdischen Theologie im Speziellen ist für die historische Ebene also gewollt und keine Unschärfe, sondern eine Stärke des gewählten Begriffes, der so auch an die geschichtliche Dimension der Versuche zu Ewigkeitsattribuierungen von Schriftzeichen erinnert. Genau diese Versuche und deren historische Kontextualisierung sind es denn auch, die im Zentrum dieser Arbeit stehen.

Dabei werden zwei Leitfragen verfolgt, wobei die erste und stärker gewichtete primär auf semiotischer, die zweite auf historischer Ebene angesiedelt ist:

27 Svenbro 2005, S. 16, 168. Er verweist dabei zudem auf eine in der Forschung selten zitierte Erzählung des Historikers Skamon von Mytilene (4. Jahrhundert v. Chr.), der den Namen für die griechische Alphabetschrift Phoinikeïa tà grámmata nicht von den Phöniziern herleitet, sondern von der frühzeitig verstorbenen Tochter Phoinike des mythischen attischen Erfinders der grámmata, König Aktaion. Hierbei dient also bereits der Name für die Schrift selbst der Verewigung (der verstorbenen Tochter); vgl. ebd., S. 16 f. und 78-82.

28 Als Beispiel hierfür gilt etwa das alte China, wo die Schrift zunächst ausschließlich dem Orakelwesen vorbehalten war (vgl. Haarmann 2003, S. 42).

29 Vgl. Kiening 2016, S. 167 f.; resp. Kiening/Stercken 2008, S. 20.

$30 \quad$ Vgl. dazu auch Nate 2018; Neumann 2018; und Theisohn 2012. Ähnliches ist zumindest im Falle der christlich (zum Teil auch der islamisch) geprägten Kultur ebenfalls für die ,sakrale lyrische‘ Stimme zu beobachten; vgl. Weigel 2006, S. 23-25. 
1. Welche innersprachlichen Operationen sind beim Versuch zu beobachten, die semiotische Flüchtigkeit von Schriftzeichen auszuschalten, um damit die Signifikate der jeweiligen schriftlichen Äußerungen für alle Zeiten festzuhalten und so mittels Schriftzeichen Gedanken, Dinge oder Personen und deren Taten zu verewigen?

Das Ziel der Beantwortung dieser Frage liegt im Erarbeiten einer Typologie dieser innersprachlichen Operationen zur Ewigkeitsattribuierung von Schriftzeichen. Der Begriff Operationen wird hier synonym mit dem in der jüngeren literaturwissenschaftlichen Forschung verwendeten Begriff Verfahren verwendet, ist diesem im Folgenden aber deshalb vorzuziehen, weil mit ihm treffender Komposita wie Grund- und Unteroperation gebildet werden können. Die Arbeit verfolgt nicht den Anspruch, eine umfassende und abschließende Typologie vorzulegen, wohl aber die (zumindest im gewählten Zeitraum um 180o) am häufigsten eingesetzten Operationen zu klassifizieren und zu behandeln. Zudem sei, um jeglichen dahingehenden Missverständnissen vorzubeugen, dezidiert festgehalten, dass hier nicht nach dem Stein der Weisen gesucht, sondern eine Typologie von Versuchen erarbeitet wird - Versuche, die semiotische Flüchtigkeit von Schriftzeichen auszuschalten. Der Begriff Versuche steht dabei nicht für eine jeweils zwingende, bewusste, ohnehin nie gänzlich zu klärende Autorintention; die betreffenden Operationen können ebenso unbewusst zum Einsatz kommen oder - wie der Hauptteil zeigen wird - sich gar verselbstständigen und die Autorintention unterlaufen. ${ }^{31}$,Versuche' soll lediglich betonen, dass die Operationen zur Ewigkeitsattribuierung von Schriftzeichen selbst nach größtem intellektuellem Aufwand aufgrund der oben dargelegten semiotischen Gesetzmäßigkeiten ihr Ziel nie gänzlich erreichen können und damit im Zuge einer Lektüre immer nur Versuche gewesen sein werden. Das verstärkte (bewusste und unbewusste) Anrennen resp. mittels jener Versuche wortwörtliche Anschreiben gegen diese Unmöglichkeit, sich mittels Schriftzeichen der Ewigkeit zu versichern, ist denn auch - so wird sich im Laufe der Arbeit zeigen - eine der zentralen Triebfedern hinter bedeutenden ästhetischen und literarischen Entwicklungen der Zeit um 1800 und vielleicht der Moderne überhaupt.

2. Wie lassen sich diese verfahrensmäßig als Praxis zu fassenden innersprachlichen Operationen zur Ewigkeitsattribuierung von Schriftzeichen in der Zeit zwischen 1755 und 1821 literatur- und geistesgeschichtlich kontextualisieren?

31 Dem allen sucht unten stehende zweite Leitfrage mit der komprimierten Formulierung „die verfahrensmäßig als ,Praxis` zu fassenden innersprachlichen Operationen“ Rechnung zu tragen. 
Hierbei geht es darum, zu beobachten, in welchem Zusammenhang die innersprachlichen ${ }^{32}$ Operationen zur Ewigkeitsattribuierung von Schriftzeichen mit zeitgenössischen geistes- und literaturgeschichtlichen Kon- und Kotexten stehen, sowie festzustellen, ob ein gewisses akzentuiertes Auftreten einzelner solcher Operationen zu erkennen ist und, wenn ja, aus welchen Gründen. Und zugleich geht es auch umgekehrt darum, zu fragen, ob die Versuche der Verewigung mittels Schriftzeichen literatur- und geistesgeschichtliche Entwicklungen und Diskurse mitbestimmt haben und, falls ja, inwiefern.

Aus dieser zweigeteilten Fragestellung ergeben sich die beiden übergeordneten Ziele der gesamten Arbeit: Erstens soll sie mittels eines literaturwissenschaftlich-semiotischen Ansatzes eine Typologie der Operationen zur Ewigkeitsattribuierung von Schriftzeichen erarbeiten, die zwar anhand deutschsprachiger, literarischer Texte um 1800 vorgenommen wird, jedoch den Anspruch erheben darf, eine Grundlage zu bilden für eine allgemeine, über einzelne Sprachen und Schriftsysteme hinausreichende Klassifizierung. ${ }^{33}$ Zweitens versteht sie sich nicht als eine abschließende, geschlossene Beantwortung der oben formulierten Leitfragen, sondern soll mit ihren Ergebnissen und dem Bestreben, Forschungszusammenhänge zu stiften, ein Feld von semiotischen, literaturwissenschaftlichen und geistesgeschichtlichen Anknüpfungspunkten eröffnen. Eine solche Offenheit ist letztlich eine wesentliche Konstituente von Forschung überhaupt, gilt für eine Arbeit wie die vorliegende aber ganz besonders. ${ }^{34}$ Das im Folgenden Erarbeitete möge denn also über die vorliegende Monographie hinaus zu einem besseren Verständnis des Verhältnisses zwischen Schrift und Verewigung, dessen Bedeutung für die Geistes- und Literaturgeschichte um 1800 und des mit ihm verknüpften Anbruchs der Moderne ebenso beitragen wie zur kritischen (Selbst-)Reflexion der philologischen Disziplinen auf eigene, ${ }^{35}$ meist unbewusste Ewigkeitsbehauptungen und -attribuierungen.

32 Inzwischen wurde mehrfach hervorgehoben, dass es sich bei den hier untersuchten Operationen um innersprachliche handelt. Auf das Adjektiv ,innersprachlich' im Zusammenhang mit diesen Operationen wird im Folgenden deshalb verzichtet, um die Begrifflichkeit nicht unnötig ,aufzublasen' und den Lesefluss nicht zu hemmen. Dasselbe gilt in geringerer Häufigkeit auch für die Kürzung oder Weglassung der Formulierung „zur Ewigkeitsattribuierung von Schriftzeichen“, vor allem dann, wenn sich Nennungen kurz nacheinander wiederholen.

33 Mindestens einige dieser Operationen wären auch in anderen Medien zu beobachten; vgl. dazu Kapitel 2.1 des Schlussteils.

34 Eine solche Offenheit ließe sich freilich der Unteroperation Unendliche Lektüre zuordnen; vgl. dazu insbesondere die abschließende kritische Reflexion auf die vorliegende Arbeit am Ende des Ausblicks.

35 Dass ausgerechnet Herders Shakespeare-Aufsatz von 1773, der die (deutschsprachige) moderne Literaturgeschichtsschreibung (mit-)begründet, bereits durchdrungen ist von 


\section{Methode, Eingrenzung des Zeitbereichs, Textauswahl und Gliederung}

Die Beantwortung der ersten der beiden Leitfragen, d. h. das Erarbeiten einer Typologie der innersprachlichen Operationen zur Ewigkeitsattribuierung von Schriftzeichen, erfolgt anhand neun exemplarischer literarischer Texte des deutschen Sprachraums aus der Zeit von 1755 bis 1821. In der Reihenfolge ihrer Behandlung sind dies: Lebens-Ansichten des Katers Murr (Schwerpunkte: Anfang und Ende, Übergänge zwischen Kreisler- und Murr-Biographie), Miss Sara Sampson (Schwerpunkt: Anfang und Ende), Der Spinnerin Nachtlied, Ermunterung, Der Zauberlehrling, Wallenstein (Schwerpunkte: Prolog und Wallensteins Name), Heinrich von Ofterdingen (,Höhlenszene'), Der Phönix und Nänie.

Die verfolgte Methode ist dabei eine dezidiert textnahe. Auch wenn die Lektüren der einzelnen Texte dekonstruktivistisch inspiriert sind, bleiben sie doch immer der auf grundlegendste Weise hermeneutisch geprägten Fragestellung der vorliegenden Arbeit verpflichtet, die auch vor einer kritischen Hinterfragung dekonstruktivistischer Ewigkeitsbehauptungen nicht haltmacht. ${ }^{36}$ Der Verfasser folgt dabei der Überzeugung, dass jene Typologie nur ausgehend von einer akribischen, wo nötig bis in den Mikrobereich der Satzzeichen reichenden analytischen Lektüre der Texte selbst erarbeitet werden kann. Dies hat einen einfachen Grund: Würde sich der Verfasser nicht einem solch dezidiert textnahen Vorgehen verpflichten, liefe er höchste Gefahr, selbst bloße Ewigkeitsbehauptungen von außen an die Texte heranzutragen.

Eine reflektierte textnahe Methode sieht sich einerseits grundsätzlich keiner Autorintention verpflichtet, andererseits hat sie dafür Sorge zu tragen, dass nicht der Anschein einer Ontologisierung der Texte erweckt wird - insbesondere bei einer Fragestellung wie der vorliegenden. Die jüngere Literaturwissenschaft hat sich eine Reihe von Begriffen zugelegt, die zumindest eine Abgrenzung von der Autorintention signalisieren, so etwa: stellt aus, verhandelt, thematisiert, gibt zu lesen und figuriert. Schnell wird dabei das Dilemma ersichtlich, dass die genannten Verben bei aller reflektierten Distanznahme noch immer ein Subjekt benötigen, will man sie in einem grammatisch korrekten Satz verwenden; bei allen ist dies ,der Text' resp. ,die Textstelle', ,der Vers' usw. Freilich kann ein Text im engeren Sinne weder verhandeln, ausstellen, etwas geben etc. noch überhaupt in irgendeiner Weise aktiv handeln. Er wird immer nur geschrieben resp. gelesen worden sein - wobei derjenige, der schreibt,

Ewigkeitsbehauptungen und -Attribuierungen gegenüber/von Schriftzeichen, ist dafür bezeichnend; vgl. dazu Kapitel IV.3.3. 
vorausgesetzt, er schreibt nicht nur im engsten Sinne ab, immer auch der erste Leser ist. Aus praktisch-heuristischen Gründen lässt sich dieser Umstand in einer literaturwissenschaftlichen Arbeit jedoch nicht jedes Mal erneut in aller Breite ausführen, weshalb jene Begrifflichkeit auch hier Verwendung finden soll. Die betreffenden Verben werden im Folgenden insbesondere dann gebraucht, wenn davon die Rede ist, dass ein Text auf eine Weise gelesen werden kann, die ihn nicht nur auf außersprachliche Referenten, sondern auch auf die eigenen innersprachlichen Bedingungen und Möglichkeiten verweisen lässt. Die Möglichkeitsbedingungen für eine solche Lesart wiederum werden zwar einerseits vom Text (mit-)vorgegeben, müssen aber andererseits vom Leser und von dessen Fragestellungen an den Text aktualisiert werden. Ein Verhältnis zwischen Text und Leser, das etwa zur paradoxalen Situation führen kann, dass im Zuge intertextueller Verfahren nicht nur die Lektüre des in seiner Niederschrift früheren Textes den späteren, auf diesen verweisenden, beeinflusst, sondern umgekehrt auch die Lektüre des späteren die des früheren. ${ }^{37}$ Ein Verhältnis, das allein schon wegen der Vergänglichkeit des Lesers jede Verewigung mittels Schriftzeichen resp. mittels Zeichen im Allgemeinen verunmöglicht; ein Verhältnis aber, das mit seinen Paradoxa noch immer Rätsel aufgibt, die als philologische und sprachphilosophische Probleme mittels unseres sprachlich bestimmten Denkens wohl nie gänzlich gelöst werden können. Es bleibt jedoch die Aufgabe, Bedingungen und Möglichkeiten dieses Verhältnisses und seiner Paradoxa - und darunter sind die Versuche der Ewigkeitsattribuierung von Schriftzeichen nicht die unbedeutendsten - weiter zu erforschen.

Dass der Fokus überwiegend auf literarischen Texten liegt, ist darin begründet, dass Literatur der ,Ort' ist, an dem am ausgiebigsten mit den Möglichkeiten und Grenzen von Sprache und Schriftzeichen experimentiert wird - zumal in einer Zeit, in der die modernen philologischen Disziplinen erst im Entstehen begriffen sind. Dies trifft bekanntlich im deutschen Sprachraum ganz besonders für die Zeit um $1800 \mathrm{zu}$ (inklusive literarisch geäußerter Bestrebungen, diese Experimentierfreudigkeit wieder einzudämmen), ${ }^{38}$ was neben den unten angeführten Gründen ein weiteres Kriterium dafür ist, dass sich die Arbeit auf diesen Zeitbereich konzentriert. Bildlich gesprochen werden hier also die einzelnen literarischen Texte als ein Experiment mit Sprache im Allgemeinen und Schriftzeichen im Speziellen betrachtet, wobei versucht wird, aus der genauen Analyse dieser Experimente neue Erkenntnisse über Möglichkeiten und Grenzen von Schriftzeichen im Allgemeinen zu gewinnen. Der Hauptteil der Arbeit ist dabei jedoch so gehalten, dass er

37 Vgl. Frey 199o, S. 8.

38 Vgl. dazu etwa das Kapitel III.1.1 zu Goethes Zauberlehrling. 
die behandelten exemplarischen Texte nicht nur als Grundlage für die zu erarbeitende Typologie verwendet, sondern immer auch einen wesentlichen Beitrag zur Gesamtinterpretation und (literatur-)historischen Bedeutung der einzelnen Texte leistet. Was die zweite der beiden Leitfragen und deren Beantwortung anbelangt, so wird einerseits ebenfalls induktiv mit einzelnen theoretischen Texten und Stellen weiterer literarischer Texte aus dem untersuchten Zeitbereich gearbeitet und andererseits einschlägige Forschungsliteratur der letzten Jahrzehnte hinzugezogen, die wesentlich zu einer breit abgestützten historischen Kontextualisierung von mit dem vorliegenden Gegenstand verwandten Gegenständen und Diskursen beigetragen hat. Beides wird, jeweils verknüpft mit den Befunden aus der Analyse der literarischen Beispieltexte, entsprechend weitergedacht und ergänzt.

Die vorliegende Untersuchung ist absichtlich in einem Zeitbereich angesiedelt, für den die Forschung schon seit Längerem eine diskursgeschichtliche Akzentuierung der Thematisierung von Ewigkeit, Vergänglichkeit und (industrieller) Reproduzierbarkeit, aber auch der Fragen nach Bedingungen und Möglichkeiten des menschlichen Verstehens festgestellt hat. ${ }^{39}$ Einige prominente, zum Teil bereits oben erwähnte Beispiele für diese historische Akzentuierung sind: 1) auf geistesgeschichtlicher Ebene die u. a. von Descartes ausgehende, in der Zeit um 1800 ihren Höhepunkt erreichende Reflexionsphilosophie; der Beginn der modernen literarischen Hermeneutik u. a. mit Schleiermacher; und die fortschreitende Säkularisierung, welche die Bibel, die Heilige Schrift, ihrer Heiligkeit und ewigen Gültigkeit beraubt und gleichzeitig zu einem gewissen Kompensationsreflex führt, der (u. a. anknüpfend an ältere humanistische Ewigkeitsbehauptungen gegenüber Schriftzeichen ${ }^{40}$ dazu tendiert, die Schrift an sich und insbesondere die Dichtung zu etwas Heiligem, Ewigem zu verklären; 2) in literaturgeschichtlicher Hinsicht eine nicht zu übersehende Zunahme der Auseinandersetzung mit Fragen der Zeit und Zeitlichkeit im Allgemeinen ${ }^{41}$ sowie der Problematik des Anfangs und Endes eines Werkes im Speziellen; zu Letzterem wären zu nennen: Gotthold Ephraim Lessing, der das vermeintliche Ende der Tragödie in ein Enden überführt, die Fragmentästhetik der Romantik, ineinander verschachtelte Paratexte, die den Anfang verwischen (z. B. bei Jean Paul und E. T. A. Hoffmann),

$39 \mathrm{Zu}$ den Belegen hierfür vgl. vor allem weiter unten die Auseinandersetzung mit dem Forschungsstand, das Unterkapitel zur historischen Problematisierung der Ewigkeitsbehauptung gegenüber Schriftzeichen zum Schluss dieser Einführung sowie dann natürlich die historisch-kontextualisierenden Kapitel des Hauptteils.

40 Vgl. A. Assmann 1999, S. 116-145; und hinsichtlich der englischen Literaturgeschichte auch Nate 2018, insbesondere S. 259 f., 262, 269 f.

41 Vgl. etwa Göttsche 2001. 
und Rahmenhandlungen (z. B. in Goethes Unterhaltungen deutscher Ausgewanderten), die nicht mehr geschlossen werden; 3) auf sozial- und wirtschaftsgeschichtlicher Ebene der Alphabetisierungsschub im Verlauf des 18. Jahrhunderts ${ }^{42}$ die epochalen, ebenfalls die Bibel durch Dichtung verdrängenden Veränderungen im Schulwesen ${ }^{43}$ neue industrielle Möglichkeiten der Vervielfältigung von Text (Erfindung der Papiermaschine 1799, der Schnelldruckpresse 1811) und der parallel dazu ausgetragene Streit um die Urheberrechte an gedruckten Texten (vgl. z. B. Fichtes Beweis der Unrechtmäßigkeit des Büchernachdrucks) ${ }^{44}$ - historische Veränderungen, die dann wiederum auch literarisch thematisiert werden (z. B. in Hoffmanns Lebens-Ansichten des Katers Murr).

Es ist also zum einen zu erwarten, dass eine Auseinandersetzung mit literarischen Texten aus der Zeit von 1755 bis 1821 besonders aufschlussreiche Ergebnisse zur Ewigkeitsattribuierung von Schriftzeichen liefern wird, zum anderen möchte der Verfasser jene bisherigen, auf topologisch-semantischer sowie zeitphilosophischer und theologischer Ebene für die Zeit um 1800 erfolgten Forschungen noch stärker um die problemgeschichtliche Situierung auf semiologischer, textkonstituierender Ebene ergänzen. Die historischen Kapitel der vorliegenden Arbeit sehen sich denn auch als Beitrag zu einer solchen Ergänzung.

Für die Begrenzung des gewählten Zeitraums stehen zwei der im Hauptteil ausführlich behandelten exemplarischen Texte: Lessings Miss Sara Sampson (1755) und E. T. A. Hoffmanns Lebens-Ansichten des Katers Murr (1819/1821). Wie bereits im Falle der Auseinandersetzung mit Widmungen zu Beginn dieser Einführung ein erstes Mal sichtbar wurde, scheint die zunehmende Herausbildung des Bürgertums einhergehend mit dessen politischen, kulturellen und wirtschaftlichen Konstitutions- und Emanzipationsbestrebungen eine wesentliche Ursache für die soeben genannte Akzentuierung zu sein. Lessings Miss Sara Sampson - dessen Untertitel in der Erstausgabe nicht umsonst ein „Bürgerliches Trauerspiel, in fünf Aufzügen“ lautete ${ }^{45}$ - ist einerseits mit der

42 Vgl. u. a. die Forschungen von Albrecht Koschorke, ders. 1994, S. 605-628.

43 Um 18 oo vollzieht sich zunehmend der Wechsel (in Preußen z. B. ab 1794) weg von einem von der Kirche hin zu einem vom Staat kontrollierten Unterricht, der „Kaplane [...] durch staatsbeamtete Gymnasiallehrer und die Bibel als Elementarbuch alteuropäischer Alphabetisierung durch poetische Fibeln" ersetzt (Kittler 1986, S. 500).

44 Vgl. z. B. Genz 2009, S. 27-41.

45 Kursive Hervorhebung durch MG; zur Editionsgeschichte des Untertitels vgl. Kapitel II.1.2. 
Etablierung der Subgattung des bürgerlichen Trauerspiels und andererseits mit der damit verbundenen Ästhetik des Mitleid(en)s diskursgeschichtlich wesentlich an der kulturellen und ethischen bürgerlichen Identitätsbildung im deutschen Sprachraum beteiligt. E. T. A. Hoffmanns Lebens-Ansichten des Katers Murr nebst fragmentarischer Biographie des Kapellmeisters Johannes Kreisler in zufälligen Makulaturblättern wiederum desavouiert 65 Jahre später ironisch-satirisch den Bürger als oberflächlichen (Bildungs-)Philister, dem der Roman das Bild des wahren Künstlertums Johannes Kreislers gegenüberstellt. Der Bürger erscheint so bei Hoffmann bereits als ein klischeehaft verfügbarer Typus, den es in seiner Erstarrung schon wieder zu überwinden gilt, womit der Roman Lebens-Ansichten des Katers Murr den vorangegangenen Prozess der (kulturellen) Konstitution eines Bürgertums implizit als abgeschlossen markiert.

Jeder und jede der neun ausgewählten exemplarischen Texte resp. Textstellen - im Folgenden auch Textbeispiele genannt - hatte im Auswahlprozess drei grundlegende Kriterien zu erfüllen, um für eine ausführliche Untersuchung im Hauptteil infrage zu kommen:

1) Es muss sich als grundlegendste Voraussetzung herausstellen, dass in ihm mindestens eine Operation zur Ewigkeitsattribuierung von Schriftzeichen zu beobachten ist.

2) Eine jener Operationen zur Ewigkeitsattribuierung von Schriftzeichen muss in dem Textbeispiel eine zentrale Stellung einnehmen, einen ästhetischen Kern des Textes bilden - auch gegenüber anderen, möglicherweise parallel auftretenden Operationen. Je stärker diese einen solchen ästhetischen Kern bildet, desto größer auch die Exemplarität, die der entsprechende Text für eine Untersuchung der jeweiligen Operation einzunehmen vermag. Nimmt eine der Operationen eine zentrale Stellung im untersuchten Text resp. in der untersuchten Textstelle ein, so ist zudem auch die Wahrscheinlichkeit sehr hoch, dass dort die Operation nicht nur auftritt, sondern zugleich auch autoreflexiv thematisiert wird, was wiederum sowohl das Erkenntnispotenzial als auch die Exemplarität des Textbeispiels erhöht. Das heißt aber, dass ebenso die Wahrscheinlichkeit hoch ist, dass alle untersuchten Textbeispiele auch die Unteroperation Autoreflexivität beinhalten. Um Missverständnissen vorzubeugen, seien deshalb die ersten beiden Kriterien für die Textauswahl gleich anhand dieser Unteroperation durchgespielt: Damit ein Textbeispiel Exemplarität für die Unteroperation Autoreflexivität beanspruchen kann, muss es erstens und selbstredend die Unteroperation Autoreflexivität aufweisen, was, freilich in unterschiedlichem Maße, auch für die anderen exemplarischen Textbeispiele zutrifft. Aber zusätzlich muss die Unteroperation Autoreflexivität gemäß 
Kriterium 2 im betreffenden Text auch eine zentrale Stellung einnehmen. ${ }^{46}$ Die exemplarische Textstelle, die in diesem Fall für die vorliegende Arbeit ausgewählt wurde, ist die Höhlenszene in Novalis' Heinrich von Ofterdingen.

3) Die Textbeispiele müssen auch auf ihrer semantischen/inhaltlichen Ebene und/oder im Rahmen des zeitgenössischen kulturellen und theoretischen Kontextes explizit oder implizit das Paradigma von Dauer, Vergänglichkeit, Ewigkeit und/oder Verewigung aufweisen. Dieses Kriterium dient dazu, sicherzugehen, dass im jeweiligen Textbeispiel die betreffende Operation entscheidend der Ewigkeitsattribuierung von Schriftzeichen dient und nicht etwa vorwiegend zu einem anderen Zweck eingesetzt wird, etwa zur ,bloßen Verfremdung des Mitgeteilten, zur reinen Spannungserzeugung etc. Die Übergänge sind dabei freilich graduell, nicht in jedem Fall klar abzugrenzen und wie bei letztlich jedem Zeichengebilde - auch von den Leserinnen und Lesern abhängig. Wenn im Folgenden auf besonders klare Fälle zurückgegriffen wird, so heißt dies also nicht, dass der Verfasser sich einer gewissen heuristisch bedingten Künstlichkeit dieser Grenzziehung nicht bewusst wäre. Vielmehr vermögen die so erlangten Ergebnisse die Perspektive auch umzudrehen: Dass sich gewisse Operationen zur Ewigkeitsattribuierung von Schriftzeichen im Speziellen mit einzelnen Konstituenten von Literarizität im Allgemeinen überschneiden, liegt vielleicht daran, dass die Ewigkeitsattribuierung von Schriftzeichen möglicherweise eine der grundlegendsten Konstituenten von Literarizität ausmacht. Im Extremfall wäre dann etwa Autoreflexivität als ,bloßes' Mittel zur Verfremdung eine abgeleitete (schwache) Form der grundlegenden Literarizitätskonstituente Ewigkeitsattribuierung und nicht umgekehrt - auf diese Möglichkeit ist im letzten Kapitel des Schlussteils noch einmal zurückzukommen.

Neben den drei genannten Kriterien wurde zudem darauf geachtet, dass bei der Wahl der exemplarischen Texte und Textausschnitte die prominentesten Gattungen des Zeitraums von 1755 bis 1821 ausgewogen vertreten sind: Drama (zweimal), Fabel (einmal), lyrisches Gedicht (dreimal), Ballade (einmal) und Roman (zweimal); was einer Auswahl von drei epischen, drei lyrischen und zwei dramatischen Texten sowie einer Ballade, die Episches, Dramatisches und Lyrisches vereint, entspricht. Ebenso zu berücksichtigen war, dass die Texte aus unterschiedlichen Federn stammen; so finden sich unter den neun ausgewählten Texten sieben verschiedene Autoren. Diese Texte werden vor allem in den historisch-kontextualisierenden Kapiteln ergänzt durch die

46 Dass dabei aus Letzterem die autoreflexive Thematisierung der Unteroperation Autoreflexivität als solcher erwächst, liegt dann auch an der Eigendynamik der Grundoperation Reflexivität, der sie angehört; vgl. Kapitel IV. 
Auseinandersetzung mit weiteren theoretischen und literarischen Schriften des gewählten Zeitraumes, u. a. von Herder und Friedrich Schlegel, oder durch einen Exkurs zu Jean Paul und dessen Hesperus. Es sei hier zudem noch einmal erwähnt, dass die vorliegende Monographie die in ihr untersuchten Beispieltexte nicht nur als Grundlage für die zu erarbeitende Typologie verwendet, sondern immer auch einen wesentlichen Beitrag zur Gesamtinterpretation und literaturgeschichtlichen Verortung der einzelnen Texte anstrebt. Es zeigt sich dabei, dass der Blick auf die Operationen zur Ewigkeitsattribuierung von Schriftzeichen oft auch neue Ansätze in der Auseinandersetzung mit den jeweiligen Texten sowie Diskursen eröffnet, die bestehende Forschungsarbeiten ergänzen und miteinander verknüpfen.

Der Hauptteil ist in drei Großkapitel gegliedert, die den drei wichtigsten Grundoperationen zur Ewigkeitsattribuierung von Schriftzeichen gewidmet sind. Die Kapitel A und C zur Unendlichen Aktualisation resp. zur Reflexivität beinhalten jeweils ein größeres Unterkapitel, das sich eigens der historischen Kontextualisierung der entsprechenden Operationen in der Zeit um 1800 widmet. Im Falle der in Kapitel III behandelten Grundoperation Autonome Performative Produktion wird $u$. a. aufgrund von Überschneidungen mit den beiden anderen historisch-kontextualisierenden Kapiteln und einer ausführlicheren Berücksichtigung des zeitgenössischen Kontextes direkt bei der Behandlung der einzelnen Textbeispiele auf ein eigenes historisches Kapitel verzichtet. Genauere Definitionen der Grundoperationen sowie der dazugehörigen Unteroperationen finden sich zu Beginn der betreffenden (Unter-)Kapitel. Auch wird den meisten Kapiteln, seien es die historischkontextualisierenden oder diejenigen zu den Beispieltexten, eine Aufarbeitung des jeweils spezifischen Forschungsstandes vorangestellt. ${ }^{47}$ Letzteres mag bei einer durchgehenden Lektüre des Buches vielleicht mit der Zeit etwas schematisch wirken; da das Lesen wissenschaftlicher Monographien aber in der Praxis oft nicht linear erfolgt, wurde eine solche klare Binnenstruktur letztlich als für die Mehrheit der Leserschaft orientierungsfreundlicher erachtet.

Der Schlussteil besteht aus zwei Unterkapiteln: Das erste führt die Ergebnisse des Hauptteils zusammen und schärft sie da, wo es nötig ist; das zweite greift als Ausblick die wichtigsten Anknüpfungspunkte auf, die sich aus dem Hauptteil für weitere Forschungen anbieten, und bettet dabei zugleich die Ergebnisse des Hauptteils weiter in bestehende Forschungsdiskurse ein. Der

47 Diesbezüglich ließe sich auch für die vorliegende Arbeit die (unbeabsichtigt eingesetzte) Unteroperation Reflexivität beobachten, da die Stuktur der Einzelteile der Arbeit jeweils bis zu einem gewissen Grad die Struktur der ganzen Monographie spiegelt, mit dem Ziel, dadurch autonomer verständlich zu sein ... 
Ausblick hat also eine öffnende und durch diese weitere Einbettung zugleich rahmende Funktion, die sich auf unten stehendes Kapitel zum Forschungsstand rückbezieht.

\section{Forschungsstand}

Eine Aufarbeitung des Forschungsstandes steht im Fall der vorliegenden Arbeit vor der Herausforderung, dass sich auf der einen Seite keine Forschung findet, die sich im engeren Sinne systematisch mit Operationen zur Ewigkeitsattribuierung von Schriftzeichen befasst, auf der anderen Seite aber die Forschungsliteratur, die in irgendeinem Sinne Zeit, Ewigkeit oder Unendlichkeit direkt oder indirekt berühren würde, nahezu uferlos ist. ${ }^{48}$ Dieser Herausforderung wird hier beschränkend begegnet, indem - nach einer grundlegenden Positionierung der Arbeit innerhalb der hermeneutischposthermeneutischen Tradition - anhand von Publikationen der letzten Jahrzehnte bloß ein repräsentatives Bild derjenigen Forschungsarbeiten skizziert sei, die nach bestem Wissen des Verfassers am nächsten an eine systematische Untersuchung von Ewigkeitsattribuierungen von Schriftzeichen heranreichen und/oder zu denen sich umgekehrt die vorliegende Arbeit als grundlegenden, ergänzenden Beitrag versteht. Diese Skizze konstituiert sich aus einer Auswahl, die in drei Teile gegliedert ist: Ein Teil widmet sich der semantisch-historischen Ebene sowie interdisziplinären Ansätzen einer Auseinandersetzung mit Ewigkeit und Unendlichkeit; der darauf folgende Teil befasst sich mit der semiotischen Ebene, spezifisch ausgerichtet auf die Informations- und Wissensvermittlung über lange Zeiträume hinweg; und schließlich folgt eine repräsentative Auswahl von Einzelstudien aus den Literatur- und Kulturwissenschaften sowie der Archäologie, die in ihre grundlegenden kulturgeschichtlichen und kultursemiotischen Forschungen ebenfalls literarische Texte miteinbeziehen und damit auch in der Art und Weise ihres Vorgehens mit der vorliegenden Arbeit verwandt sind.

Die Forschungsliteratur aber, die spezifisch für die einzelnen Textbeispiele und die historisch-kontextualisierenden Kapitel berücksichtigt wurde, ist, um unnötige Wiederholungen zu vermeiden, nicht hier, sondern jeweils direkt im die Einführung abschließenden Unterkapitel zur historischen Problematisierung der Ewigkeitsbehauptungen und in den Kapiteln des Hauptteils eingearbeitet. Gerade die zitierte Forschungsliteratur in den

48 Vgl. zu Letzterem auch Göttsche 2001, insbesondere S. 36. 
historisch-kontextualisierenden Kapiteln ergänzt die hier angeführten Studien entscheidend um Arbeiten zum 18. und frühen 19. Jahrhundert.

\section{Hermeneutik - Posthermeneutik: Ewigkeitsbehauptung gegenüber} Schriftzeichen als Axiom der hermeneutischen Tradition

Als Erstes sei auf die hermeneutisch-posthermeneutische Tradition im Zusammenhang mit Ewigkeitsbehauptungen und -attribuierungen von Schriftzeichen eingegangen. Allein dazu ließe sich eine eigene Arbeit verfassen, weshalb es hier lediglich darum gehen kann, einige für den betreffenden Problemhorizont zentrale Stellen zu umreißen und die vorliegende Arbeit in Bezug auf diese Tradition zu verorten.

Friedrich Schleiermacher, der nach der neueren Forschung zwar nicht mehr als der Begründer, aber doch als wirkmächtigster Vertreter einer modernen, universellen Hermeneutik gilt, ${ }^{49}$ nimmt in seiner Vorlesung Das Leben Jesu (1832) eine gewisse, freilich theologisch eingeschränkte Historisierung von Person, Leben und Wirken Jesu Christi vor. ${ }^{50}$ Zugleich geht er jedoch als gläubiger Christ von der Prämisse aus, dass bei Jesus „ein[] Einfluss seiner Wirksamkeit[,] und zwar ein[] über alle Völker und über alle Zeitalter sich erstreckende[r]“,,51 gedacht werden könne. Damit findet sich Schleiermacher im Paradoxon wieder zwischen der Historisierung Jesu zum einen und der Ewigkeitsbehauptung gegenüber dessen Leben, Taten und Wirksamkeit zum anderen. Schleiermachers Vorlesung ist dabei im Grunde einer doppelten Hermeneutik verpflichtet: einerseits dem Verständnis des damaligen Wirkens Jesu und andererseits dem Verständnis dieses überlieferten Wirkens für die eigene Gegenwart des 18. resp. 19. Jahrhunderts. Da das Verständnis beider aber auf den schriftlichen Texten beruht, die von Jesus berichten, hat sich Schleiermacher letztlich nicht nur mit der Ewigkeitsbehauptung gegenüber dem Wirken Jesu, sondern eben zugleich auch mit der Ewigkeitsbehauptung gegenüber den Evangelien auseinanderzusetzen. Nicht zufällig verweist er denn auch auf die Sprache Jesu (und damit implizit auf die Schriften, die von dessen Worten berichten), die als Sprache grundsätzlich dem außersprachlichen Kontext und der Zeit unterworfen sei:

49 Vgl. etwa den (von Gadamer verfassten) Eintrag „Hermeneutik“ in: Historisches Wörterbuch der Philosophie, Bd. 3, Sp. 1064; oder Reinhard 2013, u. a. S. 19 f. und 22. Zur Wirkmächtigkeit Schleiermachers und zur Berichtigung der neueren Forschung, dass er nicht als alleiniger Begründer der modernen Hermeneutik bezeichnet werden könne; vgl. u. a. überblickshaft Böhl 2013, S. 24O; oder bereits Szondi 1975, S. 135 ff.

$50 \quad$ Vgl. auch Frank 1977, S. 33 f.

51 Schleiermacher, Leben Jesu, S. 392. 
[S]o konnte sich Christus nicht anders als in der Sprache ausdrücken [sic] die ihm angeboren und anerzogen war, und auf der seine Gemeinschaft mit anderen Menschen beruhte; und fragen wir: trug diese die absolute Gotteserkenntnis in sich, oder das Vermögen, diese im Einzelnen adäquat zum Bewußtsein zu bringen? so sagen wir nein! denn sonst wäre Christus gar nicht nötig gewesen, sondern die Gotteserkenntnis hätte sich von selbst mittelst der Sprache weiter verbreitet; und also in dieser Beziehung der Sprache, in dem sinn-/lichen Ausdrucke seiner Gotteserkenntnis stand er unter der Potenz, seiner Volkstümlichkeit, deren Ausdruck die Sprache, und allerdings auch seines Zeitalters: und wenn er eine Wirksamkeit ausüben sollte in dieser Beziehung, so konnte er es nur mittelst der gangbaren Vorstellungen, deren er sich bedienen mußte. ${ }^{52}$

Nicht die Sprache selbst ist es also, die die Gotteserkenntnis beinhaltet habe, sondern Christus, der seine Gotteserkenntnis aber mittels Sprache den Menschen seiner Zeit vermitteln musste. Schleiermacher stößt hier somit zwar auf jenes der Ewigkeitsbehauptung gegenüber Schriftzeichen inhärente Paradoxon, kann es aber noch - trotz seiner in anderen Schriften angestrebten Entwicklung einer allgemeinen Hermeneutik, die apodiktische zeitgenössische Setzungen wie z. B. den interindividuelles Verstehen ermöglichenden ,gemeinsamen Geist' infrage stellte ${ }^{53}$ - mit dem Verweis auf den Glauben an Gott (und implizit dessen Ewigkeit) sowie das Göttliche in Jesus Christus wenn vielleicht nicht lösen, so doch zumindest im Falle der Heiligen Schrift stehen lassen.

Erste Ergebnisse des Kapitels zur Genieästhetik (vgl. IV.3.3) vorwegnehmend, ist hier daran zu erinnern, dass Johann Gottfried Herder in seinem Shakespeare-Aufsatz (1773) und damit bereits knapp 6o Jahre vor Schleiermachers Vorlesung die Historisierung des Genies vornimmt - und sich sogleich in demselben Paradoxon wiederfindet. Herder aber, der sich mit Menschen und deren Werken befasst, kann dieses nicht wie Schleiermacher über den christlichen Glauben an die ewige Wirkmächtigkeit Gottes umgehen, hält aber - man ist versucht zu sagen: gerade deswegen - implizit an einem Glauben an die ewige Wirkmächtigkeit der Texte des Genies fest. Als wichtigen Vorläufer Schleiermachers, der mit seinen Überlegungen zur Hermeneutik „die Äußerste Ausdehnung der transzendentalen Wende auf den Bereich der Signifikanten überhaupt ${ }^{\text {“54 }}$ wesentlich begründet, müsste man also nicht nur

52 Ebd., S. 393 .

53 Vgl. Frank 1977, S. 22 f., der hier auf Friedrich Asts Lehrbuch Grundlinien der Grammatik, Hermeneutik und Kritik (1808) verweist.

54 Ebd., S. 8. 
etwa Friedrich Schlegel hervorheben, ${ }^{55}$ sondern eventuell stärker als bisher auch Johann Gottfried Herder. ${ }^{56}$

Schleiermachers postum herausgegebenes ,Hauptwerk' Hermeneutik und Kritik, mit besonderer Beziehung auf das Neue Testament (1838) entwirft aber bekanntlich bereits eine universelle Hermeneutik, ${ }^{57}$ die 1.) der Möglichkeit, Äußerungen vollends zu verstehen, zumindest nach Manfred Frank gar kritischer begegnet als später Wilhelm Dilthey oder Hans-Georg Gadamer ${ }^{58}$ und die 2.) nicht - wie noch im Falle des Verstehens der Heiligen Schrift durch eine Verstehensgarantie Gottes abgesichert ist.

$\mathrm{Zu} \mathrm{1.)}$ Ob Manfred Franks Einschätzung letztlich zutrifft oder nicht, sei hier dahingestellt. Für den Gegenstand der vorliegenden Arbeit interessanter ist, dass er dabei auf Schleiermachers Überlegungen hinweist, die sich mit der Beziehung der eigenen Gedanken auf die zu verstehenden Gedanken eines anderen auseinandersetzen. ${ }^{59}$ In Schleiermachers Hermeneutik und Kritik heißt es dazu:

Die Beziehung der Gedanken eines andern auf die eigenen liegt, sofern sie hermeneutischer Art ist, ganz auf der Seite der grammatischen Interpretation. Hier ist sie notwendig, denn in der grammatischen Interpretation liegt die Beziehung zwischen den Gedanken eines andern und den meinigen als Ort der Sprache. Wenn aber eben die Aufgabe ist, die Gedanken eines andern als seine Produktion vollkommen zu verstehen, müssen wir uns von uns selber los machen. ${ }^{60}$

Objektive Deckungsgleichheit der Gedanken von Sender und Empfänger ist nach Schleiermacher also allein möglich auf der Ebene des überindividuellen Systems der Sprache, deren grundlegende grammatische Strukturen für alle gleichermaßen verbindlich sind. ${ }^{61}$ Für die vorliegende Arbeit und ihre Fragestellung - resp. als erste Bestätigung ihres Fokus und ihrer Methodik - mag Schleiermacher damit einen ersten Ansatzpunkt bereithalten, hieße dies doch, dass innersprachliche Operationen, die eine Unabhängigkeit des Kommunizierten von zeitlichen Veränderungen und außersprachlichem Kontext anstreben, besonders auf "die Seite der grammatischen Interpretation“

\footnotetext{
55 Vgl. ebd.; und Historisches Wörterbuch der Philosophie, B. 3, Sp. 1064.

56 Vgl. dazu auch Frank 1977, S. 10.

57 Vgl. etwa Böhl 2013, S. 239.

58 Auch wenn Dilthey und Gadamer selbst dies zum Teil anders sahen: vgl. Frank 1977,

S. $46-52$, insbesondere S. 46 f. und $5^{2}$.

59 Ebd., S. 52 f.

6o Schleiermacher, Hermeneutik und Kritik, S. 213.

61 Vgl. auch Böhl 2013, S. 238 f.
} 
abzielen müssten. Bezeichnenderweise hat auch Peter Szondi in seiner kleinen Schrift Bemerkungen zur Forschungslage der literarischen Hermeneutik (1970) bereits das Potenzial dieser "Seite der grammatischen Interpretation“ für die (literarische) Hermeneutik ausblickshaft betont: „Dabei finden sich in Schleiermachers Theorie der grammatischen Interpretation Einsichten, welche nicht nur Theoreme der modernen Linguistik vorwegnehmen, sondern auch der Anwendung der Linguistik auf die literarische Hermeneutik den Weg weisen.“62

$\mathrm{Zu}$ 2.) Schon bei Schleiermacher zeigt sich also die Übertragung der transzendentalen Wende auf die Hermeneutik ${ }^{63}$ resp. auch innerhalb derselben die Wende weg von der Dominanz der theologisch-exegetischen Hermeneutik im Sinne einer Lehre des Verstehens der Heiligen Schrift hin zu einer Disziplin des Verstehens von Texten im Allgemeinen und den Möglichkeitsbedingungen des Verstehens überhaupt. ${ }^{64}$ Diese Ausweitung deckt sich mit dem schon weiter oben vorausgreifend erwähnten Befund, dass in der Zeit um 1800 die zunehmende Abwendung von der Heiligen Schrift zu einer Heiligung der Schrift als solcher führt. Damit fällt aber auch die ewige Wirksamkeit Jesu resp. Gottes, die bei Schleiermacher die ewige Wirksamkeit der heiligen Texte selbst dann noch garantiert, wenn diese Texte historisch betrachtet und in die eigene Gegenwart übersetzt werden, weg. Trotzdem bringen es später sowohl Dilthey als auch Gadamer (wie schon Herder vor ihnen) offensichtlich nicht über sich, die Ewigkeitsbehauptung gegenüber Schriftzeichen explizit und mit aller Konsequenz als das zu behandeln, was sie ist: eine bloße Behauptung. Stattdessen bedienen sie sich gerade dort, wo es um die grundsätzlichsten Möglichkeitsbedingungen einer Hermeneutik ginge, letztlich apodiktischer Setzungen: Man findet nun „das Allgemeinmenschliche“65 in Diltheys Aufbau der geschichtlichen Welt in den Geisteswissenschaften (1910) und „das Klassische“66 in Gadamers Wahrheit und Methode (1960), die anstelle des ewigen Wirkens Gottes „über alle Völker und über alle Zeitalter"67 verstehbar bleiben sollen. Damit tragen letztlich weder Dilthey noch Gadamer

62 Szondi 1975, S. 406.

63 Vgl. Frank 1977, S. 9 f.

64 Vgl. Böhl 2013, S. 239.

65 Dilthey 1981, insbesondere S. 262-267.

66 Gadamer 199o, vor allem S. 293-295. Zum römischen Begriff der classici und der antiken Kanonbildung ausgehend von Alexandria und den dort praktizierten hermeneutischen Verfahren vgl. Böhl 2013, S. 34 f.; und J. Assmann 2005, S. 277-28o, insbesondere Anm. 36. Zur Geschichte des Klassischen als Teil einer "Strategie der Dauer“ (und der Kritik daran) als Erfindung der Humanisten vgl. A. Assmann 1999, S. 116-136.

67 Schleiermacher, Leben Jesu, S. 392. 
zu einer grundsätzlichen Auseinandersetzung mit der Ewigkeitsbehauptung gegenüber Schriftzeichen bei, sondern verstärken diese noch weiter.

Bei Gadamer findet sich jedoch auch eine Stelle, in der er "das Klassische“ in Anlehnung an Hegel als das beschreibt, "was sich bewahrt, weil es sich selber bedeutet und sich selber deutet" ${ }^{68}$ Eine solche Definition des Klassischen besitzt Ähnlichkeiten mit einer Grundoperation der Ewigkeitsattribuierung von Schriftzeichen, nämlich derjenigen der Reflexivität und insbesondere der Unteroperation der Poetologie (vgl. Kapitel IV). Hier fände sich also ein Ansatz zu einer Infragestellung der Ewigkeitsbehauptung gegenüber Schriftzeichen, ein Ansatz, der jedoch von Gadamer weder als solcher erkannt noch weiter ausgeführt wird.

Selbst die Posthermeneutik unternimmt keinen Versuch, Ewigkeitsbehauptungen gegenüber Schriftzeichen und/oder Ewigkeitsattribuierungen von Schriftzeichen systematisch zu untersuchen. Und dies, obwohl ihr Interesse an zeichentheoretischen Fragestellungen und innersprachlichen Verfahren wie etwa Performativität oder Autoreflexivität besonders groß ist Verfahren, die auch zur Ewigkeitsattribuierung von Schriftzeichen eingesetzt werden können. So trugen denn Jacques Derrida sowie die schriftzentrierte Dekonstruktion überhaupt indirekt - trotz oder gerade wegen ihres Insistierens auf einer unendlichen Verschiebung des Sinns im Zuge der Semiose - ebenfalls zu einer Stärkung der Ewigkeitsbehauptung gegenüber Schriftzeichen bei. ${ }^{69}$ Dasselbe gilt letztlich auch für den sogenannten Iconic Turn. ${ }^{70}$

Als für die vorliegende Arbeit direkt relevantes Beispiel hierzu sei kurz Derridas Aufsatz resp. Vortrag Signature, Événement, Contexte (1971) aufgegriffen, dessen Befunde die semiotische Flüchtigkeit von Sprachzeichen umreißen. Zu diesen Befunden gehören u. a.: Der Kontext zeichenhafter Äußerungen ist nicht absolut, Zeichen sind nicht an ihn gebunden und können potenziell unendlich oft in einen neuen Kontext gestellt werden; die potenziell unendliche Iterierbarkeit resp. genauer: Iterabilität ist die Bedingung sowohl für schriftliche als auch für mündlich geäußerte Zeichen und selbst bei performativen Sprechakten deren Möglichkeitsbedingung; die

68 Gadamer 1990, S. 294.

69 Mehr dazu im Kapitel zur historischen Problematisierung der Ewigkeitsbehauptungen gegenüber Schriftzeichen. Als Überblick zur Kritik an Derridas Logozentrismuskritik vgl. u. a. Weigel 2006, S. 16-22; Wiethölter 2008, S. 10 f. und 25 f.; dazu auch Svenbro 2005, S. 190; und Kiening/Stercken 2008, S. 17 .

70 Vgl. Kolesch/Krämer 2006, S. 8, wo es u. a. heißt: „Die,Wende zum Bild“ beerbt eine auf den Sehsinn zentrierte Tradition, welche im impliziten Skriptizismus der sprachkritischen Wende nicht etwa abbricht, vielmehr in veränderter Form gestärkt und fortgesetzt wird.“ 
Quelle einer sprachlichen Äußerung ist in der Äußerung selbst nie präsent. ${ }^{71}$ Bezeichnenderweise findet sich dann im Aufsatz auch folgender Gedanke zu einem weiterführenden „Projekt“:

Es ist weniger nötig, das Zitieren oder die Iteration [frz. itération, MG] der NichtIteration eines Ereignisses entgegenzusetzen, als vielmehr eine differentielle Typologie von Iterationsformen zu konstruieren, gesetzt, dieses Projekt ist durchführbar und kann Anlaß zu einem erschöpfenden Programm geben, eine Frage, die ich hier beiseite lege. ${ }^{72}$

Man könnte sagen, die vorliegende Arbeit, die eine Typologie derjenigen innersprachlichen Operationen zu erarbeiten gedenkt, die zur Ewigkeitsattribuierung von Schriftzeichen eingesetzt werden, geht in die Richtung eines solchen, an dieser Stelle von Derrida angedachten, aber nicht weiterverfolgten „Projekt[es]““. ${ }^{73}$ Dabei sieht sich die Arbeit aber nicht als Ablehnung der hermeneutischen Tradition, sondern als Beitrag zu einer kritischen ${ }^{74}$ Ergänzung derselben. Auf bereits bestehende Ansätze zu einer solchen kritischen Ergänzung u. a. von Karlheinz Stierle, Jürgen Bolten, Emil Angehrn und Daniel

71 Vgl. Derrida 1999.

72 Ebd., S. 346. Der Vollständigkeit halber sei hier erwähnt, dass Derrida in Richtung différance zielend fortfährt: „In dieser Typologie wird die Kategorie der Intention nicht verschwinden, sie wird ihren Platz haben, aber von diesem Platz aus wird sie nicht mehr den ganzen Schauplatz und das ganze System der Äußerung beherrschen können. Vor allem hat man es dann mit verschiedenen Arten von iterierbaren Zeichen (marques) und Zeichenketten zu tun, und nicht mit einer Opposition von zitathaften Äußerungen einerseits, von einzelnen und einzigartigen Äußerungen-Ereignissen andererseits.“

73 Michel Foucaults Überlegungen zur „Duplikation“/„Doppelung“ in seiner Schrift Le langage à l'infini (1963; dt. Titel: Die Sprache, unendlich resp. Das unendliche Sprechen) berühren zudem ebenfalls Derridas spätere Projektidee bezüglich einer „Typologie von Iterationsformen“ (vgl. Foucault 2003). Die ausführliche Auseinandersetzung mit diesen Überlegungen Foucaults und dann vor allem auch Maurice Blanchots, der in diesem Zusammenhang sowohl bei Derrida als auch Foucault im Hintergrund mitzudenken wäre, würde mit dem Bezug auf den ,realen` Tod das semiologische „Projekt“ Derridas resp. die vorliegende Arbeit mit ihrem semiologischen und historischen Fokus um eine anthropologische Dimension ergänzen. Dieser Herausforderung müsste man sich wohl bei einer breiten und konsequenten Weiterverfolgung der Befunde der vorliegenden Arbeit dereinst stellen (in Zustimmung oder Ablehnung); der Verfasser würde dabei aber zu höchster Vorsicht mahnen, da die Gefahr einer Ontologisierung von Zeichen bei einem solchen Unterfangen besonders hoch ist, bereits in Foucaults Aufsatz auftritt und deshalb in einem ersten Schritt schon nur bezüglich dieses Aufsatzes zu problematisieren wäre. Für den Hinweis auf Das unendliche Sprechen sei Rüdiger Campe gedankt.

74 ,Kritisch` auch und gerade im Sinne der kantischen Bedeutung von Kritik um 1800 als einer vernunftbasieren Überprüfung seiner selbst und der eigenen Verfahren. 
Müller Nielaba sowie auf den Begriff der Iterabilität wird in den Kapiteln 1.1 und 2.2 des Schlussteils zurückgekommen.

Die kurzen Ausführungen haben darauf hingewiesen, dass sowohl die Literaturwissenschaft (vgl. Herder) als auch die moderne Hermeneutik (vgl. Schleiermacher) sich bereits in ihrer Geburtsstunde mit dem Paradoxon der semiotischen Flüchtigkeit von (Schrift-)Zeichen einerseits und den zugleich mit ihnen verbundenen Ewigkeitsbehauptungen andererseits konfrontiert sahen, wobei sich eine implizite Bejahung der Letzteren durchsetzte. Noch mehr: Mit der vorliegenden Arbeit drängt sich gar die freilich etwas pointierte Hypothese auf (vgl. dazu das letzte Kapitel des Schlussteils), dass sowohl die Literaturwissenschaft als auch die Hermeneutik in ihrer modernen Form ausgehend von der zweiten Hälfte des 18. Jahrhunderts überhaupt erst aus der intellektuellen Auseinandersetzung mit jenem Paradoxon entstanden sind. Dies ist vielleicht auch der Hauptgrund dafür, dass Ewigkeitsbehauptungen gegenüber Schriftzeichen bis heute auch und gerade in diesen Disziplinen sowohl implizit als auch explizit omnipräsent sind, aber nie systematisch untersucht wurden - stellt eine Untersuchung derselben in gewissem Sinne doch auch ursprüngliche, zum Teil bis heute prägende Prämissen der eigenen Disziplinen infrage. Der Verfasser ist jedoch der Überzeugung, dass eine solche Untersuchung das Fundament der betreffenden Disziplinen letztlich nicht schwächt, sondern vielmehr zu stärken vermag.

\subsection{Studien zu Eigenzeiten sowie Unendlichkeit und Ewigkeit}

Betreffend Studien, die sich weniger auf semiotischer als vielmehr semantisch-historischer Ebene mit Zeit und Ewigkeit befassen und dennoch in die Nähe einer Untersuchung von Ewigkeitsattribuierungen von Schriftzeichen gelangen, ist hier vor allem das 2013 in Angriff genommene DFGSchwerpunktprogramm 1688 „Ästhetische Eigenzeiten, Zeit und Darstellung in der polychronen Moderne" zu erwähnen. Es umfasst in zwei Förderphasen (seit 2013 resp. 2016) insgesamt 29 Teilprojekte und „bezieht sich in seinem leitenden Forschungsinteresse auf das Verhältnis von Zeit und Darstellung“. Es untersucht

[a]n einer großen Vielfalt von Phänomenen und einem weiten Spektrum beteiligter Disziplinen [...], wie Zeitlichkeit in ihrer kulturellen und historischen Vieldeutigkeit in der Form ,ästhetischer Eigenzeiten` erfahrbar gemacht und reflektiert wird. ${ }^{75}$ 
Die Leitparadigmen sollen Zeitdarstellung und Zeit-Wissen, nicht Zeiterfahrung und Ästhetische Wahrnehmung bilden; die Ausrichtung soll in der beschriebenen Weise kulturwissenschaftlich und wissensgeschichtlich sein $[\ldots] .{ }^{76}$

Der Begriff „Ästhetische Eigenzeiten“ wird dabei wie folgt definiert:

Ästhetische Eigenzeiten werden als exponierte und wahrnehmbare Formen komplexer Zeitgestaltung, -modellierung und -reflexion verstanden, wie sie einzelnen Gegenständen bzw. Subjekt-Ding-Konstellationen eigen sind. Dies ist bei Kunstwerken unterschiedlicher medialer und materialer Provenienz in hohem Maße der Fall, trifft aber auch in vergleichbarer Weise für andere Artefakte und Objekte der materiellen Dingkultur zu, bei denen komplexe, auf vielen Ebenen zugleich stattfindende (Selbst-)Bezüglichkeiten in der Beobachtung zur Wahrnehmung idiosynkratischer Zeitlichkeiten führen. [...] Eigenzeitlich sind diese Objekte deshalb nicht aus sich selbst heraus, vielmehr sind sie eigenzeitlich, weil sie sich, ob affirmativ oder negierend, in eigensinniger Weise auf Prozesse der Synchronisierung beziehen. Die globalen Tendenzen einer Relationierung aller Zeitordnungen sind zugleich die Voraussetzung und der Motor von Eigenzeiten. ${ }^{77}$

Hierbei werden Unterschiede und Gemeinsamkeiten bezüglich der vorliegenden Arbeit ersichtlich: Das DFG-Schwerpunktprogramm „Ästhetische Eigenzeiten“ (und letztlich ebenso die umfangreiche Arbeit Dirk Göttsches) ${ }^{78}$ fokussiert auf Darstellungen von Zeit und Zeitlichkeit und auf die - mit der im 18. Jahrhundert u. a. von Herder und Kant ausgehenden Relativierung von Zeit verknüpften ${ }^{79}$ - Entstehung einer „Vielheit moderner Zeitlichkeiten“. 80 Also genau auf Aspekte, die in gewissem Sinne der vorliegenden Untersuchung gegenläufig sind. Zudem liegen die Untersuchungsgegenstände des Schwerpunktprogramms, von wenigen Ausnahmen abgesehen, allesamt in der Zeitspanne vom 19. Jahrhundert bis in die Gegenwart. Andererseits lässt sich aber der geistes- und kulturgeschichtliche Prozess einer Verzeitlichung durchaus in Verbindung bringen mit in der Zeit um 1800 akzentuiert auftretenden Bemühungen, ebendieser Verzeitlichung mittels Operationen zur Ewigkeitsattribuierung entgegenzuwirken - was aber letztlich den Prozess der Verzeitlichung nur noch weiter antreibt. Insofern mögen die parallel entstandenen Untersuchungen des DFG-Schwerpunktprogramms und der vorliegenden Arbeit sich sowohl hinsichtlich ihrer Gegenstände als auch der

$7^{6}$ http://www.aesthetische-eigenzeiten.de/konzept/\#forslage [Stand: Juni 2018].

77 Gamper und Hühn 2014, S. 23 f.

78 Göttsche 2001 .

79 Gamper und Hühn 2014, S. 27-37.

8o Ebd., S. 21. 
fokussierten Zeitspanne gegenseitig ergänzen. Im Kapitel 2.1 des Schlussteils wird deshalb auch als Ausblick noch einmal hierauf zurückgekommen. Letzteres gilt auch für Michael Theunissens Negative Theologie der Zeit, ${ }^{81}$ die mit ihrer philosophisch-theologischen Auseinandersetzung mit Zeit(en), Zeitlichkeit und Ewigkeit(en) einen für die Fragestellungen der vorliegenden Arbeit zu allgemeinen Ansatz verfolgt, über sie hinaus jedoch zahlreiche Anknüpfungspunkte bietet.

Ergänzend wäre es interessant, zu wissen, wie sich bezüglich historischer Linien des Diskurses zu Zeit und Ewigkeit dereinst das DFG-Schwerpunktprogramm zu Bruno Hillebrands Monographie Ästhetik des Augenblicks (Göttingen 1999) stellt. Der Untertitel Der Dichter als Überwinder der Zeit - von Goethe bis heute weckt allerdings (gelesen vor dem Hintergrund der Suche nach Operationen zur Ewigkeitsattribuierung von Schriftzeichen) etwas falsche Erwartungen. Generell ist man geneigt, viele der Beobachtungen Hillebrands im Grunde zu teilen, während einen die oft plakativ gehaltenen Schlussfolgerungen zuweilen jedoch kritisch stimmen. Zu Letzterem trägt auch der explizit genannte Umstand bei, dass das Buch „essayistisch konzipiert" sei und deshalb „kein Anlass [besteht, MG], akribisch alle Zitate zu belegen“ ${ }^{82}$ Für die Zeit um 1800 stellen sowohl Hillebrand als auch die historischen Kapitel der vorliegenden Arbeit ein akzentuiertes, mit dem Diskurs des Schöpferischen ${ }^{83}$ verbundenes und wirkmächtiges literarisches Ringen mit und um Ewigkeit fest. Hillebrands Thesen hingegen, „[d]ie Ewigkeit mußte komprimiert werden im Augenblick“84 und "[d]er Augenblick war die letzte Möglichkeit, den Saum des Mantels Ewigkeit zu haschen“, ${ }^{85}$ hält der Verfasser im Falle ersterer für zu ungenau, im Falle letzterer in dieser Absolutheit schlicht für falsch. Auch bei der These, dass Goethe, Schiller oder die Romantiker den Verlust der (christlichen) Ewigkeit nicht beklagt hätten, ${ }^{86}$ kann hier so nicht mitgegangen werden.

In den letzten 15 Jahren sind im deutschen Sprachraum zudem vier Sammelbände ${ }^{87}$ erschienen, die Modelle von Ewigkeit, Unendlichkeit und den damit zusammenhängenden Konzepten von Einheit und Vielheit aus

\footnotetext{
$81 \quad$ Vgl. Theunissen 1991.

82 Hillebrand 1999, S. 148.

83 Vgl. ebd., u. a. S. 12.

84 Ebd., S. 10.

85 Ebd., S. 147.

86 Vgl. ebd., S. 9.

87 Reinke 2004; Brachtendorf/Möllenbeck/Nickel 2008; Brachtendorf/Herzberg 2011. Böttigheimer/Dausner 2018. Zu nennen wären etwa des Weiteren mit historischem Ansatz: Lenz 2013; und Eire 2010.
} 
verschiedensten Disziplinen zusammentragen, um „den Problemhorizont [dieses Themas, MG] etwas erkennbar werden zu lassen und das Gespräch [zu] fördern“88 und um - ausgehend von der Feststellung, dass „, [h] öchst unterschiedliche Konzepte von Unendlichkeit [...] in der Geistesgeschichte und in den verschiedenen Disziplinen [kursieren] “89 - Fragen wie den folgenden nachzugehen:

In welchem Verhältnis stehen Unendlichkeit, Unermesslichkeit, Maßlosigkeit, Anfangs- und Endlosigkeit, Kontinuum, Grenzenlosigkeit, Vollkommenheit oder Ewigkeit zueinander? Worin besteht die Pointe der unterschiedlichen Bedeutungsnuancen von Unendlichkeiten dies- und jenseits verschiedener Wissenschaften? [...] Gibt es am Ende eine über die simple Äquivokation hinausgehende allgemeine Bedeutung der Unendlichkeit jenseits der Fächergrenzen, so dass diese als ein faszinierendes Denkbild besonderer Art fungieren kann? ${ }^{90}$

Nach semiologischen oder literaturwissenschaftlichen Beiträgen sucht man in den ersten drei dieser vier Sammelbände jedoch vergeblich. Dies ist insofern besonders bedauerlich, als die gesichteten Beiträge immer wieder an sprachliche Grenzen stoßen, die jedoch oft nicht als solche weitere Behandlung finden. Einige Beispiele hierfür seien kurz genannt. Edgar Forschbach konstatiert: „Seit 197 o beschäftigt man sich [in der Mathematik, MG] überdies mit so genannten hyperunendlichen Mengen. Das sind Mengen, die die unendlichen Mengen umfassen, sie sind nicht mehr konstruierbar, nur begrifflich erfassbar. ${ }^{411}$ Hier könnte sich die Sprach- und Literaturwissenschaft ergänzend einbringen und auf die sprachliche Figuration von Einheiten resp. Ganzheiten mittels Begriffen, denen aber nach Derrida selbst wiederum eine potenziell unendliche Verweisstruktur inhärent ist, hinweisen. Dasselbe gilt, wenn der Philosoph Colin McGinn enthusiastisch davon spricht, dass mittels des Wortes ,Ewigkeit' in der Zeit auf etwas verwiesen wird, das wir letztlich nicht erfassen können, ${ }^{92}$ oder wenn Thomas Görnitz aus Sicht der Physik anmerkt, dass es „für alle Physiker [...] heute selbstverständlich [ist], den Kosmos in seiner Frühphase als Ganzen quantenphysikalisch zu beschreiben“. ${ }^{93}$ Gerald Hartung setzt sich seitens der Philosophie und Anthropologie in seinem Aufsatz Unendlichkeit oder Maßlosigkeit? Anthropologische Überlegungen u. a. mit Nietzsche, Dilthey und Cassirer sowie dem Diskurs der „doppelten

\footnotetext{
88 Reinke 2004, S. 7 .

89 Brachtendorf 2008, S. VI f.

$90 \quad$ Ebd., S. VII.

91 Forschbach 2004, S. 53 .

92 McGinn 2004, S. 94.

93 Görnitz 2004, S. 77.
} 
Unendlichkeit" auseinander ${ }^{94}$ - jedoch ohne die in diesem Zusammenhang prominenten zeichentheoretischen Überlegungen Cassirers (etwa die begriffliche Beschränkung des Einzelnen zwecks Eingliederung desselben in ein Ganzes) miteinzubeziehen..$^{95}$ Johannes Brachtendorf und Stephan Herzberg listen in ihrer Einführung zum Sammelband Einheit und Vielheit als metaphysisches Problem Paradoxa und logische Probleme auf, die sich bei der Auseinandersetzung mit Fragen nach Einheit und Vielheit ergeben ${ }^{96}$ - aber auch hier vermisst man eine angemessene Berücksichtigung sprach- und zeichentheoretischer Ansätze. ${ }^{97}$

Wenngleich sich die vorliegende Arbeit auf die Erarbeitung einer Typologie von Operationen zur Ewigkeitsattribuierung von Schriftzeichen und deren historische Kontextualisierung beschränkt, mag sie vielleicht trotzdem mithelfen, sich seitens der Philologien noch mehr an diesem Diskurs zu beteiligen. Dabei unterstützt sie auch die Ergebnisse des jüngsten und vierten der Sammelbände: Unendlichkeit, Transdisziplinäre Annäherungen, der als erster Band einer dereinst dreiteiligen Reihe 2018 erschienen ist und auch literaturgeschichtliche Beiträge beinhaltet. Denn die Leithypothese der Reihe, dass der Begriff der Unendlichkeit "als eine europäische Kulturkonstante nachweisbar“ sei, sowie den „ideengeschichtlich höchst bemerkenswert[en]“ Befund, „dass der Rekurs auf das Unendliche eine seit Beginn der Neuzeit vorfindliche und nachweisbare Persistenz aufweist" ${ }^{98}$ bestätigt auch die vorliegende Arbeit. Während also die angekündigten zwei weiteren Bände mit Spannung erwartet werden dürfen, ist hinsichtlich der literatur- und geistesgeschichtlichen Teile der vorliegenden Monographie besonders der Beitrag von Richard Nate hervorzuheben: Nate verweist nämlich in Bezug auf die englische Literaturgeschichte vom 17. bis in das frühe 20. Jahrhundert darauf, dass „Vorstellungen von Unendlichkeit, die traditionell dem Bereich des Göttlichen vorbehalten waren, im Zuge eines allgemeinen Säkularisierungsprozesses auf irdische Phänomene übertragen und mit Ideologien individueller und kollektiver Selbsterlösung verknüpft werden“.99 In eine ähnliche Richtung gehen

94 „Pointiert gesagt: Aus der Einsicht in die unendliche Vielfalt des Seienden folgt [im Laufe des 19. und zu Beginn des 20 Jahrhundert, MG] der Gedanke, dass dieses Seiende einer unendlichen Vielzahl von Deutungen zugänglich ist“" (Hartung 2008, S. 118).

Vgl. Cassirer 2001, hierzu insbesondere S. 42 f.: „Das Einzelne als solches wird scheinbar beschränkt; aber eben damit vollzieht sich umso bestimmter und kräftiger jene Leistung, die wir als Integration zum Ganzen bezeichnet haben."

$96 \quad$ Vgl. Brachtendorf 2011, S. 3 f.

97 Vgl. auch Brachtendorf 2008, S. IX.

98 Böttigheimer/Dausner 2018, S. 5 .

99 Ebd., S. 15; vgl. zudem Nate 2018, insbesondere S. 259 f., 262, 269 f. 
Ergebnisse von Yvonne Nilges zu Thomas Mann im selben Sammelband. ${ }^{100}$ Das sprachlich-logische Paradoxon eines Nachdenkens über Unendlichkeit bringt zudem Markus Rothhaar sehr anschaulich auf den Punkt. ${ }^{101}$ Auf seinen Aufsatz wird später noch im Zusammenhang mit Kant und Hegel verwiesen, ebenso wie hinsichtlich eines möglichen historisch akzentuierten Auftretens einzelner Operationen zur Ewigkeitsattribuierung auf Michael Neumanns Beitrag zurückzukommen ist, der ausgehend von der Genieästhetik bis zur Avantgarde des 20. Jahrhunderts „einen radikalisierten Unendlichkeitsbegriff“"102 beobachtet.

\subsection{Aktuelle praktische Herausforderungen des langfristigen Wissenserhalts - am Beispiel der RK\&M-Initiative der OECD}

Aus einer ganz anderen Richtung kommend weist ein vermeintlich fremder Problemkomplex Überschneidungspunkte mit den Fragestellungen der vorliegenden Arbeit auf: Die Rede ist von praktischen institutionellen und unternehmerischen Herausforderungen, jeweils für zentral erachtete Wissensbestände für kommende Generationen zugänglich und verständlich zu halten; Herausforderungen, die im Informationszeitalter trotz neuer technischer Möglichkeiten eher größer als kleiner zu werden scheinen.

Als ein besonders erwähnenswertes Beispiel für solche Herausforderungen mag die Aufgabe unseres Jahrhunderts gelten, sichere Lagerungsorte für radioaktive Abfälle zu schaffen. Aufgrund der Zehntausenden von Jahren, die der Zerfall mancher radioaktiver Materialien in Anspruch nehmen wird, ist die Lagerung der betreffenden Abfälle nicht nur eine naturwissenschaftlichtechnische Herausforderung, sondern, ganzheitlich betrachtet, mindestens ebenso eine semiologische. Denn alle technischen Sicherheitsvorkehrungen, wie sie etwa für geologische Tiefenlager geplant sind, werden letztlich unterlaufen, wenn künftige Generationen aus Unwissenheit fahrlässig mit den betreffenden Lagern umgehen, deren Schutz zerstören, die darin gelagerten Materialien unsachgemäß handhaben usw. Deshalb haben Nationen und

\footnotetext{
100 Vgl. Nilges 2018, insbesondere S. $254 \mathrm{f}$.

101 Vgl. Rothhaar 2018, S. 162-164, insbesondere S. 167, wo er schreibt: „Es ist aber sicherlich hinreichend klar geworden, dass das Begriffspaar Unendlichkeit/Endlichkeit eine herausragende Form der reflexiven Selbstnegation einer Begriffskonstellation darstellt: Das Unendliche, das im Gegensatz zum Endlichen gedacht wird [Hervorhebung MG], erweist sich als das Gegenteil seiner selbst, als Endliches. Damit hebt es sich in einer reflexiven Wendung gegen sich selbst auf und wird zu einem Endlichen. Das Endliche wiederum, das in einem Gegensatz zum Unendlichen verstanden wird, hebt sich auf, da es als isoliertEndliches [sic] in sich selbst negativ ist."

102 Böttigheimer/Dausner 2018, S. 14.
} 
Organisationen, die sich aufgrund ihrer Nutzung von Kernenergie am stärksten mit der Frage nach der sicheren Lagerung radioaktiver Abfälle konfrontiert sehen, 2011 auf Ebene der OECD (resp. deren Nuclear Energy Agency, NEA) die Initiative zur Preservation of Records, Knowledge and Memory across Generations, kurz RK\&M, ins Leben gerufen. Diese versteht resp. verstand sich als Plattform dafür, sich auf internationaler Ebene über Strategien auszutauschen, welche die Weitergabe des Wissens um Radioaktivität, die Standorte der (geplanten) Lager und die darin aufbewahrten Abfälle an kommende Generationen so weit wie möglich sicherstellen sollen. ${ }^{103}$ Vor dem Hintergrund der vorliegenden Arbeit sind dabei drei Punkte hervorzuheben:

Erstens ist festzustellen, dass im gesamten betreffenden Diskurs der Bereich der Literatur bislang weitgehend ausgeklammert wird. Einerseits ist dies insofern erstaunlich, als gerade und insbesondere die Literatur bereits seit Jahrtausenden mit Fragen des Überdauerns des von ihr Festgehaltenen experimentiert. Damit scheint, in der Terminologie des naturwissenschaftlich geprägten Umfelds jenes Diskurses gesprochen, ausgerechnet ein enormer, bereits bestehender Daten-Pool völlig vergessen worden zu sein. Andererseits ist dies erst einmal weder den bisherigen nationalen Bestrebungen noch etwa der RK\&M-Initiative vorzuwerfen - wäre doch die Literaturwissenschaft selbst gefordert, sich dahingehend direkt einzubringen. ${ }^{104}$ Faszinierenderweise findet sich aber im betreffenden Diskurs an exponierter Stelle ausgerechnet eine Ewigkeitsbehauptung gegenüber der Literatur, und zwar in einer Aussage im Schlusskommentar der 2014 in Verdun abgehaltenen, von der Nuclear Energy Agency der OECD mitorganisierten Constructing Memory Conference:

We believe that in order to make further progress we need to go beyond the institutional, professional world and cross into the human world of daily local life. Messages of more than 5000 years old on cuneiform tablets that give us recipes for a stew or register complaints of a weary father about his lazy son are immediately clear to us. Ovid's love poems or the Shakespeare sonnets need no lengthy explanation. Try that with a chemistry treatise a few hundred years old. In contrast with the experiences of daily life that have a universal meaning over

103 Vgl. die betreffende Website: www.oecd-nea.org/rwm/rkm.

104 Erste dahingehende Versuche hat der Verfasser inzwischen erfolgreich unternommen und steht hinsichtlich konkreter Anwendungen der Ergebnisse der vorliegenden Arbeit in Kontakt mit betreffenden nationalen Behörden und Mitgliedern der RK\&M-Initiative; vgl. dazu auch die am 4. September 2019 in Zürich stattgefunden habende Konferenz „Markieren, hinweisen oder vergessen?", organisiert vom Schweizerischen Bundesamt für Energie (https://energeiaplus.com/2019/og/o5/markieren-hinweisen-oder-vergessen [Stand: 05.09.2019]). 
time and space, scientific information and professional practices are very context specific. ${ }^{105}$

Es geht hier nicht darum, diese - gemessen am philologischen, geschichtswissenschaftlichen und hermeneutischen Forschungsstand doch etwas kühne Aussage zu kritisieren, sondern erneut darauf hinzuweisen, wie tief verankert die Ewigkeitsbehauptung gegenüber Schriftzeichen und insbesondere gegenüber der Literatur in der abendländischen Kultur ist. ${ }^{106}$ Derart tief, dass selbst im Rahmen einer Konferenz, für die das Problem der Unbeständigkeit zeichenhaft vermittelter Inhalte die Ausgangslage bildete, im abschließenden, schriftlichen Kommentar die Dauerhaftigkeit genialer' literarischer Werke nicht hinterfragt, sondern erneut in aller Explizitheit behauptet wird. Dabei findet man sich in inhaltlicher und struktureller Hinsicht auf fast schon unheimliche Weise in bester Gesellschaft wieder: in derjenigen Gottfried Herders, der in seinem Aufsatz von 1773 anhand von Shakespeare die Historisierung des Genies vornimmt, um sie am Schluss, im letzten Abschnitt, dann dennoch wieder zu unterlaufen. ${ }^{107}$

Zweitens fällt auf, dass die bisherigen einzelnen Vorschläge zum langfristigen Wissenserhalt und zur Markierung der betreffenden Endlager eine geringe Systematik aufweisen und von Studien nationaler Expertengremien bis hin zu Ergebnissen von Wettbewerben in der Bevölkerung reichen. ${ }^{108}$ Diese fehlende Systematik wurde auch von der RK\&M-Initiative wiederholt explizit festgestellt. ${ }^{109}$ Inzwischen ist also weniger der Mangel an ersten Lösungsansätzen

105 Van Hove 2015, S. 105 f.

106 Vgl. dazu die historische Problematisierung der abendländischen Tradition der Ewigkeitsbehauptungen gegenüber Schriftzeichen in Kapitel 4. dieser Einführung.

107 Vgl. Kapitel IV.3.3.2.

108 Vgl. dazu auch die online zugängliche, kommentierte Reference Bibliography der RK\&MInitiative (https://www.oecd-nea.org/rwm/rkm/). Eine der in der breiten Öffentlichkeit wohl bekanntesten umfassenden Bemühungen, sich mit der langfristigen Markierung von und der Wissensweitergabe zu Lagern für radioaktive Abfälle zu befassen, war der von der US-Regierung in Auftrag gegebene sogenannte „Sandia Report": Trauth/Hora/ Guzowski 1993. Die Zeitschrift für Semiotik hat der Atomsemiotik einst einen ganzen Sonderband gewidmet, ursprünglich erschienen 1984, später neu publiziert unter: Posner 199o.

109 Vgl. etwa Claudel 2015, S. 86 f. Zudem auch Marcos Busers Literaturstudie zum Stand der Markierung von geologischen Tiefenlagern, derer "Gesamteindruck“ lautet: „Verschiedene Länder entwickelten in der Vergangenheit entsprechend ihren individuellen Bedürfnissen Strategien für den Langzeit-Wissenserhalt von Information über Tiefenlager und konkrete Markierungsstrategien an Standorten. Viel Wissen ist inzwischen zusammengetragen worden und verfügbar. Allerdings wird der Eindruck bestärkt, dass eine systematische Ausleuchtung des Themas auf internationaler Ebene erst in den Anfängen steckt. Die Einbindung von Interdisziplinarität wird die Qualität der einzelnen 
das Problem, sondern die Frage, wie man diese wissenschaftlich fundiert beurteilt, auswählt, weiterentwickelt und in ganzheitliche Strategien und Maßnahmen überführt. Die angekündigten abschließenden Dokumente der zweiten Phase der RK\&M-Initiative werden denn auch einen ersten Rahmen für eine verbesserte Systematik schaffen. Die in der vorliegenden Untersuchung erarbeitete Typologie der Operationen zur Ewigkeitsattribuierung von Schriftzeichen hätte dabei das Potenzial, bei entsprechender Adaption künftig entscheidend zu einer solchen Systematik beizutragen.

Drittens liegt im aktuellen Diskurs der Fokus weniger darauf, wie Information möglichst unabhängig von zeitlichen Veränderungen ihrer intelligiblen Seite sowie ihres Kontexts bewahrt, sondern inwiefern diese möglichst langfristig in die jeweiligen Kommunikationszusammenhänge einer Gesellschaft einbezogen werden könnte. Stellvertretend dafür sei Eleni Mitropoulou vom Centre de Recherches Sémiotiques (CeReS) der Universität Limoges zitiert, welche die französische Agence nationale pour la gestion des déchets radioactifs (ANDRA) berät:

We then introduced the premise that it was not marking (consisting in a language, image, symbol or code, etc.) that needed to be made sustainable but rather the process for communicating on it. So the initial hypothesis on the "long-term" communication process (with „long" defined in terms of the Records, Knowledge and Memory project) assumes the need for a „communication system" approach $[\ldots] .^{110}$

With reference to the above conditions, it is important to highlight that one main method of ensuring longevity in terms of integration is not to isolate the repository from people, but rather the opposite. Even if the communication system requires sustainable media it mainly requires sustainable human actions to produce its memory. ${ }^{11}$

Dieser Fokus ließe sich mit der vorliegenden Arbeit auf einer zeichentheoretischen Ebene auch wie folgt zusammenfassen: Momentan - und daran scheint nach dem besten Wissen des Verfassers auch die zweite Phase der RK\&M-Initiative nichts grundlegend geändert zu haben - konzentriert man sich auf diejenigen Strategien, die sich mit der in Kapitel II.1 untersuchten Unteroperation Unendliche Lektüre überschneiden. Man läuft dabei aber Gefahr, nicht nur die dazu komplementäre Unteroperation Unendliches Verstummen zu vernachlässigen, sondern auch die beiden anderen

Ergebnisse in diesem Sinne entscheidend beeinflussen“ (Buser 2010, S. 61). Dieser Eindruck wurde später auch von Eleni Mitropoulou bestätigt (Mitropoulou 2015, S. 94).

110 Mitropoulou 2015, S. 93.

111 Ebd., S. 95. 
Grundoperationen Autonome Performative Produktion und Reflexivität. Aus Sicht der vorliegenden Arbeit ist jenem gegenwärtigen Fokus zwar grundsätzlich zuzustimmen und sind die dabei unternommenen Bestrebungen zu unterstützen. Gerade der Versuch, nach Strategien zu suchen, wie Informationen möglichst autonom gegenüber zeitlichen Veränderungen ihrer intelligiblen Seite und ihres Kontextes bewahrt werden könnten - also ein gleichwertiger Einbezug derjenigen Operationen zur Ewigkeitsattribuierung, die nicht auf Unendlichkeit, sondern auf Autonomie abzielen (vgl. Kapitel 1.1 des Schlussteils) -, sollte dabei aber auf keinen Fall an den Rand gedrängt, sondern im Gegenteil, wo immer möglich, mit den bestehenden Ansätzen kombiniert werden. Dies gilt sowohl in Bezug auf die zu erhaltenden Informationen als auch in Bezug auf die Prozesse des Wissenserhalts selbst. Denn ohne eine solche Kombination droht jener "communication system approach“, der auf "the written form as the best guarantee for reliable transmission",112 auf eine kontinuierliche, unendliche Aktualisation der betreffenden Informationen und damit letztlich einseitig auf die semantische Ebene setzt, dereinst gänzlich und unwiederbringlich in sich zusammenzufallen. Dies wäre dann der Fall, sollte eine künftige Generation den Zugriff auf ebendiese semantische Ebene völlig verlieren, wovon mit Blick auf die Menschheitsgeschichte nahezu mit Sicherheit ausgegangen werden muss. ${ }^{113}$

Beim soeben unter "drittens" Angesprochenen handelt es sich freilich um einen momentanen Fokus, bei dem man sich durchaus offen für den Einbezug weiterer Ansätze zeigt; so lautet ein zentrales Ergebnis der ersten Phase der RK\&M-Initiative:

An important conclusion reached during the course of Phase I of the RK\&M initiative is that there is no single best means of RK\&M preservation over all time scales: a combination of mediated and non-mediated transmission

112 Ebd., S. 94.

113 Hinsichtlich der semantischen Ebene von Schriftzeichen wären das allgemein bekannte Beispiel bislang unentschlüsselte resp. unverständliche Schriften wie etwa im Falle des Etruskischen oder Meroitischen, wo die Lesbarkeit hauptsächlich daran scheitert, dass die betreffende Sprache heute weder genügend bekannt noch vollständig rekonstruierbar ist (vgl. als ersten Überblick Fuls 2009, S. 2 f.; und natürlich die neu bearbeitete Ausgabe der Einführung Ernst Doblhofers: Die Entzifferung alter Schriften und Sprachen, die nicht zufällig „Sprachen“ bereits im Titel führt, ders. 20oo, insbesondere Kapitel VII). Selbst das heutige Verständnis der altägyptischen Sprache und Schriften verdankt sich letztlich bloß einer Verkettung glücklicher Zufälle. Der Zufall musste also selbst einer Kultur zu Hilfe kommen, die (von der Architektur über institutionalisierte Rituale bis hin zur Verwendung der Schrift) eine in der Menschheitsgeschichte bislang einzigartige Gedächtniskultur war (vgl. J. Assmann 1991, insbesondere S. 17) und zudem - im Zeithorizont des nuklearen Zerfalls - lediglich eine geringe Anzahl an Jahrtausenden zurückliegt. 
methods should be preferred (dual-track strategy) within a systemic approach in which the various elements complement and reference to one another. This would provide redundancy and therefore maximise the survivability of a recognisable and comprehensible message. ${ }^{114}$

Eine systematische Kombination aller in der vorliegenden Untersuchung aufgezeigten Operationen mit bislang angedachten, vor allem auf einen mittelfristigen Zeithorizont und die Unteroperation Unendliche Lektüre abzielenden Strategien des Wissenserhalts könnte dereinst vielleicht genau einer solchen „dual-track strategy“ entsprechen.

Im Kontext dieser Überlegungen ist einschränkend darauf hinzuweisen, dass aufgrund der wiederholt angekündigten Publikation des Schlussberichts der zweiten Phase der RK\&M-Initiative zu erwarten ist, dass sich dessen Erscheinen mit den letzten Druck- und Publikationsvorbereitungen der vorliegenden Monographie überschneiden wird, die nicht mehr in den Händen des Verfassers liegen. Das hier zur Initiatve Dargelegte ist also auf seine Aktualität hin zwingend mit dem wohl bald schon einsehbaren Schlussbericht samt dazugehörigen, weiteren noch ausstehenden Dokumenten abzugleichen. ${ }^{115}$

\subsection{Einzelstudien}

Gleich anschließend an die soeben erwähnten Bestrebungen im Bereich des langfristigen Wissenserhalts wären Einzelstudien zu nennen, die sich im Schnittfeld von Archäologie, Linguistik und Literaturwissenschaft bewegen und dabei Fragen zur Ewigkeitsattribuierung von Schriftzeichen zumindest implizit streifen. Als erster Einstieg in dieses Feld wären etwa Stein und Zeit und Das kulturelle Gedächtnis von Jan Assmann, ${ }^{116}$ Aleida Assmanns Im Dickicht der Zeichen und Zeitund Tradition ${ }^{117}$ sowie JesperSvenbros Phrasikleia ${ }^{118}$ zu nennen. Zunächst zum erstgenannten Werk: Viele von Jan Assmanns Überlegungen in Stein und Zeit basieren auf spezifischer Forschung und kulturellen Annahmen zu Leben, Kultur und religiösen Vorstellungen im alten Ägypten, die hier ohne breites Einlesen in die Diskurse der ägyptologischen Forschung der letzten 30 Jahre nicht auf ihre Aktualität hin überprüft werden können. Aus

\footnotetext{
114 Claudel 2015, S. 88.

115 Man halte sich diesbezüglich an die betreffende Website: https://www.oecd-nea.org/ $\mathrm{rwm} / \mathrm{rkm} /$.

116 J. Assmann 1991; ders. 2005.

117 A. Assmann 2015; und dies. 1999.

118 Svenbro 2005 [französische Erstausgabe 1988]. - Für diesen Literaturhinweis danke ich Charles de Roche ebenso wie für seinen Hinweis auf die unten erwähnte Monographie Hans-Jost Freys.
} 
linguistisch-literaturwissenschaftlicher Perspektive aber sind für die vorliegende Arbeit und deren historische Einbettung in die ,Geschichte der Schrift ${ }^{\dagger}$ bemerkenswert:Jan Assmanns These der speziell für Ägypten geltenden Entstehung der Literatur resp. wesentlicher Konstituenten derselben aus der Epigraphik ${ }^{119}$ - mit Anknüpfungspunkten an die Forschungen Uwe Wirths zur Autor- und Herausgeberfiktion um 1800 -;120 seine semiologischen Überlegungen und die Beobachtung einer strukturellen Nähe von Mündlichkeit und epigraphischer Schriftlichkeit ${ }^{121}$ sowie des Zusammenhangs von Verewigungsversuchen mit der vertikalen Hierarchie einer „Kultur des Väterlichen“, ${ }^{122}$ der überraschende Ähnlichkeiten zu David Wellberys Studien zur Genieästhetik des 18. Jahrhunderts aufweist. ${ }^{123}$ Ähnliche Punkte sind für Das kulturelle Gedächtnis zu nennen, das die Studie auf die israelitische und altgriechische Kultur ausdehnt und daraus allgemeine Mechanismen der Wissensweitergabe und der Kanonisierung herausarbeitet - dies aber nicht in Bezug auf innersprachliche Operationen in einzelnen Texten selbst, sondern auf einer allgemeineren Ebene anhand der Unterschiede zwischen mündlicher und schriftlicher Tradierung und außersprachlichen Faktoren wie dem Verhältnis von Herrschaft und Erinnerung, Institutionalisierung, Kodifizierung von Recht, Kanonbildung oder mit Schrift kombiniertem Monumentalbau.

Aleida Assmann setzt sich aus einer Makroperspektive mit kultureller

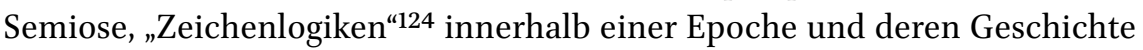
auseinander, was hier insbesondere für die Übertragung des göttlichen Attributs der Ewigkeit auf Schriftzeichen relevant ist, die vor allem im Kapitel zur Genieästhetik aufgegriffen wird. Eine vollständige Integration von Aleida Assmanns Perspektive würde jedoch den Rahmen der vorliegenden Arbeit sprengen. Abgesehen von einzelnen Verweisen - etwa zu Platons (vermeintlichem) Schriftverständnis, zur Geschichte der Hermeneutik, zur Kanonisierung sowie zum Klassischen - kann deshalb nur im Ausblick des Schlussteils darauf zurückgekommen werden.

Jesper Svenbros Studie ist für die hier verfolgten Fragestellungen vor allem dann interessant, wenn er einerseits ausführlich auf die Verknüpfung des Eigennamens mit dem altgriechischen Unsterblichkeitsdiskurs eingeht

\footnotetext{
119 Vgl. J. Assmann 1991, S. 169-199.

120 Vgl. Kapitel II.3.4; und Wirth 2008.

121 Vgl. J. Assmann 1991, S. 76-95 (insbesondere S. 87 f.) und 173.

122 Vgl. ebd., S. 96-137.

123 Vgl. Kapitel IV.3.3; und Wellbery 1996, u. a. S. 127-130.

124 Vgl. A. Assmann 2015, S. 17.
} 
(sowohl in Bezug auf die biologischen als auch die ,schriftlichen' Kinder) ${ }^{125}$ und andererseits die autoreferenzielle sowie autoreflexive, vor allem an die erste Person Singular ${ }^{126}$ geknüpfte Deixis altgriechischer Grab- und Weihinschriften behandelt. Letztere spielt mit dem Verhältnis von Schrift und (Leser-)Stimme, ${ }^{127}$ ein Verfahren, das der Ewigkeitsattribuierung von Schriftzeichen dient und das die vorliegende Arbeit unter den Grundoperationen Unendliche Aktualisation resp. Reflexivität fasst. Zu diesem zweiten hier relevanten Forschungsinteresse Svenbros gehören auch seine Beobachtungen zur altgriechischen Auseinandersetzung damit, dass die Schrift zum Tod der Stimme führe resp. das Verstummen des Schreibers und dessen Tod vorwegnehme ${ }^{128}$ - eine Auseinandersetzung, die etwa schon bei Sappho durch den Zusammenfall des nahen Todes des sprechenden Ichs mit dem Ende des verschriftlichten Gedichtes, in dem dieses Ich spricht, auch ästhetisch eingesetzt wird ${ }^{129}$ und einem Verfahren entspricht, das dann insbesondere in Kapitel II.2 im Zusammenhang mit der Unteroperation des Unendlichen Verstummens und der Fragmentästhetik wiederbegegnet.

Als ein Referenzpunkt aus der neueren Forschung zu Aleida und Jan Assmann sowie Jesper Svenbro wären die Sammelbände Stimme ${ }^{130}$ und Stimme und Schrift ${ }^{131}$ (vor allem dessen umfangreiche Einführung mit zahlreichen Verweisen) zu nennen sowie Bettine Menkes auf Texten von Brentano, Hoffmann, Kleist und Kafka basierende Monographie Prosopopoiia. ${ }^{132}$

Mit Letzterer ist denn auch der Bogen geschlagen von Arbeiten zu antiken Texten hin zu Studien, die sich für die Zeit nach 1800 mit der vorliegenden Arbeit berühren. Als Beispiele hierfür sind etwa die Dissertationen von Stefan Börnchen und Thomas Wortmann zu nennen. Stefan Börnchen entwickelt in seiner Arbeit zu Thomas Manns Doktor Faustus ${ }^{133}$ "[a]usgehend von Paul de Mans Definition der Autobiographie über die rhetorische Figur der

\footnotetext{
125 Vgl. Svenbro 2005, vor allem S. 64-102; und Kapitel III.1.2.2 zu Wallenstein und seiner Tochter Thekla.

126 Vgl. ebd., u. a. S. $136 \mathrm{f}$.

127 Vgl. ebd., vor allem S. 34-46, 81 und 141-143.

128 Vgl. ebd., S. 133-145.

129 Vgl. ebd., S. $138 \mathrm{f}$.

130 Vgl. Kolesch/Krämer 2006.

131 Vgl. Wiethölter/Pott 2008.

132 Menke 200o, insbesondere S. 217-323.

133 Börnchen 2006.
} 
Prosopopöie ${ }^{4134}$ und in expliziter Abgrenzung zu Bettine Menkes Prosopopoiia-Begriff ${ }^{135}$ seine zentrale These,

daß der Doktor Faustus wie sein Intertext Tristram Shandy prosopopoietische oder, genauer, phonopoietische Text-Bestimmungs'-Strategien als Allegorien inszeniert: Tatsächlich, das ist die Hamletlehre des Tristram Shandy, kann nur die Lektüre aus einem ,toten' Buchstabentext, einem Epitaph, einen inspiriert,lebendigen` Text, eine Elegie, machen. Diese hat als Klage jene doppelte Funktion, die Echo in Ovids Metamorphosen verkörpert: Einerseits fingiert das Echo eine ,Stimme-von-jenseits-des-Text-Grabes' und vermag so das Versprechen bio-graphischer Texte zu erfüllen, ,Leben' und ,Stimme' der Toten im Text zu bewahren. Andererseits ist ihre, Stimme', die man im Text zu vernehmen meint, nur das Echo der eigenen Stimme. Daher ist das Echo nicht nur Fiktion der ,Stimme-von-jenseits-des-Text-Grabes', sondern gleichzeitig Klage darüber, daß es sich nur um eine Fiktion handelt. ${ }^{136}$

Die vorliegende Arbeit schließt insofern an ebendiese Beobachtungen zur Prosopopoiia/Prosopopöie und zu deren allegorischen Inszenierung an, als man sagen könnte: Einzelne der untersuchten Operationen zur Ewigkeitsattribuierung zielen gewissermaßen darauf ab, jener in der Prosopopöie fingierten Stimme des Textes Dauer zu verleihen. Thomas Wortmanns Dissertation Literatur als Prozess zum Geistlichen Jahr von Annette von Droste-Hülshoff hingegen ${ }^{137}$ befasst sich wesentlich mit einem ewigen Weiterschreiben - einem Unterfangen, das etwa zeitgleich Helmut Pfotenhauer für Jean Paul beobachtet hat ${ }^{138}$ und das dann insbesondere das historisch-kontextualisierende Kapitel zur Grundoperation Unendliche Aktualisation (II.3) eingehend behandeln wird. Auch zeigt sich in Drostes Geistlichem Jahr besonders exemplarisch die Übertragung der göttlichen Attribute des Schöpferischen und der Ewigkeit auf das schöpferisch-geniale Individuum und dessen Werk. Selbst eine Autorin, die noch an die Botschaft der Heiligen Schrift glaubt, ist in der ersten Hälfte des 19. Jahrhunderts bereits derart von den vorausgegangenen geistes- und literaturgeschichtlichen Entwicklungen geprägt, dass sie an jener Übertragung und damit an der Heiligung

\footnotetext{
134 Ebd., S. 323 .

135 Vgl. ebd., S. 108-110, dazu in nuce: „Während Menke Prosopopoiia und Allegorie als Gegenmodelle begreift, beschreibe ich die Prosopopöie als Allegorie: und zwar als die für die vorliegende Doktor Faustus-Interpretation paradigmatische Allegorie, da sie gleichermaßen eine Schrift-, Stimm- und Musikallegorie ist“ (ebd., S. 108).

136 Ebd., S. 323 .

137 Wortmann 2014.

138 Pfotenhauer 2013.
} 
der Schrift als solcher mitschreibt. ${ }^{139}$ Wortmanns Arbeit ist - zusammen etwa mit dem Sammelband Redigierte Tradition ${ }^{140}$ - außerdem deshalb hier zu nennen, weil sie zum einen für Drostes Schreiben und damit für Texte, die in den Jahrzehnten unmittelbar nach dem hier im Fokus stehenden Zeitbereich entstanden sind, eine Kontinuität von zumindest gewissen, durch die geistesgeschichtlichen Entwicklungen im 18. Jahrhundert geprägten Versuchen der Ewigkeitsattribuierung von Schriftzeichen andeutet. Und zum anderen, weil sie wie schon Bettine Menke, die ebenfalls auf Kafka ${ }^{141}$ und die betreffenden einschlägigen Arbeiten Gerhard Neumanns ${ }^{142}$ verweist, oder Stefan Börnchens Arbeit zu Thomas Mann ${ }^{143}$ diese Kontinuität dahingehend anzudeuten vermag, als dass der akzentuierte Einsatz von Operationen zur Ewigkeitsattribuierung von Schriftzeichen als wesentliche Konstituente der literarischen Moderne gelten könnte. Oder vielleicht treffender formuliert: Bereits bekannte wesentliche Konstituenten der literarischen Moderne könnten vielleicht im akzentuiert auftretenden Versuch der Verewigung mittels Schriftzeichen und der Auseinandersetzung mit derselben historisch begründet werden. Dies ist freilich eine - im Schlussteil noch einmal aufugreifende - Vermutung, die über die vorliegende Arbeit hinaus weiterzuverfolgen wäre.

Hans-Jost Freys Monographie Der unendliche Text ist vielleicht dasjenige Werk der Forschungsliteratur, das der vorliegenden Arbeit in thematischer wie methodischer Hinsicht am nächsten kommt: Die von Frey detailliert untersuchte Möglichkeit, mittels Schriftzeichen intertextuelle Bezüge herzustellen, lässt sich als ein Verfahren beschreiben, das eine potenziell unbeendbare Lektüre ermöglicht und deshalb nach der hier verwendeten Terminologie zur Unteroperation Unendliche Lektüre gezählt werden kann. Frey beweist

139 Vgl. Wortmann 2014, u. a. S. 222, wo er schreibt: „Zum einen handelt es sich um eine radikale Neubestimmung des Genrekonzeptes der Perikopenlyrik: Aus der Frömmigkeitsübung, die das Abfassen der geistlichen Lieder und die Auseinandersetzung mit den Texten der Heiligen Schrift darstellen sollte, wird ein Schreibzyklus, in dem es weniger um eine Beschäftigung mit den Perikopen geht, sondern vielmehr um das Schreiben selbst, für die [sic] Kirchenjahr und die Heilige Schrift nur noch als kompositorische Fixpunkte fungieren, die das Schreiben leiten und rahmen. Die Zweckdichtung, als die die Perikopenlyrik verstanden wurde, wird zweckentfremdet; dem heteronomen Literaturkonzept wird ein radikal autonomes gegenübergestellt, nämlich ein Schreiben, das sich selbst zum Zweck und Ziel wird." Zum Stichwort ,autonom 'vgl. insbesondere das Kapitel IV.3.2 zur Autonomieästhetik.

140 Liebrand/Hnilica/Wortmann 2010.

141 Vgl. Wortmann 2014, insbesondere S. 221-226.

142 Vgl. u. a. Neumann 1982, S. 92-112; und ders. 2010, S. 339-364.

143 Vgl. bezüglich Thomas Mann auch Nilges 2018. 
anhand ausgewählter literarischer Beispiele die Einseitigkeit von Genettes Modell, worin sich lediglich der spätere Text auf den früheren beziehen kann:

Ihr [der einseitigen Beziehung des Hypertextes auf den Hypotext, MG] steht die reziproke Textbeziehung gegenüber, bei welcher nicht nur der spätere Text vom früheren her, sondern auch der frühere vom späteren her gelesen wird. In der reziproken Textbeziehung ist weder die Chronologie der Texte noch deren Bedeutung verneint, sondern das voreilige Dogma von der Unveränderlichkeit der Texte. [...] Die Texte dauern in der Veränderung. Deshalb können sie nicht auf ihren Ort in der Abfolge festgelegt werden, sondern sind immer dann gegenwärtig, wenn etwas mit ihnen geschieht, und was mit ihnen geschieht, verändert sie. ${ }^{144}$

Der Verfasser würde dem zustimmen, wenn der Begriff „dauern“ sich hier als potenzielle Bewegung verstehen lässt, die sehr flüchtig ist. Eine ausführlichere Auseinandersetzung mit Frey wird im Kapitel II.2.2 zu Hölderlins Ode Ermunterung erfolgen.

Was die von Frey festgestellte Unverortbarkeit der Texte in einer chronologischen Abfolge anbelangt, so führt dies zu Daniel Müller Nielabas Aufsatz Vom Bedeuten des Literarischen: Verstehen, verschoben, ${ }^{145}$ der nicht nur die Unverortbarkeit von Text, sondern - weitaus umfassender - auch vom Verstandenen nahelegt. ${ }^{146}$ Mit dem potenziell sich endlos verschiebenden Verstehen, das der Ausblick des Schlussteils später noch einmal aufgreift, und der damit verbundenen, potenziell ewigen Lektüre von Schriftzeichen gelangt man wieder zur Auseinandersetzung mit der hermeneutischen Tradition, womit sich der Kreis dieser Skizze zum allgemeinen Forschungsstand schließt.

\subsection{Fazit}

Es hat sich gezeigt, dass die Forschung zu Schrift und Literatur im Zusammenhang mit Ewigkeit und Verewigung bereits in der Auseinandersetzung mit der altägyptischen wie altgriechischen Schriftkultur indirekt in die Nähe von Operationen zur Ewigkeitsattribuierung von Schriftzeichen gelangt ist, während sie diese auch in Studien zu Texten für die Zeit um 1800 (siehe dazu vor allem auch die historischen Kapitel des Hauptteils) und darüber hinaus immer wieder streift. Eine systematische Untersuchung solcher Operationen - sei es anhand von schriftlichen Zeugnissen um 1800 oder aus einer anderen Zeit - fehlt hingegen nach bestem Wissen des Verfassers erstaunlicherweise bis heute. Ein möglicher Grund dafür liegt sicherlich in der

\footnotetext{
144 Frey 1990, S. 20.

145 Müller Nielaba 2005, S. 37-52.

146 Vgl. ebd., S. 40.
} 
heutigen institutionellen Trennung der Philologien in die Teilbereiche Linguistik und Literaturwissenschaft, was einerseits den Blick schärfen, andererseits aber manchmal auch arbiträre, den Gegenständen nicht immer angemessene Grenzziehungen und einseitige Perspektiven nach sich ziehen kann. ${ }^{147}$ Ein wohl noch wesentlicherer Grund hat - wie am Ende der knappen Auseinandersetzung mit der hermeneutischen Tradition angedeutet - paradoxalerweise mit der Ewigkeitsbehauptung und -attribuierung von Schriftzeichen selbst und der Entstehung der modernen Philologien im 18. und 19. Jahrhundert zu tun, worauf das letzte Kapitel der vorliegenden Arbeit noch einmal zurückkommen wird.

\section{Historische Problematisierung der, abendländischen Ewigkeitsbehauptungen gegenüber Schriftzeichen - eine Skizze}

Weiter oben wurden die Begriffe Ewigkeitsbehauptung gegenüber Schriftzeichen und Ewigkeitsattribuierung von Schriftzeichen als eine für die vorliegende Arbeit zentrale Unterscheidung eingeführt. Ebenso wurde klargestellt, dass der Fokus der Untersuchung nicht auf den Ewigkeitsbehauptungen, sondern auf den Operationen zur Ewigkeitsattribuierung und deren historischer Kontextualisierung in der Zeit um 1800 liegt. Dennoch ist es für das Verständnis und die Rahmung des Hauptteils sinnvoll, hier vorangestellt aus historischer Perspektive noch etwas ausführlicher auf die Ewigkeitsbehauptungen gegenüber Schriftzeichen einzugehen. Dabei geht es dezidiert nicht darum, eine umfassende Geschichte dieser Ewigkeitsbehauptungen zu schreiben oder etwa eine seitenlange Liste mit expliziten Textstellen dazu aufzuführen.

Werke, die sich ansatzweise mit einer solchen Geschichte der Ewigkeitsbehauptungen berühren, wären etwa die betreffenden Arbeiten von Martina Stercken und Christian Kiening, ${ }^{148}$ aber vor allem die oben bereits erwähnten Forschungen Aleida und Jan Assmanns, Jesper Svenbros sowie die dereinst drei Bände umfassende Reihe Konzeptionen des Unendlichen - eine europäische Kulturkonstante?. Zudem ist hier auch Philipp Theisohns Monographie Die kommende Dichtung hervorzuheben. ${ }^{149}$ Zur Geschichte der Schrift vergleiche

147 Vgl. dazu u. a. Bleumer et al. 2013. Zu grundsätzlichen Überlegungen zu „Reziproke[n] Nutzbarkeiten“ von Linguistik und Literaturwissenschaft vgl. Linke/Müller Nielaba 2013.

148 Vgl. Kiening/Stercken 2008; und (stellenweise identisch) Kiening 2016.

149 Theisohn 2012. Ein ausführliches In-Bezug-Setzen der vorliegenden Monographie mit derjenigen Theisohns würde in eine weitere Monographie münden; stellvertretend und als ein möglicher Ausgangspunkt für ein solches Unterfangen kann hier deshalb nur 
man etwa Harald Haarmanns Standardwerk Universalgeschichte der Schrift 150 (inklusive der darauf basierenden Texte desselben) und den vierbändigen Katalog der Grazer Ausstellung Der Turmbau zu Babel, Ursprung und Vielfalt von Sprache und Schrift, ${ }^{151}$ der aufgrund seiner zahlreichen Beiträge namhafter Wissenschaftler sowie Abbildungen und Tabellen einen hervorragenden ersten Überblick über die globale Sprach- und Schriftgeschichte der Menschheit verschafft. Betreffend die Geschichte der Diskurse zum Verhältnis von Stimme und Schrift vergleiche man ebenfalls die im vorangegangenen Kapitel genannten Titel. Zur Geschichte der abendländischen Tradition der Hermeneutik, die wesentlich an der Ewigkeitsbehauptung gegenüber Schriftzeichen beteiligt ist, vergleiche man als ersten Überblick den Band von Meinrad Böhl et al., ${ }^{152}$ des Weiteren u. a. die Forschungen Emil Angehrns ${ }^{153}$ oder, älteren Datums, Peter Szondis Einführung in die literarische Hermeneutik. ${ }^{154}$

In diesem Unterkapitel hingegen geht es um eine skizzenhaft vorgetragene, grundsätzliche Problematisierung der Tradition der Ewigkeitsbehauptungen gegenüber Schriftzeichen, die zumindest im abendländischen Kulturraum eine jahrtausendealte Geschichte aufweist, bis heute anhält und gerade in der gegenwärtig sich vollziehenden digitalen Medienrevolution vielleicht so präsent und wirkmächtig ist wie nie. ${ }^{155}$ Dieses geschichtliche Erbe gilt es - insbesondere auch in seiner Problematik angesichts der semiotischen Flüchtigkeit von Schriftzeichen - für den Hauptteil im Hintergrund stets mitzubedenken und in den historisch-kontextualisierenden Kapiteln spezifisch für die Zeit um 1800 wieder aufzugreifen.

folgende Stelle aus Die kommende Dichtung zitiert werden: „Das Bündnis, das Mantik und Dichtung im 15. Jahrhundert eingegangen waren, hatte seinen Zweck in der Ausarbeitung einer Redeform gehabt, welche die Menschheit zu einem Gesprächspartner der Vorsehung - in welcher Form auch immer sie gedacht wurde - erheben sollte. Es handelte sich dabei [...] um kein uneigennütziges Bündnis. Die Dichtung hatte sich nicht zuletzt dort hinein gefügt, weil es ihr dabei auch um die Selbstsicherung, das Vorsehen der eigenen Zukunft ging. Das Medium der Vorsehung ist immer auch selbst Teil der Vorsehung, es hat seinen Platz in dieser Welt garantiert" (ebd., S. 470).

150 Vgl. Haarmann 1991.

151 Seipel 2003, Band IIIA: Schrift.

$15^{2}$ Böhl/Reinhard/Walter 2013.

153 Vgl. Angehrn 2004; und ders. 2008.

154 Szondi 1975, S. 7-191.

155 Vgl. dazu etwa Krüger 2004, insbesondere S. 401-413. 


\subsection{Schrift als dominantes Medium im Diskurs der Verewigung: Buchreligionen und Schriftzentrismus}

Die expliziten und impliziten Ewigkeitsbehauptungen erhalten im abendländischen Kulturraum durch die Anerkennung des Christentums im Römischen Reich und dessen Erhebung zur Staatsreligion - eines mindestens 250 Jahre dauernden, schrittweisen Prozesses von den Toleranzerklärungen der Kaiser Galerius (311) und Konstantin I. (313) über die Regierungszeit Theodosius' (379-394) bis zu den Schließungen der letzten heidnischen Tempel unter der Herrschaft Justinians $(527-565)^{156}$ - einen mächtigen Fürsprecher: Die Buchreligionen des Judentums und des Christentums zelebrieren ${ }^{157}$ sowohl explizit als auch implizit die Behauptung, Schrift könne Dinge für die Ewigkeit - resp. zumindest bis zum Jüngsten Tag - festhalten. Die für den Inhalt behauptete ewige Gültigkeit der heiligen Schriften erstreckt sich dabei unmerklich auch metonymisch auf das Medium selbst, die Schrift. Zum Teil wird diese Übertragung auch bewusst forciert, etwa wenn christliche Autoren „an den vielfältigen Entsprechungen zwischen den beiden großen Büchern, dem liber naturae und dem liber scripturae", arbeiten, indem sie „zentrale Momente der Heilsgeschichte in Metaphern der Buchschriftlichkeit“ ${ }^{158}$ fassen, was bereits dem Versuch einer Ewigkeitsattribuierung von Schriftzeichen entspricht, bei der sowohl die Grundoperation Reflexivität als auch die Grundoperation Autonome Performative Produktion zum Einsatz kommen. ${ }^{159}$ Diese Übertragung schließt dabei an andere explizite wie implizite Ewigkeitsbehauptungen gegenüber Schriftzeichen an, wie sie etwa in Weih-, Grab- und Siegesinschriften schon lange vor der Niederschrift des Alten und erst recht des Neuen Testaments in Europa und im Nahen Osten präsent waren; ${ }^{160}$ und sie geht vor allem einher mit einem sich im Mittelmeerraum und im Nahen Osten vom ca. 14. vorchristlichen bis zum 7. nachchristlichen Jahrhundert sukzessive vollziehenden Übergang von einer hauptsächlich mündlich-rituellen hin zu einer vor allem schriftlich-institutionellen Organisationsform des kulturellen Gedächtnisses. ${ }^{161}$

156 Lexikon für Theologie und Kirche, Bd. 7, Sp. 303 f., und Bd. 5, Sp. 1108 f.

157 „Zelebrieren“ kann dabei durchaus auch wortwörtlich verstanden werden, z. B. in der katholischen Liturgie.

158 Kiening 2016, S. 179 .

159 Eine Analyse solcher christlichen Textstellen vor dem Hintergrund der in der vorliegenden Monographie erarbeiteten Typologie wäre demnach äußerst vielversprechend.

16 o Vgl. Haarmann 2011, u. a. S. 20-22.

161 Vgl. J. Assmann 2005, u. a. S. 289-292. Zum wohl prägenden orientalischen Einfluss, gerade was die Heiligkeit von Schriften anbelangt, vgl. zudem ebd., S. 277. 
Berühmtestes Beispiel für eine starke (implizite) Ewigkeitsbehauptung einer heiligen Schrift von Juden- und Christentum gegenüber dem Medium der Schrift im Allgemeinen ist der Empfang der Gesetzestafeln, wie ihn das Zweite Buch Mose berichtet. ${ }^{162}$ Freilich wird in dieser Erzählung - so zeigen Moses Zerschlagen der von Gott beschriebenen Tafeln im Zorn und die anschließende Neuschreibung (dieses Mal aber durch Moses) ${ }^{163}$ - gerade am Beispiel der Gesetzestafeln zugleich auch die Vergänglichkeit der Materialität der Schrift resp. der Schriftträger auf komplexe Weise mitbehandelt. ${ }^{164}$

Auch die über Jahrhunderte hinweg mit dem Juden- und Christentum konkurrierende, dritte monotheistische Religion, der Islam, stützte und stützt sich auf eine heilige Schrift. Das „Verbot, lebende Wesen direkt abzubilden“, das im arabisch-islamischen Raum insbesondere bezüglich Allah und seines Propheten vorherrschend war und ist, führte zu einer eigenen sakralen Kalligraphie, ${ }^{165}$ die noch sichtbarer und gestalterisch-architektonisch präsenter eingesetzt wurde als die Schrift im Juden- und Christentum (man denke etwa an die Verzierungen in der berühmten Burganlage Alhambra von Granada). Auch im Falle der islamischen Kalligraphie besteht eine Verbindung zu weitaus älteren Traditionen, was kalligraphische Inschriften in Südarabien belegen, die bis ins 8. Jahrhundert vor Christus zurückreichen. ${ }^{166}$

Die zwischen diesen drei monotheistischen Religionen vor sich gehende Auseinandersetzung um den Wahrheitsanspruch des jeweiligen heiligen Buches mindert den Anspruch dieser Texte und damit auch deren explizite wie implizite Ewigkeitsbehauptungen (vorerst) nicht. Da alle drei Religionen sich auf (einander noch überschneidende) ,ewig gültige' Schriftkorpora berufen, können die gegenseitigen Angriffe nur auf den Inhalt und die göttliche

162 Vgl. Exodus 24,4+7+12; 31,18; 32,15-16. Diese implizite Ewigkeitsbehauptung, die das Buch Mose an dieser Stelle vornimmt, wird dabei (vor dem Hintergrund der vorliegenden Arbeit wenig überraschend) bereits unterstützt durch mindestens eine Grundoperation zur Ewigkeitsattribuierung von Schriftzeichen, nämlich den Verweis eines Textes auf sich selbst und die eigenen Möglichkeitsbedingungen, und zwar indem der Text der Gesetzestafeln den im Buch Mose wiedergegebenen Gesetzen entspricht; ein Selbstverweis, der dann etwa bei den letzten Anordnungen des Mose (Deuteronomium 31,9-13) im Buch Josua (vgl. Josua 8,31-35) oder im zweiten Buch der Könige (vgl. 2. Könige 22,8-17) wiederholt wird (vgl. Kiening/Stercken 2008, S. 23). In literaturgeschichtlicher Hinsicht haben wir es hier geradezu mit dem Prototypus für das Buch im Buch für die spätere christlichabendländische Literatur zu tun, einer autoreflexiven Operation, der im Kapitel IV.1.1 zu Novalis' Heinrich von Ofterdingen wiederbegegnet wird.

163 Vgl. Exodus 32, 19; 34, 1+4+27-29.

164 Vgl. Kiening/Stercken 2008, S. 22 f.; und Weigel 2006, S. $20-22$.

165 Vgl. Haarmann 2011, S. 71.

166 Vgl. ebd., S. 74. 
Inspiration der Autoren, nicht aber auf das Medium an sich zielen, denn andernfalls entzöge man der eigenen Argumentation die Grundlage. Es ist deshalb - selbst wenn nicht oder nur mit enormem Aufwand wissenschaftlich messbar - anzunehmen, dass die Vorstellung, Schrift könne durch sie vermittelte Inhalte verewigen, durch die Konkurrenz der drei Buchreligionen nicht geschwächt, sondern vielmehr durch diesen gemeinsamen Nenner noch verstärkt wurde.

Hingegen bricht der schon dem Buch Mose inhärente und im Falle des Empfangs der Gesetzestafeln ausgestellte Widerspruch zwischen behaupteter Ewigkeit der Heiligen Schrift und des Wortes Gottes einerseits und der semiotischen Flüchtigkeit und materiellen Vergänglichkeit von Schrift und Schriftträgern andererseits ${ }^{167}$ über die Jahrhunderte hinweg immer wieder auf und beschäftigt Theologen von Augustinus bis Friedrich Schleiermacher. ${ }^{168}$ Ein pointiertes literarisches Beispiel aus der deutschsprachigen christlichen Literatur für ein solches Aufbrechen wäre etwa eine Stelle aus Andreas Gryphius' Catharina von Georgien, wo ausgerechnet im Kontext einer Buchreligion gegen die Verewigung durch Schrift religiös argumentiert wird:

Ihr die jhr glaubt daß euer Feder Macht Den Tod vnd Zeit hab' an ein Joch gebracht? Glaubt frey die Ewigkeit beruht nicht auff Papir. ${ }^{169}$

Dieser Widerspruch führt jedoch bemerkenswerterweise nicht dazu, dass die Betonung der semiotischen und materiellen Flüchtigkeit und Vergänglichkeit des Mediums der Schrift im abendländischen Kulturraum nachhaltig und in einem dominanten Diskurs die Ewigkeitsbehauptung gegenüber Schriftzeichen grundsätzlich verdrängt hätte. Selbst ,die Aufklärung` - und dies wird im Rahmen der historischen Kontextualisierungen, die die vorliegende Arbeit vornehmen wird, entscheidend sein - übt letztlich keine konsequente Kritik an den Ewigkeitsbehauptungen bezüglich des Mediums der heiligen Schriften, sondern an den Ewigkeitsversprechen und -ansprüchen, die in diesen Schriften auf inhaltlicher Ebene formuliert werden. ${ }^{170}$

167 Vgl. Kiening/Stercken 2008, S. 22-26. Dort auch zur Parallele zwischen der unten zitierten Textstelle im Phaidros resp. der ,Seelenschrift' von Sokrates und dem Zweiten Korintherbrief, wo „Paulus, auf der Linie Platons, die folgenreiche Opposition zwischen einer toten und einer lebendigen Schrift" begründe (ebd., S. 24).

168 Vgl. etwa Kiening 2016, insbesondere S. 129-131 und $178 \mathrm{f}$.

169 Gryphius, Catharina von Georgien, S. 14 f.

17 Vgl. u. a. Böhl 2013, S. 217-224. 
$\mathrm{Zu}$ den Buchreligionen tritt hinzu, dass bereits Jahrhunderte vor der Entstehung und Ausbreitung des Christentums in dem für die Ausbreitung der abendländischen Schriftlichkeit zentralen griechischen Kulturraum ebenso die Ewigkeitsbehauptung gegenüber und nicht die Betonung der Flüchtigkeit von Schriftzeichen den entsprechenden Diskurs bestimmte. Das bemerkenswerteste Beispiel dafür findet sich wohl in der berühmten Textstelle in Platons Phaidros, ${ }^{171}$ wo die Figur Sokrates die ägyptische Erzählung des ägyptischen Königs Thamus und des Gottes Theuth (Thot, in der ägyptischen Mythologie u. a. der Erfinder der Schrift) vorträgt und damit seine Argumentation für die Minderwertigkeit der Schrift gegenüber der (dialektischen) Rede einleitet:

\begin{abstract}
Als er aber zu den Buchstaben kam, sagte Theuth: „Diese Kunde, o König, wird die Ägypter weiser machen und ihr Gedächtnis erhöhen, denn zur Arznei für Gedächtnis und Weisheit wurde sie erfunden.“ Der aber erwiderte: „O kunstreicher Theuth, ein anderer ist fähig, die Werkzeuge der Kunst zu erzeugen, ein andrer wieder zu beurteilen, welches Los von Schaden und Nutzen sie denen erteilen, die sie gebrauchen werden. Auch du sagtest jetzt als Vater der Buchstaben aus Zuneigung das Gegenteil dessen, was sie bewirken. Denn wer dies lernt, dem pflanzt es durch Vernachlässigung des Gedächtnisses Vergeßlichkeit in die Seele, weil er im Vertrauen auf die Schrift von außen her durch fremde Zeichen, nicht von innen her aus sich selbst die Erinnerung schöpft. Nicht also für das Gedächtnis, sondern für das Erinnern erfandest du ein Mittel. Von der Weisheit aber verleihst du deinen Schülern den Schein, nicht die Wahrheit. Denn wenn sie vieles von dir ohne Unterricht gehört haben, so dünken sie sich auch Vielwisser zu sein, da sie doch größtenteils Nichtwisser sind, und sie sind lästig im Umgang, da sie statt Weise Dünkelweise geworden sind.["] ${ }^{172}$

$[\ldots]$

6o. SoKRATEs. Wer also glaubt, seine Kunst in Buchstaben zu hinterlassen, und wer sie wieder aufnimmt, als ob etwas Klares und Festes aus Buchstaben zu gewinnen sei, der strotzte von Einfalt und kennte in Wirklichkeit nicht den Wahrspruch Ammons, da er sich einbildete, die geschriebenen Reden bedeuteten noch irgend etwas [sic] mehr, als den schon Wissenden an das zu erinnern, wovon das Geschriebene handelt. ${ }^{173}$
\end{abstract}

171 Vgl. A. Assmann 2015, S. 310 f.; Kiening 2008, S. 21; aber insbesondere Svenbro 2005, S. 33, 161-194, vor allem ab S. 178.

172 Die Rede des Königs ist hier zu Ende, in der verwendeten Edition fehlt jedoch ausgerechnet das Schlusszeichen (die altgriechische Vorlage kam gänzlich ohne Anführungs- und Schlusszeichen aus), weswegen es hier ergänzt wurde. ,Ausgerechnet', da das doppelte Anführungs- und Schlusszeichen dasjenige Schriftzeichen ist, das wie kein anderes darauf verweist, was es selbst nicht ist: auf direkte Rede; vgl. Müller Nielaba 2009.

173 Platon, Phaidros, Kapitel 59 f. resp. S. 86 f. 
Die Schrift erwecke nur den Schein, selber sprechen zu können, sie vermöge auch nicht auf Fragen zu antworten, zeige immer nur dasselbe und wisse weder, zu wem sie reden solle und zu wem nicht. ${ }^{174}$ Deshalb „bedarf sie immer der Hilfe des Vaters, denn selbst vermag sie sich weder zu wehren noch zu helfen“. ${ }^{175}$ Die biologische Fortpflanzungsmetaphorik von Vater ${ }^{176}$ resp. Eltern und Kind, die schon zu Beginn der Einführung aus Platons Symposion zitiert wurde und die dort die Figur Diotima auf die schriftlichen Werke anwendet, kommt hier also wieder zum Zug und wird sodann von der Figur Sokrates auch auf das Medium der Rede übertragen:

\begin{abstract}
Aber viel schöner, glaube ich, ist der Eifer um die gleichen Dinge, wenn jemand, dialektische Kunst anwendend, die geeignete Seele wählt und sie bepflanzt und besät mit Reden der Erkenntnis, die sich selber und dem Sämann zu helfen geschickt und nicht früchtelos sind, sondern Samen tragen, aus dem sie immer von neuem in andern Seelen keimend ihn für ewig unsterblich zu machen geeignet sind und seinen Träger so glücklich zu machen, als es einem Menschen nur möglich ist. ${ }^{177}$
\end{abstract}

Die in diesen Passagen des Phaidros entworfene, vermeintliche Entlarvung der Ewigkeitsbehauptung gegenüber Schriftzeichen als eine semiologisch ungerechtfertigte und die gleichzeitig etablierte Ewigkeitsbehauptung gegenüber der mündlichen (dialektischen) Rede weisen jedoch einen entscheidenden performativen Selbstwiderspruch auf: Sokrates' Argumentation vollzieht sich zwar in einer (dialektischen) Rede, aber diese ist eine verschriftlichte Rede in einem schriftlichen Werk Platons, wobei Phaidros und Sokrates nicht als sprechende Personen aus Fleisch und Blut auftreten, sondern als Figuren eines Textes. Dieses Unterlaufen des Inhalts des Phaidros durch das Medium und die Form desselben ist denn auch in nuce lesbar, wenn an entscheidender Stelle ausgerechnet eine Schriftmetaphorik herbeigezogen wird:

SOKRATES. Und weiter! Wollen wir nicht eine andere Rede [als die schriftliche, $M G]$ betrachten, den echtgeborenen Bruder von dieser, in welcher Art sie entsteht und um wieviel sie durch ihr Wesen besser und mächtiger ist als diese?

Phaidros. Welche meinst du, und wie soll sie entstehen?

\footnotetext{
174 Ebd., Kapitel 59 f. resp. S. 87 f. Vgl. dazu auch Svenbro 2005, S. 33 (insbesondere Anm. 12) und dann vor allem S. $161 \mathrm{f}$.

175 Platon, Phaidros, Kapitel 6o resp. S. 88.

${ }_{176}$ Zum Väterlichen vgl. auch David Wellberys Beobachtungen im Zusammenhang mit der Genieästhetik des 18. Jahrhunderts, die im Kapitel IV.3.3 aufgegriffen werden.

177 Platon, Phaidros, Kapitel 61 resp. S. 89 f.
} 
SoKRATES.Jene, die mit Erkenntnis geschrieben wird in die Seele des Lernenden, die fähig ist, sich selbst zu verteidigen, die zu reden und zu schweigen weiß, gegen wen sie beides soll.

Phaidros. Du meinst die lebende und beseelte Rede des Wissenden, deren Abbild man mit Recht die geschriebene nennen kann.

61. Sokrates. Die meine ich. [...]. ${ }^{178}$

Damit macht ausgerechnet die Figur Sokrates (und mit ihm Platon), die sich gerade im Phaidros kritisch gegenüber der Rhetorik äußert, den ,Fehler', dass die von ihr hier rhetorisch eingesetzte Figur der inhaltlichen Analogie über die Schriftmetaphorik ${ }^{179}$ eine widerspruchsvolle Eigendynamik entfaltet. Die vermeintliche Unsterblichkeit der oben zitierten Rede gründet ebenso wie die ihrer ,Väter' (sei es Platon oder Sokrates oder beide) also ausgerechnet darin, dass diese Rede verschriftlicht wurde. Ohne Platons Niederschrift wäre die Argumentation der Person Sokrates - vorausgesetzt, er hat sie überhaupt je vorgetragen - vielleicht schon zum Zeitpunkt der Niederschrift des Phaidros weitgehend in Vergessenheit geraten. Auch dass Platon die Ansichten Sokrates' in Form von Dialogen verschriftlicht, ist eine Operation, die in diesem Fall nicht für das Medium der gesprochenen Rede, sondern für die Schrift sinnvoll ist: Könnten wir heute noch immer Zeugen davon sein, wie die Person Sokrates tatsächlich zur Person Phaidros spricht, würden diese nicht in einer durchgehenden ${ }^{180}$ Binnenerzählung miteinander sprechen, in der sie selbst als die beiden Figuren aufträten. Nun ist es aber so, dass Platon, der über Sokrates für die mündliche (dialektische) Rede Ewigkeit behauptet, dies in der Form einer verschriftlichten Rede tut, was dem performativen Versuch gleichkommt, nicht nur schriftlich auf eine Rede zu verweisen, sondern diese im Zuge der Lektüre auch vollziehen zu lassen - und damit Sokrates' Rede wieder zum Leben zu erwecken, was zugleich auch der Beweis für deren Unsterblichkeit wäre. Oder mit anderen Worten: Platon bedient sich hier einer innersprachlichen Operation ${ }^{181}$ der Ewigkeitsattribuierung von Schriftzeichen, im Versuch, die Ewigkeitsbehauptung gegenüber der mündlichen Rede zu bewahrheiten, was jedoch letztlich bloß die Ewigkeitsbehauptung gegenüber Schriftzeichen stärkt.

Platons Text Phaidros markiert also - entgegen dem Inhalt der darin enthaltenen Rede von Sokrates - geradezu den Beginn des Siegeszuges der

178 Ebd., S. 88.

179 Zur (Metaphorik der) Seelenschrift vgl. Svenbro 2005, S. 163 f.; aber auch den Zweiten Korintherbrief; resp. Kiening/Stercken 2008, S. 22-26.

180 Punktuell kann aber durchaus eine gleichnishafte Binnenerzählung vorkommen, wie diejenige von Theut und dem ägyptischen König.

181 Vgl. Kapitel III.1 zur Unteroperation Poetische Performativität. 
Ewigkeitsbehauptung gegenüber Schriftzeichen im abendländischen Diskurs: Die Meinung von Sokrates, der selbst keine schriftlichen Zeugnisse hinterlassen hat, ist höchstens noch eine, die schriftlich zitiert einer Figur Sokrates in den Mund gelegt wird. Und zwar von seinem Schüler Platon, der - ob bewusst oder unbewusst - offenbar nicht mehr darauf vertraut, dass sowohl Sokrates' Reden als auch die eigenen ohne (mit Operationen zur Ewigkeitsattribuierung versehene) Verschriftlichung überdauern werden. (Auf die mit der Gründung der Akademie verbundenen, der Kanonisierung der heiligen Texte der Buchreligionen ähnelnden Vorkehrungen Platons, ${ }^{182}$ die ermöglichen sollten, dass seine Schriften sich auch nach seinem Tod verteidigen und Fragen beantworten können, hat Jesper Svenbro hingewiesen. $)^{183}$

Damit verweist die soeben dargelegte Lektüre des Phaidros zwar auf denselben performativen Widerspruch bei Platon, den bereits Jacques Derrida in La Dissémination (1972) im Zuge seiner ausführlichen Auseinandersetzung mit Platons und Sokrates' Positionen zum Verhältnis Mündlichkeit und Schriftlichkeit im Allgemeinen ${ }^{184}$ und der oben zitierten Stelle im Phaidros im Speziellen beobachtet hat. Aber sie zieht daraus einen anderen Schluss als Derrida, der zur Metaphorik der ,Seelenschrift' der oben zitierten Textstelle im Phaidros schreibt:

Inhaltlich hat diese Replik [des Sokrates, MG] nichts Originelles, Alkidamas sagte fast dasselbe. Sie markiert jedoch eine Art Umkehrung im Gang der Argumentation. [...] Einem Schema gemäß, das die gesamte ,abendländische‘ Philosophie beherrschen wird, wird eine gute (natürliche, lebendige, wissende, intelligible, innerliche, sprechende) Schrift einer schlechten (künstlichen, todgeweihten, unwissenden, sinnlichen, äußerlichen, stummen) Schrift gegenübergestellt. Und die gute kann nur in der Metapher der schlechten bezeichnet werden. Die Metaphorizität ist die Logik der Kontamination und die Kontamination der Logik. Die schlechte Schrift ist für die gute gleichsam ein Vorbild sprachlicher Bezeichnung und ein Trugbild eines Wesens. Und wenn das Netzwerk der Gegensätze von Prädikaten, welche eine Schrift auf die andere beziehen, in seinem Gefüge alle begrifflichen Gegensätze des „Platonismus" enthält - hier als die dominante Struktur der Geschichte der Metaphysik betrachtet -, so wird man sagen können, daß die Philosophie sich im Spiel zweier Schriften abgespielt habe. Wo sie doch allein zwischen Sprechen und Schrift hat unterscheiden wollen.

Es bestätigt sich im weiteren, daß die Schlußfolgerung des Phaidros weniger eine Verdammung der Schrift im Namen des gegenwärtigen Sprechens ist, denn

182 Dies wären dann außersprachliche Versuche der Ewigkeitsattribuierung, die nicht Gegenstand der vorliegenden Arbeit sind.

183 Vgl. Svenbro 2005, S. 190-194.

184 Vgl. Derrida 1995, vor allem S. 73-19o; als Überblick vgl. Krämer 20o1, insbesondere S. $222-225$. 
die Bevorzugung einer Schrift gegenüber einer anderen, einer fruchtbaren Spur gegenüber einer sterilen Spur, eines zeugungsfähigen, weil im Drinnen abgelegten Samens gegenüber einem im Draußen in reinem Verlust: im Risiko der Dissemination, vergeudeten Samen. ${ }^{185}$

Selbst Derridas eigene Metaphorik - im Paradigma der Fruchtbarkeit, des Samens und des Ausstreuens desselben angesiedelt - lässt sich nämlich vor dem Hintergrund des oben Dargelegten in einen anderen Bezug zum performativen Widerspruch im Phaidros setzen: Mit Blick auf die Ewigkeitsbehauptung gegenüber Schriftzeichen schwingt in Platons schriftlich festgehaltener Schriftmetaphorik implizit durchaus selbst eine Metaphorik der Fruchtbarkeit und des Samens mit: Platons eigene, zu Beginn dieser Einführung zitierte Metaphorik des Zeugens schriftlicher Nachkommen, die er im Symposion Diotima in den Mund legt. Eine Metaphorik, die die Schrift eben gerade nicht für unfruchtbar hält.

Jacques Derrida mag also zwar in Bezug auf den Diskurs zum grundsätzlichen Verhältnis von mündlichen und schriftlichen Äußerungen von einer (freilich inzwischen in vielen Teilen von der Forschung relativierten oder zurückgewiesenen) abendländischen Tradition des Logo- resp. Phonozentrismus, einer Vorherrschaft der Mündlichkeit, schreiben. ${ }^{186}$ Im Falle der Frage aber, welches Medium die transportierten Inhalte am dauerhaftesten festzuhalten vermöge, kann von einem Logozentrismus nicht die Rede sein. Vielmehr deutet alles darauf hin, dass zumindest für diese Frage von einem ,abendländischen Schriftzentrismus‘ gesprochen und geschrieben werden müsste.

Der Widerspruch zwischen behaupteter Ewigkeit von Schriftzeichen im Allgemeinen sowie heiligen Schriften im Speziellen einerseits und der semiotischen Flüchtigkeit und materiellen Vergänglichkeit von Schrift andererseits bricht also zwar immer wieder auf, hat jedoch nie dazu geführt, dass innerhalb des abendländischen Diskurses über die Schrift die Ewigkeitsbehauptung gegenüber Schriftzeichen ihre Dominanz über die Zweifel an ebendieser Behauptung verloren hätte - und dies über einen Zeitraum hinweg, der von mindestens Platons Phaidros bis in die aktuelle Gegenwart des 21. Jahrhunderts reicht. Selbst der Anfang des Johannesevangeliums, der beim Begriff Logozentrismus sofort mitschwingt, ist im Medium der Schrift überliefert und zitiert zudem in den ersten beiden Worten den Beginn einer anderen Schrift, das erste Buch Mose:

185 Derrida 1995, S. 167 f.

186 Für Ergänzendes zu Derrida und den Einwänden betreffend seine Logozentrismuskritik vgl. das Unterkapitel zum Forschungsstand. 
Im Anfang schuf Gott Himmel und Erde. (Genesis 1,1)

Im Anfang war das Wort, der Logos,

und der Logos war bei Gott,

und von Gottes Wesen war der Logos.

Dieser war im Anfang bei Gott. (Johannes 1,1-2) $)^{187}$

Am Anfang des Johannesevangeliums selbst steht nicht nur auf inhaltlicher Ebene das mündliche ${ }^{188}$ Wort Gottes, sondern eben auch ein schriftliches Zitat eines anderen schriftlichen Textes ${ }^{189}$ - womit sich, ähnlich wie schon bei der Metapher der Seelenschrift im Phaidros, quasi mit Derrida, gegen Derrida argumentieren lässt. Dabei drängt sich eine weitere These auf, nämlich dass selbst Derridas Kritik am abendländischen Logozentrismus, die aus ihr entwickelten Theorien und deren Einfluss eine jahrtausendjährige abendländische Tradition der Ewigkeitsbehauptung gegenüber Schriftzeichen letztlich - trotz höchsten Reflexionsgrades ${ }^{190}$ - noch weiter verstärkt haben.

\subsection{Das Problem der selbsterfüllenden Prophezeiung}

Zum bislang Dargelegten ist weiter zu ergänzen, dass auf der Ebene der Religion zumindest in Europa ein unmittelbares Konkurrenzmodell, das die Ewigkeitsbehauptung der christlichen, jüdischen und islamischen heiligen Texte radikal infrage gestellt hätte, fehlte resp. nach und nach verdrängt wurde:

187 Beide Stellen zitiert nach der Zürcher Bibel 2007, die in Joh. 1,1 absichtlich „Wort“ und „Logos“ nennt, um auf die Vielschichtigkeit der Bedeutung von altgriechisch lógos zu verweisen (vgl. ebd., NT, S. 144).

188 Wenn man „Logos“ mit „Im Anfang war das [gesprochene] Wort" übersetzt (vgl. Goethes Faust).

189 Natürlich hängt der Grad der Wortwörtlichkeit des Zitates generell an der Übersetzung des hebräischen Buch Mose ins Altgriechische resp. im vorliegenden Fall an der Übersetzung beider Stellen ins Deutsche. Dass aber grundsätzlich ein Zitat vorliegt, wäre schwerlich zu bestreiten. Damit wiederum bedient sich der erste Vers des Johannesevangeliums letztlich dreier innersprachlicher Verfahren, die je einer der im Hauptteil behandelten Grundoperationen zur Ewigkeitsattribuierung von Schriftzeichen zuzuordnen sind: 1) der Verwischung des Anfangs; vgl. die Unteroperation Unendliche Lektüre in Kapitel II.1; 2) der performativen Herstellung dessen, wovon die Rede ist, indem die Sequenz „Im Anfang“ aus der Genesis tatsächlich Worte sind, die „Im Anfang“ des Johannesevangeliums vorkommen; vgl. die Unteroperation Poetische Performativität in Kapitel III; und 3) dem autoreflexiven Verweis auf das eigene geschriebene Werk, das aus Worten besteht und das demzufolge auch mit Worten beginnt; vgl. die Grundoperation Reflexivität in Kapitel IV.

190 Oder vielleicht gerade wegen dieses Reflexionsgrades, wie eine Berücksichtigung der Ergebnisse dieser Arbeit zu Reflexionsphilosophie und Autoreflexivität in Kapitel IV. zeigen mag. 
Die zunehmende Dominanz des Christentums verdrängte die vorhandenen heidnischen Religionen, die entweder weitgehend mündlichen Kulturen entstammten oder nicht auf einer heiligen Schrift basierten. So erscheint es gerade auf der Ebene religiöser Überlieferung so, als ob die Behauptung, Schrift könne Vergängliches für alle Zeiten festhalten, sich bewahrheitet hätte: Unser heutiges Wissen um jene heidnischen Religionen Europas wäre (und ist in vielen Fällen) ohne schriftliche Zeugnisse sehr beschränkt. Vieles, was wir heute von diesen Religionen wissen, verdanken wir einerseits zeitgenössischen schriftlichen Überlieferungen jener Kulturen ${ }^{191}$ - von Hesiod über Ovid bis hin zu vereinzelten Runeninschriften religiösen Inhalts ${ }^{192}$ - oder aber der schriftlichen Überlieferung von Angehörigen, meist Klerikern, einer der Buchreligionen; man denke dabei im Falle der germanisch-nordischen Mythologie z. B. an Beowulf (siehe Punkt b. weiter unten) oder die Edda des Snorri Sturluson. Um wieder auf die oben zitierte Stelle in Platons Phaidros zurückzukommen, ließe sich daraus also plakativ formulieren: Diejenigen Religionen, die Sokrates' Präferenz gefolgt sind, mussten denjenigen, die den Weg umfassender Verschriftlichung gegangen sind, weichen. Auch hier geht es nicht darum, zu untersuchen, ob und wie stark der Siegeszug der Buchreligionen die Vorstellung, Schriftzeichen könnten Inhalte dauerhaft festhalten, gefördert haben mag, sondern im Gegenteil darum, darauf hinzuweisen, dass bei solchen Überlegungen aus mindestens zwei Gründen besondere Vorsicht geboten ist:

Erstens ist die Verdrängung heidnischer Religionen durch das Christentum auf zahlreiche und nicht mit absoluter Sicherheit feststellbare Faktoren zurückzuführen, unter denen die Grundlage eines heiligen Buches für sich wohl keine direkte Rolle gespielt hat. ${ }^{193}$ Der Erfolg des Christentums ist also erst einmal weder mit einem grundsätzlichen Erfolg der Schriftlichkeit gleichzusetzen noch mit einem Erfolg eines Buches, von dessen Texten ewige Gültigkeit behauptet wurde und wird.

Zweitens - und sowohl für eine Problematisierung der Ewigkeitsbehauptungen als auch für die vorliegende Arbeit viel relevanter - begegnet

191 Dies können Überlieferungen über die eigene oder aber auch über fremde Religionen sein, die zum Teil selbst keine oder kaum schriftliche Zeugnisse hinterlassen haben.

192 Vgl. Haarmann 1991, S. 458-465.

193 Indirekt war die Schriftkundigkeit für den Organisationsgrad kirchlicher Strukturen, die Vereinheitlichung der Lehre usw. natürlich von großem Vorteil. Über Schriftkundigkeit verfügten aber auch zahlreiche heidnische Kulturen ohne Buchreligion. Im Gegenteil waren umgekehrt die Verbreitung der griechischen Sprache sowohl im Osten als auch vor allem in urbanen Zentren des Westens des Römischen Reiches und die bereits vorhandene Schriftlichkeit größerer Bevölkerungsgruppen innerhalb des römischen Imperiums für die Ausbreitung der Buchreligion Christentum äußerst hilfreich (vgl. Lexikon für Theologie und Kirche, Bd. 7, Sp. 302-309). 
einem bei den Buchreligionen wieder, was bereits weiter oben im Falle des Phaidros gestreift wurde: der Aspekt einer selbsterfüllenden Prophezeiung, der wiederum in mindestens drei Varianten auftreten kann:

a) Bei der Analyse der Textstelle im Phaidros ging es um den performativen Widerspruch eines Textes, in dem die Figur Sokrates die Schrift als Förderer des Vergessens bezeichnet. Daran lässt sich hier anknüpfen: Wenn die Verschriftlichung tatsächlich das Vergessen fördern würde, nähme die Vergesslichkeit mit der Verbreitung der Schrift zu. In diesem Fall würde mit der Zeit höchstens noch das überdauern, was verschriftlicht wurde. Die Behauptung, dass die Schrift das Überdauern der mittels ihr festgehaltenen Informationen sichere, würde sich also nur deshalb bestätigen, weil die Schrift selbst wesentlich dazu beigetragen hat, dass alles andere vergessen ging.

b) Ob Verschriftlichung tatsächlich das Vergessen fördert, ist nicht Gegenstand dieser Arbeit, es ist jedoch allgemein bekannt, dass etwa auch soziale und politische Machtausübungen das Vergessen fördern oder massiv beschleunigen können (man denke etwa an die Stichworte damnatio memoriae). In einem solchen Fall kann der soeben beschriebene Mechanismus einer selbsterfüllenden Prophezeiung durchaus erfolgreich zum Einsatz kommen. Ein Beispiel dafür wäre das altenglische Gedicht Beowulf in Kombination mit Normen und Praktiken, die durch die Buchreligion Christentum geprägt sind: Ein zuvor mündlich tradiertes heidnisch-germanisches Heldengedicht wird von einem christlichen Schreiber in einen schriftlichen Text übertragen. In diesem Text wird der christliche Gott, wenn auch nur sehr oberflächlich, in die Geschichte integriert, um eine schriftliche Festhaltung einer heidnischen Geschichte zu rechtfertigen. ${ }^{194}$ Überdauert diese Geschichte nun auch in materieller Hinsicht (die Handschrift wurde während eines Brandes beinahe zerstört), dann hilft sie, die Ewigkeitsbehauptung gegenüber der Bibel zu bestätigen. Denn ein Gedicht, das u. a. auch von Gott handelt, hat überdauert. In Wahrheit aber hat das Gedicht nicht schriftlich überdauert, weil es von Gott handelte, sondern es verweist auf Gott, weil es verschriftlicht wurde.

c) Von da aus lässt sich wiederum überleiten zur im Zusammenhang mit der Ewigkeitsbehauptung simpelsten und am einfachsten anwendbaren Variante der selbsterfüllenden Prophezeiung: der (expliziten) Behauptung innerhalb eines Textes, dass das darin Verschriftlichte überdauern werde einer Behauptung, die uns vielerorts begegnet, so bereits im alten Ägypten, z. B. als Schlusssatz der Prophezeiungen des Neferti (20. Jahrhundert v. Chr.), ${ }^{195}$

194 Vgl. dazu zusammenfassend J. Frey 2013, S. 115 f.

195 „Ein Weiser wird mir Wasser sprengen [im Sinne eines Trankopfers, MG], wenn er sieht, / dass das, was ich gesagt habe, geschehen ist“ (zitiert nach J. Assmann 1991, S. 178). 
in Ovids Nachwort zu den Metamorphosen ${ }^{196}$ oder auch in Schillers Prolog zu Wallensteins Lager (vgl. Kapitel III.1.2). Gelangt der Text in lesbarem Zustand an kommende Generationen und findet unter ihnen Leserinnen und Leser, so bestätigt sich die Behauptung. Wird der Textträger hingegen zerstört, der Text unleserlich oder nicht mehr gelesen, so wird nie jemand erfahren, dass sich die darin enthaltene Behauptung nicht bewahrheitet hat. Diese Variante der selbsterfüllenden Prophezeiung ließe sich zudem genauso bei mündlichen Überlieferungen anwenden ${ }^{197}$ und beruht somit nicht auf einer genuinen Eigenschaft der Schrift.

Die soeben genannte Tradition der gerade auch von Dichtern gepflegten selbsterfüllenden Prophezeiung kombiniert sich im 18. Jahrhundert mit der Übertragung göttlicher Attribute auf das Individuum und dessen Werke sowie der damit einhergehenden Heiligung der Schrift als solcher. Bestes Beispiel dafür ist, was Thomas Wortmann zu Friedrich Gottlieb Klopstock schreibt: „Es ist die Heilige Schrift, die für Klopstock den idealen Stoff für das Epos bildet entsprechend versteht er die biblischen Propheten als Dichter und im Umkehrschluss avancieren die Dichter christlicher Epen zu den Nachfolgern der Propheten. ${ }^{“ 198}$

Mit jenen unter „zweitens“ zusammengefassten Varianten der selbsterfüllenden Prophezeiung rückt auch der Hauptteil der vorliegenden Arbeit immer näher. Denn es geht, wie bereits erwähnt, weder in dieser Einführung noch im Hauptteil um das Verfassen einer Geschichte der Ewigkeitsbehauptungen

196 „Doch mit meinem besseren Teil werde ich fortdauernd über die hohen Sterne erhoben werden, unser Name wird unzerstörbar sein, und so weit sich die römische Macht über den unterworfenen Erdkreis erstreckt, werde ich vom Mund des Volkes gelesen werden und, sofern an den Vorahnungen der Dichter auch nur etwas Wahres ist, durch alle Jahrhunderte im Ruhm fortleben“ (Ovid, Metamorphosen, S. 866 f.), wörtlichere Übersetzung nach MG, denn es ist hier entscheidend, bei der Übertragung von „nomenque [...] nostrum“ das ,unser' beizubehalten. Nur so wird nämlich die durch die mehrdeutige Deixis entstehende poetologische Ebene von "nostrum“ bewahrt, die den Namen Ovids sowie den Namen des Textes Metamorphosen selbst ineinander verschmelzen lässt. Mit dieser Verschmelzung wird Ovids behauptetes Überdauern an dessen eigene Metamorphose zu einem Text geknüpft und zugleich performativ vollzogen. Wie weiter unten anhand des Prologs zum Wallenstein ausführlich gezeigt, ist auch bei Ovid zu beobachten, dass bei ambitionierten Autoren Ewigkeitsbehauptung und Ewigkeitsattribuierung oft auf engstem Raum miteinander kombiniert werden. Im Falle von Ovids Nachwort wären die Unteroperationen Poetische Performativität und Poetologie zu beobachten.

197 Indem im Zuge einer mündlichen Äußerung behauptet wird, dieselbe würde auch noch an kommende Generationen weitererzählt werden. Wird sie samt dieser Behauptung mündlich tradiert, findet sich hier derselbe Effekt wie oben beschrieben.

198 Wortmann 2014, S. 87; vgl. dazu auch die Behandlung von Wortmanns Monographie im Unterkapitel zum Forschungsstand. 
bezüglich Schriftzeichen, sondern vielmehr darum, herauszufinden, welche innersprachlichen Operationen dazu eingesetzt werden, jene Behauptungen so weit wie möglich zu bestätigen. Der Mechanismus einer selbsterfüllenden Prophezeiung geht dabei stark in die Richtung der im Hauptteil unter Kapitel III behandelten Grundoperation der Autonomen Performativen Produktion und wird uns dort wieder begegnen. Doch zuerst sei noch einmal kurz zur Schriftlichkeit im Zusammenhang mit der Bibel zurückgekehrt:

Die Bibel als Heilige Schrift hatte sich als religiöse Grundlage Mitteleuropas bis ins 16. Jahrhundert bereits derart etabliert, dass die Reformation eine Rückkehr zur Heiligen Schrift ausrufen konnte. Ob dies im Grunde nicht doch vielmehr eher eine Rückkehr ${ }^{199}$ zu einer Praxis war, die es so nie gegeben hatte, sei hier dahingestellt; auch zeigt die Geschichte der Theologie, dass das Prinzip sola scriptura kein genuin reformatorisches Anliegen war, sondern bereits in der Scholastik "förmlich ausgebildet“ und „in den bibl[ischen] Reformbewegungen des Spätmittelalters (Waldenser, Hussiten usw.) kirchenkritisch geltend gemacht ${ }^{\text {"200 }}$ wurde. Zu bemerken ist aber, dass der von der Reformation durchaus forcierte Imperativ sola scriptura und insbesondere Luthers Vorstellung einer Heiligen Schrift, die für alle Zeiten „durch sich selbst ganz gewiss ist, ganz leicht zugänglich, ganz verständlich, ihr eigener Ausleger, alles von allen prüfend, richtend und erleuchtend“ ${ }^{201}$ die Ewigkeitsbehauptung gegenüber Schriftzeichen weiter verstärkt. Wer die Orientierung am biblischen Originaltext und dessen Fähigkeit zur Selbstauslegung - ob nun wortwörtlich (miss-)verstanden wie von zeitgenössischen Gegnern Luthers oder doch eher gemeint als (hermeneutischer) Prozess der collatio contraiorum in Christo conciliandorum ${ }^{202}$ - derart stark betont, ${ }^{203}$ impliziert und betont auch die Behauptung der ewigen Gültigkeit desselben und fördert

199 Vgl. etwa Luther, Assertio, S. 97; sowie Luther, Wahrheitsbekräftigung, S. 79-81.

200 Lexikon für Theologie und Kirche, Bd. 9, Sp. 703 f.

201 Luther, Wahrheitsbekräftigung, S. 81. Die viel erwähnte, aber selten korrekt zitierte Stelle lautet im lateinischen Original: „Oportet enim scriptura iudice hic sententiam ferre, quod fieri non potest, nisi scripturae dederimus principem locum in omnibus quae tribuuntur patribus, hoc est, ut sit ipsa per sese certissima, facillima, apertissima, sui ipsius interpres, omnium omnia probans, iudicans et illuminans, sicut scriptum est psal. c.xviii“ (Luther, Assertio, S. 97). Zu Luthers Sprach- und Schriftverständnis vgl. u. a. Ringleben 2010, insbesondere S. 252-443; Matsuura 2015; oder Mostert 1998.

202 Vgl. Matsuura 2015, S. 166.

203 Dies wird bis heute in der Theologie diskutiert, wie die in den vorangehenden Fußnoten genannten Publikationen zeigen. Zu ersten zeitgenössischen Einwänden von John Fisher und Erasmus von Rotterdam gegen die Formulierung „sui ipsius interpres“ vgl. u. a. Matsuura 2015, insbesondere S. $173 \mathrm{f}$. 
damit die oben festgestellte metonymische Übertragung resp. Ausdehnung der behaupteten Ewigkeit vom Inhalt auf das Medium.

In der Reformation erhält die Ewigkeitsbehauptung gegenüber Schriftzeichen also eine weitere, implizite, aber äußerst starke Fürsprecherin. Und auch hier, im Falle Luthers, der Reformation und deren Auswirkungen, findet sich wieder das Element einer selbsterfüllenden Prophezeiung, das nahe an die Grundoperation Autonome Performative Produktion zur Ewigkeitsattribuierung von Schriftzeichen heranreicht: Unter anderem gerade durch die Forderung sola scriptura kommt es zu einer Förderung der persönlichen Bibellektüre der Gläubigen, einer steigenden Alphabetisierung und dabei zusammen mit dem aufkommenden Buchdruck zu einer stärkeren Verbreitung der Heiligen Schrift und von Schriftlichem insgesamt, was wiederum letztlich erst die Möglichkeitsbedingung dafür schafft, sich auch selbst und im privaten Umfeld der Heiligen Schrift (und in einem weiteren Schritt: anderen Schriften) zuwenden zu können usw. ${ }^{204}$

\subsection{Von der Aufklärung bis ins 21.Jahrhundert: Übertragung eines göttlichen Attributes}

Zum Schluss dieser einleitenden Problematisierung der Ewigkeitsbehauptungen gegenüber Schriftzeichen sei derjenige Zeitraum in den Blick genommen, auf den die vorliegende Arbeit fokussiert: die zweite Hälfte des 18. und der Beginn des 19. Jahrhunderts. Um jedoch längere Überschneidungen mit den historisch-kontextualisierenden Kapiteln II.3 und IV.3 des Hauptteils zu vermeiden, gilt es, sich hier kurz zu fassen. Das Folgende ist denn auch eine knappe Zusammenfassung grundlegender, für die Problematisierung von Ewigkeitsbehauptungen relevanter Erkenntnisse aus diesen historischkontextualisierenden Kapiteln, die erst dort ausführlich behandelt werden, für die Lektüre des Hauptteils aber stets als zentraler historischer Hintergrund mitzudenken sind.

Der oben festgestellte, im Falle der drei monotheistischen Buchreligionen besonders akzentuierte Widerspruch zwischen der Flüchtigkeit und Vergänglichkeit des Mediums der Schrift auf semiotischer und materialer Ebene einerseits und den Behauptungen, sie könne ewig gültige Informationen ewig festhalten, andererseits bricht im Zuge der Aufklärung, gerade in Bezug auf die Bibel, erneut auf. Im Unterschied aber zur bisherigen theologisch-religiösen

204 Vgl. dazu auch A. Assmann 2015, S. 313-315 und auch 328, die in dieser Entwicklung die medien- und geistesgeschichtlich höchst wirkmächtige Ablösung der Hodegetik durch die Hermeneutik sieht. 
Argumentationslinie, ${ }^{205}$ die im Zweifelsfall die ewige Gültigkeit der göttlichen Botschaft gegenüber der Flüchtigkeit des Mediums der Schrift betonte, behaupten die spätestens in der zweiten Hälfte des 18. Jahrhunderts im abendländischen Diskurs dominanten - aber letztlich bis mindestens in die Renaissance und den Humanismus zurückreichenden ${ }^{206}$ - säkularen und säkularisierenden Argumentationslinien genau das Gegenteil. Dabei drehen sie jenes theologisch-religiöse Argument chiastisch um: Nicht die religiöse Botschaft wird gegenüber dem Medium der Schrift als ewig behauptet, sondern die Schrift als solche erhält verstärkt das Attribut der Ewigkeit, während die religiöse Botschaft diese immer mehr verliert. ${ }^{207}$

Während an der Wahrheit und erst recht an der ewigen Gültigkeit der biblischen Botschaften im Zuge der Aufklärung also immer mehr gezweifelt wird, ist parallel dazu eine Akzentuierung der expliziten und impliziten Ewigkeitsbehauptungen gegenüber der Schrift im Allgemeinen zu beobachten. Oder etwas plakativ formuliert: Dieser, Verlust' der Heiligen Schrift, der Bibel, führt zu einer zunehmenden Heiligung der Schrift als solcher.

Mit Letzterem einher gehen insbesondere die ästhetischen Auswirkungen der Reflexionsphilosophie, die Genie- als auch die Autonomieästhetik mit ihren enormen Einflüssen auf die Literatur- und Geistesgeschichte der Zeit um 1800 und der Moderne insgesamt (siehe Kapitel IV.3) und ebenso die Experimente in Richtung eines ewigen Schreibens sowie einer potenziell unbeendbaren Lektüre, die immer wieder auch die semiotische Flüchtigkeit von Schriftzeichen in den Dienst der Ewigkeitsattribuierung zu stellen suchen (siehe das Kapitel II.3).

ZumSchlussdieserkurzenundskizzenhaftenhistorischenProblematisierung lässt sich somit Folgendes zusammenfassend festhalten:

Offenbar waren im ,Abendland' die impliziten und expliziten Ewigkeitsbehauptungen gegenüber Schriftzeichen über eine mehr als zweitausendjährige Tradition bis zum 18. Jahrhundert bereits derart stark verankert, dass ausgerechnet die Aufklärung und die daraus hervorgegangenen literatur- und geistesgeschichtlichen Strömungen um 1800 sich nicht gegen sie gestellt haben, sondern wesentlich daran beteiligt gewesen sind, sie noch zu verstärken.

Dass die Ewigkeitsbehauptungen gegenüber Schriftzeichen bis heute Konjunktur, ja im 21. Jahrhundert geradezu Hochkonjunktur zu haben scheinen,

205 Man erinnere sich an den oben zitierten Textausschnitt aus Gryphius' Catharina von Georgien.

206 Vgl. u. a. A. Assmann 1999, S. 121-129, die dabei auch explizite humanistische Ewigkeitsbehauptungen gegenüber Schriftzeichen zitiert; sowie Nate 2018.

207 Vgl. dazu auch Neumann 2018. 
ließe sich schließlich an zahllosen Beispielen aus den unterschiedlichsten Bereichen aufzeigen, bis hin zur 2017 (erneut) ausgebrochenen Debatte über Sinn und Zweck der Germanistik, im Zuge derselben mancherorts frei nach Gadamer die Zeitlosigkeit der ,Klassiker' der Literatur beschworen wurde einer Tradition folgend, die, so wurde oben gezeigt, viel weiter zurückreicht als bis zu Gadamers Wahrheit und Methode. Besonders präsent ist aber die Verknüpfung jener alten Ewigkeitsbehauptungen gegenüber Schriftzeichen mit den neuen Medien und der fortschreitenden Digitalisierung: ${ }^{208}$ Die Phrase ,das Internet ${ }^{209}$ vergisst nie ist bereits zum Gemeinplatz geworden, was - lässt man berechtigte Bedenken bezüglich des Datenschutzes einmal beiseite - in historischer Hinsicht für ein derart junges Medium erstaunen mag und gerade auf semiotischer Ebene differenzierter zu betrachten wäre. Facebook bietet seinen Usern an, den jeweiligen persönlichen Account nach deren Ableben in einen virtuellen Grabstein umwandeln zu lassen, der zugleich als digitales Kondolenzbuch dient, mittels dessen die Hinterbliebenen die virtuelle Biographie des Verstorbenen gewissermaßen in aeternam fortschreiben können; ${ }^{210}$ und ambitionierte Programmierer arbeiten an dem Traum, einen Code zu schreiben, der eine künstliche Intelligenz möglich macht, die der menschlichen gleichkommt und selbst schöpferisch tätig zu werden vermag. Ob Letzteres je möglich sein wird, sei hier dahingestellt; zu erwähnen ist jedoch, dass jener Traum (von den jeweiligen Beteiligten erschreckenderweise weitestgehend unreflektiert) nichts Geringeres anstrebt als eine Kombination, an der sich bereits die mythologische Figur Pygmalion versucht hatte: eine Kombination des erschaffenen (Text-)Werkes, das nicht selber direkt schöpferisch tätig sein kann, mit dem biologischen Kinde, das die Gene seiner Schöpfer - in diesem Falle den von ihnen geschriebenen Code - weiterträgt und selber Trieb und Möglichkeit zum eigenständigen Erschaffen besitzt. Eine Kombination der beiden eingangs zitierten, von Diotima genannten Möglichkeiten, Unsterblichkeit zu erlangen.

\footnotetext{
208 Vgl. auch J. Assmann 2003, S. 46; und Krüger 2004.

209 Sowohl der Begriff Internet als auch World Wide Web verweisen auf ein aus unterschiedlichsten miteinander verwobenen Fäden bestehendes, weltweites Netz, ein weltweites Gewebe resp. Textum, sie konstituieren also eine Textmetapher.

210 Vgl. dazu auch Brukamp 2011.
} 


\section{Grundoperation Unendliche Aktualisation}

Dieses Großkapitel beschäftigt sich mit Versuchen, die Leser dazu anzuhalten, die jeweiligen Schriftzeichen resp. Texte unendlich oft erneut zu lesen. Solche Versuche können einerseits positiv darauf fokussieren, die Leser direkt zum Wieder- oder Weiterlesen zu zwingen, in diesem Fall werden sie im Folgenden unter der Unteroperation Unendliche Lektüre gefasst. Sie können andererseits aber auch negativ die semiologische Flüchtigkeit eines jeden Schriftzeichens und Textes, die zugleich die Möglichkeitsbedingung von potenziell unendlich vielen neuen und weiteren Lektüren ist, derart einsetzen, dass die Leser gerade dadurch dazu gedrängt werden, diese Flüchtigkeit durch ein Wiederlesen oder gar durch ein ergänzendes Weiterdenken, Weiterschreiben und letztlich wiederum Weiterlesen aufzuhalten. Ein Aufhalten, das semiotisch nicht möglich ist und gerade deshalb zu immer weiteren Versuchen Anlass geben kann. Diese Versuche fasst die Unteroperation Unendliches Verstummen. Die beiden Unteroperationen Unendliche Lektüre und Unendliches Verstummen sind also gewissermaßen zwei Seiten derselben Medaille, zwei komplementäre Seiten der Grundoperation Unendliche Aktualisation. Es ist deshalb nicht verwunderlich, wenn es bei den Unteroperationen zu Überschneidungen kommt, bedingen sie einander doch letztlich gegenseitig. Dennoch ist eine Unterteilung in Unendliche Lektüre und Unendliches Verstummen heuristisch wertvoll, mag sie doch in vielen Fällen aufzeigen, welche der beiden Unteroperationen jeweils dominant ist. Sie führt so zu einem geschärften Blick, der sich nicht nur in der Auseinandersetzung mit den einzelnen Textbeispielen, sondern besonders auch in literatur- und geistesgeschichtlicher Hinsicht als äußerst gewinnbringend erweist.

Das Kapitel umfasst die Auseinandersetzungen mit den Textbeispielen Lebens-Ansichten des Katers Murr, Miss Sara Sampson, Der Spinnerin Nachtlied und Ermunterung. Besondere Aufmerksamkeit liegt dabei auf den Anfängen und Enden der jeweiligen Textbeispiele, da davon auszugehen ist, dass die betreffende Grundoperation dort ihre größte Wirkmächtigkeit entfaltet und somit klarer und umfassender zu beobachten ist als an anderen Stellen. Auf die Auseinandersetzung mit den einzelnen Textbeispielen folgt abschließend das Kapitel, das die Grundoperation Unendliche Aktualisation in den geistesund literaturgeschichtlichen Kontext der Zeit zwischen 1755 und 1821 einzubetten sucht. 


\section{Unteroperation Unendliche Lektüre}

Entgegen der chronologischen Folge der Erscheinungsdaten eröffnet E. T. A. Hoffmanns Lebens-Ansichten des Katers Murr und nicht Lessings Miss Sara Sampson das Kapitel zur Unendlichen Lektüre. Dies liegt weniger daran, dass die vorliegende Arbeit ihr literaturhistorisch letztes Textbeispiel an den Anfang stellen möchte, um ihrerseits die Leser nach der Lektüre des Schlussteils wieder an den Anfang der Arbeit zu zwingen, sondern hat vielmehr folgende zwei Gründe: Erstens ist das Kapitel zu den Lebens-Ansichten des Katers Murr - den Umfängen der beiden Textgrundlagen entsprechend - das wesentlich größere und kann dadurch bereits zu Beginn des Hauptteils verschiedene Aspekte und Variationen der Operation Unendliche Lektüre sowie später noch relevantere Überschneidungen zu den anderen Grundoperationen aufzeigen. Dadurch ist es absichtlich etwas breiter angelegt als die nachfolgenden Kapitel und befasst sich vertieft mit Verfahren, die auch bei anderen Textbeispielen immer wieder zu beobachten sein werden: etwa mit dem metonymischen Titel, intertextuellen Verweisen, dem gezielten Einsatz von Absatz, Abschnitt und Gedankenstrich samt deren entortender Eigendynamik oder auch mit der Undarstellbarkeit des Todes durch die Sterbenden selbst. Zweitens hat das Kapitel zur Miss Sara Sampson so die Möglichkeit, sich ergänzend und unnötige Redundanzen vermeidend ganz auf Lessings Ästhetik des Endens zu konzentrieren und damit eine wichtige Grundlage für den nächsten Schritt, nämlich die literatur- und geistesgeschichtliche Einbettung der betreffenden Operation, zu legen. Diese Einbettung wird sich dann u. a. ausführlich mit dem Einfluss von Lessings Ästhetik des Endens auf die Auflösung der aristotelischen Einheit eines aus Anfang, Mitte und Ende bestehenden Werkes befassen, die wiederum auch für die Lebens-Ansichten des Katers Murr von wesentlicher Bedeutung ist.

\subsection{Lebens-Ansichten des Katers Murr}

Das vorliegende Kapitel ${ }^{1}$ folgt mittels eines ausgeprägten Close Readings dem Zweig der Hoffmann-Forschung, der mit Blick auf die Autor- und Herausgeberfiktion sowie auf die Verhandlung der Materialität von Texten und deren drucktechnischer Herstellung bereits darauf hingewiesen hat, dass Hoffmanns

1 In dieses Kapitel ist die unveröffentlichte Masterarbeit des Verfassers eingegangen: Gut, Markus: Figur(ation) der Unverortbarkeit, unverortbare Figur(ation). Eine Untersuchung zur Konstitution von Text als Gegenstand des Verstehens anhand von E. T. A. Hoffmanns LebensAnsichten des Katers Murr, Masterarbeit zur Erlangung des akademischen Grades Master of Arts der Philosophischen Fakultät der Universität Zürich, Abgabedatum: 30.10.2013. 
Roman Lebens-Ansichten des Katers Murr (1819/1821) die auctoritas des Autors ${ }^{2}$ resp. des Herausgebers über seinen Text infrage stellt. Ein Hinweis, der bereits das Unterlaufen der vermeintlichen Einheit und Ganzheit des Romans impliziert. Ein solches Unterlaufen aber verlangt wiederum geradezu - und hier decken sich die Beobachtungen des Verfassers mit denen Uwe Wirths -, dass der Leser mittels interpretativer Aufpfropfungen rahmend tätig zu werden hat. ${ }^{3}$ Dies ist jedoch eine Tätigkeit, die selbst nie an ein Ende gelangen kann, was die folgenden Kapitel anhand der Makro- als auch der Mikroebene von Hoffmanns Doppelroman zeigen werden.

Was die erwähnte Forschung betrifft, so sind dabei von besonderer Wichtigkeit: die Monographie von Sarah Kofman, die als Erste konsequent eine solche, dekonstruktivistisch geprägte Lektüre des Kater Murr vornahm, sowie aus der jüngeren Forschung insbesondere die Arbeiten von Claudia Liebrand, Remigius Bunia und Uwe Wirth. ${ }^{4}$ Während Uwe Wirth mit Bezug auf Derrida und Foucault vor allem mit den Begriffen der Aufpfropfung und der Funktion Autor resp. Funktion Herausgeber arbeitet, ${ }^{5}$ wird hier die textlinguistische Begrifflichkeit von Hausendorf/Kesselheim hinzugezogen. Angesichts der von Wirths Fokus auf Herausgeberfiktion, Rahmung und Aufpfropfung abweichenden Konzentration auf die Frage nach Anfang und Ende eines Textes und dessen potenziell endloser Lektüre soll diese linguistische Begrifflichkeit vor allem im zweiten Teil dieses Kapitels zur terminologischen Schärfung des Close Readings beitragen.

Hausendorf/Kesselheim teilen die Hinweise, die uns ein Text (samt Textträger) liefert, ihn als solchen $\mathrm{zu}^{\mathrm{k}} \mathrm{lesen},{ }^{6}$ in folgende Gruppen ein:

2 Gerade auch des genialen Autors; vgl. Kapitel IV.3.3.

3 Siehe unten, insbesondere Kapitel II.1.1.2; resp. Wirth 2008, u. a. S. 376 f. und 385 f.

4 Die in das Jahr 1927 zurückreichende Arbeit von Gustav Egli: E. T. A. Hoffmann, Ewigkeit und Endlichkeit in seinem Werk, die auch auf die Lebens-Ansichten des Katers Murr eingeht (vgl. Egli 1927, S. 104-121), kann aus heutiger Perspektive trotz vielversprechendem Titel nichts mehr zur hier vorliegenden Fragestellung beitragen.

5 Vgl. vor allem Wirth 2008.

6 „Sie [Textualitätshinweise, MG] signalisieren Textualität und sorgen auf ebenso unscheinbare wie effektive Weise dafür, dass wir etwas Geschriebenes beim Lesen als eine Art natürliche Lektüreeinheit und in diesem Sinn als Text wahrnehmen. Was uns in unserem kommunikativen Alltag als eine natürliche Lektüreeinheit, als ein lesbares Etwas erscheinen mag - ein Buch, ein Zeitungsartikel [...] -, steht also nicht von vorneherein fest, sondern ist gerade in seiner vermeintlichen Natürlichkeit durch und durch gemacht. Die Orientierung [des von den Autoren vorgeschlagenen Modells, MG] an Textualitätshinweisen soll dabei helfen, diese Herstellung von Textualität durch Textualitätshinweise sichtbar zu machen. Was ein Text ,ist', ergibt sich deshalb erst beim Lesen: Lesen ist nichts anderes als das Aufnehmen und Verarbeiten, das Auswerten und Verstehen von Textualitätshinweisen " (Hausendorf/Kesselheim 2008, S. 21). Wie Hausendorf/Kesselheim geht auch der Verfasser der 
Abgrenzungs- und Gliederungshinweise, Verknüpfungshinweise, Themahinweise, Funktionshinweise, Textsortenhinweise, Intertextualitätshinweise. ${ }^{7}$ Die beiden im Folgenden verwendeten Begriffe - Abgrenzungshinweis und dessen Unterbegriff Ganzheitshinweis ${ }^{8}$ - sind aus ebenjener Gruppe der Abgrenzungs- und Gliederungshinweise ${ }^{9}$ entlehnt:

\begin{abstract}
Alles, was dazu beiträgt, auf das Ganze eines Textes im Sinne einer textuellen Obereinheit hinzuweisen, betrachten wir in diesem Kapitel als Abgrenzungshinweis [...]. Abgrenzungshinweise leisten die Abgrenzung einer textuellen Obereinheit nach außen [...]. Alles, was dazu beiträgt, auf die Teile eines Textes im Sinne textueller Untereinheiten hinzuweisen, betrachten wir in diesem Kapitel als Gliederungshinweise. [...] Gliederungshinweise leisten die Gliederung einer textuellen Einheit in weitere Untereinheiten [...]. Zwischen Abgrenzungsund Gliederungshinweisen ist von Fall zu Fall mit fließenden Übergängen zu rechnen..$^{10}$
\end{abstract}

Auf die weitere Unterteilung in Gliederungshinweise wird in diesem Kapitel verzichtet: einerseits, um den ausgeprägten Abstraktionsgrad der unten stehenden Ausführungen nicht zusätzlich zu erhöhen; andererseits, weil der in Titelblatt und Vorwort aufgebauten Herausgeberfiktion des Romans folgend sowohl Murr-Autobiographie als auch Kreisler-Biographie als je eigene "textuelle Obereinheit" betrachtet werden, die, wenngleich zweifellos thematisch miteinander verknüpft und in der vermeintlich zufälligen Abfolge ihrer Teile aufeinander abgestimmt, dennoch so konzipiert sind, dass sie den Anschein erwecken sollen, zwei verschiedene eigenständige Texte zu sein: eine Autobiographie und eine Biographie.

Schließlich seien zur besseren Leserorientierung vorab die für das Folgende relevanten Aspekte von Komposition und Inhalt des Romans knapp umrissen: Der volle Titel des Romans lautet Lebens-Ansichten des Katers Murr nebst

vorliegenden Arbeit davon aus, dass ein Text erst durch sein Gelesenwerden zu einem Text (geworden sein) wird.

7 Hausendorf/Kesselheim 2008, S. 37.

8 „Amäußeren RandvonTextenstehenHinweise, dieeinenTextinseinermaterialen Ganzheit als Einheit identifizieren“ (ebd., S. 42). Diese Ganzheitshinweise unterteilen Hausendorf/ Kesselheim wiederum in Textträgerhinweise, Textsammlungshinweise, Titel, bibliographische und Impressumshinweise (vgl. ebd.).

$9 \quad$ Für die folgenden Unterkapitel ist dies zweifellos die wichtigste Kategorie, wenngleich in dem hier untersuchten Roman andere Hinweise wie Verknüpfungshinweise oder Textsortenhinweise sich ebenfalls für eine Untersuchung anbieten würden; oder z. B. Intertextualitätshinweise, die - wenngleich dort nicht so benannt - in der Forschung zu den Lebens-Ansichten des Katers Murr bislang auf breites Interesse gestoßen sind (siehe dazu repräsentativ: Genz 2009; Schäfer 20o1; Swales 1992-1993; Kofman 1985). 
fragmentarischer Biographie des Kapellmeisters Kreisler überliefert in zufälligen Makulaturblättern. Wie der Titel schon verrät, handelt es sich um einen Doppelroman, ein Umstand, der gemäß dem Vorwort durch „literarischen Vandalismus" des Katers Murr sowie durch das Versehen des Herausgebers zustande gekommen sei. ${ }^{11}$ Dieser Doppelroman ist wiederum in zwei Bänden erschienen, der erste Band 1819 (vordatiert auf 1820), der zweite 1821 (ebenfalls vordatiert auf 1822). ${ }^{12}$ Der in der "Nachschrift des Herausgebers" zu Ende des zweiten Bandes angekündigte dritte Band blieb aus. ${ }^{13}$ Im Folgenden wird jeweils aus der Ausgabe der "Bibliothek deutscher Klassiker" zitiert, ${ }^{14}$ die den Erstausgaben sehr nahe folgt. Aufgrund der ausgesprochen textnahen Lektüre, die in hohem Maße auch Typographie und Interpunktion berücksichtigt, wurden die betreffenden Stellen jedoch mit der Erstausgabe abgeglichen und Abweichungen vermerkt. ${ }^{15}$

Jener für die inhaltliche Doppelung verantwortliche „literarische[] Vandalismus" hat folgende Ursache: Murr hat nämlich während der Arbeit an seiner Autobiographie die Biographie des Kapellmeisters Kreisler zerrissen und deren Seiten als Löschpapier oder Unterlage verwendet, die dann aus Versehen ebenfalls mitabgedruckt wurden. Nun sind aber die Fragmente der KreislerBiographie $^{16}$ - die sich freilich nicht zu einem lückenlos kohärenten Text zusammensetzen lassen und damit jeweils auch als Einzeltexte fragmentarisch

11 Die entsprechende Stelle wird unten zu Beginn von Kapitel. II.1.1.2 zitiert.

12 Vgl. Hoffmann, Werke, Bd. 5, S. 899.

13 Es ist nicht gänzlich zu klären, ob dies dem Tode Hoffmanns (15. Juni 1822) geschuldet ist oder ob ein dritter Band grundsätzlich gar nicht vorgesehen war. Die durch die versetzte Anordnung der Murr- und Kreisler-Teile zustande kommende Kreisstruktur, die Band 1 und 2 miteinander verschränkt, spräche für Letzteres; Hoffmanns Arbeitsweise sowie sein Verhalten resp. seine Ankündigungen gegenüber seinem Verleger für Ersteres, also die Annahme, die auch vom Forschungsstand zur Zeit des Erscheinens der hier verwendeten Textgrundlage der „Bibliothek deutscher Klassiker“ klar präferiert wurde (vgl. zusammenfassend Steinecke 1992, S. 911 f.). Neuere Forschungen, denen sich auch das vorliegende Kapitel mit seinen Ergebnissen näher verbunden fühlt, präferieren wieder das Argument der Kreisstruktur (vgl. zusammenfassend Wirth 2008, S. 392), stellvertretend dafür sei hier vor allem auf Claudia Liebrand verwiesen (dies. 1996, S. 197-200).

14 Hoffmann, E. T. A.: Lebens-Ansichten des Katers Murr, in: Werke, Bd. 5, 1820-1821, herausgegeben von Hartmut Steinecke unter Mitarbeit von Gerhard Allroggen, Frankfurt am Main 1992.

15 Dies ist jeweils mit der Sigle ,Kater Murr $1820^{\prime}$ resp. ,Kater Murr 1822 ' kenntlich gemacht. Für ihre große Unterstützung bei der Beschaffung von Scans der betreffenden Stellen der Erstausgaben bedanke ich mich herzlich bei Bernhard Schemmel von der E. T. A. Hoffmann-Gesellschaft und Gerald Raab von der Staatsbibliothek Bamberg.

16 Im Folgenden der Einfachheit und Kürze halber ,Kreisler-Teil(e)‘ genannt; Gleiches gilt für die ,Murr-Teile‘, die durch die Einschübe der Kreisler-Biographie entstandenen Teile von Murrs Autobiographie. 
sind - zufällig so überliefert, dass der erste Kreisler-Teil des ersten Bandes, in der Chronologie der Biographieerzählung betrachtet, eigentlich der letzte sein müsste; ${ }^{17}$ während der letzte Kreisler-Teil des zweiten Bandes in dieser Hinsicht eigentlich der zweitletzte ist. Zudem beginnt der erste Band mit einer Reihe von Vorworten, während der zweite Band mit einer Nachschrift endet. Schematisch dargestellt sieht dies wie folgt aus:

- Titelblatt;

- Vorwort des Herausgebers [darin ist ironisch integriert eine Liste der in der Erstausgabe des ersten Bandes tatsächlich unterlaufenen Druckfehler];

- Vorrede des Autors;

- Vorwort. Unterdrücktes des Autors [als ein fiktiver, im Zuge des Drucks unterlaufener Fehler];

- N.[ach] S.[chrift] [...] d.[es] H.[erausgebers, der sich für das Versehen, dass das unterdrückte Vorwort Murrs ebenfalls abgedruckt wurde, entschuldigt];

- 1. Murr-Teil;

- letzter Kreisler-Teil;

- 2. Murr-Teil;

- 1. Kreisler-Teil;

- 3. Murr-Teil;

- 2. Kreisler-Teil;

$-[\ldots]$

- letzter Murr-Teil;

- zweitletzter Kreisler-Teil;

- Nachschrift des Herausgebers

Bei all dem wird ersichtlich, und die oben erwähnte Forschung hat bereits darauf hingewiesen, dass Hoffmanns Roman plakativ ausgedrückt nicht nur anhand der Figur Murr die Genieästhetik im Allgemeinen und Goethes Dichtung und Wahrheit im Speziellen parodiert und ihnen in der fragmentarischen Biographie Kreislers die prekäre Seite des Genies gegenübergestellt, ${ }^{18}$ sondern auch die Konstituenten der vermeintlichen Einheit Buch hinterfragt ${ }^{19}$ - Letzteres auch und gerade unter Berücksichtigung der drucktechnischen Herstellung und Materialität eines Buches. Dass die prekäre originale Einheit des göttlichen Genies und die prekäre Einheit seiner göttlichewigen Werke eng miteinander verknüpft sind, ist noch zu zeigen. So viel sei jedoch schon vorweggenommen: Die im hier untersuchten Roman stattfindende Verhandlung beider Einheiten ist zumindest kein Zufall; ebenso

17 Vgl. u. a. Hoch 1999, S. 63 f.

18 Dass sich diese Gegenüberstellung derart plakativ nicht halten lässt und die Nähe des Genies zum Wahnsinn nicht erst in der Romantik, wenngleich dort besonders akzentuiert, mitgedacht wurde, zeigt u. a. Kapitel IV.3.3.

Vgl. dazu auch Engelmann 1985, S. 141. 
wenig die damit verknüpfte Gegenüberstellung des „göttliche[n] Murr[s]“20 einerseits, der sich selbstbewusst seiner "unsterblichen Werke“ versichert, ${ }^{21}$ und des Kreiselns Kreislers um das geniale Werk andererseits - eines Kreiselns Kreislers, der ein solches geniales Werk nie zu erreichen glaubt und der seine Kompositionen, ${ }^{22}$ seine mittels schriftlich fixierter Zeichen verewigten Stücke in Anflügen von Wahnsinn immer wieder verbrennt.

\subsubsection{Makroebene: unendlicher Anfang und unendliches Ende}

Für die Auseinandersetzung mit Verfahren, die eine potenziell unendliche Lektüre zu provozieren suchen, bietet sich selbstredend der nähere Blick auf Textenden an. Bevor jedoch ebendieser Blick eingenommen wird, gilt es aufzuzeigen, dass für die vorliegende Fragestellung die genaue Analyse von Textanfängen ebenso zu berücksichtigen ist.

Um einen Textanfang genauer zu betrachten, muss man ihn zunächst finden - eine vermeintlich banale Aufgabe, die einen jedoch insbesondere beim hier untersuchten Roman zunächst nicht zu Antworten, sondern vielmehr zu einer ganzen Reihe von Fragen führt: Beginnt er mit dem Titel, dem Vorwort des Herausgebers oder der Vorrede des Autors? Oder beginnt der Roman erst mit dem ersten Satz des ersten Kapitels?

In ihrer groß angelegten Studie zu Paratext und Textanfang von 5 o Bildungsromanen aus den letzten drei Jahrhunderten ${ }^{23}$ reflektiert Annette Retsch zu

20 „So werden meine Werke auch gewiß in der Brust manches jungen geist- und gemütreichen Katers das höhere Leben der Poesie entzünden, und nimmt denn der edle Katerjüngling meine biographischen Belustigungen auf dem Dache vor, geht er ganz ein in die hohen Ideen des Buchs [sic] das ich so eben unter den Klauen habe, dann wird er im Entzücken der Begeisterung ausrufen: Murr, göttlicher Murr, größter deines Geschlechts, dir, dir allein verdanke ich alles, nur dein Beispiel macht mich groß -“ (Hoffmann, Werke, Bd. 5, S. 38$)$.

21 Etwa Hoffmann, Werke, Bd. 5, S. 38 (ausführlicher zitiert in Kapitel IV.3.3) oder 44: „Genies werden den genialen Kater in seinen ersten Werken leicht erraten, und über die Tiefe, über die Fülle des Geistes, wie er zuerst aus unversiegbarer Quelle aussprudelte, erstaunen, ja ganz außer sich geraten. Damit die Welt sich dereinst nicht zanke über die Zeitfolge meiner unsterblichen Werke, will ich hier sagen [...]." Hinzu kommt hier: Auch Murr appelliert an die ,Gemeinschaft der Genies', die ihn verstehen würden - eine paradoxalerweise geteilte Originalität, ohne die der Absturz in den Wahnsinn droht; vgl. dazu ebenfalls Kapitel IV.3.3.

22 „Irgendwo [ein Asterisk verweist auf: „Fantasiestücke in Callots Manier. Neue Ausg. T. I. Seite 32.“, MG] heißt es von dem Kapellmeister Johannes Kreisler, daß seine Freunde es nicht dahin hätten bringen können, daß er eine Komposition aufgeschrieben und sei dies wirklich einmal geschehen, so habe er doch das Werk, so viel Freude er auch über das Gelingen geäußert, gleich nachher in's Feuer geworfen“ (Hoffmann, Werke, Bd. 5, S. 302).

23 Vgl. Retsch 2000, S. 13. 
Beginn ihres Kapitels zur „Beziehung zwischen Paratext und Textanfang“ zwar die Möglichkeit, dass "bestimmte Aufgaben des ,eigentlichen` Textanfangs“ bereits z. B. im Vorwort auftreten können, hält aber trotzdem daran fest, dass die „Textwelt“ eigentlich erst „mit dem ersten Satz des ersten Kapitels“ beginne und der Paratext lediglich "ein Signal für den, eigentlichen 'Textanfang“ sei. ${ }^{24} \mathrm{Im}$ Falle des hier untersuchten Romans ist jedoch der „Paratext", also die scheinbar rein metatextuellen Informationen zur Fiktion wie Autorangabe, Vorwort des Herausgebers etc., Teil der Fiktion, ${ }^{25}$ womit sich der „Eintritt in die Textwelt" folglich bereits mit dem Lesen des Titelblattes vollzieht. Remigius Bunia, der sich aus narratologischer Sicht mit der Typographie der Lebens-Ansichten des Katers Murr auseinandersetzt, stellt denn auch treffend fest:

Murrs und Kreislers Aufzeichnungen wechseln sich ab. Es ist dabei Teil der Fiktion, daß dieser Text durch einen Fehler des Setzers zustande gekommen ist. Während ein gewöhnlicher nicht-situativer Erzählerwechsel - das heißt ein Erzählerwechsel in der Stetigkeit des récit, der keine stetige Entsprechung in der histoire hat - von außerhalb der Fiktion bestimmt wird, Teil der Disposition eines Textes, nicht aber der Disposition der fiktiven Welt ist, ist der nicht-situative Erzählerwechsel in den Lebens-Ansichten eine fiktive Tatsache. ${ }^{26}$

Genau diese "fiktive Tatsache" ist Teil der Autorfiktion, die sich bereits im Titelblatt konstituiert: Während im Titelblatt die Angabe des Bandes, des Erscheinungsortes und -jahres sowie des Verlags (Erster Band/Berlin, 1820/bei Ferdinand Dümmler $)^{27}$ auf die ,reale Welt' verweisen, so gehört der gesamte Titel inklusive „herausgegeben von E. T. A. Hoffmann" bereits zur fiktiven Welt des Romans. Dies führt wiederum dazu, dass sich der vermeintlich eindeutige metatextuelle Hinweis auf den Verlag etc. ${ }^{28}$ mit der Fiktion zu vermischen beginnt. ${ }^{29}$ Im Vorwort des Herausgebers, in dem Hoffmann eine fiktive Herausgeberfigur darstellt, ist denn auch die Rede davon, dass ebendiese Figur sich mit Herrn Dümmler unterhalte, ${ }^{30}$ womit auch Herr Dümmler zu einer Figur

\footnotetext{
24 Vgl. ebd., S. 151.

25 Zum Beispiel: ein Kater als Autor, Hoffmann lediglich als Herausgeber, der Fehler des Setzers etc.

26 Bunia 2005, S. 382.

27 Vgl. das Titelblatt weiter unten resp. Hoffmann, Werke, Bd. 5, Abb. 1, zwischen S. 944 und 945 .

28 Nach Hausendorf/Kesselheim sind diese eine Untergruppe der Ganzheits- resp. Abgrenzungshinweise, nämlich die „Titel, bibliographische[n] und Impressums-Hinweise“ (Hausendorf/Kesselheim 2008, S. 47).

29 Vgl. dazu auch Wirth 2008, S. 388-391.

30 "[...] so lief er [der Herausgeber, MG] sofort, mit dem Manuskript in der Tasche, zu dem Herrn Dümmler unter den Linden, und proponierte ihm den Verlag des Katerbuchs. Herr Dümmler meinte, bis jetzt habe er zwar nicht unter seinen Autoren einen Kater gehabt,
} 
dieser Fiktion wird, was wiederum auch auf das Titelblatt zurückverweist, auf dem der Name des Besitzers Ferdinand Dümmler metonymisch ${ }^{31}$ für Druckerei und Verlag steht.

Damit wird deutlich, dass der Anfang des hier untersuchten Romans so konstruiert ist, dass er nicht am ", eigentlichen' Textanfang, der mit dem ersten Satz des ersten Kapitels beginnt", 32 verortet werden kann. Zumal sowohl der erste Murr-Teil des ersten Bandes mit einem Goethe-Zitat ${ }^{33}$ als auch der erste Kreisler-Teil des ersten Bandes mit einem Sterne- Zitat beginnt ${ }^{34}$ und damit jeweils sogleich eine Verweiskette eröffnet wird, die den eigentlichen Romananfang und dessen Lektüre über den Roman hinaus entortet. ${ }^{35}$ Sarah Kofman bringt den entortenden Sog dieser intertextuellen Verweise wie folgt auf den Punkt:

Der ganze Text des Katers ist durchsetzt von Zitaten, die hier und da entlehnt sind, oft fehlerhaft; sie bewirken, daß das Buch nicht mehr endliches und festumrissenes Objekt ist, ruhend im geschlossenen Raum der Bibliothek. Der Kater, dieser Bücherwurm, nagt die Bände an, bricht ihre Begrenzungen auf und vollzieht damit den Mord am Autor als Vater des Werkes. ${ }^{36}$

Wobei jedoch zu ergänzen wäre, dass Murr, selbst Autor seines Werkes, nach Kofmans Argumentation vor allem auch Selbstmord „vollzieht“. ,Ausstellt‘ wäre deshalb wohl treffender als „vollzieht“, denn der Vollzug des ,Todes des Autors' ist Möglichkeitsbedingung einer jeden Verwendung zeichenhafter Kommunikation und nicht auf das krallenbewehrte Kompilieren Murrs beschränkt.

Selbst wenn man Annette Retschs Definition des „eigentlichen“ Textanfangs trotz der bislang beobachteten Verfahren einer Verweigerung eines solchen folgen würde, bliebe noch immer der Umstand, dass der Roman ein

wisse auch nicht, daß irgend einer seiner werten Kollegen mit einem Mann des Schlages bis jetzt sich eingelassen, indessen wolle er den Versuch wohl machen“ (Hoffmann, Werke, Bd. 5, S. 11).

31 Zu den weiteren Metonymien im Titel und deren im Zuge der Lektüre ausgelösten Übertragungsbewegungen siehe weiter unten.

$32 \quad$ Retsch 2000, S. 151 .

33 Aus dem Egmont; vgl. Ende 1.1.3.

34 Spannend ist hierbei, was Annette Retsch mit Bezug auf die textlinguistische Forschung zum eigentlichen Textanfang schreibt: „Das Ende des Textanfangs kann auch durch den Übergang zur a) ,direkten Rede', b) ,indirekten Rede‘ und c) ,erlebten' Rede signalisiert werden“ (dies. 2000, S. 150). Dies wäre nämlich ein weiterer Hinweis darauf, dass der eigentliche Anfang des hier untersuchten Romans verwischt wird, da sowohl das erste Kapitel Murrs als auch der erste Kreisler-Teil mit direkter Rede beginnen.

Vgl. Liebrand 1996, S. 213-217; Kofman 1985, S. 107 f.

$36 \quad$ Kofman 1985 , S. 105. 
doppelter ist. Es wäre demzufolge nicht nur ein Anfang des (Doppel-)Romans, sondern konsequent und paradoxal zugleich zwei Anfänge desselben zu bestimmen. Wobei den Anfang der Kreisler-Biographie festzumachen, sich als noch schwieriger erweist als im Falle der vermeintlich so chronologisch beginnenden Autobiographie Murrs - oder wo wollte man den Anfang einer fragmentarischen, nur in Makulaturblättern zufällig überlieferten Biographie verorten?

Immerhin mag auf der Suche nach dem Anfang die Tatsache Unterstützung bieten, dass sowohl Murrs Autobiographie als auch die fragmentarische Kreisler-Biographie auf materialer Ebene zwischen denselben zwei ${ }^{37}$ Buchdeckeln gebunden sind, die über ihre materiale Geschlossenheit jene beiden Biographien als Einheit, als ein Buch, versprechen. Selbst diese Ebene der Materialität wird jedoch bereits im Untertitel und insbesondere im Vorwort des Herausgebers als prekär beschrieben - und trotzdem: Angesichts der behandelten Schwierigkeiten scheint auf der Suche nach dem Anfang der Weg über die von der Materialität des Buches (und dem kulturell geschulten Umgang damit) suggerierte Ordnung dessen, was seine Buchdeckel umschließen, noch der einzig gangbare zu sein.

Hält man also, noch immer auf der Suche nach dem Anfang des Romans, scheinbar ganz banal Ausschau nach dem ersten Buchstabengebilde, das einem der Roman in dieser Ordnung zu lesen gibt, so ergibt sich daraus folgender Ablauf: Man nimmt das Buch zur Hand - es wird hier von der Erstausgabe des ersten Bandes ausgegangen -, schlägt unterbewusst geleitet vom Text- und Weltwissen des abendländischen Kulturraumes den illustrierten Buchdeckel zurück, ${ }^{38}$ stößt auf das Titelblatt, das man ebenfalls aufgrund seines Textwissens überhaupt sogleich und weitgehend unbewusst als solches erkennt, ${ }^{39}$ und beginnt von oben links nach unten rechts zu lesen: ${ }^{40}$

37 Ganz streng genommen wären es gar vier Buchdeckel, es handelt sich ja um einen in zwei Bänden erschienenen Fortsetzungsroman.

38 Selbstverständlich ließe sich bereits das Titelbild mit seiner Bildsprache und den zahlreichen darin enthaltenen Anspielungen als Text (im weiteren Sinne) lesen. Im vorliegenden Rahmen kann jedoch nicht auf die Umschlagbilder des Originals eingegangen werden. Im Zusammenhang von Dekonstruktion von Autor und Buch als Ganzheitshinweisen für einen Text böte Kofmans Feststellung, das Titelbild diene als letzte Garantie, den Leser hinsichtlich der "Identität [des Autors, MG] zu beruhigen“ (Kofman 1985, S. 118), einen interessanten, aber kritisch aufzugreifenden Ansatzpunkt für eine Auseinandersetzung mit dem Titelbild des ersten Bandes.

39 Vgl. dazu auch Hausendorf/Kesselheim 2008, S. 35 f. und $39 \mathrm{f}$.

40 Natürlich ist es möglich, mitten im Titelblatt mit dem Lesen zu beginnen (die Schriftgröße von „Katers Murr“ etwa provoziert dies geradezu), was aber nichts daran ändert, dass ein jeder Text im lateinischen Alphabet den Leser zu einer gewissen Linearität zwingt. Auch wenn man mitten in einem Buch zu lesen beginnt, so ist man - sofern 


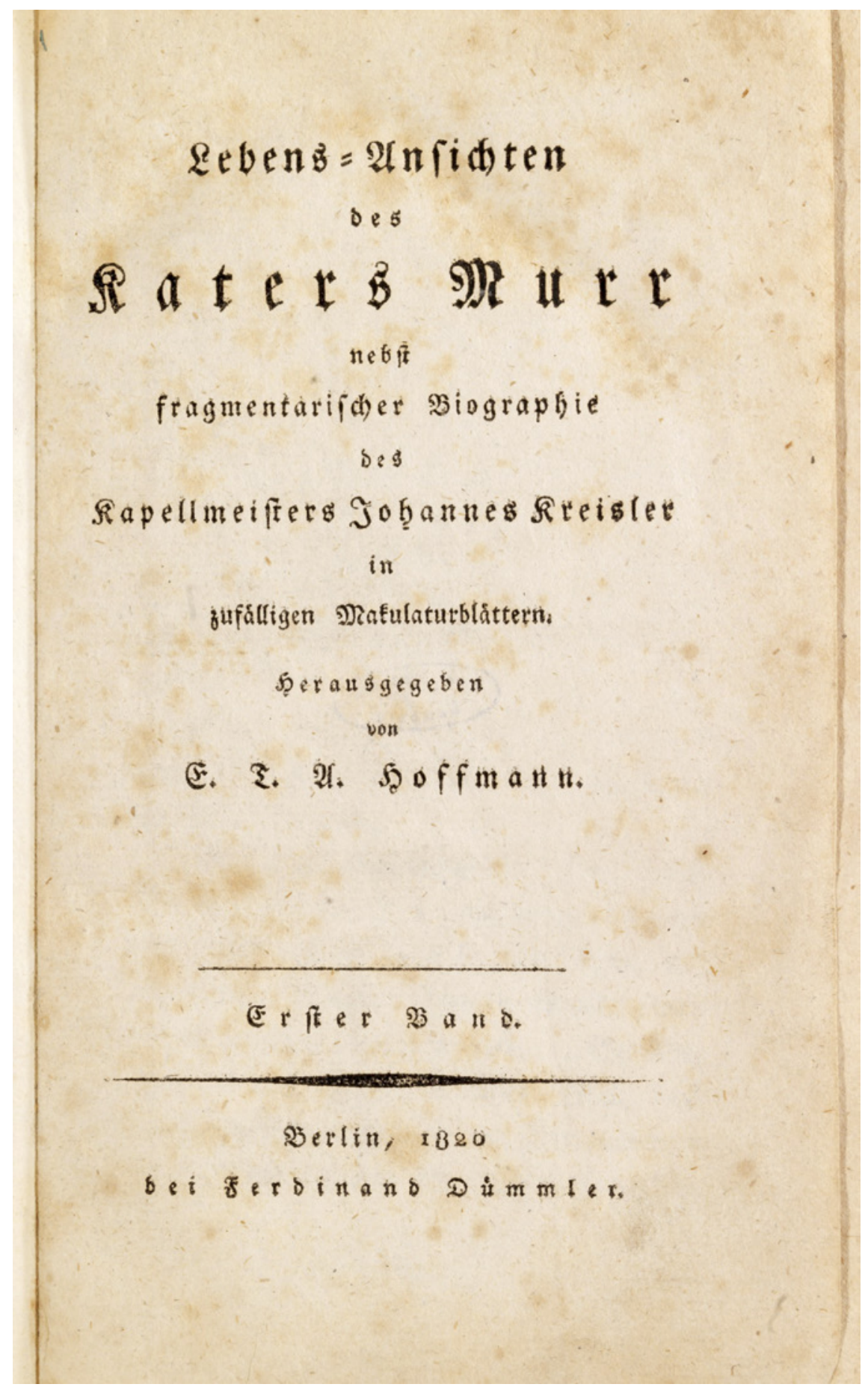

Abb. 1 Titelblatt der Erstausgabe; Staatsbibliothek Bamberg, Sigle Sel.229-1. 
Intuitiv möchte man also antworten, der Roman beginne mit dem ersten Wort des Titels: Lebens-Ansichten. An diesem Punkt nun sei dem Folgenden eine These vorangestellt, die sodann in den Abschnitten a) bis c) verifiziert werden soll. Die These lautet:

Der vermeintliche Anfang von Hoffmanns Titel, nämlich das Kompositum Lebens-Ansichten, stellt in nuce sowohl auf morphologischer und semantischintertextueller als auch auf lautlicher Ebene den Anfang des Romans als nicht exakt verortbar aus.

a) [Morphologische Ebene:] Kaum vermeint man, den Anfang des Romans im ersten Wort des Titels gefunden zu haben, so stellt sich das nächste Problem. Denn bei diesem ersten Wort ist wiederum eine Doppelung zu beobachten: Genau genommen handelt es sich nämlich um zwei mittels Fugen-s und Bindestrich(en) verbundene Wörter, um das Kompositum Lebens-Ansichten. Beginnt der Roman nun also mit dem Wort Leben oder mit dem Kompositum Lebens-Ansichten?

b) [Lautliche Ebene:] Das Wort ,Leben' bildet in der deutschen Sprache bekanntermaßen ein Minimalpaar mit ,Lesen'. In ,Lebens-Ansichten` vermag demnach auch ,Lesens-Ansichten' mitzuklingen. So wirft bereits der Titel die hermeneutischen Fragen auf, ob die Lektüre des Romans (und von Texten im Allgemeinen) mit dem Lesen oder mit den Ansichten über das Lesen und zu Lesende beginnt oder mit beidem zusammen und danach, wie Lesen und Ansichten miteinander in Verbindung stehen.

c) [Semantisch-intertextuelle Ebene:] Auch auf der semantischen Ebene gerät man in Schwierigkeiten, will man den Anfang des Titels genau festmachen. Denn der erste Titelteil Lebens-Ansichten des Katers Murr ${ }^{41}$ zitiert mindestens ${ }^{42}$ auch Sternes Romantitel Life and Opinions of Tristram Shandy, Gentleman. Der Anfang des Titels und damit die ersten Wörter des Romans verweisen demnach auf den Anfang eines anderen Titels, sind Zitat und somit

man nicht willkürlich einzelne Buchstaben , herauspickt sogleich wieder der Linearität unterworfen, indem man die einzelnen Buchstaben von links nach rechts zu einem Wort zusammenfügt.

41 Selbst der Name Murr scheint über Jean Pauls Leben Fibels ein Zitat eines Zitates des Namens eines Gelehrten aus Augsburg, Christian Gottlieb von Murrs, zu sein (vgl. Wirth 2008, S. 415, Anm. 247).

42 Zusätzlich zitiert der Titel wohl auch Ernst Wagners Romantitel Wilibald's Ansichten des Lebens (vgl. Retsch 200o, S. 67). Auch Murrs Vorrede des Autors weist Parallelen zum Vorwort in Wagners Roman auf (vgl. ebd., S. 9o). Zur Anlehnung an die typische Bildungsromantitelgebung (Geschichte und Personenname) des 18. Jahrhunderts und zur an barocke Praktiken erinnernden, titelblattfüllenden Gestaltung des Titels siehe ebd., S. 67 . 
ein Zweites, werden zur Mitte innerhalb einer intertextuellen Verweiskette. ${ }^{43}$ (Hinzu kommt natürlich, dass es sich beim Verweis des Untertitels auf den Kapellmeister Kreisler letztlich ebenfalls um ein Zitat handelt, nämlich um das Zitat einer literarischen Figur aus anderen Schriften Hoffmans. $)^{44}$

Bemerkenswert ist dabei auch die Abweichung des ersten Teils von Hoffmanns Titel gegenüber dem Titel bei Sterne. Bettina Schäfer schreibt dazu:

Jedoch bereits der Titel ,Die Lebens-Ansichten des Katers Murr impliziert in dieser Operation von Variation und Imitation des englischen Titels eine Hindeutung auf das Gestaltungsprinzip des Sterne-Textes in seiner Modifikation durch Hoffmann. Aus den Substantiven ,Leben` und ,Meinungen' wird bei Hoffmann das Kompositum ,Lebens-Ansichten', und dies durch einen Bindestrich verbunden. Gibt es im ,Tristram Shandy' korrespondierend mit der Zweiteilung des Titels zwei Erzählbewegungen, Fortschreiten im Erzählfluss und $A b s c h w e i f e n$ vom Erzählfluss, so scheint doch im ,Kater Murr' schon in der Titelgebung die Betonung auf dem Segment des Erzählflusses zu liegen. [Hervorhebungen, MG] ${ }^{45}$

Zu der von Schäfer genannten „Variation“ resp. zur „Betonung des Erzählflusses" sei je ein Punkt genannt:

1. Indem Hoffmann Sternes Titel imitiert und zugleich variiert, vermag sein Titel über den Verweis auf denjenigen Sternes Schreiben und Lesen poetologisch als „Imitation“ eines Textes bei gleichzeitiger "Variation“ desselben auszustellen. Dies wird besonders deutlich, wenn man das oben behandelte Minimalpaar Leben - Lesen sowohl auf die wörtliche Übersetzung von Sternes als auch auf Hoffmanns Titel bezieht, wobei man folgende Titel(teile) erhält: $L e[\mathrm{~s}]$ en und Ansichten resp. Le[s]ens-Ansichten. Dadurch, dass Hoffmann also den Begriff Leben für das Leben Murrs, das eben nur als Gerade-gelesenWerdendes zu haben ist, mit dem Wort Ansichten zu einem Kompositum verbindet, verhandelt sein Titel im Gegensatz zu demjenigen Sternes auch den hermeneutischen Umstand, dass Lesen und Ansichten (nach Gadamer „Vorurteile“) eben nicht klar voneinander zu trennen sind, sondern vielmehr in einer engen Beziehung zueinander stehen.

2. Mit „Betonung auf dem Segment des Erzählflusses“ meint Schäfer offenbar das vom Kompositum implizierte Erzählen von (Lebens-)Ansichten im

43 So meint denn auch Kofman mit Blick auf die Anfänge des ersten Murr-Teils und des ersten Kreisler-Teils des ersten Bandes: „Jedes ,Beginnen“ ist also ein ,Zitieren“ (Kofman 1985, S. 107), jedoch ohne auf das Sterne-Zitat im ersten Kompositum des Titels hinzuweisen. Zur Intertextualität im Kater Murr vgl. das Kapitel „Beobachtungen zur ,penetranten Intertextualität' der Lebens-Ansichten“ in Wirth 2008, S. 399-409.

44 Vgl. Liebrand 1996, S. 195.

45 Schäfer 2001, S. 120. 
Gegensatz zu dem bei Sternes Titel implizierten Erzählen eines Leben(s), von dem die Darlegung von Ansichten abschweife. Widersprüchlicherweise folgt bei Schäfer auf die oben zitierte Stelle ein von ihr nicht weiter kommentiertes Zitat Hartmut Steineckes, welches das „Fragmentarische“ bei Hoffmann gegenüber dem „zusammenhängenden Erzählfluss bei Sterne“ betont. ${ }^{46}$ Vielleicht möchte sie damit sagen, die „Betonung auf dem Segment des Erzählflusses“ mache es überhaupt erst möglich, mit fragmentarischem Erzählen zu spielen und dieses auszustellen. Dies ließe sich mit Bezug auf die Titel bei Hoffmann und Sterne wie folgt weiterziehen: Während Sternes Titel mit Life ein grammatikalisch eindeutig abgrenzbares erstes Wort besitzt, betont der Titel Lebens-Ansichten zwar die Verschmelzung von Leben und Ansichten, doch sein erstes Wort Lebens ist aufgrund des -s zugleich fragmentarisch. ${ }^{47}$ Man könnte also sagen, Hoffmanns Titel figuriert auch, dass ein jedes noch so zusammenhängend scheinendes Erzählen eine Zusammensetzung aus zitierten Fragmenten darstellt, die letzten Endes willkürlich ist, ${ }^{48}$ im Grunde weder Anfang noch Ende besitzt und deshalb ständig bedroht ist, selbst als Fragment aufzubrechen und als solches erkannt zu werden (vgl. dazu auch Kapitel II.3.3 zur Fragmentästhetik).

Zum Anfang des Titels lässt sich somit zusammenfassend festhalten: Hoffmanns Titel(variation) lehrt uns, dass es in hermeneutischer Hinsicht grundsätzlich gar kein Lesen (kein Leben zu lesen) gibt, das in Lesen (ein gelesenes Leben) und Ansichten (in Ansichten über dasselbe) zu trennen wäre. Es gibt höchstens Lesens-Ansichten, höchstens die potenziell endlose (und anfangslose) Verschmelzung von gelesenem Leben mit den Ansichten über und durch die Lektüre desselben. Murrs gesamte Autobiographie stellt dieses hermeneutische Problem aus, denn gerade die vermeintlich so genialen Lebens-Ansichten des Katers - und dies ist natürlich auch die große Parodie auf Goethes Dichtung und Wahrheit resp. die Genieästhetik der vorangegangenen Jahrzehnte im Allgemeinen ${ }^{49}$ - entpuppen sich letztendlich als nichts anderes als seine Lesens-Ansichten, als von ihm andernorts gelesene

\footnotetext{
46 Ebd.

47 Betrachtet man „Lebens“ isoliert, so ist es entweder Genitivattribut, zu dem das Bezugsglied, oder Teil eines Kompositums mit Fugen-s, zu dem das zweite Glied (oder auch mehrere Glieder) fehlt bzw. fehlen.

48 Damit ist auch schon Murrs Schreibverfahren (zitieren, herausreißen, neu kombinieren, einfügen etc.) im Titel in nuce ausgestellt.

49 Die Parodie des Genies durch Hoffmann wird in Kapitel IV.3.3 zur Genieästhetik nochmals aufgegriffen.
} 
Ansichten fremder Federn. ${ }^{50}$ Das erste Kompositum des Titels nimmt vorweg, was der gesamte Roman zuweilen bis zum Äußersten zelebrieren wird: die Unverortbarkeit seines Anfangs und Endes und die damit einhergehende potenzielle Unendlichkeit seiner Lektüre, die, da dieses Potenzial von einem sterblichen Leser nicht ausschöpfbar ist, immer schon fragmentarisch gewesen sein wird.

Um vom Anfang des hier untersuchten Romans zu dessen Ende überzuleiten, sei noch eine letzte Beobachtung zum Titel angeführt: Beim ersten Titelteil Lebens-Ansichten des Katers Murr handelt es sich um eine Metonymie. Murr tut nämlich nicht nur seine Ansichten kund, sondern erzählt sein Leben, zu dem er Ansichten äußert. Die Lebens-Ansichten Murrs sind also im wörtlichen Sinne bloß ein Teil seiner Autobiographie. Aus textlinguistischer Sicht lässt sich dazu und zu metonymischen Titeln im Allgemeinen, deren zentrale Funktion in den Beispieltexten der vorliegenden Arbeit noch wiederholt zu beobachten sein wird, folgende These festhalten:

50 Vgl. dazu auch Kofman 1985, S. 108: „Man kann sogar sagen, dass das ganze ,Leben` des Katers, seine gesamte Erfahrung, ein einziges literarisches Zitat ist, eine Wiederholung dessen, was er in den Büchern gelesen hat (selbst wenn er manchmal am eigenen Leib erfahren muss, dass sich nicht immer alles so verhält, wie es in den Büchern steht). Der Text des Lebens und der der Schrift sind eng miteinander verschränkt.“

Bemerkenswert ist zudem Martin Swales Feststellung, Murrs Autobiographie basiere „auf dem Versuch, sowohl in philosophischer als auch literarischer Hinsicht einen Metadiskurs zum eigenen Leben zu finden." Wobei dieser Versuch jedoch misslinge, „die philosophisch anvisierte Transzendenz“ am „unabdingbaren Vorhandensein des Kreatürlich-Tatsächlichen" scheitere und sich „die künstlerische Transzendenz" als bloße Zitatwut entpuppe (Swales 1992-1993, S. 51). Des Weiteren schließt er seinen Aufsatz u. a. mit folgendem Fazit: „Kater Murr gehört in die Tradition des selbstreflexiven europäischen Romans der Neuzeit. Das überaus Wichtige an Hoffmanns Roman in diesem Kontext ist, glaube ich, dass sich das Selbstreflexive gleichzeitig potenziert und kritisch durchleuchtet. Die Sehnsucht nach Transzendenz, sowohl geistiger als auch literarischer Transzendenz, die etwa der romantischen Ironie innewohnt, wird als Formprinzip von Hoffmann aufs meisterhafte gehandhabt - aber daneben, mittels der Kater-Murr-Figur aufs intensivste hinterfragt, wie wir gesehen haben. Denn es wird die Möglichkeit aufgeworfen, dass der Prozess der ewigen erzählerischen Agilität, sprich romantischer Ironie, dank welchem die jeweilige Setzung einer fiktiven Welt relativiert wird, letzten Endes in den endlosen unentrinnbaren Leerlauf eines ewig sich reproduzierenden Meta-Diskurses [er scheint damit vor allem die oben erwähnte „Zitierwut“ Murrs zu meinen, MG] mündet“ (ebd., S. 55). Falls der Verfasser Swales richtig versteht, sei hier bei aller übrigen Zustimmung Folgendes ergänzt: ,Potenzierte Selbstreflexivität‘ lässt sich nicht nur und erst bei Hoffmann, sondern z. B. auch schon bei Novalis betrachten (vgl. Kapitel IV.1), ob sie selbst jedoch überhaupt ,kritisch durchleuchtet‘ und ,hinterfragt ${ }^{\star}$ werden kann, da sind Zweifel anzumerken (vgl. Kapitel IV.3.1). 
Der metonymische Titel dient als Ganzheitshinweis ${ }^{51}$ dazu, den Roman als ganzen Text ein- und abzugrenzen. Das Kompositum Lebens-Ansichten kann aber nicht nur im übertragenen Sinne metonymisch als Verweis auf ein Ganzes (die ganze Autobiographie Murrs) gelesen werden, sondern zugleich auch im ,eigentlichen', wortwörtlichen Sinne als Verweis auf einen Teil (eines gedachten/ konstruierten Ganzen). Damit unterläuft es den Ganzheitshinweis des Titels und stellt ihn als Konstrukt aus, das zwar für die Annahme eines Ganzen denknotwendig, aber eben letztlich nur ein Konstrukt ist.

Anhand des (vermeintlichen) Endes der Murr-Biographie lässt sich diese These besonders gut verifizieren. Murr schließt das vierte und letzte Kapitel (von ihm Vierter Abschnitt genannt) seiner Autobiographie mit folgendem Abschnitt ab:

Mein Meister mußte verreisen und fand es für gut, mich auf die Zeit seinem Freunde, dem Kapellmeister Johannes Kreisler in die Kost zu geben. Da mit dieser Veränderung meines Aufenthalts eine neue Periode meines Lebens anfängt, so schließe ich die jetzige, aus der du, o Katerjüngling! so manche gute Lehre für deine Zukunft entnommen haben wirst. $-{ }^{52}$

Der erste Satz dieses letzten Abschnittes lässt sich nicht als Ansicht Murrs im engeren Sinne bezeichnen, ist er doch lediglich eine Nacherzählung der Ereignisse, ohne dass er eine Meinung oder Ansicht dazu äußern würde..$^{53}$ Letzteres holt Murr dann im zweiten Satz des Abschnittes, der zugleich den (vermeintlich) letzten Satz der Murr-Biographie darstellt, nach, indem er darin die nicht

$5^{1}$ Dieser Ganzheitshinweis ließe sich denn auch noch genauer als „Titelhinweis“ bezeichnen, siehe dazu oben die einleitenden Bemerkungen zum Modell von Hausendorf/ Kesselheim.

$5^{2}$ Hoffmann, Werke, Bd. 5, S. 436.

53 Dabei wird klar, dass, würde Murrs Autobiographie nur aus Ansichten bestehen, sie sehr fragmentarisch(!) wäre, da diejenigen Dinge, Ereignisse etc., zu denen er seine Ansichten äußert, fehlen würden. Ein Beleg dafür ist auch die Nachschrift des Herausgebers: „Der Herausgeber findet es daher der Sache nicht unangemessen, wenn er in einem dritten Bande, der zur Ostermesse erscheinen soll, dies von Kreislers Biographie noch vorgefundene den geneigten Lesern mitteilt und nur hin und wieder an schicklichen Stellen das einschiebt, was von jenen Bemerkungen und Reflexionen des Katers der weiteren Mitteilung wert erscheint" (Hoffmann, Werke, Bd. 5, S. 457 f.). Der Herausgeber kündigt also die Edition weiterer Kreisler-Fragmente an, wobei er auf eine Fortsetzung von Murrs Autobiographie nur mit den beschreibenden Begriffen (und nicht mehr mit einem Ganzheit suggerierenden, metonymischen Titel) Bemerkungen und Reflexionen des Katers verweist. Dort also, wo Murrs Autobiographie nur noch Ansichten enthält, wird sie zum Fragment, das nun als in die Kreisler-Biographie eingeschoben (vgl. „einschiebt“) bezeichnet wird - und nicht mehr umgekehrt, wie es das "nebst“ im Titelblatt des ersten und zweiten Bandes noch suggeriert hat. 
unwesentliche Ansicht über sein Leben äußert, jene Ereignisse hätten eine neue „Periode“ seines Lebens eingeläutet - und damit die vorangegangene „Periode" beendet. Mit einer Ansicht über die Wirkung des vorangegangenen Kapitels der Autobiographie auf die Leser derselben - also einer LesensAnsicht - sucht Murr sodann performativ diesen zweiten Satz und damit das Kapitel zu schließen.

Bereits in diesem letzten Abschnitt wird so vorweggenommen, was im Zuge des Weiterlesens geschehen wird: Das Ich der Murr-Autobiographie wandert vom „Meister“ zum „(Kapell-)Meister“, kreiselt zu Kreisler. ${ }^{54}$ Und die „Lehre“, die dabei vermittelt wird, ist auf poetologischer Ebene eben auch, dass eine Autobiographie zu schreiben letztlich nicht möglich resp. ein unbeendbares Unterfangen ist, da das (Be-)Schreiben des eigenen Lebens zugleich auch dieses Schreiben selbst umfassen müsste und immer so fort. Die einzige Möglichkeit, dem gerecht zu werden, wäre folglich das unendlich oft zu potenzierende Schreiben über das biographische Schreiben und dessen Unmöglichkeit: etwa das Schreiben darüber, dass auf eine Satz-„Periode“ die nächste folgt, ohne dass das Ende der letzten Lebens-„Periode“ je von demjenigen, der sein eigenes Leben (be-)schreibt, in eine Satz-„Periode“ gefasst werden könnte. ${ }^{55}$

Was die Suche nach dem Ende des Romans betrifft, so lässt sich hier gleich anknüpfen: Jener letzte Satz - der wie bereits der Titel Lebens- und LesensAnsichten vereint - kann nicht eindeutig als Ende der Autobiographie Murrs verortet werden. Dies u. a. deshalb nicht, weil der fiktive Herausgeber im Nachwort eine Fortsetzung derselben ankündigt, ${ }^{56}$ weil das noch folgende letzte Kreisler-Fragment wie alle anderen Kreisler-Fragmente auch als Teil von Murrs Schreibakt betrachtet werden könnte und weil der letzte Murr-Teil ganz genau genommen nicht mit einer Lebens-Ansicht endet, sondern mit einem Gedankenstrich. ${ }^{57}$ Ist dieser Gedankenstrich nun als Gedanken- oder eine Art Pausenstrich zu lesen? Oder verweist er - die in der Chronologie des Romans

54 Vgl. auch Wirth 2008, S. 398. Es ist Wirth jedoch an dieser Stelle zu widersprechen, dass es logisch "gar nicht" möglich sei, dass der erste Kreisler-Teil des ersten Bandes, in dem Murr von Abraham an Kreisler übergeben wird, bereits gedruckt vorliegen könne, wenn im letzten Murr-Teil des zweiten Bandes diese Übergabe erst angekündigt werde. Dies wäre nur unmöglich, wenn Murr in ,Echtzeit' seine Biographie fortlaufend schreiben würde. So aber kann Murr seine Autobiographie lange nach den darin erzählten Ereignissen verfassen, auch noch nachdem Teile seines Lebens bereits in der Biographie eines anderen beschrieben worden sind.

55 Siehe dazu auch weiter unten; sowie Kapitel II.3; Letzteres dann auch u. a. mit Blick auf Jean Paul und dem Verweis auf seine Konjektural-Biographie.

$56 \quad$ Vgl. drei Anmerkungen weiter oben.

57 Zum Gedankenstrich bei Jean Paul vgl. Kapitel II.3.2.1; resp. Wieland 2013, S. 299-306; zum Gedankenstrich bei Kleist vgl. Nehrlich 2012, insbesondere S. 115-162. 
noch ausstehende Lektüre des Nachwortes wird es nahegelegt haben - auf einen Abbruch der Autobiographie? ${ }^{58}$ Für Letzteres spräche neben dem Nachwort, dass am Ende der drei anderen Kapitel resp. „Abschnitte“, wie sie in den Überschriften benannt sind, jeweils kein Gedankenstrich steht.

Welche Antwort man auch immer wählt, die soeben genannten Lesarten des Gedankenstriches zeigen vor allem eines: Die Lektüre der Autobiographie Murrs endet nicht mit jenem Gedankenstrich, sondern verschiebt sich sogleich aufs Nachwort, auf die Enden der drei vorangegangenen Kapitel/„Abschnitte“, und vor allem auf den nachfolgenden, vermeintlich letzten Kreisler-Teil, der noch vor dem Nachwort auf den letzten Murr-Teil folgt. Was nämlich für den Anfang des eigentlichen Romans gilt, gilt auch für dessen Ende: Es ist aufgrund der Tatsache, dass Murrs Autobiographie mit Fragmenten der KreislerBiographie durchsetzt ist, mindestens gedoppelt.

Hinzu kommt noch ein weiteres, grundsätzlicheres Problem, das sich ausführlich im Kapitel zu Lessings Miss Sara Sampson anhand des Sterbens in der Tragödie stellt und das auch der Gattung der Autobiographie als solcher inhärent ist: die Undarstellbarkeit des Todes durch denjenigen, der stirbt. ${ }^{59}$ Denn wenn Murr sein Leben (> bios) selbst (>autos) schreibt (> gráfein), wer schreibt dann seinen Tod? Als Auto-bio-graph kann Murr zwar die Geschichte seines Lebens selbst verfassen, aber nie deren Ende. Denn solange er dies noch tun kann, lebt er noch, und wenn er nicht mehr lebt, kann er nicht mehr schreiben, er sei tot. Den Tod des Autors (hier für einmal wortwörtlich gemeint $)^{60}$ einer Autobiographie vermag demnach nur eine zweite Person als Nachtrag zur Autobiographie festzuhalten, nicht aber der Autor selbst. Und

58 Zum Gedankenstrich im Allgemeinen vgl. Kammasch 2009; und Nehrlich 2012, S. 117-123.

59 Vgl. dazu auch Angehrn 2017, insbesondere S. 117-130.

6o An der Autobiographie wird aber auch der,Tod des Autors' im übertragenen Sinne Barthes' als Voraussetzung für die potenziell unendlich oft erfolgende ,Wiederauferstehung $/$ das ,Leben' seines Textes besonders deutlich: Gerade dadurch, dass der Autor einer Autobiographie nie das Ende seines Lebens (be-)schreiben kann, kann er als Figur ,seiner' Autobiographie auf inhaltlicher Ebene nie sterben (zur ästhetischen Nutzbarmachung eines ähnlichen Umstandes vgl. insbesondere die Ausführungen zum mittelhochdeutschen Tagelied unter II.2.1). Und dennoch endet ihr Leben als gelesener Text immer wieder, sobald ein Leser den Text nicht mehr liest. Selbst wenn nämlich nur ihr Leben und nicht ihr Tod in der Autobiographie beschrieben wird, so können diese Figur und ihr Leben nur im Zuge des Gelesenwerdens zum Leben erwachen. Kofman interpretiert denn die Stelle, wo Kreisler über Biographie und Biographen reflektiert und dabei davon spricht, er habe sich als „Leichnam, ausgestreckt auf der Tafel liegend, bereit zur biographischen Sektion“ (Hoffmann, Werke, 1992, S. 108), erblickt, auch wie folgt: „Kreisler vergleicht die ,authentischen' Biographien mit Seziertischen, auf denen Kadaver ausgebreitet liegen, und führt so die Biographie auf eine Thanatographie zurück“ (Kofman 1985, S. 89). 
in der Tat lautet die Antwort auf die soeben gestellte Frage denn auch: der Herausgeber, und zwar im Nachwort resp. in seiner Nachschrift:

Am Schluß des zweiten Bandes ist der Herausgeber genötigt den geneigten Leser eine sehr betrübte Nachricht mitzuteilen. - Den klugen, wohlunterrichteten philosophischen, dichterischen Kater Murr hat der bittre Tod dahin gerafft mitten in seiner schönen Laufbahn. ${ }^{61}$

Der Leser muss also über die Autobiographie und die darin enthaltenen Makulaturblätter hinaus bis zur Nachschrift des Herausgebers weiterlesen, um das Ende von Murrs Leben und des Lebens, das dieser in seiner Autobiographie beschreibt (und das noch frühzeitiger zu Ende ist als das tatsächliche Leben Murrs), zu erfahren. ${ }^{62}$ Dies heißt aber auch, dass die Lektüre über das Ende der Autobiographie und des darin beschriebenen Lebens hinausgeht. Wenn es also einem Autor einer Autobiographie verwehrt ist, das Ende seines Lebens festzuhalten, so folgt daraus, dass er sein Leben allein schon deshalb nie als ein Ganzes schreiben kann, weil seiner Biographie immer das Ende, der Tod, fehlen wird. Denn um tatsächlich ein Autobiograph zu sein, müsste er zugleich auch Autothanatograph (von altgriechisch thánatos, der Tod) ${ }^{63}$ sein können.

Hinzu kommt, dass auch jeder Anfang einer Biographie eine willkürliche Setzung ist: Beginnt man mit der Geburt, mit der Zeugung (wie etwa in Tristram Shandy), ${ }^{64}$ mit einer Ahnenreihe usw.? Ähnlich wie im Falle des Todes ist der Autobiograph, der sich weder an die eigene Zeugung noch an die frühste Kindheit erinnern kann, auf die Hilfe resp. die Informationen Dritter angewiesen. Murr fehlt sogar eine solche Informationsquelle, wodurch auf die willkürliche Setzung des Anfangs einer jeden (Auto-)Biographie sogar explizit verwiesen wird: „Ja! es ist nicht anders, auf einen [sic] Boden muß ich geboren sein! - Was Keller, was Holzstall - ich entscheide mich für den Boden!'65 Oder

61 Hoffmann, Werke, Bd. 5, S. 457.

62 Da Murr am Ende seiner Autobiographie schreibt, seine Zeit bei Kreisler habe eine neue Periode dargestellt, muss man davon ausgehen, dass zwischen der Zeit, die seine Autobiographie umfasst, und dem Zeitpunkt der Niederschrift der Autobiographie ein größerer Abstand klafft, den zu schließen Murrs frühzeitiger Tod verhindert hat. Hierbei wird ersichtlich, dass die Autorfiktion quasi zu einer Dopplung von Murrs Leben führt: Erstens wird von einem lebenden Autor Murr ausgegangen, der eine Autobiographie samt Vorwort(en) verfasst. Zweitens präsentiert dieser ,reale‘ Murr sich selbst als Figur seiner Autobiographie, wobei das Leben dieser Autobiographiefigur nicht (völlig) dem des realen Murr gleichzusetzen, sondern ein (z. B. mit zahlreichen Topoi versehenes) Konstrukt eines Lebens ist.

63 Vgl. Kofman 1985, S. 89; resp. drei Fußnoten weiter oben.

64 Vgl. Sterne, Tristram Shandy, S. 11.

65 Hoffmann, Werke, Bd. 5, S. 23. 
aber Murr ignoriert eine solche Informationsquelle absichtlich, denn zumindest Meister Abrahams Erinnerung, die ,zufällig in der Kreisler-Biographie erhalten blieb, ${ }^{66}$ reicht zum Thema Murrs Kindheit weiter zurück als die vermeintliche Erinnerung von Murr selbst. Man könnte somit auch sagen, zumindest der frühste verbürgte Anfang von Murrs Autobiographie liege im ersten (resp. chronologisch letzten) Teil der Kreisler-Biographie, womit der Anfang des Romans durch eine weitere entortende Übertragungsbewegung verwischt wird.

Oben stehende Ausführungen haben also gezeigt, wie sehr die Vorstellung eines in einer Autobiographie festgehaltenen und von dieser als Ganzes suggerierten Lebens ein Konstrukt ist - ein Konstrukt, das der hier untersuchte Roman parodistisch und hoch reflektiert zugleich ausstellt. Doch damit nicht genug: Liest man nämlich über das Ende der Autobiographie Murrs hinaus und kommt dabei zum Ende des ,letzten' Kreisler-Teils, so muss man feststellen, dass auch dieser mit einem Gedankenstrich endet, ja gar mitten im Satz abbricht: 67

[...] Kommt nur lieber gleich auf der Stelle, wenn Ihr dies gelesen habt! Lauft was Ihr könnt. Bald seh' ich Euch. - Apropos! - Nehmt Euch doch vor den Pfaffen in Acht, aber den Abt lieb' ich sehr. - Adieu!

So kurz und so Inhaltsreich [sic] war dies Brieflein des alten Meisters, daß -68

Der mit „So kurz" beginnende und mit einem Gedankenstrich abbrechende resp. endende Abschnitt wird aber nicht mehr durch einen eindeutig identifizierbaren ,letzten' Absatz begrenzt. ${ }^{69}$ Gewissermaßen auf der Suche nach diesem Absatz gelangt der Leser über eine Leerzeile zu einem zentrierten Strich in der Mitte der übernächsten Zeile, der einen weiteren Abgrenzungshinweis darstellt, und von dort schließlich zum Titel Nachschrift des Herausgebers (in der Erstausgabe alles noch auf derselben Seite wie der ,Schluss' des Kreisler-Teils!). ${ }^{70}$ Spätestens mit dem ersten Buchstaben des ,Herausgebers` beginnt der Leser sodann, diesem und dessen Nachschrift seine Stimme zu leihen.

\footnotetext{
66 Vgl. ebd., S. 34.

67 Was rückwirkend die Lesart des Gedankenstrichs am Ende des Murr-Teils als Zeichen des Abbruchs stärkt.

68 Hoffmann, Werke, Bd. 5, S. 456.

69 Andernfalls würde die Nachschrift des Herausgebers sogleich nach einem Leerschlag an den Gedankenstrich anschließen.

70 Vgl. Kater Murr 1822, S. 405.
} 
Der scheinbare Abbruch des Romans war also - sofern der Leser das Buch nach dem „daß" nicht sofort zugeklappt hat ${ }^{71}$ - nur ein Verstummen des Kreisler-Biographen ${ }^{72}$ und nicht des Lesers und damit des Romans selbst. Liest der Leser nun weiter bis zum Ende der Nachschrift des Herausgebers, so endet diese wiederum, ohne durch einen weiteren Absatz resp. Abschnitt einund abgegrenzt zu werden. Die in der Erstausgabe zentrierte und mit größerer Schriftgröße gedruckte Formulierung „Ende des zweiten Bandes“73 scheint die Funktion einer solchen Eingrenzung zu übernehmen und ist denn auch durch ihre Typographie als Paratext gekennzeichnet. Das Problem hierbei ist aber, dass dies ein Paratext ist, der nicht den eigentlichen Text, sondern bereits einen anderen (vermeintlichen) Paratext, die Nachschrift des Herausgebers, begrenzt. Anstatt dass die Nachschrift selbst das Ende des Doppelromans klar ab- und eingrenzt, wird dieses Ende also - ähnlich wie bereits im Falle des Anfangs und seiner Vorworte - verwischt: Endet der Roman nun mit dem letzten Makulaturblatt und somit vor der Nachschrift; mit der Nachschrift des Herausgebers, die aber noch Teil der Fiktion ist; oder erst mit der (vermeintlich) performativen Formulierung Ende des zweiten Bandes, die dann zugleich die Nachschrift und das letzte Makulaturblatt einzugrenzen hätte?

Diese nicht abschließend zu klärenden Fragen führen den Leser wieder zurück zum vermeintlich letzten Kreisler-Teil, der jedoch auf der inhaltlichchronologischen Ebene nur der zweitletzte ist, denn der inhaltlichchronologisch erste Abschnitt des letzten Kreisler-Teils ${ }^{74}$ beginnt ja eigentlich mit dem ersten Makulaturblatt des ersten Bandes. ${ }^{75}$ Das Ende des letzten Abschnittes des letzten Kreisler-Teils des zweiten Bandes ließe sich also zu Beginn des ersten Makulaturblattes des ersten Bandes finden oder - die abwechselnden Biographieteile berücksichtigend - vor den ersten Worten in der

71 Selbst das „daß“ als Einleitung eines Konsekutivsatzes kann der Leser nicht ohne Bezug auf eine (mindestens gedachte) Fortsetzung des Textes lesen, und auch der Gedankenstrich lässt sich nur als ein Zeichen lesen, wenn man den vorliegenden Text um ein gedachtes Ganzes, den ,Rest' einer weiter gehenden Kreisler-Biographie, ergänzt und diese damit quasi in Gedanken weiterliest.

72 Genau genommen ist natürlich auch dieser nur die Erzählinstanz der Kreisler-Biographie und nicht der fiktive Biograph selbst.

73 Vgl. Kater Murr 1822, S. 406. Bemerkenswert ist an der Erstausgabe auch, dass unter dem Vermerk „Ende des zweiten Bandes“ noch ein durchgehender abgrenzender Strich steht, auf den ein Paratext mit einem (metonymischen) „Impressumshinweis“ auf die Druckerei folgt: „Berlin, gedruckt bei Conrad Feister“.

74 Der freilich selbst wiederum inmitten von Kreislers Leben, das eben nur fragmentarisch überliefert ist, beginnt.

75 Vgl. die schematische Darstellung unter II.1.1; sowie zusammenfassend Liebrand 1996, S. 198. 
Murr-Biographie. Letztere beginnt wiederum entweder mit dem von Murr verfälschten ${ }^{76}$ Egmont-Zitat „Es ist doch etwas schönes, herrliches, erhabenes um das Leben!" oder aber mit dem Titel des ersten Kapitels, wo es ausgerechnet (in der Erstausgabe in Sperrdruck) heißt: "Erster Abschnitt“.77 Damit hat - natürlich gemeinsam mit den inhaltlichen Verknüpfungen, die der Leser anstellt - die Lektüre des letzten Abschnittes des letzten Makulaturblattes den Leser zum ersten Abschnitt einer zweiten Lektüre geführt - einer Lektüre, deren potenzielle Unendlichkeit gerade auch in der Typographie des Textes angelegt ist.

Oder anders formuliert: Dadurch, dass einerseits sich die einzelnen Murr- und Kreisler-Teile zwar über beide Bände hinweg jeweils abwechseln, die Kreisler-Teile in der Chronologie ihrer Erzählung jedoch um einen verschoben mit dem letzten Teil beginnen, und andererseits das Ende des Doppelromans derart unverortbar ist, wird der Leser in eine potenziell ewig fortzusetzende Spirale der Lektüre geführt, ja mit höchstem Aufwand nahezu dazu gezwungen. Am Ende des zweiten Bandes wird ihm auf inhaltlicher, strukturell-kompositorischer und typographischer Ebene aufgedrängt, dass der vermeintlich erste Kreisler-Teil in der Chronologie der Erzählung der letzte ist, der Leser seine Lektüre der fragmentarischen Kreisler-Biographie also mit dem ersten Kreisler-Teil des ersten Bandes zu beenden hat. Doch tut der Leser dies, so hat er gewissermaßen bereits wieder mit Murrs Autobiographie begonnen, von deren erstem und zweitem Teil jener Kreisler-Teil gerahmt wird und deren Anfang nicht minder unverortbar ist. Man ist also versucht, mit Murr auszurufen, dass es nicht nur „etwas schönes, herrliches, erhabenes um das Leben" ${ }^{\text {"78 }}$ sei, sondern auch um das Lesen, im Zuge desselben Murrs und Kreislers Leben immer wieder von Neuem und immer wieder anders erweckt worden sein werden..$^{79}$

$7_{6}$ Vgl. Liebrand 1996, S. 213 f., die in einer Anmerkung auch auf die von Sabine Laussmann festgestellte zensurhistorische Brisanz des Zitates verweist.

77 Kater Murr 1820, S. 1. Was den Titel des Kapitels betrifft, so ist es mit Blick auf die zentrale Funktion von Absatz und Abschnitt sowie die autoreflexive, poetologische Lesart von „Abschnitt“ wohl kein Zufall, dass in den 16 von Retsch untersuchten Bildungsromanen des 19. Jahrhunderts ausgerechnet Hoffmanns Kater Murr und Tiecks Tischlermeister die einzigen sind, deren Kapitel mit „(Erster, Zweiter etc.) Abschnitt“ überschrieben sind, während ansonsten die Verwendung von „Capitel“ dominant ist (vgl. Retsch 2000, S. 206).

78 Hoffmann, Werke, Bd. 5 , S. 18.

79 Schäfers Kommentar zum Egmont-Zitat Murrs passt denn auch hervorragend zum Versuch, den Leser über den Tod des Katers und das vermeintliche Ende des Romans hinaus weiterlesen und damit Murr ,weiterleben' zu lassen: „Ein Zitat aus Goethes ,Egmont”, das am Ende eines Lebens, wohlgemerkt eines Lebens [gemeint ist Egmonts Leben, 
Mikroebene: Abgrenzungshinweise und ihre Eigendynamik Klammerbemerkungen, Absätze und (Lebens-)Abschnitte

Die fiktive Herausgeber-Figur ,E. T. A. Hoffmann' schreibt zu Beginn seines Vorwortes: „Keinem Buche, ist ein Vorwort nötiger, als gegenwärtigem, da es, wird nicht erklärt, auf welche wunderliche Weise es sich zusammengefügt hat, als ein zusammengewürfeltes Durcheinander erscheinen dürfte.“80 Den Grund für dieses „Durcheinander“ erfährt man im weiteren Verlauf des Vorwortes:

Als der Kater Murr seine Lebensansichten schrieb, zerriß er ohne Umstände ein gedrucktes Buch, das er bei seinem Herrn vorfand, und verbrauchte die Blätter harmlos teils zur Unterlage, teils zum löschen [sic]. Diese Blätter blieben im Manuskript und - wurden, als zu demselben gehörig, aus Versehen mit abgedruckt!

De- und wehmütig muß nun der Herausgeber gestehen, daß das verworrene Gemisch fremdartiger Stoffe durcheinander lediglich durch seinen Leichtsinn veranlaßt, da er das Manuskript des Katers hätte genau durchgehen sollen, ehe er es zum Druck beförderte, indessen ist noch einiger Trost für ihn vorhanden.

Für's erste wird der geneigte Leser sich leicht aus der Sache finden können, wenn er die eingeklammerten Bemerkungen, Mak. Bl. (Makulatur Blatt) und $M . f . f$. (Murr fährt fort) gütigst beachten will $[\ldots] .{ }^{81}$

Hierbei ergibt sich nun aber folgendes Problem: Die von ihren materialen Abgrenzungs- resp. Ganzheitshinweisen, nämlich den herausgerissenen Textträgern der ,Makulatur-Blätter', entledigten und auch in Schriftbild und Typographie zusammen mit der Murr-Biographie einheitlich abgedruckten Fragmente der Kreisler-Biographie teilen nun plötzlich ihrerseits Murrs Autobiographie in einzelne Fragmente. ${ }^{82}$ Dies sogar weitaus radikaler als noch im dem Verleger übergebenen Manuskript: Wo zuvor noch das (Makulatur-) Blatt einen materialen Abgrenzungshinweis verkörpert hat, würden sich nun

MG] einer literarischen Figur, steht, wird von Murr umgewandelt zum Beginn seines literarischen Unterfangens" (Schäfer 2011, S. 195).

8o Hoffmann, Werke, Bd. 5, S. 11.

81 Ebd., S. 12.

82 Die Murr-Fragmente ließen sich aber im Gegensatz zu den Kreisler-Fragmenten (abgesehen von den Gedankenstrichen) lückenlos wieder zusammenschließen. Dies führt gewissermaßen zu vielen kleinen Fortsetzungen, die im Kleinen die Fortsetzung des ersten Bandes in einem zweiten Band spiegeln - quasi ein Fortsetzungsroman im Fortsetzungsroman. Dabei ist es äußerst faszinierend, zu beobachten, dass, wenn man einen ganzen Text mit einem fragmentarischen kombiniert, plakativ ausgedrückt, nicht der fragmentarische nun eingebettet ganz, sondern der ganze fragmentarisch zu werden scheint. Die Fragmentierung von Murrs Autobiographie durch die Kreisler-Fragmente nimmt also vorweg, was zu Ende des zweiten Bandes offensichtlich wird: Auch die MurrAutobiographie ist letztlich ein Fragment. 
die Fragmente der Kreisler-Biographie ohne Abgrenzungshinweise (weder materiale, typographische noch begriffliche) an den Murr-Text anschließen. Dies sähe am Beispiel des ersten Wechsels zwischen Murrs Autobiographie und einem Fragment der Kreisler-Biographie wie folgt aus:

*[... ja wohl manchen Sperling haschen, und sogar hin und wieder ein Täublein erlauern. „Gewaltig ist die Liebe zu dir o Vaterland!“ -

Doch ich muß Rücksichts meiner und erinnern Sie sich gnädigster Herr! denn nicht des großen Sturms, der dem Advokaten, als er zur Nachtzeit über den Pontneuf wandelte, den Hut vom Kopfe herunter in die Seine warf? - Ähnliches steht im Rabelais $[\ldots] .^{83}$

Es wurde soeben der Konjunktiv II verwendet, weil eben dies offensichtlich nicht der Fall ist: Zum einen findet sich zwischen einem unterbrochenen MurrTeil und einem Kreisler-Fragment immer ein Absatz und zum anderen jeweils entweder der Hinweis (Mak. Bl.) oder (M.f.f.) sowie nach fast jedem Murr-Teil und nach der Klammerbemerkung eines jeden Kreisler-Teils (mindestens) ein Gedankenstrich. Die soeben zitierte Stelle lautet denn auch richtig:

[...] ja wohl manchen Sperling haschen, und sogar hin und wieder ein Täublein erlauern. „Gewaltig ist die Liebe zu dir o Vaterland!“ -

Doch ich muß Rücksichts meiner -

(Mak. Bl.) -- und erinnern Sie sich gnädigster Herr! denn nicht des großen Sturms, der dem Advokaten, als er zur Nachtzeit über den Pontneuf wandelte, den Hut vom Kopfe herunter in die Seine warf? - Ähnliches steht im Rabelais $[\ldots] \cdot{ }^{84}$

Das Weglassen materialer oder typographischer Abgrenzungshinweise führt also zu einer Eigendynamik des Fragments, die aber offensichtlich sofort mit neuen Abgrenzungshinweisen wieder eingedämmt werden muss. Die Frage dabei ist nur, wer ist für diesen erneuten Eingriff verantwortlich? Remigius Bunia schreibt gegen Ende seines die Lebens-Ansichten des Katers Murr behandelnden Aufsatzes Die Stimme der Typographie zusammenfassend:

Es sind ferner die Schriftverantwortlichen innerhalb der Diegese zu benennen; schriftverantwortlich ist, wer über Schriftzeichenfolgen entscheiden kann; in der fiktiven Welt der Lebens-Ansichten sind es Setzer, Herausgeber, Murr und Verleger - von Kreislers Biographen dagegen wird nicht erzählt. ${ }^{85}$

83 Vgl. Hoffmann, Werke, Bd. 5, S. 23.

84 Ebd.

85 Bunia 2005, S. 391. Letzteres ist in seiner etwas allgemein gehaltenen Formulierung zu ergänzen: Der Kreisler-Biograph kann zwar nicht die Anordnung der Murr- und KreislerBiographietexte beeinflussen, aber es gibt Texte innerhalb der Kreisler-Biographie, deren 
Das Buch, das man aber in der Wirklichkeit liest und sieht, zeigt weder Murrs Manuskript noch das fertige Druckwerk, das der Setzer hervorgebracht und der Herausgeber mit seinen Anmerkungen versehen hat, sondern es evoziert sie nur. ${ }^{86}$

Ergänzend sei hinzugefügt: Das Buch „evoziert“ sie - und löst dabei, wie oben dargelegt, eine Eigendynamik aus, die wiederum die Herausgeberund Autorfiktion unterläuft. Denn was Bunia hier indirekt anspricht, ist folgender Widerspruch: Der Herausgeber, der im Vorwort behauptet, er habe die Makulaturblätter nicht bemerkt und deshalb seien sie versehentlich mitabgedruckt worden, kann diese demzufolge gar nicht mit Anmerkungen ergänzt haben. Es ist denn auch weder im Vorwort noch sonstwo im Roman davon die Rede, dass der Herausgeber die Klammerbemerkungen eingefügt hat. Mit Blick auf die Ergebnisse zur Makroebene des Romans ist zudem die implizite Begründung des Herausgebers, weshalb er die Makulaturblätter übersehen habe, bemerkenswert: „[...] und da der Eingang der Historie ihm [dem Herausgeber, MG] ziemlich gut stylisiert schien, so lief er sofort, mit dem Manuskript in der Tasche, zu dem Herrn Dümmler unter den Linden, und proponierte ihm den Verlag des Katerbuchs.“87 Ausgerechnet der AutobiographieEingang Murrs mit den beiden Vorworten des Katers und der entortenden Intertextualität des eigentlichen Anfangs erschien dem Herausgeber so "gut stylisiert“, dass er offenbar nur die ersten paar Seiten der Biographie las, deshalb die Makulaturblätter übersah und in der Folge dieses Versehens mit seinem Vorwort den entortenden Stil Murrs noch potenzierte. Oder anders gesagt: Der Herausgeber scheint der erste Leser der Autobiographie Murrs gewesen zu sein, der sich in der potenzierten Entortungsbewegung ihres Anfangs verloren hat.

Es bleibt also beim oben genannten Widerspruch: Entweder der Herausgeber bemerkt das ,Versehen' rechtzeitig, und aus der Autobiographie Murrs wird keine Doppelbiographie, oder er bemerkt es nicht rechtzeitig, und das Manuskript wird ohne die Anmerkungen des Herausgebers - z. B. nach Murrs ,unterdrücktem' Vorwort - und ohne die Abgrenzungs- und

Abfolge er durchaus bestimmt. Im Falle des Briefes von Kreisler an Meister Abraham tut er dies sogar ganz explizit, indem er diesen dem Leser zu lesen gibt, noch bevor ihn Meister Abraham überhaupt erst geöffnet hat: „Hat aber nun auch Meister Abraham des Kapellmeisters Brief verschlossen in seinen [sic] Schreibepult oder Schreibtischkasten und ist er auch spazieren gegangen in den Park, doch soll der geneigte Leser den Inhalt sogleich buchstäblich erfahren. - Johannes Kreisler hatte folgendes geschrieben: [...]“ (Hoffmann, Werke, Bd. 5, S. 270).

86 Bunia 2005, S. 389.

87 Hoffmann, Werke, Bd. 5, S. 11. 
Gliederungshinweise - (Mak. Bl.), (M.f.f.), Absätze und Gedankenstriche zwischen den Biographieteilen gedruckt. ${ }^{88}$ Uwe Wirth hat bereits auf dieses Paradoxon hingewiesen ${ }^{89}$ und stellt diesbezüglich fest:

Der im Vorwort-Ensemble in Szene gesetzte performative Widerspruch wird als synekdochisches Vorspiel zur Selbstdarstellung jenes poetischen Konzepts [ebenjenes performativen Widerspruchs, des Ausstellens der Fiktion als Fiktion, MG], das dem gesamten Roman zugrunde liegt. ${ }^{90}$

Beim Versuch, diesen Widerspruch zu lösen, schreibt Wirth von einer

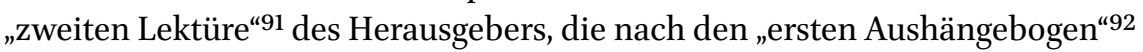
korrigierend eingegriffen habe. Doch bei Hoffmann wird nirgends erwähnt, wer die korrigierenden Klammerbemerkungen eingefügt hat. Zudem stellte sich bereits Claudia Liebrand die Frage: Wenn der Herausgeber schon korrigierend

88 Auch folgender, bemerkenswerter Einschub des Herausgebers im zweiten Band unterläuft die rahmende Herausgeberfiktion des Vorwortes:

„[...] und kein finstrer Geist vermochte den Himmel ihrer Liebe zu trüben. -

- Hier hat, wie der Herausgeber es dem geneigten Leser bemerklich machen muß, der Kater wieder ein Paar Makulaturblätter ganz weggerissen, wodurch in dieser Geschichte voller Lücken wiederum eine Lücke entstanden. Nach der Seitenzahl fehlen aber nur acht Kolumnen, die eben nichts besonders wichtiges enthalten zu haben scheinen, da das Folgende sich im Ganzen noch so ziemlich an das Vorhergegangene reiht. Also weiter heißt es:

- - - nicht erwarten durfte. Fürst Irenäus war überhaupt ein abgesagter Feind von allen ungewöhnlichen Vorfällen [...]“ (Hoffmann, Werke, Bd. 5, S. 405).

Der Herausgeber schaltet sich hier zum ersten und einzigen Mal zwischen zwei Kreisler-Teilen ein (vgl. Czezior 2008, S. 146 und 149 f.), und ebenfalls zum ersten und einzigen Mal befindet sich damit - streng genommen - zwischen zwei Kreisler-Teilen kein Murr-Teil. Der Einschub zeugt davon, dass der Herausgeber die Makulaturblätter in Murrs Manuskript nicht nur gelesen, sondern sogar noch mit einer ausführlichen Notiz versehen hat. Zufälligerweise beträgt die Anzahl der Zeilen in der Edition der „Bibliothek deutscher Klassiker“ wie die Zahl der „Kolumnen“ (freilich nicht Zeilen) ebenfalls acht, was den performativen Akt des Herausgebers, der mittels seines Hinweises auf die Lücke überhaupt erst eine Lücke in der Kreisler-Biographie (wieder-)herstellt, noch ein wenig verstärkt (zu dieser Stelle vgl. auch Wirth 2008, S. 405, Anm. 200). In der Erstausgabe beträgt der Einschub des Herausgebers jedoch zehn Zeilen (vgl. Kater Murr 1822, S. 312). Diese unscheinbare Textstelle kann also noch mehr zu lesen geben als die Ironisierung des Herausgebers, „der auch hier das Wesentliche vom Unwesentlichen nicht trennen kann" (Steinecke 2004, S. 508).

89 Ebd., S. 386-389.

$90 \quad$ Wirth 2008 , S. 387.

91 Ebd., S. 382.

92 Hoffmann, Werke, Bd. 5, S. 12. 
eingreift, weshalb entfernt er dann die Kreisler-Fragmente nicht oder gibt sie in einem eigenen Band heraus? ${ }^{93}$

Es sieht also ganz danach aus, als ob man es - zumindest bei fiktiven Metatexten wie z. B. (Mak. Bl.), (M.f.f.) und der Nachschrift zu Murrs unterdrücktem Vorwort ${ }^{94}$ - letztlich mit einem unbekannten "Schriftverantwortlichen" zu tun hat, während die Schriftverantwortlichkeit des Herausgebers plötzlich infrage gestellt ist. ${ }^{95}$ Uwe Wirth selbst beantwortet die Frage nach

93 Ihre Antwort fällt dabei wie folgt aus: „Die Fiktion will offenbar auf ihre Scheinhaftigkeit hin durchschaut werden. Ihr geht es nicht um die Suggestion von Wahrheit, Realität, Authentizität, sondern um die Etablierung eines literarischen Spielfeldes“ (Liebrand 1996, S. 203). Uwe Wirth hingegen begegnet dieser Frage vorerst damit, dass sich dabei "dem Leser der Verdacht auf[drängt], dass dem vermeintlichen Zufallsarrangement die Strategie eines impliziten Herausgebers zugrunde liegt" (ders. 2008, S. 386).

94 Auch beim unterdrückten Nachwort Murrs ist der Schriftverantwortliche nicht zu klären, obwohl dieses mit „d. H.“ (Hoffmann, Werke, Bd. 5, S. 17), also wohl mit „der Herausgeber“, signiert ist (vgl. auch Wirth 2008, S. 386-388). Interessant ist hier ebenfalls, dass es sich bei „d. H.“ - wie schon bei der Klammerbemerkung (Mak. Bl) - um eine Abkürzung handelt, bei der auf das Vorwort zurückgegriffen werden muss, um sie im Zuge einer Entortungsbewegung aufzulösen und damit erst den vollständigen Signifikanten zu erhalten.

95 Zu beachten ist in diesem Zusammenhang auch David G. Kropfs These, die Textanfänge zwischen den einzelnen Biographieteilen würden weitere herausgeberische Eingriffe provozieren, indem sie z. B. sehr oft mit einer Rede begännen, was zahlreiche Herausgeber späterer Editionen dazu gebracht habe, Anführungszeichen einzufügen, die in der Erstausgabe nicht vorhanden gewesen wären und welche die Herausgeberfiktion des Vorwortes massiv unterlaufen würden (vgl. Kropf 1994, S. 221). Man könnte also sagen, die Stellen, an denen die Schriftverantwortlichkeit nicht geklärt ist, übten eine besondere Anziehungskraft auf die Leser aus (davon zeugt auch das vorliegende Kapitel), an welche die Schriftverantwortlichkeit delegiert ist. Ist der Leser gar ein späterer Herausgeber, so übernimmt er die Schriftverantwortlichkeit derart geflissentlich, dass er in den Text eingreift, und zwar besonders in den Fällen, wo es um eine Ab- und Eingrenzung von Text geht, wie eben im Falle der Anführungszeichen. Bemerkenswert ist dabei, dass selbst in der Erstausgabe an einer Stelle dem Ende eines Makulaturblattes ein doppeltes Anführungszeichen ,beigefügt' ist: „Mit zwei Worten, sprach die Benzon [sic] erkläre ich alles. Als ich mich vor fünf Jahren in -“ (Hoffmann, Werke, Bd. 5, S. 69; resp. Kater Murr 1820, S. 96). Zu beachten ist hier zudem weiter, dass der Einschub des Erzählers „sprach die Benzon“ nicht durch ein vorangehendes Schluss- und ein nachfolgendes Anführungszeichen von der direkten Rede, ausgeklammert wird'. In Anlehnung an Müller Nielabas Überlegungen zum doppelten Anführungszeichen könnte man dazu sagen: Dadurch, dass ein doppeltes Anführungszeichen nur in Relation zu einem zweiten doppelten Anführungszeichen überhaupt als solches gelesen werden kann (vgl. ders. 2009, S. 148 f.), sah man sich an dieser Textstelle offenbar gezwungen, den Ort des für die Figuration des ersten doppelten Anführungszeichens denknotwendigen zweiten doppelten Anführungszeichens resp. Schlusszeichens nicht einfach nur dem Verstehensprozess des Lesers zu überlassen. Man druckte das Schlusszeichen deshalb ab, um ihm damit vermeintlich einen festen Ort zu geben, was jedoch wiederum gerade dadurch ad absurdum geführt wird, dass so die 
der Schriftverantwortlichkeit damit, dass dem "Drucker die Funktion“ zukomme, „die äußerste Rahmungsinstanz“ zu sein, „die bis zuletzt eine Möglichkeit zum Eingreifen und Modifizieren des Textes“ besitze. „Dadurch wird die Instanz des Druckers zur anonymen Personifikation jenes überpersönlichen ,typographischen Dispositivs', das im Rahmen der technischen Reproduktionsverfahren gleichermaßen für das Gelingen wie für das Scheitern der Verkörperungsbedingungen verantwortlich ist. ${ }^{46}$ Wenngleich Wirth damit die rahmende Funktion der Typographie betont und den Drucker als deren Personifikation bezeichnet, so ist zu ergänzen, dass von diesem Drucker im Vorwort des Herausgebers letztlich nicht die Rede ist. Es finden sich lediglich die Begriffe „Setzern“ (im Plural) und „Setzer“97 (zweimal), die höchstens metonymisch - also erneut über eine Übertragungsbewegung - für ,den Drucker stehen können. Zudem kommen sie allesamt in ein und demselben Abschnitt vor, der gar nicht direkt von dem Setzer des zur Diskussion stehenden Romans handelt, sondern von den "Setzern“ im Allgemeinen und je von dem "Setzer“ der Nachtstücke und des Fräulein Scudery (wobei die Erwähnung dieser beiden Werke wiederum mit der Identität des mit „E. T. A. Hoffmann ${ }^{498}$ signierenden fiktiven Herausgebers spielt).

Hoffmanns Doppelroman entzieht sich also letztlich jedem Versuch einer Fest-Setzung(vgl.,,Setzer"); seiner potenziellunendlichenEntortungsbewegung vermag kein Rahmen eines Autors, Herausgebers, Drucker-Setzers, von Buchdeckeln oder eines Blattes Einhalt zu gebieten.$^{99}$ Genau dies lässt sich letztlich auch an Wirths weiterer Argumentation beobachten, wenn sie der Chronologie der Vorworte folgend über das Verzeichnis der Druckfehler auf das unterdrückte Vorwort des Autors stößt:

Dieser offene Angriff des Herausgebers [der sich über die Fehler der Setzer lustig macht, $\mathrm{MG}^{100}$ ] wird vom Drucker-Setzer performativ beantwortet: Gegen den Willen des Herausgebers wird das unterdrückte Vorwort des Autors abgedruckt. Unklar bleibt dabei, wer die Kennzeichnung "Unterdrücktes des Autors" vornimmt. [...] In jedem Fall kann man sagen: Die Lebens-Ansichten des Katers

Herausgeberfiktion unterlaufen und die Entortungsbewegung an der Textgrenze letztlich nicht angehalten, sondern im Gegenteil weiter verstärkt wird.

96 Wirth 2008, S. 387.

97 Hoffmann, Werke, Bd. 5, S. 12 f.; resp. Kater Murr 182o, S. VII-VIII.

98 Ebd., S. 14.

99 Zu der in der Forschung lange Zeit dominanten Betrachtungsweise von Hoffmanns Doppelroman, die interpretatorisch ,jene ,Einheit' zu stiften [sucht], die der Text verweigert“, vgl. Liebrand 1996, S. 199, zu den „Integrationsvorschlägen und (Auf-)Lösungen“ der Forschung S. 199-202.

100 Vgl. Hoffmann, Werke, Bd. 5, S. 12 f. 
Murr thematisieren ex negativo die parergonale Kraft der Funktion Drucker durch eine Inszenierung editorialer Fehlschläge. Die Konsequenzen dieser Fehlschläge werden durch die Struktur des Textes verkörpert. So ist die in der Nachschrift zum Vorwort - „das ist zu arg!“ - zum Ausdruck kommende Ohnmacht des Herausgebers nicht nur ein Indiz für die Eigensinnigkeit der Technik, sondern auch ein Indiz dafür, daß es hinter der literarischen Szene ein übergeordnetes, unsichtbares editoriales Dispositiv gibt. Dieses editoriale Dispositiv sorgt mit einem gehörigen $\mathrm{Ma}$ an performativer Ironie dafür, daß die Instanz des Druckers den unzuverlässigen Herausgeber in einen ohnmächtigen Herausgeber transformiert. ${ }^{101}$

Nach der Logik dieser Argumentation müsste der Herausgeber nicht nur eine „zweite Lektüre“ vorgenommen haben, sondern in Auseinandersetzung mit dem Setzer auch eine dritte, die wiederum vom Setzer gekontert werden könnte usw. - ganz gemäß (früh-)romantischer sich potenzierender Ironie $^{102}$ - ad infinitum. An Uwe Wirths Lektüre selbst wird also ersichtlich, dass die Rahmungsversuche der Herausgeberfiktion Anlass zu einer potenziell unendlichen Kette interpretativer Aufpfropfungen geben, womit in gewissem Sinne eine von Wirths Kernthesen ${ }^{103}$ sowohl von ihm selber als auch von dem vorliegenden Kapitel performativ bestätigt wird.

Wirths Ergebnisse, die auf die „Konfusion von Rahmen“ und die dadurch autoreflexiv bewirkte „erhöhte Aufmerksamkeit für Rahmungen“104 hinweisen, werden hier also weitergeführt, indem aufgezeigt wird, dass Rahmenkonfusion eine potenziell unbeendbare Eigendynamik nach sich zieht, die gerade auch strategisch für den Versuch eingesetzt werden kann, den Leser zu einer (potenziell) unendlichen Lektüre zu zwingen. Oder mit anderen Worten: Sowohl die Rahmenkonfusion als auch die auf der Makroebene beobachtete Kreisstruktur des Doppelromans und die exzessiven intertextuellen Verweise lassen sich unter der Operation zur Ewigkeitsattribuierung von Schriftzeichen Unendliche Lektüre fassen, wobei es im Falle der Rahmenkonfusion auch zur Überschneidung mit der komplementären Operation Unendliches Verstummen kommt (siehe dazu das betreffende Kapitel II.2).

Aus all den Widersprüchen, in die sich der Herausgeber selbst, aber auch noch der aufmerksamste Leser verstricken kann resp. geradezu muss, geht die

\footnotetext{
101 Vgl. Wirth 2008, S. 388.

102 Vgl. dazu auch Wellenberger 1986, dessen Monographie Der Unernst des Unendlichen jedoch trotz vielversprechendem Titel für die vorliegende Fragestellung kaum Ergiebiges beinhaltet.

103 Vgl. zusammenfassend Wirth 2008, S. 419-421.

104 Ebd., S. 416.
} 
These hervor, die es für die folgenden Ausführungen dieses Kapitels im Hintergrunde immer mitzudenken gilt:

Durch das komplexe Spiel mit vom Leser normalerweise weitestgehend nicht bewusst wahrgenommenen ${ }^{105}$ Abgrenzungs- und Gliederungshinweisen entfaltet der hier untersuchte Roman eine Eigendynamik, die das stetige, potenziell unendliche Verschieben von Anfang und Ende eines Textes und dessen Bedeutungen ausstellt, das jene Hinweise anzuhalten resp. festzusetzen vorgeben.

Es sei nun in einem letzten Schritt noch einmal auf die Klammerbemerkungen (Mak. Bl.) und (M.f.f.) zurückgekommen, die von Uwe Wirth auch als "Links" bezeichnet worden sind. ${ }^{106}$ Die Bezeichnung der Klammerbemerkungen als Links hat, insbesondere mit Blick auf die heutigen digitalen Medien, etwas für sich. Sie macht aber vor allem dann Sinn, wenn bloß eine der beiden Klammerbemerkungstypen, (Mak. Bl.) oder (M. f.f.), als Link betrachtet wird, denn andernfalls läge konsequenterweise nur eine Aneinanderreihung von Links vor. Damit wird deutlich, dass die Klammerbemerkungen im Grunde letztlich doch keine einzelnen, in ihrer verweisenden Funktion für sich stehenden Links sind, sondern sich ihre ab- und eingrenzende Funktion nur in Relation zueinander konstituiert: Ohne eingeschobene Makulaturblätter würde Murr nicht unterbrochen werden, hätte also auch keinen Grund, explizit fortzufahren, und ohne den Text Murrs müssten die Makulaturblätter nicht eigens als solche abgegrenzt werden. Die fiktiven Metatexte $(M . f . f$. verweisen also sowohl darauf, dass die Murr-Biographie weitergeht, als auch vor und zurück auf die Makulaturblätter, die einen solchen Verweis überhaupt nötig machen - und umgekehrt. Oder anders formuliert: Die Klammerbemerkungen (M.f.f.) bilden nicht eigenständig einen Rahmen resp. Klammern um einen Murr-Text, wozu eine zusätzliche Bemerkung wie „Murr wird bald weiter fortfahren" am Ende eines Murr-Teils nötig wäre. Sie sind deshalb auf den zu Beginn des jeweils nächsten Kreisler-Teils folgenden Hinweis (Mak. Bl.) angewiesen - und vice versa. Die Klammerbemerkungen funktionieren somit ähnlich wie Absätze, die einen Abschnitt nur in Bezug auf einen weiteren, zweiten Absatz eingrenzen können. ${ }^{107}$

105 Vgl. Hausendorf/Kesselheim 2008, S. 21.

106 Vgl. Wirth 2002, Performative Rahmung, S. 426; sowie ergänzend Wirth 2007. Ebenfalls dazu, dass die Klammerbemerkungen auch immer auf den gewaltsamen Bruch in der Abfolge der beiden Biographietexte verweisen, den sie zugleich zu überbrücken suchen, vgl. Wirth 2004, insbesondere S. 429 .

$107 \mathrm{Zu}$ einer abstrakten, sprachphilosophischen Auseinandersetzung mit dem Bereich der Interpunktion vgl. etwa den für die Analyse der Mikroebene resp. der Typologie inspirierenden Sammelband: Abbt/Kammasch 2009. 
Als Absatz stehen sie aber immer zwischen zwei, durch sie erst voneinander abgegrenzten Abschnitten und figurieren sowohl das Ende des vorangehenden als auch den Anfang des folgenden Abschnittes. (M.f.f.) und (Mak. Bl.) sind somit als Zeichen für den Anfang und das Ende eines Textes weder eindeutig am Anfang noch am Ende eines Textes zu verorten, sondern werden im Zuge ihrer Lektüre vielmehr Anfangen und Enden gewesen sein. Dass die Klammerbemerkungen nach Wirth „typographische Anker" seien, kann hier somit keine Zustimmung erfahren.

Hinzu kommt sogar, dass die Klammerbemerkungen (M.f.f.) und (Mak. Bl.) sowie die typographischen Absätze zwischen den Kreisler- und Murr-Teilen immer sowohl Absätze als auch - in Bezug auf die Absatzfunktion der jeweils anderen Absatzart - Teil eines Abschnittes sind. Oder mit anderen Worten: Liest man die Klammerbemerkungen als Absätze, so wird der zwischen den beiden Biographieteilen liegende typographische Absatz Teil des von den Klammerbemerkungen hergestellten Abschnittes - und umgekehrt.

Dies führt dazu, dass die von der einen Absatzart gebildeten Abschnitte in die Abschnitte der anderen hineinreichen (jeweils dort, wo sich in der unten stehenden Darstellung Rot und Blau überlagern). In einer schematischen Darstellung der ersten drei Wechsel zwischen den beiden Biographien des ersten Bandes sieht dies folgendermaßen aus (typographische Abschnitte rot, durch die Klammerbemerkungen gebildete Abschnitte blau):

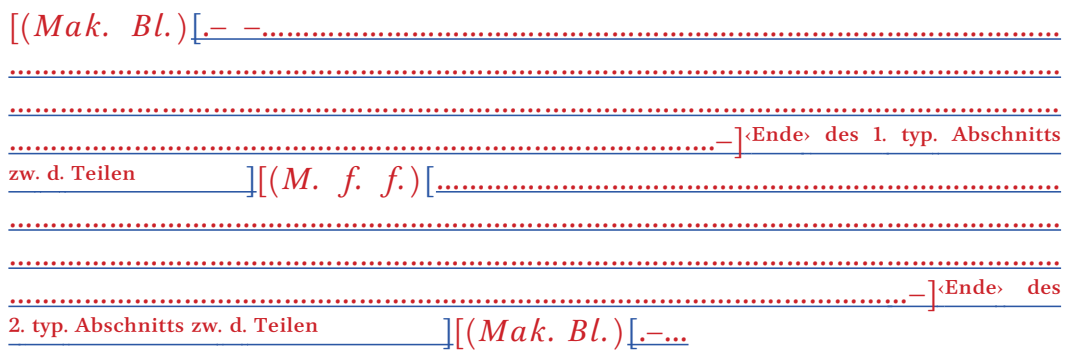

An dieser schematischen Darstellung wird nun auch ersichtlich, dass die beiden Absatzarten ebenso immer um eine Position versetzt angeordnet sind wie im gesamten Roman die inhaltlich-chronologische Reihenfolge der Makulaturblätter im Verhältnis zur chronologischen Reihenfolge der MurrAutobiographie. Verbindet man diese Beobachtung zur Mikrostruktur mit den oben dargelegten Ergebnissen zur Makrostruktur, so ergibt sich folgender Befund:

Die unendliche Lektüre, welche durch die chronologische Anordnung der Makulaturblätter innerhalb des Doppelromans erzwungen wird, steht in einem 
Ähnlichkeitsverhältnis zur potenziell unbeendbaren Übertragungsbewegung an den Grenzen der einzelnen Biographie- und Autobiographieteile. Das Strukturprinzip des gesamten Romans spiegelt sich so im Kleinen in der Doppelung in typographische Abschnitte einerseits und Abschnitte, die durch die Absatzfunktion der Klammerbemerkungen figuriert werden, andererseits.

Die so zustande kommende Situierung eines Abschnittes in einem Abschnitt schafft denn auch die Voraussetzung für eine autoreflexive Wendung der Lektüre auf die Konstituenten des jeweiligen Abschnittes und von Abschnitten im Allgemeinen. Die Überlagerung der Abschnitte macht nämlich deutlich, dass es für die Figuration eines Abschnittes - ob typographisch oder wie im Ausnahmefall des hier untersuchten Romans mittels einer Absatzfunktion von Klammerbemerkungen - immer zweier Absätze bedarf. Ähnliches gilt für die verschriftlichte direkte Rede, die immer nur durch zwei doppelte Anführungszeichen figuriert werden kann. ${ }^{108}$ Die Absätze können jedoch im Gegensatz zu den doppelten Anführungszeichen nur als solche auftreten, wenn sie ihrerseits von zwei Abschnitten begrenzt resp. figuriert werden, von denen sie in einem Fall das Ende, im anderen Fall den Anfang kennzeichnen, und dies jeweils wiederum nur in Bezug auf einen nachfolgenden oder vorangegangenen Absatz $^{1}$ - und immer so fort in einer potenziell unendlichen Bewegung, im Zuge derer die Bedeutung des Absatzes von einer weißen Absatzfläche zur nächsten vor und zurück übertragen wird. ${ }^{109}$

Nach der oben gezeigten schematischen und vereinfachten Darstellung soll nun abschließend eine besonders bemerkenswerte Folge von Übergängen zwischen Murr- und Kreisler-Teilen genauer untersucht werden. Hierbei geht es auch darum, aufzuzeigen, wie eng die typographische Ebene des Romans nicht nur mit dessen Makrokomposition, sondern auch mit dessen Inhalt verknüpft ist. Bei den genannten Übergängen handelt es sich um diejenigen zwischen dem je zweiten und dritten Murr- und Kreisler-Teil sowie den Übergang vom dritten Kreisler- zum vierten Murr-Teil des ersten Bandes. Wie schon oben steht Rot dabei für die typographischen Abschnitte, hier jedoch nur im Falle der Murr-Teile, Blau im Falle der Kreisler-Teile für die durch die Absatzfunktion der Klammerbemerkungen eingegrenzten Abschnitte. Die schwarz gehaltenen typographischen Abschnitte innerhalb der Murr-Teile helfen aufzuzeigen, dass die rot gehaltenen typographischen Abschnitte zu Beginn

108 Vgl. Müller Nielaba 2009, S. 148 f. Zum potenziell unendlichen Prozess der Figuration vgl. Müller Nielaba/Schumacher/Steier 2011.

109 Mit dem weißen „Zwischenraum“ von Texten hat sich auch Thomas Fries auseinandergesetzt, dessen Beobachtungen hiermit beizupflichten und zu ergänzen sind (vgl. Fries 2009, insbesondere S. 175). 
und zu Ende des hier mittleren Murr-Teils jeweils durch einen Kreisler-Teil unterbrochen werden. Die Klammerbemerkungen (Mak. Bl.) sind ebenfalls in Schwarz gehalten, es wird damit suggeriert, dass diese nicht zu den durch die Absatzfunktion der Klammerbemerkungen gebildeten Abschnitten und damit als metatextuelle Informationen nicht zum eigentlichen Text gehören:110

[...] Sprang wirklich ein Heldengedicht unter meinen Klauen hervor, beide hätte kein Mensch mehr gelesen.

Ich komme jetzt auf die -

(Mak. Bl.) - zum besseren Verständnis doch nötig sein, dir, geneigter Leser das ganze Verhältnis der Dinge klar und deutlich aus einander zu setzen. [es folgt nun der weitere Inhalt dieses Makulaturblatts, der mitten in einem Abschnitt mit den Worten endet, MG] Denn außerdem daß -

$(M . f . f$.$) - merkwürdige Begebenheit die, um mich des gewöhnlichen$ Ausdrucks geistreicher Biographen zu bedienen, einen Abschnitt in meinem Leben machte [kursive Hervorhebung, MG].

- Leser - Jünglinge, Männer, Frauen, unter deren Pelz ein fühlend Herz schlägt, die ihr Sinn habt für Tugend - [es folgt nun der weitere Inhalt dieses Murr-Teils, der mit einem neuen typographischen Abschnitt und mit folgenden Worten endet, MG]

So schließe ich diese Episode meines Lebens die -

(Mak. Bl.) - - nichts verdrießlicher für einen Historiographen oder Biographen, als wenn er, wie auf einen wilden Füllen reitend hin und her sprengen muß, über Stock und Stein, über Äcker und Wiesen, immer nach gebahnten Wegen trachtend, niemals sie erreichend. So geht es dem, der es unternommen für dich, geliebter Leser, das aufzuschreiben, was er von dem wunderlichen Leben des Kapellmeisters Johannes Kreisler erfahren. ${ }^{111}$ [es folgt nun der weitere Inhalt dieses Makulaturblattes, der mit den Worten Benzons mitten in einem

110 Dieser Eindruck entsteht jedoch nur, weil um der besseren Übersichtlichkeit willen nicht jede mögliche Lesart der typographischen Absätze und jeder Klammerbemerkung als Absatz miteinbezogen wurde. Dazu müsste man diese Darstellung mit der oben stehenden schematischen verbinden - eine Verbindung, die dann aber praktisch unlesbar wäre.

111 Es ist hier nicht möglich, auch die inhaltlichen Korrespondenzen zwischen den einzelnen Teilen der Murr- und Kreisler-Biographie ausführlich zu untersuchen, aber es ist kaum ein Zufall, dass der Anfang des dritten Murr- und Kreisler-Teils eine Leseransprache beinhaltet. Zudem liest sich der Beginn des dritten Kreisler-Teils wie ein Kommentar zum hier untersuchten unterbrochenen Lebensabschnitt Murrs, denn der Kreisler-Biograph beklagt ja, dass er gezwungen sei, hin und her zu springen. Ein Hin-und-her-Springen, das er in der Kreisler-Biographie natürlich an den Leser weitergibt und das, wie gerade beobachtet, sich aufgrund der Unterbrüche der Makulaturblätter ebenfalls auf die MurrAutobiographie überträgt. Vgl. dazu auch Wirth, der von einer doppelten Rahmung spricht, die zum einen von den rahmenden Eingriffen und Bemerkungen des fiktiven Herausgebers ausgeht, zum anderen aber auch von einer inhaltlichen Spiegelung (vgl. ders. 2008 , S. 405 f.). 
Abschnitt endet, MG] „Mit zwei Worten, sprach die Benzon erkläre ich alles. Als ich mich vor fünf Jahren in -“

$(M . f . f$.$) - mich überzeugte, daß in einem echten tiefen Dichtergemüt$ auch kindliche Tugend wohnt und Mitleid mit dem Bedrängnis der Genossen.

Eine gewisse Schwermut, wie sie oft junge Romantiker ${ }^{112}$ befällt, wenn sie den Entwicklungskampf der großen erhabenen Gedanken in ihrem Innern bestehen, trieb mich in die Einsamkeit. $[\ldots]^{113}$

Es sticht nun besonders ins Auge, wie stark die Abgrenzung der einzelnen Romanteile durch typographische Abschnitte einerseits sowie durch mittels Klammerbemerkungen hergestellte Abschnitte andererseits das Zur-MitteWerden des Textes ausstellt und mitkonstituiert: Ein Kreisler-Teil kommt jeweils inmitten zweier Murr-Teile zu liegen; der eigentliche Lebensabschnitt Murrs, in dem er seine Mutter trifft, wird zwischen den diesen inhaltlichen Lebens-Abschnitt performativ rahmenden typographischen Abschnitten erzählt, die wiederum von den Kreisler-Teilen unterbrochen werden usw. In den Ausführungen zur Makrostruktur wurde bereits anhand des ersten Kompositums des Titels Lebens-Ansichten auf die enge Verknüpfung zwischen Leben und Lesen hingewiesen. Genau diese Verknüpfung lässt sich auch an der soeben zitierten Stelle beobachten:

Erstens anhand der Formulierung „einen Abschnitt in meinem Leben“, also, wie Murr explizit hervorhebt, anhand „des gewöhnlichen Ausdrucks geistreicher Biographen“. Dadurch, dass das im übertragenen Sinne gebrauchte Wort „Abschnitt“ innerhalb eines typographischen Abschnittes steht, ${ }^{114}$ geht die Rede vom Lebens-Abschnitt ein Ähnlichkeitsverhältnis mit dem typographischen Lesens-Abschnitt ein. So erhält sie zugleich etwas Performatives: Es wird nicht nur darüber geschrieben, wie etwas in Murrs Leben „einen Abschnitt [...] machte“, sondern es wird gerade durch dieses Schreiben (und Lesen) ein Abschnitt gemacht resp. geschrieben - und zwar ein typographischer. Ein typographischer Abschnitt, der als solcher über zwei Absätze immer nur in Relation zu mindestens zwei anderen Abschnitten resp. zwei Absätzen figuriert wird. Und auch hierin besteht eine Parallele zu den hinsichtlich der Makrostruktur behandelten Verknüpfungen zwischen der

\footnotetext{
112 Der Verweis auf (die) „Romantiker“, die "großen erhabenen Gedanken“, das „Innere“ und die „Einsamkeit“ ausgerechnet am Ende einer Stelle potenzierter Reflexion über Leben und Lesen bis in die graphische Ebene von Schrift und Text hinein ist wohl kein Zufall; vgl. dazu Kapitel IV.3.1. Zur dem Genie stets drohenden radikalen Einsamkeit vgl. IV.3.3.

113 Hoffmann, Werke, Bd. 5, S. 44-69.

114 Auch der typographische Abschnitt ist letztlich eine Metapher und damit der Lebensabschnitt bereits eine Metapher einer Metapher.
} 
Konstitution von Murrs Leben resp. Autobiographie in Relation zu anderen Leben resp. anderen Texten.

Zweitens lässt die Abfolge ,Abschnitt in meinem Leben macht. - Absatz Gedankenstrich - Leser! - Gedankenstrich' die Stimme Murrs am Absatz verstummen und sie alslediglich vom Leser geliehene bewusst werden. Die Stimme des Lesers wird im Weiß des Absatzes, wo keine Erzählinstanz oder eine Figur spricht, so gewissermaßen , auf sich selbst zurückgeworfen', während sich am Gedankenstrich zusätzlich die (freilich vor- und zurückführende, horizontale) Linearität resp. Sequenzialität eines jeden Lesens von in lateinischer Schrift gehaltenen Texten ausstellt.

Drittens kommt hinzu, dass im Falle des hier mittleren Murr-Teils der erste typographische Abschnitt mit „Leben machte“ endet, während der zweite ausgerechnet mit der Leseransprache " - Leser" beginnt (Hervorhebungen, MG).

Die Homonymie des Wortes „Abschnitt“ ist also Teil einer extrem komplexen Verschachtelung und vereint in ihrer Semantik Lesen und Leben. Besonders faszinierend ist nun, dass bei dieser für das vorliegende Unterkapitel zentralen Textstelle der typographische Abschnitt, in dem Murr neben der Überschrift des ersten Kapitels zum ersten Mal explizit von einem Lebensabschnitt spricht, durch einen Kreisler-Teil unterbrochen wird. Mehr noch: Murr wird nicht nur in demjenigen typographischen Abschnitt unterbrochen, wo er die Erzählung dieses Lebensabschnittes explizit eröffnet, sondern auch in demjenigen, wo er sie explizit beendet. ${ }^{115}$ In der oben verwendeten Farbgebung gesprochen heißt dies: Die beiden roten typographischen Abschnitte der Murr-Biographie werden je durch die zwei blauen, durch die Klammerbemerkungen abschnitthaft figurierten Kreisler-Teile unterbrochen. Sowohl diese typographischen Abschnitte der Murr-Teile als auch Murrs inhaltlicher Lebensabschnitt sind nur über die beiden unterbrechenden Kreisler-Teile zu lesen. Ihr Anfang und Ende und damit Anfang und Ende jenes "Abschnitt[s] in meinem Leben“ sind dadurch nicht exakt zu verorten. Dies alles lässt sich in folgenden zwei Befunden komprimieren:

Die typographischen sowie die durch die Klammerbemerkungen konstituierten Abschnitte der beiden Biographien überschneiden sich ebenso, wie inhaltlich gewisse Abschnitte in Murrs und Kreislers Leben ineinanderragen. ${ }^{116}$

115 Er benutzt dabei die folgenden, performativ gebrauchten Verben: , auf etwas zu sprechen kommen' und ,(eine Episode) schließen'.

116 Zusammenfassend zu den inhaltlichen Verknüpfungen zwischen Murr- und KreislerTeilen sowie zum inhaltlichen Abdruck, den der Murr-Text auf den als Löschpapier verwendeten Makulaturblättern hinterlässt, vgl. Wirth 2008, S. 411-414, inklusive Anm. 240; sowie Liebrand 1996, S. 196 f. 
Oben stehende farbliche Markierung veranschaulicht und verdeutlicht zudem die bisherigen Beobachtungen insofern, als dass ausgerechnet dort, wo vom "Abschnitt“ die Rede ist - wo er nicht nur begrifflich verortet werden soll, sondern auch performativ hergestellt wird -, sich die ultimative Potenzierung der Entortung dieses Abschnittes findet. Eines Abschnittes, der als Lebensabschnitt, als typographischer Abschnitt und als durch die Absatzfunktion der Klammerbemerkungen figurierter Abschnitt ein mindestens dreifacher Lesensabschnitt ist, dessen drei Lesarten im Zuge der Lektüre jedoch nie gleichzeitig zu haben sind. Eines Abschnittes, an dem selbst dessen performative Herstellung als eine an die Lektüre gebundene, nicht als bleibendes Produkt zu habende, aber unendlich weiterzuführende, potenziell unbeendbare ausgestellt wird.

\subsubsection{Zusammenführung der Ergebnisse}

In E. T. A. Hoffmanns Doppelroman, dem die Ein- und Abgrenzung von Text und Textteilen als ein zentrales, wenn auch weitgehend implizites Thema dient, kommt der typographischen Ebene eine entscheidende Rolle zu. Dabei sind es gerade auch die meist unbeachteten Absätze und Abschnitte, die auf der Mikroebene des Textes wesentlich am Versuch beteiligt sind, den Leser in eine unendliche Lektüre fortzuführen. Ein Versuch, der auf der Makroebene am prominentesten durch die chronologisch versetzte resp. verschränkte Anordnung der Murr- und Kreisler-Teile unternommen wird und zu dem auch zahllose intertextuelle Verweise und Verschachtelungen ${ }^{117}$ sowie die Konzeption als Fortsetzungsroman ${ }^{118}$ beitragen.

Wenn Sabine Laussmann zu den Lebens-Ansichten des Katers Murr schreibt, „[i]n fast postmoderner Weise feiert das erste Vorwort bereits den autorlos autonomen Text und seine Teilhabe an der unendlichen Bibliothek eines zeitlosen intertextuellen Universums", ${ }_{119}$ so ist ihr also zuzustimmen und weiterführend zu ergänzen: Es ist kein Zufall, dass sie mit ihrer bildlichen Formulierung einer „unendlichen Bibliothek eines zeitlosen intertextuellen Universums“ auf die implizite Ewigkeitsbehauptung ${ }^{120}$ gegenüber Schriftzeichen verweist. Die in den Lebens-Ansichten des Katers Murr geradezu exzessiv eingesetzte Intertextualität dient nämlich auch dem Versuch, Unendlichkeit und Zeitlosigkeit zu erschreiben. Oder mit anderen Worten: Das erste Vorwort "feiert" hier nicht nur implizit behauptend die „Teilhabe“ an

117 Vgl. dazu auch Laussmann 1993, insbesondere S. 16o f.; und Wirth 2008, S. 406.

118 Auf den Aspekt des Seriellen und den Cliffhanger „Kreislers Hut, an dem blutige Spuren befindlich“ (Hoffmann, Werke, Bd. 5, S. 234) kann im vorliegenden Rahmen nicht näher eingegangen werden; man vgl. dazu insbesondere Fröhlich 2015.

119 Laussmann 1993, S. 161.

120 Vgl. dazu die betreffenden Kapitel in der Einführung. 
einer vermeintlich existierenden textuellen Unendlichkeit und Zeitlosigkeit, sondern versucht zugleich, diese Ewigkeitsbehauptung gegenüber Schriftzeichen mittels Operationen zur Ewigkeitsattribuierung überhaupt erst wahr werden zu lassen.

Im Falle der Absätze und Abschnitte kommt letztlich nicht nur die Operation Unendliche Lektüre zum Einsatz, sondern zusätzlich die Unteroperation Poetische Performativität (siehe zu dieser Operation Kapitel III), und zwar über die Analogie von typographischem Abschnitt und Lebensabschnitt, die dem jeweiligen vergänglichen Lebensabschnitt einen ewigen Abschnitt aus Schrift zu stiften sucht. Doch gerade die entortende, potenziell unendliche Bewegung der Figuration von Absatz und Abschnitt wird in Hoffmanns Doppelroman auf eine Weise ausgestellt, die jedes zeichenhaft erzählte oder gedachte Leben als ein textuell konstruiertes und strukturiertes, als solches gelesenes und zu lesendes zu enttarnen vermag. Oder anders formuliert: Unendliche Lektüre ist in den Lebens-Ansichten des Katers Murr diejenige der Operationen zur Ewigkeitsattribuierung von Schriftzeichen, die gegenüber den anderen Operationen, aber auch in einem ästhetischen, den Doppelroman auf formaler Ebene strukturierenden, rahmenden und zugleich entrahmenden Sinne dominant ist. Die Operation Poetische Performativität hingegen nimmt dort eine wichtige Rolle ein, wo nicht nur von einem Lebensabschnitt die Rede ist, sondern zugleich ein Abschnitt einer Bio-Graphie, einer Lebens-Schrift, erschrieben resp. gelesen wird. Gerade der exzessive Einsatz der Operation Unendliche Lektüre (inkl. Überschneidungen mit der komplementären Operation Unendliches Verstummen, siehe Kapitel II.2) zwingt den Leser fast schon dazu, auf einer Metaebene über Anfang und Ende von Texten, die Möglichkeitsbedingungen und Aporien eines verschriftlichen Lebens und damit auch die Ewigkeitsbehauptung gegenüber der Gattung der (Auto-)Biographie sowie von Schriftzeichen im Allgemeinen nachzudenken. Damit aber bedient sich der Doppelroman letztlich in nicht unbedeutendem Maße auch der Grundoperation Reflexivität, die in Kapitel IV behandelt wird.

$\mathrm{Zu}$ Letzterem ist hier besonders hervorzuheben, dass E. T. A. Hoffmann sowohl in der Autobiographie Murrs als auch in der fragmentarischen Biographie Kreislers die Versuche der Verewigung des Genies und seiner Werke mittels Schriftzeichen inhaltlich thematisiert. Er tut dies auf den ersten Blick mittels parodistischer und ironischer Distanz zu diesen Versuchen. Aber trotz oder eben gerade wegen aller ironischen Reflexion auf Text, „unsterbliche Werke ${ }^{\text {"121 }}$ und die ,Göttlichkeit ${ }^{\text {‘22 }}$ des Genies experimentiert Hoffmann mit

121 Unter anderem Hoffmann, Werke, Bd. 5, S. 38 oder 44.

122 Vgl. dazu den oben zitierten Ausruf "göttlicher Murr" (Hoffmann, Werke, Bd. 5, S. 38). 
den semiotisch beschränkten Möglichkeiten, Leben mittels Schriftzeichen zu verewigen. Vielleicht könnte man sogar so weit gehen und sagen, dass Hoffmann die Bestrebungen der ,Weimarer Klassik', die mit ihrem Einsatz von Operationen zur Ewigkeitsattribuierung von Schriftzeichen vor allem auf die Autonomie des Verschriftlichten abzielte, ${ }^{123}$ einerseits zwar parodiert, andererseits aber zugleich zu integrieren und mit Operationen, die vor allem auf eine unendliche Aktualisation abzielen, zu kombinieren sucht. Vieles deutet zumindest darauf hin und ließe sich auch verknüpfen mit Claudia Liebrands Makroperspektive auf die Ästhetik Hoffmanns und deren Entwicklung ${ }^{124}$ sowie der Beobachtung, ,die negative Ästhetik, an der die KreislerTeile noch entlanggeschrieben sind“, würde erzählstrukturell „mit einem Affirmativen ästhetischen Entwurf (den Kateraufzeichnungen) kontrastiert und kontaminiert". ${ }^{125}$

Was die Figur Murr aber mit größtmöglichem Selbstvertrauen für eine Qualität hält, die sich von seiner göttlichen Genialität selbstverständlich auf seine „unsterblichen Werke“126 überträgt, das muss Hoffmann mit allen Mitteln überhaupt erst herzustellen versuchen: die Unsterblichkeit eines Werkes. Ja, es deutet alles darauf hin, dass Hoffmann gerade durch das als Herausgeber vermeintlich bescheidene - und von Murrs unterdrücktem Vorwort bereits autoreflexiv infrage gestellte - Zurücktreten hinter den "göttliche[n] [Autor] Murr", 127 durch die Parodie der Göttlichkeit und Unsterblichkeit des Genies, seiner Werke und der in der Genieästhetik angelegten engen Verknüpfung von göttlich-unsterblichem Werk und Leben ${ }^{128}$ mit unglaublich komplexem Aufwand sich (selbstironisch) als das inszeniert, was er parodiert: als göttlichunsterbliches Genie. Und zugleich zeigt er auf, dass das Leben eines Genies so verhandelt es die Biographie Kreislers eindrücklich - in seiner vermeintlich göttlichen Einheit stets in Wahnsinn auseinanderzufallen droht; ${ }^{129}$ dass das Werk eines Genies - dies zeigt wiederum die potenzierte Entortung von Anfang

\footnotetext{
123 Vgl. die Kapitel II.3.x, III.1 und IV.2.

124 Vgl. Liebrand 1996, u. a. S. 234 und - in Bezug zur Genie- und Autonomieästhetik zusammenfassend $-\mathrm{S} .13 \mathrm{f}$.

125 Ebd., S. 194.

126 Hoffmann, Werke, Bd. 5 , S. 38 oder 44.

127 Ebd., S. 38.

$128 \mathrm{Zu}$ den "Paradoxien des Genies" in Hoffmanns Roman vgl. Seidler 2005, insbesondere S. 6 of.

129 Diese Gedankengänge werden wieder aufgegriffen in Kapitel IV.3.3 zur Genieästhetik; und in Kapitel II.3.
} 
und Ende des Romans und seiner Teile - stets davon bedroht ist, das zu werden, was es im Grunde immer schon gewesen sein wird: fragmentarisch. ${ }^{130}$

\subsection{Miss Sara Sampson}

Lessings (nicht Fragment gebliebene) Trauerspiele tragen allesamt einen metonymischen Titel, sind benannt nach ihren jeweils auf den letzten Seiten dem Tod geweihten Hauptfiguren: Miss Sara Sampson, Philotas, Emilia Galotti. Der Tod, das Ende der Hauptfiguren, rückt damit in ein Similaritätsverhältnis zum Ende des jeweiligen Trauerspiels; wo etwa die Figur Sara Sampson stirbt, hat auch das Trauerspiel Miss Sara Sampson nicht mehr lange zu leben.131 Dieses durch den metonymischen Titel bedingte Similaritätsverhältnis - das in abgewandelter Form schon bei den Lebens-Ansichten des Katers Murr zu beobachten war - gibt Anlass zur Hypothese, die genannten Trauerspiele handelten nicht nur vom Ende ihrer titelgebenden Protagonist(inn)en, sondern auch vom Ende jener Trauerspieltexte selbst sowie des Trauerspiels im Allgemeinen.

Dass sich diese Hypothese als zutreffend erweist, hat Daniel Müller Nielabas Aufsatz „Schlafes Bruder zu Wort gekommen: Wie Lessing enden lässt" ${ }^{132}$ ausführlich belegt. Die Kernthese dieses Aufsatzes stellt eine Überführung des Schreckensmomentes des Todes im zeitgenössischen Trauerspiel, des Endes der Hauptfigur in ein von der Protagonistin resp. vom Protagonisten ersprochenes Enden fest. Diese Überführung des Endes in ein Enden wiederum ermöglicht überhaupt erst, dass angesichts des Todes auf der Bühne die Zuschauer nicht gemäß der bis anhin geltenden und auch von Gottsched vertretenen Aristoteles-Übersetzung ${ }^{133}$ Mitleid und Schrecken überkommt,

130 Vgl. dazu auch, was Claudia Liebrand zu einem allfällig geplanten dritten Band des Romans geschrieben hat: „Offenbar hingen die Schwierigkeiten Hoffmanns, an die beiden ersten Bände der Lebens-Ansichten einen dritten, einen Schlussband zu fügen, damit zusammen, daß eine inhaltliche Auflösung der Doppelstrukturen, die das ,vollendete ' Werk postuliert hätte, weit hinter das in den ersten beiden Bänden ästhetisch Erreichte zurückgefallen wäre. Stattdessen hat sich Hoffmann entschlossen, den Text offen zu lassen und ihn zu schließen - hat er ein (wie Singer es treffend genannt hat), in sich vollendetes Fragment' geschaffen [...] “ (dies. 1996, S. 198; resp. Singer 1963, S. 327). Zum Fragmentarischen als die Kombination der Unteroperationen Unendliche Lektüre und Unendliches Verstummen vgl. Kapitel II.3.4 sowie Kapitel 1.1 des Schlussteils.

131 Vgl. dazu auch Müller Nielaba 1999, S. 286, Anm. 3 o.

132 Vgl. Müller Nielaba 1999.

133 „Sie [die Tragödie, MG] konnte in diesem ihrem Zustande gar wohl ein Trauerspiel heißen: weil sie zu ihrer Absicht hatte, durch die Unglücksfälle der Großen, Traurigkeit, Schrecken, Mitleiden und Bewunderung bey den Zuschauern zu erwecken“ (Gottsched, Versuch einer critischen Dichtkunst, S. 6o6). Und: „Diese Fabel [der Tragödie, MG] ist nun geschickt, Schrecken und Mitleiden zu erwecken, und also die Gemüthsbewegungen 


\section{sondern Mitleid und Furcht. ${ }^{134}$ Ausführlicher zusammengefasst heißt es bei Müller Nielaba:}

Lessing lässt individuell und konkret genau so enden, wie er abstrakt und allgemein den Tod, das Ende des Endens sieht. ${ }^{135}$ Seine Bühnenfiguren, zumal Sara und Emilia, erliegen ursachenmäßig der Kทp [Ker, gewaltsamer Tod, MG], welche sie aber in der Sterbensdarstellung zum $\operatorname{\theta av\alpha \tau os}$ [Thanatos, Tod, MG] wandeln. Lessing also verleiht dem konkreten, „so und so" verlaufenden Enden seiner einzelnen Bühnenfiguren in der dramatischen Darstellung selber genau

der Zuschauer, auf eine der Tugend gemäße Weise, zu erregen. Das erstere erregen seine Schandthaten, und die unverhoffte Entdeckung derselben: dieses aber, die Betrachtung, daß er sie unwissend begangen hat" (ebd., S. 612). Nach heutigem Forschungskonsens unter den Altphilologen übersetzte Lessing falsch (falls man mit dem Maßstab einer reinen Übersetzungsabsicht und -leistung an dessen einschlägige Textstellen herantritt); heute werden Aristoteles' Begriffe mit: "Jammer und Schaudern“ (Aristoteles, Poetik, 6 resp. ders. Poetik, S. 19) übersetzt.

134 So heißt es im 75. Stück der Hamburgischen Dramaturgie: „Man hat ihn [Aristoteles, MG] falsch verstanden, falsch übersetzt. Er spricht von Mitleid und Furcht, nicht von Mitleid und Schrecken; und seine Furcht ist durchaus nicht die Furcht, welche uns das bevorstehende Übel eines andern, für diesen andern, erweckt, sondern es ist die Furcht, welche aus unserer Ähnlichkeit mit der leidenden Person für uns selbst entspringt; es ist die Furcht, daß die Unglücksfälle, die wir über diese verhänget sehen, uns selbst treffen können; es ist die Furcht, daß wir der bemitleidete Gegenstand selbst werden können. Mit einem Worte: diese Furcht ist das auf uns selbst bezogene Mitleid“ (Lessing, Werke, Bd. 6, S. 556 f.; vgl. u. a. auch das 74. Stück). In ebendiesem 75. Stück verweist Lessing darauf, dass er sich bei seiner Neuinterpretation auch auf Stellen im zweiten Buch von Aristoteles' Rhetorik (also nicht nur die Poetik) gestützt habe, eine davon lautet denn auch: „[...] kurz gesagt, furchterregend ist alles, was Mitleid erweckt, wenn es anderen zustößt oder droht“" (Aristoteles, Rhetorik, S. 91). Bemerkenswert ist, dass auch Gottsched sich zur Erregung des Mitleids auf ein Ähnlichkeitsverhältnis beruft, das durch die Wahl und das Leid von Menschen „mittlerer Gattung“, die sowohl tugend- wie lasterhafte Züge haben, zustande kommen soll (vgl. Gottsched, Versuch einer critischen Dichtkunst, S. 6o7).

135 Zuvor hat Müller Nielaba aus Lessings Schrift Wie die Alten den Tod gebildet (1769) folgende Stelle zitiert: „Tot sein, hat nichts Schreckliches; und insofern Sterben nichts als der Schritt zum Totsein ist, kann auch das Sterben nichts Schreckliches haben. Nur so und so sterben, eben itzt, in dieser Verfassung, nach dieses oder jenes Willens, mit Schimpf und Marter sterben: kann schrecklich werden und wird schrecklich. Aber ist es sodann das Sterben, ist es der Tod, welcher das Schrecken verursachte? Nichts weniger; der Tod ist von allen diesen Schrecken das erwünschte Ende ..." Lessing fährt im Original unmittelbar fort: „und es ist nur der Armut der Sprache zuzurechnen, wenn sie beide diese Zustände, den Zustand, welcher unvermeidlich in den Tod führet, und den $\mathrm{Zu}$ stand des Todes selbst, mit einem und eben demselben Worte benennet" (Lessing, Werke, Bd. 6, S. 76o f.). Lessing argumentiert sodann weiter, dass jene „Armut der Sprache“ oft zur Quelle des Pathetischen werde. Eine solche Art des Pathetischen solle aber vermieden und ihr durch klare begriffliche Trennung vorgebeugt werden, die Lessing bei

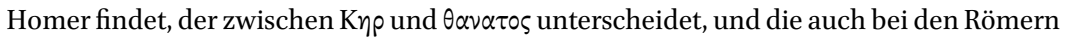
(lethum vs. mors) vorkomme (vgl. ebd.). Vgl. dazu auch Leventhal 1993, S. 312-218. 
diejenige ästhetische Qualität, die er zuvor als die allgemeine Eigenschaft des Todes, des Endes vom Enden erarbeitet hat. - Das bedeutet: Nach Maßgabe seines ästhetischen Gehalts [...] macht Lessing das Enden selber zum Ende, gestaltet er also das Ende als sein eigenes ,Davor‘. Der Tod als Übergang, so hatte es

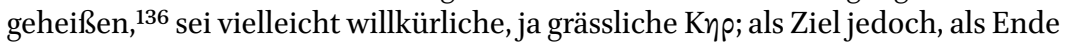
des Endens sei er stets schöner, erlösender $\theta \alpha \nu \alpha \tau \circ \varsigma$. Das ,schöne' Enden Saras und Emilias macht ästhetisch den Weg zum Ziel, gestaltet die Knp als $\theta \alpha \nu \alpha \tau \circ \varsigma$.

Wenn das vermeintlich gesicherte Ende aber, durch seine ästhetische Qualität, ins Enden eingeht, d. h., wenn das Ende selber zu jenem Prozess wird, der auf es hinzuführen scheint, dann ,ist' kein Ende mehr. Wenn ,Schlafes Bruder zu Wort kommt bei Lessing, schrecklos und schön, dann fängt das Ende an zu sprechen, über sich selbst und darüber hinaus. [...] Das Drama Lessings offeriert dem Publikum jene Leiche, die es erwartet. Es zeigt ihm aber zugleich an sich selber als Text, daß das Ende nicht dort sich befindet, wo gewaltsam geendigt wird, daß dieses vermeintliche Ende vielmehr der Beginn eines gemeinsamen Nach- und Neudenkens des Gezeigten sein muß. ${ }^{137}$

Im Folgenden wird der Fokus vor allem darauf liegen, die Ergebnisse dieses Aufsatzes ergänzend weiterzudenken und in den größeren Kontext der hier untersuchten Operationen zur Ewigkeitsattribuierung von Schriftzeichen einzuordnen. Ein erster Ansatz zu einer solchen Einordnung sei als These den unten stehenden Ausführungen bereits vorangestellt:

Lessings angestrebte Transformation des Trauerspiels des Mitleids und Schreckens hin zu einem Trauerspiel, das das Mitleid - gerade auch das selbstbezogene ${ }^{138}$ Mitleid der Furcht - ganz ins wirkungsästhetische Zentrum stellt, war nur zu erreichen durch eine gleichzeitig vorgenommene Betonung der Dauer (des Mitleidens) gegenüber dem (Schreckens-)Moment.

Die einschlägigen Aussagen Lessings dazu finden sich im 74. und 77. Stück der Hamburgischen Dramaturgie, wo es heißt:

Es ist wahr, das [sic] Schrecken ist eine Gattung der Furcht; es ist eine plötzliche, überraschende Furcht. Aber eben dieses Plötzliche, dieses Überraschende, welches die Idee desselben einschließt, zeiget deutlich, daß die, von welchen sich hier die Einführung des Wortes Schrecken, anstatt des Wortes Furcht, herschreibet, nicht eingesehen haben, was für eine Furcht Aristoteles meine. ${ }^{139}$

Aber er [Aristoteles] wollte uns zugleich lehren, welche Leidenschaften, durch die in der Tragödie erregten, in uns gereinigt werden sollten; und in dieser

$136 \quad$ Siehe die vorangehende Fußnote.

137 Müller Nielaba 1999, S. 287.

${ }_{13} 8$ Zur Operation der Spiegelung, die analog zum Paradigmenwechsel in der zeitgenössischen Philosophie dieser Neuinterpretation des aristotelischen phóbos zugrunde liegt, vgl. das Ende dieses Kapitels II.1.2; und insbesondere das Kapitel zur Reflexionsphilosophie IV.3.1.

139 Lessing, Werke, Bd. 6, S. 553. Lessing setzt diese Stelle dann unmittelbar mit dem berühmten „kleinen Ausschweif“ fort, der seine Dramentheorie entfaltet. 


\begin{abstract}
Absicht mußte er der Furcht insbesondere gedenken. Denn obschon, nach ihm, der Affekt des Mitleids, weder in noch außer dem Theater, ohne Furcht für uns selbst sein kann; ob sie schon ein notwendiges Ingredienz des Mitleids ist: so gilt dieses doch nicht auch umgekehrt, und das Mitleid für andere ist kein Ingredienz der Furcht für uns selbst. Sobald die Tragödie aus ist, höret unser Mitleid auf, und nichts bleibt von allen den empfundenen Regungen in uns zurück, als die wahrscheinliche Furcht, die uns das bemitleidete Übel für uns selbst schöpfen lassen. Diese nehmen wir mit; und so wie sie, als Ingredienz des Mitleids, das Mitleid reinigen helfen, so hilft sie nun auch, als eine vor sich fortdauernde Leidenschaft, sich selbst reinigen. ${ }^{140}$
\end{abstract}

Das Mitleid(en) und die Furcht als das auf sich selbst bezogene Mitleid(en $)^{141}$ sind also nicht nur auf das Element der Dauer innerhalb des Stückes angewiesen, sondern sie sorgen dafür, dass das Stück und ebenso diese Leidenschaften selbst, die es hervorruft, über das eigentliche Ende des Stückes fortdauern. ${ }^{142}$ Oder hinsichtlich des Fokus der vorliegenden Arbeit anders ausgedrückt: Der Schrecken korrumpiert als das Flüchtige die Ewigkeitsattribuierung des Trauerspiels. ${ }^{143}$

Diese Betonung der Dauer trifft, wie aus den Ausführungen Müller Nielabas $\mathrm{zu}$ entnehmen ist, insbesondere auf das Ende der Protagonist(inn)en zu. Ein Ende, das in seinem Enden bei den Trauerspielen Lessings nicht zufällig immer mit einem Gedankenstrich schließt. ${ }^{44}$ (Das vorangegangene Kapitel hat gezeigt, dass 65 Jahre später E. T. A. Hoffmann diesen Einsatz von Geviertresp. Gedankenstrichen an den Übergängen resp. Enden zwischen den einzelnen Murr- und Kreisler-Teilen geradezu zelebriert.) ${ }^{145}$ Darauf, dass Lessings

140 Ebd., S. 566.

141 Vgl. Schulz 1988, S. 274-279.

142 Siehe unten, insbesondere zu Ende des Kapitels 1.2.2. Zur zunehmenden Wichtigkeit der Furcht innerhalb von Lessings dramatischem Schaffen, gerade aufgrund ihrer potenziellen Dauer über die jeweilige Theateraufführung hinaus, vgl. Schulz 1988, S. 276, zusammenfassend S. 297.

143 Vgl. dazu auch das historisch-kontextualisierende Kapitel II.3.

144 Vgl. Müller Nielaba 1999, S. 288; resp. das folgende Unterkapitel 1.2.1. In Gottscheds Sterbender Cato beispielsweise stirbt die titelgebende Hauptfigur (zumindest in dem dem Verfasser zugänglichen Nachdruck der zweiten Auflage von 1736) nicht mit einem Gedankenstrich, sondern mit einem Ausrufezeichen: „Der Beste [man denke an die weiter oben in den Anmerkungen zitierte Maxime des Menschen von „mittlerer Gattung“; vgl. Gottsched, Versuch einer critischen Dichtkunst, S. 6o7] kann ja leicht vom Tugendpfade wanken. / Doch ihr seyd voller Huld. Erbarmt euch! - - Ha!“ (Gottsched, Sterbender Cato, S. 113).

$145 \mathrm{Zu}$ den Gedankenstrichen und Jean Paul, der diese schon vor E. T. A. Hoffmann virtuos einsetzte, sowie generell Lessings Einfluss auf ästhetische Verfahren späterer Jahrzehnte vgl. Kapitel II.3. Zum sprunghaften Anstieg von Gedankenstrich und Ausrufezeichen in 
mit Miss Sara Sampson angestrebte Transformation hin zu einem Trauerspiel, in dessen Zentrum das Mitleid(en) steht, sich im Drama des 18. Jahrhunderts nicht durchgesetzt hat, sondern für die nachfolgenden bürgerlichen Trauerspiele insbesondere die Maxime der „Poetischen Gerechtigkeit" ${ }^{\text {“46 }}$ galt, die dem Mitleid(en) mindestens ebenso verbunden war wie dem Schrecken, ist später zurückzukommen. ${ }^{147}$

Im folgenden Unterkapitel sei nun vor dem soeben dargelegten Hintergrund auf den Anfang und das Ende(n) von Miss Sara Sampson. Ein bürgerliches Trauerspiel, in fünf Aufzügen (1755), Lessings erstem bürgerlichem Trauerspiel, eingegangen, und zwar unter besonderer Berücksichtigung des Gedankenstrichs.

\subsubsection{Tödliche Gedankenstriche des Mitleidens}

Die ersten Gedankenstriche des Stücks finden sich bereits gleich zu Beginn des ersten Aufzugs:

SAMPSON Hier meine Tochter? - Hier in diesem elenden Wirtshause?

WAITwE LL Ohne Zweifel hat Mellefont mit Fleiß das allerelendeste im ganzen Städtchen zu seinem Aufenthalte gewehlt [sic]. Böse Leute suchen immer das Dunkle, weil sie böse Leute sind. Aber was hilft es ihnen, wenn sie sich auch vor der ganzen Welt verbergen könnten? Das Gewissen ist doch mehr, als eine ganze uns verklagende Welt. - Ach, Sie weinen schon wieder, schon wieder, Sir! Sir! ${ }^{148}$

der zweiten Hälfte des 18. Jahrhunderts vgl. die am Schluss dieses Kapitels zur Miss Sara Sampson erwähnte These Andrea Polascheggs.

146 Vgl. Mönch 1993, insbesondere S. 340-350.

147 Vgl. Kapitel II.3.4.

148 Lessing, Werke, Bd. 3, S. 433. Die Stellen aus Miss Sara Sampson werden hier zitiert nach der Ausgabe der „Bibliothek deutscher Klassiker“, die im Gegensatz zu den übrigen Editionen dem Erstdruck von 1755 folgt (vgl. ebd., S. 1202). Die von Herbert G. Göpfert herausgegebene Edition, die Müller Nielaba verwendet, und ebenso die Reclam-Ausgabe folgen direkt oder indirekt (Letztere stützt sich auf die von Muncker überarbeitete Edition Lachmanns 1886) der von Lessing revidierten Ausgabe letzter Hand von 1772. Hier zitierte Stellen aus Müller Nielabas Aufsatz können also Zitate aus der Ausgabe von 1772 enthalten; Müller Nielabas zentrale Feststellung, dass alle Protagonisten in Lessings Trauerspielen mit einem Gedankenstrich sterben, trifft (auch im Falle der beiden anderen Trauerspiele) ebenso auf die Erstausgabe zu. „Die Änderungen [der Ausgabe letzter Hand, MG] gegenüber dem Erstdruck betreffen fast ausschließlich Zeichensetzung, Wortstellung und Rechtschreibung und sind im Grunde marginal. [...] Markante Änderungen sind die Tilgung des Epithetons ,bürgerliches' im Titel [und ganz am Ende, MG] des Stücks (es heißt jetzt nur noch: ,ein Trauerspiel') sowie die durchgehende Korrektur von ,Sir Sampson' in ,Sir William' [Lessing, Werke, Bd. 3, S. 1202 f.]." Der Rückgriff auf die Erstausgabe ist dadurch zu begründen, dass der Gedankenstrich sowohl bei Müller Nielaba als auch in den folgenden Überlegungen alles andere als "marginal“ und wesentlich an der Akzentuierung der Dauer des Mitleidens gegenüber dem Moment des Schreckens beteiligt ist, die Lessings 
Der Fokus liegt im Folgenden auf dem zweiten Gedankenstrich:149 Der Satz zu seiner Linken handelt von der gewaltigen Macht des Gewissens (vor der sich niemand verbergen könne). „Das Gewissen“ und das Mitleid sind eng miteinander verknüpfte Gefühlsregungen: Oft stellt sich das (schlechte) Gewissen erst als Folge des Mit-Leidens - z. B. mit einer Person, an deren Leid man (mit-)schuldig ist - ein. Der Satz rechts des Gedankenstrichs handelt denn auch nicht zufällig vom Weinen, das die physische, sichtbare Folge von Mitleid darstellt und dadurch den Beweis liefert, dass die weinende Person auch tatsächlich des Mitleids fähig ist. ${ }^{150}$ Vergleicht man nun die Thematik dieser beiden Sätze, so lässt sich Folgendes feststellen: Während der linke Satz in einem theoretischen Gestus von der Macht des Gewissens spricht, fasst der rechte das auf der Bühne stattfindende, von Waitwell beobachtete und dem Publikum vermittelte ${ }^{151}$ Weinen in Worte. Es bleibt jedoch die Frage, wie sich hier der Wechsel zwischen theoretischem Sprechen über das durch Mitleid ausgelöste (schlechte) Gewissen hin zum Kommentieren einer sich gerade in diesem Augenblick auf der Bühne (resp. im Lesedrama über den Verweis „weinen“) zeigenden, sichtbaren Folge von Mitleid vollzieht. Die Antwort, die sich aufdrängt, lautet: über den Gedankenstrich.

Der Gedankenstrich ist es nämlich, der zwischen den beiden Sätzen Raum und (als Pause in der Rede auch) Zeit schafft, wo sich das Mitleid entfalten kann. ${ }^{152}$ Waitwell wird in seiner kurzen Redepause, als die der Gedankenstrich gelesen werden und die er dabei zugleich performativ schaffen kann, vom Theoretiker zum Zuschauer, vom Sprecher über Mitleid zum Mitleidenden. Offensichtlich ist er ein Zuschauer, der des Mitleids fähig ist, denn das erste Wort nach dieser Pause ist der Ausruf des Mitleids schlechthin: „Ach [...]!" Bekanntlich klingt in jedem ,Ach auch ein Ich mit, und zugleich ist gerade das Mitleid ein Gefühl, das sich im Individuum vollzieht, und zwar insbesondere in Bezug - und dabei über eine Similaritätsbeziehung - auf ein anderes Individuum. Das von Waitwell ausgestoßene „Ach“ klingt demnach in seiner Ähnlichkeit zum Ich an die an der Schwelle zur sogenannten Moderne

Transformation des Trauerspiels einleitet - und dies schon 1755 und nicht erst 1772. Einzig Saras Vater wird im Zuge der Argumentation nach der Ausgabe letzter Hand als ,Sir William' bezeichnet, da sich dieser Name etabliert hat.

149 Dieser wird in der Fassung letzter Hand von $177^{2}$ - wohl kaum zufällig - der erste sein.

15 O Vgl. auch Schulz 1988, S. 178 f., der bemerkt, dass im betreffenden Stück zwar das Mitleiden mittels Tränen gezeigt werden kann, nicht jedoch das Selbstleiden.

151 Wobei vor allem das Lesepublikum, das im Gegensatz zu den Theaterbesuchern Sir William und sein Verhalten nicht physisch vor sich sieht, auf diese Vermittlung angewiesen ist.

152 Zu Gedankenstrichen im Allgemeinen vgl. Kammasch 2009; und Nehrlich 2012, S. 117-123. 
sich vollziehende Erfindung des (bürgerlichen) Individuums als Bedingung für einen Paradigmenwechsel im Trauerspiel (vom Schrecken hin zu einer stärkeren Betonung des Mitleids) an, während es zugleich metonymisch auf die Gefühlsregung des Mitleids selbst verweist. Das „Ach“ Waitwells steht also als symbol (nach Peirce) für einen Seufzer, indexikalisch für das Mitleid, während es quasi als icon (sowohl graphisch als auch lautlich) ${ }^{153}$ eine Ähnlichkeitsbeziehung zum Ich generiert, das die Voraussetzung von Mitleid und Seufzer ist. Die Figur des Waitwell, die zum Zuschauer wird, thematisiert somit über ihre Similaritätsbeziehung mit den vor der Bühne anwesenden Zuschauern poetologisch die (erwünschte) Reaktion des Theaterpublikums, das ja dazu gebracht werden soll, Mitleid zu empfinden, und zwar ebenfalls dadurch, dass es mit den Figuren auf der Bühne in ein (zeichenhaft konstituiertes) Ähnlichkeitsverhältnis tritt.

Nimmt man die beiden Wörter in den Blick, die der Gedankenstrich (scheinbar) voneinander trennt, so lässt sich Folgendes beobachten: Der Gedankenstrich steht zwischen "Welt“ und "Ach“. Das Mitleid, das sich im Raum und in der Sprechpause, die der Gedankenstrich schafft, stumm entfaltet, um dann im "Ach“ indirekt/indexikalisch hörbar zu werden, wäre demnach das Bindeglied zwischen der Welt und dem Individuum, dem Ich, das im "Ach“ nachklingt. Zwischen „Welt“ und dem Individuum des „Ach“ steht der Gedankenstrich, bewegt sich das Mitleid. Damit wird an dieser Stelle in nuce poetologisch das Programm des bürgerlichen Trauerspiels erfasst: Weltzugriff des Individuums qua Similarität über einen Prozess des Mitleidens anstelle einer zeitgenössischen metonymischen Repräsentationsästhetik, die vor allem auf den Moment des Schreckens resp. Schauderns abzielt. Die Gegenüberstellung von "Welt" (als totum) und „Ach“/,Ich“ (als pars) würde noch für diesen metonymischen Weltzugriff (der Held, der König, die Märtyrerin etc. leidet stellvertretend für die übrigen Menschen) stehen, den die zeitgenössische Tragödie französisch-Gottsched'scher Prägung vermittelt. Doch der Gedankenstrich, der Raum und Zeit für die Entfaltung von Mitleid sowohl zu lesen geben als auch performativ schaffen kann, setzt "Welt" und "Ach“ an die Pole eines Prozesses des Mitleidens, der über Ähnlichkeitsbeziehungen Welt und Individuum miteinander verbindet. Weltzugriff durch Mitleiden.

Nach dieser Auseinandersetzung mit dem Anfang des Trauerspiels sei nun das Ende(n) Saras in den Blick genommen, ein Ende(n), bei dem Gedankenstriche wiederum keine unwesentliche Rolle spielen. Saras letzte Rede lautet nämlich:

153 Vgl. Peirce 1955. 
SARA Die bewährte Tugend muß Gott der Welt lange zum Beispiele lassen, und nur die schwache Tugend, die allzu vielen Prüfungen vielleicht unterliegen würde, hebt er plötzlich aus den gefährlichen Schranken - Wem fließen diese Tränen, mein Vater? Sie fallen als feurige Tropfen auf mein Herz; und doch doch sind sie mir minder schrecklich, als die stumme Verzweiflung. Entreißen Sie sich ihr, Mellefont! - Mein Auge bricht - Dies war der letzte Seufzer! - Noch denke ich an Betty, und verstehe nun ihr ängstliches Händeringen. Das arme Mädchen! Daß ihr ja niemand eine Unvorsichtigkeit vorwerfe, die durch ihr Herz ohne Falsch, und also auch ohne Argwohn der Falschheit, entschuldiget wird. der Augenblick ist da! Mellefont - mein Vater -

MELLEFont Sie stirbt! - Ach! $[\ldots]^{154}$

Ähnlich wie schon beim ersten Sprechen Waitwells ist es hier der erste Gedankenstrich, der zur Dauer beiträgt, die das Mitleid benötigt, um sich zu entfalten - und wieder steht er an der Stelle, wo der Redegegenstand wechselt, wo sich die Rede dem Weinen (wiederum demjenigen von Sir William) zuwendet. „Dies war der letzte Seufzer!“ ruft Sara aus und vollzieht dabei einen performativen Selbstwiderspruch, denn solange sie im Tempus der Vergangenheit ihren letzten Atemzug redend kommentiert, wird sie noch nicht den „letzte[n] Seufzer“ ausgestoßen haben. Und so folgt auf diesen „Seufzer“, wie könnte es anders sein, ein weiterer Gedankenstrich, der Saras Rede und das Hören und Lesen derselben fortführt: ein Lesen, das auch ihr zuvor geäußerter Ausruf „Mein Auge bricht“ unterläuft, der selbst schon wieder von einem Gedankenstrich unterbrochen resp. aufgeschoben worden ist, um erneut anzuklingen kurz vor dem Ende ihrer Rede: „- der Augenblick ist da!“ Nicht der "Augenblick“ ihres Todes ist das, was da ist - ihr Sprechen geht ja weiter -, sondern offenbar der Blick der Augen derjenigen, die gerade dabei sind, Saras Enden lesend weiter zu aktualisieren, es wortwörtlich weiterzulesen, und zwar im Stück Miss Sara Sampson, das den Tod seiner titelgebenden Figur, wenn auch nur um etwa zwei Seiten, im Zuge jeder (linearen, von Gedankenstrichen weitergetriebenen und potenziell unendlich oft wiederholbaren ${ }^{155}$ Lektüre überdauert haben wird.

\footnotetext{
154 Lessing, Werke, Bd. 3, S. 524 f.

155 Was Müller Nielaba zu einer Stelle in der Hamburgischen Dramaturgie schreibt, an der Lessing die schauspielerisch-gestische Umsetzung im Augenblick von Saras Tod durch die Schauspielerin Hensel lobt, findet sich im Dramentext zu jenem „Augenblicke“ Saras somit eindrücklich bestätigt resp. trifft für ebendiese Stelle im Dramentext genauso zu: „Was Lessings Beschreibung eines szenischen Todes versprachlicht, die Darstellung jenes ,Augenblick[s], da die Seele [weicht]', hört genau da auf, ,Augenblick` zu sein, wo es verschriftlicht und das heißt: wiederholbar wird“ (Müller Nielaba 1999, S. 271).
} 
Die bereits von Müller Nielaba festgestellte Überführung des schrecklichen "Augenblick[es]" des Todes in ein denselben immer weiter hinauszögerndes Reden schafft im Falle von Saras letztem Auftritt nicht nur den ,zeitlichen Raum', in dem sich das Mitleiden des Publikums mit Sara entfalten kann, sondern stellt dies zugleich aus, indem Sara selbst diese Zeit für das Entfalten ihres eigenen Mitleidens benötigt: Ihre Rede endet immer weiter, über das Brechen der Augen, den „letzte[n] Seufzer“, den „Augenblick“ hinaus, nicht um Sara schrecklich immer weiter leiden, sondern um sie weiter mitleiden zu lassen: mit ihrem Vater, Mellefont und schließlich auch mit ihrer Dienerin Betty.

Es sei nun noch einmal zurückgeblickt zum ersten Gedankenstrich in Saras letzter Rede sowie von dort weiter voraus zur Reaktion Mellefonts, zu dessen eigenem Enden und dem Enden des Trauerspiels selbst: Im Unterschied zu Waitwell zu Beginn des Stücks lässt Sara die Frage folgen („Wem fließen diese Tränen, mein Vater?“), die sich nicht nur bezüglich Sir Williams, sondern poetologisch auch für Lessings neue Konzeption eines Trauerspiels des Mitleidens aufdrängt: Wem gelten die Tränen? Stehen sie metonymisch für das empfundene Mitleid gegenüber einem anderen Individuum, oder gelten sie dem (Mit-)Leiden des eigenen Ichs? Eines Ichs, das in Mellefonts "Ach!“ aufschreit, welches wiederum auf einen Gedankenstrich folgt, der den Gedankenstrich am Ende von Saras Rede gewissermaßen bereits schon zitiert, damit deren Ende erneut verschiebt und in ein weiteres Enden überführt, das letztlich auch das Enden Mellefonts gewesen sein wird. Denn die Frage, wer im Zentrum des eigenen Mitleidens steht, scheint Mellefont tatsächlich über sein „Ach!“ mit ,Ich!' zu beantworten. Und wie Waitwell ganz am Anfang des Stücks Sir Williams Tränen dem (schlechten) „Gewissen“, also letztlich dem Selbstmitleid(en) des Vaters, zugeschrieben hat, so führt dieses "Gewissen“ Mellefont dazu, sich für eine selbst zugesprochene Schuld mit dem Tod zu bestrafen: „Es steht bei mir nicht, das Geschehene ungeschehen zu machen; aber mich wegen des Geschehenen zu strafen - das steht bei mir! er ersticht sich, und fällt an dem Stuhle der Sara nieder." ${ }^{156}$

In einem aber folgt Mellefont Saras, in ihrer letzten Rede geäußertem Wunsch, nämlich darin, sich der "stumme [n] ${ }^{157}$ Verzweiflung “ $z_{\text {, }}[\mathrm{e}]$ ntreißen“. Wie Sara spricht er sein Ende herbei und darüber hinaus: „MELLEFONT sterbend:158 Ich fühl es - daß ich nicht fehlgestoßen habe! - Wollen Sie mich

$15^{6}$ Lessing, Werke, Bd. 3, S. $5^{26 .}$

157 Hervorhebung MG.

$15^{8}$ Hervorhebung MG. 
nun Ihren Sohn nennen, ${ }^{159}$ Sir [...] - Gnade, o Schöpfer, Gnade! - "160 Sir William selbst hingegen (wie später Odoardo, der Vater Emilia Galottis) widersteht sowohl dem "Gewissen" als auch dem Selbstmitleid und ersticht sich nicht „wie" in „eine[r] schaale[n] Tragödie“, wie es bei Odoardo autoreferenziell heißen wird. ${ }^{161}$

Das Empfinden der Schuld seitens Mellefonts aber scheint ausgerechnet durch das Mitleiden Sir Williams verstärkt zu werden, das erneut über einen Gedankenstrich repräsentiert wird resp. durch diesen überhaupt erst Raum und Zeit in Mellefonts Rede und dem Dramentext erhält: ,- Was ist das? Ich will nicht, daß Sie einen barmherzigen Blick auf mich werfen sollen!" ${ }^{162}$ Noch mehr: Es ist gerade das Mitleiden Sir Williams, das Mellefont in den eigenen Tod sich reden lässt: Mangels eines strafenden Urteils seitens des Vaters der Geliebten sieht sich Mellefont offenbar gezwungen, sich in der rhetorisch beispielhaft gestalteten Beweisführung gegen sich selbst so lange immer weiter zu überbieten, bis diese, da Sir William nicht vom Mitleiden zum (schrecklichen) Strafen übergeht, unweigerlich im Selbstmord enden muss. Ja, ,schal' ist es bestimmt nicht, das Trauerspiel Miss Sara Sampson, und im Enden Mellefonts mag es Zuschauer und Leser gar mehr schaudern lassen als manch andere Tragödie vor ihm:

Denn am Selbstmord Mellefonts - so die These - wird deutlich, dass Lessings Trauerspiel Miss Sara Sampson bei aller Transformation der Tragödie weg von

159 Müller Nielaba schreibt dazu:„Daß die Selbstmörder Mellefont und Philotas beide explizit als ,Söhne' agieren, ist nicht ohne Belang. Vielmehr beweist es, daß Lessings Darstellung der ,Gewalt gegen sich' alles andere als eine Affirmation der heroischen Selbstnegation ist" (ders. 1999, S. 275). Bemerkenswert ist nun aber, dass auch Sara und Emilia explizit als Töchter in der Anrufung ihrer Väter sterben: „mein Vater -“ sind nämlich beider letzte Worte.

160 Lessing, Werke, Bd. 3, S. 526.

161 „Sie erwarten vielleicht, daß ich den Stahl wider mich selbst kehren werde, um meine Tat wie eine schaale Tragödie zu beschließen? - Sie irren sich!“ (Lessing, Werke, Bd. 7, S. 371; vgl. dazu auch Müller Nielaba 1999, S. 285). Wobei im „Sie“ natürlich nicht nur der Prinz, sondern auch das damit direkt angesprochene Publikum mitschwingt. Besonders bemerkenswert ist hier auch die Auseinandersetzung von Georg-Michael Schulz mit ebendiesem Satz Odoardos. Schulz wirft nämlich die Frage auf, „in welchem Maße die Verführung zum Erhabenen, der Emilia und Odoardo erliegen, von der poetischen Vermittlung ebendieses Erhabenen ausgeht, ob also bei dem hier dargestellten Ausweg in den Tod nicht vielleicht auch die Poesie in einer verhängnisvollen Weise ihre Gewalt unter Beweis stellt“ (Schulz 1988, S. 296). Freilich wäre erst zu präzisieren, ob diese ,Gewalt der Poesie' auf der Ebene der Fiktion oder auf der Ebene der Ko- und Kontexte von Lessings Schreiben ausgeübt wird (oder auf beiden); danach aber könnte ein Vergleich mit dem Verhandeln des tötenden Aspekts des Mitleids am Ende von Miss Sara Sampson (vgl. den folgenden Abschnitt) äußerst spannend sein.

162 Lessing, Werke, Bd. 3, S. 525 . 
einer Ästhetik des Schreckens hin zu einer Ästhetik des Mitleidens zugleich aufzeigt, dass erschreckenderweise auch das Mitleid tödlich sein kann.

1.2.2 Anfang - Mitte - Mitte und die Verewigung im Mitleid(en)

Im Vergleich mit dem Kapitel zu Hoffmanns Doppelroman lässt sich das bislang Festgestellte wie folgt zusammenfassen: Wie bei den Lebens-Ansichten des Katers Murr ermöglichen bereits im Falle des knapp 65 Jahre früher verfassten Trauerspiels Miss Sara Sampson der metonymische Titel und der an entscheidenden Stellen vorgenommene Einsatz von Gedanken- resp. Geviertstrichen eine Verwischung sowie eine poetologische Thematisierung von Anfang und Ende von Text. Und sowohl gegen Ende der Autobiographie Murrs als auch gegen Ende des Trauerspiels Miss Sara Sampson stellt sich das Problem der Darstellbarkeit des Todes der jeweils titelgebenden Protagonisten. Im Unterschied zu Hoffmanns Roman zwingt das hier untersuchte Stück den Leser (und letztlich auch die Zuschauerin) nicht über die chronologisch versetzte Anordnung einzelner Teile in eine potenziell endlos zu praktizierende Re-Lektüre, aber sucht doch das Ende seines Gelesen- und Gespieltwerdens immer weiter aufzuschieben, es zu überführen in ein Enden, das das Ende nahezu wortwörtlich überdauern soll. Dabei spielt der Gedankenstrich wie in allen drei Trauerspielen Lessings - die Theatermetapher scheint angebracht eine zentrale Rolle, die Müller Nielaba wie folgt beschreibt:

,Wie Lessing enden lässt': Emilia, nicht anders als Sara, Mellefont, Philotas, endet im Gedankenstrich - „Ah - mein Vater -“ (II, 204) -, in einem Zeichen also, dessen Funktion gerade darin besteht, darzustellen, daß kein Ende des Denkens dort ist, wo das Sprechen abbricht. Der Text, in der Darstellung des Endens, erweist sich als eine Darstellung seiner eigenen endlosen Dynamik, als vorbehaltlose Öffnung auf seine „Nachkommenschaft“. ${ }^{163}$

Es lässt sich also festhalten:

Der von Lessing durch seine Neuinterpretation von Aristoteles'Begriff phóbos angestrebte Paradigmenwechsel innerhalb der zeitgenössischen Gattung des Trauerspiels von einer Betonung des Schauderns/Schreckens hin zum Mitleid(en) ging nicht nur einher mit einer Priorisierung der Dauer des Mitleidens gegenüber dem schrecklichen Augenblick, sondern führte zugleich zur Auflösung einer anderen zentralen Begrifflichkeit in Aristoteles' Poetik, nämlich der für die Tragödie geforderten Dreieinigkeit von Anfang, Mitte und Ende. Dies insofern, als

163 Müller Nielaba 1999, S. 288. Mit „Nachkommenschaft“ wird eine Stelle aus Lessings Schrift Wie die Alten den Tod gebildet zitiert, siehe dazu weiter unten. 
bei Lessing das Ende in ein Enden überführt und damit zur Mitte wird. ${ }^{164}$ Lessing, so scheint es, ist damit auch ein entscheidender Wegbereiter für die gegen Ende seines Jahrhunderts erfolgende Ästhetisierung des Fragments, steht vielleicht sogar am Anfang jenes an der Schwelle zurModerne einsetzenden Infragestellens der Ganzheit eines Werkes (siehe dazu ausführlich II.3), wie sie dann beispielsweise in einem Roman wie den Lebens-Ansichten des Katers Murr richtiggehend zelebriert wird.

Der Gedankenstrich, der bei Lessings Trauerspielen sowohl auf den Tod als auch das Mitleid verweisen kann resp. im Zuge der Lektüre performativ erst die Dauer (mit-)erschafft, in dem sich das Mitleiden, aber auch das Reden und Denken über den Tod und über den Text hinaus und wieder zurück, ${ }^{165}$ entfaltet, wird dabei zum Zeichen der Mitte. Der Gedankenstrich stellt in nuce aus, woran er selbst entscheidend beteiligt ist: das Zur-Mitte-Werden des Endes.

Der Gedankenstrich als Graphem ist zudem ein Zeichen, das wie wohl kaum ein anderes die Frage nach der szenischen Darstellbarkeit eines Dramentextes aufwirft. Auch wenn er im Falle von Lessings Trauerspielen an vielen Stellen der Schaffung von Dauer dient, in der Mitleid sich entfalten kann, so ist im Allgemeinen die Lesart oder die szenische Umsetzung eines Gedankenstrichs als eine Pause bereits eine Interpretation. Als eines der wenigen Schriftzeichen der deutschen Sprache, das phonetisch stumm ist und zugleich keine eindeutige Vorgabe der Intonation (wie etwa ein Fragezeichen) nahelegt, ist der Gedankenstrich sogar das einzige Schriftzeichen, das auf einen Leerschlag folgt und dem zugleich auch ein Leerschlag nachfolgt. ${ }^{166}$ Umgeben von zwei Leerschlägen rückt es diese damit in den Blick wie kein anderes Schriftzeichen und

164 Es sei dafür bloß das in diesem Kapitel und in Müller Nielabas Aufsatz Erarbeitete mit der Stelle in Aristoteles' Poetik verglichen, dessen Definition der Mitte genau auf das Enden von Lessings Trauerspielen zutrifft: „Wir haben festgestellt, dass die Tragödie die Nachahmung einer in sich geschlossenen und ganzen Handlung ist, die eine bestimmte Größe hat; es gibt ja auch etwas Ganzes ohne nennenswerte Größe. Ein Ganzes ist, was Anfang, Mitte und Ende hat. Ein Anfang ist, was selbst nicht mit Notwendigkeit auf etwas anderes folgt, nach dem jedoch natürlicherweise etwas anderes eintritt oder entsteht. Ein Ende ist umgekehrt, was selbst natürlicherweise auf etwas anderes folgt, und zwar notwendigerweise oder in der Regel, während nach ihm nichts anderes mehr eintritt. Eine Mitte ist, was sowohl selbst auf etwas anderes folgt als auch etwas anderes nach sich zieht" (Aristoteles, Poetik, S. 25). Bemerkenswert ist hierbei auch, dass Aristoteles selbst seine Definition des Ganzen nicht mit der Definition des Endes schließt, sondern auf diese die Definition der Mitte folgen lässt.

165 Der waagrechte Strich zeugt von beiden möglichen Leserichtungen, ohne sich wie der Pfeil für eine zu entscheiden.

166 Diese Beobachtung verdankt der Verfasser der Diskussion seiner Überlegungen zum Gedankenstrich mit Daniel Müller Nielaba. Als einzige weitere, jedoch äußerst selten verwendete Zeichen, die ebenfalls von zwei Leerschlägen umgeben sind, kämen noch 
schafft so eine auch beim bloßen Überfliegen eines Textes ins Auge springende weiße Fläche - eine weiße Fläche, die einerseits eine Analogie bilden kann zu einer größeren Dauer, die zwischen der Lektüre der Zeichen vor und nach dem Gedankenstrich und den ihn umgebenden Leerschlägen vergehen soll. Eine weiße Fläche, die aber andererseits auch den Schrecken des Nichts, des leeren, unbeschriebenen Blattes, in Analogie zum ungewissen menschlichen Zustand vor der Geburt und nach dem Tode in Erinnerung zu rufen vermag. Somit ist es auch aus dieser semiologischen Mikroperspektive kein Zufall, wenn sowohl Lessings titelgebende Trauerspielfiguren als auch der Autobiograph der Lebens-Ansichten des Katers Murr nicht mit irgendeinem Schriftzeichen, sondern mit einem Gedankenstrich enden. Vielmehr zeigen sich am Gedankenstrich selbst, und wie er bei Lessing und Hoffmann eingesetzt wird (zu Jean Paul vgl. Kapitel II.3), letztlich die beiden komplementären Unteroperationen der Grundoperation Unendliche Aktualisation, nämlich Unendliche Lektüre und Unendliches Verstummen.

Es seien deshalb noch einige letzte und schließlich zur in Kapitel II.2 behandelten Operation Unendliches Verstummen überleitende Bemerkungen zu Dauer und ewigem Überdauern erlaubt. Dazu sei nochmals zurückgekehrt zum vorletzten Abschnitt und zum Zitat aus Müller Nielabas Aufsatz: Das am Ende jenes Abschnitts zitierte Wort „Nachkommenschaft“ stammt aus Lessings Schrift Wie die Alten den Tod gebildet, die den Totenglauben der ,Alten' beschreibt. Dieser Totenglaube unterteilt nach Lessing die Seelen der Verstorbenen in Lares, die ihrer Nachkommenschaft (also den noch lebenden Verwandten) wohlgesonnen sind, und in zur Strafe für begangene Verbrechen herumirrende Larvae. ${ }^{167}$ Es kann hier nicht weiter auf diese Stelle in Wie die Alten den Tod gebildet eingegangen werden, dafür jedoch auf das Ende des Stückes Miss Sara Sampson, wo zwar nicht von der "Nachkommenschaft", aber doch von einem „Vermächtnis“ die Rede ist:

SAMPSON [...] Laß mich nicht länger, Waitwell, bei diesem tötenden Anblicke verweilen. Ein Grab soll beide umschließen. Komm, schleunige Anstalt zu machen, und dann laß uns auf Arabellen denken. Sie sei, wer sie sei; sie ist ein Vermächtnis meiner Tochter! Sie gehen ab, und das Theater fällt zu.

Ende des bürgerlichen Trauerspiels ${ }^{168}$

vokalische Ausrufe oder Anreden infrage, so etwa ,O König“ resp. „o Katerjüngling!“ (Hoffmann, Werke, Bd. 5, S. 436).

${ }_{167}$ Vgl. Lessing, Werke, Bd. 6, S. 765 .

168 Lessing, Werke, Bd. 3, S. $5^{26 .}$ 
In Anlehnung an die in der Einleitung zitierte Rede Diotimas in Platons Symposion scheint am Ende des Stücks Marwood das dereinstige Fortdauern in ihrem biologischen Kinde (Arabella) abgesprochen und als "Vermächtnis“ Saras der Linie Sir Williams und seiner „Tochter“ zugesprochen zu werden. Umso bitterer für Marwood, dass nicht nur Lessing sie - wie auch Marinelli und den Prinzen in Emilia Galotti - nicht enden lässt, ${ }^{169}$ sondern dass Sara sie bereits um ihr schriftliches ,Kind" gebracht hat, indem sie deren „Zettel“ ${ }^{470}$ keiner Lektüre würdigt und ihn zerreißt:

[Mellefont:] Dies schreibet Marwood. er lieset: ,Wenn Sie diesen Zettel lesen werden, Mellefont, wird ihre Untreue in dem Anlasse derselben schon bestraft sein. [...] Ich sah es [das Giftpulver, MG] ihr geben, und gieng triumphierend fort. Rache und Wut haben mich zu einer Mörderin gemacht; ich will aber keine von den gemeinen Mörderinnen sein, die sich ihrer Tat nicht zu rühmen wagen.

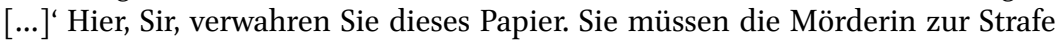
ziehen lassen, und dazu ist es ihnen unentbehrlich. - Wie erstarrt er da steht!“ SARA Geben Sie mir dieses Papier, Mellefont. Ich will mich mit meinen eigenen Augen überzeugen. er giebt es ihr, und sie sieht es einen Augenblick an: Werde ich so viel Kräfte noch haben? sie zerreißt es.

Daniel Müller Nielaba hat diese Stelle bereits wie folgt treffend analysiert:

Doch Marwoods vermeintlicher Triumph ist keiner: Jenes [auf dem „Zettel“ formulierte, MG] Lob der eigenen Tat, in dem Lessing hier die Medea des Euripides zitiert, verliert genau dadurch seine Kraft, daß es keine eigene Stimme hat, bloße Schrift ist, der der Getroffene selber die Zunge leihen muß, damit es überhaupt vernehmlich wird. Das Ungeheuerliche an Medeas Kommentierung ihres Racheaktes besteht ja genau darin, daß sie, nachdem sie die Nebenbuhlerin, deren Vater und die eigenen Kinder getötet hat, das ganze Grauen dem ungetreuen Ehemann Jason persönlich ins Gesicht sagen kann [...]. Die einzige, allerdings radikale Schmähung, die das Opfer der Täterin hier seinerseits antut, besteht darin, daß Sara bloß „Papier“ ansieht, wo es Schrift zu lesen gäbe, daß sie die Lektüre des eigenen Todesurteils und in diesem die Präsenz der sich „rühmen[den]“ Mörderin verweigert. Das „Papier“, welches in Anbetracht der Unsichtbarkeit des Giftes der einzige Beleg wäre für die Gewaltsamkeit ihres Todes und die Fremdbestimmung, der dieser Tod unterliegt: Sara "zerreißt es“ [...] und befreit durch dieses unwiderrufliche ,Zerreißen' ihr Sterben von allem Fremden und Äußerlichen und entzieht es damit willentlich der Kausalkette von Marwoods Untat, auf welche diese ihren vermeintlichen Triumph gründet. ${ }^{171}$

169 Vgl. Müller Nielaba, S. 288.

170 Lessing, Werke, Bd. 3, S. 523. Bemerkenswert ist, dass in der Nichtlektüre Saras nochmals auf der Mikroebene der „Augenblick“ betont wird, der keinen Platz für ein Mitleiden mit Marwood aufkommen lässt.

171 Müller Nielaba 1999, S. 273. 
Wo in den Lebens-Ansichten des Katers Murr das Zerreißen in gewissem Sinne zum Überdauern von Kreislers Biographie führt, dient es hier offensichtlich der Zerstörung des Nachruhms, der damnatio memoriae Marwoods. Der unsterbliche Ruhm des Schreckens der Rachehandlung, mit der sich Medea verewigt hat, scheint Marwood also verwehrt zu werden. ${ }^{172}$ Es ließe sich hingegen einwenden, dass Marwoods Nachricht im Dramentext abgedruckt ist, obwohl sie später auf der Ebene der Fiktion von Sara zerrissen wird. Damit vollzieht sich ein performativer Widerspruch: Leser wie Schauspieler haben auf der Grundlage des realen Dramentextes die Möglichkeit, Marwoods Nachricht potenziell unendlich oft zu aktualisieren resp. Mellefont Marwoods Nachricht immer wieder vorlesen zu lassen. Die damnatio memoriae Marwoods vollzieht sich aber nicht nur auf der fiktiven Ebene, sondern reicht trotz dieses performativen Widerspruchs bis in die Realität hinein. Möglichkeitsbedingung dafür ist wiederum Lessings Verknüpfung von Mitleid und Dauer. Dazu sei zunächst aus einem Brief Lessings an Friedrich Nicolai zitiert: ${ }^{173}$

Wenn es also wahr ist, daß die ganze Kunst des tragischen Dichters auf die sichere Erregung und Dauer des einzigen Mitleidens geht, so sage ich nunmehr, die Bestimmung der Tragödie ist diese: sie soll unsre Fähigkeit, Mitleid zu fühlen, erweitern. Sie soll uns nicht bloß lehren, gegen diesen oder jenen Unglücklichen Mitleid zu fühlen, sondern sie soll uns so weit fühlbar machen, daß uns der Unglückliche zu allen Zeiten, und unter allen Gestalten, rühren und für sich einnehmen muß. ${ }^{174}$

Vielmehr als das Zerreißen des Zettels durch Sara fällt demnach ins Gewicht, dass Marwood das Mitleiden des Publikums dadurch verweigert wird, dass sie im Stück nicht stirbt, ${ }^{175}$ während das Mitleid(en) - das Saras sich selbst im Modus des Mitleidens vollziehendes Enden ${ }^{176}$ hervorruft - „zu allen Zeiten“ wirksam bleiben soll (und dadurch letztlich auch Sara selbst). Dies wiederum führt zu folgender These:

Ebenso wie seine Fabellehre (vgl. Kapitel IV.2.1) scheint auch Lessings Trauerspielkonzeption darauf abzuzielen, einem moralischen Kern des jeweiligen

\footnotetext{
172 Ebd., S. $272 \mathrm{f}$.

173 Zum Briefwechsel über das Trauerspiel zwischen Lessing, Mendelssohn und Nicolai vgl. Schulz 1988, S. 197-207.

174 Briefwechsel über das Trauerspiel, Brief Lessings an Friedrich Nicolai vom November 1756 (Lessing, Werke, Bd. 3, S. 671).

175 Müller Nielaba 1999, S. 272 f.

176 Sara leidet mit Mellefont, mit Betty etc. mit, siehe oben unter 1.2.1.
} 
epischen oder dramatischen Textes - bei den Fabeln der moralische Satz, bei den Trauerspielen das Mitleid - die Dauer über "alle[] Zeiten" hinweg zu sichern. ${ }^{177}$

Zusammenfassend lässt sich jedoch aus den in diesem Unterkapitel angestellten Beobachtungen der Befund ableiten, dass der Versuch Lessings, dieses Ziel zu erreichen, im Falle seiner Trauerspielkonzeption letztlich in einen faszinierenden Zirkelschluss münden muss:

Das Mitleid, das nur als Mitleiden zu haben und deshalb im Gegensatz zum Schreckensmoment auf eine zumindest relative Dauer angewiesen ist, soll nach Lessing wiederholbar ausgelöst werden können durch ein Konservieren des Mitleidanlasses in einem Trauerspieltext, dessen Überdauern durch einen Modus garantiert werden soll, der selbst wiederum der des Mitleidens ist.

Dies ist vonseiten Lessings freilich ein Zirkelschluss, der gerade dadurch, dass er einer ist, eine potenziell endlose Bewegung lostritt. Oder anders formuliert: Gerade dadurch, dass das Mitleiden des Lesers nicht in einem absoluten Sinne dauerhaft festgehalten werden kann, birgt es in Lessings Konzeption eine gewisse abstrakte Dauerhaftigkeit durch jene Verschränkung von Dauer und Mitleid in einem potenziell unendlichen Prozess des Mitleidens.

Von hier aus bietet es sich nun an, überzuleiten zum nächsten Kapitel: Mitleid ist also auf Dauer angewiesen, die in Lessings Trauerspielen den Tod hinausschiebt und ihn zugleich zu überwinden sucht durch ein verewigendes Mitleiden. Eng damit verknüpft ist das Problem der (Un-)Darstellbarkeit des Todes, ${ }^{178}$ das bereits bei den Lebens-Ansichten des Katers Murr zu beobachten war, so Müller Nielaba:

Der „Augenblick, da die Seele“, die eigene, ,weicht': Saras Sprechen antizipiert ihn als das, was der Text selber nur in der sprechenden Leere eines Gedankenstrichs darstellen kann. Umgekehrt Mellefont: Demjenigen, was Sara, als ihr eigenes Ende, nur vorwegnehmend ausdrücken kann, jenem „Augenblick“, hinkt er, der Machtlose, um dieselbe entscheidende Zeitspanne hintennach. „Sie stirbt!" [...],

177 Interessant ist, dass hier ausgerechnet Gottsched eine ähnliche Meinung vertritt, jedoch jeweils ohne den Aspekt der Dauer: „Wie eine gute tragische Fabel [in diesem Zitat Gottscheds gemeint im Sinne von ,erzählte Handlung', nicht im Sinne der literarischen Gattung der Fabeln, MG] gemacht werden müsse, das ist schon im vierten Hauptstücke des ersten Theils einigermaßen gewiesen worden. Der Poet wählet sich einen moralischen Lehrsatz, den er seinen Zuschauern auf eine sinnliche Art einprägen will. Dazu ersinnt er sich eine allgemeine Fabel, daraus die Wahrheit eines Satzes erhellet. Hiernächst suchet er [...]" (Gottsched, Versuch einer critischen Dichtkunst, S. 611). Äußerst bemerkenswert ist zudem, dass Lessing in seinen Abhandlungen [über die Fabel] (nun Fabeln im Sinne der literarischen Gattung) Gottsched nahezu zitiert, was den moralischen Lehrsatz anbelangt, jedoch zusätzlich wiederum den Aspekt der Dauer betont (vgl. Kapitel IV.2.1 zu Lessings Fabel Der Phönix).

178 Vgl. dazu auch Leventhal 1993, S. 315 . 
muß er entsetzt feststellen, ohnmächtig darin, daß es diese "Sie“ als Sterbende [eher: Gestorbene, MG] genau dann bereits nicht mehr gibt, wo er sie als solche ansprechen kann. Der „Augenblick“ des Endes vom Enden ist sprachlich nicht zu fassen, bloß zu umschreiben, buchstäblich, in der gemeinsamen Verschränkung von vorwegnehmendem und nachfolgendem, Temporalität kontrahierendem und diese dehnendem Sprechen. - Ein letzter "gelinder Spasmus“, Sprache geworden. ${ }^{179}$

Mit Blick auf die in dieser Arbeit untersuchten Operationen zur Ewigkeitsattribuierung von Schriftzeichen lässt sich dazu ergänzend folgende These formulieren:

In Lessings Ästhetik des Endens wird die Unteroperation Unendliche Lektüre bemüht, um Dauer zu garantieren. Dabei spielt der Gedankenstrich eine entscheidende Rolle, der Raum und Zeit für die Entfaltung des Mitleidens schafft.

(Somit ergänzen und bestätigen das vorliegende Kapitel und die These Andrea Polascheggs einander eindrücklich; denn Letztere beobachtet, dass die in der zweiten Hälfte des 18. Jahrhunderts gewissermaßen zu ,Affektzeichen“ werdenden Satzzeichen - insbesondere die sprunghaft ansteigende Zahl der Gedankenstriche und Ausrufezeichen - einhergehen mit der Konstitution des modernen Individuums und der modernen Autorschaft. $)^{180}$

Der Gedankenstrich wird beiLessing des Weiteren gerade dorteingesetzt, wo der Tod, das Ende stehen müsste, was einem Verfahren entspricht, das komplementär zur Operation der Unendlichen Lektüre zugleich auch in Richtung der Operation Unendliches Verstummen tendiert. Zudem lässt sich in der Neuinterpretation des aristotelischen phóbos als Furcht im Sinne eines selbstbezogenen Mitleidens - in Einklang mit dem zeitgenössischen Paradigmenwechsel in der Philosophie ${ }^{181}$ eine Operation der Spiegelung beobachten, die der Grundoperation Reflexivität zugrunde liegt.

Wie das Problem der (Un-)Darstellbarkeit des Endes auch ästhetisch produktiv genutzt werden kann, damit beschäftigt sich nun das folgende Kapitel II.2 zum potenziell unendlich oft erfolgenden Verstummen von Schriftzeichen.

\footnotetext{
179 Müller Nielaba 1999, S. $274 \mathrm{f}$.

180 Vgl. Polaschegg 2012, insbesondere S. 16o-162 und 181 f. Dazu passen ebenso eindrücklich die Ergebnisse Uwe Wirths weiterführender Beobachtungen zum Zusammenhang zwischen Ewigkeitsattribuierung, Herausgeberfiktion und Konstitution der modernen Autorschaft, wie sie weiter unten in Kapitel II.3.3 dargelegt werden.

181 Vgl. insbesondere Kapitel IV.3.1.
} 


\section{Unteroperation Unendliches Verstummen}

\subsection{Der Spinnerin Nachtlied}

\section{Der Spinnerin Nachtlied ${ }^{182}$}

Es sang vor langen Jahren, Wohl auch die Nachtigall, Das war wohl süßer Schall

[1-4] Da wir zusammen waren

Ich sing' und kann nicht weinen Und spinne so allein, Den Faden klar und rein

[5-8] So lang der Mond wird scheinen.

$\mathrm{Da}^{183}$ wir zusammen waren

Sang süß ${ }^{184}$ die Nachtigall

Nun mahnet mich ihr Schall

[9-12] Daß du von mir gefahren

So oft der Mond mag scheinen, Gedenck ich ${ }^{185}$ dein allein, Mein Herz ist klar und rein,

[13-16] Gott wolle uns vereinen.

Seit du von mir gefahren Singt stets die Nachtigall Ich denk bei ihrem Schall

[17-20] Wie wir zusammen waren

Gott wolle uns vereinen Hier spinn ich so allein, Der Mond scheint klar und rein, [21-24] Ich sing' und mögte weinen.

182 Zitiert nach der Fassung im Brief an Achim von Arnim vom 6. September 1802 (Brentano, Werke, Bd. 29, S. 498), Abweichungen einzelner Worte (nicht der Orthographie und nicht der Interpunktion) gegenüber den Varianten des Gedichts in den beiden Fassungen der Chronicka eines fahrenden Schülers sind mit Fußnoten vermerkt.

183 "Als" anstelle von „Da“ wird bloß im kritischen Apparat zur Fassung des Liedes innerhalb der Chronicka eines Fahrenden Schülers (1. Fassung) als Variante angegeben (vgl. Brentano, Werke, Bd. 19, S. 527).

184 In der Chronicka eines fahrenden Schülers (1. und 2. Fassung): „Da sang die ...“ (ebd., S. 96 und 200).

185 In der Chronicka eines fahrenden Schülers (1. Fassung): „So denck ich ...“" (ebd., S. 96 und 527). 
Die Überlieferung des Liedes gestaltet sich komplex. Es wurde wohl im Sommer 1802 verfasst und (noch ohne Titel) in einem Brief vom 6. September 1802 an Achim von Arnim mitgeteilt. ${ }^{186}$ Als Kompositions- und von der Forschung angenommener Erstdruck erschien es ca. 1806 (terminus ante quem: 16. Juni 1806) erstmals kontextfrei. Entstanden ist es aber ursprünglich „[im] Zusammenhang mit der Chronicka eines fahrenden Schülers" und wurde 1818 dann auch als Teil dieses Erzählfragments abgedruckt. „[D]och hat es Brentano in wenigstens einer (undatierten) Abschrift selbst aus dem Prosakontext gelöst und ihm die Überschrift Der Spinnerin Nachtlied gegeben." ${ }^{187}$ Der nicht originale Titel Der Spinnerin Lied, der einem zuweilen noch begegnet (etwa bei Alewyn), ${ }^{188}$ stammt von den Herausgebern der $185^{2}$ postum erschienenen Gesammelten Schriften. ${ }^{189}$ Dass diese ausgerechnet das Bestimmungswort Nacht- strichen, mutet äußerst seltsam an, stellt der Titel doch gerade dadurch einen impliziten Bezug zu den mittelhochdeutschen Tage-Liedern her, ${ }^{190}$ der nach Kenntnis des Verfassers in der Forschung aber bislang keine Beachtung

186 Vgl. Brentano, Werke, Bd. 29, S. 498 f.

187 Das Lied wird hier außerhalb jenes Prosakontextes untersucht; zum Lied in seinem unmittelbaren Kontext der Chronicka eines fahrenden Schülers vgl. u. a. Frühwald 1994, S. 275 und 277-279; Schrimpf 1976, S. 384-386; und vor allem Kirchberger 1975, S. 420-424.

188 Vgl. den Titel seines 1971 erstmals erschienenen Aufsatzes; Alewyn 1974, S. 198.

189 Vgl. Frühwald 1994, S. 269 f.

190 Brentanos Wissen und seine Verdienste um die mittelhochdeutsche Lyrik, darunter natürlich auch Tagelieder, sind allgemein bekannt. An dieser Stelle sei als Exempel bloß aus der Einleitung der Edition des Königsteiner Liederbuches zitiert, das zu etwa zwei Dritteln aus Sehnsuchtsklagen besteht (vgl. Sappler 1970, S. 5) und vielleicht den Entstehungskontext von Der Spinnerin Nachtlied ergänzen mag: „Ein Tinteneintrag auf dem vorderen Pergamentspiegelblatt verso gibt über die Vorbesitzer Auskunft: ,Codex olim Clementis Brentanonis. Postea fratrum Grimmiorum. ' [...] Clemens Brentano scheint die Handschrift aus Neigung für die ältere deutsche Literatur gekauft zu haben; auf die Erwerbung könnte folgende Stelle aus einem Brief an Arnim vom August 1802 [also etwa einen Monat vor dem Brief, der Der Spinnerin Nachtlied enthält, MG] hindeuten: ,Ich bin fünf baare Wochen in Koblenz gewesen und habe unter andern viele seltene alte Bücher und einige Manuscripte spottwohlfeil gekauft: [...] Zwei Tagelieder der Sammlung (Nr. 6 und 40) gelangten im gleichen Jahr [1805, MG] in den ersten Band des ,Wunderhorns“" (ebd., S. 28). Diesen Hinweis verdankt der Verfasser seiner Bürogenossin und Expertin für mittelalterliche Handschriften, Dr. Lena Ötjens. 
gefunden hat. ${ }^{191}$ Man hat lediglich auf die Parallelen zu Friedrich Spee ${ }^{192}$ und Hans Jakob Christoffels von Grimmelshausen Nachtigallen-Lied aus dem Simplicissimus $(\mathrm{I}, 7)$ verwiesen, ${ }^{193}$ die jedoch selber wiederum Elemente des Tageliedes resp. der mittelhochdeutschen Lyrik aufgreifen. Der Bezug zum mittelhochdeutschen Tagelied ist - wie sich zeigen wird - vor dem Hintergrund dieser Arbeit jedoch von zentraler Bedeutung und dient deshalb für das vorliegende Kapitel als Ausgangslage, das denn auch gattungspoetologischen Aspekten des Gedichtes besondere Aufmerksamkeit schenkt. mittelhochdeutschen Tagelieder

Die mittelhochdeutschen weltlichen Tagelieder ${ }^{194}$ besingen - oft verknüpft mit den Elementen des Weckens und Wachens - die drohende Trennung eines Liebespaares (meist einer höhergestellten adligen Herrin und ihres Geliebten) bei Tagesanbruch, das im Falle einer Entdeckung Tod und Schande fürchten muss. ${ }^{195}$ Über u. a. das Auftreten mehrerer Sängerinstanzen (wozu auch Singvögel wie die Nachtigall zählen können) und die mehrdeutige Deixis der Pronomen handeln sie aber auch und nicht minder gattungskonstitutiv - so hat der Verfasser in einer Studie von 44 solcher Tagelieder gezeigt ${ }^{196}$ - von den Möglichkeitsbedingungen des Singens eines Textes, wobei sie das Verstummen des Liedes ästhetisch und poetologisch produktiv nutzen. Die zentrale Bedeutung der Tageliedszene für die in diesem Kapitel (und auch in Teilen von Kapitel II.3) entfaltete Argumentation mag folgendes, etwas längeres Selbstzitat jener Studie rechtfertigen:

191 Frühwald erwähnt zwar, dass der Schlussvers des Gedichtes „in Anlehnung an den Eingangsvers eines Tageliedes des Meisters Walther von Breisach (Ich singe und sollte weinen) gebildet“" (Frühwald 1994, S. 277) sei, ohne aber dem ganzen Lied die Nähe zur Gattung der Tagelieder zuzusprechen. Bei Walther von Breisach ist es der Wächter, dem im Falle der ersten Strophe die Stimme geliehen wird und der sich nicht erinnert, sondern vor dem Tagesanbruch warnt. In der zweiten Strophe des Liedes berichtet dann eine erzählende Instanz, dass die Geliebte aufgrund des Singens des Wächters weint: „ir leides hûsgenôz, / der trehene flôz, / begôz ir beider wengel dô vil gar“ (Tagelieder 2011, S. 166).

192 Zu Brentano und seiner Rezeption von Friedrich W. Spees Trutz-Nachtigall resp. des barocken Echogedichtes vgl. Menke 200o, insbesondere S. 496-499.

193 Darauf, dass Brentanos Lied eine Antwort auf Achim von Arnims Nachtigallenlied Dichterlohn sei (vgl. Frühwald 1995, S. 407).

194 Vgl. die bestehenden Anthologien: Tagelieder des deutschen Mittelalters ${ }^{3}$ 2011; Hausner 1983; Deutsche Tagelieder 1983; Texte zur Geschichte des deutschen Tageliedes 1947. Die einzige Anthologie geistlicher Tagelieder stammt von Schnyder 2004.

195 Zum Tageliedstoff in der mhd. Literatur außerhalb der Tageliedgattung vgl. Hausner 1983; und Mohr 1971. Für den englischen Sprachraum vgl. zudem Honegger 1999.

196 Vgl. Gut 2014. 
Der Zeitpunkt, in dem das Singen der allermeisten Sänger-Instanzen auf semantischer Ebene stattfindet, befindet sich fast immer zwischen Tag und Nacht. Insbesondere das Ende des Tageliedes ist erreicht, bevor es tatsächlich helllichter Tag geworden wäre, und fast nie erzählt eine weitere, letzte Strophe die scheinbar logische Folge des Weckens des Liebespaares, nämlich eine tatsächlich erfolgte Trennung der Liebenden. Damit vollzieht sich ein Widerspruch zwischen der semantischen Ebene, in der vom Wecken des Paares und der unmittelbar bevorstehenden Trennung die Rede ist, und dem Ende des Liedes, das genau dieses Wecken wirkungslos macht, indem es ein (Weiter-) Singen von einer tatsächlich erfolgten Trennung schlicht unterlässt. In der fiktiven (semantischen) Welt des Liedes kann somit gar keine Trennung des Paares erfolgen, da im Lied von keiner erfolgten Trennung die Rede ist. Kurz gefasst lässt sich also sagen: Die allermeisten der untersuchten Tagelieder thematisieren den performativen Widerspruch, den sie - durch den Zeitpunkt, in dem ihre ,Erzählung‘ abbricht - generieren.

Dieser Zeitpunkt aber ist ein Dazwischen: ein ,Graubereich' (Morgengrauen) zwischen Nacht und Tag. Aus diesem Dazwischen auf semantischer Ebene und der Spannung zwischen Tag und Nacht, zwischen Wach-Sein und Schlafen, zwischen Zusammensein und drohender Trennung, entfaltet sich die Gattung des Tagelieds, und selbst Variationen des klassischen Tagelied-Stoffes kommen kaum umhin, in irgendeiner Form darauf Bezug zu nehmen. [...]

Aber das Tagelied spricht nicht nur von einem Werden, sondern ,ist' zugleich auch immer ein Werden: Als Geflecht aus Sprachzeichen, das nur zu einem Lied wird, wenn jemand es singt, ist es als solches immer gerade im Begriff, gesungen zu werden. Der semantische Fokus auf ein Werden (des Tages) und auf das damit verbundene Wecken ermöglicht somit, dass das Lied vollzieht, wovon es als ganzes Lied (und nicht nur in einzelnen Passagen) spricht. Auf poetologischer Ebene wird das Werden des Liedes, auf semantischer Ebene das Werden des Tages behandelt. Der Zeitpunkt des Liedendes ist auf semantischer Ebene fast immer so gewählt, dass ebendiese semantische Ebene mit der poetologischperformativen Ebene (insbesondere genau in diesem Ende[n]) zusammenfällt.

Es gibt also eine verblüffende Ähnlichkeitsbeziehung zwischen dem Tagesanbruch auf semantischer Ebene und dem Gesungen-Werden des Liedes. Dass diese Ähnlichkeitsbeziehung gerade auch in Variationen des Tagelied-Stoffes nicht nur oft beibehalten wird, sondern z. T. sogar das zentrale produktive Element, aus dem sich die Variation entfaltet, darstellt, zeigt [innerhalb des untersuchten Korpus, MG] Morungens Tagelied. ${ }^{197}$

Es kann also kaum für einen Zufall gehalten werden, wenn Brentano die Tageliedszene ausgerechnet mit der auf poetologischer Ebene mythologisch und literaturgeschichtlich höchst aufgeladenen Szene am Spinnrad ${ }^{198}$ kombiniert. Denn als Tagelied-Spinnrad-Hybrid stellt Brentanos ,Nachtlied“ genau eine jener „Variationen des Tagelied-Stoffes“ (und umgekehrt betrachtet natürlich

197 Ebd., S. 279-282; vgl. dazu auch Mertens Fleury 2018, insbesondere S. 196 f.

198 Frühwald 1994, S. 272. 
auch eine Variation des Topos vom Weben $)^{199}$ dar. Dies gibt methodisch den Anlass dazu, die folgende Argumentation systematisch aus den wichtigsten Elementen von Brentanos Variation der Tageliedszene zu entwickeln. Diese sind, in der Reihenfolge ihrer unten stehenden Behandlung:

a) die Kombination der Spinnrad- mit der Tageliedszene

b) der Gesang/Klang einer weiteren Sängerinstanz (in diesem Fall der Nachtigall) hat eine erinnernde und keine weckend-warnende Funktion

c) die Zukunft wird als wiedervereinende erhofft, während sie im typischen mittelhochdeutschen Tagelied die Trennung herbeiführt

d) die explizite Bezeichnung des Liedes als ein Nacht- anstelle eines Tageliedes

$\mathrm{Zu}$ a), die Kombination der Spinnrad- mit der Tageliedszene: Wolfgang Frühwald erwähnt, dass Brentano

eine im späten 18. und 19. Jahrhundert häufige lyrische Szene thematisch und formal weitergebildet [hat]: das Lied des auf den Geliebten wartenden Mädchens am Spinnrade; er hat in der Form des Liedes die starke Affektbetonung dieser Lieder mit der Monotonie der Arbeit am Spinnrad konfrontiert, in der sich die Qual des Wartens sinnbildlich erneuert. ${ }^{200}$

Auf diese ,Erneuerung resp. die Iteration wird sogleich eingegangen, zuerst sei aber auf die komplexe Symbolik des Spinnens hingewiesen: Das Metzler Lexikon literarischer Symbole führt unter dem Eintrag "Gewebe/Faden“, der auch das Schlagwort "Spinnen“ abdeckt, neun verschiedene Symboliken, wovon in Brentanos Gedicht mindestens sechs in hohem Maße mitschwingen: „2. Symbol des Schicksals und der Zeit“, „3. Symbol der Kunstfertigkeit und des Darstellungsvermögens", „4. Symbol des Singens und mündlichen Erzählens“, "7. Symbol emotionaler Beziehung und persönlichen Andenkens“,201 „8. Symbol von Struktur und Textur" und in 8 schon mitschwingend: "9. Symbol des Dichtens bzw. Textens. “202 Bemerkenswert ist nun, dass die symbolischen Bedeutungen 4 (teilweise auch 3 und 7) und vor allem 8 und 9 sich mit der Tageliedszene und deren (poetologischen) Bedeutungsebenen überschneiden und diese dadurch noch verstärken, wohingegen Symbolik 2 eine zusätzliche Ebene ins Spiel bringt, die sich jedoch - auch dies ist höchst bemerkenswert mit dem Fokus der geistlichen Tagelieder deckt (siehe unten Punkt c).

199 Nichtsdestotrotz ist das Gedicht betitelt als Nachtlied einer Spinnerin und nicht als ein Spinnlied einer des Nachts Singenden. Die Titelgebung akzentuiert also stärker die Kombination des Tageliedstoffes mit dem Topos des Webens als umgekehrt.

200 Frühwald 1994, S. 272.

201 Vgl. dazu auch ebd.

202 Metzler Lexikon literarischer Symbole 2012, S. 149-151. 
Das Similaritätsverhältnis zwischen der inhaltlichen Ebene des Spinnens und der auf Wiederholung und Verschränkung beruhenden Form von Brentanos Lied und die dadurch sich eröffnende poetologische Lesart desselben wurden in der Forschung bereits ausführlich behandelt. Stellvertretend dafür sei hier Hans Magnus Enzensberger zitiert, der dies, was die Strophen und Verszeilen anbelangt, auch schematisch schön vor Augen führt:

Wenn man die ersten acht Verszeilen mit den Ziffern 1-8 bezeichnet und von den kleinen, aber bedeutungsvollen Veränderungen absieht, ${ }^{203}$ denen sie wiederkehrend unterworfen werden, so erhält man das folgende Bild:

Strophe i 1234 Strophe ii 5678

iii $4234 \quad$ iv 8675 vi234 vi 5678

Jede der beiden Strophenarten (a- und ei-Strophen) wird also in der Weise variiert, daß die zuletzt gesungene Zeile (Zeile 4 in Strophe i) in der folgenden Strophe der gleichen Art als erste erscheint, während der Strophenkern seine Reihenfolge beibehält. Die zweite Variation kehrt die Konstellation nach dem gleichen Gesetz wieder um und führt auf diese Weise beinahe (aber eben nur beinahe) zur Ausgangsstrophe zurück (i fast $=v$; ii fast $=v i)$. Die beiden Strophengruppen kontrastieren übrigens miteinander nicht nur in ihrem Klangthema, sondern auch durch das Vorwiegen der Ich-Haltung hier, der Du-Haltung dort. $^{204}$

Was die Wiederholungen auf der Wortebene betrifft, so besteht das Gedicht (ohne Titel) aus 116 Wörtern, wovon bloß 37 Wörter nicht eins zu eins wiederholt werden. Zählt man unterschiedliche Flexions- (und im Wortstamm ähnlich bleibende Zeit-)Formen von Verben und Adjektiven sowie die Pronomen ihr/ihren nicht einzeln, so erhöht sich die Iterationsdichte gar auf nur 24 nicht wiederholte Wörter. ${ }^{205}$ Nach Richard Alewyn treten total 24 Reime auf, die aber nur aus 10 Reimwörtern gebildet sind ${ }^{206}$ - die wiederum nur aus vier verschiedenen Reimen mit lediglich zwei unterschiedlichen Reimvokalen und Endkonsonanten bestehen. ${ }^{207}$

Die von der Forschung aufgezeigte, über jenes Similaritätsverhältnis sich konstituierende poetologische Ebene des Textspinnens und -webens ist jedoch vor dem Hintergrund des in dieser Arbeit Behandelten um einen weiteren Abstraktionsschritt zu ergänzen, nämlich durch folgenden Befund:

\footnotetext{
203 Vgl. dazu insbesondere Kirchberger 1975, u. a. S. 418-420.

204 Enzensberger 1961, S. 116.

205 Die einzigen Nomen, die bei dieser Iterationsdichte nicht wiederholt werden, sind wohl nicht zufällig "Jahren“, „Faden“ und "Herz", womit die inhaltlichen Leitthemen Zeit (Text -) Gewebe - Liebe hervorgehoben sind.

206 Vgl. Alewyn 1974, S. 199.

207 Vgl. ebd.; und Schrimpf 1976, S. 386.
} 
Jenes Similaritätsverhältnis gründet auf der Ebene der Form des Gedichtes derart stark auf der Iteration einzelner Wörter, ${ }^{208}$ dass dadurch der Modus der Iteration selbst sich als Gegenstand poetologischer Reflexion aufdrängt, ja als grundlegende Möglichkeitsbedingung eines jeden Textfadens resp. Gewebes ausgestellt wird. Zugleich führt eine derart oft sich vollziehende Iteration einzelner Wörter im Zuge der Lektüre resp. des Singens automatisch zu einer ebenso oft erfolgenden Iteration des Wortklanges. ${ }^{209}$ Dies unterstreicht der doppelte Binnenreim der zweiten (in V. 1 und 2) und der letzten Strophe (in V. 2 und 4) eindrücklich, indem er zum einen die Wörter, spinn (e)'und, sing' über den Reim - durch Iteration von Klang also - miteinander verwebt und zum anderen weil dieses Reimpaar (mit kleiner Abweichung, spinne\%/,spinn) wiederum selbst wiederholt wird.

Dieser Befund führt nun direkt zum nächsten wichtigen Element der Variation des Tageliedes durch Brentanos Gedicht:

$\mathrm{Zu}$ b), der Gesang/Klang einer weiteren Sängerinstanz (in diesem Fall der Nachtigall) hat eine erinnernde und keine weckend-warnende Funktion: Durch die Wiederholung von fast drei Vierteln der Wörter - die noch höher, ja fast flächendeckend ist, zählt man andere Klangfiguren wie Alliterationen und Assonanzen hinzu - vollzieht sich im Zuge der Lektürenicht nur eine Iteration des Wortklanges, sondern ebenso eine Iteration des Verstummens ebendieses Wortklanges. Eines Verstummens, das die Gattung der mittelhochdeutschen Tagelieder in ihrem Ende(n) jeweils so inszeniert, dass die primäre semantische Ebene mit der poetologischen Ebene zusammenfällt, um diesen Zusammenfall wiederum ästhetisch produktiv zur Darstellung des Wiedereinschlafens des Paares zu nutzen. Denn das eigene, sich gerade vollziehende Schlafen ist für die Schlafende mittels Sprachzeichen ebenso undarstellbar ${ }^{210}$ wie für den Toten der eigene Tod - Letzteres haben die vorangegangenen Kapitel im Falle der Autobiographie Murrs und von Saras Enden gezeigt. Dadurch, dass nun Der Spinnerin Nachtlied in Strophe I und III (erste Hälfte) den vergangenen „Schall“ der "Nachtigall“ als einen bereits verhallten, zu erinnernden (über die Verben "sang" und "waren“) und in Strophe V und III (zweite Hälfte) den aktuellen "Schall“ der „Nachtigall“ als einen erinnernden nennt, vollzieht es gegenüber dem typischen mittelhochdeutschen Tagelied einen Wechsel vom weckenden Gesang hin zum erinnernden Gesang. Die Performativität des Reimpaars

208 Womit, wie Frühwald an der oben zitierten Stelle bereits erwähnt hat, auch die Wiederholung der Handgriffe des Spinnens performativ zur Darstellung kommt.

209 Ob nun laut gesungen/gelesen oder in der stummen Lektüre imaginiert.

210 Dabei ist ein unbewusstes Sprechen im Schlaf ausgeklammert. 
„Nachtigall - Schall“ verstärkt dabei zusätzlich diesen Modus des Erinnerns:211 Der Schall nämlich des Wortes "Nachtigall“ ist bereits ein Vergangener, wenn das Wort "Schall“ gesungen resp. gelesen wird, und muss erinnert werden, um zusammen mit dem Schall des Wortes „Schall“ die Klangfigur eines Reimes zu konstituieren. Der Umstand, dass sich genau in der Mitte der drei Strophen, die von diesem Reim geprägt sind, der Wechsel von einem $z u$ erinnernden Schall hin zu einem Schall, der einen an vergangene Zweisamkeit erinnert, vollzieht, ${ }^{212}$ rückt zudem die Sängerinstanz der Nachtigall, die ohnehin bereits im Mittelalter die Metapher für den Sänger war, ${ }^{213}$ noch näher an das singende Ich und damit auch näher an den realen Sänger resp. Leser. Denn wer ist „die Nachtigall“, die "Nun“, im Jetzt, „mahnet“ und aus der Perspektive des fiktiven singenden Text-Ich "stets singt" (oder vielleicht treffender: stets gesungen haben wird)? Ist es dieses Ich oder der reale Leser, der dem Singen jenes Ich die Stimme leiht?214 All diese Punkte zusammen verstärken wiederum die schon für die Gattung des mittelhochdeutschen Tagelieds zentrale Reflexion des Verstummens des eigenen Klangs und des Verstummens von an Sänger und Leserinnen gebundenen Liedern und Textgeweben im Allgemeinen.

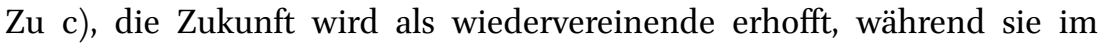
typischen mittelhochdeutschen Tagelied die Trennung herbeiführt: Im mittelhochdeutschen Tagelied ist die gegenwärtige Zweisamkeit dasjenige, das erhalten werden soll. Deshalb nimmt in der Regel die Vergangenheit nahezu keine, die Zukunft jedoch eine bedrohliche, da trennende Rolle ein, was wiederum dazu führt, dass Letztere gefürchtet oder gar geleugnet wird. ${ }^{215} \mathrm{Im}$

211 Zum Reim und zu seiner Relation zu Gedächtnis, der Textur resp. dem Text und dem ihm damit stets inhärenten autoreflexiven Potenzial sowie zum romantischen Verständnis von Musik und Mathematik, gerade auch in der Lyrik Brentanos, vgl. ausführlich Menke 2000, S. 529-539. Diese zitiert dabei auch Wilhelm Schlegel aus einer Notiz für dessen Berliner Vorlesungen, in der er zur "Wirkung des Reimes überhaupt" auch mit Verweis auf das Unendliche schreibt: „Verknüpfung, Paarung, Vergleichung. Erregte Erwartung schon im einzelnen Verse und Befriedigung. Erinnerung und Ahndung, statt dass die alte Rhythmik immer in der Gegenwart festhält, und allen Teilen eine gleiche Dignität gibt. - Daher liegt im Reime das romantische Prinzip, welches das entgegengesetzte des plastischen Isolierens ist. Allgemeines Verschmelzen und hinüber und herüber ziehen. Aussichten ins Unendliche“ (zitiert nach Menke 2000, S. 529).

212 Wobei die beiden Strophenhälften bezeichnenderweise über ebenden Reim "Schall Nachtigall" verbunden sind!

213 Vgl. Sabine Obermaier 1995.

214 Vgl. dazu Alewyns Feststellung: „Es [das Lied, MG] läßt einen Menschen singen, von seinem Singen singen, vom Singen der Nachtigall, und indessen wird es gesungen, ein echter Singsang“ (Alewyn 1974, S. 199).

215 Als eines der eindrücklichsten Beispiele dafür sei hier Wolframs von Eschenbach Sine klawen genannt, dessen zweite Strophe lautet: „Wahtaer, du singest, / daz mir manige 
Nachtlied Brentanos hingegen ist die Vergangenheit als Zeit der Zweisamkeit positiv konnotiert, aber nicht so die einsame Gegenwart, weshalb das Ich eine vereinende Zukunft ersehnt. An dieser Veränderung der typischen Tageliedszene zeigt sich die frühromantische, durch einen Dreischritt (verlorene Vergangenheit; suchende oder sehnende Gegenwart; eine Zukunft, die die beiden Ersteren miteinschließt) ${ }^{216}$ geprägte geschichtliche Perspektive besonders eindrücklich. Und ebenso zeigt sie die romantische Neubesetzung der Nacht mit Attributen des Tages und umgekehrt, wie sie wenig früher Friedrich Schlegel in der Lucinde wohl kaum zufällig ebenfalls in einer Tageliedszene ${ }^{217}$ schon meisterhaft vorgenommen hat. Es zeigt sich aber auch erneut - und viel tief greifender als der von der Forschung bisher herbeigezogene, gewissermaßen auf halber Strecke in die Vergangenheit abbrechende Verweis auf Gryphius' Nachtigallen-Lied ${ }^{218}$ - nicht nur die Verbindung von Der Spinnerin Nachtlied mit dem Barock, sondern vor allem auch mit der mittelalterlichen und spätmittelalterlichen Dichtung. Und zwar nicht nur zum weltlichen Tagelied wie bisher erwähnt, sondern auch zur Gattung des geistlichen Tageliedes. ${ }^{219}$ Diese Verbindung soll im folgenden Abschnitt kurz angetönt werden:

Ein zentraler Unterschied zwischen dem weltlichen und dem geistlichen Tagelied $^{220}$ ist, dass im Falle von letzterem

die ,reale‘ Tageliedsituation jetzt symbolisch überhöht wird. Ihre Konstituenten erscheinen nunmehr als Signifikanten für eigentlich gemeinte spirituelle Sachverhalte. Die Dame mag die Seele, den Leib der Ritter bezeichnen, oder das Paar kann für die Beziehung der Frau Welt und des Christen, jedoch auch etwa für Gott und Maria stehen; der Tagesanbruch meint den Tod und das individuelle Gericht oder auch den allgemeinen Gerichtstag, im 16. Jh. den religiösen Aufbruch im Zeichen der Reformation. ${ }^{221}$

Dabei kommt der Reflexion des Verstummens des Liedes - so die Hypothese entscheidende ästhetische wie poetologische Bedeutung zu: Die dann später

vreude nimt / unde mêret mîn klage. / maer du bringest, / der mich leider niht gezimt, / immer morgens gegen dem tage. / diu solt du mir verswîgen gar. / daz gebiut ich den triuwen dîn. / das lôn ich dir, als ich getar, / sô belîbet hier der geselle mîn." (Tagelieder 2011, S. 92).

216 Vgl. Frühwald 1994, S. 274.

217 F. Schlegel, Lucinde, S. 113-116.

218 Vgl. z. B. Frühwald 1994, S. 278.

219 Zur Gattungsfrage betreffend die geistlichen Tagelieder vgl. Schnyder 2004, S. 624-629; betreffend eine zusammenfassende gattungsgeschichtliche Skizze vgl. ebd., S. 63o-636.

220 Freilich sind die beiden Unterscheidungen in weltliches und geistliches Tagelied „im Wesentlichen Analyseinstrumente der modernen Literaturwissenschaft" (ebd., S. 3).

221 Ebd., S. 11. 
im Barock so stark betonte Vergänglichkeit alles Irdischen und damit letztlich auch der Medien, in denen diese Betonung erfolgt, ${ }^{222}$ ist gerade auch im Falle von Letzterem im geistlichen Tagelied bereits angelegt. Das Lied selbst stellt durch den Zeitpunkt seines Endes seine eigene Vergänglichkeit aus und nimmt dabei im Einzelnen performativ vorweg, was vom Tod resp. Jüngsten Tag für das Irdische im Allgemeinen prophezeit wird. Denn wo im weltlichen Tagelied das Liedende mit dem Tag zusammenfällt (der in der Erzählung des Liedes aber nie endgültig angebrochen sein wird), muss das Liedende des geistlichen Tageliedes (resp. zumindest die des eschatologischen Typus, der dann im 16. Jahrhundert im Zuge der Reformation Hochkonjunktur hat) ${ }^{223}$ mit dem Jüngsten Tag zusammenfallen, der als der Tod alles Irdischen mittels irdischer Zeichen ebenso wenig erzählbar ist wie im Falle der bislang untersuchten Texte Schlaf und Tod durch die Verstorbenen und Schlafenden.

Der Spinnerin Nachtlied kombiniert also nicht nur die Tagelied- mit der Spinnradszene, sondern innerhalb der Tageliedszene die weltliche Liebe des weltlichen mit der ersehnten Zukunft des geistlichen Tageliedes. Brentanos Lied zeigt aber auch, dass bei der Tradierung der Tagelieder deren poetologischer Kern bei aller Variation erhalten bleibt resp. derjenige ist, von dem aus sich die Variationen entfalten. ${ }^{24}$

Dieser Wechsel von einer negativen Besetzung des Tages seitens der Liebenden hin zu einer positiven, der mit dem unter b) beschriebenen Wechsel von Wecken/Warnen hin zum Erinnern einhergeht, ist dabei nahezu wortwörtlich verwoben mit dem letzten Element von Brentanos Variation des mittelhochdeutschen Tageliedes:

$\mathrm{Zu} \mathrm{d}$ ), die explizite Bezeichnung des Liedes als ein Nacht- anstelle eines Tageliedes: Dass ein Begriff für Tagelied im Lied selbst - oder zum Teil gar in einer Titelzeile - vorkommt, war schon bei den mittelhochdeutschen, weltlichen wie geistlichen Tageliedern nicht ungewöhnlich und ist ein weiteres Zeugnis von deren autoreflexivem Gehalt. ${ }^{225}$ Auch in diesem Fall schließt sich die Titelgebung von Brentanos Lied also an mittelhochdeutsche Vorbilder

222 Dazu als Beispiel die bereits in der Einführung zitierte Stelle in Andreas Gryphius' Catharina von Georgien: „Ihr die jhr glaubt daß euer Feder Macht / Den Tod vnd Zeit hab' an ein Joch gebracht? / Glaubt frey die Ewigkeit beruht nicht auff Papir“ (Gryphius, Catharina von Georgien, S. 14 f.).

223 Vgl. Schnyder 2004, S. 630 f. und 632 f. und 634, wo er schreibt: „Beginn und Ende der von uns gezogenen gattungsgeschichtlichen Linie treffen sich im Rekurs auf das Weltgericht als Grund für den geistlichen Weckruf; erstmals ertönt er bei Walther von der Vogelweide am Anfang des 13. Jh.s, vielfach dann bei den einschlägigen, meist apokalyptisch gestimmten protestantischen Kirchenliedern."

224 Vgl. dazu auch Gut 2014, S. 281.

225 Vgl. ebd., S. 261; und für die geistlichen Tagelieder Schnyder 2004, S. 626-628. 
an, freilich bei gleichzeitiger Variation, die jedoch ihrerseits wiederum, es wurde unter c) erwähnt, bereits in den geistlichen Tageliedern angelegt ist: Denn auch das typische geistliche Tagelied ist im Grunde ein Nachtlied, ${ }^{226}$ gesungen in der Nacht des irdischen Lebens in der hoffnungsvoll-mahnenden Ankündigung des Todes oder des Endes aller Tage überhaupt.

Diese im geistlichen Tagelied vorherrschende Verknüpfung des Tages mit dem Tod (und der Wiederauferstehung) ist nun in Brentanos Lied mit der symbolisch und mythologisch hoch aufgeladenen Spinnradszene kombiniert. Oder anders formuliert: Die christliche Konnotation des Tages in den geistlichen Tageliedern wird in Der Spinnerin Nachtlied mit der heidnischen (griechisch-römischen und nordischen), mythologischen Konnotation des Spinnens des Lebens- und Schicksalsfadens verwoben. Endet das Spinnen dieses Fadens oder wird er durchtrennt - so jene Mythologien - endet auch das Leben. (Ebenso wie der Gesang der Nacht-i-gall, althochdeutsch für Nachtsängerin, ${ }^{227}$ enden muss, wenn die Nacht vorüber ist.) Und genau darin begegnen sich die Tagelied- und Spinnradszenen erneut: Beide bieten die Ausgangslage dafür, dass das Verstummen des Lied(text)es insbesondere am jeweiligen Ende des Lied(text)es über das Similaritätsverhältnis zum Ende der Nacht resp. zum Ende des Lebens Undarstellbares darstellen und dies zugleich poetologisch reflektieren kann.

Dabei lassen sich im Lied zwei vermeintlich gegenläufige Bewegungen beobachten, die nur dadurch zustande kommen, dass die typische Tageliedszene hin zur Nachtliedszene gewendet wird: Eine Bewegung ist diejenige von der Nacht hin zu einem in der Zukunft liegenden, ersehnten Tag; die andere Bewegung ist die des in seiner poetologischen Metaphorik das Singen und Leben des singenden Ich garantierenden Spinnens hin zum Ende dieses Lied(text) spinnens, zum „Stillstand des Spinnrades“, zum Reißen des Fadens. ${ }^{228}$ Im Falle der hier zweitgenannten Bewegung kommt hinzu, dass sowohl in der mythologischen als auch der poetologischen Metaphorik nur das Weiterspinnen des Lebens- oder Textfadens die Ewigkeit dieses Fadens garantieren würde.

226 Im Gegensatz zum Begriff Tagelied (mhd. tageliet) gibt es keine wortwörtliche mhd. Entsprechung für ,Nachtlied'. Die Forschung bezeichnet eines von Hadlaubs Tageliedern als ,Nachtlied', was jedoch eine anachronistische Bezeichnung ist (vgl. Dietz-Rüdiger 1970, insbesondere S. 199; und Leppin 1983, insbesondere S. 208 f., die genauer auf verschiedene Fremdbezeichnungen der Forschung eingeht). Bei Hadlaubs ,Nachtlied' stehen die Erlebnisse des Liebespaares in der Nacht und nicht deren bevorstehende Trennung bei Morgengrauen inhaltlich im Zentrum, es hat also wenig mit Brentanos Gedicht zu tun, resp. beide gehen auf Variationen des Tageliedes zurück.

227 Vgl. den Eintrag „Nachtigall“ im Deutschen Wörterbuch, Bd. 13, Sp. 188-191; http:// woerterbuchnetz.de/DWB [Stand:Juni/2018].

228 Vgl. Frühwald 1994, S. 279. 
Wobei der Textfaden resp. Lesensfaden im Gegensatz zum Lebensfaden über den Modus der (Re-)Lektüre den entscheidenden Vorteil besäße, potenziell unendlich oft wiedererweckt werden zu können - nur dass die Möglichkeitsbedingung dieses Vorteils ausgerechnet im potenziell unendlich oft wieder zu erfolgenden Verstummen des gelesenen Textums liegt.

Im Falle des typischen mittelhochdeutschen Tageliedes hat diese Ästhetik des Verstummens zu einem glücklichen Ende für das Liebespaar geführt, das als Textgebilde überhaupt nur im Modus des Morgengrauens, des Aktualisiertund-sogleich-wieder-verhallt-Seins existiert haben wird und immer wieder ,einschläft', bevor es helllichter Tag geworden wäre. Ein solcher Tag wäre nämlich auf der poetologischen Ebene nichts anderes als eine Aktualisation von Zeichen, die dauerhaft aufrechtzuerhalten wäre - dauerhaft aktualisierte Zeichen, die gerade dadurch nicht mehr wiederholbar und damit auch keine Zeichen mehr wären. ${ }^{229}$ Eine derartige Dauerhaftigkeit wurde in der christlich-jüdischen Tradition denn auch allein dem göttlichen Textum zugesprochen. So ist es kein Zufall, dass Brentano - bewusst oder unbewusst und dazu noch ähnlich wie Schiller ${ }^{230}$ - für die Vereinigung des Liebespaares Gott anruft, zumal in einem der beiden einzigen Verspaare, die ohne jegliche Variation wiederholt werden: „Gott wolle uns vereinen“. Die Anrufung Gottes sowie die oben behandelte mythologische Konnotation des Spinnens deuten darauf hin, dass die Trennung der Liebenden wohl nicht auf gesellschaftlichen Konventionen beruht wie in den mittelhochdeutschen Tageliedern, sondern am ehesten auf dem Tod des Geliebten, an den sich das Ich erinnert. ${ }^{231}$ Freilich lässt sich dies nicht zweifelsfrei bestimmen, sicher ist jedoch, dass zumindest die erhoffte Vereinigung durch Gott zusammen mit dem melancholischen Grundton des Gedichts und insbesondere der poetologischen Metaphorik des Lebens- und Textfadens stark darauf hindeuten, dass zumindest eine Wiedervereinigung des Liebespaares nur nach dem Tod erfolgen kann.

Nun ist aber die Ewigkeit Gottes und seines Logos resp. Textums sowie eines Lebens nach dem Tode im Jahre 1802, in dem Brentano das Lied verfasst, längst keine gesicherte mehr. ${ }^{232}$ Und so erstaunt es letztlich nicht, dass Der Spinnerin

\footnotetext{
229 Vgl. Derrida 1999.

230 Die Gegenüberstellung des göttlichen und menschlichen Wortes begegnet uns ebenfalls in Schillers Nänie - und auch dort hält die christliche Vorstellung des Logos Einzug, wo auf den ersten Blick vermeintlich allein heidnische Mythologie hinzugezogen wird; siehe dazu das betreffende Kapitel IV.2.2.

231 Am wenigsten Hinweise aus dem Gedichttext selbst und seinem Bezug auf die Tageliedtradition finden sich für die Deutung einer Trennung aufgrund der „Treulosigkeit des Mannes“, wie sie Marita Metz-Becker vorschlägt (dies. 20o6, S. 48).

232 Vgl. die Einführung sowie die historisch-kontextualisierenden Kapitel.
} 
Nachtlied sich nicht allein auf die Anrufung Gottes verlässt - womit nun die abschließende These der hier Schritt für Schritt über die Punkte a) bis d) entfalteten Argumentation erreicht ist:

Durch die Verknüpfung der Tageliedszene mit derjenigen des Spinnens ist es möglich, analog zum mittelhochdeutschen weltlichen Tagelied das Ende des Liedes derart zu gestalten, dass es auf poetologisch-performativer Ebene die ersehnte Zweisamkeit des Liebespaares doch noch erfüllt. Wo die Tagelieder über den Abbruch der Lieder ,vor' dem hellichten Tag darauf abzielen, jene Zweisamkeit zu bewahren, sucht sie Der Spinnerin Nachtlied wiederherzustellen. Es tut dies über den Abbruch des Lied(text)fadens - und damit auch des Lebens- und Lesensfadens des Ich - am Ende des Liedes. ${ }^{233}$ Wo in den Tageliedern das Liebespaar wieder zusammen einschläft, in die ,Nacht' des unaktualisierten Lied(text) es zurücksinkt, folgt bei Brentano das nächtlich klagende Ich dem Geliebten zumindest auf formal-klanglicher Ebene in den als vereinend erhofften (im geistlichen Tagelied schon angelegten) Tod nach. ${ }^{234}$

\subsubsection{Nachtlied, Tagelied und Lessings Ästhetik des Endens}

Zusammenfassend sowie rück- und ausblickend lässt sich zum Schluss der Auseinandersetzung mit Brentanos Gedicht festhalten: Die bestehende Forschung zu Der Spinnerin Nachtlied hat bereits auf dessen außergewöhnlich hohe Iterationsdichte, die Zirkularität der Verse und das dabei performativ mitdargestellte, endlose Drehen' des Spinnrads durch das (freilich bloß potenziell), endlose Drehen' des Liedes selbst hingewiesen. ${ }^{235}$ Wobei jedoch bereits Joachim Klein und Hans Joachim Schrimpf (vor allem gegen Richard Alewyn) angemerkt haben, dass sich zur zyklisch alternierenden Bewegung des Liedes gleichzeitig in zunehmendem Maße dagegen verlaufend eine lineare, zielgerichtete Bewegung von der Vergangenheit hin zur Gegenwart und zu einer Trost und Hoffnung (auf eine jenseitige Zukunft) bergenden Anrufung Gottes vollziehe. ${ }^{236}$ Das vorliegende Kapitel geht noch weiter und

233 Zum Stillestehen des Spinnrads vgl. Frühwald 1994, S. 279.

234 Wenn man davon ausgeht, dass der/die Geliebte nicht verstorben ist, sondern dass es sich einst um eine Trennung aus anderen Gründen gehandelt hat, müsste man schreiben: Das ,Ich' geht dem/der Geliebten zumindest auf formal-klanglicher Ebene in den als vereinend erhofften (im geistlichen Tagelied schon angelegten) Tod voraus.

235 Vgl. zusammenfassend Schrimpf 1976, S. 387; und Frühwald 1994, S. 272 und 279.

236 Vgl. Klein 1974; und Schrimpf 1976, S. 389-391 (siehe auch die folgende Fußnote). Beide argumentieren zu Recht gegen Alewyns Aussage: „Ja, es fehlt nicht viel, daß man es Zeile für Zeile rückwärts lesen könnte. Es wäre nur die Syntax, nicht der Sinn, was dem im Wege steht. Wenn das Gedicht also geradezu umkehrbar ist, dann ist das ein Zeichen dafür, daß zwischen seinem Anfang und seinem Ende nichts geschehen ist, was irgendeine Folge hätte und damit eine Reihenfolge vorschriebe. Daß das Gedicht umkehrbar ist, verrät, daß die Zeit in diesem Gedicht umkehrbar ist, und das besagt: Die Zeit steht still.“ 
ergänzt die Forschung dahingehend, dass es darauf hinweist, dass Der Spinnerin Nachtlied - im Gegensatz etwa zum Kater Murr ${ }^{237}$ oder Miss Sara Sampson im Grunde weniger eine potenziell endlose Iteration seiner selbst als vielmehr die Kehrseite ebendieses endlosen Drehens resp. Singens betont und für eine eigene Ästhetik des Ende( $n$ )s nutzt: das potenziell unendliche, immer wieder erfolgende Verstummen des Lied(text)es, das immer schon die Möglichkeitsbedingung eines jeden gesungenen oder gelesenen Textgewebes gewesen sein wird.

Der oben für Brentanos Gedicht gewählte Fokus auf die Variationen gegenüber der Gattung des mittelhochdeutschen Tageliedes ermöglicht so schließlich auch den Blick auf eine weitere Variation, die für eine Untersuchung von Operationen zur Ewigkeitsattribuierung von Schriftzeichen und deren historischer Kontextualisierung mindestens ebenso entscheidend ist: eine Variation von Lessings auf dem Mitleiden beruhender Ästhetik des Endens. Eine Variation, die hier zusätzlich mitbedingt ist durch den Umstand, dass es sich bei Der Spinnerin Nachtlied um ein Gedicht resp. ein verschriftlichtes Lied handelt und nicht um ein Trauerspiel resp. einen Trauerspieltext: Das singende "Ich“ des Gedichtes endet mit "weinen“, aber eben nur mit dem Wort „weinen“, nur zeichenhaft auf jene körperliche Gefühlsregung verweisend, die im Trauerspiel, ihrerseits metonymisch, für das Mitleid und das Mitleiden über das Ende des Trauerspiels hinaus steht. Das „Ich“ singt vom Weinen, es weint nicht. Und dies ist auch nicht anders möglich, denn wer weint (sofern nicht nur die Augen tränen), kann ebenso wenig gleichzeitig singen wie jemand, der schläft oder tot ist. Die Vereinigung im Weinen, wie sie Lessings Ästhetik des Mitleide(n)s zugrunde lag und wie sie der Reim "vereinen - weinen“ nahelegt, kann also in Der Spinnerin Nachtlied auf inhaltlicher Ebene allein schon deswegen nicht zustande kommen. ${ }^{238}$

Aber dies ist nur die eine Hälfte von Alewyns Argumentation, denn er fährt im Stile eines Paradoxons weiter: „Und so muss das Gedicht auch durchaus nicht da aufhören, wo es endet. Wie es an jeder anderen Stelle hätte aufhören können, so könnte es auch noch lange weitergehen. Es hat überhaupt kein Ende, so wenig wie es einen Anfang hat, und das besagt: Die Zeit verrinnt. Stillstand der Zeit oder Verrinnen der Zeit - es ist das gleiche“ (Alewyn 1974, S. 200 f.). Wenngleich diesem zweiten Teil und insbesondere der Schlussfolgerung des letzten Satzes in dieser Radikalität ebenso wenig zugestimmt werden kann wie dem ersten Teil, so tendiert gerade jene Schlussfolgerung doch in dieselbe Richtung des hier Vorgelegten, das von zwei Seiten der gleichen Medaille einer potenziell unendlichen Aktualisation handelt.

237 Als vielleicht schlagendstes Argument zieht Schrimpf herbei, dass das letzte Reimwort der a-Strophen, „waren“ (V. 20), nicht wie bei den ei-Strophen mit dem ersten identisch ist (da dieses "Jahren“ lautet und das einzige Reimwort ist, das nur einmal auftritt), wodurch eben gerade kein ,reiner' Doppelzyklus zustande kommt (vgl. Schrimpf 1976, S. 39o), wie es etwa, freilich über andere inhaltliche und formale Mittel, beim Kater Murr der Fall ist.

238 Dies wird denn auch singend beklagt, was jedoch wiederum ein Weinen verhindert usw. Das singende „Ich“ sähe sich so in einem endlosen Klagelied gefangen, wenn die 
Vermeintlich entgegen der von Lessing in seinem Brief an Nicolai postulierten verewigenden Funktion des Mitleide(n)s $s^{239}$ wird hier also auf inhaltlicher Ebene betont, dass die geliebte Person durch das mitleidende Weinen um sie und sich selbst gerade nicht in der irdischen Welt zu halten ist. Was scheinbar bleibt, ist bloß die Hoffnung auf eine Wiedervereinigung im Tode. Aber ausgerechnet die vermeintlich resignierte Antwort auf die Vorstellung eines Mitleid(en)s, das die Beweinten mittels eines Textgewebes für alle Zeiten ${ }^{240}$ bewahren könne, sucht das Verstummen des Textgewebes auf klanglich-formaler Ebene derart zu wenden, dass das Ich nicht bloß auf einen vereinenden Tod hoffen muss, sondern sich diese Hoffnung auf klanglicher Ebene bestätigt sieht. Oder anders formuliert: Nicht das Weinen mag hier die Geliebten dauerhaft zu „vereinen“, sondern ähnlich wie bei den mittelhochdeutschen Tageliedern das, was die beiden Wörter "weinen“ und „vereinen“ als ein Reimpaar vereint: ${ }^{241}$ die potenziell unendlich oft verstummende Aktualisation ihres Gedichtes. ${ }^{242}$

\section{$2.2 \quad$ Ermunterung}

Ermunterung. ${ }^{243}$

Echo des Himmels! heiliges Herz! warum,

Warum verstummst du unter den Lebenden,

Schläfst, freies! von den Götterlosen

[1-4] Ewig hinab in die Nacht verwiesen?

Möglichkeitsbedingung für ein solches potenziell endloses Fortsingen nicht zugleich das ebenso oft erfolgende Verstummen des Gesungenen wäre.

239 Siehe II.1.2.2; resp. vgl. Lessing, Werke, Bd. 3, S. 671.

240 Vgl. ebd.

241 Denn der erste Teil dieses resp. eines jeden Reimpaares muss, gestorben' resp. verstummt sein, damit dessen zweiter Teil überhaupt erklingen resp. gelesen werden kann und umgekehrt.

242 Bemerkenswert ist in diesem Zusammenhang auch die Nähe (gerade in Bezug auf die Textmetaphorik) zu Penelope in der Odyssee, die nachts das tagsüber gewobene Textum wieder auflöst, um sich der zukünftigen Vereinigung mit ihrem Gatten Odysseus zu versichern (vgl. Homer, Odyssee 2, 93-106; S. 20), wo es in der Rede des Freiers Antinoos u. a. heißt: „Einen großen Webstuhl stellte sie auf in den Hallen, / Webte ein feines und überaus großes Gewebe, uns sagend: / Jünglinge, ihr meine Freier, da starb der hehre Odysseus, / Wartet, wie sehr ihr zur Hochzeit drängt, bis daß ich vollende / Dieses Tuch $[\ldots]^{*} /$ Und des Tages webte sie nun an dem großen Gewebe, / Nachts jedoch löste sie's stets wieder auf im Scheine der Fackeln $[\ldots]$..”

243 Als Textgrundlage dient hier die unterschriebene Druckvorlage, wie sie in der Frankfurter Hölderlin-Ausgabe wiedergegeben wird: Hölderlin, Friedrich: Ermunterung, in: D. E. Sattler und Michael Knaupp (Hg.): Friedrich Hölderlin, Sämtliche Werke. Historischkritische Ausgabe, Bd. 5, Oden II. Frankfurt a. M. 1984, S. 768 f. 
Wacht denn, wie vormals, nimmer des Aethers Licht?

Und blüht die alte Mutter, die Erde nicht?

Und übt der Geist nicht da und dort, nicht

[5-8] Lächelnd die Liebe das Recht noch immer?

Nur du nicht mehr! doch mahnen die Himmlischen,

Und stillebildend weht, wie ein kahl Gefild,

Der Othem der Natur dich an, der

[9-12] Alleserheiternde, seelenvolle.

Beim Jova! ${ }^{244}$ bald, bald singen die Haine nicht

Des Lebens Lob allein, denn es ist die Zeit,

Daß aus der Menschen Munde sie, die

[13-16] Schönere Seele sich neuverkündet,

Dann liebender im Bunde mit Sterblichen

Das Element sich bildet, und dann erst reich,

Bei frommer Kinder Dank, der Erde

[17-20] Brust, die unendliche, sich entfaltet

Und unsre Tage wieder, wie Blumen, sind,

Wo sie, des Himmels Sonne sich ausgetheilt

Im stillen Wechsel sieht und wieder

[21-24] Froh in den Frohen das Licht sich findet,

Und er, der sprachlos waltet und unbekannt

Zukünftiges bereitet, der Gott, der Geist

Im Menschenwort, am schönen Tage

[25-28] Kommenden Jahren, wie einst, sich ausspricht.

\subsubsection{Zu Hans-Jost Freys Interpretation der Ode}

Hölderlins etwas weniger bekannte Ode Ermunterung (ca. 180o) ${ }^{245}$ hat im Kapitel „Textrevision bei Hölderlin“ von Hans-Jost Freys Monographie Der unendliche Text ${ }^{246}$ bereits eingehende Behandlung erfahren, die zudem eine ähnliche Fragestellung verfolgt wie das vorliegende Kapitel. Bei Hans-Jost Frey findet sich nach bestem Wissen des Verfassers denn auch die bislang einzige derart ausführliche Auseinandersetzung mit der Ode Ermunterung; kürzere Auseinandersetzungen legten Bernd Oei und, konzentriert auf die letzten vier Strophen und deren Syntax, Charlie Louth vor. ${ }^{247}$ Des Weiteren zeugt Christof Forderers Aufsatz davon, dass das Verhältnis von „Reden und Schweigen“ auch

\footnotetext{
244 Die unterschriebene Druckvorlage der Ode weist hier eine nachträgliche Änderung auf zuerst stand „O Hoffnung!“ anstelle von „Beim Jova!“; vgl. ebd.

245 Zur Entstehung vgl. Hölderlin, Ermunterung, S. 759 f.

246 Vgl. dazu auch das Kapitel zum Forschungsstand in der Einführung.

247 Vgl. Oei 2009, S. 111-113; und Louth 1998, S. 169-176.
} 
in anderen Gedichten Hölderlins eine zentrale Rolle einnimmt, ${ }^{248}$ wenngleich er Ermunterung bedauerlicherweise nur mit einem einzigen Satz erwähnt. ${ }^{249}$

Obschon das vorliegende Kapitel Freys Interpretation in vielem äußerst schätzt, unterstützt und ergänzt, geht es hinsichtlich des Paradigmas des Verstummens und der damit verbundenden Performativität des Gedichtes einen anderen Weg. Weil dies sowohl den Kern der hier vorgelegten Lesart der Ode als auch derjenigen Freys betrifft, sei zur besseren Leserorientierung dieser entscheidende Unterschied gleich zu Beginn transparent gemacht: In beiden Interpretationen sind die Schlussstrophe und das darin formulierte Paradoxon zwischen „sprachlos waltet“ (V. 25) und „sich ausspricht“ (V. 28), auf das die ganze Ode inhaltlich und syntaktisch zusteuert, von zentraler Bedeutung. ${ }^{250}$ Dieses Paradoxon der Schlussstrophe sucht Frey sodann durch den Vergleich mit früheren Textstufen zu verstehen. In der ersten Reinschrift nämlich endet der letzte Vers entgegen dem ersten Entwurf und allen weiteren Abschriften nicht mit „sich ausspricht“, sondern lautet: „Wieder mit Nahmen, wie einst, sich nennet [Hervorhebung MG].“251 Frey legt den inhaltlichen Unterschied zwischen "mit Nahmen [...] sich nennet“ und „sich ausspricht" folgendermaßen dar:

\begin{abstract}
Wenn der sprachlos waltende Geist im Menschenwort mit Namen genannt wird, so ist er dadurch zwar gefasst, aber als im Namen stillgelegter waltet er nicht in der Rede, sondern ist deren Gegenstand. Walten könnte er nur als sich aussprechender. Aber in dem Maße, als dieses Sichaussprechen an das Menschenwort gebunden ist, muß es als ein Sichnennen geschehen und verfällt so immer wieder der Verfestigung im Namen. Wenn der sprachlos waltende Geist sich im Menschenwort aussprechen soll, ohne genannt zu werden, so muß er auf andere Weise als im Sichnennen darin gegenwärtig sein. In der Sprache selbst muß das Sprachlose walten. Sobald es genannt wird, wie in der letzten Strophe von Ermunterung, ist es schon wieder entglitten. ${ }^{252}$
\end{abstract}

Bei aller Scharfsinnigkeit dieser Überlegungen Freys kann hier jedoch einer Gleichsetzung von "sprachlos“ im ersten Vers der letzten Strophe mit ,namenlos', das auch keine der Textstufen rechtfertigen würde (in allen steht „sprachlos"), 253 nicht zugestimmt werden. „[E]r, der sprachlos waltet“ (V. 25) wird in Freys Lesart zu ,Er, der namenlos/ohne zu benennen waltet'. Diese unzulässige

\footnotetext{
248 Forderer 2000.

249 Vgl. ebd., S. 542.

250 Frey 1990, S. $78 \mathrm{f}$.

251 Hölderlin, Ermunterung, S. 766.

252 Frey 1990, S. 8o.

253 Vgl. Hölderlin, Ermunterung, S. 764-767, 769.
} 
Anpassung des Odentextes bildet fortan den Kern von Freys Argumentation und findet sich schon in der soeben zitierten Passage, die die Sprache offensichtlich vom "Menschenwort" trennt und in der impliziert wird, dass das „Menschenwort" letztendlich immer nur nennend sein könne. Aber weshalb soll das „Menschenwort" lediglich (be-)nennen können?254 Was ist das „Menschenwort", wenn nicht Sprache? Und da das „Menschenwort" offensichtlich aus Sprache besteht, weshalb soll dann das "Sprachlose“, das nach Frey „in der Sprache selbst“ walten muss, nicht auch im Menschenwort walten? Bemerkenswerterweise scheint sich Frey hier bereits wieder in dem in der Schlussstrophe formulierten Paradoxon zu verstricken, das er eigentlich aufzulösen gedenkt. Dennoch führt ihn dies zu einer sehr aufschlussreichen Analyse der Echostruktur der ersten Verse von Hölderlins Ode:

Das Wort Echo verstummt in dem Maße, als es genannt wird. Im Wort Echo geschieht kein Echo. Dieses geht im Reden darüber verloren. Aber nur insofern, als dieses Reden ein Nennen ist. Deshalb bleibt es möglich, daß gerade die Verse, die das Verstummen des Echos sagen, im Widerspruch zu ihrer Aussage echohaft reden. Der Stabreim Himmels / heiliges / Herz, die Wiederholung des Wortes warum und die Assonanzreihe Warum / verstummst / du / unter sind Echowirkungen, die geschehen, aber nicht genannt werden. So sind hier von Anfang an der Verlust des Genannten im Genanntwerden und sein namenloses [!] Walten im sprachlichen Vollzug in einem Wortlaut vereinigt. Das Gedicht spricht einerseits so, daß es nennend vom sprachlos Waltenden geschieden und damit in der Situation ist, die es thematisiert, anderseits und zugleich aber so, daß ungesagt in ihm geschieht, wozu es ermuntert. Was es herbeiwünscht, und wovon es sich nennend entfernt, hat es durch seine Redeweise schon erreicht. Es verwirklicht, was es als die bevorstehende Möglichkeit seiner selbst nennt. ${ }^{255}$

Mit anderen Worten: Hölderlins Ermunterung verweist nicht nur auf ein Echo, sondern die Bestandteile der Sequenz, die auf das Wort „Echo“ folgt, sind so ausgewählt, dass deren Klang performativ auch ein Echo herstellt. ${ }^{256}$ Auch ist Frey darin zuzustimmen, dass das Gedicht nicht nur performativ ist resp. genauer: performative Textstellen aufweist, sondern die eigene Performativität zugleich auch autoreflexiv und poetologisch verhandelt (siehe dazu die folgenden Unterkapitel). Allein dort, wo Frey jene Echostruktur auf die

254 Frey erbringt mit seiner Analyse der Echostruktur des Gedichtes ja selbst den Gegenbeweis (siehe das folgende Zitat).

255 Frey 1990, S. 81; das Ausrufezeichen wurde eingefügt durch MG.

256 Zur Verwendung des Begriffes Performativität (resp. perfomativ) in der vorliegenden Arbeit vgl. den einleitenden Teil des Kapitels III, der diese Verse Hölderlins als Beispiel verwendet. 
Schlussstrophe bezieht, ist ihm erneut zu widersprechen, und zwar in zwei Punkten:

1. Wieder liegt Freys Argumentation die unhaltbare Gleichsetzung von „sprachlos" mit dem von ihm konstruierten Adjektiv ,namenlos‘ zugrunde.

2. Auf den ersten Blick scheint sich die später von Hölderlin verworfene Formulierung "mit Nahmen sich nennet" in der letzten Strophe der ersten Reinschrift als Bezeichnung für den bloß verweisenden und nicht performativen Gebrauch von Sprache vielleicht anzubieten. Performativer Sprachgebrauch (nach Austin im engeren Sinne, vgl. Kapitel III) funktioniert aber gerade dadurch, dass im Zuge des Sprechens/Lesens das hergestellt wird, worauf sprechend/lesend verwiesen wird. ${ }^{257}$ Und auch wenn das Wort „Echo“ im Gegensatz zu performativen Verben selbst nicht performativ ist, so sind es die ihm folgenden Klangfiguren nur im Verbund mit der Benennung, die jenes Wort „Echo" vornimmt. Die verweisende resp. konstative Operation von Sprachzeichen ist zwingender Bestandteil von performativem Sprachgebrauch und nicht dessen Verhinderung.

Zudem stellt Frey sehr spät (mehr oder weniger) explizit klar, als was er den ,sprachlos waltenden Geist/Gott' interpretiert:
Was im Aufschub des Nennens ungenannt bleibt, ist die Sprache. Mit der Sprache ist nicht etwas Beliebiges genannt, sondern das, als was das Nennen sich vollzieht. Das Wort Sprache nennt, als was es geschieht. Aber indem die Sprache sich mit Namen nennt, verfestigt sich das Geschehen des Nennens zum Namen Sprache, in welchem das Sprechen erstarrt ist. Deshalb verschiebt das Gedicht die Nennung der Sprache, die es ist, und nennt schließlich das Sichnennen des sprachlos - weil ungenannt namenlos Waltenden, als das es sich versteht, als etwas Zukünftiges, ihm immer Bevorstehendes. Sprache als sich nennende steht sich immer bevor. Zwar geschieht das Nennen der Sprache als Sprache, aber im Nennen ist sie noch nicht genannt, und im Namen hat sie schon aufgehört zu geschehen. ${ }^{258}$

Hat Frey in seinen oben zitierten Überlegungen zur Echostruktur mit ,sprachlos waltenden Geist/Gott' noch die Performativität des Gedichtes gemeint, so tendiert er hier zu einer Interpretation des sprachlos Waltenden' als des Prozesses, in dem Sprache (z. B. als Text, der freilich immer an eine Lektüre gebunden wäre) dabei ist, implizit über sich selbst zu sprechen. Oder anders formuliert: Zuerst deutet Frey das sprachlos Waltende' als Performativität, später als Poetologie, ohne diesen Wechsel in seiner Argumentation

257 Betreffend ein lautes oder leises Lesen vgl. das Ende des vorliegenden Unterkapitels.

258 Frey 199o, S. 86 f. 
transparent zu machen. ${ }^{259}$ Dass sich dieser Wechsel in Freys Argumentation vollzieht, erstaunt aber letztlich nicht, denn in der Tat sind Performativität und Poetologie in der Ermunterung eng miteinander verknüpft, und zwar auch das hat Frey gestreift, ohne es aber in diese Relation zu setzen - über das Verstummen der Ode.

All diese, Hans-Jost Frey zum Teil widersprechenden, ihn aber hauptsächlich ergänzenden Beobachtungen lassen sich in einer Leitthese zusammenführen, die der im Folgenden dargelegten Auseinandersetzung mit der Ode vorangestellt sei:

Die Performativität von Hölderlins Ermunterung konstituiert sich über das Verstummen der Ode im Zuge ihrer Lektüre bei gleichzeitigem explizitem Verweis auf ein echohaftes Verstummen („verstummst“, V. 2). Dieser Verweis wiederum ist Ausgangslage dafür, dass die Ode ihr eigenes Verstummen poetologisch thematisiert. Dies, tut' sie als ein an die Lektüre gebundenes Zeichengebilde unter besonderer Berücksichtigung der Iteration resp. Iterabilität ${ }^{260}$ sowohl einzelner ihrer Bestandteile (wie etwa im Falle der Geminatio „warum, / Warum") als auch des gesamten Odentextes.

Diese Leitthese mag von Beginn an betonen, dass die Ode Ermunterung wie auch jedes Sprachzeichen - nur "sich ausspricht“, wenn ein Leser ihr seine Stimme leiht. Als Grundlage des folgenden Unterkapitels dienen denn auch, anders als bei Frey, nicht die unterschiedlichen Textstufen, sondern der Text der unterschriebenen Druckvorlage im Zuge seiner Lektüre. (Im Folgenden steht dabei explizit nicht der Unterschied zwischen mündlicher Rede resp. lautem Lesen oder Singen und einem leisen Lesen zur Diskussion. Bei der stillen Lektüre der ersten Verse von Hölderlins Ermunterung etwa vollzöge sich streng genommen kein Echo, da ja stumm gelesen wird, sondern nur ein Echoeffekt. Dieser Unterschied ist für unten stehende Ausführungen aber insofern irrelevant, als dass etwa im Falle von Klangfiguren auch bei stiller Lektüre von einem imaginierten Klang ausgegangen werden kann, während in Bezug auf das „Echo“ hier zusätzlich der Fokus stark auf der raumzeitlichen Deixis liegt.)

\footnotetext{
259 Außerdem konzentriert sich Frey die letzte Strophe betreffend allein auf die Unterschiede zwischen den Textstufen, während er ihre Gemeinsamkeiten wohl zu stark außer Acht lässt: Der Einschub „wie einst“ ist allen Textstufen gemeinsam und wird ausgerechnet in der von Frey so stark einbezogenen ersten Reinschrift zusätzlich durch das erste Wort des letzten Verses, „Wieder“, ergänzt. Sowohl „wie einst“ als auch das „Wieder“ betonen an zentraler Stelle das Paradigma der Wiederholung, das, wie zu zeigen ist, nicht nur die erste Strophe mit ihrer Echostruktur, sondern die ganze Ode durchzieht. Vgl. dazu auch Oei 2009, S. 112.

26o Vgl. zum Begriff Iterabilität Kapitel 1.1 des Schlussteils.
} 
Mit Blick auf die Gliederung der vorliegenden Arbeit zeigt die soeben formulierte Leitthese zudem, dass Hölderlins Ode sich auch als Beispieltext zu den Grundoperationen Autonome Performative Produktion oder Reflexivität behandeln ließe. Da aber sowohl ihre Performativität als auch ihre poetologisch-autoreflexive Ebene sich in ihrem potenziell unendlich oft wiedererfolgenden Verstummen gründen, ${ }^{261}$ ist das vorliegende Kapitel der angemessenste Ort, die Ode zu behandeln. Oder mit anderen Worten: In Hölderlins Ermunterung findet sich besonders exemplarisch die Unteroperation Unendliches Verstummen, die in dieser Ode gegenüber anderen, ebenfalls prominent auftretenden Operationen zur Ewigkeitsattribuierung von Schriftzeichen eine dominante Rolle einnimmt. Die Ode wird hier aber auch bewusst als letztes Textbeispiel zur Grundoperation Unendliche Aktualisation angeführt, da sie durchaus bereits vorauszuweisen vermag auf die Kapitel zu den beiden anderen Grundoperationen.

2.2 .2

Strophen eins bis drei: verstummendes „Echo“ und antithetische Zeitstruktur

Die sieben Strophen umfassende Ode Ermunterung lässt sich grob in zwei Teile gliedern: in einen ersten Teil, der die Strophen eins bis drei umfasst, und in einen zweiten, gebildet aus den Strophen fünf bis sieben. In der Mittelstrophe vier (und ein wenig schon in Strophe drei) vollzieht sich dabei der Übergang vom ersten zum zweiten Teil. Jedem dieser beiden Teile sei hier ein Unterkapitel gewidmet, dem jeweils zur besseren Orientierung eine These vorangestellt sei, die den jeweiligen Teil ein erstes Mal umreißt. Für den ersten Teil ist dies die folgende:

Die Strophen eins bis drei sind geprägt durch das Einbringen des Echos (auf semantischer und klanglicher Ebene) und den Aufbau zweier antithetischer Strukturen ,jetzt'vs. ,einst' und ,himmlisch-göttlich'vs. ,irdisch-menschlich/ sterblich'vor dem Hintergrund einer auf inhaltlicher Ebene als "ewig“ (V. 4) bezeichneten Bewegung.

Echo des Himmels! heiliges Herz! warum,

Warum verstummst du unter den Lebenden,

Schläfst, freies! von den Götterlosen

Ewig hinab in die Nacht verwiesen? [V. 1-4]

261 Bereits Bernd Oei hat festgehalten: „Das ,verstummst der ersten Strophe ist das Leitmotiv, beginnend mit dem ersten Wort ,Echo' (das die Dichter auf Göttliches geben sollen), denn um die Sprachlosigkeit des Göttlichen geht es primär“" (ders. 2009, S. 111). Wenngleich ihm hier im Falle des „Leitmotivs“ grundsätzlich recht zu geben ist, werden die im Folgenden daraus entwickelten Thesen zu anderen, differenzierteren Schlussfolgerungen führen, als sie Oei hier knapp formuliert. 
Wacht denn, wie vormals, nimmer des Aethers Licht?

Und blüht die alte Mutter, die Erde nicht?

Und übt der Geist nicht da und dort, nicht

Lächelnd die Liebe das Recht noch immer? [V. 5-8]

Nur du nicht mehr! doch mahnen die Himmlischen,

Und stillebildend weht, wie ein kahl Gefild,

Der Othem der Natur dich an, der

Alleserheiternde, seelenvolle. [V. 9-12]

Wie bereits von Frey festgestellt und oben zitiert, verweisen die ersten beiden Verse der ersten Strophe nicht nur auf semantischer Ebene stellvertretend auf ein Echo, sondern stellen auf klanglicher Ebene im Zuge einer jeden Lektüre über zahlreiche Wiederholungsfiguren ${ }^{262}$ auch performativ ein Echo resp. einen Echoeffekt her. ${ }^{263}$ Zusätzlich unterstreicht die in der ersten Strophe enthaltene dreifache Anrede („Echo des Himmels!“; „heiliges Herz!“; „freies!“) diese performative Echostruktur auf grammatikalisch-syntaktischer Ebene. Und wie ebenfalls oben genannt, bietet die Performativität der ersten Verse die Ausgangslage dafür, das "Echo“ auch als eine poetologisch-autoreflexive Metapher für das Verstummen der Ode selbst und von aktualisierten Sprachzeichen im Allgemeinem zu lesen. Denn das „Echo“, von dem die Rede ist, ist aufgrund der in den ersten Versen entfalteten Performativität auch das Echo der im Zuge ihrer Lektüre wieder verstummenden Ode selbst. ${ }^{264}$ Eine solche poetologische Metaphorik wird in der ersten und zweiten Strophe auf inhaltlicher und formaler Ebene weiter unterstützt durch folgende Elemente:

- „Herz“ stellt ebenfalls ein Similaritätsverhältnis zum Text im Zuge seiner Lektüre her, und zwar durch folgende Lesarten:

- der Rhythmus des Herzschlages als Metapher für den Rhythmus des/ eines Gedichtes

262 Darauf, dass die Ode zudem als Ganze einige ihrer Ausdrücke wiederholt, hat Oei aufzählend hingewiesen; vgl. ders. 2009, S. 112; sorgfältiger jedoch Frey 199o, S. 82. Charlie Louth betont zudem, dass durch die gestreckte, wohl über das (grammatikalisch) Mögliche hinausreichende Syntax der letzten Strophen höchste Konzentration vom Leser gefordert werde (ders. 1998, S. 172) - anders formuliert könnte man auch sagen: Die in die Länge gezogene Syntax und die damit notwendige Erinnerungsanforderung an soeben Gelesenes machen dem Leser die Flüchtigkeit der eigenen Lektüre und der immer sogleich wieder verstummenden Ode bewusst.

263 Dies geht so weit, als dass die Echoeffekte der ersten Verse auch dann noch ein Echo der einstigen Bedeutung des ersten Wortes Echo wären, wenn sich diese Bedeutung dereinst gewandelt haben wird (vgl. dazu auch den Beginn von Kapitel III).

264 Zur kulturgeschichtlichen Aufladung des Wortes Echo vgl. u. a. Menke 2003; sowie insbesondere Menke 200o; weiterhin Börnchen 2006, S. 285-316; Gehring 2006 (zum "Problem der Wiederholungsstimme“, vor allem auch in Bezug auf den Mythos bei Ovid); und Weigel 2006, S. 28-32. 
- die aufeinanderfolgenden Herzschläge als lebenspendendes Echo

- Die Deixis des Pronomens „du“ lässt sich auch als eine direkte Anrede an das Gedicht selbst lesen ...

- ... dabei wird über das Verb „verstummst“ explizit nach den Gründen für dessen Verstummen „unter den Lebenden“ gefragt.

- „Lebenden“ wiederum bildet - in Verknüpfung mit dem Leben spendenden Organ „Herz" - ein Minimalpaar mit „Lesenden“, was die Frage, welche die hier verfolgte poetologische Lesart aufwirft, wie folgt auf den Punkt bringt: „Echo des Himmels! heiliges Herz! warum, / Warum verstummst du unter den Le[s]enden [?]“

- Verse vier und fünf entfalten mit der dritten Anrufung "schläfst!" und „Nacht" das Wortfeld von Nacht/Schlaf/Einschlafen ...

- ... das im ersten Vers der zweiten Strophe durch "Wacht“ und „Licht“ implizit mit Tag, wachen, aufwecken und aufwachen ergänzt wird - einem Wortfeld also, das in seiner poetologischen Metaphorik schon in Brentanos Der Spinnerin Nachtlied zu beobachten war resp. von der Gattung der Tagelieder her bekannt ist und das nun auch hier kaum zufällig wieder begegnet.

- Das Verb „verwiesen“ wird ergänzt mit dem direktionalen Lokaladverb „hinab“ (a) und dem Temporaladverb „ewig“ (b).

- a) entspricht zugleich der Richtung des lesenden Augen-„Licht“-es, das den Versen der Ode „hinab“-folgt.

- b) signalisiert, dass es sich bei jenem Verweisen entweder um einen Prozess handelt, der nun für alle Zeiten abgeschlossen ist, oder aber um einen Prozess, der sich während seines Vollzugs einem ewig gültigen Gesetz folgend unendlich weiter "hinab“ bewegt resp. bewegt haben wird (es wird unten darauf zurückgekommen). ${ }^{265}$ Letzteres lässt sich u. a. zusammen mit der poetologischen Metaphorik von „Nacht“ zum einen als semiologischer Kommentar zur Flüchtigkeit der Aktualisation von (Sprach-)Zeichen lesen, zum anderen passt diese Lesart auch besser zum ermunternden Ton der Ode und zur damit verbundenen antithetischen Struktur ,jetzt - einst', die auf eine Operation des Erneuerns resp. Wiederholens abzielt und dadurch einem für alle Zeiten „ewig“ abgeschlossenen Prozess widerspricht.

Als Zwischenfazit lässt sich somit festhalten: Vor allem die erste Strophe der Ermunterung wirft eine der grundsätzlichsten Fragen zu Sprachzeichen im

265 Liest man es nicht als Temporaladverb, so wäre es zudem gewissermaßen ein Attribut zu „Echo“, das ,als ein Ewiges" „hinab in die Nacht verwiesen“ würde. 
Allgemeinen auf: Weshalb verstummt jedes Sprachzeichen, sobald es ausgesprochen resp. gelesen wurde? Und implizit damit verknüpft: Gibt es eine Möglichkeit, so zu sprechen, zu lesen, zu schreiben, dass die Sprachzeichen nicht verstummen, nicht wie ein Echo verhallen, nicht wieder ,einschlafen', sondern anstatt „Ewig hinab in die Nacht verwiesen“, ewig wach resp. klingend dem Tag angehören würden?

Im Anschluss an dieses Zwischenfazit ist jedoch noch einmal zum letzten oben aufgeführten Punkt zurückzukehren: Dass die Phrase „Ewig hinab in die Nacht verwiesen" einen ewig-endgültigen Zustand beschreibt, der das Resultat eines vergangenen Verweisens ist, dagegen spricht vor allem auch die zweite Strophe. Diese betont zwar in drei resp. vier Fragen einen einstigen, vergangenen Zustand (,wie vormals, nimmer [...] nicht; alte; noch immer [...] nicht"), das zweimal nachgestellte "nicht“ sowie "noch immer" deuten aber darauf hin, dass es sich allesamt um rhetorische Fragen handelt. Einer Lesart der ersten Strophe, sie handle von einer für alle Zeiten abgeschlossenen Bewegung „hinab“, wird in der zweiten Strophe also ein seit unbestimmter Zeit an- und in der Gegenwart fortdauernder Prozess entgegengehalten. Das „Nur du nicht mehr!" des ersten Verses der dritten Strophe bestätigt die Fragen in Strophe zwei als rhetorische, scheint aber zugleich nochmals zu betonen, dass sich das angesprochene „Echo“ „nicht mehr“ so verhalte wie früher. Letzteres nimmt aber der zweite Teil des ersten Verses der dritten Strophe mit dem adversativen „Doch“ sogleich wieder zurück und schlägt einen ermunterndprophetischen Ton an, der zumindest eine Wieder-in-Gang-Setzung jenes Verhaltens ankündigt. Eines Verhaltens (oder umfassender: eines über die Ode hinausreichenden Zustandes), das gemäß der hier vertretenen Lesart nichts Geringeres wäre als eine nicht verstummende, „ewig“ anhaltende Aktualisation der Ode und von (Schrift-)Zeichen im Allgemeinen.

$\mathrm{Zu}$ einer solchen antithetischen Gegenüberstellung von verstummendem "Echo" einerseits und einer „ewig" andauernden Aktualisation von Zeichen, die nie verstummt, andererseits passt auch die zweite große Antithese der Ode: In den ersten drei Strophen bilden das Attribut "des Himmels“ und das Adjektiv "heiliges“, die „Echo“ und „Herz“ ergänzen, mit „ewig“, „Aethers“, („Mutter“), „Geist“, „Himmlischen“, („Natur“) und „seelenvolle“ ein Paradigma des Himmlisch/Göttlich-Unsterblichen. Dieses wiederum ist dem Paradigma des Irdischen/Menschlich-Sterblichen gegenübergestellt, das Wörter wie "Lebenden“ und "Götterlosen“ versammelt. Diese Gegenüberstellung von Göttlich-Unsterblichem und Menschlich-Sterblichem durchzieht das gesamte Gedicht und ist im zweiten Teil der Ode gar noch stärker betont (siehe das folgende Unterkapitel). Frey schreibt denn auch: „Ermunterung handelt von 
einem Reden, worin die Entsprechung des Himmlischen und des Menschlichen sich herstellen würde. ${ }^{\text {“266 }}$ Diese These sei hier wie folgt geschärft:

Ermunterung handelt u. a. von derverstummenden Aktualisation von Sprachresp. Schriftzeichen, die einer, göttlich-himmlischen; nicht verstummenden und damit "ewig“ andauernden Aktualisation gegenübergestellt wird. Dabei wird impliziert, dass erstere letzterer einst entsprochen habe, und prophezeit, dass dies zukünftig wieder der Fall sein werde. Gleichzeitig wird dabei versucht, auf klanglich-performativer und poetologisch-autoreflexiver Ebene jene Entsprechung von sterblicher und göttlicher Aktualisation bereits im Zuge der Lektüre der Ode selbst wieder zu verwirklichen.

Es ist somit kein Zufall, dass gerade auch der zweite Teil des ersten Verses der dritten Strophe, der mit seinem „doch“ die Kontinuität betont und die in Strophe vier beginnende, auf die Zukunft gerichtete Bewegung des Gedichtes anbahnt, in dem metonymischen Verweis auf Göttliches („Himmlischen“) jene Entsprechung in der Gegenwart der Lektüre zu erreichen sucht: Dadurch, dass „Himmlischen“ als Figura etymologica auf "Himmels“ im ersten Vers der Ode anklingt, bildet es auf klanglicher Ebene wortwörtlich ein „Echo des [Wortes] Himmels“. Die „Himmlischen“ werden dadurch auch zu Metaphern für die verstummenden Klangfiguren des Gedichtes, die gerade durch dieses Verstummen ihre Performativität entfalten und damit von bloß verweisenden Zeichengebilden in die Nähe von himmlisch-ewigen Zeichen gerückt werden - und gerade dadurch "mahnen“ (V. 9) sie. Oder anders formuliert: Die Performativität des Wortes ,Himmlischen' soll offenbar die Glaubwürdigkeit und Berechtigung der „Himmlischen“, zu "mahnen“, dass ewig-göttliche Rede in menschlicher Lektüre (dereinst) wieder möglich sei, untermauern resp. vielleicht sogar überhaupt erst herstellen. Dass aber auch hier das Paradoxon einer an sterbliche Leser gebundenen Unendlichen Aktualisation zugleich mitreflektiert wird, zeigen die restlichen drei Verse der dritten Strophe, wo der "Othem der Natur" in seiner Similarität und Metonymie zum aktualisierenden Atem des Lesers als alleserheiternd ${ }^{267}$ und seelenvoll, aber zugleich eben auch als "stillebildend“ bezeichnet ist. ${ }^{268}$

266 Frey 1990, S. 78.

267 Womit auch auf das Paradigma des (Augen-)Lichts angespielt wird.

268 ,Stille` und ,Göttersprache werden damit hier anders interpretiert, als es Christof Forderer in seinem Aufsatz „Das Singen der ,Sprachen des Himmels'. Überlegungen zu Reden und Schweigen in Hölderlins Gedichten“ tut (vgl. ders. 2000, S. 539 und 541), nämlich hinsichtlich ihrer poetologischen Metaphorik. Einzig Forderers Schlusssatz weist in die Richtung des vorliegenden Kapitels, wenn er (der die Ode Ermunterung selbst nur in einem einzigen Satz erwähnt; ebd., S. 542) schreibt, Reden sei u. a. nur dann möglich, wenn es „dem 
2.2.3 Strophen vier bis sieben: Versuch einer selbsterfüllenden Prophezeiung

In der vierten Strophe, also in der Mitte der sieben Strophen umfassenden Ode, vollzieht sich der Übergang vom ersten Teil derselben zum zweiten. Der erste Teil der Ode wurde zu Beginn von Kapitel 2.2.2 wie folgt umrissen:

Die Strophen eins bis drei sind geprägt durch das Einbringen des Echos (auf semantischer und klanglicher Ebene) und den Aufbau zweier antithetischer Strukturen ,jetzt'vs. ,einst' und ,himmlisch-göttlich'vs. ,irdisch-menschlich/ sterblich“ vor dem Hintergrund einer auf inhaltlicher Ebene als „ewig“ (V. 4) bezeichneten Bewegung.

Dasselbe lässt sich für den zweiten Teil wie folgt tun:

Die Strophen fünf bis sieben sind strukturiert durch einen einzigen Konditionalsatz, dessen erste Hälfte implizit in der vierten Strophe beginnt und dessen zweite Hälfte mit dem „Dann“ der fünften Strophe einsetzt. Damit spricht der zweite Teil der Ode im Gegensatz zum ersten von zukünftigen Geschehnissen und Zuständen, die offenbar mit einem „Bunde“ von „Sterblichen“ mit den ,Göttlich/ Himmlisch-Unsterblichen' einhergehen.

Diese beiden Umrisse müssen jedoch ausgehend von der These am Ende des vorangegangenen Unterkapitels 2.2.2 um folgenden Zusatz ergänzt werden:

Beide Teile der Ode sprechen von einem vergangenen resp. zukünftigen Zustande in einem Modus, der implizit diesen Zustand in der Gegenwart der Lektüre der Ode zu verwirklichen sucht.

Vor diesem Hintergrund sei nun zunächst die vierte Strophe in den Blick genommen:

Beim Jova! bald, bald singen die Haine nicht

Des Lebens Lob allein, denn es ist die Zeit,

Daß aus der Menschen Munde sie, die

Schönere Seele sich neuverkündet, [V. 13-16]

Sie ist diejenige Strophe, die neben der ersten und sechsten aufgrund vor allem der „bald, bald“-Geminatio und der l-, m- und s-Alliterationen die stärkste und offensichtlichste Echostruktur aufweist und damit jenen Echoeffekt ebenfalls im Zuge der Lektüre herstellt. Mehr noch: Der erste Vers der vierten Strophe bildet in seiner Analogie (über die Anrufung und Geminatio) zum Beginn der ersten Strophe auch ein strukturelles Echo der ersten Strophe als solche. In der vierten Strophe findet sich innerhalb der Ode mit „neuverkündet“ hingegen auch das erste Wort, das explizit dem Wortfeld des Neuen resp.

Himmel gegenüber rechtzeitig abbricht und mit Wendungen wie ,Vieles wäre / Zu sagen davon' das Schweigen in seinen Gestus aufnimmt“ (ebd., S. 546). 
Wiederhergestellten entstammt, wobei es zugleich antithetisch auf „alte“ (V. 6), das Adjektiv zu „Mutter", verweist. Des Weiteren ist, wenngleich auf den ersten Blick weniger offensichtlich, „Haine“ ebenfalls antithetisch „kahl Gefild" (V. 10) gegenübergestellt. Es ließe sich sogar sagen, aus „kahl Gefild“ sei auf einer abstrakten, wortwörtlichen Ebene der Ode selbst bereits (wieder) ein ,Hain' geworden. ${ }^{269}$ Ähnliches gilt in grammatikalisch-syntaktischer Hinsicht mit Bezug auf die Konjunktion „denn“ (V. 14), die - es wurde bereits angedeutet - zugleich ein ,wenn“ ist, das den Konditionalsatz mit „Dann“(V. 17) bildet. Zudem muss das „ist“ (V. 14) nicht zwingend als futurisches Präsens gelesen, sondern kann auch schlicht als Präsens aufgefasst werden, womit auch das „denn“ auf die Gegenwart und nicht auf die Zukunft zu beziehen wäre. Dies alles führt zu einer weiteren, Obenstehendes ergänzenden Beobachtung:

Der Versuch, die in den Strophen fünf bis sieben angekündigte Zukunft bereits in der Gegenwart der Lektüre der Ode herzustellen, erstreckt sich nicht nur auf die klangliche, sondern auch auf die semantische und grammatikalisch-syntaktische Ebene der Ode.

Damit geht einher, dass es in einem abstrakten Sinne tatsächlich bereits "die Zeit" (V. 14) ist, in der nicht nur „die Schönere Seele“ (V. 16), sondern eben auch die Ode selbst (potenziell unendlich oft) „sich neuverkündet“, und zwar wortwörtlich, in dem Moment, in dem sie gelesen wird, „aus der Menschen Munde"(V. 15).

Über all dies wird der Eindruck vermittelt, als ob die in den Strophen eins bis drei erfolgte „Ermunterung“ an das „Echo des Himmels“ erste, kleine Erfolge zeige, was das Verschwinden der direkten Du-Anrede und der Wechsel hin zu einem mehr erzählenden, auf die dritte Person Singular gerichteten Stil unterstreichen. Dieser findet sich auch im Ausruf „Beim Jova!", der die vierte Strophe eröffnet und sich wohl an den jüdisch-christlichen Gott Jehova richtet, ${ }^{270}$ in dem aber auch der römische Gott Iovis/Jupiter (echohaft) anklingt.

269 Und zwar durch den „Othem der Natur“ (V. 11) resp. durch „der Menschen Munde“, was der Verfasser beides als poetologische Metaphern resp. Metonymien für das Lesen von Schriftzeichen interpretiert. Das „kahl Gefild“ stünde demnach auch als Metapher für den unaktualisierten, leblosen Text, während die Haine auf die durch das Lesen zum Leben erweckten Texte verweisen.

270 Im Zusammenhang mit Hölderlins Überlegungen zu Hesperiern und alten Griechen ist es durchaus denkbar, dass sogar eine Verschmelzung der beiden Namen hier mit hineinspielt. Klopstock verwendet den Namen Jova (wohl aus metrischen Gründen neben „Jehovah“) auch für den jüdisch-christlichen Gott: „Die Hand kam hervor einst, und Schrift stand: Dich wog Jova! / Und es fand dich, der den Weltkreis, wie er will, herrscht, zu leicht, König! / Daß des Gerichts Tag es vernähme, wie leicht Der sey, / Welcher an ihm sündigte!, gebot es von des Throns Höh’ Gott“ (Klopstock, Messias, S. 294 resp. Gesang 


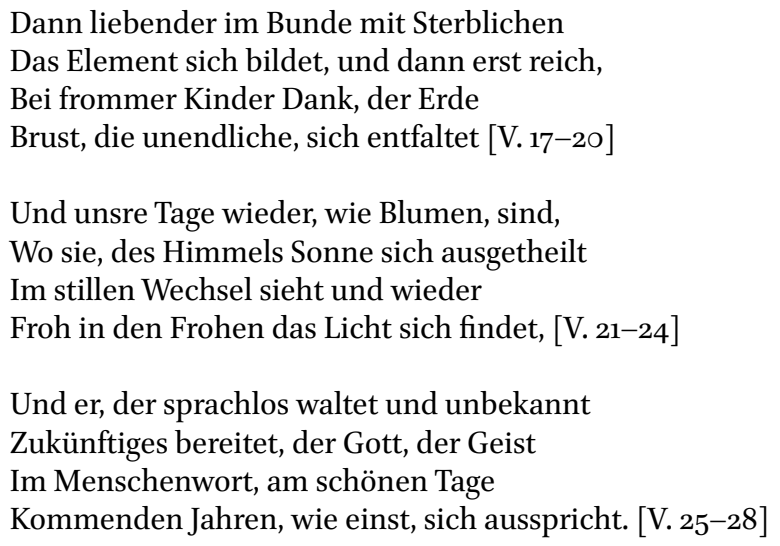

In den Strophen fünf bis sieben lässt sich vieles, wenngleich zum Teil akzentuierter, beobachten, was bereits zu den Strophen eins bis drei festgestellt wurde, und erneut sind zahlreiche Bezüge zu den vorangegangenen Strophen auszumachen: „im Bunde mit Sterblichen“ (V. 17) bezieht sich sowohl inhaltlich als auch über das Minimalpaar "Munde - Bunde“ auf "aus der Menschen Munde“ (V. 5). Dies ist eine weitere Bestätigung dafür, einerseits die reflexiven Verben der Strophen vier bis sieben, „sich neuverkündet“, „sich bildet“, „sich entfaltet“, „sich ausgetheilt“, „das Licht sich findet“, „sich ausspricht“, und andererseits die Subjekte derselben, „das Element“, „der Erde Brust“, „des Himmels Sonne“, „das Licht“, „der Gott, der Geist“, auch poetologisch zu lesen:271 Letztere als unterschiedliche Metaphern für die Ode (und Text im Allgemeinen) im Zustand ihres Gelesenwerdens, Erstere als Metaphern für die Aktion des Lesens/Gelesenwerdens, wobei Wortfelder des Akustischen und Visiblen vorherrschend sind. Damit ist hier auch, wie bereits erwähnt, dieselbe poetologische Metaphorik von Nacht und Tag wie bei Brentanos Der Spinnerin Nachtlied zu beobachten. ${ }^{272}$ Und wie schon bei den mittelhochdeutschen Tageliedern scheint auch hier die poetologische Metaphorik von ,Tag' nicht bloß für den aktualisierten Zustand von Sprachzeichen zu stehen, sondern für einen (freilich semiotisch unmöglichen) dauerhaft aktualisierten Zustand derselben, der im Falle der Ode Ermunterung prophezeit wird. ${ }^{273}$ Die Ode Ermunterung ist denn vielleicht nicht zufällig im Umfeld der Nacht-Gesänge

20, V. 984-987; vgl. dazu auch den nicht ganz präzisen Verweis in: Hölderlin, Werke, Bd. 5 , S. 760 ).

271 Vgl. dazu auch Louth 1998, S. 171.

272 Vgl. dazu auch Oei 2009, S. 111.

273 Auf die Bewegung der Ode von "Nacht“ in der ersten Strophe hin zu „Tage“ in der letzten hat zudem bereits Oei hingewiesen, wobei er "Sonne“ und „Licht“ jedoch als Metaphern 
entstanden, eine Bezeichnung, die wie schon Brentanos Nacht-lied u. a. auch eine Beziehung zur Tage-Lied-Szene herstellt.

Die soeben genannte poetologische Metaphorik verbindet sich in Hölderlins Ode mit der auf inhaltlicher und syntaktischer Ebene in Strophe vier begonnenen Prophezeiung eines Aktualisierens von Text im Allgemeinen und der Ode selbst, das sich nicht bloß aus dem Munde von sterblichen Menschen vollzogen haben wird, sondern in Vereinigung mit dem/den GöttlichHimmlischen eine Lektüre sein wird, die sich „ewig“ resp. „unendlich“ am Vollziehen ist und die nicht „verstummt“. Dass es sich bei dieser zukünftigen Aktualisation gegenüber derjenigen, die im ersten Teil der Ode noch als verstummende beschrieben wird, um eine gesteigerte handelt, wird weiter unterstrichen durch die Verwendung des Komparativs („liebender“, V. 17, der wiederum auf Liebe, V. 8, verweist) und die Formulierung "dann erst reich“ (V. 18). Und noch immer wird mit denselben Mitteln - starke Echostruktur auf klanglicher Ebene, inhaltliche Vor- und Rückverweise und auf syntaktischer Ebene die wiederholte Verwendung von Analogien - versucht, jene Prophezeiung performativ zu einer selbsterfüllenden ${ }^{274} \mathrm{zu}$ machen.

In Strophe sechs ist daran zusätzlich die Metametapher „Blumen“ (V. 21) beteiligt: „Blumen“ verweist als gängige Metapher für Redeschmuck gerade darauf, dass „unsre Tage“ tatsächlich „wie Blumen sind“, denn als Metapher resp. Metonymie für ,unsere Zeiten', die ,Gegenwart', ist die Formulierung „unsre Tage“ tatsächlich ,blumige Rede', ebenso wie die Similitudo „wie Blumen" selbst. Und wie die biologischen Blumen „des [physikalischen] Himmels Sonne“ (V. 22) zum Blühen (vgl. Str. 2) brauchen, so benötigen die rhetorischen „Blumen“ der Ode „Licht“ und "Sonne“ in deren poetologischer Metaphorik des lesenden Augenlichts. Und auch hier geht die Performativität der Strophe einher mit dem Verweis sowohl auf das Göttlich-Himmlische als auch auf das Echo, indem „des Himmels“ als Attribut zu „Sonne“ diese dem gleichen Bereich zuschreibt, wie es dasselbe Attribut in Vers eins mit dem „Echo" getan hat. Ein Echo zudem, das auf klanglicher Ebene in Strophe sechs wieder besonders dicht ist und mit der doppelten Nennung von "wieder" die Iteration und deren Verhallen als Möglichkeitsbedingung eines jeden Echos, jeder echohaften Klangfigur und überhaupt jeder Verwendung von (sprachlichen) Zeichen ausstellt.

für die Seele interpretiert, wogegen - verfolgt man keine poetologische Lesart - nichts einzuwenden ist (vgl. Oei 2009, S. 111 f.).

Die zahlreichen reflexiven Verben im zweiten Teil der Ode deuten ebenfalls darauf hin. 
All das bisher Dargelegte führt schließlich auch zu einer Lektüre der letzten Strophe, die die Exemplarität von Hölderlins Ode für die Auseinandersetzung mit der Ewigkeit oder Unendlichkeit von Text nicht wie Frey primär im potenziell endlosen Aufschub- resp. Änderungsprozess sieht, dem die Ode und ihre Textstufen und Lesarten unterworfen sind, und die vor allem ohne Freys Konstruktion "namenlos anstelle von „sprachlos" (V. 25) auskommt. Vielmehr vermag die hier dargelegte Lektüre darauf hinzuweisen, dass die Ode die zwei historischen Bedeutungen des Wortes ,sprachlos' miteinander kombiniert: einerseits die eines im älteren Neuhochdeutschen ${ }^{275}$ verwendeten Synonyms für ,stumm' (im Sinne von des Sprechens dauerhaft nicht fähig sein); und andererseits die der zeitgenössischen und noch heute gebräuchlichen Bedeutung und Verwendung von ,sprachlos - nämlich der eines vorübergehenden Zustandes des Nichtsprechens, der auch bloßes Verstummen ausdrücken kann -,276 was wiederum von der Verwendung des Verbes „verstummst“ in Vers 2 unterstützt wird. Denn die letzte Strophe thematisiert wie schon die gesamte Ode einerseits die zeitgenössische Stummheit des Göttlichen und andererseits den potenziell unendlichen Prozess eines immer wieder erfolgenden Verstummens des menschlichen Wortes. Letzteres deutet zudem darauf hin, dass Hölderlin genau die umgekehrte Perspektive auf das „abstrakte Problem der Wiederholungs-Stimme“277 einnimmt als Ovid in den Metamorphosen. Zu Ovids Narziss und Echo hat Petra Gehring nämlich beobachtet, dieser Mythos vermittle den unheimlichen Befund, dass „ein Ende jeglicher Möglichkeit des Kommunizierens [...] nicht am wirksamsten

275 „imältern nhd. bezeichnet sprachlos gewöhnlich einen, dernicht sprechen kann, dem das vermögen der sprache fehlt: die tauben macht er hörend, und die sprachlosen redend. Marc.“ (Deutsches Wörterbuch von Jacob Grimm und Wilhelm Grimm: sprachlos bis sprachmäszig; Bd. 16, Sp. 2768-2771; http://woerterbuchnetz.de/DWB/ [Stand: 6/2018]).

276 „sprachlos bezeichnet nicht immer einen dauernden, sondern auch und häufiger einen [z. B. durch Krankheit, MG] vorübergehenden zustand [...] doch meistens in milderem sinne, wenn infolge von schreck oder heftiger erregung die sprache momentan versagt (zuweilen auch blosz das verstummen ausdrückend, dann also in die bedeutung 1 übergehend). so schon mhd. [...] sprachlos in diesem sinne wird in der klassischen zeit des 18. jahrh. üblich und seitdem ist dies die gewöhnlichste gebrauchsweise; es wird dabei in der regel prädicativ (oder als apposition) verwendet und jetzt leicht als adverb empfunden: Franz ... das war dumm! (wirft sich sprachlos in einen sessel). SCHILler 2, 291 (räuber 4, 8 trauersp.)“ (ebd.). Diese Bedeutung ist auch am nächsten an der ursprünglichen Bedeutung des Wortes im Mhd. und Frühnhd.: „1) wer nicht spricht, schweigend [...]“ (ebd.).

277 Gehring 2006, S. 85 . 
durch Schweigen, sondern noch wirksamer im Medium der Stimme besiegelt [wird]“.278

Hölderlins Ode sucht gerade nicht wie jene Gestaltung des Mythos von Narziss und Echo bei Ovid ein echohaftes unendliches, aber eben auch jegliche Kommunikation zerstörendes Sprechen positiv zu konstituieren, sondern unendlich-göttliches Sprechen über ein radikales Betonen des Verstummens negativ einzuholen. Die Schlussphrase „sich ausspricht“ "spricht' dabei auf einer poetologischen Ebene und als Höhepunkt der Ode explizit ,aus', dass Ermunterung den prophezeiten Zustand einer Synthese von menschlichem und göttlichem Wort wortwörtlich gerade „ausspricht“, indem sie ihn performativ herzustellen beansprucht. Gleichzeitig aber endet die Ode auch ausgerechnet mit diesem ungeheuerlichen Anspruch, womit sie in ihrem eigenen Verstummen diesen Anspruch sogleich wieder zunichtemachen muss - einem Verstummen aber, das sie zugleich dahingehend zu nutzen sucht, jenes göttliche, ewige Aktualisiert-Sein von Sprachzeichen performativ wieder- resp. neu „im Menschenwort" herzustellen. Oder mit anderen Worten:

Hölderlins Ode ist von Anfang an das Paradoxon eingeschrieben, dass ein jedes Echo als „Menschenwort“ gemäß der Semantik von Echo kein Echo mehr ist, sollte es nicht mehrverstummen. Das Einzige, was der menschlichen Sprache in diesem Falle bleibt, um sich als göttlich-ewige zu inszenieren, ist, die potenziell unendliche Iteration ihres eigenen Verstummens selbst performativ zu nutzen, ${ }^{279}$ um sich gerade dadurch das Attribut der Ewigkeit zuzuschreiben. ${ }^{280}$

Diese Performativität ist ihrerseits wiederum an das Verstummen menschlicher Sprachzeichen gebunden, doch selbst noch dieses Verstummen performativer Textstellen - und das macht Hölderlins Ermunterung derart exemplarisch für die hier behandelte Unteroperation Unendliches Verstummen - versucht die Ode zur Stärkung resp. Dauer ebendieser Performativität zu nutzen, um Ewigkeitsattribuierung zu erreichen.

Die Ode Ermunterung ${ }^{281}$ mag aber auch - vorausblickend auf das sogleich folgende Kapitel - für die historische Kontextualisierung der bisher behandelten

278 Ebd., S. 110.

279 Bereits Claudia Benthien hat in ihren, vor allem anhand von Beispielen aus der Frühen Neuzeit und dem Beginn des 20. Jahrhunderts angestellten Überlegungen zur „vanitas der Stimme" gefolgert, dass "[g]enauso wie für das Sprechen eine performative und eine referenzielle Funktion zu unterscheiden sind, so hat das Schweigen ebendiese beiden Dimensionen inne“ (dies. 2006, S. 265).

280 Zum Verhältnis von Ewigkeit und Unendlichkeit vgl. das folgende Kapitel; sowie die Kapitel 1.1 und 2.1 des Schlussteils.

281 Und vielleicht auch andere Gedichte Hölderlins von ähnlicher Struktur wie etwa Der gefesselte Strom/Ganymed, Dichtermuth/Blödigkeit oder Chiron/Der blinde Sänger; vgl. dazu auch Forderer 2000. 
Operationen zur Ewigkeitsattribuierung von besonderer Exemplarität sein. Und zwar im Kontext eines im Zuge der zunehmenden Säkularisierung erfolgenden Verlustes der Heiligen Schrift sowie der Kompensation desselben durch eine Heiligung der Schrift als solcher. Die Ode ist vor diesem Hintergrund insofern exemplarisch, als dass in ihr einerseits vom auf die „Götterlosen“ (V.3) zurückzuführenden Verstummen des einst dauerhaft präsenten göttlichen Wortes die Rede ist, aber andererseits an ihr ebenfalls deutlich wird, dass offenbar gerade die „Götterlosen“ es sind, die über die Ewigkeitsattribuierung von Schriftzeichen eine neue Göttlichkeit in der eigenen Gegenwart zu erschreiben suchen.

\section{Historische Kontextualisierung der Grundoperation Unendliche Aktualisation}

Dass die einzelnen innersprachlichen Grundoperationen für die Ewigkeitsattribuierung von Schriftzeichen untereinander Überschneidungen aufweisen, darauf wurde in der Einführung bereits hingewiesen. Jede Gliederung, die eine Typologie vornimmt, ist letztlich heuristischer Natur. Dasselbe gilt folglich auch für die historische Kontextualisierung der einzelnen in dieser Arbeit besprochenen Operationen. So sind denn auch die Befunde und Thesen aus dem Kapitel IV.3, das ebenfalls der historischen Kontextualisierung gewidmet ist, im Folgenden ebenfalls mitzudenken - und umgekehrt. Eine der zentralen Thesen aus Kapitel IV.3.3 zur Genieästhetik bildet denn auch hier den Ausgangspunkt für die kommenden Unterkapitel:

Und genau aus diesem Versuch, sich selbst dauerhaft als, Genie' zu versichern, resultiert der implizite Zwang nach entweder endlosem Erschaffen - das freilich spätestens mit dem Tod des Genies enden wird - oder, als einzige (scheinbar) übrig bleibende Rettung, nach dem Erschaffen von Ewigem, dem Erschaffen eines ewigen Werkes.

Oder anders formuliert:

Ein Genie muss, um ein solches wortwörtlich zu bleiben, entweder Ewiges erschaffen oder aber ewig erschaffen.

Kapitel IV fokussiert denn auch, vereinfacht ausgedrückt, auf die historische Kontextualisierung vor allem von Verfahren des Erschaffens eines ewigen Werkes und der dabei zu beobachtenden Operationen des Bezuges eines Textes auf sich selber. Das vorliegende Kapitel hingegen konzentriert sich vor allem auf Verfahren eines ewigen Erschaffens. Damit ist in erster Linie nicht die unter III behandelte Grundoperation Autonome Performative Produktion gemeint, sondern eine historische Kontextualisierung derjenigen 
Unteroperationen, die besonders auf ein potenziell endloses Weiter- oder Wiederlesen (oder auch Weiterschreiben) eines Textes abzielen und deshalb unter der Grundoperation Unendliche Aktualisation zu fassen sind: Unendliche Lektüre und Unendliches Verstummen.

Unendliche Lektüre und unendliches Schreiben - mit einem Exkurs zuJean Paul

Zu Beginn der nun in Angriff zu nehmenden historischen Kontextualisierung ist zunächst ein Schritt hinter das in den Kapiteln II.1 und II.2 Erarbeitete zurückzugehen und von dem soeben beschriebenen Ausgangspunkt aus erst einmal vermeintlich trivial festzustellen: Grundvoraussetzung für ein unendlich voranschreitendes Lesen wäre ein unendlich fortfahrendes Schreiben. ${ }^{282}$ Mit Blick auf die das Genie konstituierenden und von diesem deshalb stets unter Beweis zu stellenden göttlichen Attribute des Schöpferischen und Ewigen bringt dies folgenden Problemkomplex mit sich: Während es auf der Seite der Lektüre theoretisch möglich wäre, dass nach dem Tod des stetig lesenden Lesers $\mathrm{x}$, Leser y nahtlos mit der Lektüre fortfahren würde usw., kann kein noch so großes Genie - und niemand, der schreibt - sein Schreiben über den eigenen physischen Tod hinaus fortsetzen. Was es geschrieben hat, kann zitiert, kommentiert, adaptiert, variiert usw. werden (und da kommt auch entscheidend die Funktion Herausgeber ins Spiel, siehe dazu weiter unten das Kapitel 3.3), aber selbst wenn das Genie das ganze Leben lang pausenlos geschrieben hätte, endet mit diesem Leben zwangsläufig auch sein Schreiben. ${ }^{283}$

Somit bleibt dem schreibenden Genie, das nicht direkt über die Ewigkeit des Erschaffenen, sondern über das ewige Erschaffen sich der Unsterblichkeit zu versichern sucht, nur noch ein paradoxaler Ausweg übrig: Es muss sich Operationen bedienen, die einerseits jene unendliche Lektüre zeitgenössischer und zukünftiger Leser ermöglichen - ja um sicherzugehen, gar möglichst erzwingen -, die aber andererseits nicht auf ein eigenes ewiges (Weiter-)Schreiben angewiesen sind. Bevor in den nächsten Unterkapiteln auf die Operationen Unendliche Lektüre und Unendliches Verstummen weiter eingegangen wird, sei deshalb vorab noch ein kleiner Exkurs zu demjenigen Autor erlaubt, der wohl wie kein anderer deutschsprachiger Autor des 18. und

282 Dies gilt - in Anlehnung an Derrida - auch umgekehrt.

283 Zur Unmöglichkeit eines absoluten Buches und zu deren Eigendynamik in Bezug auf die Romantik vgl., wenn auch kritisch, Schreiber 1983, insbesondere S. 183, der jedoch erstaunlicherweise kaum auf die in Kapitel IV.1.1 behandelte Höhlenszene im Heinrich von Ofterdingen eingeht. 
frühen 19. Jahrhunderts entgegen der Unausweichlichkeit des Todes auf dem Versuch eines ewigen Schreibens insistiert zu haben scheint: Jean Paul.

Die 2013 erschienene, äußerst erhellende Jean-Paul-Biographie Helmut Pfotenhauers, die für diesen Exkurs die Basis bildet, bietet die zurzeit umfassendste und profundeste Überblicksdarstellung zu Jean Paul und seinem Schreiben resp. "seine[m] Schreib-Leben[]“. ${ }^{284}$ Sie zeigt anhand von Jean Pauls Wirken und Werken in nuce vieles auf, was auch für die vorliegende Arbeit relevant ist, wobei umgekehrt die vorliegende Arbeit vieles zu bestätigen, zu ergänzen und weiterzuführen vermag, was Pfotenhauer anspricht. Während Pfotenhauer überwiegend auf das ,Wie‘ von Jean Pauls Schreiben fokussiert, konzentriert sich Dirk Göttsche in seiner groß angelegten Studie zur literarischen Zeitreflexion vor allem auf das ,Was', so auch im Falle seines Kapitels zu Jean Paul, ${ }^{285}$ in dem er festhält: „Den Ausgangspunkt und die ,Grundmelodie' der Zeitreflexion bildet bei Jean Paul die Vergänglichkeit menschlichen Lebens, die ,seit dem Barock [...] niemand so intensiv wie er zum Gegenstand literarischer Reflexion gemacht hat.“286 Wenngleich Göttsche hierbei zuzustimmen ist, interessiert im Rahmen der vorliegenden Arbeit vor allem das, $\mathrm{Wie}^{287}$ von Jean Pauls Schreiben, weshalb Pfotenhauers ,Werkbiographie‘ auch über den behandelten Autor hinaus als eines der Referenzwerke für die im gesamten Kapitel II.3 angestellten Überlegungen gelten mag.

284 Pfotenhauer 2013, S. 20.

285 Göttsche 2001, S. 115-141.

286 Göttsche 2001, S. 120. Den Begriff „Reflexion“ verwendet hier Göttsche im Sinne von „nachdenken über“/,thematisieren“ (und nicht im Sinne der unter Kapitel IV behandelten Grundoperation Reflexivität). Zur Selbstkritik, die dieser Reflexion Jean Pauls auf sich und sein eigenes Schreiben inhärent war, vgl. etwa Wölfel 1989, S. 270 f.

287 Aber auch Göttsche hält - dieses Mal u. a. im Sinne der in Kapitel IV behandelten Grundoperation Reflexivität - fest: „Spiegeln die Variationen und Schwerpunktverschiebungen der Zeitmotivik und der mit ihr verbundenen Zeitmetaphorik die Entwicklung von Jean Pauls Werk in seinen sukzessiven Phasen, so erfasst die Verzeitlichung aller Selbst- und Wirklichkeitsverhältnisse darüber hinaus auch die Erzählverfahren als solche. Das autoreflexive Spiel mit dem Verhältnis von erzählter Zeit und Erzählzeit, die Verzeitlichung des Raumes und die Verräumlichung der Zeit im Zuge der Darstellung einer von Erinnerung und Erwartung geprägten subjektiven Wirklichkeitswahrnehmung und die Entfaltung der dargestellten (Lebens-)Geschichten anhand hervorgehobener Augenblicke, in denen der epische Vorgang gleichsam aufgehoben scheint, schreiben die Zeitreflexion den grundlegenden Strukturen des Erzählens ein. Jean Pauls Werk zählt damit zu den herausragenden Belegen für die Kulmination der Verzeitlichungsprozesse im letzten Jahrzehnt des 18. Jahrhunderts" (Göttsche 2001, S. 118 f.; vgl. des Weiteren auch S. 136 f.). Zur Auseinandersetzung mit den von Göttsche, aber auch vom DFG-Schwerpunktprogramm „Ästhetische Eigenzeiten“ aufgegriffenen „Verzeitlichungsprozesse[n]“ vgl. Kapitel 2.1 des Schlussteils der vorliegenden Arbeit. 
Soeben wurde behauptet, Jean Paul hätte auf dem Versuch eines ewigen Schreibens insistiert. Dies ist denn auch einer der Hauptbefunde Pfotenhauers und manifestiert sich bereits im Untertitel seiner Biographie: „Das Leben als Schreiben/Biographie“, womit zugleich auch der performative Akt Pfotenhauers ausgestellt wird - denn auch dieser schreibt mit der Biographie ein Leben, nämlich dasjenige von Jean Paul. Es lohnt sich, einen Moment bei diesem Schreiben Pfotenhauers zu verweilen, der die Biographie wie folgt mit einem kommentierten Zitat von Ludwig Börnes ${ }^{288}$ Rede anlässlich des Todes von Jean Paul (1825) schließt:

[...] Nicht allen hat er [Jean Paul, MG] gelebt! Aber eine Zeit wird kommen, da wird er allen geboren, und alle werden ihn beweinen. Er aber steht geduldig an der Pforte des zwanzigsten Jahrhunderts und wartet lächelnd, bis sein schleichend Volk ihm nachkomme.

Heute, fast zweihundert Jahre später, will man die Hoffnung immer noch nicht aufgeben, daß Jean Paul geduldig an der Pforte neuer Jahrzehnte und des neuen Jahrhunderts stehen möge und lächelnd auf das schleichend Volk seiner Leser warte. ${ }^{289}$

Börne und Pfotenhauer setzen dabei ganz offenbar die Ewigkeitsattribuierung von Jean Pauls Schreiben und Geschriebenem fort. Bezeichnenderweise sind, einen Zitatrahmen um die Biographie bildend, dem Vorwort derselben - in an den Kater Murr erinnernder, Anfang und Ende entortender Manier - bereits drei Zitate aus Jean Pauls Werken vorangestellt. Das letzte stammt aus der Unsichtbaren Loge und beinhaltet kaum zufällig eine explizite Ewigkeitsbehauptung gegenüber Schriftzeichen:

Und eben dieses, daß die Hand des Menschen über so wenige Jahre hinausreicht und daß die [sic] so wenige gute Hände fassen kann, das muß ihn entschuldigen, wenn er ein Buch macht: seine Stimme reicht weiter als seine Hand, sein enger Kreis der Liebe zerfließet in weitere Zirkel, und wenn er selbst nicht mehr ist, so wehen seine nachtönenden Gedanken in dem papiernen Laube ${ }^{290}$ noch fort. ${ }^{291}$

Pfotenhauers Jean-Paul-Biographie ist, wie jede andere Biographie, auch ein Versuch, ein Leben zu schreiben und damit dauerhaft festzuhalten. ${ }^{292}$ Das Besondere in ihrem Fall ist jedoch, dass es in Jean Pauls Leben und Werk

\footnotetext{
2881825 noch Juda Löb Baruch geheißen.

289 Pfotenhauer 2013, S. 408.

290 Zur langen Tradition dieser Lebens-Blätter-Metaphorik vgl. Kapitel IV.3.3.2 zu Herders Shakespeare- Aufsatz und Homers Ilias.

291 Zitiert nach Pfotenhauer 2013, S. 13.

292 Vgl. dazu auch Angehrn 2017, insbesondere S. 117-130.
} 
gewissermaßen angelegt ist, dass eine künftige Biographie über ihn nicht nur über ein Leben schreibt, sondern zugleich auch ein von Jean Paul erschriebenes Leben weiterschreibt. ${ }^{293}$ Schließlich ist nun in einem dritten Schritt auch die vorliegende Arbeit selbst bis zu einem gewissen Grad an einer solchen Ewigkeitsattribuierung beteiligt, der sie einzig durch den expliziten Hinweis darauf entgegenzuwirken vermag. ${ }^{294}$ Inwiefern dieses Weiterschreiben von Jean Pauls „Schreibleben“ bereits in Verfahren angelegt ist, die in dessen Werken zu beobachten sind, sei im Folgenden knapp umrissen.

Zum fehlenden Schluss der Unsichtbaren Loge (1793) hält Pfotenhauer fest: „Auch das ist höchst charakteristisch für Richter. Nicht so sehr der Abschluss interessiert ihn, die Fertigstellung, die Rundung, sondern das Weiterschreiben, das Besserschreiben. ${ }^{2}{ }^{295}$ Dies alles manifestiere sich nicht nur im Immerweiter-Schreiben, sondern auch schon innerhalb der einzelnen Texte, deren Sprache „in unerhörte Wendungen und eine bis zum Zerreißen gespannte, schier endlose Syntax“ zerdehnt werde. ${ }^{296}$ Dabei gehe es Jean Paul letztlich vor allem

um die ständige Gewährleistung des Schreibflusses. Denn Schreiben ist das Leben. Diese Lebensbeschreibungen, diese Biographien, wie es fast alle Texte Jean Pauls sind, beschreiben anderes, fiktives Leben. Dieses Leben der Figuren wird in eine höhere, poetische, von der Erdenschwere des gemeinen Lebens befreite Sphäre transportiert. Aber dabei geht es immer auch um das Leben des Lebensbeschreibers, der sozusagen um sein Leben schreibt: Im Schreiben ist das wahre Leben, das, welches das bloß gelebte Leben mit all seinen Bedrängnissen, seiner Nähe zum Elend, zum Tod, zu den persönlichen Kränkungen vergessen läßt, das es aufhebt, ihm eine schriftliche Dauer und Situationsenthobenheit gewährt. Deshalb muß unablässig fortgeschrieben werden. ${ }^{297}$

Jean Paul sei bei seinem Versuch, sich durch die Verfahren eines endlosen Weiterschreibens der Ewigkeit zu versichern, also derart konsequent, dass sein Leben immer mehr zum Schreiben werde. Inwiefern ein solches ewiges Schreiben noch als Leben bezeichnet werden könnte, wäre genauer zu verfolgen und deckt sich mit einem der Hauptbefunde aus Albrecht Koschorkes Untersuchung Körperströme und Schriftverkehr, nämlich dass im Zuge des 18. Jahrhunderts die körperliche Distanz zwischen (lebenden) Körpern größer

\footnotetext{
293 Vgl. Pfotenhauer 2013, S. $17 \mathrm{f}$.

294 Vgl. dazu auch das letzte Kapitel des Schlussteils.

295 Ebd., S. 101. In eine ähnliche Richtung geht Sascha Michel in Bezug auf den Siebenkäs, unter besonderer Berücksichtigung von dessen Fußnoten; vgl. ders. 2006, insbesondere S. $169-173$.

296 Pfotenhauer 2013, S. 74.

297 Ebd., S. 119.
} 
wird, die der zunehmende Verkehr mittels (toter) Schrift auf paradoxaltragische Weise zugleich überbrückt und verstärkt. ${ }^{298}$ Für Koschorkes These gäbe Jean Paul - wie ihn Pfotenhauer zeichnet -, dessen Freundschaften und (Liebes-)Beziehungen vor allem Schriftbeziehungen, Schriftlieben sind, geradezu das Paradebeispiel ab. 299

Die unermessliche schöpferische Macht, die sich Jean Paul, das bestehende Geniekonzept mit aller Konsequenz aufnehmend, mit der Umwandlung seines sterblichen Lebens in ein ewiges Weiterschreiben wortwörtlich zuschreibt, manifestiert sich auch in seinem eigenen Namen: „Jean Paul benennt sich nach seiner eigenen Romanfigur. Das Leben lebt die Fiktion nach. Mit diesem Gedanken, der den größten Triumph des Autors bedeutet, wird Jean Paul von nun an immer wieder spielen. ${ }^{300}$ Das Schreiben wird damit zu einem Akt selbsterfüllender Prophezeiung, denn Pfotenhauers Argumentation hieße konsequenterweise, dass das Leben nicht nur die Fiktion nachlebe, sondern auch Umgekehrtes der Fall wäre - was der Figur eines Hysteron-Proterons im engen Sinne entspräche. Oder anders formuliert: Ein Schreiben, das zugleich das Leben wäre (und umgekehrt), wäre ein Schreiben im Modus absoluter Performativität. ${ }^{301}$ Alles Geschriebene würde nicht auf etwas Abwesendes verweisen, sondern Präsenz überhaupt erst herstellen. ${ }^{302}$

Der Versuch, dieses Schreiben ewig fortzusetzen, ist jedoch, selbst an der eigenen Binnenlogik gemessen, paradoxal: Wenn jemand ewig schreiben

298 Vgl. Koschorke 1999.

299 Vor allem was solche Beziehungen zu Frauen anbelangt, sollen sie gewissermaßen in der Rolle als Musen bloß den Fluss der Schrift befördern; bei allem, was darüber hinausgeht und darunter fällt das Befördern etwaiger Körperflüsse -, tut sich Jean Paul jedoch lange schwer. Auch direktem weiblichem Einfluss auf sein Schreiben steht er ablehnend gegenüber. So antwortet er am 8. November 1796 in einem Brief an Charlotte Kalb, die Kritik an der Mondfinsternis in Geschichte meiner Vorrede zur zweiten Auflage des Quintus Fixlein geübt hatte, mit den bezeichnenden Worten: „Ich kan [sic] viel opfern, aber nicht meine Begeisterung für die Unsterblichkeit und deren Hoffnung. Kein Verhältnis darf auf das des Dichters einen Einflus [sic] gewinnen“ (zitiert nach Pfotenhauer 2013, S. 181).

300 Ebd., S. 102.

301 Vgl. dazu die Kapitel III und IV.2.2.

302 Ein Anspruch, der allein schon in den Versuchen, ihn zu verwirklichen, zu unheimlichen Parallelen führen muss oder - aus hermeneutischer, etwas kritischer Perspektive gesagt das Suchen und Finden solcher Parallelen befördert. So schreibt Jean Paul am Todestag (ohne dies zu wissen) von Moritz am 38. Kapitel des Hesperus, dem 38. Hundposttag, in dem die Figur Emanuel stirbt, die wiederum Karl Philipp Moritz gewidmet ist (vgl. Pfotenhauer 2013, S. 116; der jedoch, sich wohl schlicht verschreibend, den 26. April 1793 als den Todestag Moritz' angibt, nach dem besten Wissen des Verfassers war es aber der 26. Juni). „Das ist nicht nur Schmerz, sondern auch Triumph. Der Tod hat in seiner literarischen Vorsehung den Schrecken des wirklichen [sic] verklärend aufgehoben“ (vgl. ebd., S. 121). 
könnte, würde dies implizieren, dass er ewig leben muss, ansonsten könnte er ja nicht ewig schreiben. Damit würde aber der Schreibende als Möglichkeitsbedingung für sein ewiges Schreiben bereits mitbringen, was er mit diesem Schreiben eigentlich zu erlangen sucht: ein ewiges Leben. Daraus lässt sich wiederum die These ableiten,

dass dem Versuch Jean Pauls, ewig weiterzuschreiben, noch ein weiteres Verfahren zugrunde liegt, das jenem Paradoxon zu entfliehen vermag und letztlich anstatt auf die Ewigkeit des Schreibens doch auf die Ewigkeit des Geschriebenen abzielt: Denn wenn das Leben nur noch aus dem Schreiben von Werken besteht, entspricht das, Gesamtwerk' dem Leben.

Diese anhand von Jean Pauls Schreiben und Pfotenhauers Untersuchung desselben ${ }^{303}$ aufgestellte These wird in Kapitel 3.4 noch einmal aufgegriffen, da sie den Ausgangspunkt für Überlegungen bietet, die den Blick auf die Grundoperationen zur Ewigkeitsattribuierung von Schriftzeichen Unendliche Aktualisation sowie Reflexivität weiter schärfen und u. a. auch als Fortführung und Ergänzung von Pfotenhauers Argumentation zu verstehen sind.

Sie sei aber nun vorerst beiseitegelegt, um die hier geführte Auseinandersetzung mit Jean Paul noch in Rücksicht auf seine Stellung zwischen der sogenannten Klassik Goethes und Schillers einerseits und der Romantik andererseits zu beschließen. Zu Jean Pauls erstem Besuch in Weimar (1796) schreibt Pfotenhauer:

Zwei Welten treffen hier ja aufeinander: hier die intellektuelle Elite Deutschlands am Schauplatz seiner kulturellen Blüte, dort der bis vor kurzem noch gänzlich unbekannte junge Schriftsteller aus der oberfränkischen Provinz. Hier, mit Goethe und Schiller, die formstrengen Klassizisten, dort der neue Vorreiter einer Auflösung der Formen, die in den romantischen Antiklassizismus führen wird, mit welchem der Protagonist aber seinerseits wiederum nichts zu tun haben will. $^{304}$

Dass freilich gerade unterschiedliche Vorstellungen zur Begehung desselben Weges zu Missverständnissen, Spannungen und Abgrenzungsreflexen führen, ist nicht nur aus der Literaturgeschichte bekannt. Was jene gegenseitige „Irritation“305 zwischen Goethe, Schiller und Jean Paul betrifft, so lässt sich

303 In dieselbe Richtung wie Pfotenhauer gehen u. a. Michel 2006, der sich zudem auch mit Figurationen der Unterbrechung bei Brentano und Wieland befasst; Wieland 2013; und der Sammelband zur Ausstellung "Jean Paul, Dintenuniversum“ im Max Liebermann Haus, Berlin, Bernauer/Steinsiek/Weber 2013. Vgl. dazu auch kritisch das Kapitel zu Jean Paul in Jochen Schmidts Geschichte des Genie-Gedankens (ders. 2004, Bd. 1, S. 430-450).

304 Pfotenhauer 2013, S. 139.

305 Ebd., S. 138. 
denn auch aus dem oben Dargelegten hypothetisch und etwas plakativ Folgendes ableiten:

Die Spannung zwischen dem überwiegend auf die Geschlossenheit und Autonomie (vgl. Kapitel IV.3.2) des Werkes abzielenden Kunstverständnis der Weimarer Klassik Goethes und Schillers einerseits und Jean Pauls (und aller, die sich auf die Linie [Cervantes -] Sterne berufen) Kunstverständnis der Digression andererseits, ${ }^{306}$ das auf ein potenziell unendlich weiter sich ausdehnendes Werk abzielt, liegt auch darin begründet, dass beide Parteien in ihrem Kunstverständnis je eine andere Gruppe ${ }^{307}$ von Operationen zur Ewigkeitsattribuierung besonders prominent einsetzen, um ihre Werke (und damit letztlich auch sich selbst) als unsterblich zu erweisen. Im Falle Ersterer sind dies Operationen, die auf eine Autonomie des Geschriebenen abzielen, im Falle von Letzterem Operationen, die eine unendliche Aktualisation des Geschriebenen zu erreichen suchen. Das heißt natürlich nicht, dass die jeweils anderen Operationen in den betreffenden Werken nicht zu beobachten wären oder dass man sich solcher Überschneidungen untereinander gänzlich unbewusst wäre. ${ }^{308}$ Dass zu jener Spannung nicht nur Ablehnung, sondern eben auch Anziehung gehört und sich die beiden Parteien in manchem ähneln, ${ }^{309}$ liegt auch an der Komplementarität dieser einzelnen Operationen.

,Die Romantiker' wiederum, so scheint es, betreiben aus dieser Perspektive weniger einen "Antiklassizismus", 310 sondern suchen vielmehr - wie unten noch zu zeigen ist - die große Synthese, indem sie in ihrer Kunstauffassung beide Gruppen von Operationen zur Ewigkeitsattribuierung, sowohl den potenziell endlosen Verweis des Textes auf sich selbst und/oder seine Möglichkeitsbedingungen

306 Vgl. dazu u. a. Michel 2006; und Wieland 2013.

307 Vgl. dazu die zusammenfassende Darstellung in Kapitel 1.1 des Schlussteils.

308 Pfotenhauer selbst schreibt dazu u. a. „Und er [Goethe, MG] selbst hat ja in den gleichzeitigen Erzählungen der Unterhaltungen deutscher Ausgewanderten, die in Schillers Horen erscheinen, Novellistisches als Augenblickhaftes und Diskontinuierliches der romanesken Verpflichtung auf Entwicklung[, die er im zeitgleich zum Hesperus erschienenen Wilhelm Meister verfolgt, MG] entgegengestellt" (Pfotenhauer 2013, S. 148). Umgekehrt wird in Jean Pauls Werken z. B. sehr oft über das Schreiben und die Möglichkeitsbedingungen desselben reflektiert, was unter die (u. a.) auf Autonomie von Zeit und Kontext abzielende Grundoperation Reflexivität fällt. Zu Goethes Einstellung zur Unsterblichkeit des Menschen in Verbindung mit auf Tätigkeit abzielenden Bewältigungsstrategien gegenüber Todesfällen resp. dem Tod, aber auch hinsichtlich des „in sich vollendeten Kunstwerks" vgl. Steinby/Schmidt 2017, S. 24 f.; und insbesondere Hilgers 2002, S. 117-139, 203-218, die sich auch vertiefter und über Goethe hinaus zum Verhältnis von Unsterblichkeitsvorstellungen im 18. Jahrhundert und zum Paradigma der Perfektibilität äußert (ebd., S. 178-196).

309 Vgl. Pfotenhauer 2013, S. 138-163, vor allem S. $148 \mathrm{f}$.

310 Vgl. das oben angeführte, eingerückte Zitat Helmut Pfotenhauers. 
als auch die potenziell unbeendbare Lektüre samt ihrer Kehrseite, ${ }^{311}$ gleichwertig zu gewichten suchen.

Hinsichtlich der Ewigkeitsattribuierung von Schriftzeichen ließe sich Jean Pauls in der Forschung vielfach vertretene Sonderstellung zwischen Klassik und Romantik somit einerseits bestätigen, andererseits auch widerlegen, hat er doch Teil an demselben - ,Klassiker' wie, Romantiker prägenden - Versuch, sich über innersprachliche Operationen der Ewigkeit zu versichern.

\section{2 Ästhetik des Endens: die Linie Lessing-Jean Paul - Romantik}

Im Kapitel zu Lessings Miss Sara Sampson (1755) wurde u. a. folgende, auf die Forschung Müller Nielabas gestützte ${ }^{312}$ These vertreten:

Der von Lessing durch seine Neuinterpretation von Aristoteles' Begriff phóbos angestrebte Paradigmenwechsel innerhalb der zeitgenössischen Gattung des Trauerspiels von einer Betonung des Schauderns/Schreckens hin zum Mitleid(en) ging nicht nur einher mit einer Priorisierung der Dauer des Mitleidens gegenüber dem schrecklichen Augenblick, sondern führte zugleich zur Auflösung einer anderen zentralen Begrifflichkeit in Aristoteles' Poetik, nämlich der für die Tragödie geforderten Dreieinigkeit von Anfang, Mitte und Ende, insofern als bei Lessing das Ende in ein Enden überführt und damit zur Mitte wird.

Im Folgenden soll dieser These weiter nachgegangen werden, und zwar hinsichtlich der literaturgeschichtlichen Auswirkungen dieses von Lessing vorgenommenen Aufbrechens der aristotelischen Einheit der Tragödie und, davon abgeleitet, eines literarischen Werkes im Allgemeinen. Berücksichtigt werden dafür Jean Paul, die Frühromantik und E. T. A. Hoffmann. Die dabei beobachtete literaturgeschichtliche Linie vermag allein schon wegen des beschränkten Rahmens, der ihr hier gewidmet werden kann, keinen Anspruch auf absolute Gültigkeit zu erheben, aber eine Tendenz aufzuzeigen, der vielleicht künftige Untersuchungen vertieft nachgehen mögen.

\subsection{1 $\quad$ Lessing und Jean Paul}

Wie bereits im Kapitel zur Miss Sara Sampson behandelt und von Lessing in der Hamburgischen Dramaturgie selbst auf den Punkt gebracht, ${ }^{313}$ ist zur Konstitution des Mitleid(en)s eine gewisse Dauer notwendig, während der Schrecken auf den (flüchtigen) Moment angewiesen ist (und damit auch eine

311 Ästhetisch prominent nutzbar gemacht vor allem im Fragmentarischen; vgl. unten Kapitel II.3.4

312 Vgl. Müller Nielaba 1999.

313 Vgl. Lessing, Werke, Bd. 6, S. 553 (Hamburgische Dramaturgie, 74. Stück), S. 556 f. (75. Stück), S. 566 (77. Stück); und Kapitel II.1.2. 
jede Ewigkeitsattribuierung unterlaufen muss). Bei Lessing ist es nun gerade das Mitleid und dessen Dauer, das den Schrecken des Todes der tragischen Figuren überführt in ein Enden, welches das Ende des Kunstwerkes - das jeweils metonymisch den Namen jener Sterbenden trägt ${ }^{314}$ - gegen den Schrecken des Todes zur Mitte werden lässt. In Lessings Trauerspiel(text)en steht, das Kapitel zur Miss Sara Sampson hat es gezeigt, also nicht nur die Dauer des Lebens der tragischen Figuren auf dem Spiel, sondern auch die Dauer des Lesens ebendieser Leben. Im vorangegangenen Exkurs zu Jean Paul wiederum wurde bereits ausführlich dargelegt, wie dieser um ein Immer-weiter-Schreiben bemüht ist, was sich nicht nur in seiner exzessiven Schreibtätigkeit, sondern und vor allem auch anhand seiner Romane zeigt. Was Lessing mit dem Trauerspiel begonnen hat, scheint Jean Paul nämlich wenige Jahrzehnte später für die neue Gattung des Romans bis ins Extrem umzusetzen.

Als Paradebeispiel dafür mag der Hesperus (1795) gelten, „[d]enn Emanuel stirbt ja über fast 700 Seiten - oder meint zu sterben, bis er dann, wirklich tot ist". ${ }^{315}$ Der Tod ereilt Emanuel im "38. Hundposttag“, in dem Emanuel zuerst zu sterben glaubt, ${ }^{316}$ dann träumt, gestorben zu sein, ${ }^{317}$ um schließlich doch zu sterben. ${ }^{318}$ Emanuel stirbt jedoch in einem Unterkapitel (oder danach?) des „38. Hundposttages“, das mit „Traum Emanuels, daß alle Seelen Eine Wonne vernichte "319 überschrieben ist und somit wiederum die Grenze zwischen Traum und Wirklichkeit verwischt. Diese Verwischung erfolgt nicht nur auf der inhaltlichen Ebene, sondern auch auf der formalen, indem das Ende des betreffenden Unterkapitels nicht durch die Überschrift eines weiteren Unterkapitels und noch nicht durch die Überschrift "39. Hundposttag" signalisiert wird, sondern bloß durch eine Leerzeile, in deren Mitte (!) ausgerechnet drei Sternchen prangen:

Endlich sagte leise der Engel des Endes: sie sind am süßesten vergangen an ihren Geliebten.-

Und er zerdrückte weinend das Wölkgen der Zeit. -

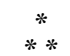

In Emanuels Augen glänzten die Fieberbilder des Todes, mit denen sich jeder Schlaf, sogar der letzte [sic] anfängt. Sein Geist hing wiegend in seinen schlaffen

314 So tragen die Trauerspiele Lessings die Titel Miss Sara Sampson, Philotas und Emilia Galotti.

315 Pfotenhauer 2013, S. 133.

316 Vgl. Jean Paul, Hesperus, S. 294-301.

317 Ebd., S. 306-308.

318 Ebd., S. 322.

319 Ebd., S. 316. 
Nerven, von sanften Lüften angeweht: denn er war schon in jener zersetzenden Nerven-Entzückung der Ohnmächtigen, der Gebährenden, der Verbluteten, der Sterbenden. ${ }^{320}$

Diese Sternchen stehen inhaltlich gesprochen am Ende von Emanuels Traum und aus textlinguistischer Sicht als Gliederungshinweise ${ }^{321}$ am Ende des Unterkapitels; damit aber auch zwischen diesen Enden und dem Rest des „38. Hundposttages“, worin dann erst Viktor den Tod Emanuels aus der Außenperspektive bestätigt. Damit spricht Viktor aus, was - wie in II.1 und II.2 bereits mehrfach behandelt - die Figur, die tot ist, nicht aussprechen kann, nämlich deren Tod: „Spiele das Lied der Entzückung fort, er ist gestorben.“322 Und noch etwas begegnet uns hier bei Jean Paul erneut: der Gedankenstrich. ${ }^{323}$ Gerade weil die Figur Emanuel wie Sara Sampson, wie Emilia Galotti, wie Philotas, wie Murr den eigenen Tod nicht aussprechen kann, ist das letzte Schriftzeichen vor dem Sternchen wie schon bei Lessing und wie später bei Hoffmann ein Gedankenstrich. Besonders bemerkenswert ist bezüglich einer von Lessing ausgehenden Ästhetik des Endens dabei auch, dass der Gedankenstrich im deutschen Sprachraum zunächst ausschließlich im Drama verwendet wurde, um dann im Zuge des 18. Jahrhunderts rasch vermehrten Eingang in die

320 Ebd., S. 320.

321 Vgl. Hausendorf/Kesselheim 2008.

322 Jean Paul, Hesperus, S. 322.

323 Magnus Wieland hat den Gedankenstrichen bei Jean Paul ein eigenes Kapitel gewidmet; vgl. ders. 2013, S. 299-306. Darin kommt er auch explizit auf das Verhältnis von Gedankenstrich und Tod zu sprechen. Die betreffende, sehr prägnant formulierte und genau in die Richtung des hier Interessierenden gehende Stelle sei deshalb ausführlich wiedergegeben: „Neben diesem typographischen Einsatz verleiht Jean Paul dem Gedankenstrich in einem frühen Aphorismus auch eine transzendente Bedeutung: ,Der Tod ist kein Punkt, sondern nur ein Abtheilungszeichen im menschlichen Dasein, ist ein Gedankenstrich, der zwo Welten verbindet' $[\ldots]$. Für einen digressiven Autor verwundert es nicht, wenn selbst der Tod kein endgültiges Ende bedeutet, kein Punkt, der dem ausufernden Schreibfluss Einhalt gebietet, sondern ein Gedankenstrich, der darauf verweist, dass nach dem ,Abbruch einer Periode' stets noch eine neue folgt. Hier eröffnet sich eine existentielle Komponente der Digression im Hinblick darauf, was Michel Foucault die ,langage à l'infini' nennt [zu Foucault und dem betreffenden Aufsatz „Das unendliche Sprechen“ vgl. die kritische Auseinandersetzung mit der hermeneutischen Tradition im Kapitel zum Forschungsstand in der Einführung, MG]. Die Digression bedeutet auch ein Anschreiben gegen den Tod. Im Schreiben und insbesondere im digressiven Schreiben liegt ein phantasmatischer und bis zu einem gewissen Grade auch melancholischer Wunsch verborgen, wie Scheherazade den Tod doch noch um eine Nacht aufschieben zu können, das Erzählen, das Schreiben nicht abbrechen und zu keinem Ende kommen zu lassen, um vor dem tatsächlichen Ende bewahrt zu sein“ (ebd., S. 303 f.). 
anderen Gattungen zu finden. ${ }^{324}$ (Auf die prominent eingesetzten Gedankenstriche bei Kleist kann hier nicht näher eingegangen werden, man halte sich hierfür zusammenfassend an das ausführliche Kapitel in Thomas Nehrlichs Monographie, wobei insbesondere dessen Ausführungen zur Marquise von $O$... und die Ergebnisse der vorliegenden Arbeit einander bestätigen mögen. ${ }^{325}$

Dass den typographischen Mitteln gerade bei Jean Paul eine wichtige Rolle zukommt, ist demnach nicht weiter verwunderlich und wurde bereits von Helmut Pfotenhauer anhand der Unsichtbaren Loge mit Blick auf Sterne angemerkt, jedoch ohne auf Lessing zurück- oder auf Hoffmann vorzuverweisen:

Typographische Mittel werden sprechend gemacht - ganz wie bei Sterne. Jean Paul' rät seinem fiktiven Verleger denn auch, sich für den Druck seiner Biographie einen großen Vorrat an Gedankenstrichen (man denke an das Motto), Frage- und Ausrufezeichen zuzulegen. Der Biograph des Romans weiß, wie sehr er ständig gegen die Zeit, den Zufall und das drohende Ende zu kämpfen hat. ${ }^{326}$

Und zum dem Roman Die Unsichtbare Loge vorangestellten Motto, das „Der Mensch ist der große Gedankenstrich im Buche der Natur“327 lautet und als (grobes) Selbstzitat aus den Teufelspapieren ${ }^{328}$ den Anfang des Romans hin auf einen anderen Text verwischt, kommentiert Pfotenhauer: „Der Mensch

324 Vgl. Nehrlich 2012, S. 118. Zum statistisch nachweisbaren, sprunghaften Anstieg von Gedankenstrich und Ausrufezeichen in der zweiten Hälfte des 18. Jahrhunderts vgl. auch Polaschegg 2012, insbesondere S. 16o-162; sie erwähnt dabei auch die hohe Gedankenstrichdichte in Lessings Trauerspielen. Äußerst bemerkenswert ist hierbei auch ihre am Ende von Kapitel II.1.2 aufgegriffene These, dass die in der zweiten Hälfte des 18. Jahrhunderts gewissermaßen zu ,Affektzeichen' werdenden Satzzeichen einhergehen mit der Konstitution des modernen Individuums und der modernen Autorschaft (vgl. ebd., S. 181 f.).

325 Vgl. Nehrlich 2012, S. 115-162. Zum Ende(n) der Marquise von $O$... schreibt Nehrlich u. a.: „Wie kein zweites typographisches Merkmal des Kleistschen Erzählwerks wirkt sich der Gedankenstrich in der Marquise auf die Materialität der Lektüre aus. Wie bereits erwähnt, veranlasst er die Änderung der Leserichtung: Während im ersten Lesegang die Neugier des Lesers ganz auf die Lösung des Rätsels zielt und die Lektüre im steten, auf den Ausgang gerichteten Vorwärtsgang weder Verzug noch Aufenthalt duldet, so bewirkt die nur halbe Aufklärung des Schlusses, dass der Leser nun, auf der Suche nach dem entscheidenden Augenblick, der seiner Aufmerksamkeit entgangen sein mag, den Text von hinten nach vorn durchkämmt: Vom Ende, das die Begier des Lesers nicht vollständig befriedigt, jäh in die Erzählung zurückgeworfen, verläuft die Lektüre nun rückwärts“ (ebd., S. 160).

326 Pfotenhauer 2013, S. 108.

327 Jean Paul, Unsichtbare Loge, S. 4.

328 Die Stelle in den Teufelspapieren weicht jedoch vom Motto der Unsichtbaren Loge ab und setzt den „lange[n] Gedankenstrich“ auch gleich performativ ein: „Der sonderbare Mensch ist im Buche der Natur der lange Gedankenstrich“ (ebenfalls nach der 
also als Schriftzeichen, als Zeichen für eine Leerstelle, die durch Gedanken auszufüllen wären, welche in ein Buch zu schreiben sind. In der Tat kann man Jean Pauls Schriftabsolutismus kaum besser zum Ausdruck bringen. Papierene Anthropologie könnte man das auch nennen. ${ }^{329}$ Diese Beobachtungen Helmut Pfotenhauers sind zu ergänzen mit den Beobachtungen zum Gedankenstrich im Kapitel zu Lessings Miss Sara Sampson und mit der dabei festgestellten Analogie dieses Satzzeichens, das als einziges allgemeingebräuchliches Schriftzeichen der deutschen Sprache zwischen zwei Leerschlägen zu stehen kommt, mit dem menschlichen Leben und Sterben. ${ }^{330}$

Die Sternchen am Ende von Emanuels Traum stehen nicht nur zwischen dessen anzunehmendem Tod, der mit dem Ende des Traums zusammenfällt, einerseits und dem von Viktor eine Seite später bestätigten Tod andererseits, sondern können zugleich auch als ikonische Zeichen gelesen werden, nämlich als Zeichen für einen Stern resp. für Sterne. Dabei eröffnen sich wiederum mindestens drei Lesarten des Verweises auf einen Stern: a) ein Stern als Verweis auf den Sterne, Laurence Sterne, den Verfasser von The Life and Opinions of Tristram Shandy, Gentleman, auf das große Vorbild Jean Pauls, wie auch auf E. T. A. Hoffmanns Kater Murr in Sachen Digression und sprechender Typographie; b) ein Verweis auf die traditionelle Symbolik des Sterns als Zeichen für die Ewigkeit im Allgemeinen, aber auch in der Tradition von Ovids Nachwort zu den Metamorphosen als Zeichen für die Unsterblichkeit des Autors im Speziellen; ${ }^{331}$ c) ein Stern als Zeichen für den Hesperus, den Abend- und Morgenstern, der zugleich sowohl Anfang und Ende des Tages als auch der Nacht figuriert; den Hesperus, der als astronomische Anadiplose als Metapher für die Figuration von Anfang und Ende des Lebens resp. poetologisch für die Figuration von Anfang und Ende des Lesens des Romans Hesperus stehen kann. ${ }^{332}$ Was oben insbesondere im Falle von Hoffmanns Kater Murr festgestellt wurde, lässt sich somit bereits in ähnlicher Weise für den 25 Jahre früher erschienenen Hesperus Jean Pauls beobachten: Auf der Mikroebene der Typographie wird an entscheidender Stelle die auf der Makroebene angestrebte Überführung des Endes hin zu einem Enden und damit zu einer Mitte ausgestellt und unterstützt.

Erstausgabe abgedruckt im Apparat von: Jean Paul, Unsichtbare Loge, S. 4; resp. vgl. Jean Paul, Teufelspapiere, S. 241).

329 Pfotenhauer 2013, S. 107.

33 O Vgl. Kapitel II.1.2.2.

331 Vgl. zu Ovid Kapitel 4.2 der Einführung.

332 Zur poetologischen Metaphorik von Tag und Nacht vgl. das Kapitel II.2.1 zu Der Spinnerin Nachtlied. 
Von hier aus sei nun wieder zur Makroebene des Hesperus zurückgekehrt, die bezeichnenderweise auch Pfotenhauer beschreibt - und dies, ohne es zu be- oder vermerken, ganz vor der Folie von Lessings Transformation der abschreckenden Tragödie hin zu einem Trauerspiel, das ganz auf das Mitleiden abzielt:

Emanuels Vernichtvision ist nun, wie der Titel [„Traum Emanuels, daß alle Seelen Eine Wonne vernichte“, MG] schon besagt, ein wonnevoller Blick in die andere Welt, kein grausiges Erschrecken über die Hinfälligkeit des Lebens. Die Literatur versucht hier ihre Macht angesichts dieser Schwellensituation zu demonstrieren. Und das merkwürdige Ineinander von Sterben und schreibendem Aufheben seiner Schrecken scheint sie eindrucksvoll zu bestätigen. Deshalb sind Emanuels sich durch das ganze Buch ziehende Vorstellungen vom eigenen Sterben, sein Beschreiben seines Sterbens, auch wiederum Sprachereignisse. ${ }^{333}$

Das „Ineinander von Sterben“- eben Dauer beanspruchendes Sterben und nicht plötzlicher Tod - „und schreibendem Aufheben seiner Schrecken“ ist denn, so die hier vertretene These, auch alles andere als "merkwürdig“, sondern Jean Pauls Übertragung von Lessings Transformation der Tragödie auf den Roman.

\subsubsection{Lessing und die frühromantische Fragmentästhetik}

Während der entscheidende Einfluss Lessings auf das Auflösen der aristotelischen Einheit des Werkes, das im Zuge der zweiten Hälfte des 18. und des frühen 19.Jahrhunderts immer stärker erfolgt und als ein wesentliches Merkmal der Moderne gilt, ${ }^{334}$ in der Forschung bislang nicht mit Blick auf dessen in den Trauerspielen entfaltete Ästhetik des Endens untersucht wurde, erfolgte dies umso mehr in anderer Hinsicht. Dabei scheinen - abgesehen von Dieter Burdorfs Aufsatz, der den vor allem durch die Übersetzungstätigkeit Wilhelm Schlegels vermittelten Einfluss der fragmentarischen Überlieferung antiker Texte stark macht ${ }^{335}$ - vor allem zwei Ausgangspunkte dominant: ${ }^{336}$ einerseits ein sehr weiter, auf die Ebene von Stil und Inhalt fokussierender Fragmentbegriff, der Friedrich Schlegels Urteil "Alles was Lessing geschrieben ein $\operatorname{Fr}[$ agment $]$ “ folgt, ${ }^{337}$ so etwa in Lothar Pikuliks Aufsatz Lessing als Vorläufer des

\footnotetext{
333 Pfotenhauer 2013, S. 132, Hervorhebungen MG.

334 Vgl. u. a. Ostermann 1991.

335 Vgl. Burdorf 2011.

336 Vgl. zum Forschungsstand u. a. zusammenfassend Braun 2002, S. 34-45; und Weiß 2015, S. 13-20.

337 Die im Zusammenhang der frühromantischen Fragmentästhetik immer wieder zitierte Stelle stammt aus den „Philosophischen Lehrjahren, [V] Philosophische Fragmente,
} 
frühromantischen Fragmentismus ${ }^{338}$ oder in der Monographie von Johannes Weiß; und andererseits, nun unter dem Gesichtspunkt der Form, Lessings Herausgabe der sogenannten Reimarus-Fragmente (1774). Der erstgenannte Ausgangspunkt ist derjenige in der Forschung stärker verfolgte und in seiner Wirkmächtigkeit höher eingeschätzte, einer Forschung die dabei ganz von Friedrich Schlegels explizitem Nachdenken über Lessing eingenommen ist. ${ }^{339}$ Dies gilt auch für die 2015 erschienene Monographie Das frühromantische Fragment. Eine Entstehungs- und Wirkungsgeschichte von Johannes Weiß, dem es ein „zentrales Anliegen“ ist, zu klären, „ob die neue, fragmentarische Weltsicht der Frühromantik tatsächlich ihre Entsprechung im Gebrauch einer neuen, fragmentarischen Darstellungsform findet" oder ob es sich dabei bloß um eine "Variante des konventionellen Aphorismus“340 handle, und der als die wesentlichen Einflüsse Chamfort, Lessing sowie Goethes und Schillers Xenien ausmacht. ${ }^{341} \mathrm{Zu}$ all dem, aber eben gerade auch hinsichtlich des hier verfolgten Einflusses von Lessings Ästhetik des Endens, kommt hinzu, dass Rüdiger Campe in den Versuchen (insbesondere Friedrich Schlegels) um 180o, den Roman theoretisch zu fassen, einen Wechsel vom statischen Formbegriff hin zu einer potenziell endlosen Operation der formation (auf Englisch auch in bezeichnender Nähe zu formation im Sinne von deutsch „Bildung“) feststellt:

Thus nearly every passage in which Schlegel speaks of the art of life is marked by the biological concept of developmental formation (Bildung). A form thus comes about that consists or rather manifests itself in its constant selfdifferentiation from non-form. In Schlegel's art of life, the form of life turns out to be the result of its being differentiated from what it is not. Thus, however, a paradox ensues: every instance of differentiating formed from formless life brings about new life that again falls outside of the limits of form. ${ }^{342}$

Der Roman, der das Leben seiner Hauptfigur zu fassen sucht, wäre demnach für Friedrich Schlegel per definitionem eine Gattung, die - drückt man den Forschungskonsens in Anlehnung an aristotelische Begrifflichkeit aus - im

Zweyte Epoche II“ [Fragment 118]: „Wolfs Proleg[omena] eine Idee von $x p$ [kritischem] Experiment. Alles was Lessing geschrieben ein Fr[agment]“ (KFSA 18, S. 333).

338 Vgl. Pikulik 1993.

339 Vgl. u. a. Braun 2002, S. 34 und 36, der sich wiederum auf Pikulik 1993 stützt.

340 Weiß 2015, S. 10.

341 Vgl. ebd., S. 21-91. Vgl. dazu auch Strack 2004; zum beschränkten Einfluss von Chamfort etwa S. 349; zu Unterschieden zwischen Friedrich Schlegels und Novalis' Fragmentkonzeption S. 355-359.

342 Campe 2011, S. 6 o f. 
Wesentlichen durch die Transformation des Endes (und des Anfangs) zur Mitte konstituiert wird.

An dieser Stelle sei noch eine Stufe weiter ,herausgezoomt' und die Fragmentästhetik vor dem Hintergrund der geistesgeschichtlichen Veränderungen des 18. Jahrhunderts in den Blick genommen. Die Begriffs- und Gattungsgeschichte, die von Michael Braun - zu großen Teilen Ernst Behler paraphrasierend $^{343}$ - zusammenfassend aufgearbeitet worden ist, lehrt, dass die Erweiterung des lateinischen Begriffs fragmentum sich erst im Mittelalter auch auf geistige Erzeugnisse beziehen konnte, während er sich ursprünglich nur auf physische Überbleibsel oder Spuren bezog und eine ästhetische Nutzbarmachung des Fragmentarischen, ganz in der Tradition des Aristoteles, noch undenkbar war. Diese Begriffserweiterung geht wohl vom Speisungswunder Jesu im Johannesevangelium aus, wo es heißt: „Als sie aber satt waren, sagte er zu seinen Jüngern: Sammelt die übrig gebliebenen Brocken, damit nichts verloren geht. Sie sammelten sie und füllten zwölf Körbe mit den Brocken, die von den fünf Gerstenbroten übrig blieben, nachdem sie gegessen hatten“ (Johannes 6:12-13). ${ }^{344}$

Jesu Auftrag, die übriggebliebenen Brocken aufzulesen, damit nichts verlorengehe, wurde im eucharistischen Sinne als Vorwegnahme des Versprechens vom Brot des Lebens gedeutet, spätestens seit Luther - der "fragmentum“ mit „Stückwerk" übersetzte - aber auch in allegorischer Auslegungsmanier so verstanden, daß Christus zum Aufsammeln der verstreuten Brocken seiner Lehre auffordere. Damit bekamen die "fragmenta" einen heilsgeschichtlichen Nebensinn: Als Überreste einer göttlichen Speise sind die Fragmente Zeugnisse des Wunders und Mittel religiöser Erkenntnis. So konnte der Begriff auf den StückwerkCharakter der menschlichen Erkenntnis übertragen werden [...]. Diese Bedeutungserweiterung des Fragments steht anthropologiegeschichtlich an der Schnittstelle zwischen Philosophie, Theologie und Medizin, die im späten 18. Jahrhundert eine einflußreiche Liaison eingingen. ${ }^{345}$

\section{Und Elizabeth Wanning Harries stellt ergänzend dazu fest:}

As long as the Bible was understood to be the word of God, unmediated by human efforts, this kind of critical inquiry was not possible. It had to be seen as essentially a seamless narrative, with only occasional and almost inexplicable lapses and inconsistencies. When the biblical text was understood, however, as having a history parallel to that of classical texts - as a palimpsest of various

343 Vgl. Behler 1985, vor allem S. 126-137.

344 Zitiert nach der Zürcher Bibel 2007. Michael Braun weist darauf hin, dass „fragmentum“, hier mit „Brocken“ übersetzt, in diesem Zusammenhang neunmal bei den Evangelisten auftaucht, wobei er auch die Stellen angibt (vgl. Braun 2002, S. 30).

Braun 2002, S. $30 \mathrm{f}$. 
versions, written over time by actual people, human if inspired - it became possible to examine the textual layers that had accreted through time, to carry out what might be called textual archaeology. ${ }^{346}$

Ein hervorragendes, bereits von Behler und dann von Braun genanntes Beispiel $^{347}$ für die im 18. Jahrhundert erfolgende Verknüpfung der heilsgeschichtlichen Konnotation des Fragmentbegriffs mit der menschlichen Erkenntnis ist der Schluss des Achten Fragments aus Lavaters Physiognomischen Fragmenten (1775), der an den ersten Korintherbrief ${ }^{348}$ angelehnt ist:

Das letzte, was ich diesem Fragmente noch beysetze - sey, wiewohl es in anderer Absicht gesagt worden seyn mag, einem großen Manne [gemeint ist Paulus, MG] nachgestammelt [...] [:] "Jetzt erkennen wir noch Stückweise - und unser Auslegen und Commentiren ist Stückwerk! weg mit diesen Fragmenten, wenn die Vollkommenheit kömmt! Noch ist's Stammlen eines Kindes, was ich schreibe! Kindische Einfälle und Bemühungen werden sie mir einst scheinen, wenn ich Mann seyn werde! Denn jetzt sehn wir die Herrlichkeit des Menschen nur durch ein düster Glas - bald von Angesicht zu Angesicht - Itzt fragmentsweise; dann werd ich's durch und durch erkennen - wie ich - von dem erkennt bin, aus dem und durch den und in dem alle Dinge sind! Ehr' sey ihm in Ewigkeit! Amen!"349

Was jedoch weder Behler noch Braun erwähnen (und auch nicht zitieren), ist, dass abgesehen von jener Verknüpfung Gott am Ende des Achten Fragments dieses Fragment selbst wortwörtlich mit seiner „Ewigkeit“ rahmt und dass mit dem lateinisch-liturgischen Wort für Ende, „Amen“, das Ende des Fragments performativ im Namen Gottes gesetzt wird.

Der Fragmentbegriff hatte also seit dem Mittelalter eine enge Anbindung an das Heilsgeschehen, an das Sammeln und schriftlich dauerhafte Festhalten desselben. Dabei war in dem Begriff schon damals eine autoreflexive Ebene angelegt, die auf die Bibel selbst, welche die ewig gültige und zur Ewigkeit

346 Wanning Harries 1994, S. 38 f.

347 Vgl. Behler 1985, S. 129; Braun 2002, S. 31.

348 „8 Die Liebe kommt niemals zu Fall: Prophetische Gaben - sie werden zunichte werden; Zungenreden - sie werden aufhören; Erkenntnis - sie wird zunichte werden. 9 Denn Stückwerk ist unser Erkennen und Stückwerk unser prophetisches Reden. 1o Wenn aber das Vollkommene kommt, dann wird zunichte werden, was Stückwerk ist. 11 Als ich ein Kind war, redete ich wie ein Kind, dachte wie ein Kind, überlegte wie ein Kind. Als ich aber erwachsen war, hatte ich das Wesen des Kindes abgelegt. 12 Denn jetzt sehen wir alles in einem Spiegel, in rätselhafter Gestalt, dann aber von Angesicht zu Angesicht. Jetzt ist mein Erkennen Stückwerk, dann aber werde ich ganz erkennen, wie ich auch ganz erkannt worden bin. 13 Nun aber bleiben Glaube, Hoffnung, Liebe, diese drei. Die größte unter ihnen aber ist die Liebe." (1. Korinther 13, 8-13; Zürcher Bibel 2007). 
hinführende Botschaft mittels Schriftzeichen bis zum Jüngsten Tag bewahren soll, Bezug nimmt. (Es verwundert also wenig, dass dann das Autoreflexive und das Attribut der Ewigkeit bei den Frühromantikern derart eng mit dem Fragment verknüpft sein werden.) In einem weiteren Schritt lässt sich nun das bislang zu Lessing und zum Fragmentarischen Dargelegte in folgende These überführen:

Im Zuge des 18. Jahrhunderts, in dem die ewige Gültigkeit der Heiligen Schrift und das ewige Leben nach dem Tode infrage gestellt ist, wird der Fragmentbegriff in dem Maße, in dem er nicht mehr in einem heilsgeschichtlichen Sinne auf die Ewigkeit Gottes verweist, für die Ewigkeitsattribuierung der Schrift resp. des schriftlichen (Kunst-)Werkes fruchtbar gemacht. Dabei spielt die Grundoperation Unendliche Aktualisation mit ihren beiden komplementären Unteroperationen Unendliche Lektüre und Unendliches Verstummen eine zentrale Rolle.

Die in der Einführung genannte Beobachtung, im Zuge des 18. Jahrhunderts führe der Verlust der Heiligen Schrift zu einer Heiligung der Schrift als solcher, findet sich hier somit eindrücklich bestätigt. Etwas plakativ ließe sich denn auch sagen: Während etwa bei Lavater 1775 noch Gott „in Ewigkeit“ (gar wortwörtlich) die Fragmente zu einem Ganzen vereint, sollen 25 Jahre später Fragmente die verlorene Ewigkeit wieder einholen. ${ }^{350}$ Oder mit anderen Worten:

Während der ewige, einheitliche Text der Bibel zu einer fragmentarischen Sammlung von Fragmenten wird, sollen die künstlich erschaffenen Fragmente zum ewigen Text werden.

Bestes Beispiel dafür ist die von Eberhard Ostermann festgestellte, vehemente frühromantische Besetzung des Fragments als eines futurischen: ${ }^{351}$

Das Fragmentarische der [frühromantischen, MG] Poesie ist mithin nicht ihr defizitärer Status, sondern die negative Erscheinungsform ihres Ermöglichungsgrundes, der sich als abwesender und dennoch realer manifestiert. Als Fragmente aus der Zukunft sind die Werke der Poesie Emanationen einer schon

$35^{\circ}$ Bereits bei den resp. dem Enden von Lessings Trauerspielen lässt sich beobachten, wie (der christliche) Gott als Garant der Hoffnung auf ein Leben nach dem Tode immer mehr in den Hintergrund tritt: Bezieht sich die sterbende Sara in ihren letzten beiden Äußerungen noch direkt auf Gott (vgl. Lessing, Werke, Bd. 3, S. 524) und Philotas zumindest noch auf "Götter" und die "Göttin des Friedens" (Lessing, Werke, Bd. 4, S. 35), so ist es beim Ende(n) von Emilia Galotti nur noch Odoardo, der sich indirekt an den „Richter von uns allen“ (Lessing, Werke, Bd. 7, S. 371) wendet. Die letzten Worte beider weiblichen Hauptfiguren, „- mein Vater -“ (Lessing, Werke, Bd. 7, S. 370; ebd., Bd. 3, S. 525; vgl. auch II.1.2), lassen sich jedoch in beiden Fällen nicht nur auf den leiblichen Vater, sondern auch auf Gott-Vater beziehen.

$35^{1}$ „Dieses futurische Element des Fragments ist das eigentlich Neue und Revolutionäre [mit Blick auf die heilsgeschichtliche Konnotation der fragmenta in der Bibel vielleicht eher: Evolutionäre, MG] an Schlegels ästhetischer Konzeption“ (Braun 2002, S. 43). 
vorhandenen, aber jenseits der Geschichte liegenden dynamischen Totalität, die mit Namen wie „unendliche Fülle“, „werdende Gottheit“, „das Höchste“ bezeichnet wird, und deren wirkliche Erscheinung sich als Bruchstück indirekt ankündigt. ${ }^{352}$

Und Michael Braun, der vieles des soeben Besprochenen komprimiert und dabei zugleich vorauszuweisen vermag auf die in Kapitel IV zu behandelnde Grundoperation Reflexivität, hält fest:

Die frühromantische Theorie des Fragments meint „weder das Werk als monolithischen Torso noch als Vanitas-Symbol; sie zielt vielmehr auf jenen Kristallisationspunkt der poetischen Reflexion, an dem sich das Unendliche im Endlichen zusammenzieht". [ein Zitat Eberhard Ostermanns, MG] Auf diese Weise entwickelt Schlegel das Fragment zur Erkenntnisform der Dialektik von Endlichkeit und Unendlichkeit, von Diesseits und Jenseits, ohne übrigens den Bezug zum biblischen Begriffsursprung preiszugeben: „Die poetischen Fragmente ganz biblisch - Sprüche “. ${ }^{353}$ Die biblische Gattung der Sprüche wird in den Dienst der Fragmentkunst gestellt. ${ }^{354}$

Nach diesen Betrachtungen zur Geschichte des Fragments sei nun vorerst übergeleitet zur Funktion des Herausgebers, um dann noch einmal auf das Fragmentarische zurückzukommen.

\subsection{Der Herausgeber als Ewigkeitsgarant}

Verknüpft man nun die soeben in Kapitel 3.2 behandelte Ästhetik des Endens mit den grundsätzlichen Überlegungen zum Genie und zum Schöpferischen in Kapitel 3.1 (und IV.3.3), so ist festzuhalten, dass jeder Versuch eines ewigen Schreibens mit dem Tod desjenigen, der schreibt, zwangsläufig in einem Fragment enden muss. Das Unternehmen, ewig zu erschaffen, scheitert an der Sterblichkeit des Menschen, schlimmer noch: würde es in aller Konsequenz verfolgt, so kann es zugleich auch die Hoffnung zunichtemachen, Ewiges zu erschaffen. Dann nämlich, wenn aufgrund des Todes desjenigen, der ewig schreiben wollte (und sich deshalb um nichts anderes kümmern konnte), das Geschriebene weder gedruckt noch sonst wie einer Leserschaft zugänglich gemacht, von den Hinterbliebenen übersehen oder vernichtet wird usw. Und genau hier tritt eine Instanz resp. nach Uwe Wirth eine „Funktion“355 auf den Plan, die nicht zufällig im Verlauf des 18. Jahrhunderts Hochkonjunktur

352 Ostermann 1991, S. 194.

353 Braun zitiert hier Friedrich Schlegel, Philosophische Lehrjahre, S. 72.

354 Braun 2002, S. 44.

355 Vgl. Wirth 2008, vor allem S. 19-43. 
hat: die Funktion Herausgeber. Sie allein besitzt die Macht, dafür zu sorgen, dass ein Werk postum erscheint. ${ }^{356}$ Selbst die Autobiographie des "göttliche[n] Murr[s]“357 (und damit auch er selbst) wäre der Vergessenheit anheimgefallen, wäre da nicht ein Herausgeber gewesen, der sie gedruckt und veröffentlicht hätte. Im Folgenden sei deshalb vor dem Hintergrund von Uwe Wirths Monographie Die Geburt des Autors aus dem Geiste der Herausgeberfiktion dem Beitrag der Funktion Herausgeber resp. der Herausgeberfiktion zur Ewigkeitsattribuierung von Schriftzeichen nachgegangen.

Die Auseinandersetzung mit den Lebens-Ansichten des Katers Murr hat es bereits angedeutet: Nicht nur der reale Herausgeber ist es, der im 18. und frühen 19. Jahrhundert verstärkt auf den Plan tritt, sondern insbesondere auch die Herausgeberfiktion, „die in der Literatur des 18. Jahrhunderts aufgrund der Briefromanpoetik der Regelfall ist“. ${ }^{358}$ Neben der „Rahmungsfunktion“, 359 welche die Herausgeberfiktion innehat, ist sie auch in zunehmendem Maße und mit immer komplexeren Spielarten einer „aufklärerischen Tendenz“ verpflichtet, die den Leser dazu anregen soll, „das Verhältnis von Wahrheit und Fiktion“, 360 aber auch von Rahmen und Gerahmtem kritisch zu reflektieren, insbesondere dann, wenn sich der fiktive Herausgeber als unzuverlässig erweist. ${ }^{361}$ Damit sind mindestens vier Tendenzen des 18. Jahrhunderts eng mit der Herausgeberfiktion verknüpft: die Aufwertung des Fiktiven bei gleichzeitiger, impliziter Aufforderung zur kritischen Hinterfragung (und Rahmung) desselben; das Aufbrechen der aristotelischen Werkeinheit, bestehend aus Anfang, Mitte und Ende, sowie die Rahmung, die das Zur-Mitte-Werden von Anfang und Ende erfordert (vgl. die folgenden Abschnitte); eine sich über die Herausgeberfiktion konstituierende, selbstbewusste Autorschaft, die eng mit dem Geniediskurs verknüpft ist; und - so die hier vertretene und Wirth

356 „Wie der Autor ist der Herausgeber eine Instanz, die das ,Prinzip einer gewissen Einheit des Schreibens' sichert, und zwar auch dann noch, wenn der Autor abwesend gestorben - ist" (Wirth 2008, S. 13).

357 Hoffmann, Werke, Bd. 5, S. 38.

$35^{8}$ Und weiter: „Erst, um 1800` wird die Herausgeberfiktion allmählich von der Fiktion eines auktorialen Erzählers abgelöst - etwa in Goethes Wilhelm Meister, auf dessen Titelblatt die Interferenz von Autorschafts- und Herausgeberschaftskonzepten anschaulich zum Ausdruck kommt, denn es heißt im Untertitel: ,Ein Roman. Herausgegeben von Goethe ${ }^{\text {u“ }}$ (Wirth 2008, S. 13); vgl. auch ebd., S. 143-16o.

359 Ebd., insbesondere S. 16o-164.

36o Ebd., S. 231.

361 Ebd., S. 179. Ein Paradebeispiel für solche Strategien wäre z. B. Wielands Agathon, der darauf abzielt, „den Leser durch eine Modulation seines Deutungsrahmens in einen philosophischen Leser zu verwandeln“ (ebd., S. 23o.); oder eben auch Hoffmanns LebensAnsichten des Katers Murr (vgl. dazu auch Wirth 2008, S. 377-421). 
ergänzende These - die akzentuierte Ewigkeitsattribuierung von Schriftzeichen resp. insbesondere von literarischen Texten. Denn während der reale Herausgeber die Veröffentlichung eines Werkes über den physischen Tod des Autors hinaus sicherzustellen vermag, kann der Autor über die Herausgeberfiktion versuchen, den eigenen Tod zu antizipieren und so für das Überdauern seines Werkes ,vorzusorgen ‘ ${ }^{362}$ Für Letzteres wiederum werden alle hier behandelten Grundoperationen zur Ewigkeitsattribuierung von Schriftzeichen bemüht:

Erstens hat, wie von Uwe Wirth aufgezeigt, die Herausgeberfiktion immer eine grundlegend performative Konstituente (vgl. die Grundoperation Autonome Performative Produktion): Sie setzt mittels einer paradoxalen Operation den Rahmen des Werkes, das sie ,herausgibt' und von dem sie - meist in einem Vorwort, aber zuweilen auch schon auf dem Titelblatt (vgl. die LebensAnsichten des Katers Murr), in Einschüben, in einem Nachwort - spricht: „Mit anderen Worten, die editoriale Tätigkeit ist zum einen die rahmensetzende Entgegensetzung jeder absoluten auktorialen Setzung, zum anderen ist sie der performative und parergonale Rahmen jeder auktorialen Tätigkeit.“363 Die fiktive Herausgeberschaft muss dabei - wenn nicht bloß im Titelblatt genannt - ebenfalls auf irgendeine Weise erzählt und dadurch konstituiert werden. Dies geschieht über einen Paratext, typischerweise ein Vorwort, das aber auch durch Texteinschübe und/oder ein Nachwort ergänzt resp. ersetzt werden kann. Hier kommen die beiden anderen Grundoperationen ins Spiel:

Zweitens bildet bereits die Nennung einer Herausgeberfiktion auf dem Titelblatt ${ }^{364}$ und erst recht die explizite Entfaltung derselben in den weiteren Paratexten, etwa in einem Vorwort, die Grundlage dafür, den Text auf sich selbst und seine Möglichkeitsbedingungen verweisen zu lassen (vgl. die Grundoperation Reflexivität). Dies wiederum kommt insbesondere der romantischen Poetik einer Poesie der Poesie (vgl. Kapitel IV.3.1) zugute resp. steht mit ihr in

362 Dafür spricht auch Wirths These, dass sich Autorschaft wesentlich durch Selbstherausgeberschaft konstituiert (vgl. Wirth 2008, u. a. S. 283). Als Paradebeispiel für ein solches Vorausschreiben bei gleichzeitiger Reflexion desselben mag Jean Pauls KonjekturalBiographie (1799) gelten, deren erste Sätze lauten: „Lieber Otto! Jetzt treibt mich eine Idee durch die Alleen und Gärten, die schon alle Wände meines Kopfes mit Grün und Hesperiden-Fruchtschnüren überzogen hat; - sie soll aber vollends herauswachsen ins Freie mit ihren vollen Zweigen dem Publikum in die Hand. Sieh'! ich will meine Lebensgeschichte, die mir noch bevorsteht, treu in poetischen Episteln aufsetzen. Sollt' ich sie wider Verhoffen nicht erleben: so hab’ ich doch die Komödienprobe, die gestikulierende Lufterscheinung, das Panorama davon gehabt und halb Europa die Beschreibung“ (Jean Paul, Konjekturalbiographie, S. 453; vgl. dazu auch Pfotenhauer 2013, S. 127).

363 Wirth 2008, S. 329.

364 In den Lebens-Ansichten des Katers Murr beispielsweise die Phrase: „Herausgegeben von E. T. A. Hoffmann". 
einer Wechselwirkung, was auch eines der zentralen Ergebnisse von Wirths Untersuchung ist: „In der Romantik weicht die fingierte Herausgeberschaft einer Spielform der Herausgeberfiktion, die der ironischen,Selbstbespiegelung narrativer Rahmungsverfahren dient. “365 Verbindet man nun die Herausgeberfiktion mit der frühromantischen Auseinandersetzung mit Kant und Fichte, so hieße dies weiter,

daß Novalis und Schlegel die ,poesis‘ als Akt begreifen, der zwischen dem Ideal einer ursprünglich-setzenden, auktorialen Tätigkeit und der Realität einer nachträglich-umbildenden, editorialen Tätigkeit oszilliert. Diese editoriale Autorschaft verbindet die Geste absorbierenden Zitierens mit der autoreflexiven Geste des Sich-selbst-Zitierens. ${ }^{366}$

Die Möglichkeit des „Sich-selbst-Zitierens“, die für die Herausgeberfiktion und die daraus entstehende moderne Autorschaft konstitutiv ist, führt den hier verfolgten Gedankengang sodann zu:

Drittens - und mit besonderem Fokus auf die im vorliegenden Kapitel II zur Diskussion stehende Grundoperation Unendliche Aktualisation - gilt für all jene Formen des Paratextes, ja für Paratexte im Allgemeinen, was Wirth mit Verweis auf Derrida und Swift für das Vorwort festgestellt hat: „Der Vorwortakt erweist sich als Collage von immer neuen ersten Seiten [...] Durch die prinzipiell unbegrenzte Möglichkeit der Wiederholbarkeit dieser Geste bringt das Vorwort als aufpfropfende Vor-Schrift einen unentwegten Rahmungsprozess in Gang - und eben hierdurch ist die préface incessante ausgezeichnet."367 Oder anders und wiederum in Anlehnung an Aristoteles' Terminologie ausgedrückt: Das Vorwort, insbesondere wenn es einer Herausgeberfiktion dient, soll verhindern, dass der Anfang zur Mitte wird, führt aber gleichzeitig gerade zu einer Entgrenzung des Anfangs, die mit einem weiteren Vorwort zum Vorwort eingegrenzt werden müsste usw. ad infinitum. Als Paradebeispiel dafür sei an die drei Vorworte (und an die Nachschrift des Herausgebers zum letzten derselben) des ersten Bandes der Lebens-Ansichten des Katers Murr erinnert.

Aus all dem leitet sich wiederum folgende Ergänzung von Wirths Überlegungen (sowie deren Kombination mit der These Andrea Polascheggs, vgl. das Ende von Kapitel II.2.1) ab: Dieser fragt sich zu Beginn seiner Untersuchung, „welche Rolle der fiktive Herausgeber bei der Genese moderner Autorschaft spielt, ja ob der emphatische Autorbegriff der Genieästhetik womöglich nur eine spezifische Transformation der Funktion Herausgeber

365 Wirth 2008, S. 423 f.

366 Ebd., S. 288.

367 Ebd., S. 97 . 
ist “, 368 und beantwortet im weiteren Verlauf seiner Monographie dieses „ob“ mit einem Ja. ${ }^{369}$

Nun zeigt die vorliegende Arbeit, dass einerseits eine zentrale Konstituente des Genies und seiner Werke das Attribut der Ewigkeit ist (vgl. Kapitel IV.3.3) und andererseits die Funktion Herausgeber und insbesondere die Herausgeberfiktion als Garanten ebenjener Ewigkeit auftreten. Die Ewigkeitsattribuierung von Schriftzeichen ist somit eine wesentliche, wenn nicht gar die entscheidende Konstituente sowohl des "fiktive[n] Herausgeber[s]" als auch der "Genese moderner Autorschaft", die umgekehrt wiederum - also in einer selbst potenziell endlosen Operation der Wechselwirkung - zur Ewigkeitsattribuierung von Schriftzeichen beitragen. ${ }^{370}$

Dieser Befund geht zudem einher mit der folgenden Feststellung Uwe Wirths: „Dabei ist die Funktion Herausgeber als Rahmen von Autorschaft in spezifischer Weise auf die allgemeine Iterabilität der Schrift bezogen: ${ }^{371}$ Autorschaft als Recht an den Kopien des eigenen Werks impliziert das Recht, sich selbst zu zitieren“372 - und, so ist nun anzufügen, sich selbst zu verewigen.

\subsection{Zusammenführung der Ergebnisse}

Zum Schluss dieses historisch-kontextualisierenden Kapitels zur Grundoperation Unendliche Aktualisation sei nun das bisher Dargelegte zusammengeführt und dabei in sechs aufeinander aufbauenden Schritten folgende literaturgeschichtliche Beobachtung angestellt:

1. Die bisherige Fragmentforschung ergänzend lässt sich eine Tendenz beobachten, die von Lessings tragischer Ästhetik des Endens ausgeht, welche anstelle eines Moments des Schreckens eine das aristotelische Ende zur Mitte transformierende Dauer des Mitleidens schafft. Jean Paul mag dabei als Extrembeispiel dafür gelten, wie Lessings Ästhetik des Endens - von der Orientierung an der Linie Cervantes - Sterne unterstützt und deren Prinzip der Digression ${ }^{373}$ zugleich implizit legitimierend - auf den Roman übertragen

368 Ebd., S. 13 .

369 Vgl. ebd., u. a. S. 283.

370 In diesem Zusammenhang wäre es äußerst spannend, sich umfassender auch mit älteren Formen der Herausgeber- und Autorfiktion auseinanderzusetzen; z. B. auch unter Einbezug von Texten aus dem alten Ägypten, wo etwa im Papyrus Chester Beatty (13. Jahrhundert v. Chr.) fiktive Assertoren inklusive Rahmenerzählung vorkommen, und zwar in Texten, in denen es explizit um Verewigung geht (vgl. J. Assmann 1991, S. 176, Anm. 6).

371 Zur Iterabilität im Zusammenhang mit den Operationen zur Ewigkeitsattribuierung von Schriftzeichen vgl. Kapitel 1.1 des Schlussteils.

372 Wirth 2008, S. 114.

373 So schreibt Helmut Pfotenhauer zur Digression bei Jean Paul: „Denn dieser Autor hasst oder verachtet nachgerade das unaufhörlich Voranschreitende der Lebenszeit, weil dies 
wurde. Und wie schon in Lessings Trauerspielen ist auch bei Jean Paul das Enden ein Anschreiben gegen das Ende und den Schrecken des Todes.

(Auch der eingangs des Kapitels zur Miss Sara Sampson angemerkte Befund Cornelia Mönchs breit angelegter Studie zum bürgerlichen Trauerspiel des 18. Jahrhunderts, „[d]as Lessing'sche Modell des bürgerlichen Trauerspiels spielt [innerhalb der Gattung der Trauerspiele, MG] eine untergeordnete, zeitlich begrenzte Rolle“, ${ }^{374}$ ließe sich von hier aus kritisch weiterverfolgen. Es wäre dabei zu fragen, ob die Stücke, die nach der sich in der Gattung des Trauerspiels durchsetzenden Maxime der "poetischen Gerechtigkeit“ gebildet sind und die „Auflösung des Mitleids mit der verfolgten Tugend in einen gerechten Befriedigungsaffekt ${ }^{4375}$ vornehmen, Lessings Ästhetik des Endens übernehmen oder nicht. Und ob, falls Letzteres zuträfe, das „eklatante ,Versagen der ,Miss Sara Sampson' als Modellvorgabe “376 für die Gattung des Trauerspiels nicht einhergeht mit einer - so die hier vertretene These - Übertragung ebendieser Modellvorgabe von der Dramatik auf die Epik resp. den Roman. Einer Modellvorgabe, die in dieser Hinsicht sowohl in ihrer Ästhetik des Endens als auch in ihren Auswirkungen auf die Ästhetik des Fragmentarischen von literaturgeschichtlich herausragender Bedeutung wäre.)

2. Parallel zu dem unter 1 . Genannten ist eine zweite Tendenz zu beobachten, nämlich ein immer stärkeres Aufkommen der,Form` des Fragments. Sie scheint im deutschsprachigen Raum, gemäß der bisherigen Forschung, in der zweiten Hälfte der 175oer-Jahre von den künstlichen Fragmenten von Johann Georg Hamann ${ }^{377}$ und Herder und dann später vor allem von Lessings Reimarus-Fragmenten ${ }^{378}$ ausgegangen zu sein und wurde in den folgenden Jahrzehnten von zahlreichen Autoren aufgegriffen - darunter dann auch

das Leben ja letzten Endes in das Zeichen des physischen Verfalls, des Todes, stellt. Aufgabe der Dichtung ist es für Jean Paul, dagegen anzuschreiben, das heißt, das Kontinuum erzählerisch zu unterbrechen, wo immer es nur geht“ (Pfotenhauer 2013, S. 103).

374 Mönch 1993, S. 35 o.

375 Ebd., S. 341.

376 Ebd.

377 Hamanns erstes publiziertes Werk, Beylage zu Dangueil, enthält bereits eine „protoSternean nonchalance" und das Einfügen eines fragmentarischen Blattes (vgl. Wanning Harries 1994, S. 36). Besonders bemerkenswert ist für die hier vertretene Wirkmächtigkeit von Lessings Ästhetik des Endens aber, dass es 1756 und damit ein Jahr nach Lessings Miss Sara Sampson erschien.

378 Vgl. Braun 2002, S. 35 f.; und vor allem Wanning Harries 1994, S. 34-38. 
Goethe, ${ }^{379}$ Jean Paul und die Frühromantiker. ${ }^{380}$ Letztere sind zudem weiter beeinflusst durch den aphoristisch-fragmentarischen Stil Chamforts und von Goethes und Schillers Xenien.

3. Die Frühromantiker, allen voran Friedrich Schlegel, erheben das Fragmentarische sodann zu einem zentralen Prinzip ihrer Poetik resp. der romantischen Ironie. Friedrich Schlegel nimmt in seinen theoretischen Überlegungen ausgerechnet explizit Bezug auf den vermeintlich aphoristischfragmentarischen Stil Lessings, ${ }^{381}$ der aber letztlich eine bloße Zuschreibung seitens Friedrich Schlegels war. ${ }^{382}$ Und dennoch - so die hier vertretene These ist Friedrich Schlegels Verweis auf Lessings Einfluss auf die frühromantische Fragmentästhetik richtig, bloß ist dieser Einfluss weniger in Lessings Stil begründet als vielmehr in seiner Transformation der Tragödie und der damit verbundenen Ästhetik des Endens, die entscheidend daran beteiligt ist, die aristotelische Einheit eines Werkes aufzulösen. Denn Lessing - dessen Miss Sara Sampson noch vor Hamanns erstem publiziertem Werk erscheint ${ }^{383}$ - trägt damit wesentlich zum "fragmentarischen Bewusstsein des achtzehnten Jahrhunderts" bei, aus dem dann bei „Friedrich Schlegel und Novalis die Form oder Gattung des Fragments erzeugt wurde". 384

Der Einfluss von Lessings Ästhetik des Endens ${ }^{385}$ vermag dabei auch zu erklären helfen, weshalb sich eine Fragmentästhetik in der zweiten Hälfte des 18. Jahrhunderts gerade „in Deutschland quer zur europäischen Tradition des Fragments herauszubilden beginnt ${ }^{\prime,}, 386$ und dabei aufzuzeigen, dass wohl auch

379 Vgl. die nicht mehr geschlossene Rahmenhandlung am Ende der Unterhaltungen deutscher Ausgewanderten - dazu auch Pfotenhauer 2013, S. 148 f.

380 Vgl. Behler 1985, S. 129 f.; Wanning Harries 1994, S. 34-37; Braun 2002, S. 35 f. und 38 f.; Weiß 2015, u. a. S. 15-16; vgl. ergänzend dazu auch Gesine Lenore Schiewers Arbeit zu den historischen Bezügen zwischen Lamberts Semiotik, Herder, Jean Paul und Novalis; Schiewer 1996.

381 Vgl. u. a. Weiß 2015, S. 21-128, insbesondere S. 76-83.

382 Vgl. dazu Weiß: „Da Schlegel in den Fragmenten keine ,Kunstwerke der Darstellung, sondern bloß Mittel der Anregung' sieht, kommt es ihm vorrangig auf die Wirksamkeit dieser Anregung und nicht auf die Erfüllung bestimmter formaler und inhaltlicher Kriterien an. So kann er selbst Lessing zum vorbildlichen Fragmentisten erklären, obwohl dieser weder in Aphorismen noch über die für die Frühromantiker einschlägigen Themen geschrieben hat" (ebd., S. 79 f.). Und Behler: „Was den fragmentarischen Charakter Lessings für Schlegel ausmachte, lag wiederum nicht so sehr in der Form seiner Schriften, als in der Art seines Denkens" (Behler 1985, S. 130).

383 Vgl. Punkt 2 und die dazugehörigen Fußnoten; resp. Wanning Harries 1994, S. 36.

384 Behler 1985, S. 141.

385 Dazu, dass Lessings Miss Sara Sampson noch ein Jahr vor Hamanns erstem publiziertem Werk erschienen ist, vgl. Punkt 2 und die dazugehörigen Fußnoten.

386 Behler 1985, S. 131. 
im Falle des Fragments - indirekt über Lessings Trauerspiel - die Auseinandersetzung mit ${ }^{387}$ und die Abgrenzungsbestrebungen von der zeitgenössischen französischen Literatur eine zentrale Rolle gespielt haben.

4. Nun ließe sich aber einwenden, weshalb ausgerechnet Lessings Ästhetik des Endens, die sich der Operation Unendliche Lektüre bediene, wesentlich an einer Ästhetik beteiligt sein soll, der im Fragment die radikalst mögliche Ausprägung der Operation Unendliches Verstummen zugrunde liege. Die Antwort darauf ist: Aufgrund der Komplementarität der beiden Operationen führt die radikalste Ausprägung der Operation Unendliche Lektüre zwangsläufig in das Fragmentarische. (Dasselbe gilt umgekehrt: Die bei Brentanos Der Spinnerin Nachtlied, den mittelhochdeutschen Tageliedern und deren Adaptionen ${ }^{388}$ sowie in Hölderlins Ermunterung beobachtete ästhetische ,Nutzbarmachung‘ der semiotischen und klanglichen Flüchtigkeit von Schriftzeichen würde in ihrer radikalsten Form etwa einem fragmentarischen Gedicht entsprechen, das mitten in der Strophe abbricht.) Oder in anderen Worten: die radikalste Umsetzung einer Ästhetik, die das Ende immer weiter auszudehnen sucht, ist der Verzicht auf ein Ende - und letztlich auch auf einen Anfang. Ein Höhepunkt dieser Entwicklung findet sich in E. T. A. Hoffmanns Lebens-Ansichten des Katers Murr: Nicht nur das Ende wird in diesem Doppelroman zur Mitte, sondern auch der Anfang, und beide gehen sowohl auf der Mikro- als auch auf der Makroebene ineinander über, womit Aristoteles' Einheitsbegriff bestehend aus Anfang, Mitte und Ende endgültig abgelöst wird.

5. Eine Ästhetik des Fragments sucht, gerade in dessen potenziell unendlich oft erfolgendem Abbrechen, so weit wie möglich einen Prozess des unendlichen Weiterlesens (und Weiterschreibens) auszulösen und damit eine Immanenz der Transzendenz und eine Transzendenz der Immanenz zu erreichen. Das Fragmentarische, so ließe sich sagen, ist somit die radikale Ausprägung zweier Operationen zur Ewigkeitsattribuierung von Schriftzeichen (der Operation Unendliche Lektüre und der Operation Unendliches Verstummen), die gerade aufgrund ihrer Radikalität zugleich eine die fragmentarischen Texte weiterführende, potenziell unendliche Bewegung lostritt. Oder anders ausgedrückt:

Das ausgehende 18. Jahrhundert findet im Fragmentarischen gewissermaßen die bestmögliche Kombination der Unteroperationen Unendliches Verstummen und Unendliche Lektüre, was zum wirksamst möglichen Auftreten der Grundoperation Unendliche Aktualisation führt.

387 Vgl. u. a. Weiß 2015, S. 21-62.

388 Vgl. dazu auch Wolf 2011. 
6. Die ebenfalls in der zweiten Hälfte des 18. Jahrhunderts sich verstärkt vollziehende Genese der modernen Autorschaft steht dabei in enger Verbindung mit der aufkommenden Ästhetik des Fragmentarischen und der Ewigkeitsattribuierung von Schriftzeichen, sucht sie doch Fragmentarisches zu rahmen und dadurch dessen Überlieferung zu sichern - und ist dabei zugleich selbst Teil einer potenziell endlosen Wechselwirkung. 
Markus Gut - 978-3-8467-6517-3

Downloaded from Fink.de@4/26/2023 07:48:17AM via free access 


\section{Grundoperation Autonome Performative Produktion}

Das vorangegangene Großkapitel hat sich ausführlich mit Versuchen auseinandergesetzt, die auf eine unendliche Aktualisation von Schriftzeichen abzielen. Dieses Großkapitel hingegen fokussiert ganz auf Versuche, über die im Zuge einer Lektüre erfolgende performative Produktion dessen, wovon die Rede ist, den betreffenden Textstellen Autonomie gegenüber zeitlichen Veränderungen ihrer intelligiblen Seite ${ }^{1}$ sowie ihres Kontextes zu verleihen. Im Gegensatz zu den beiden anderen Großkapiteln des Hauptteils wird hier jedoch nur eine und nicht zwei Unteroperationen behandelt. Es könnte sich deshalb die berechtigte Frage aufdrängen, weshalb denn überhaupt eine Unterteilung in eine Grundoperation Autonome Performative Produktion und eine Unteroperation Poetische Performativität erfolgt. Hinter dieser Unterteilung steht schlicht das Bestreben, die in der vorliegenden Monographie erarbeitete Typologie der Operationen zur Ewigkeitsattribuierung von Schriftzeichen derart zu strukturieren, dass sie für zukünftige Ergänzungen offenbleibt. Bereits in der Einführung wurde klargestellt, dass die hier vorgelegte Typologie keinen Anspruch auf abschließende Vollständigkeit erheben kann und sich auf die wichtigsten Operationen beschränkt. So deutet denn auch einiges darauf hin, dass nicht nur die Unteroperation Poetische Performativität darauf abzielt, der betreffenden Textstelle performativ eine möglichst hohe Autonomie zu verleihen. Erste Hypothesen zu möglichen weiteren, aber selteneren Unteroperationen der Grundoperation Autonome Performative Produktion werden denn auch im Kapitel 2.1 des Schlussteils genannt.

\section{Unteroperation Poetische Performativität}

Uwe Wirth schreibt auf der ersten Seite der Einführung des von ihm herausgegebenen Sammelbandes Performanz, zwischen Sprachphilosophie und Kulturwissenschaften:

1 Etwa durch Bedeutungswandel; vgl. das erste Kapitel der Einführung. 
Auf die Frage, was der Begriff Performanz eigentlich bedeutet, geben Sprachphilosophen und Linguisten einerseits, Theaterwissenschaftler, Rezeptionsästhetiker, Ethnologen oder Medienwissenschaftler andererseits sehr verschiedene Antworten. Performanz kann sich ebenso auf das ernsthafte Ausführen von Sprechakten, das inszenierende Auffïhren von theatralen oder rituellen Handlungen, das materiale Verkörpern von Botschaften im "Akt des Schreibens“ oder auf die Konstitution von Imaginationen im „Akt des Lesens“ beziehen. ${ }^{2}$

Es kann und soll hier nicht darum gehen, diese Diskussion flächendeckend aufzuarbeiten, zumal dies bereits Wirth mit dem soeben zitierten Sammelband überblickshaft angestrebt hat. Was bei der Auseinandersetzung mit bestehenden Modellen zur Performativität jedoch auffällt, ist - das hat auch ein dazu an der Universität Zürich abgehaltener Workshop mit Erika FischerLichte gezeigt $-{ }^{3}$ dass es erstaunlicherweise bislang kein etabliertes Modell zu geben scheint, das Textstellen, die kein performatives Verb beinhalten, aber dennoch in gewisser Weise performativ sind, präzise begrifflich zu fassen vermag. ${ }^{4}$ Um ein Beispiel für eine solche Textstelle zu nennen, sei noch einmal an die ersten zwei Verse von Hölderlins Ode Ermunterung erinnert:

Echo des Himmels! heiliges Herz! warum,

Warum verstummst du unter den Lebenden, ${ }^{5}$

Auf semantischer Ebene verweist das Wort „Echo“ auf ein Echo, während im Zuge der Lektüre der gesamten beiden Verse zugleich auf klanglicher, aber auch grammatikalisch-syntaktischer Ebene mittels Wiederholungsfiguren ein Echoeffekt hergestellt wird (vgl. dazu das Kapitel zur Ermunterung).

Ein präziser begrifflicher Umgang mit derartigen Textstellen ist für die Auseinandersetzung mit Performativität als Operation zur Ewigkeitsattribuierung von Schriftzeichen von zentraler Bedeutung. Im Folgenden werden deshalb auf der Basis von John Langshaw Austin und Roman Jakobson zwei Definitionen vorgenommen: 1) Eine Definition von Performativität im engeren Sinne des frühen Austin, die aber nicht wie bei diesem an performative

2 Wirth 2002, Einführung, S. 9.

3 „Performanz/Performativität“, Workshop mit Erika Fischer-Lichte, 9. März 2016 an der Universität Zürich, organisiert von Johannes Hunziker und dem Doktoratsprogramm "Deutsche und Nordische Philologie“.

4 Am nächsten dahin kommt wohl David Martyn, der sich ausführlich mit solchen Textstellen befasst und das Adjektiv performativ für deren Beschreibung verwendet - und zwar in einem engeren Sinne nach Austin, ohne sich aber mit der Entwicklung des Begriffes performative bei Austin und den daraus resultierenden Problemen für eine uneingeschränkte Übernahme dieses Begriffes auseinanderzusetzen (vgl. Martyn 1992).

5 Hölderlin, Ermunterung, S. 768. 
Verben in der ersten Person Singular Indikativ Präsens gebunden ist. Dass damit ein weiterer Begriff, nämlich der der poetischen Performativität eingeführt wird, ist angesichts des heuristischen Gewinns in Kauf zu nehmen. 2) Eine Definition, inwiefern diese Form von Performativität als Operation zur Ewigkeitsattribuierung von Schriftzeichen zu beobachten ist.

\section{1) Poetische Performativität}

Vergleicht man Austins ,Entdeckung' des performative ${ }^{6}$ mit performativen Textstellen wie den oben zitierten Versen Hölderlins, so sind mindestens drei Unterschiede festzumachen:

a) Der erste ist im Grunde weniger ein Unterschied des Gegenstandes als vielmehr eine Unschärfe oder Unvollständigkeit in Austins Definition, die wohl nicht unentscheidend dazu beigetragen hat, dass Austin sich im Falle der Performativität auf Verben fokussierte. Ein Fokus, in dessen Folge bis heute Textstellen, wie sie hier von Interesse sind, definitorisch vernachlässigt worden sind. Austin definiert den performative in seiner "Ersten Vorlesung“ nämlich wie folgt:

[A]ll will have, as it happens, humdrum verbs in the first person singular present indicative active. Utterances can be found, satisfying these conditions, yet such that

A. they do not, describe' or ,report' or constate anything at all, are not ,true or false'; and

B. the uttering of the sentences is, or is part of, the doing of an action, which again would not normally be described as, or as ,just', saying something. ${ }^{7}$

Zu Beginn seiner „Zweiten Vorlesung“ fasst er dies wie folgt zusammen, bevor er sich den Umständen widmet, in denen performative Sprechakte misslingen oder missbraucht werden:

We were to consider, you will remember, some cases and senses (only some, Heaven help us!) in which to say something is to do something; or in which by saying or in saying something we are doing something. ${ }^{8}$

Auch wenn Austin dies in Abgrenzung zu den konstativen resp. beschreibenden Äußerungen ${ }^{9}$ absichtlich etwas pointiert formuliert, so ist ihm beim ersten Teil von Punkt A seiner Definition nicht zuzustimmen: performatives beschreiben

6 Vgl. Austin 1962, S. 6.

7 Ebd., S. 5 .

8 Ebd., S. 12.

9 Vgl. ebd., S. 4. 
durchaus etwas, nämlich das, was sie vollziehen - und sie vollziehen das, was sie beschreiben. Oder in Uwe Wirths Worten:

Die explizit performativen Äußerungen der Sprechakttheorie [Austins, MG] sind dabei in zweierlei Hinsicht selbstreferentiell: erstens liefert das performative Verb eine Selbstbeschreibung dessen, was es tun wird; zweitens ist der Akt des Äußerns dieses performativen Verbs bereits selbst Teil der Handlung, welche durch das performative Verb beschrieben wird. Die Tatsache, dass das Verb geäußert wurde, dient also der Initialisierung eines Handlungsprozesses, bei dem die geäußerte Handlungsankündigung bereits Teil des Handlungsvollzuges ist. ${ }^{10}$

Wirth sucht damit Austins Definition zusammenzufassen - nur dass diese Zusammenfassung, wie soeben aufgezeigt wurde, eben gerade nicht exakt Austins Definition, sondern einer kleinen, aber entscheidenden Korrektur derselben entspricht (mehr dazu weiter unten).

b) Eine Textstelle wie die ersten Verse der Ode Ermunterung ist stärker an eine sprachliche Sequenz gebunden als die performativen Verben bei Austin. Auch ein Versprechen besteht zwar in der Regel bis zu einem gewissen Grad aus einer ganzen Sequenz, man denke z. B. an den Satz „Ich verspreche dir, dass ich zurückkehren werde“. Der Nebensatz ist hier aber nicht selbst performativ, sondern bloß eine Beschreibung dessen, was versprochen wird; und das „dir“ beschreibt lediglich den Adressaten. Die Performativität dieser Aussage steckt, streng genommen, letztlich also doch in der Minisequenz "Ich verspreche“. Diese Sequenz wiederum ließe sich - dafür ist ,versprechen freilich ein Extrembeispiel - bei entsprechendem Kontext gar ganz auf das performative Verb reduzieren (etwa in folgendem Dialog: „Versprichst du es mir?“ / "Versprochen.“).

c) Eine Textstelle wie die ersten Verse der Ode Ermunterung ist nicht an eine erste Person Singular und einen einmaligen mündlichen oder schriftlichen Akt gebunden. Wenn man ein schriftliches Versprechen einer anderen Person liest, so stellt man als Leser oder Leserin jenes Versprechen nicht her, indem man es liest, sondern man aktualisiert bloß die Mitteilung, die nun nur noch darauf verweist, dass einem der Sender mittels seines Schreibaktes performativ etwas versprochen hat. Dies ist auch der Grund, weshalb Austin Poesie oder eine Theateraufführung - und letztlich jeden Sprachgebrauch innerhalb einer Fiktion - von seinem performative ausschließt." (Dieser Unterschied wird

10 Wirth 2002, Einführung, S. 11.

11 Vgl. Austin 1962, S. 22; dass aber in der Fantasyliteratur (poetische) Performativität ausgerechnet als ästhetisches Mittel zur Beglaubigung einer fiktiven Welt resp. einer Welt zweiter Ordnung eingesetzt werden kann, hat der Verfasser andernorts aufgezeigt (vgl. Gut 2015). 
dann vor allem relevant, wenn Performativität der Ewigkeitsattribuierung von Schriftzeichen dient.)

Nach der Benennung dieser drei entscheidenden Unterschiede sei nun zuerst eine allgemeine, konsequent semiologische Definition von Performativität vorgeschlagen, die zwar im Geiste Austins früher Definition entsprechen mag, im buchstäblichen Sinne aber von ihr abweicht. Danach folgt die Suche nach einer Definition für die Performativität, wie sie z. B. jene Verse Hölderlins aufweisen.

Oben wurde unter Unterschied a) festgestellt, dass performatives durchaus etwas beschreiben, nämlich das, was sie vollziehen. Lässt man zunächst einmal außersprachliche Faktoren außen vor, so ergibt sich als semiotische Minimalbedingung folgende, allgemeine Definition: Die Qualität der Performativität ist einer Äußerung dann inhärent, wenn diese Äußerung:

1. explizit auf etwas verweist,

2. das herstellt, worauf sie verweist.

Dazu sei ein Beispiel genannt, und zwar absichtlich zunächst mit einem performativen Verb: Nach dem Ausklammern des Begleitkontextes - wie z. B. der vorausgegangenen Frage, etwaiger nonverbaler Gesten usw. - ergibt sich für eine Äußerung wie „Versprochen." folgende Minimalbedingung, damit für sie die Qualität der Performativität gegeben ist:

1. Die Äußerung „Versprochen.“ verweist explizit auf etwas.

- Das tut sie, indem sie explizit darauf verweist, dass ein Versprechen gegeben wird.

2. Im Zuge der Äußerung „Versprochen.“ wird das hergestellt, worauf sie verweist.

- Auch dies ist der Fall, da im Zuge des Verweises darauf, dass ein Versprechen gegeben wird, zugleich dieses Versprechen gegeben wird.

Hierbei wird Folgendes ersichtlich:

Jeder performativen Äußerung ist nicht bloß ein beschreibender resp. konstativer Teil inhärent, sondern dieser ist immer zugleich auch die Möglichkeitsbedingung für die Konstitution einer performativen Äußerung, da in einer solchen rein konstative und rein ${ }^{12}$ performative Äußerungen chiastisch miteinanderverschränkt sind.

Damit wird auch deutlich, dass ausgerechnet durch die Ausklammerung des beschreibenden resp. konstativen Teils des performative sich der Fokus von Austins Untersuchung immer stärker auf die vom Kontext abhängigen, oft auch außersprachlichen Gelingensbedingungen performativer Sprechakte

12 Eine ,rein performative Äußerung kann demnach gar nicht existieren, das Adjektiv ,rein` dient hier also bloß einer heuristischen, veranschaulichenden binären Opposition. 
verschiebt, was bei ihm zu einer Ausdehnung und letztendlichen Aufgabe von Performativität als einer eigenen Kategorie führt. Dadurch erbringt Austin im Zuge seiner Argumentation zwar schließlich die beachtliche Leistung einer allgemeinen Sprechakttheorie - aber um den Preis, den Spezialfall der Performativität nicht auch auf eine allgemeinere Weise definiert zu haben, die einerseits seine frühe, enge Definition beibehält, aber andererseits vielleicht auch breiter und über performative Verben hinaus anwendbar gewesen wäre. Oder anders ausgedrückt: Auch die oben formulierte Definition gibt zwar wie der spätere Austin die strikte binäre Trennung von konstativen und performativen Äußerungen auf, aber genau mit der umgekehrten Überlegung. Denn behält man eine enge, letztlich auch von Austin zu Beginn zumindest angedachte Definition bei, so ist nicht jede konstative Äußerung auch performativ, sondern jede performative Äußerung auch konstativ. ${ }^{13}$

Damit stellt sich nun die Frage, wie man, ausgehend von der soeben formulierten allgemeineren Definition von Performativität, auch die Performativität jener Hölderlin-Verse beschreiben und sie zugleich in Bezug zur Performativität eines performativen Verbes setzen könnte. Nachdem die oben erbrachte Definition hauptsächlich aus der bei Austin festgestellten definitorischen Unschärfe a) heraus entwickelt wurde, ist es deshalb an der Zeit, vor allem Unterschied b) herbeizuziehen: Dieser Unterschied liegt in der Größe der Sequenz, die für die Konstitution von Performativität notwendig ist. Bislang ist klar geworden, dass performative Äußerungen auch eine zentrale konstative und damit semantische Konstituente besitzen. Wird nun zusätzlich die Ebene der Sequenz hinzugezogen, so ist also letztlich die Frage die, wie das spezifische Verhältnis zwischen den Ebenen des Paradigmas und des Syntagmas einerseits und der Ebene (resp. hier wohl unmissverständlicher: Qualität) der Performativität andererseits geartet ist. Und hier kommt, nun wenig verwunderlich, die poetische Funktion von Roman Jakobson ins Spiel, die da lautet:

Die poetische Funktion projiziert das Prinzip der Äquivalenz von der Achse der Selektion auf die Achse der Kombination. ${ }^{14}$

13 Damit wird hier eine von Martyn abweichende Position eingenommen, der (unter Berufung auf Derrida und de Man) vertritt, dass eine konstative und eine performative Lektüre nie gleichzeitig zu haben sind (vgl. Martyn 1992, S. 671). Dies mag zwar theoretisch zutreffend sein, dennoch ist mindestens im Falle der ,poetischen Performativität ${ }^{\prime}$ und wohl selbst für performative Verben die konstative Äußerung resp. Lektüre Möglichkeitsbedingung und entscheidende Konstituente der performativen Äußerung resp. Lektüre. 
Gegen die oben aufgestellte allgemeinere Definition von Performativität könnte man vielleicht auf den ersten Blick einwenden, sie sei letztlich nichts anderes als eine Umformulierung der poetischen Funktion Roman Jakobsons. Ein solcher Einwand wäre ungerechtfertigt, aber er mag die Lösung des hier vorliegenden definitorischen Problems veranschaulichen: Die poetische Funktion Jakobsons zielt bloß auf die Anordnung des Syntagmas nach paradigmatischen Prinzipien ${ }^{15}$ - und nicht auch auf den umgekehrten Fall. Ein direktes Zusammenspiel von Paradigma und Syntagma, von Inhalt und Form ist für Jakobsons grundlegende Definition weder zwingend noch konstitutiv. ${ }^{16}$ Es geht um eine Übertragung des strukturierenden Prinzips von der einen Ebene auf die andere, nicht um eine direkte Relation zwischen den beiden Ebenen. Die in der poetischen Funktion enthaltene Operation vollzieht sich also nur in eine Richtung: von der paradigmatischen Ebene hin zur syntagmatischen.

Damit ein Syntagma aber nicht nur nach der poetischen Funktion konstituiert ist, sondern zusätzlich auch die Qualität der Performativität aufweist, muss die Projektion des Prinzips der Äquivalenz zwischen den beiden Achsen reziprok sein.

Im Falle des hier verwendeten Beispiels heißt dies: Eine Äußerung über ein Echo, die in Versen getätigt wird, ist nicht per se performativ; sie ist es erst dann, wenn die Anordnung des Syntagmas auch ein Äquivalenzverhältnis zur semantischen Auswahl auf der Ebene des Paradigmas aufweist. ${ }^{17}$ Hier geschieht dies, indem die syntagmatisch echohaft angeordneten Worte in ein Äquivalenzverhältnis zur Semantik mindestens eines paradigmatisch selektierten Wortes, in diesem Fall „Echo“, treten. Diese Form der Performativität sei deshalb poetische Performativität genannt. ${ }^{18}$ Beruht das Äquivalenzverhältnis hingegen nicht auf Ähnlichkeit/Similarität, sondern auf Abweichung/

15 „Die Äquivalenz wird zum konstitutiven Verfahren der Sequenz erhoben“ (ebd., S. 94).

16 Dies wird beispielsweise besonders deutlich an den langen Ausführungen zum Vers, die unmittelbar auf die Definition der poetischen Funktion folgen (vgl. ebd., S. 95-106).

17 Die Reziprozität beschränkt sich in dieser Gegenrichtung also auf die semantische Ebene der aus einem Paradigma ausgewählten Wörter und nicht auf das Paradigma im Allgemeinen. Sie ist deshalb, ganz präzise betrachtet, letztlich keine Reziprozität im engsten Sinne. Dieser Makel ist jedoch der verkraftbare Preis für eine Definition, die zwei bestehende Modelle miteinander zu kombinieren, diese zu ergänzen und damit auf verwirrende begriffliche Neuschöpfungen so weit wie nur möglich zu verzichten sucht.

18 Bemerkenswerterweise hat bereits Wirth den Begriff „poetisches Performativ“ verwendet, jedoch nicht auf Basis einer Kombination von Austin und Jakobson, sondern aus der Auseinandersetzung mit dem 116. Athenäumsfragment heraus: „Die Folge dieser ,schönen Selbstbespiegelung‘ [der im 116. Athenäumsfragment ,vorgeführten‘ Transzendentalpoesie, MG] ist, dass ,das Gesagte und der Akt des Sagens selbst‘ zugleich präsentiert werden. Genau das geschieht im Athenäumsfragment 116: Das Programm der Universalpoesie wird durch ein poetisches Performativ dargestellt, das auf der Ebene der Verkörperung vorführt, was auf der semantischen Ebene gesagt wird“ (Wirth 2008, S. 294). 
Deviation, so wäre ein - wiederum in seiner Stärke und Reichweite graduell zu bemessender - poetisch-performativer Selbstwiderspruch gegeben.

Wie bei Jakobsons poetischer Funktion sei hier sogleich mit aller Deutlichkeit festgehalten, dass sich die poetische Performativität nicht allein auf sogenannte Poesie bezieht, ${ }^{19}$ sondern eine qualitative ${ }^{20}$ Eigenschaft von Äußerungen ist, die, unterschiedlich stark ausgeprägt, grundsätzlich in allen Formen sprachlicher Äußerungen ${ }^{21}$ vorkommen kann. Die Eigenschaft der Performativität ist somit, wie die der Poetizität, keine absolute, sondern eine graduell-qualitative. Am Beispiel von Hölderlins Versen bedeutet das: Würde das Wort „Echo“ in einer Sequenz vorkommen, die aus Versen mit allein sich wiederholendem Metrum bestehen würde, wäre die Performativität schwächer, als wenn etwa auch über die Wortwiederholung „warum, / Warum“ ein Echoeffekt hergestellt wird, der selbst bei Unkenntnis der deutschen Sprache und des lateinischen Alphabets auch noch graphisch wahrnehmbar ist. Und die Performativität eines performativen Verbes ist wiederum stärker als die jener Hölderlin-Verse, da das Verb in geringerem Maße (und im Falle etwa des oben angeführten Beispiels „Versprochen." gar nicht) an eine Sequenz von weiteren Wörtern gebunden ist, um das zu vollziehen, worauf es verweist.

Zusammengefasst führt dies alles zu folgender Definition der poetischen Performativität:

Eine sprachliche Äußerung weist dann poetische Performativität auf, wenn das Prinzip der Äquivalenz von der Achse der Selektion nicht nur auf die Achse der Kombination projiziert wird, sondern die semantische Ebene des Paradigmas zugleich auch ein Äquivalenzverhältnis mit der Anordnung des Syntagmas eingeht. Entspricht die derart reziproke Äquivalenz einem Similaritätsverhältnis, so ist die Äußerung (poetisch-)performativ; entspricht sie einem Deviationsverhältnis, so vollzieht die Äußerung einen (poetisch-)performativen Selbstwiderspruch.

Die poetische Performativität ist eine qualitativ-graduell zu bestimmende Eigenschaft einer sprachlichen Äußerung. In einem semiotischen Sinne heißt das für entsprechende Äußerungen:Je kürzer das Syntagma, desto stärker, aber von der syntagmatischen Reichweite begrenzter ist die Performativität; je länger aber das Syntagma, desto schwächer, aber von der syntagmatischen Reichweite weitreichender ist die Performativität. (Hierbei wird nun auch ersichtlich, dass die von Austin entdeckten performativen Verben nicht den Normalfall performativer Äußerungen ausmachen, sondern im Gegenteil den Ausnahmefall von

\footnotetext{
19 Vgl. Jakobson 2016, u. a. S. 95.

20 Qualitativ nicht im Sinne von ,besser', sondern in Opposition zu ,quantitativ‘.

21 Und letztlich wohl auch in allen zeichenhaften Äußerungen.
} 
maximaler performativer Stärke ohne reziprokes Äquivalenzverhältnis zwischen Syntagma und Paradigma bilden.) $)^{22}$

2) Poetische Performativität als Operation zur Ewigkeitsattribuierung von Schriftzeichen

Wenngleich die Definition der poetischen Performativität in einem allgemeinen Sinne notwendig war und der Verfasser diese auch als einen linguistischen und literaturwissenschaftlichen Gewinn über die vorliegende Untersuchung hinaus betrachtet, so ist hier noch einmal dezidiert zu betonen: Wie schon bei der Autoreflexivität und Poetologie in Kapitel IV steht für diese Arbeit poetische Performativität nur dort im Fokus, wo sie in besonderem Maße als Operation zur Ewigkeitsattribuierung von Schriftzeichen zu beobachten ist (um sie jeweils als solche spezifische Operation zu kennzeichnen, werden in diesen Fällen jeweils beide Begriffsteile grossgeschrieben). Deshalb seien hier auch zur Poetischen Performativität als derart zu beobachtende Operation noch einige präzisierende Überlegungen angestellt, wiederum im Vergleich mit dem Extremfall des performative/der performativen Verben des frühen Austin.

Es wurde bereits festgehalten, dass der Sonderfall der performativen Verben einerseits nur in geringem Maße an ein Syntagma gebunden ist und dabei andererseits kein (zwingendes) reziprokes Ähnlichkeitsverhältnis zwischen ihrer Bedeutung und jenem Syntagma eingeht. Doch ausgerechnet dies macht performative Verben umso abhängiger vom außersprachlichen Kontext und damit hinsichtlich ihrer Einsetzbarkeit als Operation zur Ewigkeitsattribuierung von Schriftzeichen weit weniger geeignet als Äußerungen, die poetische Performativität aufweisen. Hinzu kommt nun der bereits angemerkte Unterschied, dass ein performativer Sprechakt, der mittels eines performativen Verbs vollzogen wird, zwar als Lautfolge schriftlich festgehalten werden kann, nicht jedoch im eigentlichen Sinne seine Performativität. ${ }^{23}$ Zwar beruht die Möglichkeitsbedingung eines solchen performative - wie bei aller zeichenhaften Kommunikation - auf dessen Wiederholbarkeit, ${ }^{24}$

22 Als Beispiel für den gegenteiligen Extremfall von minimaler performativer Stärke bei maximaler syntaktischer Reichweite wäre vielleicht eine sprachliche Sequenz nach dem Prinzip von Robert Müllers Roman Tropen zu nennen. Der Inhalt des Romans umfasst über nahezu 3 oo Seiten das Verrücktwerden im Dschungel, während dies auf syntagmatischer Ebene derart erzählt wird, dass die Lektüre des Romans den Leser selbst an den Rand des Wahnsinns treibt (vgl. Müller, Robert: Tropen. Der Mythos der Reise. Urkunden eines deutschen Ingenieurs. Hamburg 2010).

23 Dies ist auch - wie oben bereits erwähnt - der Grund dafür, dass Austin gerade fiktive performative Sprechakte ausklammert; vgl. Austin 1962, S. 22.

24 Vgl. Derrida 1999. 
und der jeweilige, spezifische performative Sprechakt ist zwar mündlich oder durch ein schriftliches Dokument nacherzählbar, diese bleiben aber bloße Verweise, ohne diesen erneut zu vollziehen. Dies macht einen spezifischen, mittels eines performativen Verbes getätigten Sprechakt einerseits äußerst dauerhaft, andererseits äußerst flüchtig: äußerst dauerhaft insofern, als dass ein solcher, einmal getätigt, gültig bleibt - meist innerhalb eines zuvor definierten Rahmens (z. B. „bis auf dass der Tod euch scheidet") - oder nur durch einen anderen Sprechakt aufgehoben werden kann (vgl. dazu z. B. weiter unten das Kapitel zu Goethes Zauberlehrling). Äußerst flüchtig insofern, als dass die Qualität der Performativität eines solchen Sprechaktes nicht wiederholbar und damit auch nicht tradierbar ist. Eine Taufurkunde oder ein Bericht über eine Hochzeit, ob schriftlich oder mündlich, verweisen nur noch auf eine Taufe oder eine Hochzeit und vermögen nicht im Zuge ihrer Äußerung resp. Lektüre die Taufe oder die Hochzeit, von der sie sprechen, zu vollziehen. ${ }^{25}$ Im Falle der poetischen Performativität hingegen verhält es sich genau umgekehrt: Hinsichtlich einer außersprachlichen Dauer ist sie äußerst flüchtig, da sie immer direkt an eine Äußerung gebunden bleibt, deren Performativität zusammen mit der Äußerung sogleich wieder verstummt. ${ }^{26}$ Aber gerade dies macht sie potenziell unendlich oft wiederholbar und damit weitaus kontextunabhängiger als jene performativen Verben - und gerade deshalb eignen sie sich besonders dafür, im Dienste der Ewigkeitsattribuierung Verwendung zu finden.

Nach diesem einleitend-definitorischen Teil folgt nun die ausführliche Auseinandersetzung mit zwei Textbeispielen: Goethes Zauberlehrling und Schillers Wallenstein (insbesondere mit dem Prolog und Stellen, die von der Unsterblichkeit des Namens handeln). Wie immer in der vorliegenden Arbeit wurden damit Textbeispiele ausgewählt, in denen die jeweils zu untersuchende Operation zur Ewigkeitsattribuierung von Schriftzeichen nicht nur vorkommt, sondern einerseits auch eine für den jeweiligen Text zentrale Stellung einnimmt und dabei andererseits die jeweilige Operation und deren Möglichkeitsbedingungen implizit mitthematisiert. Nachdem im

25 Die Übernahmegewisser Namensteile des Ehemannes durch dieEhefrau (oderumgekehrt) oder ein auf Ähnlichkeitsverhältnissen beruhendes Namenssystem unter Verwandten (wie z. B. im germanischen Namenssystem) sind hingegen jeweils - je nach Syntagma (mindestens zwei zusammengehörige Namen müssen genannt werden) - Extremfälle von Äußerungen mit poetischer Performativität, die die in diesen Fällen vorausgehenden performatives quasi unterstützend begleiten.

26 Im Falle des Beispiels der ersten Verse von Hölderlins Ode Ermunterung meint dies: Kaum ist die Bedeutung des Wortes „Echo“ über die echohaften Wiederholungsfiguren der beiden Verse performativ hergestellt, so sind die Verse samt ihrem Echoeffekt auch schon wieder verstummt - was ja das Gedicht als Ganzes dann auch verhandelt; vgl. Kapitel II.2.2. 
vorliegenden einleitenden Teil anhand von Hölderlins beiden Versen das Grundprinzip der poetischen Performativität veranschaulicht wurde, folgen nun also ganz bewusst Textbeispiele, in denen poetische Performativität sich über eine weitaus längere Sequenz konstituiert und zugleich implizit auf äußerst komplexe Weise autoreflexiv und poetologisch thematisiert wird: ${ }^{27} \mathrm{Im}$ Kapitel zum Zauberlehrling wird es u. a. um die Eigendynamik performativer Äußerungen und die historische Kontextualisierung des Umstandes gehen, dass gerade diese Eigendynamik in der Ballade so prominent verhandelt wird. Im Kapitel zum Wallenstein wiederum geht es u. a. darum, wie möglichst weitreichende, also über eine möglichst lange Sequenz sich konstituierende poetische Performativität konsequent zur Ewigkeitsattribuierung ebendieser Sequenz, deren Inhalts und deren Verfassers, eingesetzt werden kann. Um der höheren Leserfreundlichkeit willen ist - wo nicht explizit anders erwähnt im Folgenden mit Performativität immer die oben definierte poetische Performativität gemeint.

\subsection{Der Zauberlehrling}

Hat der alte Hexenmeister

Sich doch einmal wegbegeben!

Und nun sollen seine Geister

Auch nach meinem Willen leben.

Seine Wort' und Werke

Merkt' ich, und den Brauch,

Und mit Geistesstärke

[1-8] Tu' ich Wunder auch.

Walle, walle

Manche Strecke!

Daß, zum Zwecke,

Wasser fließe,

Und mit reichem, vollem Schwalle

[9-14] Zu dem Bade sich ergieße.

Und nun komm du alter Besen!

Nimm die schlechten Lumpenhüllen.

Bist schon lange Knecht gewesen;

Nun erfülle meinen Willen!

Auf zwei Beinen stehe,

Oben sei ein Kopf.

Eile nun, und gehe

[15-22] Mit dem Wassertopf!

27 Nicht dass eine solche Reflexion nicht auch in Hölderlins Ode stattfinden würde, sie geschieht jedoch mit klarem Fokus auf das Verstummen; vgl. Kapitel II.2.2. 
Walle walle

Manche Strecke!

Daß, zum Zwecke,

Wasser fließe,

Und, mit reichem, vollem Schwalle,

[23-28] Zu dem Bade sich ergieße.

Seht, er läuft zum Ufer nieder;

Wahrlich! ist schon an dem Flusse,

Und mit Blitzesschnelle wieder

Ist er hier mit raschem Gusse.

Schon zum zweitenmale!

Wie das Becken schwillt!

Wie sich jede Schale

[29-36] Voll mit Wasser füllt!

Stehe, stehe!

Denn wir haben

Deiner Gaben

Vollgemessen! -

Ach, ich merk' es! Wehe! wehe!

[37-42] Hab' ich doch das Wort vergessen!

Ach! das Wort, worauf am Ende

Er das wird, was er gewesen.

Ach! er läuft und bringt behende.

Wärst du doch der alte Besen!

Immer neue Güsse

Bringt er schnell herein,

Ach! und hundert Flüsse

[43-5o] Stürzen auf mich ein.

Nein, nicht länger

Kann ich's lassen;

Will ihn fassen.

Das ist Tücke!

Ach! nun wird mir immer bänger!

[51-56] Welche Miene! Welche Blicke!

O, du Ausgeburt der Hölle!

Soll das ganze Haus ersaufen?

Seh' ich über jede Schwelle

Doch schon Wasserströme laufen.

Ein verruchter Besen,

Der nicht hören will!

Stock, der du gewesen,

[57-64] Steh doch wieder still! 


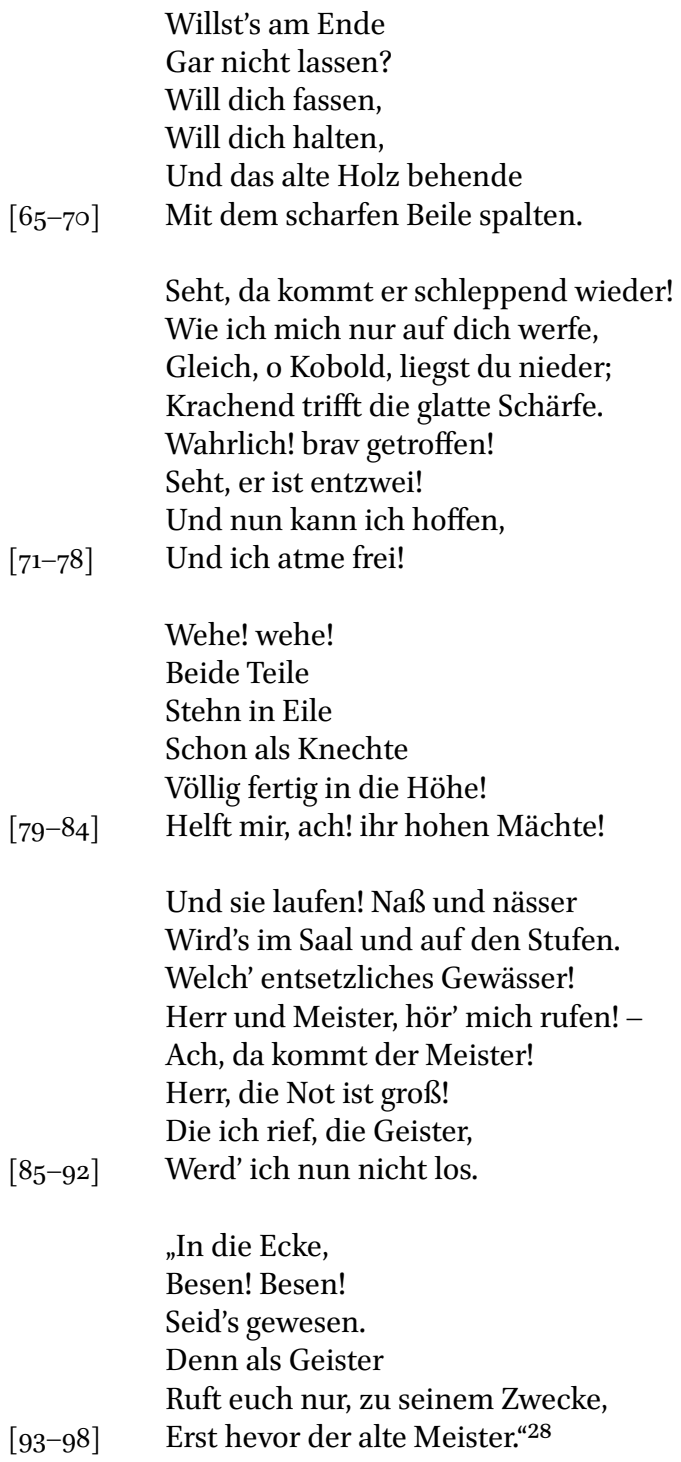

Goethes Kunstballade Der Zauberlehrling erschien im von Schiller herausgegebenen Musen-Almanach resp. Balladen-Almanach $1797 \cdot{ }^{29}$ Sie orientiert

28 Goethe, Werke, 1. Abteilung, Bd. 1, S. 683-686.

29 Zur Entstehung und Datierung vgl. die ausführliche Zusammenfassung bei Laufhütte 1979, S. 59, Anm. 37. 
sich inhaltlich sehr genau an einer Passage aus dem Philopseudes (Der Lügenfreund) des antiken Schriftstellers und Satirikers Lukian von Samosata (2. Jahrhundert n. Chr.), die Goethe entweder im Original bekannt war ${ }^{30}$ und/oder ihm in der zeitgenössischen Übersetzung von Wieland (1788) vorgelegen hat. ${ }^{31}$ In formaler Hinsicht nimmt Goethe jedoch eine entscheidende Änderung gegenüber der antiken Vorlage vor: ${ }^{32}$ Handelt es sich bei Lukian noch um eine Binnenerzählung innerhalb eines Dialoges, macht Goethe bei der Übertragung des Stoffes vollen Gebrauch von den Möglichkeiten der Epik, Dramatik und Lyrik vereinenden Kunstballade: ${ }^{33}$ Im Gegensatz zum Philopseudes, wo eine Drittperson von der Begebenheit mit dem Meister und seinem Zauberlehrling berichtet, gibt es in seiner Ballade keinen Erzähler, sondern bloß die direkte Rede des Lehrlings und, in der letzten Strophe, des Meisters. ${ }^{34}$ Dies - so wird sich zeigen - ermöglicht es Goethe, das Sprechen der Figuren resp. deren performative Sprechakte direkt wiederzugeben und so einerseits ins Zentrum der Ballade zu stellen sowie andererseits das Sprechen der Figuren unmittelbar in Analogie zum Sprechen des Lesers zu setzen, womit wiederum die Voraussetzung für eine Selbstbezugnahme der Ballade geschaffen wird. ${ }^{35}$

Der Zauberlehrling umfasst sieben eigentliche Strophen, die sich mit sieben Refrainstrophen abwechseln. Während die ersten beiden Refrainstrophen als ein Refrain im engen Sinne eingeführt werden, indem sie identisch sind, verändert sich im Weiteren bei gleichbleibendem Rhythmus und Reimschema ihr Inhalt und trägt damit wesentlich zur Dramatisierung und Pointe (sofern sich eine festmachen ließe $)^{36}$ der Ballade bei. Zudem spiegelt sich in dieser

$30 \quad$ Vgl. Brügger 1951.

31 Vgl. Witte 2008, S. 716 f., der diese Stelle bei Lukian in der Reclam-Sammlung von Goethes Gedichten mitabdruckt. Eine kurze Besprechung der von jüdischen Gelehrten Ende des 18. Jahrhunderts versuchten Herstellung einer Verbindung des Besens im Zauberlehrling mit der Golem-Figur der jüdischen Mystik nimmt Cathy S. Gelbin vor und hält fest, dass eine solche Verbindung heute nicht belegt werden könne (vgl. Gelbin 2013, S. 24).

32 Einen Vergleich der beiden Texte - wenngleich dieser weniger Raum einnimmt, als es der Titel des Aufsatzes suggeriert - hat Lilo Brügger vorgelegt; vgl. dies. 1951, S. 246 und 253-255.

33 Die Vereinigung von Epik, Lyrik und Drama in der Kunstballade ist am komplexesten und zugleich übersichtlichsten dargestellt in einer Graphik bei Conrad 2014, S. $74 \mathrm{f}$.

34 Damit erweitert Goethes Gedicht „den strukturellen Umkreis der [Gattung, MG] Ballade, soweit er sich bisher abzeichnete, beträchtlich. Es zeigt, daß die Vorgangsgestaltung ausschließlich mit Hilfe der ,szenischen' Mittel der situationsgebundenen Rede ohne jede innerfiktionale Erzählerdistanz zustande kommen kann“ (Laufhütte 1979, S. 63).

35 Laufhüttes Befund, „[d]ie zu völliger Konsequenz geführte innerfiktionale Unmittelbarkeit schlägt in diesem Gedicht um in die Ermöglichung weitgehender Distanznahme durch den Leser oder Hörer" (ders. 1979, S. 63), trifft somit nur halb zu.

36 Vgl. Laufhütte 1979, S. 63. 
Veränderung durch den Bruch mit der Refrainkonvention die Machtlosigkeit des Zauberlehrlings gegenüber der Eigendynamik der Wortmagie. Die einzelnen Strophen sind in zwei Hälften à vier Versen aus vier- resp. dreihebigen Trochäen ${ }^{37}$ geteilt, gefolgt von den Refrainstrophen bestehend aus sechs Versen, zusammengesetzt aus jeweils vier Versen zweihebiger und zwei Versen vierhebiger Trochäen. Die Anzahl der Hebungen alterniert dadurch über die ganze Ballade hinweg nach einem Schema von vier zu drei zu zwei und von dort wieder zu vier etc. Hebungen, was ihr - passend zum steigenden und am Ende eingeleiteten, wieder sinkenden Wasserspiegel - etwas Wogendes verleiht. ${ }^{38}$ Die Reimschemata gestalten sich nach folgenden Prinzipien: jeweils zwei Kreuzreime (a,b,a,b,c,d,c,d) im Falle der ,normalen' Strophen und eine „kunstvolle Kombination zweier Umschließungsgruppen ${ }^{439}\left(a_{p} b_{r} b_{r} c_{r} a_{n} c_{r}\right)^{40}$ für die Refrainstrophen. ${ }^{41}$ Hartmut Laufhütte wertet die hier als Refrainstrophen bezeichneten Verse nicht als Refrain, da sie „Teil am Geschehensprozeß“42 hätten. Das haben sie durchaus; ihre formale Anlehnung an einen Refrain nutzt aber gerade die inhaltliche und formale Abweichung von demselben ästhetisch produktiv und damit noch immer in Relation zu einer Refrainfunktion. Laufhütte fasst die Refrainstrophen mit der jeweils vorangegangenen achtzeiligen Strophe als je eine Strophe zusammen. Dem Verfasser erscheint hingegen zumindest aus heuristischen Gründen eine separate Zählung der Refrainstrophen für präziser und besser dazu geeignet, die inhaltlichen Wechsel zwischen performativem Sprechakt und Beschreibung sowie die damit verbundene poetologische Ebene der Ballade angemessen zu behandeln. ${ }^{43}$

37 Lilo Brügger sieht in diesen den passenden Versfuß für ein Gedicht, das von Zauber handelt: „denn der schwere Einsatz und eine gewisse Monotonie stimmen zur Grandezza einer Beschwörung" (dies. 1951, S. 255).

38 Die wogende Bewegung erstreckt sich also - weiterreichend als von Annemarie Christiansen vermerkt (vgl. dies. 1987, S. 43) - über die gesamte Ballade und ist nicht allein und isoliert für die Refrainstrophe zu betrachten.

39 Brügger 1951, S. 6o.

40 Das tiefgestellte $r$ signalisiert, dass Reim a der ersten Refrainstrophe nicht Reim a der ersten Strophe entspricht etc. Der erste Reim der ersten Strophe entspricht jedoch dem letzten Reim des letzten Refrains und damit dem letzten Reim der Ballade überhaupt, siehe dazu unten.

41 Vgl. ausführlich zu Metrik und Reim Laufhütte 1979, S. 59 f.

42 Ebd., S. 59.

43 Die jüngeren Beobachtungen Martin Todtenhaupts zur Bedeutung der Zahl Sieben für die Struktur der Ballade konstatieren sieben Achtzeiler und sieben Sechszeiler, die zusammen sieben Strophen à vierzehn $(=2 \times 7)$ Verse ergeben würden (vgl. Todtenhaupt 1999, S. 191). Letzteres ließe sich jedoch - und dies mahnt zugleich zur Vorsicht bei der Anführung zahlenkombinatorischer Belege - auch als Argument für die Einteilung des Verfassers verwenden. 
Forschungsliteratur zum Zauberlehrling ist erstaunlicherweise kaum vorhanden. Die spärliche Forschungslage geht einher mit einer dreißigjährigen Forschungslücke, die die Gattung der Ballade insgesamt umfasst. Gunter E. Grimm eröffnet seine Einleitung der 1988 erschienenen Sammlung Deutsche Balladen der Reclam-Reihe „Gedichte und Interpretationen“ mit den Worten: „Die Ballade ist tot! Seit den späten sechziger Jahren ertönte dieser Ruf mehrfach. Nur in den Schulen fristete sie unverdrossen ihr pflichtschuldiges Dasein. Neue Interpretationen [...] fanden sich denn auch vorwiegend im Angebot didaktisch zubereiteter Handreichungskost. ${ }^{44}$ Maren Conrad wird diese Einleitung Grimms in ihrer 2014 erschienenen Monographie zur phantastischen Kunstballade wieder aufgreifen und festhalten, „wie zutreffend diese Aussage weiterhin ist“. ${ }^{45}$ Der Zauberlehrling wird weder in Grimms Anthologie noch - abgesehen von der Monographie Hartmut Laufhüttes - in anderen älteren Untersuchungen der 196oer- und 197oer-Jahre zur Ballade behandelt, und wenn er überhaupt erwähnt wird, dann in einem ungenügend reflektierten Verweis. ${ }^{46}$ Auch Conrad behandelt den Zauberlehrling nicht, ${ }^{47}$ obschon er ein äußerst fruchtbares Beispiel für ihre Kernthese abgeben würde, die lautet: Der Ursprung der deutschsprachigen Phantastik gehe wesentlich auf die Kunstballade, wie sie von den 1770er-bis in die 189oer-Jahre entstand, zurück. ${ }^{48}$

Ohne im vorliegenden Rahmen auf das Phantastische oder gar auf eine allgemeine Balladentheorie eingehen zu können, lässt sich doch ausblickhaft darauf hinweisen, dass Conrads äußerst spannende Befunde zur gattungskonstituierenden autoreflexiv-poetologischen Ebene der Kunstballaden ${ }^{49}$ sowie zum "phantastischen Sprechakt" ${ }^{40}$ und die unten stehende Auseinander-

44 Grimm 1988, S. 9.

45 Conrad 2014, S. 23.

46 So bei Norbert Mecklenburg in der Sammlung Balladenforschung von Walter Müller Seidel: „Im Zauberlehrling bildet eine ziemlich hölzerne Lehre, der wohl nicht ganz Unrecht geschieht, wenn man sie als revolutionsfeindlich überinterpretiert, den Zielpunkt für eine unterhaltsam-virtuose Erzählung“ (Mecklenburg 1980, S. 197). Den Verweis auf eine im Zauberlehrling mitschwingende, zusätzliche Allegorie auf die Französische Revolution macht schon Brügger 1951, S. 256 f.

47 Vielleicht weil er nicht ihrem Prototypen der Kunstballade entspricht, die (durchaus plausibel) das "Subsystem“ „[Liebes-]Paar“ (vgl. Conrad 2014, S. 32 f. und u. a. 265) als gattungskonstitutives Element führt.

48 Vgl. ebd., u. a. S. 26 und 29.

49 Vgl. ebd., u. a. S. 3 o f. und $40 \mathrm{f}$.

5 O Vgl. ebd., u. a. S. 36, 73-75, 88-92, 257-265. Conrads Begriff "phantastischer Sprechakt“ bleibt jedoch zuweilen etwas schwammig, gerade deswegen könnte die Auseinandersetzung mit demselben unter Miteinbezug der performativen Sprechakte der Ballade äußerst gewinnbringend sein. Zumal performative Sprechakte - ebenso wie autoreflexivpoetologische Operationen - in der Phantastik ein zentrales, konstitutives Element des 
setzung mit der Performativität sowie der gleichzeitigen poetologischen Thematisierung derselben in und durch die Ballade Der Zauberlehrling einander in einer allgemeinen Theorie zur Kunstballade (aber auch zur Phantastik) gegenseitig bestärken und ergänzen könnten.

Abgesehen von den bereits von Grimm erwähnten schuldidaktischen Arbeiten zum Zauberlehrling, einer kurzen Abhandlung von Annemarie Christiansen, ${ }^{51}$ Lilo Brüggers Vergleich von Goethes Ballade mit der Stelle bei Lukian ${ }^{52}$ und Martin Todtenhaupts Beobachtungen zur "Siebenzahl als Strukturmerkmal“ der Ballade ${ }^{53}$ bleiben nur weitere kleinere Arbeiten, die es bei oberflächlichen Behandlungen belassen oder über einen bloßen Verweis nicht hinausgehen. ${ }^{54}$

Somit bleibt das oben bereits mehrfach zitierte Unterkapitel Laufhüttes die längste dem Verfasser bekannte literaturwissenschaftliche Auseinandersetzung mit dieser Ballade in den letzten 40 Jahren. Sie bietet in den Anmerkungen, die den Lauftext an Umfang übertreffen, eine Auseinandersetzung mit dem damaligen Forschungsstand, geht sehr präzise auf Reim und Rhythmus ein, auch in Verbindung zum Inhalt der Ballade, hat aber überwiegend beschreibenden Charakter, was im Rahmen von viereinhalb Seiten Lauftext auch kaum anders möglich ist. Das vorliegende Kapitel ist deshalb - zumindest nach den Kenntnissen des Verfassers - die eingehendste literaturwissenschaftliche Auseinandersetzung mit Goethes Zauberlehrling in den letzten Jahrzehnten.

Erschaffens von (phantastischen) Welten zweiter Ordnung ausmachen können (vgl. dazu Gut 2015).

$5^{1} \quad$ Vgl. Christiansen 1987; die Auseinandersetzung mit der Ballade selbst umfasst dabei drei Seiten.

52 Ein Vergleich, der eigentlich mehr noch ein Anführen von zeitgenössischen Briefen, Textstellen und Verweisen zum im Zauberlehrling behandelten Stoff ist.

53 Todtenhaupt betont selbst, dass es sich dabei hauptsächlich um strukturelle Beobachtungen handelt, aus denen „sich keine grundsätzlich neuen Erkenntnisse für Goethes Zauberlehrling ableiten [lassen]" (ders. 1999, S. 193).

54 Vgl. Gelbin 2013, S. 24; Aeka Ishihara befasst sich nicht mit der Ballade selbst, sondern bezieht diese, gestützt auf ein Zitat des späten Goethe (1828), allegorisch auf eine erste zeitgenössische Problematisierung von ,Informationsflut' in der ersten Hälfte des 19. Jahrhunderts (der Haupttitel ihres Aufsatzes „Der Zauberlehrling in der internationalen Flut“ ist irreführend); vgl. dieselbe 2008, S. 167-181; Gloria Flaherty wiederum verweist in ihrer Publikation in einem einzigen Satz darauf, dass Der Zauberlehrling vom zeitgenössischen Schamanismusdiskurs beeinflusst sei, ohne aber weiter auf die Ballade einzugehen; vgl. dieselbe 1989, S. 595. Zur Stelle bei Frieder von Ammon siehe den Beginn des folgenden Unterkapitels. 
1.1.1 Ausgangspunkt der Argumentation

Als Einstieg in die folgende Argumentation soll aber trotz der spärlichen Forschungslage die kritische Auseinandersetzung mit einer - durch glücklichen Zufall entdeckten - Stelle zum Zauberlehrling in Frieder von Ammons Dissertation zu den Xenien (also nicht zu den Balladen) Goethes und Schillers dienen. ${ }^{55}$ Ammon weist nämlich darauf hin, dass der Zauberlehrling eine satirische Allegorie gegen die Gegner der selbst wiederum polemischen Xenien Goethes und Schillers beinhalte, und zieht dazu eine Stelle aus einem Brief Karl Ludwig von Knebels, eines Freundes von Goethe, an Karl August Böttiger vom 1. November 1797 heran. Dieser Brief wird bereits bei Lilo Brügger, ${ }^{56}$ wieder bei Laufhütte ${ }^{57}$ und auch in den Anmerkungen zum Zauberlehrling in der Reclam-Anthologie von Goethes Gedichten zitiert und belege, „[d]ass die Zeitgenossen in dem Gedicht aktuelle Anspielungen fanden“:58

\begin{abstract}
Die poetische Welt ist durch den Schillerschen ,Almanach' mit hellen Sternen bezeichnet. [...] Goethe hat sich in der Tat glänzend hervorgetan, und seine Abfertigung der Anti-Xenisten durch den ,Zauberlehrling hat mir trefflich gefallen. Wie werden sie es denn nun machen, die Wassermänner? Distichen glaubten sie hervorbringen zu können; werden ihnen denn die gereimten Balladen auch gelingen? ${ }^{59}$
\end{abstract}

Auch die Rede von den "Gaben“ in der dritten Refrainstrophe deutet Ammon als Anspielung auf die Xenien (deutsch „Gastgeschenke“) ${ }^{60}$ und erarbeitet zwei Aspekte des Zauberlehrlings als satirische Allegorie im Xenien-Streit: Erstens impliziere die Ballade, dass „[n] ur Goethe und Schiller [...] sich ein ,tolles Wagstück' wie die Xenien erlauben [dürfen]; alle anderen werden unter der von ihnen selbst losgetretenen Xenien-Lawine begraben."61 Zweitens wende sich der Zauberlehrling gegen den, freilich von Goethe und Schiller selbst ausgelösten, „Prozess der Kanonisierung"62 der Xenien als literarische Gattung: „Mit dem ,Meisterstück' in der neuen Form der klassischen Ballade also wollte der ,alte Meister' Goethe dem Spuk des Xenien-Streits ein Ende machen.

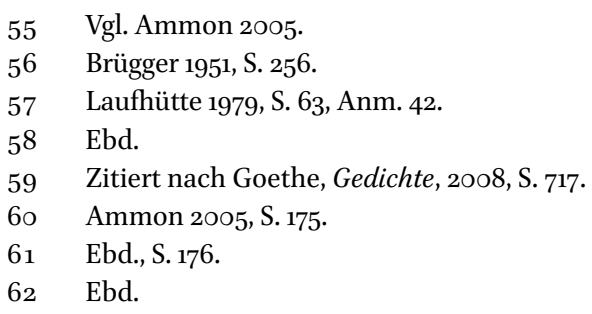


Die Gattung Xenion wurde von ihm symbolisch in die Ecke [vgl. die letzte Strophe des Zauberlehrlings, MG] der Literaturgeschichte verbannt. “63

Die Ballade mag vielleicht eine Spitze gegen die sogenannten Anti-Xenisten beinhalten, eine konsequente Interpretation des Zauberlehrlings im Zeichen einer solchen satirischen Allegorie ${ }^{64}$ muss jedoch, ohne dass dies Ammon erwähnt, auf zwei performative Widersprüche stoßen:

Erstens müssten die Teile der Ballade, in denen der Zauberlehrling ,am Werk' ist, d. h. spricht (also stolze 84 von 9o Versen), konsequenterweise alles andere als eine Meisterleistung sein, was sie jedoch - so wird unten ersichtlich werden - sehr wohl sind. Hinzu kommt zweitens, dass die Ballade eine solche (vermeintliche?) Allegorie gegen die Gegner im Xenien-Streit bereits in der ersten Strophe äußerst komplex gestaltet: Die erste Strophe, in der der Zauberlehrling vom Nachahmen von "Wort'“ und "Werke“ des alten „Hexenmeister[s]“ spricht, kann sich nämlich auch poetologisch auf Goethes Unterfangen, ebendiese Ballade zu verfassen, beziehen. Wie der "Zauberlehrling“ hat auch Goethe sich "Wort" und „Werke" eines alten Meisters "[gem] erkt", nämlich diejenigen Lukians von Samosata, der im Philopseudes (Der Lügenfreund) dieselbe Geschichte erzählt wie Goethes Ballade. ${ }^{65}$ Jener Allegorie wäre demnach auch in diesem Sinne ein performativer Widerspruch inhärent, indem der vermeintliche Meister Goethe sich selbst als Lehrling entpuppen würde.

Damit wäre eine schlüssige umfassende allegorische Lesart wohl nur noch in einem Fall möglich: Dann nämlich, wenn die Ballade auf die Pointe abzielte, dass der wahre Meister derjenige (vermeintliche Lehrling) wäre, der den Meister performativ zu setzen vermag. Wenn Der Zauberlehrling also tatsächlich eine satirische Allegorie auf unliebsame Zeitgenossen ist, dann eine mit einem Gestus durchdrungen von einer an Selbstbewusstsein kaum noch zu überbietenden Inszenierung Goethes als eines Genies, das im Erschaffen sich selber schafft. Wie dem auch sei: Performativität nimmt im Zauberlehrling eine derart gewichtige Rolle ein, dass er weit mehr ist als eine bloße Satire auf die „Wasserträger“. Es sei deshalb erlaubt, die Spekulationen über allfällige Spitzen gegenüber Zeitgenossen zunächst beiseitezulassen und die Performativität

63 Ebd., S. 177. Ein Versuch, so beweist Ammon mit seiner Monographie, der misslang; der gar schon zum Zeitpunkt des Erscheinens des Zauberlehrlings im Balladen-Almanach 1797 misslungen war, denn „das Xenion als neue Form literarischen Streitens [hatte sich] bereits im Kanon der literarischen Gattungen etabliert“ (ebd.).

64 Ohne dies Ammon vorzuwerfen, der den Zauberlehrling vor allem als Referenz zu eigenen Überlegungen zu den Xenien benutzt, ist zu erwähnen, dass bereits Laufhütte davor gewarnt hatte, den allegorischen Gehalt des Verhältnisses Meister - Zauberlehrling nur auf „eine mögliche Beziehung fest[zu]legen“ (Laufhütte 1979, S. 63).

65 Vgl. Goethe, Gedichte, 2008, S. 716 f., wo die Stelle aus dem Philopseudes mitabgedruckt ist. 
der Ballade und die Verhandlung von Performativität durch die Ballade ins Zentrum der folgenden Auseinandersetzung zu stellen - in einer Lesart, die die Ballade Der Zauberlehrling vor allem als implizite Lehre für diejenigen begreift, die über die performative Macht von Worten etwas lernen wollen.

\subsubsection{Das (zu) dauerhafte Werk des Zauberlehrlings}

Neben der oben erwähnten und performativ widersprüchlichen poetologischen Anspielung auf den ,Meister' Lukian von Samosata bergen die Verse fünf und sechs noch einen weiteren Verweis: Die dem Metrum der Rede des Zauberlehrlings angepasste Elidierung des Plural-e von "Wort[e]“ nimmt vorweg, dass gerade dieses Merken der Worte des "Meisters" und der eigene „Brauch" derselben, wenn nicht fehlerhaft, so doch unvollständig ist. Es wird sich denn bekanntlich auch herausstellen, dass der Zauberlehrling nur eine Zauberformel kennt, die zum Beleben des Besens, nicht jedoch die zweite, die dem Besen das Leben wieder nimmt. Der performative Akt der belebenden Zauberformel, gesprochen in den Refrainstrophen eins und zwei, ${ }^{66}$ wird damit in der ersten Strophe nicht nur vorbereitet, sondern bereits auch unterlaufen.

Hinzu kommt in der zweiten Strophe eine weitere, wortwörtliche Ungereimtheit im Sprachgebrauch des Lehrlings: die Reimworte "-hüllen“ und „Willen“ bilden einen unreinen Reim. Dies kommt zwar - in Anbetracht der zaubersprachlichen Machtlosigkeit des Lehrlings wenig überraschend - im weiteren Verlauf der Ballade noch mehrmals vor, nicht jedoch im Schlussrefrain des Meisters. Auch ist es der erste dieser unreinen Reime, der dabei zwei entscheidende Verse verbindet: „Nimm die schlechten Lumpenhüllen, / [...] / Nun erfülle meinen Willen." Der Inhalt des ersten dieser beiden Verse mutet auf den ersten Blick seltsam an, bezieht sich jedoch auf die Vorlage Lukians, in der zur Ausführung des Zaubers das Ankleiden des zu verzaubernden Objektes notwendig ist. ${ }^{67}$ Dass ausgerechnet diese beiden Reimworte einen unreinen Reim bilden, deutet bereits an, dass die metonymisch für den Besen (und den Zauber) stehenden „Lumpenhüllen“ den „Willen“ des Lehrlings eben gerade nicht vollends „erfülle[n]“ werden. Eine poetologische Lesart des Gewebes, des Textums, der „Lumpenhüllen“ würde diesen Befund weiter unterstützten,

66 Brügger sieht in der ersten Refrainstrophe eine stille Vergewisserung des Lehrlings, um sie dann in der zweiten mit "pathetischer Wiederholung“ erneut zu sprechen (ders. 1951, S. 254). Laufhütte meint, die Formel werde „erst einmal zur ,Probe‘ gesprochen oder memoriert, was zur Situation des aufgeregten Anfängers ja gut" passe (ders. 1979, S. 6o). Mit Derrida wäre zu ergänzen: In der Doppelung der Zauberformel wird ausgestellt, dass die Möglichkeitsbedingung auch von performativen Sprechakten auf der Iterabilität dieser Sprechakte beruht (vgl. ders. 1999).

67 Vgl. Goethe, Gedichte, 2008, S. 716. 
indem sie implizierte, dass das Textgewebe des Zaubers nicht (oder nicht nur) dem Willen des Lehrlings folgt. Eine poetologische Lesart hingegen, die „Lumpenhüllen“ auf den Intertext Lukians bezieht, würde nahelegen, das erneute Füllen alter ,Texthüllen' durch Goethe - also die Umwandlung jener Textstelle aus Lukians Satire Philopseudes in eine Kunstballade - bärge eine Eigendynamik, die sich Goethes Willen nicht unterordne.

Aus den Überlegungen in den vorangegangenen beiden Abschnitten geht neben den performativen Selbstwidersprüchen in der Rede des Lehrlings, die dessen Scheitern vorwegnehmen - hervor, dass jeweils dort, wo sich ein poetologischer Verweis auf die Adaption resp. Nachahmung von ,Meister' Lukians Text findet, etwas auf formaler Ebene schiefgeht, was das Scheitern desjenigen, der nachahmt, vorwegnimmt. Paradoxalerweise ist es jedoch genau dieses Scheitern, das dann genau der Geschichte Lukians entspricht. Daraus lässt sich für Goethes Zauberlehrling zwischenzeitlich das folgende Prinzip ableiten, das die kurze Zeit später sich formulierende frühromantische Dialektik vorwegnimmt:

Darstellung gescheiterter Nachahmung bei poetologischer Reflexion derselben und des eigenen Nachahmens führt zu einer geglückten Nachahmung, die gar das nachgeahmte Original übertreffen mag.

Oder in Anlehnung an Friedrich Schlegels Formulierungen anders ausgedrückt:

Die Ballade Der Zauberlehrling ahmt die Vorlage Lukians nach, aber auf eine potenzierte Weise, indem sie Nachahmung und Scheitern von Nachahmung zusätzlich auch auf den eigenen Nachahmungsversuch bezogen reflektiert.

Ein Lehrling, der solches zu tun vermag, übertrifft - so die auf dieser poetologischen Ebene implizit mitschwingende Botschaft - gar den Meister. Auf die Problematiken, die dies mit sich bringt, ist am Ende dieses Kapitels zurückzukommen. ${ }^{68}$

Nun aber sei von jener poetologischen Ebene zuerst wieder zurückgekehrt zur Ebene der fiktiven Welt der Ballade und zu dem Problem, das sich der eigentliche Zauberlehrling einbrockt: Während der Zauberlehrling in der dritten Strophe noch voller Stolz und Freude über den eigenen Wortzauber die „Blitzesschnelle“ des Besens feiert, gerät sein Zauber in der dritten Refrainstrophe außer Kontrolle: Es stellt sich nämlich heraus, dass das in Strophe eins durch die Elision des Plural-e von ,Worte' bereits als unvollständig

68 Zum humoristischen Aspekt des Kompositums „Zauber-Lehrling“ und generell zur Kombination des Wortfelds des Handwerks und Zunftwesens mit dem der Zauberei vgl. Christiansen 1987, S. 42. 
gekennzeichnete Merken der "Wort" tatsächlich unvollständig ist, denn der Lehrling hat die Worte des Meisters, die zum Beenden des Zaubers notwendig wären, „vergessen“. Er wiederholt sogar denselben Fehler, der in Strophe eins angedeutet ist, indem er - dieses Mal (und auch zu Beginn der nächsten Strophe) sogar noch ohne Elisionszeichen - wieder vom "Wort“ im Singular spricht. Dieses „[V]ergessen“ führt sodann dazu, dass sich der Befehl aus Strophe zwei, „Nun erfülle meinen Willen“, übererfüllt. Analog zum unreinen Reim von "Wille“ - „erfülle“, der den Reimkonventionen wider- und zugleich teilweise entspricht, gehorcht der Besen dem Zauberlehrling und gehorcht ihm zugleich nicht, indem er dessen Willen wortwörtlich nimmt, ihn wortwörtlich er-füllt und damit über-er-füllt. Dies wird noch dadurch verstärkt, dass der zweite unreine Reim der Ballade wiederum das Verb "füllt" beinhaltet, und zwar im letzten Vers der dritten Strophe (V. 36), unmittelbar vor der Refrainstrophe, in der der Zauber außer Kontrolle gerät: „füllt" reimt sich hier auf „schwillt“ und unterstreicht, dass es mit dem Füllen und Schwellen etwas Ungereimtes haben wird.

Dass der Zauberlehrling mehr „vergessen“ hat als bloß ein „Wort“, dafür gibt es zwei weitere Indizien: Erstens fehlt dem Lehrling zur Komplettierung der Refrainstrophe nicht bloß ein Wort, sondern zwei Verse. Selbst wenn „Wort“ metonymisch für die fehlenden Worte dieser beiden Verse gelesen würde, zeigt der Vergleich mit der letzten Strophe der Ballade, der Refrainstrophe des Meisters, dass bereits die Verse 37-40 nicht den Worten entsprechen, die den Zauber beenden. Der Zauberlehrling hat offenbar den kompletten zweiten Spruch "vergessen“.

Das „Stehe, stehe“ hat denn auch keine performative Macht über den Besen, was der Wechsel von (versuchtem) performativem Sprachgebrauch in den Versen 37-40 hin zu bloß beschreibendem, auf ebenjenes Versagen des performativen Sprechaktes verweisenden Sprachgebrauch in den Versen 41-32 noch hervorhebt. Und gerade diese Hervorhebung ist von besonders tief reichender Art: Genau an dieser Stelle nämlich, die den ästhetischen Kern der Ballade birgt, von dem aus sich das Gedicht voraus- und zurückverweisend entfaltet, geht es dezidiert um Performativität, womit deutlich gemacht wird, dass die Ballade auch grundsätzliche Fragen nach schöpferischer Sprachmacht und deren Dauer verhandelt. Die entscheidende Frage, die diese Stelle dabei aufwirft, ist: Was tut derjenige, der die Macht beansprucht, mittels eines Sprechaktes direkt Außersprachliches zu verändern, wenn dieser performative Sprechakt nicht mehr rückgängig gemacht werden kann und eine Eigendynamik entwickelt? Und sie gibt sogleich auch eine erste Antwort seitens des Lehrlings: weitersprechen. Denn ähnlich wie in Miss Sara Sampson 
oder im Kater Murr signalisiert der Gedankenstrich ${ }^{69}$ am Ende von Vers 40 einen Abbruch, der letztlich keiner ist. Der Besen steht nicht still und ebenso wenig - um im Wortfeld des Fließens und Gießens zu bleiben - der Redefluss des Zauberlehrlings:

\author{
Stehe, stehe! \\ Denn wir haben \\ Deiner Gaben \\ Vollgemessen! - \\ Ach, ich merk' es! Wehe! wehe! \\ Hab' ich doch das Wort vergessen! (V. 37-42)
}

Im Gegenteil: Selbst das Eingeständnis, „das Wort vergessen“ zu haben, belegt in der Art und Weise, wie es (und die noch folgenden Strophen) formuliert ist, dass der Zauberlehrling sich zumindest einen „[Wort-]Gebrauch“ tatsächlich "[gem] erkt“ (vgl. Str. 1) hat, nämlich den „Gebrauch“ gemäß Reimschema und Versmaß der vorangegangenen Strophen: Noch immer findet "Stehe“ einen Reimpartner in „wehe“, noch immer wird das Versmaß „[v]ollgemessen“.70

Damit erhält diese entscheidende Stelle der Ballade, und damit die Ballade insgesamt, eine poetologische Metaphorik, die den Aspekt der Dauer in die Verhandlung von Performativität einbringt: Das Stillstehen des Besens entspräche dem Stillstehen der Ballade, dem Ende des Gedichtes (was ja dann auch vom Refrain des Meisters als letzter Strophe der Ballade bestätigt wird doch dazu weiter unten mehr). Die Versfüße bleiben aber nicht stehen, und während auf der Ebene der fiktiven Erzählung „das ganze Haus“ und mit ihm der Zauberlehrling selbst zu „ersaufen“ (V. 58) drohen, ist Letzterer auf poetologischer Ebene umgekehrt existenziell abhängig, nicht vom „Besen“, aber vom „[Weiter-]Lesen“, vom Weiterfließen der Ballade, der sein gelesenes Leben angehört. Es ist deshalb wohl kein Zufall, dass ausgerechnet der Befehl „Stehe!

69 Die Gedankenstriche in Vers 40 und 88 sind in der Druckvorlage der Ballade enthalten, der Gedankenstrich in Vers 88 wurde jedoch im Musenalmanach für das Jahr 1798 nicht mitabgedruckt (vgl. Todtenhaupt 1999, S. 191 f.).

70 Die Stelle ist also noch komplexer als die dazu angestellten, durchaus präzisen Beobachtungen Laufhüttes zur dritten Refrainstrophe: „Die neue Formel ahmt die erste nach. Auch sie beginnt mit einem doppelten Imperativ, auch sie strebt nach dem Effekt des von Assonanzen getragenen magischen Schwebens. Daß sie dennoch das zweimal eingeprägte Schema mangelnder Länge wegen verfehlt, weist als böses Vorzeichen auf ihre Wirkungslosigkeit voraus. [...] in dem Ausruf „Wehe!, wehe!“ [...], der ironischerweise mit dem auch hier als Reimwiederholung gestalteten Anfang der untauglichen Beschwörungsformel korrespondiert, ist das Leitmotiv des zweiten Teils vorweg formuliert: Schrecken, Angst, Verzweiflung“ (Laufhütte 1979, S. 61). 
stehe!" als einziger Reim der Ballade ein doppelter sein wird, denn dessen Reimpartner "Wehe! wehe!" impliziert ein doppeltes Weh: zum einen das Weh, das durch das Vergessen der den Zauber beendenden Worte seinen Lauf zu nehmen beginnt und das in das drohende „[E]rsaufen“ des Hauses resp. des Zauberlehrlings mündet; zum anderen das Weh, das dem Zauberlehrling droht, wenn die Ballade Der Zauberlehrling - wie in einigen der in der vorliegenden Arbeit behandelten Textbeispielen befördert auch hier der metonymische Titel eine autoreferenzielle Lesart - zum Stehen kommt. Außerdem kommt noch hinzu, dass in dieser Doppelung des Reimes bereits die wortwörtliche Doppelung des Besens vorweggenommen ist, die in der sechsten Refrainstrophe denn auch mit der wiederaufgegriffenen Geminatio „Wehe! wehe!“ (V. 79) eingeläutet wird.

Hinsichtlich der Ewigkeitsattribuierung von (schriftlichen) Werken hieße das bislang Beobachtete nun aber, dass ausgerechnet das Scheitern des Lehrlings dessen größter Erfolg wäre: Denn sein performativer Sprechakt hat ein (offenbar zu) dauerhaftes Werk erschaffen. Zugleich aber führt offenbar die Angst vor dem Kontrollverlust über das potenziell unendliche Wirken seines Werkes dazu, dass der Lehrling gleichsam an dieses sein Geschöpf gebunden bleibt, indem er dessen potenziell unendliches Wirken sprechend - und somit in letzter Konsequenz ebenfalls potenziell unendlich lange - begleitet. Die Worte des „Meisters“ mögen „vergessen“ sein, aber das "Wort" des Lehrlings bleibt gerade dadurch präsent. Dies alles führt dazu, dass das (zu) dauerhafte Werk des Lehrlings letztlich ein doppeltes ist: Auf der Ebene der fiktiven Welt des Zauberlehrlings ist es der belebte Besen; auf poetologischer Ebene ist es eine potenziell unendliche Ballade.

\section{1 .3 \\ Die der Versuch zu verewigen rief, die Geister, / Werd'n wir nun nicht los}

Das Sprechen des Lehrlings ist nach der entscheidenden, dritten Refrainstrophe (V. 37-42) ein anderes, ein vermeintlich nicht mehr performatives und damit auch in dieser Hinsicht machtloses Sprechen: In allen folgenden Strophen versucht sich der Lehrling an keinem performativen Sprechakt (im engeren Sinne nach Austins performativen Verben) mehr. ${ }^{71}$ Besonders deutlich wird dies an den Refrainstrophen, die keine Zauberformel mehr zu

71 Einzig dem Vers 88, „Herr und Meister! Hör’ mich rufen!“, könnte man zumindest performative Macht zuschreiben, da in Vers 89 der Meister als wieder zurückkehrend erzählt wird. Ob der Ausspruch „hör' mich rufen“, tatsächlich direkt performativ das Hören des Meisters bewirkt hat oder ob dieser ohnehin und von sich aus zu diesem Zeitpunkt zurückkehrt, lässt sich aber aufgrund mangelnder weiterer Informationen dazu nicht entscheiden. 
formulieren suchen, sondern nur noch der Beschreibung des Geschehens und der zunehmenden Verzweiflung des Zauberlehrlings dienen. ${ }^{72}$ Die eingangs erwähnte, die Dramatik der Ballade steigernde inhaltliche Variation der Refrainstrophe bei gleichbleibender Form macht dabei deutlich, wie sehr selbst das ohnmächtige Reden des Lehrlings noch an den Zauber gebunden ist, dessen Form es noch immer folgt.

Aber gerade dadurch - so die These - ist das vermeintlich machtlose, beschreibende Sprechen des Lehrlings als Ganzes performativ (im Sinne poetischer Performativität): Indem es potenziell unendlich lange das unendliche Wassertragen des Besens und dessen Auswirkungen beschreibend begleitet und damit das Gesprochene noch immer demjenigen entspricht, worauf verwiesen wird: einem unendlichen Prozess.

Damit werden zentrale Aspekte der Genieästhetik - man bedenke dabei auch die etymologische und semantische Verwandtschaft der Wörter „Geister“ und Genius - sowie der Verknüpfung derselben mit den göttlichen Attributen des Schöpferischen und Ewigen im Kontext performativen Sprachhandelns kritisch thematisiert: Liest man den Zauberlehrling als Genie, das mittels seiner Sprachkunst gottgleich Unbelebtes durch sein Wort und nach seinem Willen beleben kann, so führt die Ballade vor, welch gefährliches und für es selbst vernichtendes Potenzial die Gebundenheit des Genies an sein Erschaffenes und Erschaffen birgt, die Gebundenheit an die ewige Aufrechterhaltung eines performativen Sprechaktes. ${ }^{73}$

Die für Wandrers Sturmlied, das als für den Sturm und Drang und die Genieästhetik prototypisches Gedicht gilt, zentrale Phrase, die dort schon die Gefahren der Geniekonstitution anspricht, ${ }^{74}$ wird also ausgerechnet in der prototypisch klassischen Ballade Der Zauberlehrling erneut aufgegriffen, ${ }^{75}$ bloß mit umgekehrten Vorzeichen: ,Wenn du nicht verlässest den Genius ... resp. ihn nicht wenigstens zuweilen verlassen kannst ...' Um nicht in der Eigendynamik eines unendlichen ,Sich-als-Genie-konstituieren-Müssens ‘ zu ertrinken ${ }^{76}$ müsste das Genie seinen Genius auch verlassen können.

\section{Vgl. Brügger 1951, S. 254.}

73 Vgl. dazu auch das Kapitel II.3 zum ,unendlichen Schreiben'.

74 Vgl. Kapitel IV.3.3.1.

75 Es zeigt sich dabei auch einmal mehr, dass eine trennscharfe Einteilung in einen Goethe des ,Sturm und Drang' und einen der,Weimarer Klassik‘ nicht aufrechtzuerhalten und in vielen Fällen vielmehr eine zwar in ihren Formen und Akzenten sich verschiebende, aber kontinuierlich sich vollziehende Auseinandersetzung mit einzelnen Themenkomplexen zu beobachten ist (vgl. dazu auch Wellbery 1996).

76 Selbst die wohl auf Horazens Pindar-Lob zurückgehende, für die Genieästhetik bei Herder, Goethe, Hölderlin und anderen wichtige Strommetapher (vgl. Schmidt 2004, 
Gleichzeitig ist aber das Genie per definitionem an seinen Genius gebunden, sonst droht ebenfalls der Verlust der eigenen Existenz, zumindest der Existenz als Genie. Wahrhaftig, „Die Noth“, die das Beschwören des Geistes ,Genius“ hervorgerufen hat, "ist groß“ (V. 9o), und sie ist - auch dies wird in der vorliegenden Arbeit wiederholt gezeigt - Triumph und Fluch der anbrechenden Moderne zugleich.

Triumph und Fluch, auf die im ausgehenden 18. Jahrhundert unterschiedliche Antworten gesucht werden: eine Antwort ist die des "Meisters“, welche die Ballade selbst vorschlägt. Eine andere wäre die des Verstummens. Beide sind zudem unterschiedliche Antworten darauf, ob das potenziell unendliche Reden des Zauberlehrlings bloß dem unendlichen Treiben des Besens beschreibend folgt und damit streng genommen nur Performativität vortäuscht - ein Vorwurf, den man poetischer Performativität im Vergleich zu performativen Verben vermeintlich grundsätzlich machen könnte - oder ob die potenziell unendliche Rede des Zauberlehrlings nicht gar für das potenziell unendliche Treiben des Besens verantwortlich ist.

Zuerst zur Antwort des Verstummens, die allein auf der poetologischen Ebene anzusiedeln wäre: Weiter oben wurde bei der Auseinandersetzung mit der formalen und inhaltlichen Doppelung des „Wehe!“ (V. 41 und später 79) auf den autoreferenziellen Gehalt des metonymischen Titels der Ballade verwiesen, nämlich insofern, als dass das Ende der Belebtheit des Besens auch das Ende des lesenden Belebens der Ballade Der Zauberlehrling und damit auch der Figur des Zauberlehrlings bedeuten würde. Betrachtet man das Verhältnis von Balladentitel und Ballade jedoch noch genauer, so fällt auf, dass eine solche Lesart zwar durch den metonymischen Titel befördert wird, sie jedoch noch stärker und expliziter wäre, bezöge sich die Metonymie des Titels nicht auf den Zauberlehrling, sondern direkt auf den Besen. Einem solchen Titel - analog etwa zur Titelgebung Der Spinnerin Nachtlied (vgl. II.2.1) oder auch Der Phönix (vgl. IV.2.1) - würde sich ein offenes, fragmentarisches Ende der Ballade anerbieten, welches das Verstummen des Zauberlehrlings mit dem Verstummen der Ballade zusammenfallen ließe und dabei die Operation Unendliches Verstummen (vgl. Kapitel II.2) ins Zentrum der Reflexion von Dauer und Eigendynamik performativer Schöpfungskraft stellen würde. Dies tut die Ballade aber gerade nicht. Damit ist nun der Moment gekommen, abschließend überzuleiten zur Antwort des Meisters, die sich sowohl bloß auf die fiktive Welt der Ballade als auch auf die poetologische Ebene derselben beziehen lässt:

Bd. 1, S. 182-184) wird damit im Zauberlehrling mit ebenjenen umgekehrten Vorzeichen kritisch verhandelt. 
In die Ecke,

Besen! Besen!

Seid's gewesen.

Denn als Geister

Ruft euch nur, zu seinem Zwecke,

Erst hervor der alte Meister." (V. 93-98)

Denn es gibt zwei mögliche Lesarten, wie der Meister das potenziell endlose Weiterreden des Lehrlings ab Vers 41 wertet:

a) Auf der Ebene der fiktiven Welt der Ballade wertet er es nicht performativ: Daraus ergibt sich die erste Lehre für den (Wort-)Zauberlehrling, nämlich dass sich über einen performativen Sprechakt Hergestelltes nicht über nicht sprachliche Handlungen rückgängig machen lässt. ${ }^{77}$ Der Lehrling hatte in seiner Verzweiflung noch versucht, die eigene performative Sprachhandlung durch eine physische, nicht sprachliche Handlung zu beenden, indem er den Besen „[m] it dem scharfen Beile spalten“ (V. 70) wollte. Auf dieser physischen Ebene war die Handlung zwar durchaus erfolgreich: „Wahrlich! brav getroffen! / Seht, er ist entzwei!" (V. 75 f.). Doch da der performative Sprechakt resp. der Zauberspruch davon nicht betroffen ist und unbeirrt weiterwirkt, ist er nun zwei Besenteilen inhärent und damit in seiner belebenden Funktion verdoppelt. Die nicht sprachliche Attacke auf performativ Konstituiertes hatte also - ganz nach der Vorlage Lukians ${ }^{78}$ - den Zauber nur noch verstärkt. Der Meister nun aber beendet den Spuk mit einem den ursprünglichen performativen Sprechakt des Lehrlings aufhebenden zweiten performativen Sprechakt. ${ }^{79}$

Der Wechsel zwischen performativer Rede des Lehrlings, physischer Handlung desselben und erneuter performativer Rede des Meisters findet sich dabei auch in der Anordnung der einzelnen Strophen wieder: Die ersten beiden Refrainstrophen sind identisch, erwecken dadurch am meisten den Eindruck einer Zauberformel und rahmen zugleich die zweite Strophe, die mit ihnen zusammen den performativen Sprechakt des Lehrlings ausmacht. Diese Doppelung des ersten Refrains stellt zum einen aus, dass Iteration resp.

77 So kann etwa eine Taufe oder Namensgebung nur über einen erneuten Sprechakt rückgängig gemacht resp. geändert werden und nicht über die Vernichtung der Namensurkunde, ja nicht einmal durch den Tod des Namensträgers. Das Vergessen eines Namens ebnet dabei bloß den Weg zu einem neuen Taufakt, auch bei Toten, makaberes Paradebeispiel für Letzteres wäre etwa der berühmte „Ötzi“.

78 Vgl. Goethe, Gedichte, 2008, S. $716 \mathrm{f}$.

79 Und dies auf eine wahrhaft meisterlich zu nennende Weise, die - über die Ansprache der Besen als (lebendig) "gewesen[e]“ - den eigenen performativen Sprechakt und dessen Wirkung sogleich live mitkommentiert. 
Iterabilität auch die Möglichkeitsbedingung performativer Sprechakte ist, ${ }^{80}$ und zum anderen weist sie auf die Eigendynamik der Verdoppelung des belebten Besens voraus: der belebende Spruch wird zweimal aufgesagt, und in der sechsten und letzten Refrainstrophe des Lehrlings sind es dann auch tatsächlich zwei verzauberte Besen, während aus der Zauber- eine Klageformel wurde. Letzteres ist am deutlichsten ersichtlich daran, dass der die Zauberformel eröffnende Befehl "Walle, walle“ (V. 9 und 23) durch die Klage "Wehe! wehe!" ersetzt ist:

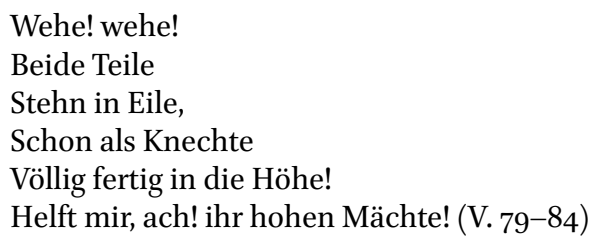

Dieser Doppelung der ersten beiden Refrainstrophen gegenübergestellt ist die ungedoppelte Refrainstrophe des Meisters: Meisterhaft bezieht er sich in der Geminatio „Besen! Besen!“ auf beide durch den Lehrling belebten Besen"Teile" und damit auch auf dessen beide ersten Refrainstrophen und setzt so dem Treiben mit einer Strophe, den performativen Rahmen gewissermaßen schließend, ein Ende.

b) Auf einer poetologischen Ebene wertet die Figur des Meisters das potenziell unendliche Sprechen des Lehrlings performativ oder zumindest, falls nicht performativ, so doch als gefährlich und mit einem eigenen performativen Akt zu stoppen: In diesem Falle legt die Ballade eine zweite Lehre nahe:

Der Meister ist derjenige, der sowohl die Macht besitzt, zur rechten Zeit die geforderten performativen Sprechakte zu vollziehen, als auch vermag, sich performativ als Meister zu setzen.

Denn der Schlussrefrain, die Zauberformel des Meisters, enthält nicht nur einen, sondern zwei ${ }^{81}$ performative Sprechakte: Zum einen beendet der „Meister" mit seiner eigenen Zauberformel das Sprechen und den Zauber des Lehrlings, zum anderen erweist er sich damit als der Meister, als den er sich selber nennt.

8o Vgl. Derrida 1999.

81 Vgl. dazu auch Laufhütte, der festhält: „Zwar sind alle 6 Verse der Schlußgruppe an die beiden Besen gerichtet - daher der doppelte Vokativ -, aber die umfangreichere Schlußpartie ist situationsbezogen, also nicht mehr zur Formel gehörig, und richtet sich in Wirklichkeit an die Andresse [sic] des Schülers, mit dessen voraufgegangenem Bekenntnis sie korrespondiert" (ders. 1979, S. 63). 
Kehrt man schließlich zu den eingangs angestellten Überlegungen zur allegorischen Bedeutung von Lehrling und Meister zurück, ließe sich nun also folgern: Wenn Der Zauberlehrling tatsächlich eine satirische Allegorie auf unliebsame Zeitgenossen im Xenien-Streit ist, dann eine mit einem Gestus durchdrungen von der alten, an Selbstbewusstsein kaum zu überbietenden Idee des Genies, das im Erschaffen sich selber schafft. Goethe - so wäre nun eine allegorische Lesart anzupassen - kopiert zwar den Prosatext des „alten []meister[s]" (vgl. V. 1) Lukian, variiert ihn aber zugleich, indem er die Auseinandersetzung mit performativen Sprechakten und deren Dauer aufgrund der dialogisch-dramatischen Struktur seiner Ballade noch vertieft - und sich dabei zugleich und wiederum performativ ebenfalls als Meister erweist.

An dieser Stelle ist jedoch noch einmal ganz genau hinzuschauen: Die Auseinandersetzung der Ballade mit dem Aspekt der Dauer eines performativen Sprechaktes erfährt nämlich eine bedeutende Akzentuierung durch den Ort, an dem das Wort (!) „Meister“ (V. 98) performativ gesetzt wird: am Ende und damit nebst der inhaltlichen auch in kompositorischer Antithese zum Titel Der Zauberlehrling sowie, zusammen mit dem „Hexenmeister“ im ersten Vers, in rahmender Funktion. Dies impliziert, dass es nicht nur meisterhaft ist, sich als Meister performativ zu setzen, sondern auch, dass sich Meisterschaft gerade auch durch das Setzen eines (rahmenden) Endes konstituiert. Der Lehrling strebt zwar auch nach Meisterschaft, jedoch droht er sich in der oben und im Kapitel zur Genieästhetik (vgl. IV.3.3.1) erwähnten Gefahr zu verlieren: in der Gefahr, sich in einem unendlichen Schöpfungsprozess ewig als Genie konstituieren zu müssen und dabei früher oder später zu scheitern.

Aus der Sicht des sich durch u. a. das Setzen eines Endes als solchen konstituierenden Meisters, der im Weitersprechen des Lehrlings keinen performativen Akt sieht (vgl. oben Punkt a), bedient sich der Lehrling einer Operation, die potenziell unendlich und damit ewig weiterführbar wäre, dadurch aber jede meisterhafte Vollendung verfehlt. Die obige historische Kontextualisierung hat im Zusammenhang mit Jean Paul und dem Fragmentarischen bereits auf ein differenzierteres Bild des Goethe der Weimarer Klassik verwiesen, und so lässt sich gemäß der Lesart b) eben auch formulieren: Der Meister anerkennt vielleicht den Lehrling als schöpferisches Genie, greift aber ein, aus der Furcht, der Lehrling könnte sich im Versuch, sich dauerhaft als Genie zu konstituieren, ein Verfahren wählen, das dem Meister obschon (oder gerade weil) er selbst dem Lehrling bereits einen Teil dieses Weges vorgemacht hat - nicht $(\mathrm{mehr})$ geheuer ist. ${ }^{82}$

82 Das Verhältnis zwischen „dem Wortschwall des Schülers“ und der „souveräne[n] Knappheit des Meisters" ist also weitaus komplexer als die bloße antithetische Gegenüberstellung, auf die schon Brügger verwiesen hat (ders. 1951, S. 254). 
Ein solches, dem Meister nicht mehr ganz geheures Verfahren wäre die Kombination der hier behandelten Operation Poetische Performativität mit der Operation Unendliches Verstummen. Dabei wäre jedoch letztere, anders als in der vorliegenden Ballade, die dominante. Die Operation Unendliches Verstummen und deren performatives Potenzial in Bezug auf die Ewigkeitsattribuierung von schriftlichen Werken werden wesentliche Konstituenten der romantischen Poetik sein, die jedoch der Ästhetik des Weimarer Klassikprojektes zumindest teilweise widerspricht. Wäre Der Zauberlehrling nach jener Kombination verfasst, so entspräche dies einer Ballade, die ohne schließende ,Meisterstrophe' mit einem Verstummen des Lehrlings enden würde. Es wäre dies, so könnte man sagen, der ,romantische‘ Zauberlehrling. ${ }^{83}$ Goethe hingegen sucht seine klassische Ballade nicht ex negativo ins Unendliche, Unbeendbare zu öffnen, sondern ihr mit aller Sprachmacht ein Ende zu setzen. Ein Ende, das der Ballade aufgrund der damit verbundenen Reflexion auf die Ballade selbst, auf deren Performativität sowie auf die performative Schöpfungskraft im Allgemeinen eine gewisse Autonomie verleiht.

Es zeigt sich damit einmal mehr, dass die ästhetischen Positionen der Weimarer Klassik und der Romantik nicht trennscharf voneinander zu scheiden sind, sondern sich in vielem überschneiden, so auch in der Art und Weise, wie Ewigkeitsattribuierung von Schriftzeichen angestrebt und reflektiert wird. Beide literarischen epochalen Konfigurationen - dies wird u. a. in Kapitel II.3 im Zusammenhang mit dem Fragment und in Kapitel IV.3 im Zusammenhang mit der Reflexionsphilosophie, Genie- und Autonomieästhetik gezeigt - setzten dabei auf Operationen der Performativität, der Autoreflexivität und der Poetologie. Während aber die frühromantische Ästhetik das Unabschließbare und damit auch das potenziell Endlose vehement bejaht, indem sie gerade auch die Operation Unendliches Verstummen zur Ewigkeitsattribuierung ihrer Werke einsetzt, ${ }^{84}$ steht die Ästhetik der Weimarer Klassik in dieser Hinsicht vor einem (unlösbaren) Problem:

Gerade die von ihrvertretene Autonomieästhetik, die die Autonomie und damit auch die Ewigkeit der betreffenden Werke durch jene Operationen zu erreichen sucht, hat zugleich das potenziell Unendliche jener Operationen einzudämmen, um die ebenfalls angestrebte und jene Autonomie festigende Abgeschlossenheit und Ganzheit des Werkes nicht zu gefährden.

Oder in anderen Worten:

83 Vgl. dazu insbesondere Kapitel II.2.1 zu Brentanos Der Spinnerin Nachtlied.

84 Vgl. die Kapitel II.2 und II.3. 
Die Geister der Verewigung, die Exponenten wie Goethe, Herder und Schiller zur Zeit der Weimarer Klassik, aber auch und gerade in ihrer vorklassischen, genieästhetischen Vergangenheit gerufen haben, werden sie nun nicht mehr los.

Den Xenien-Streit und das versuchte Eindämmen der Eigendynamik, die die selbst eingeführte Gattung des Xenions angenommen hatte, mag man ebenfalls als "Geister" lesen. Sie sind aber - so wurde soeben gezeigt - weder die größten noch die wirkmächtigsten Geister, mit denen nicht nur (selbsternannte) Meister bis heute zu ringen haben. ${ }^{85}$ Dass jenes Problem sich auch einem anderen ,Meister', dem Roman Wilhelm Meister nämlich, stellt, ist denn auch vor diesem Hintergrund nicht weiter erstaunlich. ${ }^{86}$

\subsection{Wallenstein}

Wie bereits in der Einführung erwähnt, strebt dieses Kapitel keine umfassende Auseinandersetzung mit Friedrich Schillers gesamter Wallenstein-Trilogie (1798) an. Es beschränkt sich im Wesentlichen auf die ersten drei Abschnitte des Prologs und auf diejenigen Textstellen, die im Zusammenhang mit Wallensteins Sehnsucht nach der Unsterblichkeit seines Namens besonders relevant sind. Aufgrund dieses spezifischen Fokus wird auf einen einleitenden Überblick über die Forschung zur Wallenstein-Trilogie insgesamt verzichtet und jeweils direkt dort auf die Forschungsliteratur eingegangen, wo sie für den hier untersuchten, spezifischen Gegenstand relevant ist. An dieser Stelle sei jedoch auf eine an der Universität Zürich entstandene, kurz vor der Publikation stehende Dissertation verwiesen, die ganz der Performativität und Metatheatralität der Wallenstein-Trilogie gewidmet ist. Zwei der darin von Kathiana Meyer verfolgten, grundlegenden Thesen lauten, dass sich einerseits eine Analogie zwischen der Figur Wallenstein und einem Schauspieler aufdränge, was eine poetologische, metatheatrale Lesart unterstütze, und dass sich andererseits Wallensteins Macht (und Ohnmacht) auf performative Sprechakte gründen würde. ${ }^{87}$ Meyers Arbeit und der im vorliegenden Kapitel erarbeitete Befund, Performativität werde in der Wallenstein-Trilogie auch ganz spezifisch

85 Als ein fast schon unheimlicher Zufall erscheint es da, dass Oliver Krüger in seiner Monographie Virtualität, Unsterblichkeit in der Mediengesellschaft ein Zitat von Johannes Rohbeck aufgreift, der Goethes Zauberlehrling als Allegorie verwendet, um die Kränkung zu veranschaulichen, die der (moderne) Mensch durch seine eigenen Schöpfungen erlebe: die Kränkung, dass sie ihre Schöpfer (gerade auch hinsichtlich ihrer Lebensspanne) übertreffen und eine eigene Dynamik entfalten können (vgl. Krüger 2004, S. 85).

86 Vgl. dazu das Kapitel IV.1 zur Operation Autoreflexivität und den am Schluss desselben skizzierten Vergleich des Wilhelm Meister mit Novalis' Heinrich von Ofterdingen.

87 Vgl. Meyer, Kathiana: Performativität und Metatheatralität in Schillers Wallenstein (Arbeitstitel), noch unveröffentlichte Dissertation an der Universität Zürich. 
als Operation zur Ewigkeitsattribuierung von Schriftzeichen resp. schriftlicher Dichtkunst eingesetzt, vermögen sich somit gegenseitig zu ergänzen und zu bekräftigen.

1.2.1 Prolog (Abschnitte eins bis drei)

Die bislang eingehendste Auseinandersetzung mit dem Prolog der WallensteinTrilogie stammt von Martin Wagner, der "die inhaltliche und formale Kohärenz des Prologs erstmals ausführlich zur Diskussion" stellt: ${ }^{8}$

Nachvollzogen werden kann [über den ganzen Prolog hinweg, MG] ein (nicht immer expliziter) Gedankengang, der von der im Augenblick des Vortrags gegenwärtigen Szene im neueröffneten Theater zu einer Erfahrung von Zeitlichkeit und zu einer historischen Reflexion führt, die dann in einem letzten Schritt an ein ästhetisches Modell rückgebunden wird. ${ }^{89}$

DarausleitetWagner - vorallem Diltheys Argumentation in dessen WallensteinAufsatz von 1895 folgend ${ }^{90}$ - eine Sonderstellung von Schillers Trilogie in der Literaturgeschichte ab:

Dies ist es, was Wallenstein mitsamt seinem Prolog von allen früheren historischen Dramen unterscheidet: dass ihm die Geschichtlichkeit seines Stoffes, die Distanz des Stoffes zur Gegenwart, thematisch und problematisch geworden ist. Die Wallenstein-Trilogie ist das erste deutsche Drama, das nicht einfach einen Fall aus der Vergangenheit als zeitloses bzw. direkt übertragbares Exempel vorführt (wie es bei Shakespeare, in den historischen Dramen des deutschen Barocks und in gewisser Weise noch bei Lessing und Schillers Zeitgenossen Zacharias Werner und Heinrich Joseph Collin der Fall war), sondern die Vergangenheit an sich, in ihrer Distanz zur Gegenwart, auf die Bühne bringt. ${ }^{91}$

Der Verfasser stimmt Wagner im Grundsatz zu; einer derart pointiert vertretenen Sonderstellung Schillers ist jedoch etwas kritisch zu begegnen: Einerseits ist schwer nachzuvollziehen, dass z. B. ausgerechnet Shakespeare

88 „Selbst in den Arbeiten zum Wallenstein, die den Prolog ausführlicher diskutieren (u. a. Hinderer 19[8o], 127-134, Oellers, Lamport, Golz, Michelsen), werden meist nur einzelne Zitate herausgegriffen, ohne deren Position im Gesamtgefüge des Prologs näher zu berücksichtigen“ (Wagner 2012, S. 366 resp. 379, Anm. 2). Dem ist auch hinsichtlich der Stellen des Prologs zur Ewigkeit und Vergänglichkeit der Künste zuzustimmen; auf sie wird etwa bei Hinderer nur in einem Satz beschreibend verwiesen (vgl. Hinderer 1980, S. 33; so auch bei Lamport 1989, S. 329).

$89 \quad$ Wagner 2012, S. 368.

$90 \quad$ Vgl. Wagner 2012, S. 377; und Dilthey 1977, insbesondere S. $76 \mathrm{f}$.

91 Wagner 2012, S. 376; vgl. auch ebd., Anm. 25, S. 385 . 
Vergangenes distanzlos auf die Bühne bringen soll. Andererseits ist hier auf die historische Relativierung des Genies, dessen Werke und deren Dauer, die Herders Shakespeare-Aufsatz bereits 1773 vornimmt, zu verweisen..$^{92}$ Schiller stünde demnach mindestens im Kontext einer bereits seit Jahrzehnten bestehenden geistes- und literaturgeschichtlichen Kontinuität der historischen Relativierung. Vor diesem Hintergrund wird ersichtlich, dass das von Wagner beobachtete und soeben zitierte Vorgehen Schillers letztlich demjenigen, das Herder zur historischen Relativierung des Genies bemüht, entspricht:

Denn gerade dadurch, dass die Wallenstein-Trilogie eine historische Distanzierung des aufgeführten Exempels vornimmt, sucht sie ein zeitloses Exempel - nicht die Person Wallenstein, sondern das dramatische Werk, Wallenstein' - zu erschaffen und festzuhalten.

Und wenn Wagner seine Untersuchung mit dem Satz „[s]o oder so bildet die Inszenierung von Vergangenheit die entscheidende Erfahrung für das ästhetische Programm der Weimarer Klassik“93 schließt, so vermag das vorliegende Unterkapitel zum Prolog der Wallenstein-Trilogie zu ergänzen, dass diese „Inszenierung von Vergangenheit" eng verknüpft ist mit der Ewigkeitsattribuierung von (insbesondere dichterischen, schriftlichen) Kunstwerken, vielleicht gar dieser überhaupt erst entspringt. Ähnliches gilt auch für Wagners Beobachtung zur Autonomieästhetik, das im Prolog entworfene „neue[] Verständnis von Vergangenheit im historischen Drama" führe zu einem "Geschichtsbegriff", der mit dem Autonomiebegriff der Weimarer Ästhetik koinzidiere. ${ }^{94}$ Eine Beobachtung, die - abgesehen von der in dieser Pointierung mit Vorsicht zu genießenden Verwendung des Adjektivs „neue[]“95 von den im Kapitel zur Autonomieästhetik aufgestellten Thesen ${ }^{96}$ unterstützt wird und auf die weiter unten noch einmal zurükzukommen ist. Nach dieser Auseinandersetzung mit Martin Wagner, die der Leser im Folgenden im Hintergrund mitbedenken möge, sei nun zum Prolog selbst und zur textnahen Analyse von dessen ersten drei Abschnitten übergegangen:

Die ersten beiden Absätze des Prologs zu Wallensteins Lager resp. zur gesamten Wallenstein-Trilogie, „[g]esprochen bey Wiedereröfnung der Schaubühne in Weimar im Octobr. 1798“, entfalten u. a. prominent das Wortfeld der Erneuerung und Verjüngung:

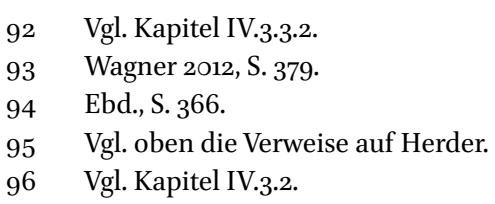


Der scherzenden, der ernsten Maske Spiel, Dem ihr so oft ein willig Ohr und Auge Geliehn, die weiche Seele hingegeben, Vereinigt uns aufs neu in diesem Saal Und sieh! Er hat sich neu verjüngt, ihn hat Die Kunst zum heitern Tempel ausgeschmückt, Und ein harmonisch hoher Geist spricht uns Aus dieser edeln Säulenordnung an, Und regt den Sinn zu festlichen Gefühlen.

Und doch ist dies der alte Schauplatz noch, Die Wiege mancher jugendlichen Kräfte, Die Laufbahn manches wachsenden Talents. Wir sind die Alten noch, die sich vor euch, Mit wahrem Trieb und Eifer ausgebildet. Ein edler Meister stand auf diesem Platz, Euch in die heitern Höhen seiner Kunst, Durch seinen Schöpfergenius entzückend. O! möge dieses Raumes neue Würde Die Würdigsten in unsere Mitte ziehn, Und eine Hoffnung, die wir lang gehegt, Sich uns in glänzender Erfüllung zeigen! Ein großes Muster weckt Nacheiferung Und giebt dem Urtheil höhere Gesetze. So stehe dieser Kreis, die neue Bühne, Als Zeugen des vollendeten Talents Wo möcht es auch die Kräfte lieber prüfen, Den alten Ruhm erfrischen und verjüngen, Als hier vor einem auserlesnen Kreis, Der rührbar jedem Zauberschlag der Kunst, Mit leis beweglichem Gefühl, den Geist In seiner flüchtigsten Erscheinung hascht?97 (Prol., V. 1-31)

Dabei vollzieht sich zu Beginn des zweiten Abschnittes eine komplexe chiastische Verschränkung von Alt und Neu: Die Rede bewegt sich im ersten Abschnitt von der implizit als alt erinnerten Schaubühne zur nun wiedereröffneten und als „neu verjüngt“ eingeführten. Der zweite Abschnitt beginnt mit dem „Und doch“ eine Antithese, die implizit an das im ersten Abschnitt soeben etablierte Neue anknüpfend zum „alte[n] Schauplatz“ zurückkehrt, der mit dem „noch“ einerseits als dauernd und andererseits als Ursprung,

97 Die Textstellen des Prologs werden im Folgenden zitiert nach dem Text des am 12. Oktober 1798 bei der Uraufführung von "Wallensteins Lager" gesprochenen, von Goethe bearbeiteten Prologs, wie er in der Schiller-Nationalausgabe in der neuen Ausgabe von Band 8, Teil 2, S. 383-386, wiedergegeben ist. 
als „Wiege mancher jugendlicher Kräfte“, bezeichnet wird. Schematisch dargestellt ergibt dies folgende Bewegung:

$$
\text { von Altem zu Neuem - }
$$

von diesem Neuen zu Altem, das (im Neuen) überdauert -

von diesem Alten als Ursprung von Neuem gerade dadurch wieder zum Neuen

Die schematische Darstellung macht dabei nicht nur die chiastischen Verschränkungen deutlich, sondern auch sichtbarer, dass die dritte Bewegung zum einen der ersten entspricht und zum anderen sich zugleich als Ursprung derselben bezeichnet. ${ }^{98}$ Damit wird die Schaubühne in Weimar als Ort inszeniert, an dem sich ein ewiger „Kreis“99-Lauf der Hervorbringung von Neuem, von Verjüngung und Überdauern des Alten vollzieht.

Wo das Wortfeld des Überdauerns sich entfaltet, da ist - wie u. a. im Zusammenhang mit der Genieästhetik belegt wird ${ }^{100}$ - das Wortfeld des Schöpferischen, des neben der Ewigkeit zweiten zentralen göttlichen Attributes, nicht weit. Es erstaunt also nicht, wenn der "Schöpfergenius" in Vers 17 dann auch explizit genannt wird, freilich sich (vermeintlich) bescheiden noch auf Friedrich Ludwig Schröder beziehend. ${ }^{101}$ Doch was sich für Herder und Goethe beobachten lässt - nämlich dass sie, wenn sie von einem anderen Genie sprechen, auch sich selbst mitmeinen,$-{ }^{102}$ das trifft hier auch auf Schiller zu: Ein Prolog, der äußerst kunstfertig schöpferisch-genialische Kunst feiert, feiert immer auch sich selbst und den eigenen Verfasser. ${ }^{103} \mathrm{Im}$ Zusammenhang mit dieser metonymischen Verknüpfung des Gelobten und dessen Werk mit dem Lobenden und dem (lobenden) Werk desselben erlangt wiederum die Rede von dem Ort und dessen architektonischer Wirkung eine poetologische Metaphorik (insbesondere die Verse $5^{-14}$ ), die sich auf die

98 Eine ähnliche Bewegung lässt sich für die Grobstruktur des gesamten Prologs beobachten, „die von der Reflexion des Augenblicks und der Zeit auf der Bühne zu einer Geschichtsphilosophie führt, die ihrerseits wiederum das Kunstverständnis beeinflusst“ (Wagner 2012, S. 368 f.).

99 V. 24. Das Wort "Kreis“ kommt dabei nicht nur in Bezug auf den Ort, sondern, vier Verse später, auch in Bezug auf die Rezipienten vor.

100 Vgl. Kapitel IV.3.3.2.

101 Kurt Rothmann vermerkt in den Kommentaren der Reclam-Ausgabe von Schillers Wallenstein hierzu: „[Vers, MG] 15 Ein edler Meister: Friedrich Ludwig Schröder (1744-1816), der in Weimar gastiert hatte und nach Schillers Brief vom 2o. Februar 1798 bereit war, den Wallenstein zu spielen“ (Rothmann 2009, S. 140).

102 Vgl. Kapitel IV.3.3.

$103 \mathrm{Zu}$ Schillers (und seines Namens) eigenen „Tode[n] und Unsterblichkeiten“ sowie der zentralen Bedeutung von Unsterblichkeit im Schreiben und Denken Schillers vgl. Helmstetter 2010. 
architektonische Wirkung des Prologs und der Wallenstein-Trilogie selbst beziehen lässt. Nicht nur der Ort der Rede, die neue Schaubühne, sondern vor allem auch Schillers Tragödie, zu der der Prolog bereits gehört, ${ }^{104}$ stehen also im Zeichen der Verhandlung von Altem und Neuem sowie deren Verschränkung, und dies in mindestens zweifacher Weise:

1. Die Tragödie nimmt auf inhaltlicher Ebene wiederholt explizit Bezug auf Aufstieg, Fall und Wiederaufstieg (des historischen) Wallensteins. ${ }^{105}$ Das dreiteilige Stück steigt dabei ein auf dem Höhepunkt ebenjenes Wiederaufstiegs und führt hin zu einem zweiten Fall, von dort zur Hoffnung auf einen erneuten raschen Wiederaufstieg, die aber jäh beendet wird durch Wallensteins Tod, der zugleich auch den dritten Teil der Tragödie, Wallensteins Tod, in ein Ende(n) überführt.

2. Der Prolog, selbst bereits Teil der Tragödie, thematisiert im dritten Abschnitt explizit die Vergänglichkeit der Schauspielkunst:

Denn schnell und spurlos geht die mimische Kunst

Die wunderbare, an dem Sinn vorüber,

Wenn das Gebild des Meißels, der Gesang

Des Dichters nach Jahrtausenden noch leben;

Hier stirbt der Zauber mit dem Künstler ab,

Und wie der Klang verhallet in dem Ohr,

Verrauscht des Augenblicks geschwinde Schöpfung.

Und ihren Ruhm bewahrt kein dauernd Werk.

Schwer ist die Kunst, vergänglich ist ihr Preis,

Dem Mimen flicht die Nachwelt keine Kränze,

Drum muß er geitzen mit der Gegenwart,

Den Augenblick, der sein ist, ganz erfüllen,

Muß seiner Mitwelt mächtig sich versichern

Und im Gefühl der würdigsten und besten

Ein lebend Denkmal sich erbaun - So nimmt er

Sich seines Nahmens Ewigkeit voraus,

Denn wer den Besten seiner Zeit genug

Gethan, der hat gelebt für alle Zeiten. (V. 32-49)

Dies ermöglicht, ähnlich wie schon im ersten Abschnitt implizit im Falle der Architektur, die Herstellung von Äquivalenzverhältnissen zwischen der

104 Diese Zugehörigkeit des Prologs zum Stück bezieht sich nicht nur auf das Lesedrama, sondern auch auf die Uraufführung, bei der „der als Kürassier verkleidete Schauspieler Vohs" und damit in Gestalt eines Kürassiers bereits eine Figur aus Wallensteins Lager den Prolog sprach (vgl. Rothmann 2009, S. 140). Vohs soll sogar der Schauspieler gewesen sein, der später bei der Aufführung von Die Piccolomini und Wallensteins Tod den Max Piccolomini gespielt habe ...! (vgl. Lamport 1989, S. 323).

105 So u. a. in den Versen: II, V. 246-257; III, V. 549-623. 
Schauspiel- und der Dichtkunst, die jetzt auch teilweise explizit gemacht werden: War in den ersten beiden Abschnitten noch das Wortfeld der (unendlichen) Verjüngung dominant, so entfaltet sich nun - bereits eingeleitet durch den letzten Vers des zweiten Abschnittes - das Wortfeld des Flüchtigen und der Vergänglichkeit in Bezug auf die Schauspielkunst: Deren "Schöpfung“ ist an den flüchtigen „Augenblick“ gebunden, „ihren Ruhm bewahrt kein dauernd Werk". Jenes zuvor in den Abschnitten eins und zwei entfaltete Wortfeld der (unendlichen) Verjüngung wird jedoch zugleich weitergeführt, expliziert und als Paradigma der Ewigkeit der Dichtkunst der Flüchtigkeit der Schauspielkunst antithetisch gegenübergestellt.

Parallel zu seinem vermeintlich eigentlichen Gegenstand, der Schauspielkunst, zelebriert der dritte Abschnitt damit eine explizite Ewigkeitsbehauptung sowohl gegenüber der bildenden Kunst als auch gegenüber der Dichtkunst, wobei die Erwähnung der bildenden Kunst hier in mehrfacher Anspielung auf Horaz' Metaphorik des dauerhaften Monuments (und weiter unten dann auch auf Ovid ${ }^{106}$ hauptsächlich im tropischen Dienste der Ewigkeitsbehauptung gegenüber der Dichtkunst steht. Dass dabei das schriftliche Werk des Dichters gemeint ist, wird daran klar, dass zwar metonymisch vom „Gesang des Dichters“, der "nach Jahrtausenden noch leb[t]“, die Rede ist, „der Klang“ aber als der, der „verhallet in dem Ohr", beschrieben wird. ${ }^{107}$ Und hier kommt nun auch entscheidend die Operation der Performativität ins Spiel: Indem der Prolog- und der gesamte Dramentext als schriftlich festgehaltenes Werk das Potenzial besitzen, die Textgrundlage der flüchtigen Schauspielkunst für immer zu bewahren, vermögen sie „Die Wiege mancher jugendlicher Kräfte, / Die Laufbahn manches wachsenden Talents“ zu sein; jedes Mal nämlich, wenn dieses schriftliche Werk wieder aufgeführt wird. So vollzog denn auch im Grunde schon der Schauspieler Vohs, der im Gewande eines Kürassiers - und damit schon als Figur von Wallensteins Lager - an der Uraufführung den schriftlich festgehaltenen Prolog auswendig sprach und damit wiederbelebt hat, performativ, was der dritte Abschnitt des Prologs der Dichtkunst zuschreibt. ${ }^{108}$

\footnotetext{
106 Vgl. die Einführung, in der beide betreffende Textstellen von Horaz und Ovid zitiert sind.

107 Zu dieser Problematik der Flüchtigkeit, die letztlich doch auch keinen Halt vor dem lesenden ,Gesang' macht, siehe die folgenden Abschnitte - und (umfassender) Kapitel II.2.2 zu Hölderlins Ode Ermunterung.

108 Jesper Svenbros These, der Ursprung des stillen Lesens im antiken Griechenland sei aus der stummen Rezeption der im Theater dargebotenen "Vokalschrift“ entstanden, würde hier (zusammen mit Svenbros weiteren, zum Teil bereits in Kapitel 3.4 der Einführung erwähnten Beobachtungen) einen faszinierenden Anknüpfungspunkt finden; vgl. Svenbro 2005, S. 146-168.
} 
Der Prolog - so die These - bringt hier vielleicht weniger "die Vergangenheit an sich, ihre Distanz zur Gegenwart, auf die Bühne ${ }^{409}$ als vielmehr die Ewigkeitsattribuierung der Dichtkunst. ${ }^{110}$ Oder in anderen Worten:

Dass der Prolog einerseits bereits als Teil des Dramas inszeniert wird und andererseits implizit sich selbst in Abgrenzung zur Schauspielkunst als ewiges dichterisches Werk bezeichnet, ist die Voraussetzung dafür, dass er als Werk der Dichtkunst das vollziehen kann, worauf er verweist. Und zwar indem er die (Text-)Grundlage für die flüchtige mimische Kunst schriftlich festhält. Gerade durch diesen performativen Vollzug dessen, worauf er selbst verweist, schafft der Prolog sich ein Stück Zeitenthobenheit - und kann im Grunde erst dadurch einhalten, was er sich zuschreibt. ${ }^{111}$

Die Verhandlung von Flüchtigkeit und Ewigkeit gewinnt in der zweiten Hälfte des dritten Abschnitts (V. 41-49) noch weiter an Komplexität, nämlich dort, wo von der Ewigkeit der Schauspielkunst die Rede ist. Zur besseren Übersicht sei die folgende Auseinandersetzung mit diesen Versen in vier Schritte unterteilt:

1) Aufgrund der mehrdeutigen Zeilen ist nicht klar zu entscheiden, welche Art von Ewigkeit der Schauspielkunst zugesprochen wird. Einerseits kann man das „lebend Denkmal“ als bloßes Qualitäts- und Intensitätsmerkmal für eine schauspielerische Leistung verstehen, die sich „im Gefühl der würdigsten und besten“ im "Augenblick“ der Darbietung aufbaut, aber keinen Anspruch auf Dauer haben kann.

2) Andererseits - und es gibt wohl mehr Anlass, diese Lesart anstatt a) zu favorisieren - lässt sich die Stelle so verstehen, dass der Eindruck, den der Schauspieler „im Gefühl der würdigsten und besten“ hinterlässt, sich in deren Gefühlswelt wie „das Gebild des Meißels“ (V. 34) resp. wie Schriftzeichen eingeprägt hat und darin bis zum Zerfall der Materialität des Bildnisses resp. des Schriftträgers überdauert. Da dieser Zerfall nun aber einhergeht mit dem Tod "der würdigsten und besten“, geben diese einen weitaus vergänglicheren Datenträger ab als jene der bildenden oder dichterischen Kunst. Denn eine dauerhaftere Konservierung eines schauspielerischen Werkes ist in einer Zeit vor dem Medium des Films nur möglich, wenn es selber Gegenstand der Dichtung wird. Ein Beispiel dafür hat der Prolog bereits performativ vollzogen,

\footnotetext{
109 Wagner 2012, S. 376.

110 Und zwar im Sinne sowohl eines Genitivus obiectivus als auch subiectivus.

111 Die personifizierenden Formulierungen in dieser These dienen nicht der Anthropomorphisierung des Prologs, sondern sind rein heuristischer Natur, um ausschweifende, das Verständnis erschwerende Passivkonstruktionen etc. zu vermeiden; vgl. zu solcher Art Begrifflichkeit auch Kapitel 2 der Einführung.
} 
indem er im zweiten Abschnitt die schauspielerische Leistung von "Meister“ (V. 15;) Friedrich Ludwig Schröder würdigte. ${ }^{12}$

3) Der Schluss liegt deshalb nahe, dass die Ewigkeit des schauspielerischen Werkes nicht direkt in jenem „lebend Denkmal“ „im Gefühl der würdigsten und besten" liegt, sondern in einem weiteren Übertragungsschritt darin, dass die „würdigsten und besten“ dieses „Denkmal“ vor Ergriffenheit selbst in ein dauerhafteres Kunstwerk übersetzen oder sich zu Taten angespornt fühlen, die dann wiederum Anlass dazu geben, sie in einem Kunstwerk (dauerhaft) festzuhalten. Die „würdigsten und besten“ wären dann diejenigen, die einerseits der Empfindung jenes „lebend Denkmal“ fähig sind und andererseits über Künste verfügen, die sich besser zur Verewigung eignen; oder aber diejenigen, die als ein künftiger Gegenstand dieser Künste taugen).

4) Gerade die Zeitstruktur des Schlusses des dritten Abschnitts ist besonders schwierig zu deuten: „Den Augenblick, der sein ist, ganz erfüllen / [...] Ein lebend Denkmal sich erbaun - So nimmt er / Sich seines Nahmens Ewigkeit voraus, / Denn wer den Besten seiner Zeit genug / Gethan, der hat gelebt für alle Zeiten." Des „Nahmens Ewigkeit“, von der hier mit Anklang an Ovids Nachwort der Metamorphosen und antiker Erinnerungskultur die Rede ist, ist bereits ein Eingeständnis an die sprachliche Kunst. Denn letztlich ist sie es, in der das Kunstwerk und, in Form des Namens, der Schauspieler überdauern - nicht direkt der Schauspieler selbst noch dessen mimisches ,Werk'. Und wie bereits im Übergang vom ersten zum zweiten Abschnitt begegnet uns hier erneut die rhetorische Figur eines (doppelten) Chiasmus, die die Zeitstrukturen - dieses Mal Gegenwart und Zukunft - miteinander verschränkt und damit in einen verjüngenden (vgl. V. 5 und 27) Kreislauf überführt. Schematisch dargestellt wird dies wie folgt sichtbar:

Der Schauspieler hat den Augenblick zu erfüllen, um ein Denkmal von Dauer zu errichten

Dadurch holt er sich die Ewigkeit in die Gegenwart

Wem dies in der Gegenwart gelungen ist, wird für immer gelebt haben

Die behauptete "Ewigkeit" ist also letztlich keine mimische, sondern eine genuin sprachlich-rhetorische und zeigt weniger die Ewigkeit der Schauspielkunst als vielmehr die Fähigkeit der Dichtkunst, dieses Attribut sich selbst zuzuschreiben.

Doch wer jetzt denkt, die Ewigkeitsattribuierung der Dichtkunst würde in diesen Versen ohne jegliche kritische Reflexion betrieben, sieht sich durch

112 Rothmann 2009, S. 140. 
eine erneute Wendung getäuscht, die ausgerechnet die soeben beobachtete chiastische Verschränkung bereithält. Was von der Schauspielkunst behauptet wird, trifft nämlich ebenso, wenn nicht noch mehr, auf die Ewigkeit der Dichtkunst zu: Letztlich ist eben auch „der Gesang [d]es Dichters“ (V. 34 f.) auf einen ,Sänger angewiesen, der diesen Gesang im „Augenblick“ der „Gegenwart" aktualisiert. Des Dichters "Nahmens Ewigkeit" bleibt - wie es Ovid im Nachwort der Metamorphosen schon bewusst war - an die Leser gebunden. Oder eben an einen Schauspieler, der den Text des schriftlichen Dramas vorträgt: Der Dramendichter schafft für die Ewigkeit, aber ausgerechnet die Ausresp. Aufführung seines Dramas erfolgt in der vom Prolog als das flüchtigste Medium bezeichneten Mimenkunst. Man denke dabei nur an V. 37 des dritten Abschnittes, wo es zur Schauspielkunst heißt: „Und wie der Klang verhallet in dem Ohr“. Ein Verhallen, das letztlich ebenso sehr auf die Werke der Dichtkunst zutreffen muss, gerade für ein Werk, das wie Wallensteins Lager durchgehend in Reimen gehalten ist.

Liest man die Reime in Wallensteins Lager auf dieser im Prolog eingeführten, poetologischen Ebene, so lässt sich sagen: Der in den Gesprächen seiner Soldaten festgehaltene unsterbliche Ruhm sowohl der Figur als auch der historischen Person Wallenstein wird eben letztlich auch als ein an die Aktualisation durch Rezipienten gebundener, verhallender, vergänglicher und damit jene explizite Ewigkeitsbehauptung unterlaufender inszeniert (mehr dazu weiter unten). ${ }^{113}$ Dies ist wohl auch der Grund, weshalb, dem quasi wiederum entgegenwirkend, die Rezipienten (wie zuvor der Ort, vgl. V. 24) metonymisch - aber hinsichtlich der potenziell endlos erneuerbaren Rezeption eines schriftlich fixierten Werkes auch metaphorisch - als "Kreis“ (V. 28) bezeichnet sind. Als die geometrische Figur, die weder Anfang noch Ende besitzt, als „Kreis“, der auch die „flüchtigste[] Erscheinung“ (V. 31) erhaschen könne. ${ }^{114}$ (Dass die behauptete „Ewigkeit“ letztlich keine mimische, sondern eine genuin sprachlich-rhetorische ist, gilt dabei auch für die Wiederaufnahme alter Formen, wie sie Schiller mit den Knittelversen in Wallensteins Lager vornimmt, deren „altes deutsches Recht“ (V. 131) er erinnert und wofür

113 Vielleicht ist dies auch mit ein Grund für den Meinungswechsel Schillers, Wallensteins Lager in Paarreimen zu halten - entgegen seiner eigenen ursprünglichen, in der Vorrede zum Don Carlos vertretenen Ablehnung des Reimes im Drama (vgl. Wagner 2012, S. 367 und 379, Anm. 2).

114 Es mag in den ersten Abschnitten des Prologs durchaus auch eine ironische Ebene hinzutreten, diese jedoch als dominant zu erachten und die Verse 29-31 als eine bloße „humorige Demagogie, die mit Augenblinzeln sich selbst decouvriert“, zu bezeichnen, wie Wolfgang Heise es in seiner Auseinandersetzung mit dem Prolog tut, hält der Verfasser für verfehlt (vgl. Heise 199o, S. 405 f.). 
er Zuhörer und Leser am Ende des Prologs um Wohlwollen bittet (V. 124 f., 129-132). ${ }^{115}$ Die Wiederaufnahme der Knittelverse trägt damit ebenfalls performativ zur neuen Verjüngung (vgl. V. 5 und 25) bei, von der das Stück im Prolog zu sprechen begonnen hat.) ${ }^{116}$

Dieses Unterkapitel zusammenfassend lässt sich somit zum Prolog ein wesentlicher Befund festhalten:

Dort, wo Schiller von der Flüchtigkeit des schauspielerischen Werkes schreibt, zelebriert er - insbesondere unter Einsatz der Operation Poetische Performativität, aber auch der Operationen Poetologie und Autoreflexivität ${ }^{17}$ - die Ewigkeit des schriftlichen dichterischen Werkes, das selbst den Rahmen resp. die Textgrundlage der "mimische[n] Kunst" festzuhalten vermag. Dabei unterläuft in den letzten Versen des dritten Abschnitts ausgerechnet die Ewigkeit, die der Schauspielkunst zugeschrieben wird, die Ewigkeit der Dichtkunst, indem sich auch letztere als ebenso "Augenblick[s]"-gebunden entpuppt. Doch ausgerechnet durch diesen poetologischen Selbstbezug der Dichtkunst sucht sie sich - selbst und gerade in der Rede von ihrer Vergänglichkeit ${ }^{118}$ - ein Stück Zeitenthobenheit (performativ) zu erschreiben.

Daraus wiederum ergibt sich folgende Hypothese, der es in den unten stehenden Kapiteln nachzugehen gilt:

Wenn im Prolog derart explizit von der Ewigkeit der Dichtkunst die Rede ist und zugleich implizit versucht wird, diese Ewigkeitsbehauptung gegenüber der Dichtkunst performativ zu bestätigen, so ist davon auszugehen, dass der Prolog gerade auch in dieser Hinsicht eine programmatische Stellung für den gesamten Wallenstein einnimmt, dessen Untertitel, ein dramatisches Gedicht, ihn explizit als dichterisches Werk ausweist.

Bemerkenswert ist hier zudem der Umstand, dass auch Wilhelm von Humboldt in seinem langen Brief an Schiller über den Wallenstein (Paris, Anfang September 180o) sowohl auf Autoreflexivität im philosophischen und sprachlichen Sinne zu sprechen kommt als auch die Performativität (wenngleich nicht im engen Sinne der hier behandelten poetischen Performativität) des Wallenstein streift, indem er von den Betrachtungen zum Stück zu

\footnotetext{
115 Vgl. dazu Wagner 2012, S. 367, auch wenn dabei dessen Aussage, der Reim ändere nichts am Inhalt selbst, eine seltsam verkürzte, nicht zu befürwortende Auffassung des Reimes ist (siehe dazu z. B. zu Ende des vorangegangenen Abschnitts); Kaiser 1977, S. 352 f.; und Lange 1973, S. 78-82.

116 Vgl. zur Verjüngung auch Müller-Seidel 1977, S. 383-385.

117 Vgl. dazu auch Wagner 2012, S. 371 f.; und insbesondere Kapitel IV.3.2 zur Autonomieästhetik.

118 Vgl. dazu auch das Kapitel IV.2.2 zu Schillers Nänie.
} 
Aussagen über die kognitiv-schöpferische Macht von Sprache gelangt. ${ }^{119}$ Auf die Bedeutung von Humboldts Wallenstein-Lektüre für dessen genau um diese Zeit beginnende verstärkte Auseinandersetzung mit der menschlichen Sprache hat Jürgen Trabant hingewiesen. ${ }^{120}$ Eine eigene Arbeit zu Humboldts Semiotik, die die Beobachtungen Trabants fortführt und mit den Ergebnissen des vorliegenden Kapitels kombiniert, wäre u. a. für die Geschichte der modernen Sprachwissenschaft und deren frühe (implizite) Prämissen hoch interessant: Ähnlich wie im Falle Herders und der Enstehung der modernen Literaturwissenschaft ${ }^{121}$ drängt sich nämlich die Hypothese auf, dass Humboldts beginnender Fokus auf die Sprache eng verknüpft ist mit der Ewigkeitsbehauptung und -attribuierung literarischer Texte.

\subsubsection{Flüchtigkeit des Krieges und Überdauern des Namens}

Im oben zitierten dritten Abschnitt des Prologs wird bereits - schon in der Antike präsenten Vorstellungen folgend ${ }^{122}$ - die Ewigkeit und Vergänglichkeit der Künste mit der Ewigkeit und Vergänglichkeit des Namens der Künstler in Verbindung gebracht. Der soeben aufgestellten Hypothese zur Programmatik des Prologs für den gesamten Wallenstein sei deshalb im Folgenden dahingehend nachgegangen, als dass der Name Wallenstein und der sich mit dem Namen verbindende „Ruhm“ (Prolog, V. 39) des Feldherrn in den Fokus rückt. Den Anfang macht Wallensteins Lager: Da in diesem ersten Teil der Trilogie der Feldherr nicht persönlich auftritt, seine Soldaten aber umso mehr von ihm sprechen, führen sie dessen Namen und Ruhm einerseits ein, andererseits wäre zu erwarten, dass hierzu der Name Wallenstein besonders oft fällt. Wallenstein wird aber neben dem/den Titel(n) im gesamten Stück Wallensteins Lager bloß viermal auch bei ebendiesem Namen genannt. Diese vier Stellen haben es bei genauer Lektüre jedoch in sich:

Die erste Nennung ist ausgerechnet eine, die den Träger des Namens nicht als berühmt, sondern als berüchtigt einführt, und zwar in einem Wortspiel des Kapuziners:

Lässt sich nennen den Wallenstein, Ja freylich ist er uns, allen ein Stein (I, V. $619 \mathrm{f}$.) $)^{123}$

\footnotetext{
119 Vgl. Humboldt 1962, u. a. S. 206-208.

120 Vgl. Trabant 2008, insbesondere S. 55-59 und 65.

121 Vgl. die Auseinandersetzung mit Herders Shakespeare-Aufsatz in Kapitel IV.3.3.2.

122 Vgl. die Einführung.

123 Die Textstellen aus Wallensteins Lager (I), Die Piccolomini (II) und Wallensteins Tod (III) werden im Folgenden zitiert nach dem Erstdruck von 180o, wie er in der SchillerNationalausgabe in der neuen Ausgabe von Band 8, Teil 2, S. 449-777, wiedergegeben ist.
} 
Die erste Nennung von "Wallenstein“ schreibt diesem Namen also explizit eine fast schon performative ${ }^{124}$ Macht zu, nämlich die, dass die darin enthaltenen Worte allen und Stein ${ }^{125}$ nicht nur auf etwas verweisen, sondern in der Person Wallenstein zur Wirklichkeit werden.

Die drei weiteren Nennungen hingegen stammen nicht von Gegnern Wallensteins, sondern von seinen Soldaten und verbinden dessen Namen auf den ersten Blick mit (für die Soldaten) positiven Attributen:

ZWEYTER JÄGER.

Auf des Friedländers Wort und Kredit allein

Haben wir Reitersdienst genommen;

Wär's nicht aus Lieb' für den Wallenstein,

Der Ferdinand hätt' uns nimmer bekommen. (I, V. 709-712)

WACHTMEISTER.

(auf den Trompeter zeigend).

Und der da und ich, wir sind aus Eger.

$[\ldots]$

Wer hat uns so zusammen geschmiedet,

Daß ihr uns nimmer unterschiedet?

Kein andrer sonst als der Wallenstein!

ERSTER JÄGER.

Das fiel mir mein Lebtag nimmer ein,

Daß wir so gut zusammen passen;

Hab mich immer nur gehen lassen. (I, V. 795-8o9)

ZWEITER JÄGER.

Freyheit ist bey der Macht allein.

Ich leb' und sterb' bey dem Wallenstein. (I, V. 1022-1023)

Auf den zweiten Blick hingegen unterlaufen die in den drei Namensnennungen verwendeten Reime die einende sowie um sich scharende Macht des Namens „Wallenstein“ - und das weitaus spezifischer als nur über die Hörbarmachung des Verhallens (vgl. Prolog, V. 37) des wortwörtlich zugesprochenen Ruhmes. Denn ausgerechnet dort, wo seine Soldaten eine Petition in die Wege leiten, die bekräftigen soll, dass sie ihn unter keinen Umständen allein lassen werden, ausgerechnet dort reimt sich „Wallenstein“ zweimal auf „allein“ und einmal auf

124 Im Sinne der eingangs von Kapitel III aufgestellten allgemeinen Definition von Performativität.

125 Etymologisch eigentlich von ,Wald-Stein; vgl. Rothmann 2009, S. 159; und Davies 2010, S. 153-159. Letzterer auch mit einer ausführlichen Darstellung der um die Namen ,Waldstein' und ,Wallenstein' ausgetragenen nationalistischen Debatten im 19. und frühen 20. Jahrhundert. 
"ein“. So nehmen die mit dem Namen verbundenen Reime das Schicksal des Namenträgers, der am Ende der Trilogie allein, von fast allen verlasen, einsam sterben wird, bereits vorweg. Nicht nur das Wort ,Stein', wie der Kapuziner bemerkt, findet sich in Wallensteins Name, sondern eben auch das Wort ,ein. ${ }^{126}$

Überdies verwenden die Soldaten resp. die Marketenderin zwei zusätzliche Male die Bezeichnung „Wallensteiner“:

ERSTER JÄGER.

Ja, ja, im Ganzen, da sitzt die Macht!

Der Friedländer hat das wohl erfahren,

Wie er dem Kaiser vor acht - neun Jahren

Die große Armee zusammenbracht.

[...]

Und so wurden wir Wallensteiner. (I, V. $748-75^{6}$ )

WACHTMEISTER ( fährt in die Tasche).

Wollt ihr mein Wort nicht gelten lassen,

Sollt ihr's mit Händen greifen und fassen.

(Eine Münze zeigend.)

Wes ist das Bild und Gepräg?

MARKETENDERIN.

Weist her!

Ei, das ist ja ein Wallensteiner! (I, V. 870-872)

Im ersten Fall wird Wallensteins Name zum metonymischen Sammelbegriff für diejenigen, die unter ihm dienen und ihm folgen. Es zeigt sich darin auch wortwörtlich die einende Macht, die der Name - nicht zuletzt auch auf sprachlich-grammatikalischer Ebene - (noch) ausübt. Im zweiten Fall unterstreicht der Besitz des Münzrechts Rang und zugleich Anspruch Wallensteins, ${ }^{127}$ ist aber auch Sinnbild dafür, dass jene einende Macht, die Wallenstein auf seine Soldaten ausübt, auch wesentlich auf den finanziellen Möglichkeiten des Feldherrn beruht.

Abgesehen von den soeben angeführten Nennungen von "Wallenstein“ verwenden die Soldaten in Wallensteins Lager üblicherweise den Namen „Friedländer“, so auch an der ersten Stelle, an der sie explizit von ihrem Feldherrn sprechen:

\footnotetext{
126 Neben der heutigen Bedeutung als Indefinitartikel vgl. auch eine der mittelhochdeutschen Bedeutungen von ,ein' im Sinne von ,allein, einsam' (vgl. Lexer 1992, S. 36).

127 Vgl. I, V. 874.
} 


\section{WACHTMEISTER.}

Merkst du wohl? sie trauen uns nicht, Fürchten des Friedländers heimlich Gesicht.

Er ist ihnen zu hoch gestiegen,

Möchten ihn gern herunter kriegen. (I, V. 77-80)

Dabei wird bereits das für das vorliegende Unterkapitel zentrale Paradoxon eingeführt, das der Figur Wallenstein und ihres „Nahmens Ewigkeit“ (Prolog, V. 47) inhärent ist: Bei Fried-land handelt es sich um den Fürstentitel Albrechts Wenzel Eusebius von Wallenstein, den dieser sich durch Krieg erworben hat. ${ }^{128}$ Sein (Kriegshand-)Werk ist damit metonymisch in seinen Namen eingegangen, in einen Namen aber, der mit dem Bestimmungswort ,Fried' ausgerechnet dem Umstand, dem er sich verdankt (nämlich dem Krieg), entgegensteht. Dieses Paradoxon wird mit Blick auf des "Nahmens Ewigkeit" dahingehend zum Problem, als dass der Krieg ein schlechter Garant für Dauer ist. Nun strebt aber das Genie, wie in der vorliegenden Arbeit wiederholt dargelegt, in hohem Maße nach ewiger Dauer, dem göttlichen Attribut, das es für seine Konstitution letztlich ebenso braucht wie das göttliche Attribut des Schöpferischen. Seine einzigartige Schöpfungskraft beschreibt Wallenstein gegen Ende der Trilogie gleich selber. Er wird dadurch nicht nur über die im Verlaufe der Stücke erfolgten Zuschreibungen anderer, sondern auch über seine Selbstzuschreibung als Genie inszeniert:129

Den Schmuck der Zweige habt ihr abgehauen,

Da steh' ich, ein entlaubter Stamm! Doch innen Im Marke lebt die schaffende Gewalt, Die sprossend eine Welt aus sich gebohren.

[...]

Ich sollte aufstehn mit dem Schöpfungswort

Und in die hohlen Läger Menschen sammeln.

Ich that's. Die Trommel ward gerührt. Mein Nahme

Ging wie ein Kriegsgott durch die Welt. [...]

- Noch fühl' ich mich denselben, der ich war!

Es ist der Geist, der sich den Körper baut,

Und Friedland wird sein Lager um sich füllen. (III, V. 1791-1814)

Es ist ein bemerkenswerter Zufall (?), dass die Metapher des entlaubten Stammes, die Herder in seinem Shakespeare-Aufsatz als Sinnbild für die

128 Vgl. Rothmann 2009, S. 159 .

129 Vgl. dazu u. a. Borchmeyer 1988, S. 142-145; Kaiser 1977, S. 362; und schon Dilthey 1977, S. 86. 
Vergänglichkeit der Menschen aus der Ilias übernimmt, ${ }^{130}$ ausgerechnet hier wieder auftaucht, und zwar mit der Implikation, dass das selbstbewusste Ich Wallensteins die Kraft habe, jener Vergänglichkeit entgegenzuwirken und neue Blätter zu treiben. Wie „ein Kriegsgott“ beschreibt Wallenstein seinen Namen und damit metonymisch auch sich selbst. ${ }^{131}$ Wenn der Kapuziner in Wallensteins Lager ausruft, "Weiß doch niemand an wen der [Wallenstein, MG] glaubt!" (I, V. 594), wäre die Antwort also vor allem: an sich selbst'. Damit entpuppt sich aber Schillers Wallenstein weniger als historische Figur des 17. als vielmehr des zeitgenössischen späten 18. Jahrhunderts, in dem die religiöse Hoffnung auf ewiges Leben derart unsicher geworden ist, dass der Versuch, sich über weltliche Strategien der Unsterblichkeit zu versichern, zu größten intellektuellen Anstrengungen führt. ${ }^{132}$ Was aber Wallenstein - und mit ihm jedem Genie vom 18. Jahrhundert bis heute - zu wahrer Göttlichkeit fehlt, ist und bleibt bei aller Schöpfungskraft die ewige Dauer seiner Werke und seiner selbst. Dies wiederum führt einen wieder zurück zum Paradoxon des durch Krieg erworbenen Namens ,Friedland':

Octavio - und zwar in Belehrung seines Sohnes Max, der Wallenstein ausgerechnet dahingehend in Schutz nimmt, als dass der Feldherr im Kriege „[n] icht todte Bücher, [...] nicht modrigte Papiere“ (II, V. 461 f.) befragen soll - bemerkt dazu:

- Du hast den Frieden nie gesehn! Es giebt

Noch höhern Werth, mein Sohn, als kriegerischen, Im Kriege selber ist das letzte nicht der Krieg.

Die großen, schnellen Thaten der Gewalt, Des Augenblicks erstaunenswerthe Wunder, Die sind es nicht, die das Beglückende,

Das ruhig, mächtig Daurende [sic] erzeugen. (II, V. 483-489)

Es zeigt sich hier das Dilemma des nach Unsterblichkeit strebenden Genies, ein Dilemma, das im Verlaufe der vorliegenden Untersuchung bereits mehrmals zu beobachten war: Um sich dauerhaft als Genie zu konstituieren, muss es entweder ein ewiges Werk erschaffen oder ewig erschaffen. Letzteres ist für einen Feldherrn wie Wallenstein der noch weitaus prekärere Weg als etwa im Falle

\footnotetext{
130 Vgl. IV.3.3.2 und die Auseinandersetzung mit Wagner und der historischen Relativierung, die Schiller vornehme, im vorangegangenen Unterkapitel III.1.2.1.

131 Vgl. zu dieser Stelle auch Borchmeyer 1988, S. 144.

132 Vgl. dazu insbesondere die historisch-kontextualisierenden Kapitel dieser Arbeit. Bezeichnend dafür ist zudem auch die von Borchmeyer festgestellte Ähnlichkeit der letzten beiden Monologe Fausts mit der oben zitierten Selbstbeschreibung Wallensteins (vgl. ders. 1988, S. 144 f.).
} 
des Dichters Jean Paul, ${ }^{133}$ denn während ein ewiges Schreiben im Falle des (unabwendbaren) Scheiterns noch immer auf das Überdauern des Geschriebenen hoffen kann, so gilt dies nicht für die kriegerische Tätigkeit des Feldherrn. Der Krieg ist - und dahin gehen Octavios Worte - keine Werke erschaffende und Menschen bewahrende, sondern eine Werke und Menschen vernichtende Kraft, die deren Vergänglichkeit umso deutlicher macht. Keiner bringt dies alles besser auf den Punkt als Wallenstein selbst in seiner berühmten Aussage: "Wenn ich nicht wirke mehr, bin ich vernichtet" (III, V. 528). ${ }^{134}$

Wallenstein ist also nur so lange (genialer) Feldherr, wie er Krieg führt; will er ein Feldherr bleiben resp. gar ein unsterblicher Feldherr sein, so müsste er auf ewig Krieg führen, denn die Möglichkeit, sich über ein Kriegswerk von Dauer metonymisch zu verewigen, hat er nicht. In Schillers Wallenstein wird so eine Analogie zwischen dem Darstellungsraum Krieg und dem Darstellungsraum Theater konstituiert, die Leistungen des Feldherrn sind nur so lange von Dauer, wie ihm dazu die Bühne des Krieges zur Verfügung steht.

Damit befindet sich die Figur Wallenstein in derselben Situation, wie sie für den „Mimen“ (Prolog, V. 41) resp. Schauspieler im Prolog beschrieben wird, ${ }^{135}$ denn sowohl für den „Mimen" als auch für den Feldherrn gilt: Es „[v]errauscht des Augenblicks geschwinde Schöpfung, / Und ihren Ruhm bewahrt kein dauernd Werk" (Prolog, V. $38 f$.$) - dazu sind sie auf Werke anderer Künste angewiesen.$

Auf die für den Fokus dieser Arbeit besonders interessierende poetologische und performative Dimension, die diese Analogie von "Mimen“ und Feldherrn mit sich bringt, wird weiter unten zurückgekommen. Zunächst seien aber die Auswirkungen in den Blick genommen, die das oben Dargelegte auf inhaltlicher Ebene des Stücks zeitigt: Wallenstein betrachtet sich, im Aufstieg Jupiters geboren (vgl. II, V. 966-1002), selbst als eines der „hellgebohrnen, heitern Joviskinder" (II, V. 985), als ein Kind desjenigen also, der Saturn $\left(\right.$ Kronos/Chronos) ${ }^{136}$ und damit die Zeit besiegt hat. Nichtsdestotrotz ist sich Wallenstein der Vergänglichkeit seines Tuns und seiner selbst durchaus bewusst und sucht nach einem Weg, seine vergänglichen kriegerischen Werke

\footnotetext{
133 Vgl. das Kapitel II.3.

134 Vgl. dazu auch Gerhard Kaiser, der die Rolle von Wallenstein als „der Vater, der Schöpfer, der Gott dieser Armee“ bei gleichzeitiger chiastischer Abhängigkeit dieses Schöpfers von seinen Truppen (und damit seinem Kriegswerk) betont (ders. 1977, S. 334 f.).

135 Vgl. dazu auch den einen Satz bei Lamport 1989, S. 329 f.; und die nicht viel längere Bemerkung (unter Verweis aber auf Schillers Ästhetische Briefe) bei Graham 1974, S. 126.

${ }_{13}$ Zur bereits antiken Gleichsetzung von Kronos (Saturn) und Chronos (Zeit) sowie zu Saturn in Schillers Lyrik vgl. Borchmeyer 1988, S. 50-53.
} 
in ein Werk von Dauer zu überführen. ${ }^{137}$ Der Weg, den er dafür zunächst einzuschlagen gedenkt, führt über seine Tochter Thekla, wozu es zwei zentrale Stellen gibt: Die erste befindet sich im vierten Auftritt des zweiten Aktes von Die Piccolomini, wo sich Thekla und ihr Vater nach Jahren der Trennung zum ersten Mal wiedersehen. Neben den hier ersichtlichen - und in der zweiten Stelle erneut geäußerten - Plänen Wallensteins ist auch bemerkenswert, dass Thekla Wallenstein als nicht der Zeit unterworfen wahrnimmt, während umgekehrt Wallenstein im Bewusstsein seiner Vergänglichkeit Thekla als Mittel zur Unsterblichkeit ins Auge fasst:

\section{HERZOGIN (zur Prinzessin).}

Du hättest deinen Vater wohl nicht wieder

Erkannt, mein Kind? Kaum zähltest du acht Jahre,

Als du sein Angesicht zuletzt gesehn.

THEKLA.

Doch, Mutter, auf den ersten Blick - Mein Vater

Hat nicht gealtert - wie sein Bild in mir gelebt,

So steht er blühend jetzt vor meinen Augen.

WALLENSTEIN (zur Herzogin).

Das holde Kind! Wie fein bemerkt und wie

Verständig! Sieh', ich zürnte mit dem Schicksal,

Daß mir's den Sohn versagt, der meines Namens

Und meines Glückes Erbe könnte seyn,

In einer stolzen Linie von Fürsten

Mein schnell verlöschtes Daseyn weiter leiten.

Ich that dem Schicksal Unrecht. Hier auf dieses

Jungfräulich blühende Haupt will ich den Kranz

Des kriegerischen Lebens niederlegen,

Nicht für verloren acht' ich's, wenn ich's einst,

In einen königlichen Schmuck verwandelt,

Um diese schöne Stirne flechten kann. (II, V. 736-753)

Gemäß den in der Einführung zitierten Worten Diotimas in Platons Symposion bleiben dem Menschen zwei Möglichkeiten, sich selber zu verewigen: entweder biologisch über die Nachkommen oder - von der Figur Diotima höher

137 Ein Versuch, dessen Tragik bereits Wilhelm von Humboldt in seiner Wallenstein-Lektüre aufgefallen zu sein scheint. So teilt er Schiller in seinem Brief von Anfang September 1800 mit: „Wallenstein gleicht einer Naturkraft, und jeder tragische Held muß es unfehlbar mehr oder weniger. Es muß ein gleichsam unreiner, fremdartiger Stoff in die Masse kommen, damit eine Gärung entstehe und das Lautre und Fehllose, das eigentlich auf den Zuschauer wirken soll, sich rein abscheide. Aber Wallenstein ist es dadurch auf eine so große Weise, daß alles Schiefe in ihm und alles Mißgeschick außer ihm allein aus seinem Charakter, und in diesem nur aus jenem Verwechseln der Sphären, aus dem Suchen des Unvergänglichen im Vergänglichen entsteht“ (Humboldt 1962, S. 194). 
bewertet - über dauernde Werke. Für Wallenstein bedeutet dies aber, dass sein Wunsch, sich und seinen Werken Dauer zu verleihen, noch schwieriger umzusetzen ist als bisher dargelegt. Nicht allein Wallensteins Werke sind flüchtiger Natur, auch der biologische Weg zur Unsterblichkeit ist ihm erschwert: Der Feldherr gibt in der soeben zitierten Stelle aus Die Piccolomini zu, dass er sich einen Sohn gewünscht hätte, der seinen Namen und Fürstentitel über Wallensteins „schnell verlöschtes Dasein“ hinaus hätte weitertragen können. Da ihm dies das „Schicksal“ aber verwehrt hat, setzt er nun ganz auf seine Tochter. Und diese Tochter trägt bei Schiller - kaum zufällig abweichend vom Namen Marie Elisabeths, der historischen Tochter Wallensteins - ausgerechnet den Namen Thekla, zusammengesetzt aus theos, ,Gott', und kléos, ,Ruhm'. Jesper Svenbro hat in seiner Monographie Phrasikleia, die nach einem Grabmal für ein Mädchen benannt ist, deren Name ebenfalls das Wort kléos beinhaltet, ${ }^{138}$ u. a. ausführlich den komplexen Zusammenhang untersucht, der im antiken Griechenland oft zwischen der Hoffnung der Eltern auf ewigen Nachruhm und dem Namen ihrer Kinder besteht. ${ }^{139}$ Dass Schiller mit der Änderung des historisch korrekten Namens Marie Elisabeth in Thekla (bewusst?) ${ }^{140}$ direkt an diese Tradition anknüpft, ist bemerkenswert, denn was Wallenstein nun anstrebt, ist eine Kombination jener beiden von Diotima formulierten Möglichkeiten zur Erlangung der Unsterblichkeit:Wallenstein sucht sein (Kriegs-)Werk auf seine Tochter zu übertragen und damit Thekla letztlich zu seinem einzigen „dauernd Werk“ (Prolog, V. 39) zu machen. Sie soll den „Ruhm“ (Prolog, V. 39) des „Kriegsgott[es]“, als den er sich selber sieht resp. mit dem er sich als gottgleiches Kriegsgenie vergleicht, bewahren und damit letztlich auch „seines Nahmens Ewigkeit“ (Prolog, V. 47) über ihren Namen, ihren Königinnentitel und ihre Nachkommen sicherstellen. Dies bestätigt sich in der sehr ähnlichen, zweiten Stelle, wo Wallenstein dann auch explizit von "mein vollendet Werk“ spricht:

WALLENSTEIN.

Ließ ich mir's so viel kosten, in die Höh

Zu kommen, über die gemeinen Häupter

138 Zur Übersetzung des Namens Phrasi-klea als „Die auf das kléos achtgibt“ oder „Die auf das kléos aufmerksam macht" vgl. Svenbro 2005, S. 20.

139 Vgl. ebd., u. a. S. 15-30, 64-102 und 192 f. Und gerade in diesem spezifischen Zusammenhang bekunden auch bereits in den griechischen Texten Väter ihre Mühe, die für ihre eigene Verewigung benannten Töchter zu verheiraten (ebd., u. a. S. 87).

140 Nach den Anmerkungen von Kurt Rothmann sei Theklas Name „einem Moderoman, Gräfin Thekla von Thurn von Benedikte Naubert, entnommen“ (ders. 2009, S. 161). Dass der Name aus jenem Moderoman entnommen worden ist, mag sein, weshalb gerade dieser Name entnommen wurde, verdeutlichen Svenbro und das vorliegende Kapitel. 
Der Menschen wegzuragen, um zuletzt

Die große Lebensrolle mit gemeiner

Verwandtschaft zu beschließen? - Hab ich darum -

(plötzlich hält er inne, sich fassend.)

Sie ist das einzige, was von mir nachbleibt

Auf Erden, eine Krone will ich sehn

Auf ihrem Haupte, oder will nicht leben.

$[\ldots]$

(Er besinnt sich.)

Und ich sollte nun

Wie ein weichherz'ger Vater, was sich gern hat

Und liebt, fein bürgerlich zusammengeben?

Und jetzt soll ich das thun, jetzt eben, da ich

Auf mein vollendet Werk den Kranz will setzen -

Nein, sie ist mir ein langgespartes Kleinod,

Die höchste, letzte Münze meines Schatzes,

Nicht niedriger fürwahr gedenk' ich sie

Als um ein Königsscepter loszuschlagen - (III, V. 1516-1534)

Gerade diesem „vollendet Werk“ resp. seinem Schöpfer "flicht die Nachwelt keine Kränze“ (Prolog, V. 41), weswegen Wallenstein „den Kranz“ selbst zu flechten und zu „setzen“ bemüht sein muss. Die Analogie zwischen dem Feldherrn Wallenstein und dem „Mimen“ (Prolog, V. 41) tritt dabei noch stärker zu Tage als in der so ähnlichen Stelle in den Piccolomini, bedient sich Wallenstein hier in den Versen 1516-1519 gar selbst und explizit der Theatermetapher: Er fürchtet sich vor der Flüchtigkeit seiner „Lebensrolle“, denn er will kein "gemeine[r]" Schauspieler sein, an den und dessen „Werk" sich keiner erinnert, so „vollendet“ es auch (gewesen) sein mag.

Dieses Streben nach Unsterblichkeit spiegelt sich auch in Wallensteins Vertrauen in die Astrologie und in den Saturn-/Zeitbesieger Jupiter, ${ }^{141}$ es liefert sogar eine entscheidende Begründung für das lange Zögern der Figur Wallenstein: Wallenstein beschließt nämlich erst dann zu wirken (zu Beginn von Wallensteins Tod; und selbst da noch zögerlich), ${ }^{142}$ wenn er glaubt, dass Saturn - und damit auch die Zeit, wofür dieser steht ${ }^{143}$ - keine Macht besitzt und damit der perfekte Moment für ein ihn verewigendes Werk gekommen sei. ${ }^{144}$

141 Vgl. dazu ausführlich Borchmeyer 1988, der sich in seiner Monographie Macht und Melancholie. Schillers Wallenstein ausführlich mit der Astrologie und der Bedeutung Saturns in der Wallenstein-Trilogie auseinandersetzt.

142 Vgl. ebd., S. 70-72.

143 Vgl. dazu ebd., S. 53 .

144 „SENI. / Und beyde große Lumina von keinem / Malefico beleidigt! der Saturn / Unschädlich, machtlos, in cadente domo. 
1.2.3 Überdauern im Textum: Wallensteins Tod und Wallensteins Tod Am Ende des Unterkapitels zum Prolog wurde die These aufgestellt, dass, wenn im Prolog derart explizit von der Ewigkeit der Dichtkunst die Rede sei und zugleich implizit versucht werde, diese vermeintliche Fähigkeit der Dichtkunst performativ zu bestätigen, davon ausgegangen werde könne, dass der Prolog gerade auch in dieser Hinsicht eine programmatische Stellung für den gesamten Wallenstein einnehme. Und dies erst recht in einem Stück, das in seinem Untertitel ein dramatisches Gedicht explizit als Werk der Dichtkunst bezeichnet ist. Das bislang Dargelegte zur Flüchtigkeit des kriegerischen Werkes und zur erhofften Dauer des Namens hat diese These für die inhaltliche Ebene exemplarisch anhand von Wallensteins Plan mit Thekla bestätigt. Daran anknüpfend sei abschließend auf weitere, entscheidende Wechselwirkungen eingegangen, die sich daraus zwischen dem Prolog und dem restlichen Stück ergeben und über die rein inhaltliche Ebene hinausgehen.

Die Figur Wallenstein betrachtet ihr Werk als ebenso flüchtig, wie das Werk des Mimen im Prolog beschrieben wird. Sein Plan, aus Thekla ein unsterbliches Werk zu machen, scheitert zusammen mit den Plänen, Frieden zu schaffen, der - nach den Implikationen des Stücks - als Garant für Dauer (vgl. oben das Zitat Octavios) jenen ersten Plan überhaupt ermöglicht hätte. Als sich mit dem Verrat Octavios und zahlreicher Feldherren das Scheitern all dieser Pläne abzeichnet, zieht Wallenstein gar eine weitere Möglichkeit zur Erlangung der Unsterblichkeit in Betracht. Eine Möglichkeit, die nicht auf den positiven, in

WALLENSTEIN. / Saturnus' Reich ist aus, der die geheime / Geburt der Dinge in dem Erdenschooß / Und in den Tiefen des Gemüths beherrscht, / Und über allem, was das Licht scheut, waltet. / Nicht Zeit ist's mehr zu brüten und zu sinnen, / Denn Jupiter, der glänzende, regiert / Und zieht das dunkel zubereitete Werk / Gewaltig in das Reich des Lichts - Jetzt muß / Gehandelt werden, schleunig, eh' die Glücks- / Gestalt mir wieder wegflieht über'm Haupt, / Denn stets in Wandlung ist der Himmelsbogen“ (III, V. 22-35).

Das „dunkle Werk“ aus Saturns Reich der Vergänglichkeit wird dem Licht Jupiters preisgegeben und vernichtet, während nun eine Zeitspanne für ein Werk gekommen ist, das nicht jenem Reich des Vergänglichen angehören soll. Man vergleiche dazu auch Schillers handschriftliche Regieanweisungen für die Bühnenbilder, die wie schon das Paradigma des Verhallens resp. Verstummens am Ende des dritten Abschnittes des Prologs die behauptete Dauer unterlaufen und Wallensteins Scheitern vorwegnehmen: Die Planetenreihe soll so aufgestellt werden, dass ausgerechnet „Mars und Saturn dem Auge die nächsten sind“ (Rothmann 2007, S. 144). Ein Hintergrund, der für die siebte Szene also in derjenigen, in die auch Wallensteins Zitat „Wenn ich nicht wirke mehr, bin ich vernichtet“ (III, V. 528) fällt - zu wiederholen sei. Vgl. dazu auch Borchmeyer, der zum soeben zitierten Gespräch zwischen Seni und Wallenstein feststellt, dass Wallenstein das Zögern und Aufschieben „so zur Natur geworden [ist, MG], dass er sogar in der von ihm selbst bestimmten Stunde des Handelns der saturnischen Sphäre des ,Brütens und Sinnens" verhaftet bleibt" (ders. 1988, S. 72 ). 
Theklas Namen enthaltenen kléos abzielt, sondern auf einen gewissermaßen ,negativen Ruhm'. Eine Möglichkeit, die, wie schon die Positionen Diotimas, seit der Antike bekannt und berüchtigt ist und verstörenderweise auch im 21. Jahrhundert als terroristisches Prinzip Hochkonjunktur zu haben scheint. Die Rede ist vom Versuch, über eine größtmögliche Schandtat für immer in Erinnerung zu bleiben; ein Versuch, der bekanntlich in der Zerstörung des Artemis-Tempels von Ephesos, eines der sieben antiken Weltwunder, seinen Inbegriff gefunden hat. ${ }^{145}$ Dazu Wallensteins Worte zum Vorschlag seiner Schwester, „ein großer König [zu] seyn - im Kleinen“ (III, V. 511):

Wenn ich nicht wirke mehr, bin ich vernichtet; Nicht Opfer, nicht Gefahren will ich scheu'n, Den letzten Schritt, den äußersten, zu meiden; Doch eh' ich sinke in die Nichtigkeit, So klein aufhöre, der so groß begonnen, Eh' mich die Welt mit jenen Elenden Verwechselt, die der Tag erschafft und stürzt, Eh' spreche Welt und Nachwelt meinen Namen Mit Abscheu aus, und Friedland sey die Losung Für jede fluchenswerthe That. (III, V. 528-537)

Ob der historischen Person Wallenstein eine solche Form der Unsterblichkeit bis zu einem gewissen Grad gelungen ist, sei dahingestellt; im Stück selber scheint sie der Figur Wallenstein zu misslingen. Klar ist jedoch, dass sowohl für die historische Person und die Figur Wallenstein als auch für alle Ruhmestaten gilt (sei es in negativem Sinne wie beim Brand des Artemis-Tempels in Ephesos, sei es wie im - im Nachhinein - eher positiv in Erinnerung bleibenden Sinne wie etwa im Falle Julius Cäsars $\left.{ }^{146}\right)$ :Wären diese flüchtigen Taten nicht in

145 Obwohl derjenige, der dies der Legende nach zu verantworten hat, hier absichtlich nicht mit Namen genannt sei, ist allein schon der soeben knapp 2400 Jahre später vollzogene (gerade auch schriftliche) Verweis auf ihn eine Bestätigung für das Gelingen seines Unterfangens. Auf eine erschreckende Weise bemerkenswert ist dabei, dass sowohl in der Antike als auch im 21. Jahrhundert solche Schandtaten es offenbar ganz besonders auf die Zerstörung von Werken abgesehen haben, die selber explizit oder implizit den Anspruch, ein heiliges und ewiges Werk zu sein, erheben.

146 Vgl. III, V. 834-843: „Wallenstein: So laß uns das Nothwendige mit Würde, / Mit festem Schritte thun - Was thu ich Schlimmres [sic], / Als jener Cäsar that, deß Name noch / Bis heut' das Höchste in der Welt benennet? / [...] Warf er das Schwert von sich, er war verlohren, / Wie ich es wär', wenn ich entwaffnete. / Ich spüre was in mir von seinem Geist, / Gieb mir sein Glück, das andre will ich tragen." Bemerkenswert ist hierbei, dass die positive Wertung von Cäsars Taten und die Überlieferung derselben bis heute im Wesentlichen auf die (geschönte) Übertragung derselben in ein schriftliches Werk durch Cäsar selbst zurückzuführen sind. Der zweitletzte Vers wiederum spielt zudem auf die im 
dauerhaftere Werke der Dichtung und der Geschichtsschreibung übertragen worden, so wären sie heute bereits vergessen.

So ist es denn auch kein Zufall, dass der letzte Auftritt der Figur Wallenstein, die nicht nur die Rolle eines Feldherrn, sondern auch die eines „Mimen“ innehat, eine Textmetapher enthält: „Wallensteins Leichnam wird in einem roten Teppich hinten über die Szene getragen" (III, Regieanweisung zum elften Auftritt des fünften Aufzugs). Wallensteins Tod - entgegen dem Namen des Stücks - ist für den Zuschauer nicht sichtbar. Das Stück Wallensteins Tod geht über den Tod der Figur Wallenstein hinaus. Ja, es birgt die Figur Wallenstein bereits innerhalb des Stücks in dem, was sie immer schon gewesen sein wird und was ihr gemäß Prolog Dauer zu verleihen mag: in einem textum. Der Name, der Nam ${ }^{\prime 147}$ Wallensteins, kann nur in resp. als Text auf Ewigkeit hoffen. Während die Bezeichnung als Fürst - also ausgerechnet der Teil von Wallensteins Name, der dessen Kriegstaten festhält - im letzten Vers des Stücks kraft eines Textes, nämlich der Anrede, auf einem kaiserlichen Brief, auf Octavio übergeht, ${ }^{148}$ so führt die Szene mit dem Teppich auf poetologischer Ebene vor, was der Prolog explizit behauptet und das Stück als Ganzes performativ vollzogen hat. Was hier genau mit diesem "was" gemeint ist, sei nun abschließend dargelegt, um der höheren Leserfreundlichkeit willen erneut in vier aufeinander aufbauenden Schritten:

1) Wie bereits oben im Falle von E. T. A. Hoffmanns Kater Murr für die Vorworte und den eigentlichen Roman beobachtet, verwischen sich auch in Schillers Wallenstein die Grenzen zwischen Prolog und eigentlichem Stück. Bei Hoffmann wird durch dieses Verfahren vor allem die implizite Thematisierung von Ganzheit, Anfang und Ende des Romans selbst und des Mediums Buch im Allgemeinen ermöglicht. Bei Schiller, bei dem dies zwar durch jene Verwischung zwangsläufig auch mitschwingt, liegt der Akzent aber auf der Vermischung zweier Ebenen des Unsterblichkeitsdiskurses: einerseits der explizit kunsttheoretischen Ebene, die über Schauspielkunst im Allgemeinen spricht; und andererseits der inhaltlichen Ebene des eigentlichen Stückes, auf der Wallenstein die Vergänglichkeit und Dauer seiner selbst und seiner Werke umtreibt.

2) Dadurch nun, dass die kunsttheoretischen Abschnitte des Prologs bereits Teil des eigentlichen Stückes sind, weisen sie bereits darauf hin und sind

18. Jahrhundert geläufige Vorstellung an, dass ein Genie vor allem oder gar nur durch ein anderes Genie entzündet werden könne (vgl. Kapitel IV.3·3).

147 Auch wenn keine direkte etymologische Beziehung zwischen ,Name` und dem Grundwort von Leich-nam, ,Leib-Kleid', besteht (vgl. Deutsches Wörterbuch, Bd. 12, Sp. 625 bis 628), existiert eine klangliche, die hier dichterisch eingesetzt wird.

148 „Dem Fürsten Piccolomini“ (III, V. 3867). 
wesentlich daran mitbeteiligt, dass auch umgekehrt jene inhaltliche Ebene eine poetologisch-autoreflexive Dimension besitzt, die Teil der kunsttheoretischen Überlegungen zu Dauer und Vergänglichkeit von Kunst, Künstlern und ihrer Werke ist.

3) So wird virtuos die in Kapitel IV behandelte Grundoperation der Reflexivität angewandt, die der am Ende des dritten Abschnitts des Prologs implizit eben doch auch als vergänglich - oder zumindest als von Vergänglichkeit bedroht - reflektierten Dichtkunst ein gewisses Maß an Zeitenthobenheit zu verleihen sucht.

4) Aufgrund der Punkte 1-3 wird es möglich, dass das gesamte Stück Wallenstein, inklusive Prolog, überhaupt erst performativ zu vollziehen versuchen kann, was der Prolog für die Dichtkunst und damit auch vom eigenen Stück behauptet: Vergänglichem Dauerhaftigkeit zu verleihen. Und dies auf doppelte Weise:

a) durch die schriftliche Festhaltung dessen, was als vergänglich bezeichnet wird; das sind: die sprachliche Grundlage für die Mimenkunst und die flüchtigen Taten und Werke der historischen Person Wallenstein, der als exemplarischer Mime inszeniert wird.

b) durch die poetologische und autoreflexive Thematisierung ebendieser schriftlichen Festhaltung, was als Operation zur Ewigkeitsattribuierung des Stücks eingesetzt wird und zwar in (dominanter) Form der Unteroperation Poetische Performativität. ${ }^{149}$

Oder in anderen Worten in folgenden Befunden zusammengefasst:

Da das Stück im Prolog eine explizite Ewigkeitsbehauptung vornimmt, im Prolog und im Stück aber zugleich konsequent - durch schriftliche Festhaltung von Vergänglichem und die autoreflexive Thematisierung dieser Verschriftlichung zuvollziehen sucht, was es behauptet, setzt es auf einer Makroebene die Operation Poetische Performativität ein. Dies im Bestreben, die Figur Wallenstein, das Stück Wallenstein selbst und damit auch den Namen von deren dichterischem (und eben nicht mimischem) Schöpfer, Schiller, unsterblich zu machen resp. zu verewigen.

149 Dabei wäre auch in Betracht zu ziehen, ob hierfür nicht zusätzlich noch die Unteroperation Unendliche Lektüre zu beobachten wäre, und zwar durch eine QuasiKreisstruktur zwischen Komödie in Wallensteins Lager und Tragödie in Wallensteins Tod resp. durch die damit verbundene Bewahrung, Aufhebung und Wiederherstellung der Gemütsfreiheit, wie sie Gerhard Kaiser in Anlehnung an Schillers Abhandlung Über naive und sentimentalische Dichtung behauptet hat (vgl. Kaiser 1977, S. 362 f.). Dies wäre jedoch erst noch näher zu überprüfen, aber vor dem Hintergrund des in diesem Kapitel Erarbeiteten nicht überraschend. 
Schillers Wallenstein-Trilogie ist damit nicht nur eine Trilogie, bei der ein wesentliches inhaltliches Element aus Wallensteins Streben nach Unsterblichkeit besteht, sondern zugleich auch der Versuch, "ein dauernd Werk" (Prolog, V. 39) zu erschaffen.

Es sei zum Schluss auch noch einmal mit Verweis auf die oben vorgenommene Definition betont: Die Operation Poetische Performativität funktioniert hier in diesem stückübergreifenden, ein sehr langes Syntagma umfassenden Grade nur deshalb, weil der Prolog das gesamte Stück programmatisch rahmend auch das verewigende Potenzial der Dichtkunst konstativ nennt. 
Markus Gut - 978-3-8467-6517-3

Downloaded from Fink.de@4/26/2023 07:48:17AM via free access 


\section{Grundoperation Reflexivität}

Die beiden vorangegangenen Großkapitel haben Operationen zur Ewigkeitsattribuierung von Schriftzeichen behandelt, die entweder eine unendliche Aktualisation oder eine möglichst hohe Autonomie des Verschriftlichten zu erreichen suchen. Das letzte Großkapitel des Hauptteils ist nun Operationen gewidmet, die darauf abzielen, eine unendliche Aktualisation der Schriftzeichen zu forcieren, und/oder die eine möglichst hohe Autonomie der betreffenden Textstellen anstreben. Der Grundoperation Reflexivität ist nämlich grundsätzlich immer beides inhärent (das ist auch der Grund dafür, weshalb hier diese Grundoperation nach den beiden anderen zu behandeln ist). Es variiert jedoch von Textstelle zu Textstelle, ob sie primär auf eine unendliche Aktualisation der Schriftzeichen oder primär auf die Autonomie derselben von zeitlichen Veränderungen ihrer intelligiblen Seite und ihres Kontextes abzielt. Am korrektesten wäre es demnach, die Grundoperation Autonome und/ oder Unendliche Reflexivität zu nennen, worauf jedoch aus Gründen der Lesefreundlichkeit verzichtet wird; dasselbe gilt für die beiden Unteroperationen Autoreflexivität und Poetologie.

Hinsichtlich dieser Relationen der drei Grundoperationen untereinander ist aber folgender entscheidender Unterschied zu beachten: Autonomie wird von der Grundoperation Reflexivität nicht über die performative Herstellung dessen, wovon die Rede ist, angestrebt, sondern über den Verweis der betreffenden Textstellen auf sich selbst und/oder deren semiotische Möglichkeitsbedingungen. Ähnliches gilt für das Abzielen auf eine unendliche Aktualisation, das hierbei nicht über etwa Kreisstrukturen, potenzierte Entortungsbewegungen mittels komplexer Verweise, Rahmenkonfusionen usw. oder die ästhetische Nutzbarmachung der semiotischen Flüchtigkeit von Schriftzeichen erfolgt, sondern über die potenziell unendliche Bewegung, die einem jeden Selbstverweis inhärent ist (vgl. u. a. Kapitel IV.3.1.1). Oder in anderen Worten und etwas pointiert ausgedrückt: Die Grundoperation Reflexivität kombiniert zwar die Ziele der beiden anderen Grundoperationen Unendliche Aktualisation und Autonome Performative Produktion, besteht abernicht in einem engen Sinne aus einer Kombination von deren Operationen, sondern ist eine eigenständige Operation zur Ewigkeitsattribuierung von Schriftzeichen. Wenngleich also die Großkapitel des Hauptteils der vorliegenden Arbeit in einer dialektisch anmutenden Reihenfolge angeordnet 
sind, so verhalten sich die einzelnen Grundoperationen selbst zueinander nur beschränkt dialektisch.

Was die Begrifflichkeit der Unteroperationen Autoreflexivität und Poetologie betrifft, so sei diese hier - um allfällige Missverständnisse zu vermeiden - ebenfalls kurz erklärt: Eine autoreflexive Textstelle bezieht sich nicht bloß autoreferenziell auf sich selbst, sondern nutzt diesen Selbstverweis dafür, den eigenen Inhalt und/oder die eigene Form zu thematisieren. So ist das im folgenden Kapitel behandelte Buch in der Höhlenszene des Heinrich von Ofterdingen kein bloßer direkter Verweis auf das Buch Heinrich von Ofterdingen (im Sinne von: „Dies ist ein Buch!“), sondern darüber hinaus eine metaphorisch-allegorische Selbstthematisierung des Romans, die u. a. eine Lektüreanweisung für ebendiesen Roman bereithält. Oder in anderen Worten: „Der selbstreflexive Text bezieht sich auf sich selbst über den Umweg allegorischer, also mindestens gedoppelter Referenz. [...] Selbstreflexive Texte als komplexe Zeichensysteme sind folglich immer auch autoreferenziell, jedoch nicht notwendig vice versa. ${ }^{{ }^{1}}$ Unter der Grundoperation Reflexivität und den entsprechenden Unteroperationen ist Autoreferenzialität also immer auch mitgemeint. Autoreferenzialität wird aber nicht als eigene Unteroperation zur Ewigkeitsattribuierung von Schriftzeichen aufgeführt, weil jede autoreferenzielle Textstelle, die als eine solche Operation gelesen würde, zugleich auch etwas Autoreflexives erhält.

Als poetologisch wiederum werden in der vorliegenden Arbeit Textstellen bezeichnet, die zwar autoreflexiv (und damit immer auch autoreferenziell sind) sind, darüber hinaus jedoch nicht nur spezifisch die jeweilige Textstelle thematisieren, sondern zusätzlich und noch grundsätzlicher die semiotischen und/oder materialen Möglichkeitsbedingungen sowie die Schaffungskraft (vgl. die Etymologie von griechisch poesis) von Schriftzeichen und Zeichen im Allgemeinen verhandeln. ${ }^{2}$

Autoreflexivität und Poetologie können also - wie etwa poetische Performativität - ganz grundsätzlich als Operationen zur Ewigkeitsattribuierung von Schriftzeichen betrachtet werden. Sie rücken als solche aber besonders dann in den Blick, wenn autoreflexive oder poetologische Textstellen aufgrund des inhaltlichen und formalen Kontextes, in dem sie sich befinden, Ewigkeitsattribuierung zu einer zentralen ästhetischen Konstituente oder gar zum ästhetischen Kern des jeweiligen Textes machen. Dies ist in den folgenden drei Textbeispielen jeweils der Fall. Im Gegensatz zu den Unteroperationen Unendliche Lektüre und Unendliches Verstummen, die als zwei

1 Steier 2014, S. 14.

2 Vgl. dazu auch Müller Nielaba 2013, insbesondere S. 11. 
komplementäre Seiten derselben Medaille bezeichnet werden können, ist der Unterschied zwischen den Unteroperationen Autoreflexivität und Poetologie ein gradueller. Dies hat freilich zur Folge, dass die beiden nicht trennscharf voneinander abzugrenzen sind. Wie unten ersichtlich wird, ist die begriffliche Unterscheidung aber heuristisch durchaus wertvoll und führt $\mathrm{zu}$ einer präziseren Auseinandersetzung mit den betreffenden Texten und deren Ewigkeitsattribuierung.

\section{Unteroperation Autoreflexivität}

Im Unterschied zu den anderen Kapiteln, die den einzelnen Unteroperationen zur Ewigkeitsattribuierung von Schriftzeichen gewidmet sind, findet sich im Kapitel zur Autoreflexivität nur ein Textbeispiel und nicht zwei. Dies hat den einfachen Grund, unnötige Redundanzen zu vermeiden. Einerseits lässt sich nämlich die betreffende Operation in der Höhlenszene des Heinrich von Ofterdingen derart ausführlich behandeln, dass eine ähnliche Untersuchung an einem anderen Textbeispiel zu zu vielen Wiederholungen führen würde, insbesondere da andererseits poetologische Textstellen, wie sie in Kapitel IV.2 behandelt werden, immer auch einen autoreflexiven Gehalt besitzen. Hinzu kommt, dass auch bei den bislang untersuchten Textbeispielen immer wieder auf an Ewigkeitsattribuierung beteiligte autoreflexive Stellen hingewiesen wurde.

\subsection{Heinrich von Ofterdingen (Höhlenszene)}

Die literaturwissenschaftliche Forschung, die für ganzheitliche Auseinandersetzungen mit dem hier untersuchten Roman inzwischen doch mehrheitlich älteren Datums ist, hat wiederholt auf das Verfahren der Spiegelung als zentrales Stilprinzip in Novalis' Heinrich von Ofterdingen (1802) hingewiesen. Ebenso darauf, dass dies insbesondere in der im 5. Kapitel der Erwartung enthaltenen Höhlenszene, ${ }^{3}$ in der Heinrich ein Buch mit seiner eigenen Geschichte findet, ersichtlich resp. autoreflexiv ausgestellt werde. ${ }^{4}$ Zur Höhlenszene sei hier stellvertretend Marion Schmaus zitiert:

3 Zur literaturgeschichtlichen, topologischen Wirkmächtigkeit der Höhlenszene vgl. Uerlings 2004, S. 56 f.

4 Vgl. dazu zusammenfassend z. B. Frühwald 2008, S. 247 f.; und insbesondere Uerlings 1991, der den Forschungsstand bis 1990 ausführlich behandelt; mit Blick auf das vorliegende Kapitel siehe vor allem S. 398-405, 419-443 und den Epilog „Konstruktion oder Dekonstruktion?", S. 615-625. Zur Höhlenszene im Zusammenhang mit Selbsterkenntnis und Identitätsbildung 
Der ,Roman im Roman' ist ein ausgezeichnetes Beispiel für die Selbstreflexivität des,Ofterdingen' und seine durch den retardierenden Stil erzeugte Zirkelstruktur: Der Roman bestimmt, interpretiert und präfiguriert sich selbst als ganzen in einem seiner Bausteine. Und so wird das Motiv des ,Romans im Roman' zum eindrücklichen Sinnbild einer Hermeneutik, die für Heinrich ebenso interessant ist wie für den Leser. ${ }^{5}$

In Bezug auf die Gesamtstruktur des fragmentarischen Romans beschreibt Wolfgang Frühwald zusammenfassend dieses prägende Prinzip der Spiegelung auf inhaltlicher Ebene des Romans wie folgt:

„Nichts ist poetischer, als Erinnerung und Ahndung, oder Vorstellung der Zukunft", ist in den Vermischten Bemerkungen des Novalis zu lesen. Erinnerung und Ahnung sind im Ofterdingen die Grundelemente der Spiegelung. „Vorstellung der Zukunft", das heißt Spiegelung des Künftigen im Gegenwärtigen, ist das heitere Thema des ersten Teiles, „Vorstellung der Vorzeit“, das heißt Spiegelung des Vergangenen im Gegenwärtigen, der schmerzliche Grundton des zweiten Teiles. ${ }^{6}$

Diese Spiegelung sei jedoch „wie Zeit und Raum zur Auflösung durch Identifikation bestimmt; d. h. aber, dass die Spiegelung selbst von Beginn an auf Identifikation zustrebt. "7 Woraus Frühwald mit Bezug auf Novalis' Notizen zur Fortsetzung des Heinrich von Ofterdingen schließt: „,Die Verklärung“ sollte das Buch sein, in dem die Spiegelung aufgeht in totaler Identifikation. Diese entspricht als Stilmittel der fortschreitend klareren Erscheinung der inneren Welt in der äußeren."8 Und betreffend das im Roman prominent auftretende Paradigma der Ewigkeit schreibt er: „Das ,Zeitgefühl“ des [geplanten, MG] dritten Buches ist also nicht Erinnern oder Ahnen, sondern Ewigkeit, in der alles ineinanderfließt $[\ldots] .{ }^{“ 9}$

Dieses Paradigma der Ewigkeit wurde in der Forschung hauptsächlich auf inhaltlicher Ebene - mit dem Fokus auf die Frage, was Konstituenten und Aufgaben der Dichtung und des Dichters, wie sie im Roman dargestellt werden, seien - ausführlich und kontrovers diskutiert, besonders oft anhand

vgl. insbesondere Schmaus 2000, S. 68-72; zur „allegorische[n] Bildlichkeit des Weges“ im Heinrich von Ofterdingen vgl. Geisenhanslüke 2003, S. 115-122.

5 Schmaus 2000, S. 68.

6 Frühwald 2008, S. 249.

7 Ebd., S. 251.

8 Ebd., S. 252.

9 Ebd., S. 253. 
von Klingsohrs Märchen..$^{10}$ Als Beispiel für die Forschung vor 1970, aber auch generell für die zu wenig textnahe Untersuchung dieses Paradigmas bis heute, mag Eberhard Haufes Aufsatz „Die Aufhebung der Zeit im Heinrich von Ofterdingen“ von 1957 gelten, in dem dieser zur Höhlenszene schreibt:

Im gleichen Kapitel [dem fünften, MG], genau in der kompositorischen Mitte des ersten Teils, gewinnt diese romantische Zusammenkunft von Vergangenheit und Zukunft ihre deutlichste Verkörperung. Heinrich entdeckt das geheimnisvolle Buch, das sich ihm als eine Art höheres Bilderbuch seines Lebens offenbart. Nicht nur sein vergangenes Leben sieht er darin, auch seine Zukunft ist schon im Bilde gezeichnet, nur das Ende fehlt. Im Bilde ist Vergangenes und Zukünftiges magisch gegenwärtig, magisch eins. [...] Die große Wunde, an der die Welt leidet, ist [gemäß dem Roman Heinrich von Ofterdingen, MG] die Zeit; am Ende der Tage wird der Dichter sie schließen. [...] Damit überschreitet aber Novalis, jedenfalls der Intention nach, die der Poesie gesetzten Grenzen. Denn ihr Ausdrucksmittel ist die Sprache, die ihrerseits gerade vollkommen an die Zeit gebunden ist $[\ldots] \cdot{ }^{11}$

Vieles ist hier - wie auch in späteren Arbeiten - angetönt, aber nicht textnah weiterverfolgt und überprüft: Was hat es mit den Bildern im gefundenen Buch genau auf sich, und was genau bedeutet der kryptische Satz „Im Bilde ... magisch eins“ für die diskutierte Textstelle? Wie auch immer Novalis' „Intention“ genau ausgesehen haben mag: Ist es nicht entscheidender, zu fragen, wie er „die der Poesie gesetzten Grenzen“ innerhalb des von Haufe treffend festgestellten Paradoxons der Zeitlichkeit von Sprachzeichen ${ }^{12} \mathrm{zu}$ überschreiten sucht? Haufes Fazit, „die Herstellung der Märchenwelt“ sei „für Novalis der gattungsmäßige Ausdruck der Zeitlosigkeit", ${ }^{13}$ weil das Märchen „außerwirklich“ und damit „auch zeitlos“ sei, bleibt denn auch hinter diesen entscheidenden Fragen zurück. Johannes Mahr setzt sich in seiner Monographie Übergang zum Endlichen kritisch mit der Forschung vor $1970 \mathrm{zu}$ diesem Thema auseinander, ${ }^{14}$ kritisiert dabei auch Haufe, stößt aber wie dieser nicht genügend zur textnah entfalteten Frage des Wie? vor. Dies führt wiederum dazu, dass Herbert Uerlings in seinem Standardwerk zur Novalis-Forschung Mahrs

10 Zur Thematisierung von Zeitlichkeit und Ewigkeit in Klingsohrs Märchen, auf das in diesem Rahmen nicht näher eingegangen werden kann, vgl. zusammenfassend Uerlings 1991, S. 495-513, insbesondere S. 498 und 5 o6 f.

11 Haufe 1957, S. 187.

12 Leider verfällt auch Haufe kurz darauf dem weit in die Antike zurückreichenden Topos der ,Ewigkeit der Zahlen' (vgl. ebd., S. 188), was zeichentheoretisch haltlos ist.

13 Ebd., S. 187.

14 Vgl. Mahr 1970, insbesondere S. 262-267. 
Interpretation einer Entwicklung Heinrichs „vom Unendlichen zum Endlichen ${ }^{15}$ sowie Mahrs Versuch, „den Ofterdingen konsequent als Entwicklungsroman“16 im Allgemeinen zu lesen, „wohl als gescheitert und vor allem als unergiebig ${ }^{{ }^{17} 7}$ beurteilt. ${ }^{18}$ Auch hält er dessen These, „der Dichter erlebe eine Aufhebung der Zeit in der Zeit",19 mit guten Gründen für zu „vage“ erläutert, wobei sie auch offenlasse, „[w]ie dies mit der dichterischen Produktivität verbunden wird“. ${ }^{20}$ Alexander Knopf, der u. a. Novalis' Sprachauffassung herauszuarbeiten sucht, vertritt für den Heinrich von Ofterdingen wiederum die These, „dass das, was sich im Laufe des dargestellten Bildungswegs [Heinrichs, MG] entwickelt, Heinrichs Sprachkompetenz ist". ${ }^{21}$ In Kombination der von ihm postulierten Entwicklung Heinrichs mit der erarbeiteten Sprachauffassung Novalis', die „die Idee vom Ich als absoluter Potenz" als "nicht länger haltbar“ erachte, da das Ich jederzeit durch Sprache determiniert sei, ${ }^{22}$ schreibt Knopf sodann:

Die Aufgabe der ,Poësie‘, im Grunde die Weise ihres Daseins, besteht in der Herstellung eines ,unendlichen Einverständnisses‘ zwischen dem Ich und der Welt. Man könnte deshalb sagen, dass der Afterdingen den - symbolischen - Versuch eines Individuums darstellt, die Wände des Sprachgehäuses zu sprengen, in das es sich eingesperrt findet. ${ }^{23}$

Eine breiter angelegte Auseinandersetzung mit dieser Diskussion kann im Rahmen der vorliegenden Arbeit nicht geleistet werden; ebenso wenig eine Gesamtinterpretation des Heinrich von Ofterdingen. Man vergleiche dazu vor allem die neue, soeben zitierte Arbeit von Alexander Knopf und deren ausführlichere Aufarbeitung der bisherigen Forschung. ${ }^{24}$ Die in diesem einleitenden Kapitel angeschnittenen Forschungsdiskussionen bilden aber für die Kapitel zur Höhlenszene vor allem in folgender Hinsicht die Ausgangslage: Wie auch

15 Mahr 1970, S. 38 und 265-267.

16 Uerlings 1991, S. 398 f.

17 Ebd., S. 399.

18 Im Folgenden wird aufgezeigt werden, dass auf semiologischer Ebene im Gegenteil von einem versuchten Übergang vom Endlichen zum Unendlichen gesprochen werden müsste.

19 Uerlings 1991, S. 433; vgl. Mahr 1970, S. 208.

$20 \quad$ Uerlings 1991, S. 433.

21 Knopf 2015, S. 18.

22 Vgl. ebd., S. 64.

23 Ebd.

24 Vgl. Knopf 2015. In Kapitel IV.3.1 wird jedoch u. a. unter Einbezug von Uerlings umfassender Arbeit nochmals auf die Forschungsdiskussion zu Verfahren der Reflexion und der damit verbundenen ,Freiheit' zurückgekommen. 
immer im Heinrich von Ofterdingen die Beziehung zwischen Ewigkeit, Unendlichkeit, Dichter und Dichtung auf primär inhaltlicher Ebene dargestellt sein mag, so ist in der Forschung doch unbestritten, dass in Novalis' Roman das Paradigma der Ewigkeit und Unendlichkeit eng mit dem von Dichtung und damit auch von in Schriftzeichen verfasster Dichtung verknüpft ist. Die vorliegende, primär semiologische Untersuchung ist hingegen Verfahren der Spiegelung gewidmet, die nicht bloß dazu dienen, letztlich die Romanwelt inhaltlich, also verweisend, in Beziehung zu Ewigkeit zu setzen, sondern durch solche Spiegelungen resp. durch die Operation Autoreflexivität den betreffenden Textstellen Ewigkeit zu verleihen suchen.

Vom Forschungskonsens der Spiegelung als einer zentralen formalen und inhaltlichen Operation des Heinrichs von Ofterdingen ausgehend und diesen ergänzend fokussiert das folgende Close Reading der Höhlenszene also ganz auf die semiologischen und rhetorischen Konstituenten des im Roman auftretenden Paradigmas der Ewigkeit. Damit vollzieht es gegenüber der oben beschriebenen bestehenden Forschungsdiskussion einen gewissen Perspektivenwechsel. Dieser mag, obwohl hier wie erwähnt keine Gesamtinterpretation angestrebt wird, dabei helfen, allgemeine Aussagen der Forschung zu Novalis, die mancherorts fast schon zu Gemeinplätzen geworden sind - von der Art wie etwa: „Sie [die Enzyklopädie ${ }^{25}$ Novalis', MG] belegt mit ihren Entwürfen die Gemeinschaft des Endlichen und Unendlichen“26 -, textnah auch auf semiologischer Ebene nachzuprüfen.

Mads Nygaard Folkmann und Marion Schmaus beispielsweise haben dazu bereits einen ersten Schritt unternommen. Letztere hat darauf hingewiesen, dass der Roman durch seinen „retardierenden Stil[]“ sich permanent selbst deute und damit „durch seine formale Struktur die paradoxe Verbindung von Zeit und Ewigkeit" leiste, ${ }^{27}$ ohne diesen Ansatz jedoch im Detail und nah am Text weiterzuverfolgen; Ähnliches gilt für Folkmann. ${ }^{28}$ Und wenn Alexander

25 Zur Enzyklopädie und zum Heinrich von Ofterdingen vgl. u. a. Wellmon 2011 oder Baumann 1999.

26 Baumann 1999, S. 26o.

27 Vgl. Schmaus 200o, S. 98 f.

28 Selbst Folkmann, der ein Kapitel zur Bildlichkeit vor allem in Zusammenhang mit dem Unendlichen bei Novalis anführt, setzt sich letztlich zu wenig textnah mit der Komplexität dieses Themenfeldes auseinander; z. B. schreibt er: „Es gibt bei Novalis auch ein ,Mehr', wie die Frage generell die ist, wie ein Unendliches darzustellen ist, - aber seine Bilder sind vielmehr unterdeterminiert [eine Fußnote nimmt hier zumindest Klingsohrs Märchen von dieser ,Unterdeterminiertheit' aus, MG], da sie sich als defizitär erweisen oder stattdessen im Prozess ihrer Realisation aufgelöst werden. Novalis' Bilder sind Figuren, denen zu wenig Bedeutung innewohnt. Die blaue Blume in Heinrichs erstem Traum im Ofterdingen ist so ein Bild. [...] Die spezifische Bedeutung der Blume erscheint unklar. Sie lässt 
Knopf die These vertritt, der Heinrich von Ofterdingen situiere sich nicht nur im geistesgeschichtlichen Übergang von der Erkenntnis- zur Sprachkritik, „der mit Hamann und Herder einsetzte und in Humboldt und Schleiermacher ${ }^{29}$ einen vorläufigen Höhepunkt fand“, sondern handle vielmehr von diesem Übergang, so wäre mit dem vorliegenden Kapitel ebenfalls anhand des Heinrich von Ofterdingen zu ergänzen, dass mit jenem Übergang nicht nur „nunmehr sämtliche Wissensformen auf die Sprache bezogen werden“, ${ }^{30}$ sondern dass auch das göttliche Attribut der Ewigkeit offenbar nur noch mittels Sprache einholbar scheint. $^{31}$

\subsection{1 "Zeichen“, „Ewigkeit“, „Bild“ und Metabild}

Im Verlaufe des fünften Kapitels des Heinrich von Ofterdingen macht sich die titelgebende Hauptfigur in Gesellschaft mehrerer anderer Personen auf, ein Höhlensystem zu erkunden. Dabei spielen, kaum hat die Gesellschaft die Höhlen betreten, das Deuten von Zeichen und die Eigenschaft von Zeichen, auch auf zeitlich weit Zurückliegendes verweisen zu können, eine zentrale Rolle. Dies beginnt damit, dass die Abenteurer auf eine „unzählige Menge von Knochen und Zähnen, die den Boden bedeckten“ (S. 253, Z. 10 f.), ${ }^{32}$ stoßen, die sie als indexikalische Zeichen für das Leben tierischer Kreaturen deuten und so einen hermeneutischen Prozess in Gang setzen:

Der Alte freute sich über diese Überbleibsel einer uralten Zeit; nur den Bauern war nicht wohl dabey zu Muthe, denn sie hielten sie für deutliche Spuren naher Raubthiere, so überzeugend ihnen auch der Alte die Zeichen eines undenklichen Alterthums daran aufwies, und sie fragte, ob sie je etwas von Verwüstungen

sich nicht als Totalität von Bild und einheitlicher Substanz fassen, sondern sie generiert dagegen eine unendliche Verschiebung von wundersamer Bedeutung. Sie verweist auf ein ,Mehr', das nicht in ihr versinnbildlicht werden kann. [...] Einerseits wirkt also die Blume als ,Symbol', als Verkörperung und Versinnlichung einer unbegreiflichen Bedeutung - das erfährt ja Heinrich -; andererseits verschiebt der Text konsequent ihren genauen Sinn und lässt sie nur als eine Spur eines sonst verwischten Wunderbaren erscheinen“ (Folkmann 2006, S. 102-104). Während der Verfasser in Bezug auf die potenziell „unendliche Verschiebung“ mit Folkmann übereinstimmt, so steht er dem Begriff der ,Unterdeterminiertheit' insbesondere mit Blick auf die Metabildlichkeit der „Bild“-Metapher im Heinrich von Ofterdingen (siehe das folgende Unterkapitel) kritisch gegenüber.

29 Vgl. dazu auch die betreffenden Ausführungen zu Schleiermacher in der Einführung.

$30 \quad$ Knopf 2015, S. 11.

31 Was wiederum mit Knopfs Beobachtungen zur Sprachauffassung von Novalis und zu deren Nähe zum Religiösen korrespondiert, vgl. zusammenfassend ebd., S. 285-288.

32 Als Textgrundlage wird im Folgenden die historisch-kritische Ausgabe von Paul Kluckhohn und Richard Samuel (1977) verwendet. Die neuste historisch-kritische Ausgabe des Heinrich von Afterdingen, die 2015 von Alexander Knopf herausgegeben wurde, kommt nur dann zum Zug, wenn erstere entscheidend vom Erstdruck von 1802 abweicht. 
unter ihren Heerden und vom Raube benachbarter Menschen gespürt hätten, und ob sie jene Knochen für Knochen bekannter Thiere oder Menschen halten könnten? (S. 253, Z. 15-22) 33

Dieser hermeneutische Prozess, in dessen Beschreibung sich kaum zufällig der Begriff „Zeichen“ findet, stellt zwei wesentliche Aspekte von Zeichen aus: Erstens, Zeichen verweisen auf einen Gegenstand, der in ihnen nicht präsent ist (in diesem Fall Knochen als Index für einst lebende Kreaturen); zweitens, die Abwesenheit ebendieses Gegenstandes eröffnet im Zusammenspiel mit den Lesern und dem Kontext der Lesesituation zwangsläufig unterschiedliche Lesarten $^{34}$ (in diesem Fall die Lesart der „Bauern“ vs. die Lesart des „Alten“) insbesondere, wenn die Zeichen auf etwas verweisen, das aus einem „undenklichen Alterthum[]“ stammt und damit in der Zeit undenkbar weit von den Lesern entfernt ist.

Sowohl die Bezeichnung „Bauern“ als auch „der Alte“ sind metonymischer Art. Während jedoch der Name „Bauern“ von deren Tätigkeit abgeleitet ist, die nicht - wie es z. B. bei ,Jäger' der Fall wäre - in einer direkten Relation zu den vorgefundenen „Zeichen“ steht, konstituiert sich der Name „der Alte“ in Relation zur (menschlichen Lebens-)Zeit. ${ }^{35}$ So steht „der Alte“ in einem Ähnlichkeitsverhältnis zu den „Zeichen eines undenklichen Alterthums“, 36 was ihm offenbar im hermeneutischen Prozess einen Vorteil verschafft. Doch

33 Hervorhebungen durch MG.

34 Obwohl es sich in diesem spezifischen Fall der Knochen nicht um Schriftzeichen handelt, wird hier der Begriff „Leser“ etc. verwendet, da die Gesellschaft die Knochen ähnlich wie einen Text zu lesen und zu interpretieren beginnt.

35 Ausführlich zur Figur des „Alten“/des ,Bergmanns“ vgl. Gold 199o, insb. S. 77-94. Helmut Gold schlägt überzeugend gegen Versuche der älteren Forschung, „den Bergmann als einheitlich - ob modern oder mittelalterlich - zu charakterisieren“, eine differenzierte Lesart des Bergmanns vor, die „in der ,Mixtur‘ aus beiden Aspekten“ den „Schlüssel“ sieht, und erkennt in der von der zeitgenössischen Chemie inspirierten „frühromantische[n] Theorie der Mischung“ die grundlegende „Struktur nicht nur für die Konstruktion des ,goldenen Zeitalters` [...], sondern gerade auch für die Konstruktion des Bergmanns“ (ders., S. 88). Dennoch verdient der dominante metonymische Name „der Alte“ hier nähere Betrachtung: Dass fast ausschließlich die Bezeichnung „der Alte“ und nicht etwa „Schatzgräber“ (Novalis, Heinrich von Ofterdingen, S. 239, Z. 25) oder ,Bergmann' (womit er hauptsächlich in der Forschungsliteratur bezeichnet wird) oder ein wechselweiser Gebrauch dieser verschiedenen Namen zu beobachten ist, mag ein weiterer Hinweis darauf sein, dass ihre Relation zum Paradigma Zeit offenbar einen zentralen Aspekt der Figur des Alten ausmacht. Auch bezeichnet ihn der Erzähler schon bei der ersten Erwähnung als „alten Mann“ (ebd., S. 239, Z. 20).

$\mathrm{Zu}$ den Einflüssen von Novalis' Mittelalterrezeption auf die Figur des ,Bergmanns (und des Einsiedlers) vgl. Kasperowski 1994, S. 220-227.

36 Hervorhebung durch MG. 
damit nicht genug: Während die „Bauern“ es vorziehen, nicht weiter in die Höhlen vorzudringen, geht der Rest der Gesellschaft weiter, sichert sich aber gegen ein Verirren im Höhlensystem ab: „Sie gelangten bald in eine zweyte Höhle, wobey der Alte nicht vergaß, den Gang[,] aus dem sie hereingekommen waren, durch eine Figur von Knochen, die er davor hinlegte, zu bezeichnen“ (S. 253, V. 25-28). Der "Alte“ transformiert also nach der Begrifflichkeit von Charles Sanders Peirce ${ }^{37}$ die Indizes („Knochen“) zu einem Symbol, einem auf Arbitrarität und Konvention beruhenden Zeichen: Die Knochen dienen nun als Signifikanten für die Information „Hier ist der Gang, der aus den Höhlen herausführt“. Besonders interessant ist dabei, dass „der Alte“ dies durch das Errichten einer „Figur" tut. Die Beschreibung der Vorkehrungen des Alten stellt dadurch einen weiteren Aspekt von Zeichen aus: die Möglichkeit, sie zu (rhetorischen) Figuren anzuordnen, um Bedeutung zu figurieren. Doch die Beschreibung verweist nicht nur auf diese Möglichkeit, sie nimmt sie in gewissem Sinne auch sogleich performativ wahr: Die Verwendung des Begriffes „Figur" für ein Gebilde aus Knochen ist nichts anderes als eine metaphorische. Nun ist eine Metapher zwar keine rhetorische „Figur“, sondern eine Trope, jedoch wird ihre Bedeutung im Zuge der Lektüre ebenfalls über ein Ähnlichkeitsverhältnis, also letztlich figurativ in Relation zu einem anderen, hier dem Tertium Comparationis, konstituiert. ${ }^{38}$

Der einmal durch das Auffinden der Knochen in Gang gebrachte hermeneutische Prozess setzt sich im Folgenden weiter fort - auch Heinrich selbst sucht die Knochen als Indizes zu lesen (S. 253, Z. 29, bis S. 254, Z. 7) - und wird durch das Auffinden neuer indexikalischer Zeichen, die „ziemlich frische Menschenspur" (S. 254, Z. 9) und den "Gesang“ (ebd., Z. 13), vorangetrieben resp. in neue Richtungen gelenkt.

Bevor nun näher auf ebendiesen Gesang eingegangen wird, lässt sich folgendes Zwischenfazit ziehen: Bereits auf den ersten eineinhalb Seiten der Höhlenszene stehen Zeichen und deren Deutung im Zentrum. Dabei wird den „Zeichen“ u. a. durch das Genitivattribut „eines undenklichen Alterthums“ implizit die Fähigkeit zugeschrieben, Informationen über eine undenkliche Zeitspanne hinweg überliefern zu können, während der Modus der Ähnlichkeit einen Vorteil im erfolgreichen Lesen derselben zu gewähren scheint. (Alle drei Elemente werden sich, wie noch zu zeigen ist, im weiteren Verlauf des Abenteuers unter Tag nicht nur fortsetzen, sondern geradezu potenzieren.)

37 Vgl. Peirce 1955.

38 Vgl. dazu Quintilian, Institutio Oratoria, Teil 2, S. 251; resp. den Beginn von Kapitel IV.3.1.1, wo die betreffende Stelle bei Quintilian auch in den Anmerkungen zitiert wird; vgl. zudem Alder 2015, insbesondere S. 27 f. 
Schon der vermeintlich in simplem Abenteuerstil gehaltene Beginn der Höhlenszene verhandelt Zeichen und deren Deutung derart komplex, dass sich folgende These aufdrängt:

Erstens, der Gang in die Höhlen kann nicht nur als Allegorie für die Erforschung des eigenen Ich seitens Heinrichs, ${ }^{39}$ sondern auch als Allegorie für das Erforschen des Inneren des Romans Heinrich von Ofterdingen resp. von Text und Dichtung im Allgemeinen, zu deren grundlegendsten Konstituenten Sprachzeichen gehören, gelesen werden. ${ }^{40}$ Dabei gibt, zweitens, der Beginn der Höhlenszene zusätzlich zu lesen, dass eine Orientierung innerhalb der Höhle als poetologische Allegorie für den Text, die ,Höhle aus Zeichen' also, selbst wiederum nur mittels Zeichen möglich ist. ${ }^{41}$

Wurden auf den ersten eineinhalb Seiten der Höhlenszene bislang die Zeichentypen indices (Indizes) und symbols (Symbole) thematisiert, so wird im Gesang, den die Gesellschaft aus den Tiefen der Höhlen vernimmt, Peirces Trichotomie der Zeichentypen gewissermaßen durch das icon (Ikon), ein bildliches, auf dem Prinzip der Ähnlichkeit beruhendes Zeichen, komplementiert, und zwar besonders prominent in der vierten Strophe:

Bangverweinte Jahre haben

Diesen schlechten Thon verklärt,

Und ein Bild ihm eingegraben,

Das ihm Ewigkeit gewährt. (S. 254., Z. 27-30)

Damit vereint das Lied in seiner Stellung in der Höhlenszene alle drei Zeichentypen: Es ist auf rein akustischer Ebene einerseits der Gesellschaft ein Index für den ihr unbekannten Sänger jener Strophen. Doch anders als die Fußspuren auf dem Höhlenboden ist das Lied nicht nur ein primär physikalischer, sinnlich wahrnehmbarer Index (der freilich nur zu einem Index wird, wenn man ihn als solchen liest), sondern besteht auf intelligibler Ebene andererseits auch

39 Vgl. Schmaus 200o: „Die Höhle [nicht nur diejenige in Kapitel 5 des Romans, MG] ist im Roman durchgängig der Ort, an dem solche Identitätserfahrungen statthaben, und fungiert mithin als topographisches Symbol für den Gang ins Innere des menschlichen Gemüts und für den Weg zur Selbsterkenntnis." Wobei Schmaus ansatzweise ebenfalls einen ersten Schritt weiter in dieselbe Richtung geht wie die soeben aufgestellte These (vgl. die folgende Fußnote).

40 Zur Funktion der Poesie bei Novalis als „Vorbild des sich suchenden Ich“ vgl. Schmaus 2000, S. 45 .

41 Diese Lesart scheint von Heinrich selbst im zweiten Teil des Romans bestätigt zu werden: „Ich weiß nur so viel, daß für mich die Fabel[, zu der Heinrich als literarische Figur gehört, MG] Gesamtwerkzeug meiner gegenwärtigen Welt [und somit (auch) des Romans Heinrich von Ofterdingen, MG] ist“" (Novalis, Heinrich von Ofterdingen, S. 171). 
aus arbiträren, konventionalisierten Symbolen, dem Liedtext. Die Symbole des Liedtextes wiederum formen zwar (vermeintlich) ${ }^{42}$ kein eigenes Ikon, wie etwa in der Konkreten Poesie, thematisieren ein solches jedoch besonders prominent. Letzteres erfolgt dadurch, dass die Deixis des Demonstrativpronomens in der vierten Strophe eine autoreferenzielle Lesart ermöglicht, ja beinahe erzwingt. Der Vers „Diesen schlechten Thon“ lässt sich nämlich mangels vorhandenen Kontextes letztlich nur plausibel auf das Lied selbst beziehen, indem man den Teil "Diesen Thon“ metonymisch resp. in seiner mittelhochdeutschen Semantik ${ }^{43}$ als ,dieses Lied' liest. ${ }^{44}$

Es scheint also das Lied selbst zu sein, in das „Bangverweinte Jahre“ ein „Bild“ „eingegraben“ haben, „[d]as ihm Ewigkeit gewährt“. Doch diese Lesart wirft noch immer zwei entscheidende Fragen auf: 1. Wie kann in einem Lied ein Bild „eingegraben“ sein? In einen Schriftträger aus Metall, Holz oder Stein - wir befinden uns bekanntlich in einer Höhle - lassen sich Zeichen, sei es ein Bild oder ein Liedtext, „eingraben“, nicht jedoch in die Schrift resp. den Liedtext selbst. 2. Und wie soll das Lied dabei „Ewigkeit" gewähren?

$\mathrm{Zu}$ 1.: In der Tat hält das Lied eine eigene Antwort bereit: Ja, es ist möglich, ein „Bild“ in den Text selbst „einzugraben“, sofern man sich unter dem Wort „Bild“ kein Bild im eigentlichen ikonischen, sondern im übertragenen (meta-) symbolischen Sinne vorstellt. Oder anders formuliert: Das Symbol „Bild“ verweist im eigentlichen Sinne auf ein Bild, auf ein Ikon. Ein solches ist jedoch im

42 Ein in Strophen gehaltenes Lied innerhalb des Lauftextes eines gedruckten Buches ist jedoch durchaus graphisch wahrnehmbar, was denn auch wenig später in Heinrichs Lektüre reflektiert wird (siehe unten).

43 Mittelhochdeutsch dôn bedeutet neben ,Laut', ,Ton', ,Stimme‘ zuerst und vor allem die vom Dichter verfasste und komponierte Einheit von Text und Melodie, nhd. ,Lied“ (mhd. liet = Strophe); vgl. Lexer 1992, S. 32. Die mittelhochdeutsch geprägte Bedeutung von „Thon“ passt zum Paradigma des Mittelalters, in dem die Figur Heinrich und dessen Geschichte angesiedelt ist und das zweieinhalb Seiten weiter durch das Grabmal derer von Hohenzollern stärker in den Vordergrund tritt. Freilich ließe sich „Thon“ als irdener Werkstoff auch metonymisch auf „Schale“ in Strophe 4 beziehen. Die Verwendung des Demonstrativpronomens „Diesen“ anstelle von ,jenen“ widerspricht jedoch einer solchen Lesart.

Zur christlichen Konnotation des Liedes, die jedoch undeutlich und ohne direkten Bezug auf Gott sei, wobei „die Ewigkeit gewährende visio beatifica des Himmels schon in dieses Leben verlegt“ werde, vgl. Mahr 1970, S. 143.

44 Wohl ebenfalls in der mittelhochdeutschen Wortbedeutung ist auch „schlechten“ zu lesen, nicht als Gegenteil von ,gut', sondern im Sinne von, sleht' als ,gerade, glatt; aufrichtig; einfach, kunstlos schmucklos'; später auch ,leer'. (vgl. Lexer 1992, S. 197; Deutsches Wörterbuch, Bd. 15, Sp. 523; und das heute gebräuchliche Wort ,schlicht'). Gerade die Bedeutung ,schlicht', ,schmucklos' würde, passend zur unten vorgeschlagenen Lesart, darauf hinweisen, dass das ,schmucklose` Lied mit einem (Sprach-)Bild geschmückt wurde. 
Liedtext nicht präsent. Es kann darin nicht präsent sein, da der Liedtext selbst nur aus Zeichen besteht, die als solche nicht Zeichenträger für ein Ikon zu sein vermögen. ${ }^{45}$ Das Symbol „Bild“ kann jedoch auch im übertragenen Sinne gelesen werden. Dann verweist es als eine nahezu habitualisierte Metapher auf ein Sprachbild; wobei ein Sprachbild wiederum nichts anderes ist als eine Metapher. Eine Transformation resp. Übertragung des ikonischen Referenten des Signifikanten „Bild“ in einen symbolischen Referenten, eine Metapher, ist also möglich, wenn das Wort „Bild“ nicht wörtlich, sondern metaphorisch gelesen wird - als Bild für ein sprachliches Bild, als Metapher für eine Metapher.

Es ist beindruckend, dass die oben beschriebene Umwandlung der Indizes in Symbole durch den Alten für die eben beschriebene Transformation resp. Übertragung bereits eine implizite Anleitung bereithält, und zwar im Modus oder besser gesagt: als Figur der Analogie. Damit erfährt das Wort „Figur“ in der weiter oben zitierten Textstelle eine Potenzierung, indem es an der Figuration der rhetorischen Figur Analogie beteiligt ist. Diese Potenzierung bildet selbst wiederum eine Analogie zur Potenzierung, welche die analoge Transformation eines vermeintlichen Referenten Bild zu einem Symbol beinhaltet. Eine Analogie in der Analogie also. Damit ist ein Reflexionsgrad erreicht, der eine Spiegelung auslöst, die an die Grenzen der nachvollziehbaren Abstraktion führt und sich bereits in einer sich potenziell fortsetzenden Spiegelung zu verlieren droht, sucht man sie von diesem Punkt aus weiterzudenken.

Potenziell endlose Spiegelung ist eine, wenn nicht die Konstituente des hier behandelten Höhlenabenteuers, die weiter unten noch eingehender zu behandeln ist. Zuerst sei aber zur Lesart des Wortes „Bild“ als Sprachbild zurückgekommen, denn dadurch vollzieht sich wiederum eine Potenzierung des Wortes „Bild“ zu einem Metabild, zu einer Metametapher. Das Wort „Bild“ ist hier eine Metapher, die zunächst auf eine Metapher im Allgemeinen verweist. Da sie aber selbst eine Metapher ist, verweist sie zugleich, wie alle Metametaphern, immer auch auf sich selbst, und deshalb gräbt sie im Zuge der Lektüre performativ in gewissem Sinne tatsächlich „ein Bild“ in den „Thon“ ein, nämlich die eigene Lesart als Sprachbild. ${ }^{46}$ (Es ließe sich somit auch festhalten, dass jede Metametapher letztlich performativen Charakters ist, vollzieht sie doch, worauf sie verweist.) Oder in anderen Worten: Die vierte Strophe des Liedes verweist nicht nur darauf, dass dem Lied selbst eine Metapher

45 Selbst noch in der konkreten Poesie, die ebendies zu erreichen sucht, sind die Zeichen entweder icons oder symbols und können als solche weder gleichzeitig gelesen werden noch als Zeichenträger dienen, in den der jeweils andere Zeichentyp „eingegraben“ wäre.

46 Zur bereits in der mittelalterlichen Dichtung (Novalis' Roman spielt ja im Mittelalter) virtuos zelebrierten Selbstbezüglichkeit von Liedtexten vgl. Kapitel II.2.1 zu Brentanos Der Spinnerin Nachtlied. 
„eingegraben“47 ist, sondern sie gräbt im Zuge der Lektüre zugleich sich immer auch eine Metametapher ein. Das grammatikalische Subjekt von „haben ... eingegraben“ ist freilich („bangverweinte“) "Jahre“, was die soeben dargelegte Lesart nicht unterläuft, sondern im Gegenteil unterstützt: Es ist gerade der Faktor der Zeit, der zum einen am Eingraben wesentlich beteiligt ist (eine jede Lektüre vollzieht sich in der Zeit), der zum anderen aber zugleich mittels des Gewährens von Ewigkeit durch das „Bild“ aufgehoben werden soll.

Auf die übrigen Strophen des Liedes kann hier nicht näher eingegangen werden, jedoch scheinen insbesondere die Strophen eins bis drei des Liedes von Sprachbildern, von Metaphern zu wimmeln resp. eine metaphorische Lesart von u. a. „Thale“, „Nacht“, „der Liebe volle Schaale“, „Tropfen“, „Himmels Thor“, „Königinn der Frauen“, „ihr getreues Herz“ besonders stark zu provozieren. Es deutet also vieles darauf hin, dass das Lied in Strophe vier autoreflexiv die Metaphorizität des gesamten Liedes verhandelt. Es ist dem Lied also im Grunde nicht nur "ein Bild eingegraben“, sondern viele, aber vielleicht nur eines, „das ihm“ "Ewigkeit [zu] gewähr[en]“ sucht.

$\mathrm{Zu}$ 2.: Die metaphorische Lesart von „Bild“ modifiziert die oben aufgeworfene zweite Frage lediglich dahingehend, als dass diese nun lautet: Inwiefern soll ein Sprachbild Ewigkeit gewähren? Aber gerade diese Modifikation ist entscheidend, führt sie doch zu einer weiteren Frage: Ist es vielleicht weniger irgendein Sprachbild, das dies zu leisten vermag, als vielmehr ebendiese soeben beschriebene Spiegelung, diese autoreflexive Potenzierung, die der Ausdruck „ein Bild“ als Metametapher auszulösen vermag? Mit dieser Spur, die im vergänglichen Medium des gesungenen Liedes durch die Höhlen hallte, beschäftigt sich das folgende Unterkapitel, und zwar anhand der wenig später, kurz vor dem Ende des Höhlenabenteuers sich abspielenden Szene. Dort findet Heinrich seine eigene Geschichte im (vermeintlich) beständigeren Medium des Buches und versucht, sie zu lesen.

\subsection{2}

Bilder sehen, Bilder lesen: Hermeneutik, Spiegelung und Iterabilität

Die Szene wird eröffnet durch den Satz: „Der Einsiedler zeigte ihnen seine Bücher" (S. 264, Z. 1). Diese vom Erzähler berichtete, zeigende (Sprach-)Handlung des Einsiedlers, auf den die Gesellschaft in den Höhlen gestoßen war, beendet die zuvor vorgetragenen Ausführungen ebendieses Einsiedlers (ab S. 255). Sie lässt ihn auf etwas verweisen, das für seine Zuhörer sichtbar ist oder vielmehr - man befindet sich ja in einer Höhle - dadurch erst sichtbar

47 Das Partizip „eingegraben“ ist dabei selbst wiederum eine metaphorische Verwendung dieses Verbes. 
wird. Es vollzieht sich dabei also ein Wechsel von der lautlichen zur visuellen Wahrnehmung. Dennoch mag es auf den ersten Blick erstaunen, dass die unmittelbar folgende Lektüre Heinrichs fast ausschließlich durch wortwörtliche „Bilder" (S. 264, Z. 4) - also nicht von Symbolen im engeren Sinne - geprägt ist. Dies in zweierlei Hinsicht: Erstens betrachtet Heinrich die Illustrationen in den Büchern, und zweitens nimmt er auch die Symbole selbst vor allem in ihrer Bildlichkeit und Materialität ${ }^{48}$ wahr:

Es waren alte Historien und Gedichte. Heinrich blätterte in den großen schöngemahlten Schriften; die kurzen Zeilen der Verse, die Überschriften, einzelne Stellen, und die saubern Bilder, die hier und da, wie verkörperte Worte, zum Vorschein kamen, um die Einbildungskraft des Lesers zu unterstützen, reizten mächtig seine Neugierde. (S. 264, Z. 1-6)

„Kurze[] Zeilen der Verse“ und „Überschriften“ sind grundsätzlich nicht zu hören, sondern zielen als Gliederungshinweise ${ }^{49}$ durch ihre graphische Unähnlichkeit mit dem Lauftext auf eine visuelle Wahrnehmung im Zuge des Lesens ab. Diese graphische Unähnlichkeit ermöglicht es - das notwendige Textsortenwissen vorausgesetzt -, „Verse“ und „Überschriften“ selbst ohne Kenntnis der Sprache, in der sie gehalten sind, als solche zu erkennen resp. $\mathrm{zu}$ lesen, wenngleich ihr Inhalt unverständlich bleiben muss. Auch die Formulierungen "großen schöngemahlten Schriften" und "saubern Bilder" verweisen auf bildlich Wahrnehmbares. Der Relativsatz zu "saubern Bilder“ beschreibt gar explizit eine Abgrenzung von den rein geistig zu erschließenden, (un-),verkörperte[n] Worte[n]“. Lediglich „einzelne Stellen“ lässt die Lesart offen, es handle sich dabei um (Text-),Stellen“. Auch ist der ganze Passus - wie bereits im oben behandelten Lied beobachtet - selbst in bildlicher Sprache gehalten: z. B. „wie verkörperte Worte“ (ausgeführte Metapher/Similitudo), „zum Vorschein kamen“ (Metapher). Das Blättern Heinrichs ist demzufolge als Mischform zwischen Betrachten und Lesen anzusehen, wobei Ersteres deutlich dominanter ist. ${ }^{50}$

48 Chad Wellmons Aufsatz „Touching Books“ hat diesen materialen Aspekt, auch für Novalis' Werk insgesamt, stark gemacht, ist jedoch in seiner Pointiertheit mit Vorsicht zu genießen (vgl. Wellmon 2011, insbesondere S. 92 f.).

49 Vgl. Hausendorf/Kesselheim 2008, S. 40 f.; resp. das Kapitel II.1.1 zu den Lebens-Ansichten des Katers Murr.

50 Neben der starken Betonung der Bildlichkeit deutet die Notwendigkeit von Erklärungen seitens des Einsiedlers auch auf mögliche mangelnde Sprachkenntnisse Heinrichs hin, die zumindest im Falle des Buches mit seiner eigenen Geschichte dann auch expliziert werden (S. 264, Z. 23). 
Das Blättern hat zudem auch etwas Haptisches, was das Sinnliche, nahezu Erotische der Szene unterstreicht. Vom Unterstützen der „Einbildungskraft“ und vom ,mächtigen Reizen“ der "Neugierde“ ist die Rede, der Einsiedler bemerkt die „innere Lust“ (S. 264, Z. 6 f.) Heinrichs, und als die Gesellschaft ihn für eine Weile bei den Büchern zurücklässt, scheint sich diese „Lust“ gar ins Unendliche zu steigern: „Er [Heinrich] blätterte mit unendlicher Lust umher“ (S. 264, Z. 21 f.). Es scheint dabei so, als ob die oben im Lied verheißene „Ewigkeit" des Bildes die visuelle Wahrnehmung Heinrichs nicht nur angekündigt hat, sondern auch in der „unendliche[n] Lust“ des Blätterns nachhallt. Eine Unendlichkeit aber, die zu Beginn des nächsten Satzes sogleich wieder paradoxal und antithetisch zugleich - durch das Wort „endlich“ einem (vermeintlichen?) Ende zugeführt wird: „Endlich fiel ihm ein Buch in die Hände“ (S. 264, Z. 22). ,Zugeführt', weil das Adjektiv ,endlich` nicht direkt ein Ende bezeichnet, sondern, streng etymologisch betrachtet, eine Ähnlichkeitsbeziehung zu einem Ende herstellt: die Beschaffenheit eines Endes habend, also ,end-gleich' sein. Damit spiegelt sich in der antithetisch-paradoxalen Gegenüberstellung von „unendlicher" und „endlich“ auf der Mikroebene das wider, was sich im weiteren Verlauf der Szene entfalten wird: „endlich“ scheint die „unendliche[] Lust“ zu beenden, führt sie jedoch in eine neue Unendlichkeit hinein, die wiederum die „unendliche Lust“ am Lesen in ein potenziell unbeendbares, sich in Spiegelungen - im Modus der Ähnlichkeit, des Ikons und der Metapher - verlierendes Lesen überführt.

Dieser Unendlichkeit sei nun weiter nachgegangen, wobei es angemessen ist, die für die hier behandelte Operation Autoreflexivität wichtigste Textstelle im Heinrich von Ofterdingen ausführlich zu zitieren:

Er [Heinrich, MG] blätterte mit unendlicher Lust umher. Endlich fiel ihm ein Buch in die Hände, das in einer fremden Sprache geschrieben war, die ihm einige Ähnlichkeit mit der lateinischen und italienischen $\mathrm{zu}$ haben schien. Er hätte sehnlichst gewünscht, die Sprache zu kennen, denn das Buch gefiel ihm vorzüglich, ohne daß er eine Sylbe davon verstand. Es hatte keinen Titel, doch fand er noch beym Suchen einige Bilder. Sie dünkten ihm ganz wunderbar bekannt, und wie er recht zusah, entdeckte er seine eigene Gestalt ziemlich kenntlich unter den Figuren. Er erschrack und glaubte zu träumen, aber beym wiederholten Ansehn konnte er nicht mehr an der vollkommenen Ähnlichkeit zweifeln. Er traute kaum seinen Sinnen, als er bald auf einem Bilde die Höhle, den Einsiedler und den Alten neben sich entdeckte. Allmählich fand er auf den anderen Bildern die Morgenländerinn, seine Eltern, den Landgrafen und die Landgräfinn von Thüringen, seinen Freund den Hofkaplan, und manche Andere seiner Bekannten; doch waren ihre Kleidungen verändert und schienen aus einer anderen Zeit zu seyn. Eine große Menge Figuren wußte er nicht zu nennen, doch däuchten sie ihm bekannt. Er sah sein Ebenbild in verschiedenen Lagen. Gegen das Ende kam er sich größer und edler vor. [...] Die letzten Bilder waren dunkel 
und unverständlich; doch überraschten ihn einige Gestalten seines Traumes mit dem innigsten Entzücken; der Schluß des Buches schien zu fehlen. Heinrich war sehr bekümmert, und wünschte nichts sehnlicher, als das Buch lesen zu können, und vollständig zu besitzen. Er betrachtete die Bilder zu wiederholten Malen und war bestürzt, wie er die Gesellschaft zurückkommen hörte. Eine wunderliche Schaam befiel ihn. Er getraute sich nicht, seine Entdeckung merken zu lassen, machte das Buch zu und fragte den Einsiedler nur obenhin nach dem Titel und der Sprache desselben, wo er denn erfuhr, daß es in provenzalischer Sprache geschrieben sey (S. 264, Z. 21, bis S. 265, Z. 20).

Heinrichs Auseinandersetzung mit dem Buch, das seine eigene Geschichte enthält, muss uns heute im Zuge unseres eigenen, sich während unserer Lektüre vollziehenden hermeneutischen Verfahrens wie eine Exemplifikation von Gadamers 16o Jahre später vertretener Hermeneutik erscheinen:51 Heinrich ist der provenzalischen Sprache, in der das Buch gehalten ist, nicht mächtig, versucht jedoch trotzdem, eine zusammenhängende Geschichte zu konstruieren und mit Sinn zu versehen, wobei ihm das Bekannte, das dreimal explizit genannt wird (zweimal „bekannt“; „seiner Bekannten“), als Leitfaden dient. Der Einstieg in den hermeneutischen Zirkel gelingt Heinrich also erst über das Herstellen von Ähnlichkeitsbeziehungen zwischen dem Text und seinem bisherigen Leben. ${ }^{52}$ Auch jeder Leser dieser Textstelle des Heinrich von Ofterdingen steht in einem analogen Verhältnis zum hermeneutischem Verfahren der Figur Heinrich. Der Leser stellt nämlich ebenfalls die oben zitierten Zeilen in ein Ähnlichkeitsverhältnis, jedoch nicht wie Heinrich primär in ein Ähnlichkeitsverhältnis zu seinem Leben, sondern zu seinem Lesen: Er erinnert sich, kurz zuvor gelesen zu haben, dass sich Heinrich in einer Höhle befindet etc.53 Sein Lesen erweckt dabei das Zeichengebilde „Heinrich“

$5^{1}$ Vgl. Gadamer 199o, Bd. 1, S. 296: „So läuft die Bewegung des Verstehens stets vom Ganzen zum Teil und zurück zum Ganzen. Die Aufgabe ist, in konzentrischen Kreisen die Einheit des verstandenen Sinnes zu erweitern." Hiermit erhält die zitierte Szene etwas geradezu Prophetisches. Betrachtet man zudem die sich gerade in dieser Szene entfaltende, jede „Einheit des verstandenen Sinnes“ als Figuration ausstellende Entortungsbewegung, so findet man gar über Gadamer Hinausgehendes, das neben dem mit Blick auf Heinrichs Zukunft vorhandenen prophetischen Zug mitschwingt (vgl. auch Schmaus 2000, S. 68; und die Auseinandersetzung mit u. a. Gadamer und Schleiermacher in der Einführung).

$5^{2} \quad$ Vgl. punktuell Johnson 1998, S. 28.

53 Kurz darauf erfährt man zudem vom Einsiedler: „Der Schuss [sic] fehlt an dieser Handschrift [...]“ (Novalis, Heinrich von Ofterdingen, S. 265, Z. 25). Beim „Schuss“ handelt es sich um einen Fehler in der HKA; man könnte hinzufügen: ausgerechnet an dieser Stelle ... Im Erstdruck steht hingegen korrekterweise „Schluss“, wie die neue Edition von Alexander Knopf belegt; vgl. ders. 2015, S. 80, Z. 22, resp. S. 292. Durch den Fragmentcharakter, den der fehlende Schluss dem Buch verleiht, erhält es, in dem Heinrich zu lesen sucht, eine weitere Ähnlichkeit mit dem Fragment Heinrich von Ofterdingen, das der reale Leser 
zum Leben, das wiederum als Figur Heinrich die eigene Lebensgeschichte lesend zum Leben erweckt. Damit rückt die Figur Heinrich, die ihre eigene Geschichte zu lesen sucht, in ein Ähnlichkeitsverhältnis zu uns Lesern, die gerade dabei sind, Novalis' Heinrich von Ofterdingen zu lesen: unser Lesen gespiegelt in Heinrichs Lektüre, die wiederum in sich selber gespiegelt wird, weil sie auch ebenjene Höhlenszene, in der sich die Figur Heinrich gerade befindet, beinhaltet - und immer so fort (mit „unendliche[r] Lust“!) in einer potenziell endlosen Spiegelung.

Die hier behandelte Textstelle setzt somit einerseits die fiktive Figur Heinrich in ein Ähnlichkeitsverhältnis zum realen Leser, was eine poetologische Thematisierung von Lesen und Text im Allgemeinen ermöglicht, und tut dies andererseits auf eine Weise, die eine potenziell endlose autoreflexive Spiegelung der Geschichte Heinrichs und ebenso eine potenziell endlose Spiegelung des Lesens ${ }^{54}$ lostritt. Dies erfolgt jeweils im Modus der Ähnlichkeit resp. genauer ausgedrückt (in Anlehnung an Roman Jakobsons Terminologie): im Modus der Äquivalenz, die Similarität und Deviation umfasst. Bevor weiter unten auf diesen Modus im Zusammenhang mit der potenziell endlosen Spiegelung zurückgekommen wird, sollen jedoch die folgenden zwei Abschnitte zunächst noch die Metaphorizität zweier Wendungen genauer untersuchen.

Die Formulierung „Kleidungen [...] aus einer anderen Zeit“ lässt aufhorchen. Folgt man nämlich der oben dargelegten Beobachtung, dass die hier untersuchte Textstelle nicht nur zu lesen gibt, dass Heinrich liest, sondern auch autoreflexiv das Lesen ebendieser Textstelle und des Romans Heinrich von Ofterdingen insgesamt thematisiert, so ergibt sich folgende Lesart: Die

gerade in Händen hält. An dieser Stelle soll auch Erwähnung finden, dass es sich beim ersten Teil des Romans, der im Erstdruck entgegen seinem Titelblatt ohne die Blätter des zweiten Teils erschienen ist (vgl. Knopf 2015, S. 133; und Frühwald 2008, S. 219), um ein äußerst kunstvolles Fragment handelt, das wiederum in einem frappanten Ähnlichkeitsverhältnis zu Goethes Märchen am Ende der Unterhaltungen deutscher Ausgewanderten steht: Wie dieses befindet sich Klingsohrs Erzählung in einer Rahmenhandlung, die jedoch am Ende nicht geschlossen, als Fragment im Fragment präsentiert wird und damit die vermeintliche Einheit eines Textes radikal infrage stellt (vgl. dazu auch Kapitel II.3). Selbst die in der Reclam-Ausgabe zumindest Klingsohrs Erzählung als solche (vermeintlich) beschließenden und eingrenzenden Anführungs- und Schlusszeichen (man erinnere sich auch an die betreffenden Schlusszeichen im Kater Murr) sind bloße, wenn auch in gewissem Sinne sehr aussagekräftige editorische Zusätze aus unseren Tagen: „Anführungszeichen bei direkter Rede wurden durchwegs ergänzt“ (Frühwald 2008, S. 221). In der HKA wurde hingegen auf eingrenzende Anführungszeichen verzichtet (vgl. S. 315 der HKA).

Des Lesens der fiktiven Figur Heinrich ebenso wie des Lesens der realen Leser. 
„Kleidungen [...] aus einer anderen Zeit" tragen dem Umstand Rechnung, dass jedes Mal, wenn Heinrich und die anderen Figuren als Zeichengebilde von einem Leser aktualisiert werden, sie zwar als fiktive Figuren wiedergeboren werden, aber jedes Mal - je nach Leser und Art oder Zahl der Lektüre - als leicht andere. ${ }^{55}$ Die jeweils unmittelbar vorangegangene Lesart wird hier also ausgestellt als etwas Bekanntes und im Zuge des hermeneutischen Prozesses zugleich wieder Fremdgewordenes - oder eben metaphorisch ausgedrückt: als bekannte Figuren in „Kleidungen aus [...] einer anderen Zeit“. Die Figur Heinrich sieht in den Bildern, dass die ihr bekannten Gefährten und letztlich auch sie selbst als Zeichengebilde schon mal gelesen wurden resp. gelesen worden sein werden, und antizipiert damit in einem prophetischen Gestus gewissermaßen metaleptisch die Lektüre des realen Lesers. Dies jedoch immer nur für den kurzen Moment, in dem ein menschlicher Leser ebendiese Stelle aktualisiert und es der Figur Heinrich damit ermöglicht, deren Gefährten und sich selbst zu betrachten. Sieht man zudem, die poetologische Metaphorik von „Kleidungen“ weiterverfolgend, im fiktiven Leser Heinrich eine Metapher für den realen Leser im Allgemeinen und in den „Kleidungen“ das Wissen und die Vorannahmen desselben über einen Text (vgl. den $\mathrm{Zu}-$ sammenhang: „Kleidungen“, mithin gewebter Stoff, lateinisch textum), so gibt diese Stelle ergänzend Folgendes zu lesen: Nicht nur das Gelesene verändert sich während einer Lektüre stets, sondern auch der Leser: Denn nicht nur die Figur Heinrich, sondern auch der reale Leser sieht sich in dieser Stelle gespiegelt und wird Zeuge, wie er gerade in diesem Augenblick seine Einstellung zum Text verändert, wie er - in der Metaphorik der „Kleidungen“ gesprochen im Begriff ist, seine alten abzulegen und neue anzuziehen. Diesen Abschnitt zusammenfassend lässt sich somit festhalten:

Die untersuchte Textstelle thematisiert, indem sie eine weitere autoreflexive Spiegelung hinzufügt, metaleptisch die Iterabilität ihres eigenen Gelesenwerdens. Sie beinhaltet damit nicht nur eine potenziell endlose Spiegelung ihrer selbst, des Lesens und des dabei sich abspielenden hermeneutischen Prozesses, sondern thematisiert auch den Umstand, dass diese Spiegelung selbst wiederum potenziell unendlich oft, aber freilich nie im exakt gleichen Gewand, wiedergelesen werden kann.

55 Damit ergäbe sich auf poetologischer Ebene auch eine Antwort auf das Paradoxon, dass das Buch Heinrichs Geschichte enthält und zugleich dessen Geschichte bereits als geschehene, vergangene abbildet. Vgl. dazu auch Deghaye 200o, S. 429-438, der jedoch dieses Paradoxon u. a. damit zu erklären sucht, dass Novalis zeigen wolle, "que le personnage de fiction précédait le personnage réel“ (ebd., S. 432) sowie dass Heinrichs Traum hier „la consistance du livre“ (ebd., S. 433) einnehme. 
Die zweite metaphorische Wendung, die hier genauer in den Blick genommen werden soll, leitet die versuchte Lektüre der eigenen Geschichte seitens Heinrichs ein: „Endlich fiel ihm ein Buch in die Hände“ (S. 264, Z. 22). Ist dies ein Hinweis darauf, dass Heinrich, der in diesem Moment seine eigene Geschichte in Händen hält, nun erwachsen geworden ist, sein Leben wortwörtlich im Griff hat und fortan in die eigenen Hände nimmt? Dafür spräche die Beschreibung der Wirkung, die die Ausführungen des Einsiedlers kurz zuvor auf Heinrich ausgeübt haben und in denen ebenfalls das Verb "fielen“ metaphorische Verwendung fand: „Manche Worte, manche Gedanken fielen wie belebender Fruchtstaub, in seinen Schooß, und rückten ihn schnell aus dem engen Kreise seiner Jugend auf die Höhe der Welt“ (S. 263, Z. 32-34). Oder schwingt - wie es etwa Johannes Mahr vertritt ${ }^{56}$ - im „ihm“ gar der Autor Novalis mit, der den Stoff des ,Heinrichs von Afterdingen' ebenfalls aus alten Chroniken bezogen hat ${ }^{57}$ Dafür sprächen die „Hände“ als Organ des Schreibens und der Beginn der gesamten Leseszene, in der „Historien“ explizit genannt werden: „Der Einsiedler zeigte ihnen seine Bücher. Es waren alte Historien und Gedichte" (S. 264, Z. 1-2). Wenngleich diese beiden Lesarten sicherlich mitschwingen, so ist erstens das „Buch“ keine „Historie“, sondern ein „Roman“ (S. 265, Z. 24) und damit mehr als nur eine Anspielung auf die Quelle Novalis', und zweitens hält Heinrich sein Leben nicht nur in Händen, sondern er liest es. Aus diesen Gründen soll hier eine ergänzende Lesart vorgeschlagen werden: Das Verb "fiel" bezeichnet zwar metaphorisch den Vorgang, dass sich Heinrich zufällig gerade dieses „Buch“ greift, doch grammatikalisch gesehen ist in dieser Formulierung nicht mehr Heinrich das Subjekt, sondern das „Buch“. Dadurch kehrt sich, liest man die Metapher wörtlich, der eigentliche Vorgang um: Das „Buch“ als Subjekt scheint Heinrich zu finden, bevor dieser seine Geschichte entdeckt - was dadurch unterstrichen wird, dass sich Heinrich bereits 90 Seiten in seiner Geschichte, Novalis' Heinrich von Ofterdingen, befindet, bevor er sie entdeckt und zu lesen versucht. Wendet man die oben dargelegte Ähnlichkeitsbeziehung zwischen der Figur Heinrich und dem realen Leser an, so heißt dies scheinbar paradoxal, dass der Leser im Text schon enthalten ist, bevor der Leser den Text zu lesen beginnt! Wie oben bereits angetönt, ließe sich dieses Paradoxon auch in Anlehnung an Genette als Metalepse bezeichnen, die sich jedoch nicht wie bei diesem auf der Ebene des Erzählens, sondern auf der der Lektüre vollzieht. ${ }^{58}$

56 Vgl. Mahr 1970, S. 146.

57 Vgl. Frühwald 2008, S. 236.

$5^{8}$ Vgl. dazu auch, wenngleich in Bezug auf E. T. A. Hoffmann, Stašková 2011. 
Zweierlei wird damit bereits zu Beginn von Heinrichs Lektüre der eigenen Geschichte vorweggenommen: erstens, wenngleich nur implizit resp. poetologisch, Derridas Beobachtung, die Möglichkeitsbedingung für die Äußerung eines Zeichens liege in dessen Wiederholbarkeit, in dessen Reaktualisation;59 und zweitens der Umkehreffekt, der für Heinrichs gesamte Lektüre oben aufgezeigt wurde: Heinrich liest nicht nur, sondern wird gleichzeitig gelesen (und zwar in doppeltem Sinne) - die fiktive Figur Heinrich und ebenso der reale Leser verlieren die Macht über den Roman, den sie zwar in Händen halten, der sie aber seinerseits in einer endlos gespiegelten Lektüre potenziell ewig gefangen zu halten vermag.

Zum Schluss dieses Unterkapitels sei noch einmal auf die oben festgestellten Ähnlichkeits- resp. Äquivalenzbeziehungen zurückgekommen: Heinrich findet in der ausführlich zitierten Szene ein „Buch“, das in einer ,fremd[en] Sprache geschrieben' ist, und sucht es durch das Herstellen von Äquivalenzbeziehungen zu lesen - also durch die Suche nach Similarität und Deviation etwa zwischen der ihm fremden Sprache und ihm bekannten Sprachen oder zwischen den Abbildungen und seiner Lebenswelt. Dabei findet er heraus, dass er gerade dabei ist, seine eigene Geschichte zu lesen. Dies wiederum setzt die Figur Heinrich und das von ihm gelesene „Buch“ selbst auf einer abstrakten Metaebene in ein Similaritätsverhältnis zum realen Leser und zu dessen Lektüre. Diese Lesart wird weiter bestätigt durch den Einsiedler, der auf die Frage Heinrichs nach dem Buch antwortet, es handle sich dabei um einen "Roman“ (S. 265, Z. 24). Betrachtet man Heinrich und den „Roman“ als poetologische Metaphern für den realen Leser, der gerade Novalis' Roman Heinrich von Ofterdingen liest, so scheint einem Heinrichs Leseszene mitzuteilen, dass der Text dem Leser primär unverständlich und nur über Äquivalenzbeziehungen, insbesondere bildliche Äquivalenzbeziehungen zum Weltwissen des Lesers, erschließbar sei. Oder mit anderen Worten: Der Roman Heinrich von Ofterdingen gibt uns zu lesen: „Wenn ihr mich verstehen wollt, dann achtet auf die Bilder." Wie bereits weiter oben behandelt, hält sich die Figur Heinrich mit einigem Erfolg an die Abbildungen im Buch. Da der dem realen Leser vorliegende Roman Heinrich von Ofterdingen dem "Roman“, den Heinrich liest, jedoch insofern unähnlich ist, als dass er nicht illustriert ist, bleiben dem realen Leser nur noch die sprachlichen Bilder übrig. Die implizite Leseanleitung müsste also letztlich lauten: „Achtet auf die sprachlichen Bilder!“ Dies ließe sich nun als Ausgangspunkt dafür nehmen, den gesamten Roman, der bereits mit Traumbildern und dem Lesen/Deuten derselben beginnt, nach dieser hier erarbeiteten, impliziten Anleitung zu lesen und dabei den Metaphern,

Vgl. Derrida 1999, am prägnantesten formuliert auf S. 349 . 
Allegorien und Similitudines besonders genau nachzugehen. ${ }^{60}$ Ein solch umfangreiches Unterfangen kann an dieser Stelle jedoch nicht geleistet werden.

1.1.3 „Ewigkeit“ und potenzierte Autoreflexivität

Dennoch soll zum Schluss der Auseinandersetzung mit der Höhlenszene zumindest noch ein „Bild“ mit Bezug auf die Lektüre Heinrichs gelesen werden, nämlich das in Kapitel 1.1 behandelte. In jenem Unterkapitel wurde festgestellt, dass das „Bild“, das durch „[b]angverweinte Jahre“ in das von der Gesellschaft in den Höhlen gehörte Lied „eingegraben“ ist und ebendiesem Liede „Ewigkeit gewähr[e]", als Sprachbild und damit als Metametapher gelesen werden kann, die sich im Zuge der Lektüre performativ in das Lied eingräbt. Das Paradigma von Dauer, Überlieferung und Ewigkeit in Zusammenhang mit Sprach- und Schriftzeichen wird zudem durch zahlreiche weitere Textstellen zu einem, wenn nicht gar dem zentralen Paradigma der Höhlenszene. Zu nennen sind dabei insbesondere: das unter 1.1 behandelte, gewissermaßen in das Paradigma einführende Deuten von "Zeichen eines undenklichen Alterthums" (S. 253, Z. 18); das Grab derer von Hohenzollern mit der ikono- und epigraphischen Verewigung der Beigesetzten (vgl. S. 257, Z. 9-14); die Betonung der Wichtigkeit von Geschichtsschreibung und Überlieferung (vgl. insbesondere S. 257 f.); der Umstand, dass der von Heinrich gefundene „Roman“ weder Anfang („Es hatte keinen Titel“, S. 264, Z. 26) noch Ende („Der Sch[1] uss fehlt an dieser Handschrift [...]“, S. 265, Z. 25) besitzt; und schließlich der Hinweis des Einsiedlers, dass er ebendiesen "Roman“ aus Jerusalem - der Stadt der Auferstehung Christi und des damit im Christentum verbundenen Gewährens ewigen Lebens - zum „Andenken“ eines verstorbenen Freundes aufbewahre (vgl. S. 265, Z. 25-27).

Jenes Lied wiederum ist Teil des Romans Heinrich von Ofterdingen. Nun ist aber ausgerechnet dieser Roman im „Roman“, den die Figur Heinrich in der oben behandelten Szene liest, gespiegelt - und zwar hauptsächlich in der Form von Bildern, als Text, der sich Heinrich als ein textum aus Bildern erschließt. Dieser "Roman“, so ist zu folgern, enthält konsequenterweise auch die Höhlenszene, jenes darin enthaltene Lied und ebenso Heinrichs Lektüre, die dann wiederum seine Geschichte enthält usw.

Als Zwischenfazit lässt sich somit festhalten: Sowohl das Lied in der Höhle als auch Heinrichs Lektüre beinhalten autoreflexive Elemente, diese

6o Damit wird hier noch einen Schritt weiter gegangen als bei Marion Schmaus, die die Bilder nicht als Metametaphern, sondern als Metaphern für die „einzelnen Bausteine des Romans“ interpretiert, die vom Lesenden zu einem Ganzen zusammenzufügen seien (vgl. Schmaus 2000, S. 72). 
fokussieren inhaltlich auf Bildlichkeit. Oder präziser ausgedrückt: Das Prozesshafte der Autoreflexivität affiziert offenbar die Metaphorizität jener Textstellen und öffnet jene Metaphern dadurch hin zur Allegorie. Bildlichkeit und Metaphorizität beruhen wiederum immer auf einem Äquivalenzverhältnis. Sowohl das Lied als auch die Szene von Heinrichs Lektüre betonen stark das Paradigma des Bildes und der Äquivalenz. Und gerade über dieses Paradigma der Äquivalenz stehen die beiden Textstellen selbst in einem Äquivalenzverhältnis, was sie zusätzlich je den eigenen Modus - den der Äquivalenz, in dem sie gehalten sind - autoreflexiv ausstellen lässt.

Hinzu kommt nun, dass letztlich der Begriff Autoreflexivität selbst schon als ein bildlicher, metaphorischer zu bezeichnen ist: Er wendet nämlich das in ihm implizierte Bild des reflektierenden Spiegels auf Text im Allgemeinen an, der als solcher nicht der Spiegelung im physikalischen Sinne mächtig ist. ${ }^{61}$ Dieser Unterschied wird insbesondere in der Vorsilbe ,Auto- 'klar, die sich zwar auf den Text, nicht aber auf einen Spiegel anwenden lässt. Ein Spiegel vermag sich nicht selbst zu spiegeln, sondern nur in einem anderen - dann freilich ad infinitum. ${ }^{62}$

Genau nach dem - letztlich der gesamten Reflexionsphilosophie seit Descartes zugrunde liegenden ${ }^{63}$ - Vorbild zweier, einander derart gegenübergestellter Spiegel scheint Heinrichs Lektüre der eigenen Geschichte konzipiert zu sein. Und gerade weil sich diese im Medium Text konstituiert und nicht in physischen Spiegeln, ist eine Kombination der beiden Reflexionstypen möglich: des Modus der physikalischen, unendlichen Spiegelung zweier Spiegel ineinander mit dem Modus des Autoreflexiven, der Spiegelung in sich selbst.

Die Kombination dieser beiden Modi führt, und das ist das Geniale an Novalis' Höhlenszene, ganz nach der frühromantischen Ästhetik zu einer Potenzierung, nämlich zu einer potenzierten Autoreflexivität. Dadurch nämlich, dass der Text - als Spiegelbild und Spiegel zugleich - sich in sich selber spiegelt, vermag er nicht nur sich selbst als Spiegelbild zu reflektieren, sondern zusätzlich auch den Modus resp. das Verfahren des Autoreflektierens. Oder

61 Freilich kann in gewissen Fällen das Material der Buchstaben oder des Textträgers spiegeln, aber nicht der allein im Zuge der Lektüre sich als solcher konstituierende Text im engeren, hier gemeinten Sinne.

62 Natürlich kann sich der Text selbst im engsten Sinne auch nicht spiegeln, denn dafür braucht er einen Leser, durch den er überhaupt zum Text wird. Es soll hier, es sei nochmals darauf hingewiesen, keine Ontologisierung von Text betrieben werden. Doch auch für das Spiegelbild ließe sich sagen, dass es ohne ein (menschliches) Auge, das es betrachtet, nicht als solches existiert.

Vgl. dazu Kapitel IV.3.1. 
anders formuliert: Heinrichs Lektüre der eigenen Geschichte ist im Unterschied zu zahlreichen anderen autoreflexiven Textstellen in der Literatur nicht nur bloß eine autoreflexive Stelle, sondern eine autoreflexive Stelle, die zugleich die eigene Autoreflexivität reflektiert. ${ }^{64}$

Dies wird nirgends so deutlich wie in der Antwort des Einsiedlers auf Heinrichs Frage nach dem „Buch“:

Ich kann mich nicht genau mehr des Inhalts entsinnen. Soviel ich weiß, ist es ein Roman von den wunderbaren Schicksalen eines Dichters, worinn die Dichtkunst in ihren mannichfachen Verhältnissen dargestellt und gepriesen wird. (S. 265., Z. 21-25)

Der Einsiedler bestätigt hier explizit, dass der „Roman“ u. a. von der „Dichtkunst" und damit autoreflexiv - resp. ,mannichfach' sich spiegelnd - auch von sich selbst handelt, was ebenso auf Novalis' Roman Heinrich von Ofterdingen zutrifft, der gerade an dieser Stelle autoreflexiv die eigene Dichtkunst ausstellt, zu der wiederum in besonders hohem Maße das Autoreflexive gehört!65 Doch damit nicht genug: Mit Blick auf den Ausgangspunkt der hier vorgetragenen Argumentationskette ist hinzuzufügen, dass in der Höhlenszene nicht nur der Roman und der Modus der Potenzierung autoreflexiv ad infinitum potenziert werden, sondern dass diese doppelte autoreflexive Potenzierung sich auch noch auf einer Metametaebene als Operation ausstellt, im Zuge derselben „Ewigkeit gewährt“66 werden soll. Oder in anderen Worten: Das dem Lied in der Höhle und damit dem Roman „eingegraben[e]“

64 Vgl. dazu u. a. Ito 1992, insbesondere S. 195-198. Shuichi Ito betont, dass bei der frühromantischen „unendlichen Potenzierung der Reflexion“ immer auch eine ,qualitative Potenzierung der Reflexion gemeint war, die ,jede erreichte Reflexionsstufe [verlässt], um darüber hinaus- und aufs neue ins unendliche Spiel einzugehen“ (ebd., S. 198). Diese vertikale Potenzierung wird denn auch in der Darstellung am Ende dieses Kapitels 1.6 besonders deutlich.

65 Zur Bedeutung dieser Szene auf der primären, inhaltlichen Ebene für Heinrichs Werdegang vgl. u. a. Mahr 1970, S. 148 f., welcher der Komplexität dieser autoreflexiven Spiegelung nicht weiter folgt, sondern es bei dem Bezug auf Heinrichs Leben belässt, indem er festhält: „Durch die Objektivierung von Heinrichs Schicksal in einem Buch, das ,die Schicksale eines Dichters‘ enthält, werden Heinrichs Leben und das Leben ,des Dichters identisch. Der fehlende Schluss der Handschrift bezeichnet die Offenheit und Unentschiedenheit, in der das Schicksal des Dichters Heinrich von Ofterdingen steht, und zeigt vor allem, dass die Vollendung dichterischer Wirksamkeit von nun an Heinrichs freiem Entschluss überantwortet ist."

66 Der passive Charakter, der durch das Verb „gewährt“ mitschwingt, mag darauf verweisen, dass die potenziell ewig sich fortsetzende autoreflexive Spiegelung nicht vom Text selbst losgetreten, sondern ,von diesem“ im Zuge einer Lektüre nur dem Leser ,dargeboten', „gewährt" werden kann. 
„Bild“, „[d]as ihm Ewigkeit gewährt“, verweist wiederum autoreflexiv auf die in der Höhlenszene angelegten, potenziell unendlich weiter sich potenzierenden autoreflexiven Operationen, indem es diese nahezu explizit als Operationen zur Ewigkeitsattribuierung bezeichnet.

Eine ähnliche Selbstthematisierung von Autoreflexivität als Operation zur Ewigkeitsattribuierung gilt zudem für den Umstand, dass Heinrich ausgerechnet die „Bilder“ (S. 264, Z. 27) in dem von ihm gefundenen „Roman“ noch am ehesten zu verstehen vermag. Die enge Verknüpfung dieser „Bilder“ mit der an dieser Stelle sich vollziehenden autoreflexiven Potenzierung lässt die Stelle die hermeneutische Qualität potenzierter Autoreflexivität thematisieren: Die zeitliche, kulturelle etc. Distanz zwischen dem Leser und dem ursprünglichen Kommunikationszusammenhang des gelesenen Textes kann in einem hermeneutischen Sinne unüberwindlich groß scheinen. Doch solange der Leser Zugang zu autoreflexiven Textstellen findet, kann er zumindest diese Operation der Autoreflexivität verstehen. Denn diese steht in geringerem Maße in kotextueller Abhängigkeit zur Welt außerhalb des Textes als bloße Verweise auf diese Außenwelt, da autoreflexive Stellen innerhalb eines Textes auf ebendiesen Text selbst verweisen.

Die äußerst komplexe Potenzierung, die eine solche Kombination der Reflexionsebenen nach sich zieht, soll nun folgende Darstellung aufzeigen, in die alle in dieser Hinsicht relevanten Ergebnisse dieses Kapitels zur Höhlenszene im Heinrich von Ofterdingen einfließen, geordnet nach Ebenen der Potenzierung von unten nach oben. Dies trägt auch dem Ziel des vorliegenden Kapitels Rechnung, nicht mit Gemeinplätzen, die mit dem Heinrich von Ofterdingen verknüpft sind, über die Höhlenszene sozusagen hinwegzuargumentieren, sondern so analytisch und genau wie möglich das Vorgefundene in all seiner Abstraktheit zu beschreiben. Die Buchstaben A-C stehen dabei für die drei aufeinander aufbauenden Grundebenen der Reflexion, Metareflexion und Metametareflexion, denen jeweils wiederum je selbst eine potenziell unendliche Selbstspiegelung inhärent ist. Die mit dem Zeichen ${ }^{\wedge}$ versehenen Stufen stehen in Anlehnung an die mathematische Schreibweise für jeweils eine Ebene der Potenzierung. ${ }^{67}$ Die Darstellung ist deshalb von unten nach oben zu lesen, beginnend mit A:

67 Die Darstellung ist wiederum nur eine Anlehnung an die mathematische Schreibweise, wie sie es schon bei den Frühromantikern war. Der „Roman“, den Heinrich findet, ist natürlich nicht mathematisch deckungsgleich mit dem Roman Heinrich von Ofterdingen, ebenso wie jede Spiegelung des Romans Heinrich von Ofterdingen in sich selbst mehr als die Summe der Kombination des Romans mit sich selbst ist und in gewissem Sinne immer auch den realen Leser und seine Lektüre (hermeneutischer Zirkel, Iterabilität) mitspiegelt. 
$\left[\wedge_{2} \rightarrow \infty\right.$ Die Reflexion von C; wozu, freilich über den Heinrich von Ofterdingen hinausgehend, auch die vorliegende Arbeit zu rechnen wäre; die hiermit soeben sich selbst reflektiert hat usw.]

$\wedge$ C. Das dem Lied und damit dem Roman Heinrich von Ofterdingen „eingegraben[e]“ „Bild“, das „Ewigkeit gewährt“, rückt in eine Äquivalenzbeziehung zur im Zuge der Lektüre sich potenziell unendlich weiter potenzierenden Spiegelung $\left(\mathrm{A}^{\wedge} 2\right.$ bis $\left.\mathrm{B}^{\wedge} 2 \rightarrow \infty\right)$. Diese Äquivalenzbeziehung und Heinrichs Verständnis des von ihm in der Höhle gefundenen „Roman[s]“ durch die stark an der autoreflexiven Potenzierung beteiligten „Bilder“ stellen Autoreflexivität und deren Potenzierung als Operation aus, die einen von Zeit und Außenwelt unabhängigen hermeneutischen Zugang zu einem Text garantieren und diesem damit „Ewigkeit gewähr[en]“ soll.

$\wedge_{2 \rightarrow \infty}$ Reflexive Bezugnahme der Autoreflexivität auf sich selbst potenziert sich parallel zu $\mathrm{A}^{2}$ bis $\mathrm{A}^{4} \mathrm{usw}$.

${ }^{\wedge}$ B. Die potenzierte Bezugnahme der einzelnen Ebenen $\mathrm{A}^{2}$ bis $\mathrm{A}^{4}$ vollzieht sich unter starker Betonung der Bildlichkeit und damit des Modus der Äquivalenz: autoreflexive Textstellen nehmen Bezug auf ihre Autoreflexivität. Dies wird nahezu explizit gemacht durch die Antwort des Einsiedlers, der „Roman“ stelle die „Dichtkunst in ihren mannichfachen Verhältnissen“ dar.

$\wedge_{4 \rightarrow \infty}$ Ebene 3 impliziert einen Roman im „Roman“ im Roman Heinrich von Ofterdingen. Ersterer würde konsequenterweise wiederum die Höhlenszene mit der Lektüre des „Roman[s]“ beinhalten usw.

$\wedge_{3}$ Der gefundene „Roman“ beinhaltet die Höhlenszene, impliziert damit die Spiegelung von sich selbst und seines Gelesenwerdens.

$\wedge_{2 c}$ ) Lied [er] im von ihm gefundenen „Roman“ sind für Heinrich nur als graphisch wahrnehmbare ,Vers-Bild[er]' als solche zu verstehen/wiederzuerkennen.

$\wedge_{2}$ b) Es besteht eine Äquivalenzbeziehung zwischen Heinrich und dem realen Leser: Spiegelung von dessen Lektüre, die zugleich über die Metaphorik von „Kleidungen“ „aus einer andern Zeit“ metaleptisch ihre eigene Iterabilität zu lesen gibt.

$\wedge_{2 a)}$ Autoreflexive Bezugnahme des „Roman[s]“, den Heinrich findet, auf den Roman Heinrich von Ofterdingen und damit auch auf jenes im Roman enthaltene Lied und dessen „Bild“.

A. Stelle im Lied, das als Gesang in den Höhlen vernommen wird: „Bild“, das „Ewigkeit gewährt“. „Bild“ lässt sich autoreflexiv auf die eigene Metaphorik und die des Liedes beziehen: Metabild.

Oder in Anlehnung an Novalis' und Friedrich Schlegels Schreibweise formelhafter und vereinfachter dargestellt:

$$
\begin{aligned}
\left(\left(\operatorname{Roman}^{\wedge} \infty\right)^{\wedge} \infty\right)^{\wedge} \infty= & \text { ein Roman, der }(\text { sich }) \text { selbst }(\text { als }) \text { potenzierte „Bilder“ ent- } \\
& \text { hält, sich so „Ewigkeit [zu] gewähr[en]“ sucht }- \text { und dies } \\
& \text { wiederum reflektiert, was seine Ewigkeitsattribuierung } \\
& \text { noch weiter verstärkt }
\end{aligned}
$$


Im Stile eines zusammenfassenden Ausblicks seien nun zum Schluss der Auseinandersetzung mit der Höhlenszene in Novalis' Heinrich von Ofterdingen und der Autoreflexivität als Unteroperation zur Ewigkeitsattribuierung von Schriftzeichen die wichtigsten Ergebnisse in drei Punkten festgehalten und weitergedacht:

Erstens: Die Höhlenszene sucht mittels potenzierter resp. unendlich sich weiter potenzierender autoreflexiver Spiegelung eine endlose Operation des Selbstverweises loszutreten, die zugleich auf einer Metaebene auch sich selbst als eine solche Operation reflektiert, während beide wiederum auf einer Metametaebene als „Ewigkeit gewähren[de]“ Operation verhandelt werden. Es handelt sich dabei um eine Operation, die jedoch - stets an einen Leser gebunden - immer nur passiv „gewähr[en]“, eine solche Lektüre anerbieten, sie aber nie selber vollziehen kann. Somit sucht die hier untersuchte Textstelle nicht nur bloß im Zuge der Lektüre mittels der Operation Autoreflexivität sich Ewigkeit einzuschreiben resp. einzugraben, sondern verweist zusätzlich selbst, also wiederum autoreflexiv, auf dieses Potenzial der Autoreflexivität. Oder anders formuliert:

Novalis nutzt im Heinrich von Ofterdingen zum einen Autoreflexivität zur Ewigkeitsattribuierung von (Schrift-)Zeichen, Text und Dichtung. Er tut dies über die potenziell unendliche Lektüre, die ein potenziell unendlich sich weiter potenzierender Verweis des Textes auf sich selbst lostritt, sowie über die durch diesen Selbstverweis generierte potenzielle Autonomie der betreffenden Textstelle. Zum anderen stellt er - noch einen Schritt weiter gehend und dadurch für die vorliegende Untersuchung als besonders exemplarisch geltend - Autoreflexivität zugleich als Konstituente für ebendiese Ewigkeitsattribuierung von (Schrift-) Zeichen aus.

Mit Blick etwa auf Platons Höhlengleichnis oder insbesondere auf das Lesen der eigenen Geschichte seitens Wilhelms in Goethes Wilhelm Meisters Lehrjahre ${ }^{68}$ ließe sich zudem parallel zur Operation Autoreflexivität wohl auch die Operation Unendliche Lektüre beobachten, und zwar u. a. anhand des potenziell endlos sich verschiebenden, intertextuellen Verweises. ${ }^{69}$ Obwohl

68 Vgl. dazu u. a. Göttsche 2001, S. 93 f.

69 Resp. dahingehend, dass unter Einbezug des Verweises auf etwa Wilhelms eigene Lesezene mindestens eine weitere Reflexionsebene hinzukäme. Zur die Romane Wilhelm Meister und Heinrich von Ofterdingen vergleichenden Forschung (bis 1990) siehe zusammenfassend Uerlings 1991, S. 444-458. Auch eine gewisse strukturelle Austauschbarkeit von Anfang und Ende spricht für den Einsatz jener Unteroperation (siehe ,Drittens'), ebenso wie das Fragmentarische für die Unteroperation Unendliches Verstummen resp. für eine Kombination dieser beiden Unteroperationen. 
auf die Stelle in Goethes Roman hier nicht detailliert eingegangen werden kann, sollen doch einige als fruchtbar betrachtete Ansätze im Folgenden noch Platz finden. Den Anfang macht die Stelle aus dem ersten Kapitel des letzten Buches von Wilhelm Meisters Lehrjahre:

Endlich entschloß er [Wilhelm, MG] sich, die Rolle seiner Lehrjahre aus dem Turme von Jarno zu verlangen; dieser sagte: es ist eben zur rechten Zeit, und Wilhelm erhielt sie.

[...] und wenn er gleich das Pergament mit einiger Hast aufrollte, so ward er doch immer ruhiger, je weiter er las. Er fand die umständliche Geschichte seines Lebens in großen, scharfen Zügen geschildert; [...] und er sah zum erstenmal sein Bild außer sich, zwar nicht, wie im Spiegel, ein zweites Selbst, sondern wie im Porträt, ein anderes Selbst: man bekennt sich zwar nicht zu allen Zügen, aber man freut sich, daß ein denkender Geist uns so hat fassen, ein großes Talent uns so hat darstellen wollen, daß ein Bild von dem, was wir waren, noch besteht, und daß es länger als wir selbst dauern kann. ${ }^{70}$

Sowohl Heinrichs als auch Wilhelms Leseszene ${ }^{71}$ sind absolut zentral für Inhalt und Struktur der beiden Romane. Und auch Goethe schreibt dem „Bild“, das „länger als wir selbst dauern kann“, die Fähigkeit, zu verewigen, zu. Ein präziser Vergleich dieser Textstellen vor dem Hintergrund der hier präsentierten Ergebnisse birgt denn auch das Potenzial, die Beziehung von Novalis' Roman zum Wilhelm Meister von dieser Seite neu resp. ergänzend in den Blick zu nehmen. So ließe sich z. B. festhalten, dass die Verwendung des Wortes „Bild“ in Wilhelms Szene eine metaphorische ist, ${ }^{72}$ während die „Bilder“ in Heinrichs Leseszene tatsächlich Illustrationen und zugleich metaphorisches Metabild sind.

Wichtigster Vergleichsgegenstand wäre jedoch die Operation der Autoreflexivität: Bei Goethe scheint sie nahezu explizit verneint zu werden („nicht, wie im Spiegel“"); ${ }^{73}$ wohl, weil sie gegen Ende des Romans stehend eine (von Novalis zu Recht infrage gestellte) rahmende Funktion übernehmen soll und obwohl sie sich in einem performativen Widerspruch gerade vollzieht. ${ }^{74}$

$70 \quad$ Goethe, Werke, Bd. 9, S. 884.

71 Wilhelms Leseszene vor allem auch zusammen mit der früher sich ereignenden Szene zum Auffinden der „Rolle seiner Lehrjahre“, in der jedoch noch keine Lektüre der „Rolle“ stattfindet. Zu Heinrichs Höhlenszene und der Struktur des Romans siehe weiter unten ,Drittens'.

72 Auch die Polysemie von ,Rolle', als physische Schriftrolle oder als Theaterrolle, müsste in den Vergleich der Tropen der beiden Textstellen miteinbezogen werden.

73 Man könnte also sagen, die beiden Leseszenen sind chiastisch verschränkt: „nicht, wie im Spiegel, sondern“ - obwohl nur als Text vorhanden - „wie im Porträt bei Goethe“; und wie ein Text - obwohl nur als Bilder-Geschichte lesbar - als potenziell endlose Spiegelung bei Novalis.

74 Bei Goethe scheint die Spiegelung nicht nur explizit verneint zu werden, sondern die Operation der Spiegelung ist in Wilhelms Leseszene bereits nur noch eine verweisende, 
(Man denke dabei auch an die in Kapitel III.1.1 erfolgte Auseinandersetzung mit Goethes Zauberlehrling und deren These, der Goethe der Klassik stehe Operationen zur Ewigkeitsattribuierung von Schriftzeichen, die Ewigkeit durch Unendlichkeit einzuholen suchen, kritischer gegenüber als die Romantiker, die diese dezidiert aufgreifen.) Novalis hingegen scheint diesen performativen Widerspruch erkannt zu haben und nutzt ihn nun produktiv: ${ }^{75}$ Bei Goethe wird zwar Wilhelms „Rolle“ und einem „Porträt“ als Metapher für eine Biographie explizit die Fähigkeit, den Dargestellten zu über-,dauern“, zugeschrieben. Bei Novalis erfolgt diese Zuschreibung impliziter resp. etwas vor der Leseszene, dafür wird noch stärker versucht, Ewigkeit dem Text nicht nur zuzuschreiben, sondern mittels Text Ewigkeit herzustellen. Vielleicht ist dies gar einer der entscheidenden Unterschiede zwischen den beiden Romanen: Die Spiegelung - exakt in der Mitte des ersten Teils angesiedelt - wird bei Novalis vehement bejaht und tritt von jener Mitte aus eine jeden (vermeintlichen) Rahmen sprengende, potenziell unendliche autoreflexive Operation los, die nicht nur auf Autonomie des Verschriftlichten abzielt, sondern potenziell unendlich weiter auf sich selber verweisend weder Anfang noch Ende kennen soll.

Zweitens: Die unter 1.1 aus dem Beginn der Höhlenszene entwickelte These, dass Heinrichs Gang in die Höhlen als poetologische Allegorie für das Erforschen des Inneren des Romans Heinrich von Ofterdingen resp. von Text und Dichtung im Allgemeinen gelesen werden kann, hat sich bestätigt. Der Roman Heinrich von Ofterdingen und insbesondere die darin enthaltene Höhlenszene ließen sich damit auch als eine implizite Theorie der Literarizität von Texten interpretieren. Novalis' Roman bezeichnet sich autoreflexiv als „Roman [...], worinn die Dichtkunst in ihren mannichfachen Verhältnissen dargestellt und gepriesen wird“ (S. 265, Z. 23-25). Er stellt dabei Autoreflexivität und die Thematisierung von Ewigkeit und Verewigung im Zusammenhang mit Sprache und Dichtung als ein wesentliches Merkmal von Dichtung resp. Literarizität aus. Dies ist ein Umstand, der gerade hinsichtlich der im Schlussteil (Kapitel V.2.3) der vorliegenden Arbeit angestellten Überlegungen zum

nicht eine sich im Zuge der Lektüre von Wilhelms Lektüre ,eins zu eins‘ vollziehende, wie es bei Heinrichs Leseszene der Fall ist. Denn was Wilhelm liest, sind seine Lehrjahre, die er zum Zeitpunkt der Lektüre bereits hinter sich gelassen hat (der Abbé verkündet im letzten Satz des siebten Buches: „deine Lehrjahre sind vorüber“) und nun, im achten Buch, bereits abgeschlossener Teil seines Lebens, Vergangenheit, sind.

75 Vgl. dazu auch Berghahn 2012, S. 14: „[...] sein [des Bildungsromans, MG] Paradigma, Wilhelm Meisters Lehrjahre, wurde von Friedrich Schlegel zum romantischen Kunstwerk schlechthin erklärt und, schon im Moment seiner ersten emphatischen Rezeption durch die Frühromantik, hineingerissen in einen nicht endenden Strudel der Reflexion, an dessen Ende er als Paradigma schließlich abdanken muss.“ 
Verhältnis von Ewigkeitsattribuierung und Literarizität Beachtung verdient. Die ebenfalls unter 1.1 vertretene These, der Beginn der Höhlenszene gebe zu lesen, dass eine Orientierung innerhalb der ,Höhle aus Zeichen' selbst wiederum nur mittels Zeichen möglich sei, ist jedoch zu ergänzen um den Hinweis auf die stete Bedrohung, der sich jene Orientierung ausgeliefert sieht: nämlich die, sich innerhalb potenziell endloser Selbstspiegelungen zu verirren und zu verlieren. ${ }^{76}$

Drittens: Die in der vorliegenden Arbeit dargelegte, auf (potenzierte) Autoreflexivität fokussierende Lesart ergänzt den bisher vorherrschenden Grundton der Interpretationen der Höhlenszene nicht nur, sondern vermag diesen auf einer formalen, abstrakten Ebene auch zu integrieren: Denn liest man Heinrichs Erkunden der Höhlen allgemein als „Spiegelung des Innen im Außen“77 und damit auch als Allegorie „für den Gang ins Innere des menschlichen Gemüts und für den Weg zur Selbsterkenntnis",78 so heißt dies, dass die oben beschriebene autoreflexive Potenzierung sich selbst schon innerhalb eines Sprachbildes, einer Metapher, vollzieht. Dadurch verdichtet sich etwa die Metametaphorik von "Bild“ noch weiter. ${ }^{79}$

Hinzu kommt, dass sowohl der Traum Heinrichs als auch der Traum seines Vaters sowie die Atlantis-Sage selbst eine Szene in einer Höhle beinhalten. Natürlich ließe sich auch diese Beobachtung in Zusammenhang mit anderen Textstellen des Romans stellen. So hat etwa bereits Johannes Mahr beobachtet, dass sich sowohl der Einsiedler in der Höhle im Traum des Vaters spiegelt als

76 Diese Gefahr des Sich-Verlierens wird in Kapitel IV.3.1 zur Reflexionsphilosophie sowie in IV.3.3 zur Genieästhetik wieder aufgegriffen. Diese Gefahr ist besonders zu berücksichtigen, wenn man wie Alexander Knopf im Heinrich von Ofterdingen einen Entwicklungsweg hinsichtlich Heinrichs "Sprachkompetenz“ sieht (vgl. Knopf 2015, u. a. S. 18).

77 Frühwald 2008, S. 250; vgl. auch Mahr 1970, S. 24.

78 Schmaus 2000, insbesondere S. 70.

79 Diese Teil-Ganzes-Relation innerhalb der sich potenzierenden autoreflexiven Spiegelung rückt dabei in ein Ähnlichkeitsverhältnis zur bereits von Frühwald festgehaltenen TeilGanzes-Relation auf der Ebene der Gesamtstruktur des Romans: „So weist auch die Folge der in sich geschlossenen Einzelkapitel, deren jedes Ausgangspunkt einer Gesamtinterpretation werden kann, worin stets ,eins an alles erinnert', auf die arabeske Einheit des Romans“ (ders. 1987, S. 252). Frühwald spricht vom "retardierenden Stil“ (vgl. das Zitat zu Beginn von 1.1). Die Figur Sylvester scheint diese Relationen implizit zu bestätigen: „Das Weltall zerfällt in unendliche, immer von größeren Welten wieder befasste Welten“ (S. 331, Z. 8-9). 
auch Heinrichs Traumbilder ${ }^{80}$ in den Bildern der Bücher des Einsiedlers. ${ }^{81}$ Dies bestätigt die in Kapitel 1.1.2 entfaltete Lesart, die Höhlenszene beinhalte auch eine implizite Leseanleitung, sich an Sprachbildern zu orientieren. Zudem ließe sich hinzufügen, dass das Paradigma Bilder und damit wohl auch die autoreflexive Thematisierung von Sprachbildern nicht nur in der Höhlenszene und am Romananfang eine zentrale Rolle spielen, sondern besonders auch im Märchen des ersten Teils (das nicht nur zahlreiche Metaphern und Allegorien beinhaltet, sondern als Ganzes selbst allegorische Züge trägt), im Astralis-Gedicht ${ }^{82}$ und in der letzten, den fragmentarischen zweiten Teil beschließenden Rede Sylvesters. ${ }^{83}$

Die Reihenfolge der letzten beiden ist freilich auf Tiecks Herausgeberschaft zurückzuführen. Geht man aber von dieser - für eine derartige Strukturanalyse zugegebenermaßen problematischen - Gesamtheit des fragmentarischen Romans aus, so ließe sich beobachten: Insbesondere die von Sylvester erzählte Erinnerung an sein Elternhaus und die starke Verbindung der beschriebenen Gegenstände mit Bildern, Text und Überlieferung ${ }^{84}$ reihen sich ein in eine Reflexionskette ${ }^{85}$ mit Heinrichs und seines Vaters Traum ${ }^{86}$ im ersten und mit der Höhlenszene im fünften Kapitel. Dies insofern, als dass der Traum von Heinrichs Vater, den er seinem Sohn zu Beginn des Romans erzählt, chiastisch verschränkt ist mit Sylvesters letzten Sätzen, die er als Sohn über den Vater erzählt (Vater - Sohn; Sohn - Vater); während Heinrichs Lesen der eigenen Geschichte wiederum fast exakt in der Mitte dieser beiden chiastischen Pole

8o Zum Traum als „an Iconic text“ in chiastischer Beziehung zum Märchen als „a verbal Icon" vgl. Pfefferkorn 1988, S. 180-186, insbesondere S. 185.

81 Mahr 1970, S. 138 und 147; resp. vgl. die Stellen im Heinrich von Ofterdingen selbst: „[...] er lebte mit mannichfaltigen Menschen, bald im Kriege, in wildem Getümmel, in stillen Hütten. [...] Er durchlebte ein unendlich [!] buntes Leben; starb und kam wieder [...], klarer und bleibender wurden die Bilder" (S. 196, Z. 5-9); und „Die mannichfaltigsten Lebensscenen waren abgebildet. Kämpfe, Leichenbegängnisse, Hochzeitfeyerlichkeiten. Schiffbrüche, Höhlen [...]“ (S. 264, Z. 7-9). Vgl. dazu auch die Beobachtungen von Deghaye 200o, S. 433-437.

82 "Nicht einzeln mehr nur Heinrich und Mathilde / Vereinten beide sich zu Einem Bilde“ (Novalis, Heinrich von Ofterdingen, S. 318, Z. 40 f.).

83 „Man sah steinerne Menschen Bilder, mit Geschichten bemahlte Gefäße, kleinere Steine mit den deutlichsten Figuren [...]. Auch lagen in Fächern übereinander viele Pergamentrollen, auf denen in langen Reihen Buchstaben die Kenntnisse und Gesinnungen, die Geschichten und Gedichte jener Vergangenheit in anmuthigen und künstlichen Ausdrücken bewahrt standen“ (Novalis, Heinrich von Ofterdingen, S. 334, Z. 25-29).

84 Vgl. die vorangegangene Fußnote.

85 Zur „Galvanischen Kette“ als Novalis' Inspiration für die „Verkettung heterogener Bezugssysteme“ im Heinrich von Ofterdingen vgl. Daiber 2001, S. 227-233.

86 Vgl. Schmaus 2000, S. 70. 
steht, nämlich am Ende von Kapitel fünf von neun resp. zehn. Hinsichtlich der Gesamtstruktur des Romans wären deshalb nicht nur weitere prominente, mit der Höhlenszene und deren Autoreflexivität verknüpfte Stellen zu beobachten, sondern auch die chiastische Verschränkung von Anfang und Ende des fragmentarischen Romans; ${ }^{87}$ eine chiastisch figurierte Austauschbarkeit resp. Verwischung von Anfang und Ende, ${ }^{88}$ deren einander überkreuzende Linien sich in der potenziell unendlichen autoreflexiven Spiegelung der Höhlenszene treffen.

\section{Unteroperation Poetologie}

\subsection{Der Phönix}

[1. Buch] XIII. DER PHÖNIX.

Nach vielen Jahrhunderten gefiel es dem Phönix, sich wieder einmal sehen zu lassen. Er erschien, und alle Tiere und Vögel versammelten sich um ihn. Sie gafften, sie staunten, sie bewunderten und brachen in entzückendes Lob aus.

Bald aber verwandten die besten und geselligsten mitleidsvoll ihre Blicke, und seufzten: Der unglückliche Phönix! Ihm ward das harte Los, weder Geliebte noch Freund zu haben; denn er ist der einzige seiner Art! ${ }^{89}$

Die Fabel Der Phönix von Gotthold Ephraim Lessing erschien in dessen dreibändiger Fabelsammlung Fabeln. Drei Bücher. Nebst Abhandlungen mit dieser Dichtungsart verwandten Inhalts (1759). Da dem Verfasser keine Stelle aus der Forschungsliteratur bekannt ist, die sich eingehend mit dieser Fabel Lessings auseinandersetzt, muss im Falle dieses Textbeispiels auf eine einleitende Aufarbeitung des Forschungsstandes verzichtet werden. Forschungsarbeiten zu Lessings Fabeln und den dazugehörigen Abhandlungen sowie zu Theorie, Gattung und Geschichte der Fabel im Allgemeinen werden im Folgenden direkt dort eingearbeitet, wo sie für die vorliegende Untersuchung relevant sind. ${ }^{90}$ Dafür soll den möglichen Inspirationsquellen Lessings bei de La Fontaine und de La Motte sowie Lessings eigenen Abhandlungen zu den Fabeln etwas mehr Platz eingeräumt werden.

\footnotetext{
87 Zur Unvollendbarkeit des Romans vgl. zusammenfassend Uerlings 1991, S. 43 o f.; sowie natürlich Kapitel II.3.

88 Vgl. dazu Kapitel II, insbesondere die Stellen zum Zur-Mitte-Werden von Anfang und Ende.

89 Im Folgenden zitiert nach: Lessing, Gotthold Ephraim: Werke, Bd. 4, S. 307-308; [Fabel XIII des ersten Buchs der Erstausgabe von 1759].

9o Zu den Fabeln bei Lessing im Allgemeinen vgl. vor allem Eichner 1974.
} 
Der Phönix scheint zu denjenigen Fabeln zu gehören, für die Lessing nicht auf eine bereits bestehende Fabelvorlage zurückgegriffen hat, zumindest nennt er im Gegensatz zu anderen seiner Fabeln keine Quelle. ${ }^{91}$ Bemerkenswert ist jedoch, dass er sich offensichtlich beim Phönix und vor allem bei dessen (Charakter- ${ }^{92}$ Eigenschaft der Einzigartigkeit von Jean de La Fontaine und Antoine Houdar de La Motte inspirieren ließ. ${ }^{93}$ Bei de La Motte existiert nämlich eine Fabel Le Phoenix et le Hibou, ${ }^{94}$ in welcher der Phönix in seiner christlichen Metaphorik („,comme un vrai Saint ${ }^{495}$ ) in Bezug auf die Wiederauferstehung der Frommen und Gerechten auftritt; hinsichtlich Lessings Fabel ist dabei aber vor allem der Schluss der nachgestellten Lehre(n) der betreffenden Fabel zu erwähnen:

Mais, c'est dommage, ce me semble,

D'avoir encore à dire une autre vérité.

Le Phønix est unique; \& pour la rareté,

Le Juste à peu près lui ressemble. ${ }^{96}$

In Jean de La Fontaines Fabel Le Corbeau et le Renard taucht ein phénix auf zwar nicht als Figur wie bei Lessing, aber als Metapher für Einzigartigkeit im listigen Kompliment des Fuchses:

Et bonjour Monsieur du Corbeau.

Que vous êtes joli! que vous me semblez beau!

Sans mentir, si votre ramage

Se rapporte à votre plumage,

Vous êtes le phénix des hôtes de ces bois[.] $]^{97}$

91 Lessing hat im Inhaltsverzeichnis der Erstausgabe für etwa die Hälfte seiner Fabeln Quellen angegeben, vgl. Lessing, Werke, Bd. 4, S. 963, 939, 936.

92 Vgl. ebd., S. 380; resp. das folgende Unterkapitel 2.1.1.

93 Weitere Quellen der Inspiration sind durchaus denkbar; es kann jedoch nicht die Aufgabe dieses Kapitels sein, eine umfassende Studie zur Intertextualität von Lessings PhönixFabel zu entfalten. De La Motte und de La Fontaine sind insofern äußerst wahrscheinliche Inspirationsquellen, nicht nur weil sie die Elemente Phönix und Einzigartigkeit miteinander verbinden, sondern auch weil Lessing sich in den Abhandlungen ausführlich mit diesen beiden Autoren auseinandersetzt (vgl. Lessing, Werke, Bd. 4, insbesondere S. 347-355 und 398-405) und deshalb davon ausgegangen werden kann, dass er deren Fabeln genau gelesen hat.

94 CEuvres de Monsieur Houdar de La Motte, l'un de quarante de l'Académie Françoise. Tome neuvième. Paris 1754, Buch 5, Fabel 1 [google books, Stand: Juni 2018].

95 Ebd., S. 265.

96 Ebd., S. 267.

97 La Fontaine, Fables, 1668, Bd. 1, Fabel 2, Quelle: http://www.lafontaine.net/lesFables [Stand: Juni 2018]. Der Kommentar auf der Website vermerkt für das Wort phénix u. a.: „Il 
Falls sein (Vogel-)Gesang, ramage, seinem - zuvor als wunderschön bezeichneten - Gefieder entspräche, dann sei der Rabe der Phönix der Gäste resp. Bewohner dieses Waldes, so lobt der Fuchs. Ob der Fuchs lobt, ohne zu lügen („sans mentir“), wie er selbst behauptet, und ob gerade dieser Satz des Fuchses auch eine tiefere poetologische Wahrheit zu lesen gibt, kann hier nicht weiter ausgeführt werden. Es seien aber wenigstens ein paar Hinweise genannt, die doch sehr für zumindest Letzteres sprechen: die Erwähnung des (Vogel-)Gesangs in einem Gedicht als fast schon habitualisierte poetologische Metapher für Gesang und Dichtkunst im Allgemeinen; die des Gefieders, das metonymisch mit der Schreibfeder in Verbindung steht; die interessante Deixis von "des hôtes de ces bois“, wobei das Demonstrativpronomen auch auf die Lesergäste resp. ,Bewohner' ebendieser Textwälder, die als Fabeln vorliegen, verweisen mag; und dann natürlich vor allem die poetologische Metaphorik des Wortes phénix selbst (siehe die folgenden Unterkapitel).

Wie dem auch sei, Lessing scheint nun - mit der Terminologie seiner Abhandlungen gesprochen - genau jene Charaktereigenschaft des Phönix, die Einzigartigkeit nämlich, zur Veranschaulichung eines „allgemeinen moralischen Satz[es]" ${ }^{498}$ ins Zentrum einer neuen Fabel zu stellen. Es lässt sich hier also ein Verfahren beobachten, das Lessing selbst als „eine Art von Jagd“99 in alten Fabeln bezeichnet hat, um durch Variation und Inspiration neue Fabeln zu erschaffen. Ob jene Charaktereigenschaft des Phönix tatsächlich die einzige in der Fabel verhandelte ist, erscheint - es wurde darauf hingewiesen - bereits bei de La Fontaine zweifelhaft. Ist es das nicht erst recht bei einer Fabel, die den Phönix ins Zentrum ${ }^{100}$ ihrer Handlung stellt; bei einer Fabel, die selbst den Namen Der Phönix trägt? Damit sind denn auch die Leitfragen für das vorliegende Unterkapitel gegeben: Ist die Einzigartigkeit des Phönix wirklich die einzige Charaktereigenschaft desselben, die in der Fabel behandelt wird, oder spielt, wenngleich impliziter, nicht auch die Eigenschaft der Unsterblichkeit eine ebenso große Rolle? Und falls ja, wie stehen die beiden Eigenschaften in Beziehung zueinander?

Diesen Fragen soll nun zunächst in drei Schritten nachgegangen werden: Kapitel 2.1.1 widmet sich knapp dem Topos des Fabelwesens Phönix und nimmt sodann die hier zu untersuchende Fabel mit Lessings eigenen Abhandlungen

[das mythische Wesen Phönix] était donc considéré comme un Symbole de l'éternité. Ici, par extension, le sens est personne unique, exceptionnelle.“

$98 \quad$ Siehe das folgende Unterkapitel 2.1.1.

99 Lessing, Werke, Bd. 4, S. 410.

100 ,Zentrum' hier im übertragenen Sinne gemeint; zum ,wortwörtlichen' (oder eher weißen)

Zentrum der Handlung der Fabel siehe Kapitel 2.1.3. 
in den Blick, während unter 2.1.2 die oben stehenden Fragen das Close Reading der Fabel eröffnen, das dann unter 2.1.3 fortgesetzt wird.

Zum Topos des Phönix, zu Lessings Fabel-Abhandlungen und der „Bestandheit der [Fabel-]Charaktere“

Die Enzyklopädie des Märchens, die hier stellvertretend zitiert sei, nennt den Phönix als ein mit dem Vogel Benu aus der altägyptischen Mythologie eng verwandtes, aber wohl nicht direkt von diesem abgeleitetes „Fabelwesen“. ${ }^{101}$ Das beim Benu „bereits angelegte Motiv der stets wiederkehrenden Erneuerung und Ewigkeit wurde in der griechischen und römischen Mythologie in einer späten Phase kristallisiert im Symbol des Vogels, der sich nach bestimmten Zeitabständen auf seinem Nest selbst verbrennt und erneuert aus der Asche aufsteigt [...] “. ${ }^{102}$ Das Christentum greift diese Symbolik auf in Bezug auf die Ähnlichkeit mit Christus (Opfertod/Martyrium, Auferstehung), betont aber auch (erstmals?) die Einmaligkeit des Phönix, und zwar einerseits im Verweis auf die Ewigkeit des einen Gottes sowie andererseits, mangels geschlechtlicher Fortpflanzung des Phönix, im Verweis auf die Jungfräulichkeit Marias im Speziellen resp. die Keuschheit im Allgemeinen. ${ }^{103}$ Betreffend die bei Lessing zentrale Betonung der Einzigartigkeit ist zudem bemerkenswert, dass auch die Fabel Der Phönix selbst zur Einzigartigkeit innerhalb der Gattung der Märchen und Fabeln tendiert:

Aufgrund seines solitären, sakralen und ätherischen Charakters, seiner tendenziellen Transzendenz und seiner Wundersamkeit [...] spielt die symbolträchtige Gestalt des Wunder-, Feuer- und Sonnenvogels in der säkularen Fabel keine prominente Rolle, ist auch im Märchen kaum eine eigentliche, profilierte Figur. $^{104}$

Bevor auf dieses gattungstypologische Merkmal der Einzigartigkeit zurückgekommen wird, seien nun aber Lessings Abhandlungen mit dieser Dichtungsart [den Fabeln] verwandten Inhalts in den Blick genommen, von denen er in der Vorrede schreibt, sie sollten in die Beurteilung seiner Fabeln miteinfließen, wenngleich er sich selbst nicht immer an die eigenen Vorgaben halte. ${ }^{105}$ Wohlan, so soll es sein; Lessing definiert am Ende von Abhandlung I (Von dem Wesen der Fabel) die Fabel wie folgt:

\footnotetext{
101 Enzyklopädie des Märchens, Bd. 10, Sp. 1021.

102 Ebd., Sp. 1022.

103 Vgl. ebd., Sp. 1021-1023.

104 Ebd., Sp. 1024.

105 Vgl. Lessing, Werke, Bd. 4, S. 299.
} 
Wenn wir einen allgemeinen moralischen Satz auf einen besondern Fall zurückführen, diesem besondern Falle die Wirklichkeit erteilen, und eine Geschichte daraus dichten, in welcher man den allgemeinen Satz anschauend erkennt: so heißt diese Erdichtung Fabel. ${ }^{106}$

Des Weiteren gibt Lessing in Abhandlung II (Von dem Gebrauche der Tiere in der Fabel) zwei Hauptgründe für die Verwendung von Tieren in Fabeln an. Der erste Grund ist folgender:

Ich komme vielmehr sogleich auf die wahre Ursache, - die ich wenigstens für die wahre halte, - warum der Fabulist die Tiere oft zu seiner Absicht bequemer findet, als die Menschen. - Ich setze sie in die allgemein bekannte Bestandheit der Charaktere. ${ }^{107}$

Lessing meint damit den Umstand, dass der Charakter (z. B. eines Fuchses) in seiner Bedeutung als „unterscheidendes merkmal, kennzeichen, grundzug“ oder "gemütsart, wie sie sich in den menschen ausgeprägt hat" ${ }^{108}$ - als bekannt und beständig resp. stabil ${ }^{109}$ vorausgesetzt werden kann. Der zweite Grund wiederum ist enger mit der oben zitierten Fabeldefinition verknüpft:

Die Fabel hat unsere klare und lebendige Erkenntnis eines moralischen Satzes zur Absicht. Nichts verdunkelt unsere Erkenntnis mehr als die Leidenschaften. Folglich muß der Fabulist die Erregung der Leidenschaften so viel als möglich vermeiden. Wie kann er aber anders, z. B. die Erregung des Mitleids vermeiden, als wenn er die Gegenstände desselben unvollkommener macht, und anstatt der Menschen Tiere oder noch geringere Geschöpfe annimmt?110

Sowohl die „Leidenschaften“ resp. „die Erregung des Mitleids“ als auch insbesondere die „Bestandheit“ sind für die weiter unten dargelegte Lektüre der Fabel von Bedeutung und werden dort weiterverfolgt. Der Begriff der „Bestandheit“ ist dabei aber so wichtig, dass ihm ein kleiner Exkurs einzuräumen ist.

Das Deutsche Wörterbuch nennt für „Bestandheit“, für die es neben drei anderen Beispielen (bei Mendelssohn, Herder und Schiller) ebendiese Textstelle bei Lessing anführt, die Bedeutungen „firmitas, stabilitas.“ In den

\footnotetext{
106 Lessing, Werke, Bd. 4, S. 376.

107 Ebd., S. 380.

108 Deutsches Wörterbuch von Jacob und Wilhelm Grimm, Bd. 2, Sp. 611 [Deutsches-Wörterbuch online, http://woerterbuchnetz.de, Stand: 04.02.2016].

109 Vgl. ebd., Bd. 1, Sp. 1653 [Deutsches-Wörterbuch online, http://woerterbuchnetz.de, Stand: Juni 2018].

110 Lessing, Werke, Bd. 4, S. 384 f.
} 
Beispielen von Herder und Schiller wird sie offenbar in einer festen Wendung mit ,Dauer" verwendet: „dauer und bestandheit“. ${ }^{111}$ Der Begriff meint also so viel wie ,Stabilität über die Zeit hinweg` oder eben, mit dem heutigen Wort dafür ausgedrückt: ,Beständigkeit‘.

Wenn nun nach Lessing für die Anschaulichkeit des moralischen Satzes einer Fabel notwendig ist, dass die "Charaktere" der dazu herbeigezogenen Figuren möglichst stabil, aber eben auch stabil über die Zeit hinweg sein sollen, so verbirgt sich darin - so die hier vertretene These - noch etwas anderes: nämlich und letztlich vor allem die „Bestandheit“ des moralischen Satzes.

Ein weiterer Hinweis hierauf findet sich bei Klaus Doderer, der in seinem Kapitel „Einblicke in die Geschichte der Fabeln“ überzeugend für eine differenzierte, nicht einseitig die Antike, die Reformationszeit und das 18. Jahrhundert betonende Auseinandersetzung mit der Geschichte der Fabel plädiert. ${ }^{112}$ Er stellt dabei aber auch fest:

Zeiten jedoch, in denen der Fabel größere Beachtung in der Öffentlichkeit geschenkt wird, in denen sie literarische Bedeutung erlangt und in denen ihre Form zur Entwicklung von Theorien Anlaß gibt, entsprechen interessanterweise Zeiten gesellschaftlicher Umstrukturierungen. Die Reformation, die Bauernkriege, die Entwicklung des Bürgertums im 15. und 16. Jahrhundert sind Ereignisse, die mit der Aktualisierung der Fabel bei Luther, Burkard, Waldis, Erasmus Alberus, Hans Sachs und anderen geschichtlich zusammenfallen. Und die Entdeckung der ,selbstverschuldeten Unmündigkeit', die Befreiung von der feudalherrschaftlichen Lebensordnung, die geistige, soziale und politische Aufklärung, die zur Französischen Revolution mit all ihren internationalen Konsequenzen führte, muß als Hintergrund der Aktualisierung der Fabel im 18. Jahrhundert erkannt werden. ${ }^{113}$

Dies sind Beobachtungen, die Doderer später im Unterkapitel zum 18. Jahrhundert ergänzt:

Es gibt kaum einen Dichter des Zeitalters der Aufklärung, der nicht auch Fabeln verfasst hätte. Fabeln zu schreiben war nicht nur Mode (,Fabelepidemiec), sondern auch Erfüllung einer poetologisch ${ }^{114}$ fundamentierten Aufgabe der Aufklärung: Enthüllung der Wahrheit. Denn nach der rationalistischen

111 Deutsches Wörterbuch von Jacob und Wilhelm Grimm, Bd. 1, Sp. 1653 [DeutschesWörterbuch online, http://woerterbuchnetz.de, Stand: Juni 2018].

112 Vgl. Doderer 1970, S. $261 \mathrm{f}$.

113 Ebd.

114 Der Begriff „poetologisch“ wird bei Doderer nicht gleich verwendet wie in der hier vorliegenden Arbeit, sondern im Sinne eines poetischen Programms der damaligen Zeit, also als direktes Adjektiv für eine explizit formulierte Poetik resp. Theorie, wie zu schreiben und dichten sei. 
Dichtungstheorie Gottscheds, Bodmers, Breitingers, Wolffs, Lessings und anderer ist diese Dichtungsgattung in der Lage, Belehrung, Genuss und Phantasie miteinander zu vereinigen. Der Glaube an die unbeschränkte Macht der Wahrheit erkennt in den Fabeln Exempla praktischer Sittenlehre an.

Insofern streift die Aufklärung mehr, als dies je im Mittelalter, der Reformationszeit und dem Zeitalter des Barock geschehen ist, die Tendenz religiöser Unterweisung ab und ist moraldidaktisch und fortschreitend sozialkritisch orientiert. Jean de La Fontaines Wirkung war groß, auch dort, wo man sich kritisch mit ihm auseinandersetzte (Lessing). ${ }^{115}$

Um einen Punkt sollte dieser letzte Abschnitt bei Doderer jedoch ergänzt werden, nämlich um den, dass sich der Prozess der Loslösung vom Denken in religiösen Kategorien in jener moraldidaktischen Unterweisung, für die sich die Fabeln so gut zu eignen scheinen, nicht einfach nur passiv abspielt, sondern diesen besonders befördert:

In einer Zeit, in der religiöse Normen an Sicherheit verlieren oder ganz verworfen werden, scheinen die Hunderten von Fabeln das Bedürfnis nach Wahrheit und moralischen Richtlinien zu kompensieren. Die heiligen Schriften des Judentums und Christentums sprachen in Gleichnissen mit dem Anspruch der Vermittlung ewig gültiger, durch Gott garantierter Wahrheit; die Propheten der neuen Vernunftreligion tun es ihnen nun nach und hoffen ebenso, moralische Sätze von ewiger „Bestandheit“ in Schrift zu bannen.

Im Fabelboom des 18. Jahrhunderts findet sich also ein weiteres Beispiel dafür, wie der Verlust der Heiligen Schrift im Zuge der Aufklärung durch eine Hinwendung zur Schrift als solcher und zur Heiligung derselben zu kompensieren versucht wird. Dabei ist es ein durchaus bemerkenswerter $\mathrm{Zu}$ fall(?), dass das von Lessing in Zusammenhang mit „Bestandheit“ verwendete Wort „Charaktere“ auch im Deutschen - wie heute noch z. B. im Englischen ,Schriftzeichen' bedeuten konnte ...116

Nach diesem insbesondere auch für Kapitel 2.1.3 zu berücksichtigenden Exkurs zum Begriff „Bestandheit“ sei nun wieder zu Lessings Abhandlungen zurückgekehrt: Nach den in Abhandlung III (Von der Einteilung der Fabeln) vorgestellten Kategorien Lessings lässt sich die Fabel Der Phönix zum einen als eine „mythisch sittliche “117 einteilen: sittlich, weil sie nur dann möglich sein kann, wenn gewisse Voraussetzungen gegeben sind; mythisch, weil diese Voraussetzung darin besteht, dass „die Subjecte“ (in diesem Fall der Phönix)

\footnotetext{
115 Doderer 1970, S. $299 \mathrm{f}$.

116 Vgl. Deutsches Wörterbuch von Jacob und Wilhelm Grimm, Bd. 2, Sp. 611 [DeutschesWörterbuch online, http://woerterbuchnetz.de, Stand: 04.02.2016].

117 Lessing, Werke, Bd. 4, S. 391.
} 
als wirklich angenommen werden. ${ }^{118}$ Zum anderen wird sie nahezu explizit als Beispiel für ebendiese mythisch sittliche Kategorie genannt:

[...] kurz alle Fabeln, die aus Gottheiten, aus allegorischen Personen, aus Geistern und Gespenstern, aus andern erdichteten Wesen, dem Phönix z. E. [Hervorhebung MG] bestehen, sind sittliche Fabeln, und zwar mythisch sittliche; denn es wird darin vorausgesetzt, daß alle diese Wesen existieren oder existieret haben, und der Fall, den sie enthalten, ist nur unter dieser Voraussetzung möglich. ${ }^{119}$

Dabei wäre die Fabel Der Phönix genau genommen gar an eine doppelte Voraussetzung geknüpft: erstens die Voraussetzung, dass die Existenz eines Phönix angenommen wird; zweitens, dass an eine dereinstige Wiederkehr des Phönix geglaubt wird.

Als Zwischenfazit lässt sich nun festhalten, dass die bislang zitierten Richtlinien der Abhandlungen, abgesehen von der Einteilung in Abhandlung III, die hier behandelte Fabel Der Phönix vor einige Probleme und Widersprüche stellen, die da u. a. sind:

- Was ist die "allgemein bekannte Bestandheit" des Charakters eines Phönix?

- Worin besteht die Einzigartigkeit, die der Phönix bereits bei Antoine Houdar de La Motte und Jean de La Fontaine repräsentiert?

- Worin besteht sein durch das jeweilige Wiedererstehen aus der eigenen Asche garantierte ewige Leben? Oder mit anderen Worten: Worin besteht die „Bestandheit“ des Phönix selbst?

- Und was wäre die „allgemein bekannte Bestandheit" des Charakters von „alle[n] Tiere[n] und Vögel[n]“, die sich in der Fabel um den Phönix versammeln?

- Wenn „der Fabulist die Erregung der Leidenschaften so viel als möglich vermeiden“ soll, weshalb wenden dann ausgerechnet "die besten und geselligsten“ der Tiere „mitleidsvoll ihre Blicke“?

- Setzt das Verstehen dieses Mitleids einiger „Tiere und Vögel“ nicht voraus, dass der Leser der Fabel sich in ein eben auch leidenschaftliches Ähnlichkeitsverhältnis zu ihnen (und dem Phönix) setzt?

- Außerdem ist das Verhältnis zu den „Leidenschaften“ bereits an jener Stelle in den Abhandlungen paradoxal, denn ausgerechnet die eigenen „Leidenschaften“ scheinen Lessing auf jenes Definitionsmerkmal gebracht zu haben: „Ja, ich will es wagen, den Tieren, und andern geringern Geschöpfen in der Fabel noch einen Nutzen zuzuschreiben, auf welchen ich vielleicht durch Schlüsse nie gekommen wäre, wenn mich

118 Vgl. ebd., S. 39 o f.

119 Ebd., S. 391. 
nicht mein Gefühl darauf gebracht hätte. "120 Zumindest lässt sich hier einwenden, dass dieser Prozess bei den „besten und geselligsten“ Tieren umgekehrt abläuft: Bei ihnen scheint zuerst (signalisiert durch den Absatz und das „denn“) ein vernunftbasierter Verstehensprozess abzulaufen, der dann in einem zweiten Schritt ihr Mitleid auslöst. ${ }^{121}$

- Diese Mehrdeutigkeiten und Paradoxa wiederum lassen Zweifel daran aufkommen, ob man „den allgemeinen Satz“ der Fabel „anschauend erkennt“.

- Lehrt dieser "Satz“, dass Einzig-art-igkeit (im Sinne von ohne Artgenossen/Gleichgesinnte zu sein) einsam macht?

- Oder ist es mehr das ewige Leben (und damit allein zurückzubleiben resp. zurückzukommen, während alle anderen sterben), das zu Einsamkeit führt?

- Oder ist die Lehre vielmehr, man solle niemanden unkritisch bewundern?

Es scheint also fast so, als ob Lessing mit seiner Phönix-Fabel systematisch eigene zentrale, in den Abhandlungen für diese Gattung aufgestellte Regeln ignoriert - oder aber vielleicht gerade dadurch reflektiert. Letzteres führt wiederum zurück zu der Frage, ob in dieser Fabel nicht noch etwas anderes verhandelt ist als die Einzigartigkeit des mythischen Vogels Phönix. Als zweite Charaktereigenschaft des Phönix wurde oben wiederholt sein an einen endlosen Prozess des Verbrennens und Wiedererstehens gebundenes, ewiges Leben erwähnt. Es ist nun an der Zeit, ebendiesem Charakterzug mittels genauer Lektüre der Fabel selbst nachzugehen.

\subsubsection{Das Fabelwesen Phönix und das Wesen der Fabel}

Um der besseren Übersicht willen sei hier die kurze Fabel noch einmal zitiert:

\section{[1. Buch] XIII. DER PHÖNIX.}

Nach vielen Jahrhunderten gefiel es dem Phönix, sich wiedereinmal sehen zu lassen. Er erschien, und alle Tiere und Vögel versammelten sich um ihn. Sie gafften, sie staunten, sie bewunderten und brachen in entzückendes Lob aus.

Bald aber verwandten die besten und geselligsten mitleidsvoll ihre Blicke, und seufzten: Der unglückliche Phönix! Ihm ward das harte Los, weder Geliebte noch Freund zu haben; denn er ist der einzige seiner Art!122

\footnotetext{
120 Ebd., S. 384.

121 Zum Mitleidsdiskurs vgl. das Kapitel II.1.2 zur Miss Sara Sampson; sowie das Kapitel II.3.

122 Lessing, Werke, Bd. 4, S. 307 f.
} 
Es wurde bereits auf Jean de La Fontaines Fabel Le Corbeau et le Renard hingewiesen, in welcher das Wort "phénix“ im frech-zweideutigen, da an einen Bedingungssatz gebundenen Kompliment des Fuchses (vermeintlich) bloß als Metapher für die herausragende Einzigartigkeit des Raben verwendet wird. Bei Lessing hingegen ist dem Phönix selbst eine Fabel gewidmet, die durch eine metonymische Übertragung auch dessen Namen trägt: Der Phönix. Wie alle solche metonymischen Titel - von denen im Laufe der vorliegenden Arbeit bereits einige zu beobachten waren - führt auch dieser zu einer Doppelung: ,Der Phönix‘ kann sowohl für die „Phönix“-Figur, die in der Fabel auftritt und von der sie handelt, als auch für die Fabel Der Phönix stehen.

Es besteht aber nicht nur ein metonymisches Verhältnis zwischen der Figur Phönix und dem Fabeltext desselben Namens, sondern auch ein metaphorisches, und dies in doppelter Hinsicht: in Hinsicht auf die Gattung der Fabel (1) und in Hinsicht auf Text im Allgemeinen (2).

$\mathrm{Zu} \mathrm{1:} \mathrm{a)} \mathrm{Die} \mathrm{Einzigartigkeit} \mathrm{des} \mathrm{Phönix} \mathrm{in} \mathrm{Lessings} \mathrm{Fabel} \mathrm{entspricht} \mathrm{der}$ Einzigartigkeit der Fabel selbst: Sie ist - neben der Fabel Merops (Buch 1, Fabel 24), in der dieser aber nicht als Figur auftritt, sondern lediglich von anderen Tieren besprochen wird - die einzige der Fabeln in der 1759 erschienenen Sammlung Lessings, die ihre Lehre anhand eines mythologischen Tieres entfaltet. Und sie ist, wie oben aus dem Zitat der Enzyklopädie des Märchens ersichtlich, eine der wenigen Fabeln der abendländischen Literatur überhaupt, in denen der Phönix als Figur vorkommt. Des Weiteren ist sie z. B. im Gegensatz zur antiken Überlieferung und zu de La Motte und de La Fontaine - vielleicht die einzige Adaption und Variation des Phönix-Stoffes überhaupt, die die Charaktereigenschaft der Einzigartigkeit als bemitleidenswert ins Zentrum stellt.

b) Die Gattung der Fabel erfährt zur Zeit Lessings intensive Bearbeitung und Diskussion. Klaus Doderer argumentiert jedoch überzeugend dafür, nicht davon auszugehen, dass dies einem Wiederaufkommen aus dem Nichts der seit der Reformation verschwundenen Gattung gleichkommt, sondern dass es sich bloß um ein erneutes akzentuiertes Auftreten handelt. ${ }^{123}$ Dennoch stehen diese wiederkehrenden Phasen gesteigerter Auseinandersetzung mit der Gattung/Art der Fabeln in einem Ähnlichkeitsverhältnis zur je nach Quelle unterschiedlichen Anzahl an Jahrhunderten, die gemäß Mythologie vergehen müssen, bis der Phönix „sich wiedereinmal sehen“ lässt. Und die Fabel beginnt denn auch mit „Nach vielen Jahrhunderten [...]“.

$\mathrm{Zu}$ 2: a) Ebenso wie der mythische Vogel Phönix immer wieder stirbt, um wiederzuerstehen, wird ein jedes Schriftzeichen im Zuge der Lektüre

123 Siehe Kapitel 2.1.1. 
wiederbelebt, um unmittelbar darauf wieder zu sterben, was jedoch zugleich auch die Voraussetzung für ein erneutes lesendes Wiederbeleben ist - und immer so fort. Die Fabel Der Phönix als ein Gebilde aus Schriftzeichen teilt also diesen (in ihrem Fall lediglich potenziell) ewigen Zyklus von Tod und Wiedergeburt $^{124}$ mit dem Vogel Phönix. Lessing selbst verwendet andernorts gar explizit den Phönix als eine Textmetapher, und zwar in seinem Aufsatz resp. seiner Nachdichtung Die Nachtigall:

Dieses alles, meine ich, beweiset so ziemlich, welch eine Seltenheit unsere Bibliothek an den Abschriften derselben besitzet. Eine Seltenheit, die allein schon wert ist, daß ich es wage, aus einer Nachtigall einen Phönix zu machen, der aus seiner Asche jünger und schöner wieder hervorsteiget. ${ }^{125}$

b) Wie der Text der Fabel selbst stumm und an Leser gebunden ist, so ist auch die Figur Phönix stumm: Obwohl er die zentrale und titelgebende Figur der Fabel ist, spricht der Phönix nicht - und dies ist gegenüber anderen Fabeln außergewöhnlich, um nicht zu sagen einzigartig. Nur "alle Tiere und Vögel“ begaffen und bewundern ihn und brechen in „entzückendes Lob“ aus, wobei Letzteres zwingend sprachlich artikuliert werden muss. Im zweiten Abschnitt kommt durch die "besten und geselligsten“ das Bemitleiden hinzu, das dann auch in direkter Rede wiedergegeben wird und die Fabel beschließt. Es sind also „alle Tiere und Vögel“ und insbesondere die „besten und geselligsten“, die dem „Phönix“ in dieser Fabel eine Stimme leihen und ihn - zumindest im Falle Letzterer - auch zu ,lesen' und zu verstehen versuchen.

Die Punkte 1 und 2 zusammenfassend lässt sich also festhalten, dass - neben der oben erwähnten metonymischen Verbindung zwischen der Figur Phönix und der Fabel Der Phönix - die Figur Phönix auch als eine poetologische Metapher für den Fabeltext resp. von Text im Allgemeinen gelesen werden kann: das Fabelwesen Phönix thematisiert dabei das Wesen der Fabel. ${ }^{126}$ Diese Lesart soll nun im nächsten Kapitel weiterverfolgt werden.

124 Vgl. dazu auch das Kapitel II.2.1 zu Brentanos Der Spinnerin Nachtlied.

125 Lessing, Werke, Bd. 7, S. 449.

126 Dass eine Thematisierung der Fabeln innerhalb einer Fabel Lessing nicht fremd ist, zeigt auch und am deutlichsten seine in der Abhandlung IV explizit dargelegte Lesart seiner Fabel Der Besitzer des Bogens (vgl. ebd., S. 403; und auch Eichner 1974, S. 352-354) aber natürlich auch die erste Fabel des ersten Bandes und z. B. die Fabeln X. Die Grille und die Nachtigall; XIX. Der Sperling und der Strauss; XVIII. Der Strauss; XXIV. Merops (auffälligerweise alle aus dem ersten Buch und Vögeln resp. singenden oder fliegenden Tieren gewidmet, die traditionell als poetologische Metaphern für Sänger/Dichter und damit metonymisch auch für deren Zeichengebilde stehen; vgl. zu Letzterem auch das Kapitel II.2.1 zu Brentanos Der Spinnerin Nachtlied). 


\subsubsection{Unverortbares Verstehen und ewige „Bestandheit“}

Steht der Phönix als poetologische Metapher auch für die Fabel Der Phönix und für Text im Allgemeinen, so rücken wiederum „alle Tiere und Vögel“ in ein Ähnlichkeitsverhältnis zu den Lesern der Fabeln und zu Lesern im Allgemeinen, was - wie weiter oben bereits erwähnt - dadurch unterstützt wird, dass sie es sind, die dem stummen Phönix ihre Stimme leihen. Nun leihen sie ihm, wie die Leser dem Text, nicht nur ihre Stimme, sondern sie versuchen auch, ihn zu verstehen. Hierbei spielt auf formaler Ebene ausgerechnet der Absatz zwischen den beiden Abschnitten der Fabel eine zentrale Rolle. Siglinde Eichner beobachtete bereits: „Lessing hat in der Fabeltheorie nur Prägnanz und Kürze gefordert - die ästhetische Bedeutsamkeit dieses Stilmerkmals hat er nicht erörtert, wohl aber in der Dichtung bewiesen.." ${ }^{127}$ Sie weist denn auch auf die in dieser Hinsicht zentrale Funktion hin, die der "Syntax als Bedeutungsträger “ ${ }^{\prime 28}$ und dem „Satzbau als Spiegel des Denkens [der Fabelfiguren, MG] ${ }^{\text {“129 }}$ zukommt. Das gilt - so muss hier hinzugefügt werden - ebenso für die Typographie. Der Denk- und Verstehensprozess, der „besten und geselligsten“ der „Tiere und Vögel“, der dazu führt, dass sie den „Blick verwandten“, spielt sich nämlich in ebenjenem Absatz ab. Absatz und Abschnitt wurden bereits im Kapitel zu E. T. A. Hoffmanns Lebens-Ansichten des Katers Murr im Zusammenhang mit den Prozessen der Figuration und des Verstehens ausführlich behandelt, weswegen hier nur sehr knapp nochmals auf die Unverortbarkeit von Absatz, Abschnitt und des Verstehens von Text im Allgemeinen zurückgekommen sei.

Die Leerschläge des Absatzes figurieren das stumme Nachdenken der „Tiere und Vögel“, die den Phönix im Vergleich mit der eigenen „Art“ zu verstehen suchen. Dies suggerieren zumindest das Verb "verwandten“, das auf den Absatz folgt und dessen Grund in ebendiesem Absatz zu liegen scheint. Und ebenso der denn-Satz, weil nicht ausformuliert wird, wie denn die „besten und geselligsten" auf die Einzigartigkeit des Phönix geschlossen haben und wie im Detail sich der Stimmungsumschwung von Bewunderung zu Mitleid abgespielt hat. Der Absatz steht also in der Mitte der beiden beinahe exakt gleich großen Abschnitte der Fabel, ist primär nur über das Auge, also das Lesen, wahrnehmbar und bewirkt im Lesefluss einen Bruch, der auf inhaltlicher Ebene der Fabel einerseits Bewunderung von Mitleid trennt, andererseits

127 Eichner 1974, S. 228.

128 Vgl. ebd., S. 228-23o.

129 Vgl. ebd., S. 230-233. 
für die Nachvollziehbarkeit des Zustandekommens ebendieses Mitleids seitens der "besten und geselligsten" notwendig ist. ${ }^{130}$

Nun besteht aber auch und gerade im Falle der Funktion(en) des Absatzes ein Ähnlichkeitsverhältnis zwischen jenen Tieren innerhalb der Fabel und den Lesern der Fabel: Die Leser sind durch den Absatz gezwungen, bereits in der Mitte der Zeile den Blick wieder nach links auf die nächste Zeile zu wenden, wo sie im dritten Wort, „verwandten“, erkennen können, dass sie soeben das (Lese-)Verhalten einiger Tiere nachvollzogen haben. ${ }^{131}$ Sie sind in dieser Hinsicht den „besten und geselligsten “ ähnlich, um nicht zu sagen,verwandt' ein Modus, der wiederum für das Empfinden von Mitleid konstitutiv ist. ${ }^{132}$ Der Phönix hingegen ist in seiner Einzigartigkeit nicht ,gesellig‘ und gehört damit - das Homoioteleuton ",-sten/-sten“ sowie das kausal daherkommende „und“133 figurieren die enge Verknüpfung der beiden Adjektive - nicht zu den „besten“. Aufgrund der Einzigartigkeit des Phönix können sich die „Tiere und Vögel“ auch nicht qua Ähnlichkeit auf ihn beziehen, sondern nur qua Unähnlichkeit. Eine Unähnlickeit, mit der ein jeder Leser an einen Text, jeder Hörer an eine Aussage herantritt und sich hermeneutisch-gesellig zum schriftlichen oder mündlichen Zeichengewebe in ein Verhältnis zu setzen sucht.

Da sich jener Verstehensprozess der "besten und geselligsten“ unausformuliert im Absatz abspielt, wird die im Kapitel zum Kater Murr behandelte Unverortbarkeit des signifiés, aber letztlich auch des signifiants des Absatzes und von Zeichen als Gegenstand des Verstehens ausgestellt. Der potenziell unendliche Prozess der Figuration von signifiant und signifié korrespondiert sowohl mit der unendlichen Wiedergeburt des Phönix als auch mit dessen Einzigartigkeit: Wie der Phönix einzigartig ist, so ist auch jedes Sprachzeichen, jeder Text in seiner phönixhaften, potenziell unendlich oft wiederholbaren Lektüre, in seiner Iterabilität, einzigartig. Jede Lektüre wird nie dieselbe gewesen sein.

Und wie Lessing in seiner Variation des Phönix-Stoffes dem Unsterblichkeitscharakter des Phönix im zweiten Abschnitt eine tragische Wendung gibt, indem er den Charakter der Einzigartigkeit und Einsamkeit damit verknüpft und betont, so wird dadurch auch die Tragik des menschlichen

130 Eichner hat bereits für die Fabel Der Hamster und die Ameise (Buch 1, Fabel 2) beobachtet, wie die inhaltliche Wendung auch formal vollzogen wird: in diesem Fall nicht über das Wenden des Blickes, sondern über eine chiastische Operation (vgl. Eichner 1974, S. 233).

131 Dies entspricht demselben Prinzip der Form-Inhalt-Korrespondenz durch die ästhetische Nutzbarmachung der Leserichtung wie bei Ovids Fassung von Orpheus und Eurydike; vgl. dazu das Kapitel IV.2.2 zu Schillers Nänie.

132 Vgl. dazu ausführlich Kapitel II.1.2 zur Miss Sara Sampson.

133 Die „Tiere und Vögel“ sind die „besten“, gerade weil sie die „geselligsten“ sind. 
Verstehensprozesses in seiner radikalen jeweiligen Einzigartigkeit ausgestellt: Denn die Möglichkeitsbedingung einer jeden Lektüre eines Sprachzeichens ist die, dass es immer wieder aufs Neue mit einem immer leicht anderen oder leicht anders konnotierten Signifikat versehen werden kann. Die Möglichkeitsbedingung, sich mittels Sprachzeichen zu verständigen, liegt - und das ist das Tragische - gerade darin begründet, dass es nie möglich ist, exakt das Gleiche zu verstehen. Ein Umstand, der die Leser, gerade die „besten und geselligsten“ unter ihnen, veranlassen kann, „mitleidsvoll“ gegenüber dem Text, aber auch gegenüber sich selbst (vgl. Lessings Ästhetik des Mitleidens), den „Blick“ zu verwenden, abzuwenden vom Text und vom eigenen Verstehensprozess, der nie deckungsgleich mit dem eines anderen Individuums sein kann. Oder anders ausgedrückt: In dem Versuch, sich paradoxal qua Unähnlichkeit verstehend in eine gesellige Ähnlichkeit zum Phönix zu setzen, wird das Verstehen der „Tiere und Vögel" und damit auch das analog verfahrende Verstehen eines Textes durch den Leser ${ }^{134}$ als letztlich eben doch ungesellig, als jeweils wortwörtlich einzigartig ausgestellt. Gerade die "geselligsten“, die folglich am meisten nach Gleichartigkeit sich sehnen, muss diese Erkenntnis über die unüberwindbare Distanz zeichenhafter Nähe am meisten rühren - in Mitleid und Selbstmitleid.

Nun war ausgerechnet Gleichartigkeit resp. Gleichheit/égalité im 18. Jahrhundert Programm unter den Aufklärern und wurde insbesondere mittels Schrift verbreitet. Man könnte also mit Bezug auf den historischen Kontext von Der Phönix auch so weit gehen und ergänzen: Diese wundervoll-tragische, tragisch-wundervolle Fabel verhandelt in nuce auch die von Albrecht Koschorke festgestellte, ${ }^{135} \mathrm{im}$ 18. Jahrhundert zunehmende Distanz resp. Ungeselligkeit zwischen den Körpern der neuen Individuen; eine Distanz, die durch die intensivierte zeichenhafte Kommunikation mittels Schrift zugleich befördert und überbrückt wird.

Aus all dem folgen drei Thesen, die die Beobachtungen zu Der Phönix abschließen:

1. Lessings Fabel Der Phönix - und dies ist bei einem Fabeldichter, der der Individuation derart große Bedeutung beigemessen hat, ${ }^{136}$ besonders

\footnotetext{
134 Resp. generell das Verstehen von Sprachzeichen.

135 Vgl. Koschorke 1999.

${ }_{13}$ Am schlagendsten ist dies ersichtlich in der ersten Abhandlung zur Fabel in Ablehnung einer Biberfabel des Dichters Planudes: „Die Wirklichkeit kommt nur dem Einzeln, dem Individuo zu; und es lässt sich keine Wirklichkeit ohne die Individualität gedenken. Was also hier von dem ganzen Geschlechte der Biber gesagt wird, hätte müssen nur von einem einzigen Biber gesagt werden; und alsdenn wäre es eine Fabel geworden“ (Lessing, Werke, Bd. 4, S. 371). Zur Ästhetik der Individualität im zeitgenössischen Kontext (etwa auf der geistigen Linie Leibniz - Baumgarten - Lessing) vgl. Eichner 1974, S. 84-121.
} 
bemerkenswert - weist in einer Zeit, die man gemeinhin als die Geburtsstunde des Individuums bezeichnet, bereits auf die Abgründe hin, die sich in radikaler menschlicher Individualität auftun und damit auch in der radikalen Individualität der Lektüre von (phönixhaften) Sprachzeichen, deren Sinn nicht mehr durch ein transzendentales Signifikat garantiert wird.

Und um wieder zurück auf die oben aufgeworfene Frage nach dem Charakter des Phönix zu kommen, einem Charakter, der in seiner „Bestandheit" ${ }^{4137}$ entscheidend dazu beitragen soll, dass man "den allgemeinen moralischen Satz" der Fabel "anschauend erkennt":

2. Trägt man dieser radikalen Individualität des Verstehens und Konstituierens von Zeichen Rechnung, so liegt hier eine, wenn nicht die entscheidende (relative) "Bestandheit“ des Fabelwesens Phönix in dessen Existenz als Zeichengebilde, in dessen Textcharakter, den die Figur Phönix und die Fabel Der Phönix als Ganze in ihrer poetologischen Tropik ausstellen.

Mit Blick auf die Ewigkeitsattribuierung von Schriftzeichen heißt dies schließlich:

3. Der poetologische Charakter des Phönix ist also in der Fabel Der Phönix letztlich das Einzige, was in die Nähe einer die Zeit überdauernden „Bestandheit" des Charakters der Fabelfigur und der damit angestrebten ewigen Gültigkeit des in der Fabel vermittelten "moralischen Satz[es]“ kommt. Der beständigste Charakterzug eines Fabelwesens ist nämlich sein Wesen als Fabel, sein Fabel-Sein - also seine Existenz als Text, als phönixhaftes Zeichengebilde.

Die dem Fabelwesen Phönix gewidmete Fabel Der Phönix ist damit auch eine Metafabel über das Wesen der Fabel; insbesondere der Fabel als Textgebilde und darüber, was dies für die Fabeldichtung und die darin vermittelten, ,ewig gültigen' moralischen Sätze bedeutet. Und gerade deshalb kommt die Fabel Der Phönix näher an ein textuelles Festhalten ewig gültiger moralischer Sätze heran als so viele andere Fabeln - auf eine derart komplexe und auf engstem Raum virtuos entfaltete Weise, die vielleicht auch sie zur „einzige[n]“ ihrer „Art" macht. Oder anders formuliert: Als poetologischer Metafabel im doppelten Sinn - als Fabel über die Gattung der Fabeln und über die Fabel in der Bedeutung von aus Sprachzeichen bestehender Dichtung selbst - gelingt es ihr, Fabeltext derart zu thematisieren, dass die daraus entspringende

137 Eichner stellt auch zur „Bestandheit der Charaktere“ fest, dass dies „sich in den Gesamtzusammenhang von Baumgartens ästhetischen Erörterungen über die bildliche Funktion der Eigennamen und der Tropen überhaupt" füge (ebd., S. 113). 
semiologische Lehre und die mit dieser verknüpfte Moral grundsätzlichster Art sich auch „[n]ach vielen Jahrhunderten“ noch „sehen [...] lassen“ können. ${ }^{138}$

\section{$2.2 \quad$ Nänie}

NÄNIE
Auch das Schöne muß sterben! Das Menschen und Götter bezwinget,
Nicht die eherne Brust rührt es des stygischen Zeus.
Einmal nur erweichte die Liebe den Schattenbeherrscher,
Und an der Schwelle noch, streng, rief er zurück sein Geschenk.
Nicht stillt Afrodite dem schönen Knaben die Wunde,
Die in den zierlichen Leib grausam der Eber geritzt.
Nicht errettet den göttlichen Held die unsterbliche Mutter,
Wann er, am skäischen Thor fallend, sein Schicksal erfüllt.
Aber sie steigt aus dem Meer mit allen Töchtern des Nereus,
Und die Klage hebt an um den verherrlichten Sohn.
Siehe! Da weinen die Götter, es weinen die Göttinnen alle,
Daß das Schöne vergeht, daß das Vollkommene stirbt.
Auch ein Klaglied zu seyn im Mund der Geliebten ist herrlich,
Denn das Gemeine geht klanglos zum Orkus hinab.

Für den hier gewählten Blick auf Schillers Nänie (18oo) ist aus der Forschungsliteratur insbesondere Daniel Müller Nielabas Aufsatz „Nänie‘ oder: ,Auch Schiller muss sterben!“ zu berücksichtigen. Er vertritt darin - entgegen der traditionellen Forschungsmeinung, die in Nänie einen "gewissen Schlusspunkt" von "Schillers Schönheitslehre" sieht ${ }^{140}$ - überzeugend eine Lesart, die aufzeigt, dass das Gedicht die vermeintliche, im Tode vollendete, schöne Abgeschlossenheit des "Vollkommene[n]“ unterlaufe. Stattdessen gebe es eine Vollkommenheit zu lesen, die ihre Schönheit gerade nicht im Abgeschlossenen, sondern im Unbeendbaren zu finden suche. Damit wendet sich Müller Nielaba letztlich auch implizit gegen die von Wolfram Groddeck vertretene Lesart des Gedichts: Obwohl seine Argumentation ebenfalls auf poetologischen Stellen des Gedichts aufbaut, kommt Letzterer nämlich zu einer geradezu entgegengesetzten Schlussfolgerung:

Das Gedicht vermittelt eine Poeten-Metaphysik, die den eigenen Idealismus als Nihilismus kenntlich macht. Das Reale, das sinnlich Schöne, der hübsche Knabe Adonis, der göttliche Haudegen Achill - all das wird vernichtet und muß in den Orkus des Ideals. Nur eins, die „herrliche Klage“ selbst, erhält sich (dadurch) ihre

${ }_{13} 8$ Die Betonung liegt in diesem letzten Nebensatz auf dem, kann und der damit implizierten Betonung eines Potenzials.

139 Schiller, Nationalausgabe, Bd. 2, Teil 1, S. 326.

140 Vgl. Müller Nielaba 2010, S. 76-78. 
Unsterblichkeit. Daß alles, was schön ist, irgendwann einmal dahin muß, mag ja wahr sein. Aber was bedeutet es im Gedicht für das Gedicht? Es bedeutet, daß im poetischen Gestus des Gedichts ein Einverständnis mit Vernichtung besteht. ${ }^{141}$

Auf diese Schlussfolgerung Groddecks ist - auch mit Stefan Börnchen - am Ende des vorliegenden Kapitels noch einmal zurückzukommen. Als eine der entscheidendsten Stellen für jene, nicht auf dem „Einverständnis mit Vernichtung", sondern auf dem Enden insistierende Lesart aber führt Müller Nielaba die letzten vier Verse des Gedichtes an; insbesondere den das Auge, das Organ des Lesens, betonenden Imperativ Siehe!, der auch als „deiktische[] Lektüreanweisung ${ }^{\text {“142 }}$ gelesen werden könne. Dem Siehe! komme in dieser Hinsicht eine doppelte Funktion zu: Es nimmt als metonymischer Verweis auf das Lesen einerseits die im zweitletzten Vers durch die explizite Nennung von Klaglied sich vollziehende autoreferenziell-autoreflexive Wendung des Gedichtes Nänie auf sich selbst ${ }^{143}$ vorweg; andererseits unterläuft es auf figuraler Ebene gleichzeitig die Vollkommenheit der chiastischen Verschränkung des viert- und drittletzten Verses und stellt über diese Doppelung dem vermeintlichen Ende des Gedichtes sein Werden und Enden im Zuge der Lektüre entgegen: ${ }^{144}$

Vollkommen also ist gerade dieses,Vollkommene dann genau nur, wenn es nicht vollkommen ist, sondern als ein Gesehenes, als ein Gelesenes in unbeendbarer, in unbeschließbarer Weise zu dem würde, was es sein nicht kann: vollkommend, wie Achill, der „sein Schicksal“ - es gilt genau hinzusehen - „fallend“ nur „erfüllt“, nicht als Gefallener. Das Sehen macht das Vollkommene, als dessen Lesbarwerdung; und das Sehen hebt das Vollkommene auf, als dessen Defiguration. ${ }^{145}$

An die von Daniel Müller Nielaba aufgezeigte, auch schon bei Wolfram Groddeck in geringerem Maße behandelte, ${ }^{146}$ überaus komplexe Wendung des Gedichtes auf sich selbst und die dabei entfaltete poetologische Thematisierung von Anfang und Ende desselben sowie von Texten resp. der Lektüre im Allgemeinen knüpft das Folgende ergänzend an, und zwar mit dem Fokus auf die in Nänie überall mitschwingende Vorstellung der Verewigung.

\footnotetext{
141 Groddeck 2008, S. 219.

142 Müller Nielaba 2010, S. 85; vgl. auch Börnchen 2006, S. 202.

143 Vgl. dazu auch Hilliard 2006, S. 5 .

144 Vgl. ebd., S. $84 \mathrm{f}$.

145 Ebd., S. 84.

146 Vgl. Groddeck 2008, S. 218-220.
} 


\subsubsection{Ein Paradoxon, das selbst die Götter zum Weinen bringt}

Als Einstieg bietet sich dazu zunächst eine nähere Auseinandersetzung mit den „drei Mythologemen [...], die den deklarierten Tod des Schönen rhetorisch durcharbeiten“, an: ${ }^{147}$ Mit dem Verweis auf den Tod der Sterblichen Orpheus und Eurydike, Adonis und Achilles ${ }^{148}$ greift das Gedicht Nänie jahrtausendealte Mythen auf, schreibt deren Überlieferung fort und hat damit Anteil an einer Verewigung der Sterblichen, über deren Tod es klagt. Oder mit anderen Worten: Nänie verweist als „Klaglied“-Text auf antike Texte (und die Tradition ihrer Adaptionen etc.), die mit dazu beitrugen, dass jene in der Antike und zum Teil bis weit in die Neuzeit hinein als historische Persönlichkeiten gedachten Sterblichen, von denen die Mythen sprechen, als verschriftlichte Mythen, als Gebilde aus Schriftzeichen „im Mund der Geliebten“149 bis in die Zeit Schillers fortlebten. ${ }^{150}$ Das vermeintliche Ende von Orpheus und den anderen mythologischen Sterblichen als Figuren, als Zeichengebilde, wird also im Zuge des Fortgeschriebenwerdens ${ }^{151}$ sowie der Lektüre jener Mythen und ihrer Übersetzungen, Adaptionen etc. in ein Enden überführt. ${ }^{152}$ Ein Enden, so ließe sich mit Blick auf die semiotische Flüchtigkeit von (Sprach-)Zeichen festhalten, das jene Zeichenfiguren immer schon gewesen waren, nämlich „im Mund“ ihrer Leser oder - man denke an die mündliche Überlieferung jener Mythen „im Mund“ der Vortragenden. (Auf die Formulierung „im Mund der Geliebten“ wird am Ende dieses Kapitels nochmals zurückgekommen.) ${ }^{153}$

Das Fortschreiben antiker Überlieferung vollzieht sich, die inhaltliche Ebene unterstützend, ebenso auf metrisch-formaler Ebene, indem das Gedicht

147 Müller Nielaba 2010, S. 82.

148 Zur Häufung an Synekdochen in der Beschreibung dieser Mythologeme vgl. Groddeck 2008, S. 216-218.

149 Zur poetologischen Lesart von im "Munde der Geliebten“ vgl. auch Groddeck 2008, S. 218; wenngleich dessen Aussage, "[solche] wirkungsästhetische Selbstbezüglichkeit führt aber dazu, dass das Gedicht gar nichts Bestimmtes mehr meinen kann oder will“, im Folgenden nicht zugestimmt werden kann. Was Groddeck zudem nicht aufgefallen ist, ist, dass „im Munde der Geliebten“ selbst wiederum an einen antiken Text erinnert, nämlich an Ovids Nachwort zu den Metamorphosen („ex ore legar populi“; vgl. die Einführung und unten).

150 An Letzterem hatte Schiller keinen geringen Anteil, wie man bereits an diesem Abschnitt der vorliegenden Arbeit sieht.

$15^{1}$ Dazu trägt auch die vorliegende Arbeit bei; vgl. die Einführung und das letzte Kapitel des Schlussteils.

$15^{2}$ Oder, der Flüchtigkeit einer Lektüre Rechnung tragend, genauer formuliert: Sie werden überführt worden sein.

153 Zur im Schreiben und Denken Schillers zentralen Bedeutung des Paradigmas der Unsterblichkeit, das entscheidend von seiner kulturellen Sozialisation mittels antiker Texte und Mythologien geprägt ist, vgl. Helmstetter 2010, insbesondere S. 106-110. 
Nänie ganz nach antiker „Klaglied“-Tradition in elegischen Distichen gehalten ist. Das antike Versmaß, der Wechsel zwischen Hexameter und Pentameter, ist also nicht nur bloß schönes formales Zusammenspiel antiker Metrik und Klagliedtradition mit sich auf antike Mythologeme beziehendem Inhalt, sondern hat im Zuge von u. a. Opitz' und vor allem Klopstocks Fruchtbarmachung lateinischer Metrik für die deutsche Sprache ebenfalls performativ Anteil an der Verewigung antiker Tradition.

Kombiniert man nun das soeben Dargelegte mit den eingangs eingebrachten poetologischen Lesarten Daniel Müller Nielabas und Wolfram Groddecks, dass das Gedicht Nänie nicht nur vom Schönen handelt, sondern auch von sich selbst als (schönem) „Klaglied“ und von Gedichten im Allgemeinen, so ergibt sich folgende These:

Das Gedicht Nänie stellt die Ewigkeitsbehauptung, Dichtung resp. Texte im Allgemeinen könnten Vergängliches verewigen, obwohl Schriftzeichen - und damit auch das Klaglied Nänie - selbst wiederum vergänglich sind, als ein Paradoxon aus.

Vergänglich sind (Schrift-)Zeichen, auch das wurde bereits in der Einführung erwähnt, in mindestens dreifacher Hinsicht: (1) mit Blick auf die Vergänglichkeit ihrer Materialität und ihres Schriftträgers; und semiologisch betrachtet: mit Blick (2) auf die Vergänglichkeit ihrer potenziellen Leser sowie (3) die Flüchtigkeit des aktualisierten Zeichens, das, kaum zum Leben erweckt, sogleich wieder stirbt, je nach Leser, Kontext, Bedeutungswandel usw. immer ein anderes gewesen sein wird. Nun ist es aber bemerkenswert, dass im Gedicht Nänie eine starke antithetische Struktur zwischen vergänglichen Menschen und unsterblichen Göttern vorherrscht. Diese antithetische Struktur stellt dabei gerade auch den vergänglichen menschlichen (Schrift-) Zeichen die Ewigkeit der Zeichen der unsterblichen Götter (scheinbar) gegenüber. Im Falle der Götter Hades und Thetis entwirft das Gedicht nämlich eine Semiotik, die die Vergänglichkeit von menschlichen (Schrift-)Zeichen zu überwinden scheint:

Im Falle von Hades: Der "stygische[] Zeus“ versprach auf Bitten Orpheus' hin, Eurydike erneut das Leben zu gewähren, freilich an eine Bedingung geknüpft. ${ }^{154}$ Als diese Bedingung von Orpheus nicht erfüllt wurde, „rief er zurück sein Geschenk“. Bitten, versprechen/gewähren (und zumindest in Nänie widerrufen) - im Mythos von Orpheus und Eurydike sind performative Verben zentral. Nun scheint aber Schillers Nänie gerade auf den Unterschied zwischen den Sprechakten in jenem Mythos hinzuweisen, und zwar auf den Unterschied zwischen göttlicher und menschlicher Performativität. Orpheus'

154 Vgl. Ovid, Metamorphosen, Bd. 10, V. 50-52 resp. S. 524. 
bittendes Klagelied vor den Thronen der Unterwelt ${ }^{155}$ entfaltet im Mythos eine offenbar derart starke Performativität, dass es nicht nur eine ungeheure Bitte erschafft, sondern zugleich auch die Erfüllung derselben bewirkt. Doch und dies zeigt Hades' berühmt-berüchtigte Bedingung - mittels menschlicher Zeichen mündlich oder schriftlich gewirkte Performativität lässt sich nicht ewig, im Falle von Orpheus nicht einmal bis zum Verlassen der Unterwelt, aufrechterhalten. Wie von Derrida aufgezeigt und in der vorliegenden Arbeit mehrfach erwähnt, ist die Wiederholbarkeit und damit auch die Vergänglichkeit von (Sprach-)Zeichen auch die Möglichkeitsbedingung für performative Sprechakte. (Rainer Maria Rilke wird genau dies ins Zentrum seines den hermeneutischen Rückblick - und, so mag Nänie nun darauf hinweisen, auch die Möglichkeitsbedingung menschlicher Performativität - betonenden Gedichts Orpheus, Eurydike, Hermes stellen.) ${ }^{156}$ Anders jedoch die göttliche Performativität Hades': „[S]treng, rief er zurück sein Geschenk“ - und dieser Ruf ist, wie wir wissen, nicht nur wirksam, sondern ewig wirksam, für alle Zeiten, und von keinem Menschen zu verändern. ${ }^{157}$ Es gibt keine Möglichkeit für Eurydike, der performativen Gewalt von Hades' Sprechakt zu entkommen: Er ruft sie zurück, und sie geht zurück, und sie bleibt - und das ist das Entscheidende - in der Unterwelt, ohne Hoffnung auf weitere Fluchtversuche, die ein Wiederholen von Hades' Sprechakt nötig machen würden, denn dieser Sprechakt dauert ewig an. Eurydike bleibt nicht einmal die Hoffnung, die Macht des Sprechaktes würde mit dem Tode dessen, der ihn gewirkt hat, erlöschen, denn Hades selbst ist unsterblich. ${ }^{158}$

Im Falle von Thetis: Achilles' „unsterbliche Mutter" stimmt mit ihren 49 Schwestern, „mit allen Töchtern des Nereus“, zur „Klage“ an „um den verherrlichten Sohn“ Achilles, der „am skäischen Thor fallend, sein Schicksal erfüllt". Ein Chor von 50 unsterblichen Stimmen singt also ein Klagelied für Achilles, ${ }^{159}$ das offenbar von allen „Göttinnen“ und „Götter[n]“ vernommen wird.

$155 \mathrm{Zu}$ Schillers Entwurf einer Ballade, die diese Szene ganz ins Zentrum stellt und den Namen Orpheus in der Unterwelt trug, vgl. Helmstettter 2010, S. 118.

${ }_{15}$ Die Thematisierung jenes hermeneutischen Rückblicks des Lesers ist bereits bei Ovids Version des Mythos angelegt, siehe dazu den Exkurs zu Orpheus und Eurydike weiter unten.

157 Es ist bemerkenswert, dass Schiller hier - zumindest entgegen Ovids Fassung - von einem Zurückrufen seitens Hades' spricht und damit dem Mythos einen weiteren Sprechakt hinzufügt, dessen performative Macht Eurydike umkehren lässt.

${ }_{15} 8$ Zur Resistenz von Performativität gegenüber dem Tod derjenigen, die sie gewirkt haben oder davon betroffen waren, vgl. zudem Kapitel III.1.

159 Zum Vergleich mit der Quellengrundlage bei Homer siehe Hilliard 2006, S. 6-8, der u. a. zur Klage von Thetis kommentiert: „Homer gives this motherly grief its due. But she [Thetis, MG] does not have the last word. Her lament is taken up by the Muses. Theirs is 
Sowohl die göttlich-unsterbliche Performativität Hades' als auch die göttlich-unsterbliche „Klage“ von Thetis und ihren Schwestern entwerfen somit ein Gegenmodell zur oben dargelegten, mindestens dreifachen (siehe Punkte 1-3) Vergänglichkeit menschlicher Schriftzeichen: ${ }^{160}$ Der Vergänglichkeit der Materialität von Schriftzeichen und ihres Schriftträgers (1) wird die unsterbliche Stimme entgegengesetzt, die, so scheint es, mindestens im Falle von Hades die fortwährende Aktualisation seines Sprechaktes garantiert; der Vergänglichkeit des menschlichen Lesers (2) werden gegenübergestellt die unsterblichen Zuhörer der Göttergemeinschaft, die „alle“ zumindest der „Klage“ von Thetis unsterblichem Chor zu lauschen scheinen. In beiden, der unsterblichen Stimme und dem unsterblichen Zuhörer, liegt das Potenzial, ewig präsente Zeichen zu wirken, die der Flüchtigkeit der Aktualisation menschlicher Zeichen (3) nicht unterworfen sind. Kurzum: Die Unsterblichkeit der Götter hat das Potenzial, sich auf deren (Sprach-)Zeichen zu übertragen.

Ist dies nun alles nur schöne, antithetische Spielerei? Offenbar nicht, in den vier letzten Versen nämlich folgt auf die Klage der Nereiden eine zweite Übertragungsbewegung: Bereits angedeutet durch das in Vers drei implizierte Klagelied Orpheus' und eingeleitet durch den in seiner Deixis auch als Leseaufforderung auffassbaren ${ }^{161}$ Imperativ „Siehe!“ überträgt sich die unsterbliche „Klage“ der Unsterblichen im zweitletzten Vers auf „ein Klaglied“, auf Klagelieder im Allgemeinen ${ }^{162}$ und damit auch auf das Klagelied, das uns als Schillers Gedicht Nänie in Schriftzeichen vorliegt. Die letzten vier Absätze zusammenfassend muss also die oben aufgestellte These um folgende ergänzt werden:

Das Gedicht Nänie stellt mittels einer doppelten Übertragungsbewegung eine ungeheuerliche Ewigkeitsbehauptung auf: Dies beginnt über den Verweis auf Orpheus ${ }^{163}$ mit den vergänglichen menschlichen Zeichen und führt über die

a song of sorrow, certainly; but the Muses are the daughters of Memory, and their song anticipates Homer's own, which despite all is devoted to celebrating Achilles's fame. Thus an even-handed plurality of voices is preserved“ (ebd., S. 8). Ebenso zu Schillers Das Glück und Siegesfest, insbesondere der Strophe, die den im Liede unsterblichen Ruhm und Namen Achilles' besingt (vgl. ebd., S. 9 f.).

16o Daraus ließe sich die These ableiten, Schiller experimentiere hier mit den Möglichkeiten und Grenzen einer göttlichen Performativität, was in Bezug auf die gerade in seinem dramatischen Werk omnipräsenten performativen Sprechakte (vgl. das Kapitel III.1.2 zum Wallenstein) andernorts unbedingt weiterverfolgt werden müsste.

161 Siehe oben.

162 In Anlehnung an Groddecks Betonung der Synekdochendichte in Nänie ließe sich auch sagen: auch „Klaglied“ ist in diesem Falle eine Synekdoche.

163 Der als Sänger hier nicht bloß für Mündlichkeit steht, sondern als Metapher für den Dichter, eben auch für schriftlich festgehaltene Lieder - wovon bereits Ovids geniales 
zumindest in der Unterwelt ewig präsente performative Sprachmacht von Hades' Zurückrufen hin zur potenziell ewigen Klage aus den ewigen Mündern der Götter (erste Übertragung); und von dort aus, gewissermaßen göttlich aufgeladen, chiastisch wieder zurück zu einer Übertragung jener potenziell ewigen Klage göttlicher Münder auf das „Klaglied“, auf die menschlichen (Schrift-)Zeichen und damit auch auf das schriftlich festgehaltene Klagelied Nänie selbst.

Verbindet man schließlich die beiden Thesen, so ergibt sich daraus eine dritte, die lautet: Schillers Gedicht Nänie betreibt nicht nur eine vergöttlichende Ewigkeitsbehauptung gegenüber Schriftzeichen, sondern stellt diese Ewigkeitsbehauptung zugleich auch als Paradoxon aus.

Das in der ersten These erfasste Ausstellen des Paradoxons wird nicht vom ungeheuren Anspruch, den die zweite These beobachtet, aufgelöst. Es erstreckt sich vielmehr auf diesen Anspruch. Daran haben zwei Textstellen wesentlichen Anteil: zum einen der Indefinitartikel „ein (Klaglied)“, der zusammen mit der unmittelbar folgenden selbstbezüglichen Wendung auf das schriftliche „Klaglied“ Nänie selbst eine Öffnung der exklusiv göttlichen „Klage“ hin zu menschlichen „Klaglied[ern]“ bewirkt. Und zum anderen die Formulierung „im Mund der Geliebten“, die als lokale Angabe den vermeintlich göttlich-universalen Anspruch des „Klaglied[s]“ eingrenzt. Als Metonymie überschreitet sie die bloße Lokalität einer ,gewöhnlichen', „[g]emeine[n]“ lokalen Angabe, da sie selbst schon stets unverortbare Übertragung ist: von der Stimme zum Mund und umgekehrt. Damit setzt sie aber die in der zweiten These beschriebene, vermeintlich zum ewig-gültigen Stillstand gekommene Übertragungsbewegung fort und ergänzt sie um eine dritte, paradoxale (vgl. die dritte These) Übertragung: von der Göttlichkeit der „Klage“ der Unsterblichen, die implizit auch für das Gedicht Nänie behauptet wird, zur Vergänglichkeit resp. Flüchtigkeit menschlicher Schriftzeichen „ein[es] Klaglied[s]“, das an einen "Mund“, an ein lautes oder bloß gedachtes Lesen gebunden ist. Man könnte so weit gehen und hinzufügen: Das Gedicht Nänie, das als schönes „Klaglied“ selbst ein "Schöne[s]“ ist, [d] as „Menschen und Götter bezwinget", bezwingt ${ }^{164}$ die Götter insofern, als dass es diese in menschlichen,

Spiel mit der Leserichtung der Lektüre seiner Verse über Orpheus zeugt; siehe dazu den Exkurs zu Orpheus und Eurydike im folgenden Unterkapitel.

164 Gemessen an der Reaktion der Götter, nämlich dem „[W]einen“, müsste es eigentlich eher ,rühret‘ als „bezwinget“ heißen, wobei im zweiten Vers denn auch tatsächlich „rührt“ nachgeschoben wird. Dieser in Nänie besonders präsente Aspekt der Rührung - der auch bereits in Ovids Version von Orpheus und Eurydike eine zentrale Rolle einnimmt (vgl. Ovid, Metamorphosen, Bd. 10, V. 40-48) - erinnert doch sehr stark an Lessings bürgerliches Trauerspiel und dessen Konzept der Rührung und müsste in diese Richtung weiterverfolgt werden (vgl. auch das folgende Unterkapitel). 
vergänglichen Text, in Gebilde aus Schriftzeichen überführt. ${ }^{165} \mathrm{Ja}$, es „weinen die Götter, es weinen die Göttinnen alle“ - aber vielleicht "weinen“ sie vor allem um sich selbst. ${ }^{166}$

\subsubsection{Göttlicher Trost? Poetologie als (Meta-)Operation zur Ewigkeitsattribuierung - mit einem Exkurs zu Ovids Orpheus und Eurydike}

„Am Ende [des Gedichts Nänie, MG] steht also erneut Orpheus“, ${ }^{167}$ hat bereits Müller Nielaba beobachtet. Ein Orpheus, so lässt sich nun ergänzen, dessen Gesang resp. dessen „Klaglied“ nahe an göttliche „Klage“ heranzureichen versucht, aber letztlich nicht der Vergänglichkeit der Menschen und ihrer Zeichen, seien sie mündlich oder schriftlich, entrinnen kann. Ein Umstand, der auch dem Orpheus bei Ovid letztlich bewusst scheint, denn Orpheus bittet dort nicht um ein "Geschenk“, wie Schiller impliziert, sondern explizit darum, dass die Götter ihm Eurydike „leihen“ mögen. ${ }^{168}$ Und dennoch - oder vielleicht gerade deswegen - ist seine Bitte noch ungeheuerlicher als der Wunsch, „im Mund der Geliebten" als Textmetamorphose weiterzuleben: Orpheus möchte Eurydike nicht einfach bloß in Gesang verewigen, sondern durch seine vorgetragene Bitte wortwörtlich wieder ins Leben singen! Oder in anderen Worten: Der Mythos von Orpheus und Eurydike ist die radikalste (dem Verfasser bekannte) Thematisierung der Ewigkeitsbehauptung von Dichtung im Allgemeinen und verschriftlichter Dichtung im Speziellen, ${ }^{169}$ denn er nimmt diese Behauptung wortwörtlich. ${ }^{170} \mathrm{Ja}$, der Mythos spielt dies derart konsequent

165 Besonders lohnenswert wäre hier wohl eine ausführlichere Verknüpfung von Nänie mit den in eine ähnliche Richtung gehenden Überlegungen Maurice Blanchots (vgl. das Kapitel zum Forschungsstand in der Einführung; und ders. 1982).

166 Womit man auch hier wieder bei Lessings Ästhetik des Mitleidens angelangt wäre, die auf Dauer abzielt und bei der ,Furcht' als Mitleid(en) mit sich selbst definiert ist. Man könnte vielleicht sogar noch einen Schritt weiter gehen und behaupten, Schillers "Göttinnen" und "Götter" weinten hier auch um die an Sterbliche gebundene, nicht ewig aufrechtzuerhaltende und deshalb letztlich eben nicht verewigende Funktion des Mitleidens, wie Lessing es vertritt. Oder in anderen Worten: Vielleicht weinen sie auch um das Weinen, das wiederum metonymisch resp. synekdochisch für jene Ästhetik steht.

167 Müller Nielaba 2010, S. 83.

168 Die Stelle bei Ovid lautet wörtlich: „pro munere poscimus usum“ (Ovid, Metamorphosen, Bd. 10, V. 37), Albrecht (Ovid, Metamorphosen, S. 525) übersetzt freier: „Ich bitte euch nicht, sie mir zu schenken, nur zu leihen."

169 Man bedenke, dass der betreffende Mythos bereits zu Ovids Zeiten vor allem schriftlich überliefert wird (wofür die Metamorphosen das beste Beispiel sind) und Orpheus auch damals schon metonymisch-metaphorisch für den schreibenden Dichter stehen konnte.

170 Und dies ist auch einer der Gründe, weshalb eine in ihrer Vorlage auf die Zeit um 1800 zurückgehende Darstellung von Orpheus und Eurydike den Umschlag der vorliegenden Monographie ziert. 
durch, dass das für die Geschichte von Orpheus und Eurydike entscheidende Verbot, das Wenden des Blickes, eben auch das lesende Wenden am Ende des Verses und damit letztlich das lesende Wiedererwecken der Toten und das Erschaffen von Versen (von lat. versus, ursprünglich das,Wenden ' des Pfluges) im Allgemeinen umfasst. Oder anders ausgedrückt: Hades und Persephone verbieten mit dem Verbot des Wendens des Blickes auch die Verse des Sängers und Dichters Orpheus, aber gerade dessen Verse waren es ja, die Eurydike (vermeintlich) wortwörtlich ins Leben zurückzusingen vermögen. Auf einer poetologischen Ebene betrachtet kann Orpheus also gar nicht anders, als an diesem Verbot scheitern. Und Ovid stellt genau dies auf großartige Weise in den entscheidenden Versen aus:

hic, ne deficeret, metuens avidusque videndi

flexit amans oculos: et protinus illa relapsa est $\mathrm{t}^{171}$

Das für den Mythos und dessen Tragik (ebenso wie für die Tragik des hermeneutischen und lesenden Prozesses im Allgemeinen) zentrale Verb "flexit (oculos)“, er wandte (die Augen/den Blick), steht zu Beginn eines Verses, während der vorangegangene Vers ebenfalls mit einem Verb des Sehens („videndi“) endet. Die Position des Verbes "flexit“ lässt damit den Leser, der selbst begierig zu sehen („avidus[] videndi“) resp. zu lesen ist, den Blick zurückund hinabwenden zum nächsten Vers. Der Leser vollzieht also im Zuge seiner Lektüre am Übergang der Verse Orpheus' Wenden des Blickes nach und rückt damit in ein Ähnlichkeitsverhältnis zu demselben. So wird die poetologische Ebene dieses Mythos in den Blick des Lesers gerückt.

Der Mythos macht somit deutlich, dass der ungeheure Anspruch von Orpheus' Bitte - die die Vorstellung,jemanden mittels Dichtung im Liede zu verewigen, wortwörtlich nimmt - die Möglichkeitsbedingung von Sprachgesang, Dichten, Schreiben und letztlich von jedem Zeichengebrauch zunichtemachen würde. Und genau aus diesem Grund kann weder der Dichtersänger Orpheus noch der gedichtete Mythos selbst mit dem Verbot der Unterweltherrscher leben: Entweder stirbt Eurydike erneut, wie Dichtung im Zuge ihrer Lektüre immer wieder aufs Neue stirbt, wie jedes Lied in den ,Tod zurückfallen' muss, um erneut gesungen werden zu können; oder es stirbt Orpheus als Sänger und Dichter und mit ihm Dichtung, Text im Allgemeinen und der aus Zeichen bestehende Mythos von Orpheus und Eurydike im Speziellen. Oder anders ausgedrückt: Dieser Mythos und insbesondere Ovids Adaption desselben lässt

171 Ovid, Metamorphosen, Bd. 10, V. 56 f.; „,besorgt, sie könne ermatten, und begierig, sie zu sehen, / wandte Orpheus voll Liebe den Blick [wortwörtlich: die Augen, MG]: und alsbald fiel jene zurück“. 
Orpheus' Bitte durch das Verbot von Hades und Persephone am ungeheuren Anspruch dieser Bitte selbst scheitern. Und zwar indem er aufzeigt, dass jeder Versuch, etwas mittels Sprachzeichen dem Tod zu entreißen, zeichenhaft und deswegen unhintergehbar an die vergängliche Aktualisation dieser vergänglichen Zeichen gebunden ist. ${ }^{172}$

Diese Vergänglichkeit menschlicher Zeichen wird, um nun noch einmal entscheidend auf Schiller zurückzukommen, ebenfalls besonders deutlich an der Formulierung im zweitletzten Vers des Gedichtes Nänie: „ein Klaglied im Mund der Geliebten". Sie ist neben dem Gesang von Thetis und den Nereiden nicht nur ein Verweis auf das Klagelied des Liebhabers Orpheus um seine Geliebte vor Hades und Persephone; sondern „im Mund“ erscheint nämlich auch als ein direktes Zitat (ex ore $)^{173}$ aus Ovids Nachwort der Metamorphosen, das dort schon die Ewigkeit von Ovids eigener Metamorphose zu einem Text wieder einschränkt, ${ }^{174}$ indem Ovid selbst sie, wie Schiller in Nänie, an den Mund der sterblichen Leser bindet.

Es lässt sich aber auch feststellen, dass das Paradigma der Liebe in Nänie omnipräsent ist - explizit genannt in "Einmal nur erweichte die Liebe den Schattenbeherrscher" - und auch in den anderen untersuchten Textbeispielen immer wieder im Zusammenhang von Ewigkeit und Verewigung zu beobachten war. Reicht der "Mund“ allein also nicht aus, ist es dann letztlich die Liebe (vgl. der „Mund der Geliebten“), der zugeschrieben wird, Vergängliches verewigen zu können?

Zumindest scheint die Liebe in der abendländischen Kulturgeschichte ähnlich stark mit Ewigkeitsbehauptungen verknüpft zu sein wie die Schriftzeichen $^{175}$ - und vielleicht treten die Ewigkeitsbehauptungen gegenüber beiden deshalb so oft quasi Hand in Hand auf. Das Paradigma der ewigen Liebe, das gerade im Zuge seiner christlichen Prägung als ein mindestens in weltliche und geistlich-göttliche Liebe gedoppeltes auftritt, ist jedoch so umfassend, dass es Gegenstand eigener Untersuchungen sein müsste. Dennoch sei an dieser Stelle folgender Gedankengang erlaubt: Tritt das Paradigma der

172 Eine ausführliche Auseinandersetzung mit den antiken Versionen des „Orpheus und Eurydike“-Mythos, derjenigen Rilkes in Orpheus, Eurydike, Hermes und Schillers in Nänie im Zusammenhang mit der Ewigkeitsbehauptung gegenüber und Ewigkeitsattribuierung von Schriftzeichen - wobei gerade in dieser Hinsicht auch die Variation des Stoffes in Tolkiens Beren und Lúthien zu berücksichtigen wäre - kann im Rahmen der vorliegenden Arbeit nicht erbracht werden. Der Verfasser beabsichtigt jedoch, dies andernorts zu leisten.

173 Ovid, Metamorphosen, Bd. 15, V. 878.

174 Vgl. dazu auch die betreffende Anmerkung in Kapitel 4 der Einführung.

175 Bereits in Platons Symposion etwa, das in der Einführung zitiert wurde, sind Liebe und Unsterblichkeit eng miteinander verknüpft, vgl. u. a. Platon, Symposion, 25 (resp. S. 109). 
Liebe in einem Text auf, so kommt es zwangsläufig immer selbst wiederum in Text, als Text daher. Selbst die in Texten beschworene Ewigkeit der Liebe scheint also, gewissermaßen als sekundäre Ewigkeitsbehauptung, an die Behauptung gegenüber Schriftzeichen gekoppelt zu sein, Vergängliches verewigen zu können. Besonders bemerkenswert ist nun, dass Nänie genau dies thematisiert, indem es gerade im Zuge des Verweises auf Orpheus und Eurydike und noch stärker im Verweis auf Aphrodite und Adonis der Liebe an sich das Potenzial der Verewigung des Sterblichen abspricht und sie nur gewissermaßen als Antrieb gelten lässt, ${ }^{176} \mathrm{im}$ Medium der Dichtung und letztlich der gelesenen Schrift, im „Klaglied“, „im Mund der Geliebten“, die Geliebten immer wieder (und dabei immer wieder anders) auferstehen zu lassen. ${ }^{177}$

Bislang wurde vor allem auf die ungeheuerliche Ewigkeitsbehauptung, die in Nänie entfaltet und zugleich als Paradoxon ausgestellt wird, hingewiesen. Zum Schluss nun soll aufgezeigt werden, inwiefern ausgerechnet dies zur Ewigkeitsattribuierung des Gedichtes beiträgt und weshalb sich Nänie als letzter Beispieltext der vorliegenden Arbeit besonders anbietet: Das Gedicht Nänie scheint letztlich alle der hier behandelten Operationen zur Ewigkeitsattribuierung von Schriftzeichen auf engstem Raum zu beinhalten oder zu thematisieren: Es thematisiert auf inhaltlicher Ebene entscheidend die Grundoperation Autonome Performative Produktion über den Gegensatz göttliche vs. menschliche Performativität; es beinhaltet prominent die Operation Autoreflexivität, insbesondere durch die explizite Verwendung von „Klaglied“, und eng damit verknüpft auch die der Unendlichen Lektüre ${ }^{178}$ bei gleichzeitiger ästhetischer Nutzbarmachung des potenziell unendlich oft sich wiederholenden Sterbens resp. Verstummens des Klaglied $[s]$ Nänie selbst. In sein poetologisches Ausstellen der Verewigung mittels vergänglicher Schriftzeichen als ein Paradoxon bezieht das Gedicht Nänie also - und das macht hier

${ }_{17} 6$ Darin klingen ebenfalls antike Glaubensvorstellungen an, insbesondere verknüpft mit dem Namen (vgl. Svenbro 2005).

177 In diesem Zusammenhang müsste gerade um 1800 auch Kittlers eng mit dem Paradigma der Liebe verbundene These zum Transzendentalsignifikat Frau in der Goethezeit weiterverfolgt werden; vgl. Kittler 1986, S. 490-492; z. B.: „Auf transzendentalem Feld dagegen, als sichtbare Seele aller andernfalls leeren Wörter, gibt das Idol Frau Dichtern eine Ursprache ein, deren Tiefe Stummheit ist. [...] Zuerst und zuletzt heißt Dichtung zur Goethezeit: Übersetzung einer elementaren und nie ergehenden Frauenrede in artikulierte Sprache“ (ebd., S. 491). Und zu Novalis' Heinrich von Ofterdingen schreibt er: „Ohne eine Frau, die als sichtbare Seele‘ alle Gesänge und Zaubersprüche firmiert, fällt das Medium Literatur auf seine trostlose Buchstäblichkeit zurück“ (ebd., S. 49o). Zur Bedeutung „Zauberlied“/,Zauberformel“ neben „Klage-Lied“ des lat. Wortes nenia (Nänie) vgl. Müller Nielaba 2010, S. 79 f.

178 Vgl. oben zu Thetis und Müller Nielaba 2010. 
seine schlagende Exemplarität aus - auf engstem Raum alle in dieser Arbeit behandelten Operationen zur Ewigkeitsattribuierung von Schriftzeichen mit ein und zeigt damit, dass gerade auch diese Operationen, da selbst an Zeichen gebunden, wesentlicher Bestandteil dieses Paradoxons sind.

Die Thematisierung dieses Paradoxons an sich selbst lässt Nänie einen performativen Selbstwiderspruch entfalten: Das „Klaglied“ Nänie beklagt seine eigene Vergänglichkeit, aber gerade diese Klage über sich selbst dreht die Kausalkette von Vergehen und Beklagen um: Dass Nänie im Zuge der Lektüre die eigene Vergänglichkeit beklagen kann, beruht auf der Wiederholbarkeit, auf der Möglichkeit zur Re-Lektüre des Gedichtes, denn ohne potenziell immer schon vorausgegangene Lektüre gibt es nichts zu beklagen; Nänie ,weiß' um die eigene Vergänglichkeit und beklagt sie, aber dass es diese Klage überhaupt zu lesen geben kann, beruht ausgerechnet auf der (potenziell unendlichen) Wiederholbarkeit ebendieser Klage und zielt auf eine solche potenziell unendliche Wiederholung ab, die es wiederum zu beklagen gälte usw. (vgl. die Grundoperation Unendliche Aktualisation). Doch ausgerechnet durch das radikale poetologische Ausstellen dieses Paradoxons an sich selbst - und dabei insbesondere an den im Gedicht enthaltenen Operationen zur Ewigkeitsattribuierung von Schriftzeichen - sucht Nänie diesem Paradoxon zu entrinnen.

Schillers Gedicht stellt dieses Paradoxon als ein ewig gültiges aus, an dessen Ewigkeit es gerade dadurch selbst Teil zu haben sucht, indem es die eigene Klage und dadurch sich selbst aus ebendiesem Paradoxon entfaltet. Ähnliches gilt letztlich auch für Ovids Fassung von Orpheus und Eurydike.

Das vorliegende Kapitel hat somit gezeigt, dass die eingangs zitierte Schlussfolgerung Groddecks und dessen Aussage, ,[g]egen den Schreck unbeseelter Buchstäblichkeit hilft nur noch der Glaube an Ideen“, 179 zu stark Schiller, dem Idealisten, verpflichtet zu sein scheinen, worauf bereits Börnchen hingewiesen hat. ${ }^{180}$ Sie vernachlässigen deshalb die zentralen, dem Gedicht immanenten

179 Groddeck 2008, S. 219. Des Weiteren hat bereits die Einführung anhand des Phaidros aufgezeigt, dass schon Platons Verhältnis zur Schrift weitaus komplexer ist als die bloße Bezeichnung ,unbeseelter Buchstäblichkeit'. Noch spezifischer und nicht auf Platons Phaidros, sondern den Kratylos bezogen, berichtigt Stefan Börnchen Wolfram Groddecks Lesart (vgl. Börnchen 2006, S. 200).

180 Der Verfasser schließt sich somit Stefan Börnchen an (wenngleich die vorliegende Arbeit aus einer anderen Richtung kommt und eine differenziertere Auffassung der Performativität von Nänie vertritt), der hinsichtlich Groddecks Interpretation schreibt: „Glaube und Vertrauen richten sich auf die performative Macht des Gedichttextes und darauf, dass seine Lektüre (und nicht der ,Glaube an Ideen') gegen den ,Schreck unbeseelter Buchstäblichkeit‘ hilft. [...] Fatal für das Gedicht und die in seiner Schrift wie in einem Grab bewahrten Toten wäre es also, nicht gelesen zu werden. Denn dann bliebe es bei der 
Operationen zur Ewigkeitsattribuierung und sind dahingehend zu ergänzen. Auch Müller Nielabas Aussage zu Nänie, „Das, Schöne', als dasjenige, was schön wäre, nicht dieses selbst also; und das ,Vollkommene', als ein anderes zu sich, [...] es ,stirbt' bzw. es ,vergeht' in Funktion des ,lebendigen', des unvergänglichen Textes, ${ }^{\prime 181}$ wäre nun insofern zu modifizieren, als dass das Unvergängliche, das Ewiggültige des Textes Nänie, nur dadurch konstituiert wird, dass Nänie poetologisch das ewig gültige Gesetz der Vergänglichkeit von (Schrift-) Zeichen - und damit auch von sich selbst - radikal ausstellt. Oder anders formuliert: Die poetologische Thematisierung der Vergänglichkeit der Versuche, schriftlicher Dichtung Ewigkeit zu verleihen, dient hier als (Meta-) ${ }^{182}$ Operation Poetologie selbst wiederum zur Ewigkeitsattribuierung von Schriftzeichen.

\section{Historische Kontextualisierung der Grundoperation Reflexivität}

Im Folgenden sollen die Wechselwirkungen von drei zentralen geistes- resp. literaturgeschichtlichen Konfigurationen der Zeit um 1800 mit den hier behandelten Operationen, insbesondere der Grundoperation Reflexivität, näher untersucht werden. Diese drei Konfigurationen sind die Reflexionsphilosophie, die Autonomieästhetik und die Genieästhetik. Freilich ist diese Dreiteilung auch heuristischer Natur, zeigen doch gerade die unten stehenden Kapitel, wie eng jene letztlich miteinander verwoben sind. Es geht dabei - dies sei noch einmal betont - nicht um eine allgemeine Darstellung jener drei Konfigurationen, sondern um eine dem vorliegenden Rahmen entsprechende Skizze ihrer spezifischen Wechselwirkungen mit den Operationen zur Ewigkeitsattribuierung von Schriftzeichen.

\subsection{Reflexionsphilosophie}

Albrecht Koschorke schreibt mit Verweis auf den von ihm u. a. untersuchten medizin- resp. physiologiehistorischen Wechsel von der Verabschiedung der

,klanglos[en]' Existenz des (All-),Gemeinen', also aller Dinge, im ,Orkus' der Schrift, mit deren Feststellung im gnomischen Präsens Schillers Gedicht endet" (Börnchen 2006, S. 200 f.). Und etwas später: „In diesem Sinne würde ich ,[i]m letzten Distichon' nicht, wie Groddeck, einen ,Salto mortale` sehen, sondern im Gegenteil einen Salto ravvivamento“ (ebd., S. 202).

181 Müller Nielaba 2010, S. 85 .

182 ,Meta' bezeichnet hier die spezielle Funktion, die die Operation Poetologie im Gedicht Nänie innehat, und meint damit nicht eine jeweils zwingende Eigenschaft dieser Operation im Allgemeinen. 
Vier-Säfte-Lehre Galens und der Entdeckung der Nervenreize im 17. resp. 18. Jahrhundert:

Welchen Unterschied es in kognitiver Hinsicht bedeutet, ob die Sinnesdaten dem Gehirn auf humoralem Weg oder durch galvanische Reizübertragung mitgeteilt werden, soll in einem späteren Teil dieser Arbeit Gegenstand der Darstellung sein. Vorwegnehmend sei nur gesagt, daß die beschriebenen Körperumschichtungen mit einem Definitionswandel des Menschen von einem rezeptiven zu einem wirklichkeitskonstituierenden Wesen einhergeht [sic]. ${ }^{183}$

Der Mensch, der sich im Zuge der Aufklärung selbst als solchen und damit auch als wissenschaftlichen Gegenstand ,erfindet', definiert also auch seine physische Innerlichkeit neu. Dies wiederum begünstigt eine Reflexion auf jenes vermeintliche Erkennen seiner Erkenntnisgegenstände und damit auch seiner selbst - und umgekehrt. Dieser von Koschorke festgestellte „Definitionswandel des Menschen von einem rezeptiven zu einem wirklichkeitskonstituierenden Wesen" erreicht, ausgehend von Descartes' berühmtem, wenngleich nicht wortwörtlich so geäußerten, cogito ergo sum (1641) ${ }^{184}$ bekanntlich einen ersten Höhepunkt in den Kritiken Kants (1781-179o) und bei Fichte (Grundlage der Gesamten Wissenschaftslehre 1794/95), die den Möglichkeitsbedingungen menschlicher Erkenntnis und Sinneswahrnehmung selbst nachgehen, so zusammenfassend Manfred Frank:

Zu den Grundcharakteristika der philosophischen Moderne zählt die allgemeine Überzeugung, daß sie ein Denken aus der Gewißheit des Selbstbewußtseins gewesen sei. Dieses Denken, von Descartes bahnbrechend eingeleitet, habe nach Leibniz und einem empiristischen Intermezzo in Kants und zumal in Fichtes Philosophie seinen Höhepunkt erreicht - denn dort wird Subjektivität zum Prinzip eines deduktiv entwickelten Systems von Kenntnissen, die kraft ihrer Ableitbarkeit aus dem Selbst die ihnen eigene Form objektiver Begründetheit gewinnen. ${ }^{185}$

Und das Lexikon der Philosophie weist im Eintrag zum Begriff Reflexion bereits auf dessen Metaphorik hin, auf die weiter unten noch vertiefter einzugehen ist:

,R.'[eflexion] ist ein Terminus aus der Optik, der erst spät in den philosophischen Sprachgebrauch eingeht [...] als Grundbegriff einer Hauptrichtung der neuzeitlichen Philosophie, die nur im kritischen Rückgang auf die menschliche

183 Koschorke 1999, S. 13 o.

184 Vgl. Angehrn 2008, S. 69.

185 Frank 1990, S. 5 oo. 
Geistestätigkeit eine gesicherte Erkenntnis gewährleistet sieht. Durch seine Herkunft bleibt der R.-Begriff später auch häufig mit der Metapher des Spiegels und des Sich-Spiegelns verbunden $[\ldots]^{186}$

Es kann hier freilich nicht eine vertiefte Auseinandersetzung mit der abendländischen Philosophie von Descartes bis Hegel mit Blick auf die Operationen zur Ewigkeitsattribuierung von Schriftzeichen geleistet werden; ${ }^{187}$ dies wäre Stoff für (mindestens) eine andere Arbeit. Es bleibt jedoch, folgende zwei geistesgeschichtliche Beobachtungen zu skizzieren:

I) Die philosophische (Auto-)Reflexion weist eine Metaphorizität auf, die ihr die Eigendynamik einer potenziell endlosen Spiegelung verleiht.

Damit werden sich die folgenden zwei Unterkapitel befassen.

II) Der Modus der philosophischen Reflexion ist strukturell gesehen derselbe wie der der oben definierten Grundoperation Reflexivität.

Hiermit ist gemeint: Wie eine autoreflexive und/oder poetologische Textstelle (freilich nur im Zuge ihrer Lektüre) über sich selbst und ihre eigenen Möglichkeitsbedingungen nachdenken lassen kann, so denkt das denkende Ich der Reflexionsphilosophie über sich selbst und die eigenen Möglichkeitsbedingungen nach. Diese Parallele ist, wie schließlich Kapitel 3.1.3 zeigen wird, für die historische Kontextualisierung der Grundoperation Reflexivität für die Zeit um 1800 und die von ihr gefassten Unteroperationen Autoreflexivität und Poetologie zentral. Um an diese Parallele zu erinnern, wird hier jene philosophische Reflexion fortan auch (Auto-)Reflexion genannt.

Die Metaphorik der philosophischen Reflexion und deren

Eigendynamik

Dass die philosophische (Auto-)Reflexion eine Metaphorizität aufweist, die ihr die Eigendynamik einer potenziell endlosen Spiegelung verleiht, ${ }^{188}$ ist in folgenden Punkten festzustellen:

1) Der zunächst vermeintlich vorbehaltslos aus dem denkenden Ich operierenden Reflexionsphilosophie liegt die Denkfigur einer Metapher zugrunde. (Freilich ist die Metapher gemäß der klassischen rhetorischen Tradition keine Figur, sondern eine Trope. Der Terminus Denkfigur ist denn hier auch nur heuristischer Natur und selbst wiederum metaphorisch: Er sucht über

186 Vgl. Historisches Wörterbuch der Philosophie 1992, Bd. 8, Sp. 396-405, hier Sp. 396.

187 Als Überblick etwa zur Antinomie der Unendlichkeit bei Kant und Hegel vgl. Rothhaar 2018.

188 Zur Unabschließbarkeit des cartesianischen cogito im Allgemeinen vgl. Angehrn 2008, insbesondere S. 69-92. 
den Begriff Figur zu veranschaulichen, dass eine jede Metapher nicht stabil, sondern eine letztlich stets sich in Bewegung befindliche, figurale Operation zwischen drei Elementen ist resp. immer schon gewesen sein wird: von der eigentlichen Bedeutung über ein Tertium Comparationis hin zur uneigentlichen Bedeutung.) $)^{189}$ Der Begriff Reflexion nämlich, ursprünglich ein Terminus aus der Optik, ${ }^{190}$ ist immer schon ein metaphorischer, verweist auf eine Selbstspiegelung, auf einen Blick in einen Spiegel. Manfred Frank schreibt dazu:

[E]ine Analyse des Selbstbewußtseins muß unter anderem den Befund erbringen, daß unser Selbst die relative Identität, in der es sein bewußtes Leben durchmisst, als das Werk einer Instanz begreift, die seiner eigenen Struktur vorgeordnet ist. Das kann man sich leicht klar machen, wenn man daran denkt, daß, was wir gewöhnlich unter ,Selbstbewußtsein` verstehen, das Werk einer Rückwendung des Bewußtseins auf sich selbst ist. Diese Rückwendung nennt die philosophische Kunstsprache ,Reflexion. ${ }^{\prime 11}$

Ein weiteres Problem dieser Selbstspiegelung ist, dass seit Descartes jener Spiegel nicht mehr in der Natur resp. außerhalb des Menschen zu finden, sondern der Mensch selbst ist. Zurückübersetzt in die Metaphorik, die der Reflexionsphilosphie zugrunde liegt, heißt dies nun: Der Spiegel spiegelt sich in letzter Konsequenz (auf der etwa Novalis insistieren wird) selbst; was wiederum nur insofern bildlich vorstellbar ist, als dass man sich einen Spiegel dem Spiegel gegenübergestellt imaginiert. Das selbstreflektierende Ich wird in dieser Metapher also zum Spiegel, der sich selber spiegelt. Nun weiß aber jedes Kind - insbesondere jedes Kind - was passiert, wenn man zwei Spiegel einander gegenüberhält: Sie spiegeln einander; und sie spiegeln die Spiegelung dieser Spiegelung; und die Spiegelung davon und so fort, immer weiter, bis sich die Spiegelbilder in der Unendlichkeit verlieren - unendlich

189 Bemerkenswerterweise spricht auch Quintilian, wenngleich in leicht anderem Zusammenhang und umgekehrt von den Tropen ausgehend, in seinem Kapitel zu Der Unterschied zwischen Redefiguren und Tropen (Institutio Oratoria, Vol. 9, Kap. 1, Abschnitt 2) von „Bewegungen“, die letztlich sowohl den Tropen als auch den Figuren zugeschrieben wurden: „Haben doch sehr viele die Figuren für Tropen gehalten: ob sie nämlich deren Namen daher abgeleitet haben, dass sie in bestimmter Weise gestaltet sind, oder daher, dass sie die Rede wandeln, weshalb sie auch ,Bewegungen' heißen [unde et motus dicuntur], so wird man zugeben müssen, dass jede dieser beiden Bestimmungen auch bei den Figuren zutrifft." Quintilian, Institutio Oratoria, Teil 2, S. 251. Vgl. dazu auch Alder 2015, S. 11-28; und Müller Nielaba/Schumacher/Steier 2011.

190 Siehe die dem vorliegenden Kapitel vorangestellte Auseinandersetzung mit der Geschichte des Begriffs der Reflexion.

191 Frank 199o, S. 500 f. 
faszinierend und unendlich schrecklich zugleich, ${ }^{192}$ zwei Seiten derselben Operation, wie sie nach Kant insbesondere die Romantiker beschäftigen wird.

2) Da der Reflexionsphilosophie letztlich die Denkfigur einer Metapher zugrunde liegt, ist in ihr die unter 1) beschriebene, grundlegende Operation einer jeden Metapher angelegt: Jede Metapher ist ihrerseits nicht stabil, sondern im Zuge ihrer ,Figuration' stets in Bewegung, sie wird immer nur über ein Ähnlichkeitsverhältnis, über ein Tertium Comparationis, konstituiert worden sein. Daraus folgt wiederum:

2.a) Damit das Ich Erkenntnis autoreflexiv konstituieren kann, müsste es paradoxalerweise aller Erkenntnis vorausgehend nicht nur das Ich, das (wieder-) erkannt werden soll, sondern auch das Tertium Comparationis zwischen dem Ich und dessen Spiegelbild vor-erkannt haben, um das Spiegelbild überhaupt erst als Spiegelung des Ich erkennen zu können.

Problem 2.a) ist hier lediglich mit Perspektive auf die Metapher der (Auto-) Reflexion ausgedrückt, Manfred Frank hat dasselbe Problem unter anderer Perspektive bereits wie folgt formuliert:

In der Reflexion ist eines Subjekt und eines Objekt der Selbstbespiegelung. Wie aber sollte ich die Tatsache, in einem elementaren Sinne einer zu sein, aus der

192 Wohl keiner hat diese unendliche Spiegelung in ihrem Schrecken derart kompakt und humoristisch zugleich auf den Punkt gebracht wie der Berner Troubadour Mani Matter in seinem Lied Bim Coiffeur (beim Frisör); im Folgenden aus dem Berndeutschen übersetzt von MG: „Ich saß beim Frisör [Coiffeur] vor dem Spiegel und blicke [in diesen] hinein und sehe darin den Spiegel, der an der Wand gegenüber hängt. Und dort drin spiegelt sich wieder der Spiegel hier vor mir. Und in diesem Spiegel wiederum der hintere Spiegel. Und so immer weiter, es war wie ein langer Korridor, in dem mein Kopf gewiss hundertfach von hinten und von vorne in einer Reihe aufgereiht war, bis zuhinterst mein Kopf - ich habe ihn nicht mehr erkannt - so klein war wie ein Nadelkopf. Mein Kopf hat sich dort in der Weite - stellen Sie sich das vor - verloren in der Unendlichkeit des langen Korridors. Ich habe mich selber hinten verschwinden sehen, habe das gesehen am hellichten Vormittag, wie wenn nichts geschehen wäre. Vor Schreck habe ich den Mund aufgesperrt, da öffneten sich im Korridor gleich hundert Mäuler mit wie ein Männerchor. Ein Männerchor aus mir allein, ein äußerst seltsames Gefühl und ein metaphysisches Grauen hat mich ergriffen im Frisörstuhl [...]“ (berndeutsches Original, aufgenommen 1966; Remastering der Aufnahmen: Zytglogge Verlag 2003).

Interessanterweise wirkt diese unendliche Spiegelung auf Kinder nicht so sehr grauenvoll als vielmehr komisch und gibt Anlass zu großem - wenngleich nicht ewigem - Vergnügen, die eigenen Grimassen ins Unendliche zu zelebrieren - und auch dies beinhaltet die Komik des Chors bei Mani Matter. Vielleicht ist dieser Umgang, den die Kinder aufzeigen, für den modernen Menschen der einzig erträgliche: das Lachen über sich und die (selbstkonstituierte) Welt; selbstironisch lachend oder lachend überspielend, dass es auch zum Weinen sein könnte, dass selbst dieses Lachen auf einer selbstreflexiven Operation beruht. 
Dualität von Schein und Widerschein lernen können? Und wie sollte ich andererseits daran zweifeln, daß diese Einheit ein Wesenszug meines bewußten Lebens ist? Ist beides der Fall, so die frühromantische (und Hölderlinsche) Konsequenz, muß Selbstbewußtsein abkünftig sein aus einer fugenlosen (irreflexiven) Identität, die in Denkverhältnisse nicht mehr auflösbar ist und die diese Generation mit Friedrich Heinrich Jacobi „Seyn“ nannte. ${ }^{193}$

Die Frühromantik sei „überzeugt, dass Selbstsein einem transzendenten Grunde sich verdankt, der sich nicht in die Immanenz des Bewusstseins auflösen lasse. So wird der Grund von Selbstsein zu einem unausdeutbaren Rätsel."194

Novalis nun - und das ist für die vorliegende Arbeit besonders relevant sucht, ausgehend von Kant und Fichte, ${ }^{195}$ sich diesem „Grund von Selbstsein“ dahingehend zu nähern, als dass er die (Auto-)Reflexion potenziert. Dies führt zu seiner Denkfigur „reflexiver Inversion“, 196 dem ordo inversus:

Die erste Reflexion (115) verwandelt nämlich das zuständliche Sein, dem das reine Gefühl innewohnt, als Form desselben, in Schein, schaut ihn aber als Realität an. Die zweite Reflexion als die Form des Nichtseyns (181) stellt das ursprüngliche Verhältnis aber dadurch wieder her, daß sie, was ihre Realität zu sein schien, abermals negiert und so auf das ursprüngliche Seyn hin überschreitet. [...]

Solche Unterscheidung dessen, was im Bewußtseyn, von dem, was im Grunde geschieht (115), ja die Behauptung, daß die eine Bewegung das Gegentheil der anderen vorstelle, mag als eine Sophistik der sich selbst überspringenden Reflexion erscheinen. In Wahrheit ist sie erstes Signal radikaler Selbstkritik des idealistischen Ansatzes [...]. [...]

Die wirkungsgeschichtliche Relevanz dieser Deduktion besteht darin, daß sie die Kritik an der Reflexion von der Reflexion selbst leisten läßt: weder wird die Endlichkeit übersprungen noch anders als im Ausgang von der Erfahrung endlicher Selbstvermittlung auf ein ,transreflexives Sein' geschlossen. ${ }^{197}$

Novalis glaubt also, das Problem der reflexiven Erkenntnis mittels Reflexion angehen zu können, was letztlich nichts anderes heißt als das Problem unter Punkt 2.a) mit Punkt 1) zu lösen, was jedoch nur zu einer Verschiebung

193 Frank 1990, S. 5 o1.

194 Ebd.

$195 \mathrm{Zu}$ Fichte, Kant und Novalis vgl. etwa zusammenfassend Uerlings 2004, insbesondere S. 22-39; sowie u. a. Hörisch 1976, insbesondere S. 19-23; und (unter Einbezug Benjamins) ders. 1975. Zu Fichtes und Friedrich Schlegels Auseinandersetzung mit der der Reflexionsphilosophie inhärenten, potenziell unendlichen Spiegelung vgl. zusammenfassend Wirth 20o8, insbesondere S. 289-295.

196 Frank und Kurz 1977, S. 78.

197 Dies., S. 79. Die Zahlen in runden Klammern sind die Seitenangaben für: Paul Kluckhohn und Richard Samuel (Hg.): Novalis, Schriften, Das philosophische Werk I, Stuttgart 1965. 
des Problems führt: Denn ist nicht auch die (Auto-)Reflexion der (Auto-) Reflexion, also die Operation des ordo inversus, überhaupt erst durch eine (Auto-)Reflexion derselben als solche zu erkennen? Damit wäre man aber, in Anlehnung an die Schreibweise in der Mathematik, schon bei einer (Auto-) Reflexion ${ }^{3}$ angelangt, ${ }^{198}$ die ihrerseits wieder reflektiert werden müsste und immer so fort. Und noch etwas lässt sich am ordo inversus beobachten: Ihm liegt die paradoxale Vorstellung zugrunde, eine Art transzendente Indexikalität herzustellen. Die erste (Auto-)Reflexion ist in dieser Vorstellung selbst schon bloß Index auf das (vermeintliche) Absolute oder eben ,Seyn'. Die zweite (Auto-) Reflexion soll durch die Umkehr der ersten nun jene Indexikalität als solche erkennbar machen und dadurch letztlich doch auf das verweisen, worauf sich nicht verweisen lässt, auf das ,Seyn'. ${ }^{199}$ Liegt nun eine solche paradoxale Vorstellung einer transzendenten Indexikalität dem ordo inversus zugrunde, so ist diese letztlich auch der Reflexionsphilosophie insgesamt inhärent, was zu folgender These führt:

Sowohl Novalis' ordo inversus als auch der neuzeitlichen Reflexionsphilosophie als solcher liegt nicht nur die Denkfigur der Metapher eines sich selbst spiegelnden Spiegels zugrunde, sondern auch - zeichentheoretisch ausgedrücktdie (paradoxale) Vorstellung einer transzendenten Indexikalität.

Bevor das folgende Unterkapitel wieder auf die Überlegungen Novalis' und Schlegels ${ }^{200}$ zurückkommt, sei trotz des hier beschränkten Rahmens zumindest noch auf den Ansatz Hegels und Schellings verwiesen: Beide versuchen nämlich nach Manfred Frank das Problem der Eigendynamik der (Auto-)Reflexion wie folgt zu lösen:

Jacobi glaubte, einen vollkommenen Dualismus zwischen der unmittelbaren Gewißheit des Seins und der endlosen Relativität des rationalen Begründens ausmachen zu können. Dadurch hat er den Tübingern, aber auch den Jenensern zu der ihr ganzes Denken nachhaltig bestimmenden Einsicht verholfen, daß Unbedingtes nicht von der Kette der Bedingungen her erreicht werden kann. Das Denken von Friedrich Schlegel und Novalis nimmt aber eine andere Wendung als dasjenige Jacobis einerseits, des absoluten Idealismus der Schelling und

198 Uwe Wirth hat gar auf die Ähnlichkeit zwischen dem Verfahren des Druckens und der Spiegelung verwiesen, die in der Herausgeberfiktion der Lebens-Ansichten des Katers Murr wiederum über die Verwendung der Kreisler-Biographie als Löschpapier gespiegelt werde (vgl. Wirth 2008, S. 412), was auf literarischer Ebene genau einer solchen Reflexion ${ }^{3}$ entspräche.

199 Zur Diskussion der Positionen von Frank und Menninghaus dazu vgl. das Ende des nächsten Unterkapitels.

200 Zum „so reziprok[en] wahrlich wie komplementär[en] “Verhältnis von Friedrich Schlegels und Novalis' „Zentralideen“ vgl. zusammenfassend Mathy 1999, insbesondere S. 26. 
Hegel andererseits. Die beiden letzten glauben, das Wissen des Absoluten sei einerlei mit der Selbstaufhebung der Relativität $[\ldots] .^{201}$

Mit Blick auf die oben dargelegte Eigendynamik heißt dies: Schelling und Hegel versuchen Punkt 1) und 2) zu lösen, indem sie glauben, die potenziell endlose Spiegelung ließe sich durch deren Selbstaufhebung gewissermaßen anhalten; ein Zustand, der wohl gleichzeitig auch das Tertium Comparationis für 2a) liefern würde. Konsequenterweise muss ein solcher Ansatz - wird ihm noch immer die Metaphorik zugrunde gelegt, deren Eigendynamik er lösen soll - aber in das Paradoxon des Endes aller Reflexion und damit aller Erkenntnis münden.

Das bislang Dargelegte lässt sich zusammenfassend wie folgt festhalten: Die Metaphorik des sich selber spiegelnden Spiegels, die der abendländischen Reflexionsphilosophie seit Descartes zugrunde liegt, birgt eine Eigendynamik, die - über Kant - dann spätestens bei Fichte und in der frühromantischen Philosophie zutage tritt und die sodann Schelling und Hegel wieder einzudämmen suchen. ${ }^{202}$ Sie generiert spätestens ab Husserl wieder neue Formen und Stufen der Reflexion, welche wiederum von den folgenden Generationen bis hin zur vorliegenden Arbeit - reflektiert wurden und werden und immer neue Varianten und Stufen (der Potenzierung) der Reflexion hervorbringen. ${ }^{203}$ (Man könnte sogar behaupten, diese Reflexionsbewegung habe in jüngsterVergangenheit auch die Materialität von Schrift und Schriftträgern selbst erfasst. Erstere wird in ihrer digitalen Form zu einer Repräsentation eines Zeichens, also zu einer Repräsentation einer Repräsentation.) Diese Eigendynamik, so wurde oben gezeigt, hat zweierlei Gründe: Erstens (ver-)birgt die Metapher der Reflexion im Speziellen die endlose Spiegelung, die ein Spiegel, der sich in einem Spiegel reflektiert, auslöst. Zweitens - und im Allgemeinen - wird eine jede Metapher immer in potenziell endloser Figuration sich befindend konstituiert worden sein.

Philosophische (Auto-)Reflexion, Ewigkeit zweiter Ordnung und die Grundoperation Reflexivität

Die im Kapitel zu Novalis' Heinrich von Ofterdingen behandelte Höhlenszene sucht auf besonders eindrückliche Weise das einzuholen, worauf sich mittels

\footnotetext{
201 Frank 199o, S. 5 O2.

$202 \mathrm{Zu}$ den verschiedenen Reflexionsbegriffen resp. den unterschiedlichen Konzepten von Stufen der Reflexion von Descartes bis Hegel vgl. zusammenfassend den Eintrag im Historischen Wörterbuch der Philosophie 1992, Bd. 8, Sp. 396-401. Als Überblick zur Antinomie der Unendlichkeit bei Kant und Hegel vgl. Rothhaar 2018, insbesondere S. 166-168.

203 Vgl. ebd., Sp. 401-404.
} 
Sprache letztlich nicht verweisen lässt: das ,Seyn', das ,Absolute‘. Oder in zeitlicher Perspektive ausgedrückt: Sie sucht mittels Unendlichkeit Ewigkeit einzuholen. Mit dieser Beobachtung gelangt man, freilich aus einer anderen Richtung kommend, letztlich an denselben geistes- und literaturgeschichtlichen Punkt, wie ihn bereits Manfred Frank beschrieben hat:

Dagegen [in Abgrenzung zum Idealismus Fichtes, Schellings und Hegels, MG] ist die Frühromantik überzeugt, daß Selbstsein einem transzendenten Grunde sich verdankt, der sich nicht in die Immanenz des Bewußtseins auflösen lasse. So wird der Grund von Selbstsein zu einem unausdeutbaren Rätsel. Dies Rätsel kann nicht mehr (allein) von der Reflexion bearbeitet werden. Darum vollendet sich die Philosophie in der und als Kunst. Denn in der Kunst ist uns ein Gebilde gegeben, dessen Sinnfülle von keinem möglichen Gedanken erschöpft wird. ${ }^{204}$ Darum kann der unausschöpfbare Gedankenreichtum, mit dem uns die Erfahrung des Kunstschönen konfrontiert, zum Symbol werden jenes in Reflexion uneinholbaren Einheitsgrundes, der der Fassungskraft des dualen Selbstbewußtseins aus strukturellen Gründen entgehen muß. Diesen Typ von symbolischer Repräsentation nennt die Frühromantik in polemischer Absetzung vom klassizistischen Wortgebrauch Allegorie. ${ }^{205}$

Hier ließe sich nun freilich eine ausführliche Untersuchung des Allegorie-, des Symbol- und auch des Ironiebegriffs ${ }^{206}$ im Zusammenhang mit den

$204 \mathrm{Ob}$ und inwiefern dies zutrifft, müsste allerdings überprüft werden. Es ist hier auch nicht ganz klar, ob vom Kunstverständnis der Frühromantik oder demjenigen Manfred Franks die Rede ist.

205 Frank 1990, S. $501 \mathrm{f}$.

206 Vgl. zu Ironie (und Allegorie) Frank 199o, S. 504, wo es zu Schlegels Umgang mit dem Problem Zeit u. a. heißt: „Dem Bewußtsein der Relativität jeder Bindung und Fixierung wie es z. B. in den punktuellen Vereinigungen des ,Witzes' gelingt - antwortet die ,Ironie', die das mit sich Einige ,allegorisch' an das Unendliche verweist, seine Vorläufigkeit und Unvollständigkeit entlarvend. [...] Welche philosophische Methode kann diesem ungleichzeitigen Sowohl-als-auch gerecht werden? Die ironische, die etwas Bestimmtes, Positives so setzt, daß sie in die Geste der Setzung physiognomisch das heitere Bewußtsein seines prinzipiellen Auch-anders-sein-Könnens miteinarbeitet, das Endliche so verweisend an das undarstellbare Unendliche.“

Zur Ironie bei Paul de Man - freilich kritisch zu hinterfragen - vgl. etwa zusammenfassend Werner Hamachers Vorwort zur deutschen Erstausgabe der Allegorien des Lesens: „An Texten von Friedrich Schlegel, Hoffmann und Baudelaire kann de Man deutlich machen, daß die ironische Sprache in einer unbegrenzten Sequenz von Momenten ihre Negationen immer aufs Neue wiederholen und so in eine Leere des Bedeutens sich verlaufen muß, der keine Erkenntnis, nicht einmal die negative der Erkenntnisunfähigkeit, entsprechen kann. [...] Was sich in der Ironie vollzieht, ist, trockener formuliert, die Reflexion eines bloß noch sprachlichen Subjekts auf die Sprachlichkeit eines Bewußtseins, das seiner empirischen Realität niemals gewiß sein kann und seine sprachliche Idealität in eben dieser Reflexion verlorengeben muß. Ironie ist als diejenige 
Operationen zur Ewigkeitsattribuierung von Schriftzeichen anschließen; um den Rahmen dieser Arbeit nicht zu sprengen, bleibt es aber bei einer Konzentration auf die allgemeinere philosophische (Auto-)Reflexion, d. h. bei einer Fokussierung auf die Frage, ob und inwiefern sich mit der hier gewählten Perspektive für die frühromantische Verschränkung von Philosophie und Literatur neue Erkenntnisse gewinnen lassen. Hinsichtlich des Kapitels zu Novalis' Höhlenszene sei deshalb noch einmal Manfred Frank zitiert, und zwar mit seiner Lesart Friedrich Schlegels:

\begin{abstract}
Das An-sich-Sein, welches anzuschauen dem reflexiven Ich versagt ist, äußert sich [gemäß Schlegels Denken, MG] ex negativo als „Freiheit“; darin, daß es sich in seiner Endlichkeit nicht etablieren kann, sondern, ständig über seine Grenzen hinausgetrieben [Hervorhebung durch MG], nie in der Identität mit seinem jeweiligen Zustand aufgehen kann. [...] „Die Zeit“, sagt Schlegel, ist die „,in Unordnung gerathene (aus den Fugen gebrachte) Ewigkeit“ (KA X, 550). Als Zeit also offenbart sich der Verlust des Seins (des Ewigen) im endlichen Ich und perpetuiert sich im reflexiven Zugriff [Hervorhebung durch MG]. So begegnet Schlegel tatsächlich Schellings Diagnose über Fichtes Philosophie. Sie hatte besagt, wer das Absolute nicht im Nu und vollständig ergreife, sehe sich auf einen „unendlichen Progressus" verwiesen (SW I/4, 358), der in der Zeit vergeblich, nämlich unendlich, die Ewigkeit antizipiert [Hervorhebung durch MG]. Da er das Absolute für unerkennbar erklärt, muß er die von Schelling spöttisch skizzierte Konsequenz zunächst bejahen. Sie wird ihm aber Ausgangspunkt seiner Theorie des Fragmentes. ${ }^{207}$
\end{abstract}

Ähnlich wie Friedrich Schlegel bejaht auch der Verfasser im Anschluss an die im Kapitel zur Höhlenszene im Heinrich von Ofterdingen beobachtete potenzierte Autoreflexivität jene „von Schelling spöttisch skizzierte Konsequenz“ - und zwar mit folgender These:

Die Endlichkeit des reflexiven Ich bedingt, dass in dem nur potenziell unendlichen - da an das Ich gebundenen - Prozess der Reflexion, der der Reflexionsphilosophie durch deren Denkfigur des sich selbst spiegelnden Spiegels inhärent ist, lediglich eine Unendlichkeit resp. Ewigkeit, zweiter Ordnung'möglich

rhetorische Figur, die alle rhetorischen Figuren auflöst, die radikalste Sprachform der Endlichkeit und Unversicherbarkeit des Subjekts" (Hamacher 1988, S. 12). Wobei die vorliegende Arbeit aufzeigt, dass gerade jene „unbegrenzte Sequenz von Momenten“, dass gerade jene „radikalste Sprachform der Endlichkeit“ in ihrem potenziell endlosen Prozess der Reflexion die Unendlichkeit, zu deren Verlust ebendieser Prozess beigetragen hat, wieder einzuholen sucht (siehe dazu u. a. die folgenden Abschnitte; und die Kapitel 1.1 und 2.1 des Schlussteils).

207 Frank 199o, S. 503. Zum Fragment vgl. insbesondere Kapitel II.3, dessen Ergebnisse von dieser Beobachtung Franks weiter gestützt werden. 
ist. Diese ist der potenziell ewig sich weiter potenzierende, potenziell unendliche Prozess der (Auto-)Reflexion selbst.

Dieser potenziell unendlich sich weiter potenzierende Prozess der Reflexion ist jedoch nicht die Ewigkeit des von den Frühromantikern nach Frank alle Reflexion begründenden ,Seyns' und wird hier deshalb ,Ewigkeit zweiter Ordnung $^{\prime}$ genannt. ${ }^{208}$ Mit Ewigkeit zweiter Ordnung ist aber auch nicht Winfried Menninghaus' Interpretation gemeint, die besagt, dass das Absolute durch den ordo inversus erst konstituiert werde. Dies wäre nämlich nur dann der Fall, wenn die sprachlich-reflexive Konstitution der Ewigkeit erster Ordnung möglich wäre. ${ }^{209} \mathrm{Am}$ genausten trifft das hier Gemeinte hingegen die Formulierung Dirk Göttsches:

Im Begriff der Zeit (als dem Mangel absoluter Einheit) denkt die Romantik den geschichtlichen Zusammenhang der Welt transzendental als Synthesis von Subjekt und Objekt, Ich und Welt in einem unendlichen Prozess, in dem zugleich die christlich-neuplatonische Antithetik von Zeitlichkeit und Ewigkeit zu einer dialektischen Bewegung zwischen Endlichem und Unendlichem temporalisiert ist. Diese dialektische Einheit der Zeit wird als die zeitliche Repräsentation und geschichtliche Entfaltung des transzendenten Anderen der Zeit (der Ewigkeit als Metapher absoluter Einheit der Zeit) begriffen und in diesem Sinne als „Einheit von Einheit und Differenz" gestaltet. ${ }^{210}$

Ob nun jene Ewigkeit zweiter Ordnung, wie von Novalis und Friedrich Schlegel erhofft, analogisch resp. als transzendenter Index auf jenes von ihnen

208 Bereits Michael Theunissen hat etwas plakativ formuliert: „Wohl verweisen uns die Idealisten auf Reflexion. Aber wenn Reflexion auch Freiheit gewährt - Freiheit von der Zeit gewährt sie sicherlich nicht. Vom Raum, als Form äußerer Anschauung, wird das sich auf sich zurückwendende Subjekt sich abwenden können. Die Zeit hingegen nimmt es auf seinem Weg nach innen, als Form seiner inneren Anschauung, notwendig mit“ (Theunissen 1991, S. 285).

209 Vgl. Uerlings 1991, S. 617; resp. Menninghaus 1987, S. 46-48. Herbert Uerlings hat die Positionen Franks und Menninghaus' zusammenfassend dargestellt und verglichen, mit folgendem Schluss: „Man kann durchaus die Kritik des Ursprungsdenkens in den Mittelpunkt von Hardenbergs Philosophieren stellen und den von Derrida betonten Doppelsinn von ,différance (Aufschiebung, Verzeitlichung und Nicht-Identität, Anderssein) hier vorgedacht finden. Ob man [wie es Menninghaus tut, MG] aber deshalb schon behaupten kann (und muß), Hardenberg habe auch den Gedanken dekonstruiert, daß diese Dualität in einer ihr zugrunde- und voraufliegenden und der philosophischen Reflexion nicht weiter zugänglichen Einheit begründet sei - das bliebe als einzige Differenz zwischen Menninghaus und Frank -, ist sehr fraglich“ (Uerlings 1991, S. 619). Vgl. zu dieser Diskussion auch den Beitrag neueren Datums von Wirth 2008, S. 292 f.

210 Göttsche 2001, S. $141 \mathrm{f}$. 
vorausgesetzte ,Seyn' verweisen kann?211 Der Verfasser bezweifelt es; fragt sich jedoch auch, ob dieser Anspruch andererseits überhaupt beweis- oder widerlegbar ist. Eines steht jedoch fest, nämlich, dass sich in dieser Ewigkeit zweiter Ordnung die enge Verschränkung von frühromantischer Philosophie und Kunst beobachten lässt, nämlich anhand der Verschränkung der philosophischen (Auto-)Reflexion mit der Grundoperation der Reflexivität.

Oder - in Anlehnung an Herbert Uerlings' These der, narrativen Konstruktion immanenter Transzendenz ${ }^{212}$ - anders formuliert:

Die mittels potenziell unendlicher Reflexion konstituierte Ewigkeit zweiter Ordnung sucht in einem Text - wie z. B. dem Heinrich von Ofterdingen ${ }^{213}$ immanent nicht nur indexikalisch auf Transzendenz zu verweisen, sondern vielmehr sie zugleich auch einzuholen resp. zu erschaffen.

Letzteres ist freilich nur (und das wäre wohl allenfalls auch gegenüber Uerlings zu betonen) im Modus einer zweiten Ordnung möglich. ${ }^{214}$

Philosophische (Auto-)Reflexion und deren Wechselwirkung mit den Operationen Autoreflexivität und Poetologie

Die beiden oben skizzierten Umgangsformen mit der Eigendynamik der philosophischen (Auto-)Reflexion - sei es durch deren vermeintliche Stabilisation (Schelling und Hegel) oder durch deren radikale Bejahung in der Hoffnung, sie dadurch als transzendenten Index für das aller (Auto-)Reflexion zugrunde gelegte ,Seyn' zu machen (vor allem bei Novalis) - stehen also in einem Ähnlichkeitsverhältnis zur Funktionsweise der Unteroperationen zur

211 Vgl. dazu auch Pott [inzwischen Richter] 2004; und oben stehende Fußnote vor dem Zitat Göttsches.

212 Vgl. Uerlings 1991, insbesondere S. 229-232 und 624 f. Sein Begriff ist letztlich ein anderer Name für die grundlegende Denkfigur bei Novalis, die Manfred Frank und Gerhard Kurz in Hardenbergs eigener Terminologie ordo inversus nennen (vgl. Uerlings 1991, S. 229 f.).

213 An dieser Stelle muss für einmal Manfred Frank widersprochen werden, der findet, Tieck „tut im Bereich des Symbolischen, wovon seine mehr spekulativ aufgelegten Freunde [Novalis und Fr. Schlegel, MG] nur reden“ (Frank 199o, S. 506) - auch ,Tiecks Freunde‘ waren ganz schön tatkräftig.

214 Vgl. dazu auch Uerlings 2004, S. 25 f.; und das Kapitel IV.3.3 zur Genieästhetik. Auch wäre es äußerst spannend, diese Ewigkeit zweiter Ordnung mit Hegels Unterscheidung zwischen ,relativer' und ,absoluter oder unendlicher Reflexion' in Verbindung zu bringen, denn, so zusammenfassend das Historische Wörterbuch der Philosophie: „Bei der ersteren kommt man von einem Endlichen immer wieder zu einem weiteren Endlichen, sei dies nun ein Gegenstand oder ein Trieb, bei der zweiten dagegen richtet sich das Ich nur auf sich als denkendes und handelndes und ist als dieses reine Beziehung, die allerdings unbestimmt bleibt und sich durch die relative R.[eflexion] fortlaufend zu bestimmen sucht [...]“ (Historisches Wörterbuch der Philosophie 1992, Bd. 8, Sp. 401). Zu Hegel und der ,schlechten Unendlichkeit' vgl. auch das Kapitel 2.2 des Schlussteils. 
Ewigkeitsattribuierung von Schriftzeichen Autoreflexivität und Poetologie. Beiden Operationen sind dieselben zwei auf Autonomie und Unendlichkeit abzielenden Aspekte inhärent: zum einen der potenziell den außersprachlichen, zeitlichen Veränderungen enthobene Verweis von Textstellen auf sich selbst, was in die Richtung einer gewissen Stabilisation des Verweisprozesses geht, der zumindest auf den jeweiligen Text und/oder dessen Medialität eingeschränkt wird; zum anderen die radikale Bejahung der diesem Selbstverweis inhärenten, potenziell unendlichen Spiegelung. Bei der Operation Poetologie, so könnte man vielleicht sagen, steht eher Ersteres im Vordergrund; im Falle der Operation Autoreflexivität eher Letzteres.

Letztlich stehen jene zwei oben skizzierten erkenntnistheoretischen Umgangsformen mit der Eigendynamik der philosophischen (Auto-)Reflexion auch in einem Ähnlichkeitsverhältnis zu der von Derrida postulierten, potenziell endlosen Verweisstruktur von zeichenhafter Kommunikation. Um überhaupt mittels Zeichen kommunizieren zu können, muss im Zuge ihrer Verwendung so getan werden, als ließe sich jene Verweisbewegung anhalten; oder aber, diese wird radikal ausgestellt, um eben dadurch paradoxal indexikalisch auf sie zu verweisen zu suchen - wobei sich freilich auf sie nur als eine Einheit verweisen ließe, die sie nicht ist. Oder anders formuliert, in Anlehnung an Albrecht Koschorkes bereits auf der These Christian Fürchtegott-Gellerts beruhenden ${ }^{215}$ Gedankengang, dass der Schrift- resp. Zeichenverkehr im 18. Jahrhundert die Veränderung im Umgang mit der Körperlichkeit zugleich vorantreibt und zu kompensieren versucht, ohne den ersehnten ursprünglichen Zustand wiederherstellen zu können:

Jene ewige Einheit, die das moderne Denken zerstört haben soll, suchen die philosophischen Entwürfe des langen 18. Jahrhunderts wieder zurückzugewinnen, und zwar mittels sprachlichen, zeichenhaften Denkens des Ich über sich selbst. Doch sie ist nicht mehr einholbar durch diese philosophische (Auto-)Reflexion, die mit einer vergänglichen, prozesshaften Verzeitlichung 216 der einstigen, den Sinn aller Zeichen garantierenden (göttlichen) Einheit einhergeht, aber zugleich das Potenzial birgt, sich als Ewigkeit zweiter Ordnung in einem potenziell autonomen Selbstverweis unendlich weiter zu spiegeln.

Kombiniert man diese Beobachtung nun mit den oben aufgezeigten Parallelen zwischen der philosophischen, im Medium der Sprache angestellten (Auto-)Reflexion und der Reflexivität als Grundoperation zur Ewigkeitsattribuierung von Schriftzeichen, so ergibt sich zusammenfassend die These:

215 Wiethölter 2008, S. 31.

216 Vgl. dazu auch Wirth 2008, S. 292. 
Die abendländische Philosophie jener Zeit sucht, ausgehend von Descartes, insbesondere Ende des 18., Anfang des 19. Jahrhunderts die durch die Reflexionsphilosophie verlorene Ewigkeit des Absoluten wiederzugewinnen und bedient sich damit - da mittels des Mediums Sprache angestrebt - derselben Operationen, wie sie Texten schon lange vor dem 18. Jahrhundert als Operationen zur Ewigkeitsattribuierung von Schriftzeichen inhärent sind.

\subsection{Autonomieästhetik}

Noch einmal sei ein Kapitel mit einem Zitat Albrecht Koschorkes eröffnet; dieser hat nämlich beobachtet, wie "die volle Durchsetzung der Schriftkultur“ im Laufe des 18. Jahrhunderts „mit zwei Tendenzen“ einhergehe:

Die eine [Tendenz] besteht in einer Multiplikation des Imaginären: es hört auf, autoritativ und intentional kontrollierbar zu sein, der Bewußtheit eines souveränen Sprechens zu unterstehen. Die andere, in einer paradoxen Weise damit verschränkt, besteht in der Ausbildung subjektiver Autonomie. Erst wenn Kommunikation einen Grad von Arbitrarität erreicht, der die Indeterminiertheit aller Kommunikationsakte und damit die Nichtübereinstimmung zwischen den Kommunikanten irreversibel macht, der andererseits ihre semantische Außensteuerung minimiert, kann sich die Vorstellung einer voraussetzungslosen freien Selbsttätigkeit bilden. Unter oralen oder rhetorischen Bedingungen ist das nicht möglich, wohl aber unter denen der Schrift. ${ }^{217}$

Jene „Multiplikation“ erfährt nun nach Koschorke insbesondere gegen Ende des 18. und anfangs des 19. Jahrhunderts gewissermaßen eine Gegenbewegung, ${ }^{218}$

217 Koschorke 1999, S. 388.

218 Diese Gegenbewegung ist bis heute nicht zum Stillstand gekommen, betrachtet man etwa den Eskapismusvorwurf, mit dem Fantasy- und Science-Fiction-Literatur noch immer begegnet wird, oder deren noch immer systematischen Ausschluss vom Universitätskanon bei gleichzeitiger Explosion zumal des Fantasygenres außerhalb der Akademia in Literatur, Film, Video- und herkömmlichen Spielen. Und denkt man nur schon etwa an die Werke Tolkiens und Rowlings, so ist im Vergleich mit dem 18. Jahrhundert ebenfalls ein gewisser Alphabetisierungsschub zu beobachten, nämlich die enorme Popularisierung des Bücherlesens, das die betreffenden Werke gerade unter Kindern und jungen Erwachsenen ausgelöst haben. Es tun sich somit Parallelen auf, die andernorts unbedingt weiterverfolgt werden müssten, hier sind bloß einige mögliche Ansätze zu nennen: Ähnlich wie um 1800 erfährt unsere Zeit mit der digitalen Revolution und Vernetzung eine weitere radikale Irritierung bisheriger Zeichensysteme und Kommunikationsformen usw. Bedingen sich die wachsende Beliebtheit gerade des Fantasygenres und die weitere Freiheit der Zeichennutzung und damit der Vorstellungskraft (?) gegenseitig, und stellt Ersteres gegenüber Letzterem paradox-gleichzeitig auch einen Kompensationsmechanismus dar? Gerade die Fantasyliteratur zielt auf das (geniale) Erschaffen autonomer Welten zweiter Ordnung ab und benutzt dabei ebenfalls schon um 1800 akzentuiert auftretende Techniken wie die Herausgeber- und Autorfiktion. 
welche die durch sie entstehende Fülle an zeichenhaft gedachtem und kommuniziertem Imaginärem ${ }^{219}$ und damit an Zeichen im Allgemeinen einzudämmen sucht. Als einen zentralen Teil dieser Gegenbewegung sieht Koschorke die Furcht vor "Lesesucht" und die damit verbundene „Zeichendiät“. Letztere werde um 1800 z. B. im Literaturkanon und in der Form der Gymnasien institutionalisiert ${ }^{220}$ - beide wirksam bis heute. ${ }^{221}$ Als einen anderen wesentlichen Teil sieht er - „sowohl in Erfüllung [...] als auch im Widerspruch“222 ${ }^{\text {zur }}$ Zeichendiät - die Herausbildung der klassischen Autonomieästhetik. Dieser Prozess hat laut Koschorke „mit dem Bemühen, den Überschuss der Phantasie gegenüber der Wirklichkeit abzubauen, zumindest vordergründig nichts mehr zu tun". Und weiter:

Statt dessen [sic] geht es nun darum, diesen Überschuß ästhetisch gleichsam einzufangen und zu verwalten. Im 18. Jahrhundert werden die Bereiche der Sinnlichkeit, der Leidenschaft und der Einbildungskraft in dem Maß rehabilitiert, in dem sie ästhetisch werden. Die Arbeit der Restriktion verwandelt sich in eine Arbeit der Ästhetisierung. 223

Das Resultat dieser „Arbeit der Ästhetisierung“ legt Koschorke wie folgt dar:

Die Einbildungskraft, in deren Reich der Lesende flieht, hat nichts mehr von der mimetischen Defizienz, die ihre älteren Kritiker an ihr erkannten, oder sie hat vielmehr ihren Mangel in ein Vorrecht verwandelt. Ihre Zeichen sind die wirklichere und wahrere Welt geworden. Das Substitut erscheint ,voll', das Substituierte ,leer'. So ist am Ende der Lesesuchtdiätetik, sowohl in Erfüllung ihrer Forderungen als auch im Widerspruch zu ihnen, eine große Operation des Vergessens gelungen, nämlich das Vergessen der Tatsache, daß die Kunst künstlich ist. Auf die Kritik an der Naturvergessenheit der Schrift gibt die etablierte Schriftkunst der Goethezeit eine unerwartete Antwort: Das Medium ist die Natur. ${ }^{224}$

Daraus lässt sich die unten stehenden Ausführungen einleitend die These gewinnen:

219 Vgl. dazu neben Koschorke und Schneider auch Berghahn 2012, S. 14 f.

220 Vgl. Koschorke 1999, S. 419.

221 „Der Ökonomie der Mimesis, die auf den Idealzustand einer Eins-zu-Eins-Beziehung zwischen Zeichen und Bezeichnetem hinstrebt, tritt ein Konzept des freien imaginativen Spiels gegenüber, das die Objektbindung der Zeichen aufhebt und damit genau den Prozess ratifiziert, gegen den nach der Argumentationsweise der Lesesuchttherapeuten die klassische Kanonbildung in Gang gesetzt wurde“ (ebd., S. 423).

222 Ebd., S. 430.

223 Ebd., S. 422.

224 Ebd., S. 430. 
Das Künstliche von Schrift resp. von Zeichen im Allgemeinen und damit gerade auch das Vergängliche resp. gar Tote derselben - Moritz scheint an dieser Vergänglichkeit festzuhalten, vielleicht als Einziger - wird über jene von Koschorke festgestellte chiastische Operation vergessen gemacht, um sie als ewig zu glauben.

Von Koschorke ausgehend und am Schluss des Kapitels einerseits wieder auf ihn zurückverweisend und andererseits die am Ende von IV.3.1 aufgestellte These ergänzend soll nun im Folgenden die Debatte des ausgehenden 18. Jahrhunderts zur Ästhetik des Kunstwerks und zu dessen Autonomie näher betrachtet werden. Neben der Behandlung zweier Textstellen aus Herders Kalligone und Schillers Kallias Briefen dienen dabei als Leitlinie hauptsächlich die Arbeiten Sabine Schneiders.

\subsubsection{Autonomie und Zeitlichkeit}

Sabine Schneiders Forschung, die einer ähnlichen Methodik folgt wie die zur gleichen Zeit entstandene Arbeit Koschorkes, sucht „die Komplexität der Autonomietheorien dadurch zu erhellen, dass sie die Bezüge deutlich macht, welche die scheinbar so weltenthobenen Modelle [der Kunstautonomie, MG] mit den zentralen Fragestellungen der Wirklichkeitskonstitution der Zeit [um 180o, MG] verbinden“.225 Diese „zentralen Fragestellungen“ der Zeit um 180o, die eng mit den Modellen der Autonomieästhetik verknüpft sind, fasst sie in folgenden Punkten zusammen, die grundsätzlich auch die vorliegende Arbeit bereits berührt hat, wenngleich nicht direkt auf jene Ästhetik bezogen:

Die Krise der Zeichensysteme, die zugleich eine der Wahrnehmung ist, der Verlust der metaphysischen Ganzheit, auf welche die mimetische Kunstauffassung sich gestützt hatte, die Dynamisierung des statischen Naturraums durch das Eindringen der Zeit und die Störungen, die sich daraus für das Verhältnis von Natur und Subjekt ergeben $[\ldots] .{ }^{226}$

Die „Dynamisierung des Naturraums“ geschieht insofern, als dass die Präformationstheorie - alle Lebewesen liegen in ihrer heutigen Form bereits seit dem Schöpfungsakt Gottes vor - im 18. Jahrhundert zusehends seitens des evolutionären Modells der Epigenesis unter Druck gerät, in dessen Zug dann im 19. Jahrhundert Darwins Evolutionstheorie ihren Triumph erleben wird. ${ }^{227}$ Schneider zitiert aus der 1772 in deutscher Übersetzung erschienenen $B e$ trachtung über die Natur des zu dieser Zeit bereits unter Rechtfertigungsdruck

225 Schneider 1998, S. 8.

226 Ebd. Vgl. dazu auch den anfangs IV.3.1 zitierten Berghahn 2012, S. 14 f.

227 Vgl. Schneider 1998, S. 244-256. Vgl. ergänzend dazu zum Paradigma der Perfektibilität Hilgers 2002, S. 178-196; und zu Darwin Nate 2018, S. 268 f. 
stehenden Charles Bonnet. Dieser geht noch, gestützt auf das Modell der Präformation, von einem zeitlich geschlossenen Kosmos aus, in dem die „Zeit als produktive Macht und eigenständiger Faktor“228 keine Rolle spielt: „Hieraus entspringt ferner diese unauflösliche Verknüpfung, welche das Vergangene, das Gegenwärtige, das Zukünftige und die Ewigkeit zu einer einzigen Existenz, zu einem unzertrennlichen Ganzen machet. ${ }^{“ 29}$ Gerade die Kunstauffassung, die bis anhin sich auf antike Traditionen und dieselben Grundannahmen wie Bonnet stützend durch das stabile Prinzip der Mimesis geprägt war, wird durch die Verzeitlichung der Natur erschüttert: ${ }^{230}$

Anstelle des von Gott für alle Ewigkeit geschaffenen Formenreservoirs immer gleicher Gestalten, das im Tableau der Naturgeschichte sichtbar geordnet zu überblicken ist, treten Entwicklung und Neubildung einer sich in steter Veränderung befindlichen empfindenden Materie. [...] Dass solche Beunruhigungen auch in der Kunsttheorie ausgetragen werden, zeigen gerade die scheinbaren Digressionen im Diskurs über das Schöne [...]. ${ }^{231}$

Dass sowohl bei Bonnet als auch bei Schneider das Wort ,Ewigkeit' fällt, ist bemerkenswert, tönt es doch - wenn auch nicht explizit - bereits an, was hier im Folgenden gezeigt wird, nämlich, dass die durch die Erschütterungen des 18. Jahrhunderts verlorene Ewigkeit Gottes, die man auch auf seine Zeichen in der Heiligen Schrift oder in der als heiliges Buch gelesenen Natur übertragen hatte, nun im autonomen Kunstwerk angesiedelt werden sollte.

Schneiders Auseinandersetzung mit Karl Philipp Moritz und seiner Sonderstellung innerhalb der Kunstautonomiedebatte zeigt sehr schön die unterschiedlichen Paradigmen innerhalb dieser Debatte und erlaubt es dadurch, hier exemplarisch und gleich in medias res gehend die Skizze zum historischen Zusammenhang von Autonomieästhetik und zu den Operationen zur Ewigkeitsattribuierung von Schriftzeichen zu eröffnen:

Grob gesagt verfolgt die Hauptlinie innerhalb der Kunstautonomiedebatte von Winckelmann über Lessing und Mendelssohn, Sulzer u. a. bis zu Schiller, Goethe und Herder einen Paradigmenwechsel vom Mimesis- zu einem pygmalionistischen Modell, in dem die Einbildungskraft zu einer

\footnotetext{
228 Schneider 1998, S. 253.

229 Bonnet 1772, S. 20.

230 Zur Abkehr vom Mimesisgebot und zu deren Auswirkung auf das 19. und frühe 20. Jahrhundert insbesondere auf das Inszenieren des Schreibens „als unabschließbaren Prozess“ vgl. u. a. Mahler 2011; zur dezidierten frühromantischen Abkehr vom Mimesisgebot vgl. Uerlings 2004, S. 39-56.

231 Schneider 1998, S. 9.
} 
Verlebendigung des Kunstwerkes beiträgt. ${ }^{232}$ Zur Unterstützung der Einbildungskraft empfiehlt etwa Goethe in seiner Schrift Über Laokoon das augenblickhafte Betrachten bei anschließendem Geschlossenhalten der Augen oder die von den Italienreisenden praktizierte gesellschaftliche Kunstbetrachtung bei Fackelschein. ${ }^{233}$ Moritz wiederum sind diese Vitalisierung und die dafür entwickelten Techniken nicht fremd, wobei bereits Schneider festgestellt hat, dass „[d]as Beglückende dieser Erfahrung [...] in der Aufhebung von Zeit“ liegt. Sie zitiert aus Moritzens Reisen eines Deutschen in Italien in den Jahren 1786-88 eine ebensolche Betrachtung marmorner Statuen bei Fackelschein: „der Begriff von Zeit verschwindet, und alles drängt sich in einen Moment zusammen, der immer dauern könnte, wenn wir bloß betrachtende Wesen wären.“234 Im Gegensatz aber zur oben erwähnten Hauptlinie sucht Moritz den Tod, den Lessing schon in seinem Laokoon als Kehrseite der Verlebendigung des Kunstwerkes auf Distanz zu halten suchte ${ }^{235}$ und der die Möglichkeitsbedingung einer jeden Vitalisierung - um mit Blanchot und Derrida zu sprechen, gar einer jeden Aktualisation resp. eines jeden Gebrauchs eines Zeichens ${ }^{236}$ - ist, nicht auszublenden. Denn Moritz versieht

die Lösung eines geglätteten Klassizismus, wonach die Kunst Dauer und Festigkeit gegen die Kontingenz des Lebens setzen könne, mit einem Fragezeichen. Dem Anspruch an die Kunst, daß womöglich in ihr ,dies zerstörende Schaffen, dies schaffende Zerstören' der Natur unterbrochen werden könne und der Künstler ,schafft, daß sein Werk bleibe', der in Herders Kalligone noch einmal einen längst obsoleten normativen Klassizismus begründet, steht in Moritzens Theorie die unabweisbare Macht der Zeitlichkeit entgegen. ${ }^{237}$

Bereits anhand dieses knappen Querschnitts zur Kunstautonomiedebatte wird offensichtlich, wie sehr diese mit dem Paradigma der Zeitlichkeit und der (ewigen) Dauer von Kunst verknüpft ist, das - so ließe sich mit der

232 Vgl. Schneider 1998, S. 19; und dies. 1999, S. 179.

233 Vgl. ebd., S. 176.

234 Moritz, Werke, Bd. 2, S. 753.

235 „Solch imaginativen Freiraum, aus dem das Spiel pygmalionistischer Verlebendigung sich speist, gewährt das Kunstwerk aber nur dann, wenn die letzte Grenze des Todes nicht so bedrängend nah erscheint, dass die Phantasie, über den sinnlichen Eindruck nicht hinaus kann' und Laokoon ,schon tot' sehen muss" (Schneider 1999, S. 175). Die von Schneider angeführten Zitate Lessings stammen aus: Gotthold Ephraim Lessing, Laokoon oder über die Grenzen von Malerei und Poesie, Werke, herausgegeben von Herbert G. Göpfert, Bd. 6, S. $25 \mathrm{f}$. Zu Lessings Gewichtung der Zweiteilung des Todes in der altgriechischen Sprache in kér und thánatos in seiner Schrift Wie die Alten den Tod gebildet vgl. Kapitel II.1.2.

236 Vgl. das betreffende Kapitel zum Forschungsstand in der Einführung.

237 Schneider 1999, S. 183. 
vorliegenden Arbeit behaupten - vielleicht sogar der Kern ist, von dem aus sich die Debatte entfaltet. ${ }^{238}$ Dazu sei hier exemplarisch auf die oben bereits von Schneider angetönte Stelle in Herders Kalligone (180o) eingegangen; sie handelt von der "Naturkunst" im Unterschied zur menschlichen Kunst und sei hier ausführlich zitiert:

Eben nur unsre Eingeschränktheit macht, daß wir menschliche von der Naturkunst unterscheiden: denn wie arm und ohnmächtig sind wir gegen die mächtige Wirkerin, Natur!

Erstens. Zu dem, was die Natur macht, findet sie überall Stoff, Mittel und Wege; sie kann, was sie will und will nur, was sie kann. Wo ihren strebenden Kräften Hinderungen in den Weg treten, wendet sie sich und braucht ihre Kräfte anders. Wir müssen Stoff und Mittel mit Mühe suchen, mit Vorsicht gebrauchen.

Zweitens. Jedes Kunstwerk der Natur hat seinen Zweck in sich, daß es der ihm geschenkten Form, d. i. seiner selbst sich erfreue und in ihr lebe. Unsre Kunstwerke, tot in sich, sind nur für andre zu Zwecken berechnet.

Drittens. Da die Werkstätte der Natur so groß ist, wie das All und ihre Energie wirkt, so lange Moment auf Moment folget, so kann sie nicht anders, als die entgegengesetzten Enden zusammenknüpfen; sie schafft, indem sie zerstört, und zerstört [sic] indem sie schaffet, eine immer emsige Penelope, die ihren Schleier webt und trennt, trennt und webet. Individuen läßt sie sinken und erhält Geschlechter. Gegenteils, da dem Werk des menschlichen Künstlers das Leben gebricht, dadurch es sich selbst fortpflanzen könnte, so hört dies zerstörende Schaffen, dies schaffende Zerstören bei ihm von selbst auf. Er schafft, daß sein Werk bleibe.

Viertens. Im All muß Alles sein, das Schwächste und Stärkste, das Größeste und Kleinste; es ist da. Da dem Menschen ein solcher Umfang, eine solche Dauer nicht gegönnet ist, so muß er sich gegen die Anfälle der zerstörenden Natur, aus deren Schoß er seine Werkzeuge nimmt, aus deren Schoß er selbst entsprang, in deren Schoß er zurückkehret, waffnen; er muß sein Werk schnell, nutzbar, dauerhaft ausführen, so gut er kann, also das Beste, das er vermag, aufs Beste mit Plan und Absicht. So und deshalb setzt er seine Kunst der Natur entgegen. Ein böser Haushalter wäre er, wenn er es der großen Haushälterin nachtun wollte. Unbekümmert spräche sie zum Nachlässig-Stolzen: „ich kenne dich nicht!“ und ließe ihn sinken.

Das Gabenreichste Kunstprodukt der Natur, der Mensch, soll selbst Künstler sein; darauf ist alles bei ihm berechnet. [...] Er lebet nur kurze Zeit, und muß rasch zu Werk gehn, wenn er was Bleibendes ausrichten, und auch für die Nachwelt gelebt haben will. ${ }^{239}$

238 Vgl. die Zusammenfassung am Ende von 3.2.2.

239 Herder, Werke, Bd. 8, S. 76o f. 
Freilich ist diese Textstelle sowohl inhaltlich als auch formal so dicht, dass sie selbst zum Ausgang einer eigenen Arbeit werden könnte; ${ }^{240}$ hier sind deshalb bloß zwei Punkte - und unter 3.2.2 nochmals zwei weitere - hervorzuheben:

1. Herders dritter Punkt liest sich wie die in der Einführung zitierten Worte Diotimas in Platons Symposion, wo sie die zwei Möglichkeiten, mit denen der Mensch seinen Tod überdauern könne, nennt: durch die Zeugung von Kindern, was nach Herder dem metonymisch-chiastischen, natürlichen Prozess von Werden und Vergehen resp. der „Kunst“ der Natur entspricht und ebenfalls in der Formulierung „Individuen läßt sie sinken und erhält Geschlechter" sichtbar wird; oder aber durch das Erschaffen von (schriftlichen) Kunst-Kindern, das bei Herder mit dem auf Dauer ausgerichteten „Werk" korrespondiert. Und wie bei Diotima, wenngleich weniger explizit, herrscht ein Grundton, der das Überdauern des Individuums in seinem Kunstwerk dem biologischen Erhalt der "Geschlechter" vorzieht. Dem gesamten oben zitierten, für Herders Kapitel zu Natur und Kunst in der Kalligone zentralen Passus liegt also der Subtext einer Ewigkeitsbehauptung gegenüber dem menschlichen Kunstwerk zugrunde.

Dass die menschlichen Kunstwerke „tot in sich sind“, ${ }^{241}$ ist die eigentliche „Eingeschränktheit" des Menschen und seiner Kunst, ${ }^{242}$ gegen die Herder und mit ihm - so die hier vertretene These - der gesamte Diskurs einer autonomen, einer eben gerade auch als von der menschlichen Vergänglichkeit autonom erträumten Kunst anschreibt. ${ }^{243}$

Kein Zufall also, dass Herder den Passus mit der Feststellung jener „Eingeschränktheit" eröffnet, nur um sie im Zuge desselben hin zum Nachleben des Künstlers in und durch dessen dauerndes, den Künstler verewigendes Werk zu wenden. ${ }^{244}$

240 Zur Nähe dieser Textstelle zum Renaissance-Humanismus vgl. etwa den Beginn des letzten zitierten Abschnittes mit Picos della Mirandola Über die Würde des Menschen (1486/87), wo Gott zu Adam spricht: „[...] Weder als einen Himmlischen noch als einen Irdischen habe ich dich geschaffen und weder sterblich noch unsterblich dich gemacht, damit du wie ein Former und Bildner deiner selbst nach eigenem Belieben und aus eigener Macht zu der Gestalt dich ausbilden kannst, die du bevorzugst. Du kannst nach unten hin ins Tierische entarten, du kannst aus eigenem Willen wiedergeboren werden nach oben in das Göttliche“ (Pico della Mirandola, S. 9).

241 Vgl. Herders zweiten Punkt.

242 Vgl. den ersten Satz der oben zitierten Stelle Herders.

243 Freilich nicht nur ,anschreibt', sondern auch ,anmalt' etc. - und doch ist, wohl nicht zufällig, gerade die Schrift das zentrale Medium dieses Diskurses (in ihr wird er hauptsächlich ausgetragen), denn es ist das Medium, das seit seinem Aufkommen im abendländischen Kulturraum die stärkste Ewigkeitsbehauptung erfahren hat und noch immer erfährt.

244 Daran ändert auch nichts die Verwendung des als Futur zwei gebrauchten Perfekts in „für die Nachwelt gelebt haben will“, mit dem der Passus schließt. Ob diese Formulierung 
2. Nun fällt aber auf, dass Herder für die nähere Beschreibung der Schöpfungs- und Vernichtungskraft der "Naturkunst“ ausgerechnet den Text des bereits mehr als zwei Jahrtausende überdauernden menschlichen Kunstwerks der Odyssee als Metapher verwendet - und mit dem Weben und Trennen der Penelope gar noch eine Stelle, die in der Ähnlichkeit des Webens des Textums mit dem Verfassen und Lesen eines Textes autoreflexives und poetologisches Potenzial birgt. ${ }^{245}$ Und tatsächlich vollzieht Herders Argumentation beim Weben ihres „Stoff[es]“ (poetisch-)performativ ${ }^{246}$ genau diese chiastische Verschränkung von „Naturkunst“ und menschlicher (Text-)Kunst: die „Naturkunst" wird, mittels (meta-)textueller Metaphorik beschrieben, zum menschlichen Textkunstwerk; während das menschliche Kunstwerk in seiner Zeichenhaftigkeit (ob nun etwa als Bild oder Text) plötzlich die zentralen Eigenschaften der „Naturkunst“ zugeschrieben bekommt. In diesem Sinne ist es gerade auch die menschliche Kunst, die, „solange Moment auf Moment folget“, nicht anders kann, „als die entgegengesetzten Enden zusammen [zu]knüpfen“; im Zuge ihrer Rezeption durchläuft sie nämlich ebenso ein potenziell endloses Werden (in der Aktualisation der icons, symbols etc.) und Vergehen (kaum aktualisiert ist es bereits wieder nur "todt[er]“ Marmor, ,leblose Tinte etc.). ${ }^{247}$ Herders Passus figuriert dieses Zusammenknüpfen der Enden durch eine gehäufte Verwendung von Anfang und Ende austauschenden Chiasmen. Der Passus ist also doppelt (poetisch-)performativ zum einen am durch die Textmetapher betriebenen chiastischen Austausch der Eigenschaften von Natur- und menschlicher Kunst beteiligt und gibt sich zum anderen damit gleichzeitig selbst als Kunstwerk zu lesen. Aus diesen Beobachtungen folgt wiederum:

den dem gesamten Passus zugrunde liegenden Verewigungstopos abschwächen oder gar verschleiern sollte? Herder lässt sich dazu nicht mehr befragen. Doch sie könnte auch der Präzisierung dienen, resp. sie unterläuft die erstrebte Dauerhaftigkeit eines Werkes, denn in dieser Formulierung scheint die paradoxale Struktur eines jeden Zeichens auf, dessen Aktualisation nie „in sich“ dauerhaft präsent sein kann (siehe dazu unten das Zitat von Moritz), sondern - „nur für andre zu Zwecken berechnet“ - immer nur von außen, von Rezipienten aktualisiert worden sein wird.

245 Faszinierenderweise hatte auch Moritz in seiner Schrift In wie fern Kunstwerke beschrieben werden können (1788, also vor Herder) bereits auf eine Webszene aus der griechischen Mythologie zurückgegriffen, nämlich auf die Geschichte Philomenes. Und wie später bei Herder entfaltete diese Gewebemetapher bereits bei Moritz eine Eigendynamik. Vgl. ausführlich dazu Schneider 1999, deren Aufsatz von ebendieser Metaphorik ausgeht, insbesondere S. 167 f. Ein hinsichtlich der Metaphorik der beiden Texte von Moritz und Herder angestellter Vergleich wäre also einen eigenen Aufsatz wert.

246 Vgl. Kapitel III.

247 Womit mit „zusammenknüpfen“ wiederum eine Gewebe-, eine Text(um)metapher vorliegt. 
2.a) Die von Herder - und zwar entgegen der eigenen Formulierung "tot in sich" - beschworene Dauer des menschlichen Kunstwerks wird dadurch unterlaufen, dass es wie die "Naturkunst" das „zerstörende Schaffen“, das „schaffende Zerstören“ bereits in sich trägt und insofern nur "dauerhaft" ist, solange „andre“ es rezipieren. Dem „Werk des menschlichen Künstlers“, dem wie er selbst schreibt - „das Leben gebricht, dadurch es sich selbst fortpflanzen könnte“, muss vom Rezipienten Leben geliehen werden. ${ }^{248}$ Diese notwendige Vitalisierung von außerhalb seiner selbst mag das menschliche Kunstwerk tatsächlich vom „Kunstwerk der Natur ${ }^{\text {249 }}{ }^{2}$ unterscheiden. Doch ist dieser Unterschied, dass es „nur für andre zu Zwecken berechnet“ ist, paradoxalererweise ausgerechnet die Möglichkeitsbedingung dafür, nicht nur in ein Ähnlichkeitsverhältnis zum „Kunstwerk der Natur“, das „seinen Zweck in sich“ hat, zu treten, sondern diesen Selbstzweck als den Kern einer neuen Ästhetik für sich zu beanspruchen. Und von diesem paradoxalen, über die Vitalisierung hergestellten Ähnlichkeitsverhältnis her, so scheint es, sucht man in der Autonomieästhetik die „Dauer“ der Werke der Natur auf die Werke der Menschen zu übertragen.

2.b) Auf das Paradoxale, das der Autonomieästhetik innewohnt, hat Schneider bereitshingewiesen (wenngleich aus anderer Richtung kommend, da nicht auf die „Dauer“ der menschlichen und natürlichen Werke fokussierend):

Es ist die paradoxe Grundstruktur der Autonomieästhetik, daß gerade die aus allen Referenzen abgeschnittene Kunst die von der Künstlichkeit der Moderne zerstörte Totalität [nun zu ergänzen mit: Totalität auch und gerade in zeitlicher Hinsicht, MG] der Natur „durch eine höhere Kunst wieder herzustellen“250 hat. Das Genie hat in diesem komplizierten Konstrukt, das an die Stelle des Mimesisgebots getreten ist, eine Schlüsselrolle inne. ${ }^{251}$

Und Koschorke (die Stelle wurde bereits unter 3.2 zitiert), ebenfalls aus anderer Richtung kommend, schreibt zusammenfassend als Antwort auf die von ihm selbst gestellte Frage, wie eine Ästhetik, die auf gesteigerter Kontingenz und Komplexität beruhe, sich den Bonus der Vereinfachung, der Rückkehr zum Natürlichen zueignen könne: „Auf die Kritik an der Naturvergessenheit der Schrift gibt die etablierte Schriftkunst der Goethezeit eine unerwartete Antwort: Das Medium ist die Natur. ${ }^{252}$ Oder - es sei an die

\footnotetext{
248 Zur Vitalisierung des Kunstwerks siehe weiter oben das vorliegende Unterkapitel.

249 Wobei, kritisch bemerkt, der Begriff „Kunstwerk der Natur“ selbst wiederum ein Kunstwerk des Menschen ist.

250 Zitat Schillers aus Ueber die ästhetische Erziehung des Menschen, Nationalausgabe, Bd. 20, S. 328 .

251 Schneider 1998, S. 14; zum Genie vgl. Kapitel IV.3.3.

$25^{2}$ Vgl. Koschorke 1999, S. 424.
} 
Kapitel 3.2 vorangestellte These erinnert - hinsichtlich der Zeitlichkeit von Schrift und Kunst anders formuliert: Das Vergängliche der Schrift (von Statuen, Bildern etc., von Kunst, von Zeichen im Allgemeinen) wird - genau wie es Herder im Zuge seiner Argumentation zu tun scheint - vergessen, um sie (die Schrift, die Kunst etc.) als ewig zu glauben.

Betrachtet man nun zum Schluss dieses Unterkapitels die Hauptlinie der Kunstautonomiedebatte, zu der auch Herder zählt und die (u. a.) auf eine Vitalisierung des Kunstwerks im Zuge von dessen Rezeption abzielt, sowie die davon abweichende Position Moritzens als Varianten der Auseinandersetzung mit der Zeitlichkeit von Kunstwerken resp. von Zeichen im Allgemeinen, so fällt im Vergleich mit den in dieser Arbeit behandelten Operationen zur Ewigkeitsattribuierung von Schriftzeichen in frappierender Weise folgende Analogie auf: Die für jene Hauptlinie zentrale Vitalisierung des Kunstwerks folgt einem ähnlichen Verfahren wie die Unteroperation Unendliche Lektüre, während Moritzens Variante, die das Aufscheinen, das (sinnlich) Präsentische von Zeichen - jedoch bei gleichzeitiger Betonung des Flüchtigen -, verfolgt, analog zur Unteroperation Unendliches Verstummen verfährt.

Dass die dauernde Vitalisierung des Kunstwerks, um die es bei der zitierten Textstelle Herders letztlich geht, freilich an eine ewige Rezeption desselben gebunden wäre, war - neben dem Kapitel zur Grundoperation Unendliche Aktualisation - bemerkenswerterweise auch in Schillers Gedicht über das Schöne, Nänie, zu beobachten, und zwar an der antithetischen Gegenüberstellung von vergänglich-menschlicher und ewig-göttlicher Performativität. Auch Moritz hat diese Gebundenheit an eine ewige Rezeption bereits kritisch festgestellt, wenn er zur oben zitierten Betrachtung von Marmorstatuen im Fackelschein schreibt: „der Begriff von Zeit verschwindet, und alles drängt sich in einen Moment zusammen, der immer dauern könnte, wenn wir bloß betrachtende Wesen wären [Hervorhebungen, MG]."253 Schneider kommentiert diese Stelle - gerade auch mit Blick auf die Grundoperation Reflexivität - treffend:

Die Zeitentrücktheit der Betrachtung und das Glück imaginativer Spiegelungen ist eben dem geglückten Moment ästhetischer Kontemplation aufgespart, aber sie vermag nicht auszublenden oder gar aufzuheben, was unser zeitliches Dasein als ein ,von dieser armen zerstörbaren Maschine‘ abhängiges Wesen ausmacht. $^{254}$

253 Moritz, Werke, Bd. 2, S. 753 .

254 Schneider 1999, S. 176. 


\subsubsection{Reflexivität und Autonomieästhetik - mit einem Fabel-Exkurs}

Der soeben zitierte Kommentar Sabine Schneiders mag hier stellvertretend darauf hinweisen, dass sowohl Moritzens Position als auch die jener Hauptlinie innerhalb der Kunstautonomiedebatte nicht nur gewisse Analogien zur Grundoperation Unendliche Aktualisation aufweisen, sondern mindestens ebenso zur unter 3.1 beschriebenen Metapher der Selbstspiegelung und damit ebenfalls zur Grundoperation Reflexivität. Dem soll nun kurz und exemplarisch anhand von Stellen bei Herder, Schiller und mit einem Verweis auf Moritz nachgegangen werden:

Gen Ende des oben angeführten Zitats aus der Kalligone schreibt Herder: „Das Gabenreichste Kunstprodukt der Natur, der Mensch, soll selbst Künstler sein; darauf ist alles bei ihm berechnet." ${ }^{255}$ Und eine Seite weiter:

Wenn in jedem Element alle Fühlbarkeiten desselben zusammen kamen, um Geschöpfe dieses Elements mit allen Kräften seines Gebrauchs und Genusses zu bilden, müßte nicht auch der Vernunftgeist der Schöpfung sich ein Organ bereiten, worin $E r$ wirke?

Er tats: und machte seinem eigensten Geschöpf, das alles durch sich selbst werden sollte, den Weg zu seiner Bildung - leicht oder schwer? ${ }^{256}$

Geht man vom vermeintlich autonomen menschlichen Kunstwerk aus an die Argumentation Herders heran, so lässt sich beobachten, dass in ihr eine dreifache Operation der Selbstspiegelung impliziert ist, die jeweils die Autonomie des sich selbst Spiegelnden garantieren soll: 1.) Das autonome Kunstwerk, das Zeichen, das sich selber zeigen soll, tut dies im selben Modus und in Analogie zu: 2.) dem Menschen, der selbst als das autonome „Kunstprodukt der Natur" angenommen wird und aus seiner autonomen Selbstreflexion heraus fähig sein soll, jene Kunstwerke zu schaffen, die ihm darin gleichkommen und dabei gleichzeitig seine eigene Spiegelung spiegeln. All dem, so lässt sich unschwer erkennen, liegt 3.) die absolute Autonomie und Schöpfungsmacht des ewigen, da auch Zeit-autonomen Gottes zugrunde. Die Stelle zeigt damit beispielhaft, wie sich (Zeit-)Autonomie (und Schöpfungsmacht) im Zuge der voranschreitenden Säkularisierung der Gesellschaft und Zeichen ${ }^{257}$ im 18. Jahrhundert von Gott aufs schöpferische Individuum (vgl. Kapitel IV.3.3) übertragen; und von dort aus, gerade weil das Leben des menschlichen

255 Herder, Werke, Bd. 8, S. 761; vgl. auch den weiter oben schon zu dieser Stelle zitierten Pico della Mirandola, insbesondere S. 9 .

256 Herder, Werke, Bd. 8, S. 762.

257 Vgl. u. a. Schneider 1998, S. 21. 
Individuums nicht von Dauer ist, in einer weiteren metonymischen Bewegung auf die Schöpfungen resp. Kunstwerke ebendieses (genialen) Individuums.

Dabei wird heute, rund zwei Jahrhunderte später, noch immer dem Verlebendigungsparadigma des Pygmalion-Mythos folgend und ganz nach der unter 3.1 besprochenen, potenziell endlosen Eigendynamik der Spiegelmetapher bereits ernsthaft über 4.) superintelligente, in Analogie zum Menschen autonom schöpferische, künstliche Intelligenz nachgedacht. Dass es eben nicht so wäre, dass „dem Werk des menschlichen Künstlers“ - und letztlich dem Künstler selbst - „das Leben gebricht“, ${ }^{258}$ ist die Sehnsucht hinter der Vorstellung eines autonomen Kunstwerks oder Zeichens. Eine Sehnsucht, die wohl generell in Zeiten besonders stark wird, in denen der Glaube an das Überdauern des eigenen Lebens in der Ewigkeit (eines) Gottes oder generell an einen ewigen Zustand nach dem Tode zutiefst erschüttert ist. 259

Auch in Schillers Kallias-Briefen (1793) zeigt sich, wie das autonome und ästhetisch schöne Kunstwerk sowohl auf einer Operation der Spiegelung beruht $^{260}$ als auch in Analogie zum autonomen Individuum gedacht wird. Die Verortung des Schönen in der praktischen - und nicht in der von Begriffen abhängigen, theoretischen - Vernunft soll dabei die Autonomie des Schönen garantieren. ${ }^{261}$ Dies alles ließe sich breit ausführen; der Herausforderung der Beschränkung soll jedoch dahingehend begegnet werden, als dass hier auf die in Schillers Kallias-Brief vom 18. Februar 1793 als Exempel auftretende "Geschichte" fokussiert wird. Schiller geht dabei vom Problem der vermeintlich paradoxalen Struktur der Verortung des Schönen als etwas als sinnlich Erscheinendes in der praktischen Vernunft aus:

Denn eben darum, weil Vernunft und Sinnlichkeit einen verschiedenen Willen haben, so wird der Wille der Sinnlichkeit gebrochen, wenn die Vernunft den ihrigen durchsetzt. Nun ist unglücklicher weise [sic] der Wille der Sinnlichkeit gerade derjenige, der in die Sinne fällt; gerade also wenn die Vernunft ihre Avtonomie [sic] ausübt (die nie in der Erscheinung vorkommen kann) so wird unser Auge durch eine Heteronomie in der Erscheinung beleidigt. Indessen wird der Begriff der Schönheit doch auch in uneigentlichem Sinn auf das moralische angewendet, und diese Anwendung ist nichts weniger als leer.

\footnotetext{
258 Herder, Werke, Bd. 8, S. 761.

259 Vgl. dazu auch J. Assmann 1991, S. 73 f.

26o Schon im ersten Brief an Körner: „Ich bin wenigstens überzeugt, dass die Schönheit nur die Form einer Form ist" (Schiller, Nationalausgabe, Bd. 26, S. 176).

261 „Die Form der praktischen Vernunft annehmen oder nachahmen heißt also bloß: nicht von außen, sondern durch sich selbst bestimmt sein, autonomisch bestimmt sein oder so erscheinen“ (ebd., S. 398).
} 
Obgleich Schoenheit nur an der Erscheinung haftet, so ist m oralische Schönheit doch ein Begriff, dem etwas in der Erfahrung correspondirt. Ich kann Dir keinen beßern empirischen Beweis für die Wahrheit meiner Schönheitstheorie aufstellen, als wenn ich Dir zeige, daß selbst der uneigentliche Gebrauch dieses Worts nur in solchen Fällen statt findet, wo sich Freiheit in der Erscheinung zeigt. Ich will deswegen, meinem ersten Plane zuwider, in den empirischen Theil meiner Theorie vorausspringen und Dir zur Erhohlung eine Geschichte erzählen.

Ein Mensch ist unter Räuber gefallen, die ihn nackend ausgezogen, und bey einer strengen Kälte auf die Straße geworfen haben. $[. . .]^{262}$

Die „Geschichte“, die Schiller nun erzählt, ist nichts anderes als eine Fabel, in der der Überfallene nacheinander fünf Begegnungen mit unterschiedlichen Personen erfährt. Schiller fasst diese Fabel im darauffolgenden Schreiben an Körner einen Tag später zusammen, indem er den Brief wie folgt beginnt:

Ich kann noch einige Zeilen zu dem gestrigen Brief beilegen, und will Dir die Fabula docet der erzählten Geschichte nicht länger schuldig bleiben.

Die Schönheit der fünften Handlung muß in demjenigen Zuge liegen, den sie mit keiner der vorhergehenden gemein hat.

Nun haben. 1) Alle 5 helfen wollen. 2) Die meisten haben ein zweckmäßiges Mittel dazu erwählt. 3) Mehrere wollten es sich etwas kosten laßen. 4) Einige haben eine große Selbstüberwindung dabey bewiesen. 5) Einer darunter hat aus dem reinsten moralischen Antrieb gehandelt. Aber nur der Fünfte hat unaufgefordert und ohne mit sich zu Rath zu gehen geholfen, obgleich es auf seine Kosten gieng. Nur der Fünfte hat sich selbst dabey vergeßen, und „seine Pflicht mit einer Leichtigkeit erfüllt, als wenn bloß der Instinkt aus ihm gehandelt hätte“ - Also wäre eine moralische Handlung alsdann erst eine schöne Handlung, wenn sie aussieht wie eine, sich von selbst ergebende, Wirkung der Natur. Mit einem Worte: eine freie Handlung ist eine schöne Handlung wenn die Avtonomie des Gemüths und Avtonomie in der Erscheinung coincidiren. [...]

Offenbar hat die Gewalt, welche die practische Vernunft bei moralischen Willensbestimmungen gegen unsre Triebe ausübt, etwas beleidigendes, etwas peinliches in der Erscheinung. [...] Daher kann eine moralische Handlung niemals schön seyn, wenn wir der Operation zusehen, wodurch sie der Sinnlichkeit abgeängstigt wird. Unsre sinnliche Natur muß also im moralischen frey erscheinen, obgleich sie es nicht wirklich ist $[\ldots] .{ }^{263}$

Nun kommentiert Schiller seine Fabel jedoch in dem Brief vom 19. Februar, also in dem Brief nach demjenigen, in dem die Fabel steht. Denn der Brief vom Tag davor endet bemerkenswerterweise mit ebendieser Fabel ${ }^{264}$ und dem Satz: „Herzliche Grüße von uns allen. Besinne Dich unterdeßen warum die

262 Schiller, Nationalausgabe, Bd. 26, S. 195.

263 Ebd., S. 198.

264 „[...] Steige auf meinen Rücken, so will ich mich frisch aufmachen und dich hinbringen. Aber was wird aus deinem Bündel werden, das du hier auf freier Landstraße zurücklassen 
Handlung des Lastträgers schön ist. Dein S.“265 Die „Geschichte“, in der der fünfte auf den Überfallenen treffende Passant so handelt, dass innerhalb der Fabel „sich Freiheit in der Erscheinung zeigt", endet nämlich ohne das erst im Brief vom 19. Februar nachgereichte „Fabula docet“. Und gerade dadurch erhebt die Fabel selbst Anspruch darauf, „Freiheit in der Erscheinung“ zu zeigen! Sie verweist auf semantischer Ebene nicht nur auf eine moralische Handlung, in der „sich Freiheit in der Erscheinung zeigt“, sondern sie sucht dies auf eine Weise, um nicht zu sagen in einer „Form“ zu tun, die selbst als frei erscheint (und etwa keines erklärenden Nachsatzes bedarf). Die „Geschichte“ hat also etwas auffallend Performatives. ${ }^{266}$ Bereits im letzten Satz des einleitenden Passus wird sie als „zur Erholung“ getarnt und lässt im Folgenden "dabey vergeßen“, dass sie als Kunstwerk, als Fabel nicht nur dem Zwecke eines moralischen Satzes (vgl. Lessings Fabeldefinition in Kapitel IV.2.1), sondern auch dem Zwecke eines Exempels für Schillers Theorie des Schönen dient. Als Fabel mag die Geschichte als ästhetisch schön gelten, da die ihr zugrunde liegende Moral durch sie selbst veranschaulicht wird. Ebenso mag die Geschichte als ästhetisch schönes Exempel gelten, da sie diese schöne Fabel als ihre Form gewählt hat. Denn durch diese Wahl erklärt sich auch das Exempel selber und bedarf theoretisch keiner weiteren Erklärung - einer Erklärung, die, würde der Brief mit ihr enden, den Brief selbst um seine Schönheit brächte. So ist denn der Brief vom 18. Februar wahrhaftig ein Exempel für Schillers Überzeugung, „daß die Schönheit nur die Form einer Form ist“. 267

Die Wahl einer Fabel hält der Verfasser also keineswegs für einen Zufall: Wie im Kapitel zur Phönix-Fabel gezeigt, hat bereits Lessing, wenngleich in anderer Terminologie, in seinen Abhandlungen über die Fabel gefordert, dass der jeweils eine, der Fabel zugrunde liegende moralische Satz durch die Fabel selbst veranschaulicht werden müsse - und nicht etwa durch einen fabula docet-Nachtrag. Dass nun Schiller eine autonome Fabel nach Lessing'scher Definition als Exempel für seine Theorie der autonomen ästhetischen Schönheit verwendet, lässt Exempel und Theorie, denen beiden das Prinzip der

mußt? - Das weiß ich nicht und das bekümmert mich nicht, sagt der Lastträger. Ich weiß aber [sic] daß du Hülfe brauchst und daß ich schuldig bin, sie dir zu geben“ (ebd., S. 197).

265 Ebd.

266 Betreffend Performativität und Genieästhetik siehe Kapitel 3.3; sowie zu Performativität im Zusammenhang mit Autonomie und Genie Kapitel 1.2 des Schlussteils.

267 Schiller, Nationalausgabe, Bd. 26, S. 176: «Ich bin wenigstens überzeugt, daß die Schönheit nur die Form einer Form ist, und daß das was man ihren Stoff nennt schlechterdings ein geformter Stoff seyn muß. Die Vollkommenheit ist die Form eines Stoffes, die Schönheit hingegen ist die Form dieser Vollkommenheit; die sich also gegen die Schönheit wie der Stoff zu der Form verhält.» 
Autonomie zugrunde liegt, ineinander spiegeln, sich gegenseitig reflektieren und erklären. Und dies stärkt, wenn nicht gar potenziert, wiederum die Autonomie resp. autonome ästhetische Schönheit von Exempel und Theorie.

Dabei handelt es sich um ein Verfahren, das bereits in den Bespieltexten zur Grundoperation Reflexivität feststellbar war. Und wie schon bei Lessings Der Phönix wird auch hier eine Fabel im Modus der Reflexion verwendet: Weniger als bei jener in einem poetologischen, die Möglichkeitsbedingungen von Text und Lektüre desselben thematisierenden Modus, dafür mehr in einem autoreflexiv-performativen. Beiden liegt aber die Absicht zugrunde, durch und an sich selber eine selbst wiederum - auch und gerade in zeitlicher Hinsicht als autonom betrachtete Lehre zu veranschaulichen. Die im Kapitel zu Lessings Der Phönix aufgestellte These, der Fabelboom des 18. Jahrhunderts hänge auch mit dem Verlust der ewigen Lehren der Gleichnisse der Bibel zusammen, der mit sich selbst erklärenden und damit unabhängig von der zeitlichen Veränderung äußerer Gegebenheiten vermittelbaren Fabellehren kompensiert werden soll, erfährt hier also weitere Bestätigung.

Es ist damit auch kaum ein Zufall, wenn nicht nur Schiller, sondern auch Herder - wie Lessing selbst ein Verfasser von Fabeln und Fabeltheorie, der in Sachen Selbsterklärung der Fabel noch weiter geht als Lessing, indem er nicht nur wie dieser den fabula docet-Nachtrag, sondern auch den Fabeltitel ablehnt $-^{268}$ im oben besprochenen Passus der Kalligone an zentraler Stelle in den Fabelstil übergeht. Er tut dies mit der allegorisch auftretenden Natur, den substantivierten Adjektiven und der abschließenden Pointe, die auch die Pointe des gesamten Abschnitts ist und am Schluss desselben steht: „Ein böser Haushalter wäre er, wenn er es der großen Haushälterin nachthun wollte. Unbekümmert spräche sie zum Nachlässig-Stolzen: ,ich kenne dich nicht!' und ließe ihn sinken. ${ }^{269}$

Karl Philipp Moritz hingegen scheint sich mit der Betonung der sinnlichen Ebene, der undurchlässigen, „sich abschließenden“ Oberfläche von Kunstwerken und deren Rezeption gegen eine Ästhetik, der eine Reflexionsmetapher zugrunde liegt, auszusprechen. Sabine Schneider schreibt dazu:

Wenn Minerva, die Göttin der Künste, das versteinernde Haupt der Medusa als Emblem auf ihrem Brustschild trägt, so läßt sich mit Moritz weiter assoziieren, dann eignet „die zurückschreckende Kälte“270 der Göttin auch den sich

268 Vgl. zu Herders Fabeldichtung Pichtownikowa 20o8, S. 148-152, vergleichend und zusammenfassend S. $159 \mathrm{f}$.

269 Herder, Werke, Bd. 8, S. 761.

270 Schneider zitiert hierbei Moritz aus: Minerva, in: Monatsschrift der Akademie der Künste und mechanischen Wissenschaften zu Berlin, 2. Jg., 3. Bd. (1789), S. 70-73, hier S. 71. 
abschließenden Gestalten der Kunst. Das Kunsterleben scheint demnach für Moritz kein Erlebnis gesteigerten Selbstgefühls zu sein, wo das Subjekt sich über der imaginativen Aneignung des Fremden seiner selbst versichern könnte. Vielmehr ist der Rezipient angesichts der medusenhaften Schönheit der Kunst und einer Unverfügbarkeit, die sich genau der projektiven zu widersetzen scheint, durch welche der Aufklärer Perseus ihre Fremdheit und bedrängende Dinglichkeit zum bloßen Zeichen depotenzieren konnte, von Ichauflösung bedroht. „Eben dies Verlieren, dies Vergessen ${ }^{271}$ unsrer selbst“272 bei Betrachtung eines Kunstwerks wird bereits in Moritzens erster kunsttheoretischer Schrift gegen die anthropozentrischen Zurichtungen der Aufklärungsästhetik zum Programm erhoben: „Wir opfern in dem Augenblick unser individuelles eingeschränktes Dasein einer Art von höherem Dasein auf." Es ist bezeichnend, dass Moritz die Subjektmetapher des Spiegels verwendet, um die manifeste Sinnlichkeit des Kunstwerks gegen seine Vereinnahmung durch den „angelaufenen Spiegel“ einer verstimmten Subjektivität zu verteidigen. ${ }^{273}$

In Anschluss an die bereits in Kapitel 3.1 behandelte Spiegelmetapher, die sowohl der Reflexionsphilosophie als auch der Autonomieästhetik inhärent ist, ließe sich anfügen: Moritz, in vielerlei Hinsicht Vordenker der Autonomieästhetik der Weimarer Klassik, kommt mit seinem kritischen Umgang mit jener Metapher bereits sehr nahe an die von der Romantik - insbesondere dann auch von E. T. A. Hoffmann - aufgegriffene, ,dunkle‘ Seite einer potenziell endlosen Spiegelung heran. Diese verleiht einem Kunstwerk vielleicht ein gewisses Maß an Autonomie. Es besteht sowohl in sinnlicher (Moritz) als auch intelligibler Hinsicht für den Betrachter, die Hörerin, den Leser etc. eines solchen Kunstwerks aber auch die Gefahr, sich in dieser die vermeintliche Kunstautonomie entscheidend (mit-)konstituierenden, potenziell unendlichen Spiegelung zu verlieren.

Zusammenfassend lässt sich festhalten: Die verlorene Ewigkeit durch und in Gott sowie der göttlichen Schöpfung, der Natur, ist also auch durch das als ewig dauernd erhoffte, autonome Kunstwerk nicht zu haben - und wo es in die Nähe dieser Ewigkeit zu kommen sucht, sieht sich das rezipierende individuelle Subjekt sofort von Ich-Verlust bedroht. „Das sich in den Zeichen aussprechende Signifikat hat sich nach dem Wegfall metaphysischer Verbindlichkeiten vom

\footnotetext{
271 Das „Vergessen unsrer selbst“ erinnert hier an Schiller, nämlich an das Sich-Vergessen während der moralisch-schönen Handlung im oben behandelten Kommentar zu seiner Fabel in den - freilich acht Jahre nach Moritzens Schrift erschienenen - Kallias-Briefen.

272 Schneider zitiert hier und im Folgenden Moritz aus: Versuch einer Vereinigung aller schönen Künste und Wissenschaften unter dem Begriff des in sich selbst Vollendeten. An Herrn Moses Mendelssohn, Berlinische Monatsschrift (1785), V, S. 225-36, hier S. 229, 230 und $235 \mathrm{f}$.

273 Schneider 1999, S. $169 \mathrm{f}$.
} 
Bereich der Natur in den Bereich des Menschen verschoben“274 - und von dort in die Kunst. (Beide, die Verschiebung göttlicher Attribute auf die Kunst resp. das Kunstwerk und jene Gefahr des Ich-Verlustes, sind auch für die im folgenden Kapitel behandelte Genieästhetik zentral.) Es hat sich dabei gezeigt, wie sehr in den besprochenen Konzepten zu einer autonomen Kunst alle - mit Varianz innerhalb der Grundoperation Unendliche Aktualisation - in dieser Arbeit behandelten Operationen zur Ewigkeitsattribuierung von Schriftzeichen, insbesondere aber die Grundoperation Reflexivität, bemüht werden, um die Kunst gerade auch als von der Zeit autonom zu gestalten. Ein Unterfangen, das in einer geistesgeschichtlich gewaltigen Anstrengung die im Zuge der Aufklärung ausgelöste, vom christlich-jüdischen Gott sich fortbewegende, metonymische Verschiebung von Sinn ${ }^{275}$ und Ewigkeit im Kunstwerk anzuhalten sucht - und das, wie schon bei der Reflexionsphilosophie beobachtet, diese Verschiebung zugleich weiter antreibt. Jene oben mit Sabine Schneiders Worten beschriebene Verschiebung des Signifikats von der (göttlichen) Natur „in den Bereich des Menschen“, was „lediglich eine Steigerung jener Anthropozentrik [ist], die die metaphysische Ordnung der Natur im Prozess der Aufklärung ablöste um den Preis einer Übertribunalisierung des Menschen, der sich als Subjekt emphatisch autonom setzt“, und der beobachtete Umgang mit ebendieser Verschiebung ergänzen die am Ende des Kapitels zur Reflexionsphilosophie aufgestellte These wie folgt:

Die einst durch und in Gott garantierten Kategorien des Sinns und der Ewigkeit sollen um 1800 nicht nur durch Reflexionsphilosophie wiedergewonnen werden, sondern auch durch das autonome Kunstwerk, und zwar strukturell gesehen mittels derselben Operationen, wie sie Texten schon lange vor dem 18. Jahrhundert als Operationen zur Ewigkeitsattribuierung von Schriftzeichen inhärent sind.

Die „Semiotik der Sinnlichkeit“, die sich im „ausgehenden [18.] Jahrhundert als übergreifende Problemstellung ${ }^{\text {"276 }}$ herausbildet, schließt sich also der alten Suche nach dem Zeichen, das sich selber zeigt, ${ }^{277}$ und derselben Hoffnung auf Verewigung und Ewigkeit an, wie sie bereits mit den intelligiblen Zeichen verbunden wurde. Die Ergebnisse dieses Unterkapitels ergänzen somit auch die eingangs zitierte Feststellung Koschorkes insofern, als dass „die volle Durchsetzung der Schriftkultur “278 und die zeitgenössischen Auseinandersetzungen

\footnotetext{
274 Schneider 1998, S. 26.

275 Vgl. Berghahn 2012, S. 14 f.

276 Schneider 1998, S. 12.

277 Vgl. ebd.; sowie in diesem Zusammenhang spezifisch zu Novalis Rommel 1998, insbesondere S. $11 \mathrm{f}$.

278 Koschorke 1999, S. 388 .
} 
mit Zeichenhaftigkeit im Allgemeinen eng mit der Autonomieästhetik verknüpft sind. Denn was im Falle der Reflexionsphilosophie zu Ende des betreffenden Kapitels festgestellt wurde, gilt auch hier: Nicht nur betreiben die besprochenen Konzepte der Autonomieästhetik Ewigkeitsattribuierung von Schriftzeichen (und von Kunstwerken und Zeichen im Allgemeinen), sondern die Operationen zur Ewigkeitsattribuierung bilden umgekehrt auch die Basis, auf der die Autonomieästhetik (mit-)aufbaut.

\subsection{Genieästhetik}

Eng verwoben mit der Reflexionsphilosophie und der Autonomieästhetik ist der im 18. Jahrhundert aufkommende Geniediskurs, der hier wiederum ganz mit Blick auf die Ewigkeitsattribuierung von Schriftzeichen aufgegriffen werden soll. Jochen Schmidts Standardwerk ${ }^{279}$ zum Geniegedanken sowie, in kritischer Ergänzung dazu, David Wellberys The Specular Moment bilden den Orientierungspunkt für dieses Kapitel, das in einen knappen geistesgeschichtlichen Überblick einerseits und in eine exemplarische, nähere Betrachtung einzelner Textstellen von Goethe, Herder und E. T. A. Hoffmann andererseits gegliedert ist.

\subsubsection{Die Übertragung göttlicher Attribute auf das Genie und dessen Werk}

Jochen Schmidt weist gleich zu Beginn seines einleitenden Kapitels zu den geschichtlichen und begrifflichen Voraussetzungen des Geniegedankens auf die Übertragung göttlicher Attribute auf den Menschen, insbesondere den Dichter, hin:

Die Anschauung vom außerordentlichen Rang der Dichtkunst hat sich erst im 18. Jahrhundert herausgebildet. Schon durch Klopstock, um das Jahr 1750, vollends dann aber in der Geniezeit, zwischen 176o und 1775, erhielt der Dichter die Würde eines mit höchster Autorität auftretenden Schöpfers. Galt Dichtung zu Anfang des 18. Jahrhunderts nach dem Horazischen Rezept, aut prodesse volunt aut delectare poetae' als ergötzliche und belehrende Angelegenheit, so erhält sie schon bald nach der Jahrhundertmitte das Pathos und die einmalige Verbindlichkeit einer Offenbarung - einer Offenbarung von Wahrheiten, die nur dichterisch zugänglich und deshalb nur vom Dichter vermittelt werden können. ${ }^{280}$

Der Gottesbegriff werde dabei weitgehend durch den Naturbegriff abgelöst $\mathrm{t}^{281}$ wobei „Spinozas Gleichsetzung Gottes mit der Natur“, die „in der zweiten

\footnotetext{
279 Schmidt 2004.

280 Ebd., Bd. 1, S. 1.

281 Ebd., S. 6.
} 
Hälfte des 18. Jahrhunderts zur Weltanschauung der Gebildeten“282 wird, eine zentrale Rolle spielt - und verschiebt sich in der Folge weiter auf den Menschen:

Der Mensch übernimmt alle Prädikate, die bisher dem Göttlichen zugeschrieben wurden. Die Auffassung des Genies als eines Schöpfers ist das deutlichste Zeichen für diesen Vorgang. In der religiösen Tradition ist der Mensch nur Geschöpf. Die Schöpferwürde blieb Gott vorbehalten. Wie bewußt die bisher göttlichen Qualitäten auf den Menschen übertragen werden, zeigt die häufige und provozierende Umfunktionierung von Bibelstellen, die sich in ihrem ursprünglichen Kontext auf die Größe und Herrlichkeit Gottes beziehen. Nun werden sie eingesetzt, um die neue Würde des Menschen hervorzuheben. Besonders Goethe kultivierte dieses Verfahren, indem er blasphemisch säkularisierend die Bibel zitierte. ${ }^{283}$

Wenig verwunderlich findet sich hier vieles von dem wieder, was in den beiden vorangegangenen Kapiteln bereits besprochen wurde, wobei Schmidt unter dem Aspekt der Offenbarung nochmals, wenn auch unterschiedlich explizit, auf die verschiedenen bereits festgestellten Verschiebungsbewegungen verweist: von der schriftlich festgehaltenen Offenbarung der Bibel - über die Tradition des Lesens der Natur als Offenbarung Gottes - zum Dichter und von dort zur Dichtung als Offenbarung. Die Formulierung „erhielt der Dichter die Würde eines mit höchster Autorität auftretenden Schöpfers“ wäre demnach wie folgt zu präzisieren: Der Dichter resp. genauer: die sich als Genies inszenierenden Dichter erhalten die Schöpferwürde nicht, sondern sie schreiben (und zwar wortwörtlich) sie sich selbst zu.

Dass dabei immer auch schon der potenzielle Absturz aus der selbst zugeschriebenen göttlichen Höhe mit eingeschrieben ist, darauf hat bereits David Wellbery am Beispiel Goethes hingewiesen. In Kapitel fünf seiner einschlägigen Monographie The Specular Moment erarbeitet er denn auch sechs „determinations of the Symbolic position of genius“. ${ }^{284}$ Äußerst bemerkenswert ist dabei, dass in allen seinen Textausschnitten Goethes (in Wellberys Zählung die Texte 11-14), die er exemplarisch anfügt, explizit das Paradigma der Ewigkeit resp. der Dauer vorkommt, Wellbery dieses Paradigma jedoch weder näher untersucht noch ihm einen Platz unter seinen "determinations“ einräumt. Dies sei im Verlaufe des vorliegenden Kapitels ergänzend nachgeholt. Vorerst ist aber auf die Gefahren des Genies und jene "determinations“

282 Ebd. Zur faszinierenden antiken Parallele und Kontinuität dieses Naturgedankens ausgehend vom Ägypten des 14. Jahrhundert v. Chr. vgl. J. Assmann 2018, insbesondere S. 35 f.

283 Schmidt 2004, Bd. 1, S. 6.

284 Wellbery 1996, S. 13 . 
einzugehen, unter denen bezeichnenderweise auch folgende zwei zu finden sind:

Zum einen: „(1) [Das Genie] occupies the origin“.285 Das führe zwangsläufig immer zum Agon mit einem vorangehenden Genie und stelle damit das Paradoxon aus, dass das Genie das vermeintlich Ursprungslose schaffen soll. ${ }^{286}$ Ein Unterfangen, dem immer schon qua radikaler Referenzlosigkeit radikalste Einsamkeit droht:Wer absolut Neues schafft, der und dessen Werk können von den übrigen Menschen nicht verstanden werden, da jeglicher Referenzpunkt, an den ein hermeneutischer Prozess anschließen könnte, fehlt. Oder in Wellberys Worten: „[H]ow can this radical originality be conceived if not through reference to another origin that serves as its paradigm?“287 Dieses „paradox of mimesis that denies mimesis“, ${ }^{288}$ dieses Problem des referenziellen Bezugs auf einen anderen Ursprung resp. Schöpfer, findet sich auch besonders prominent in denjenigen Gedichten Goethes, die als Inbegriff der ,Geniezeit' der 1770er-Jahre gelten: Wandrers Sturmlied und Prometheus. ${ }^{289}$ Nicht umsonst schwingt in den eröffnenden Zeilen der ersten vier Strophen von Wandrers Sturmlied „Wen du nicht verlässest Genius“ resp. „Den/Dem du nicht verlässest Genius“290 immer auch die Bedrohung mit, auf dem Flug „[m]it den Feuerflügeln“ (V. 12) von allem und jedem verlassen in jene Referenzlosigkeit abzustürzen. Eine Gefahr, die nicht nur auf dem Weg jenes "Wandrers“ droht, sondern - das von Wellbery formulierte Paradoxon hat es gezeigt-insbesondere und besonders tragisch auch am Ende jenes Weges, der konsequenterweise in absoluter Referenzlosigkeit liegen würde. Es ist denn auch kein Zufall, wie jene beiden Gedichte enden:

Mut Pindar - Glühte -

Armes Herz -

Dort auf dem Hügel -

Himmlische Macht -

Nur so viel Glut -

Dort ist meine Hütte -

Zu waten bis dort hin. ${ }^{291}$

285 Ebd., Hervorhebung durch MG.

286 Vgl. Wellbery 1996, S. 122 f.

287 Ebd., S. 123.

288 Ebd.

289 Auf diese kann hier nicht ausführlich eingegangen werden (es sei dazu auf David Wellbery verwiesen), ein paar kurze Bemerkungen seien jedoch erlaubt.

290 Hier zitiert nach der Kopie der ältesten Handschrift (diese Handschrift stammte vom 31.08.1774 aus einem Brief an Jacobi) im Frankfurter Goethe-Museum: Goethe, Werke, 1. Abteilung, Bd. 1, S. 145; Kommentar, S. 854-867.

291 Ebd. 
Der Weg des "Wandrers" endet - wie David Wellbery bereits beobachtet hat mit der Kapitulation („surrender“) ${ }^{292}$ gegenüber der „Himmlische[n] Macht“ oder drastischer ausgedrückt: im Absturz in den "Schlamm(pfad)“ (V. 11), den es zur „Hütte“ hin zu durch-,waten“ gilt.. ${ }^{293}$ Und im Falle von Prometheus:

Und dein nicht zu achten Wie ich!294

Das vermeintlich so selbstbewusst auftretende „ich“ am Ende des Prometheus braucht das „dein" Gottes als Referenzpunkt genauso wie die von Prometheus erschaffenen Menschen sich wiederum über Prometheus, ihren Schöpfer, konstituieren: „Wie ich“ [Hervorhebung MG]. Oder anders formuliert: Ein „ich“, das in der Grundstruktur einer Gerichtsrede ${ }^{295}$ seine Stimme anklagend gegen Zeus resp. Gott und die Götter insgesamt erhebt, ist weder frei von diesen noch hat es sie abgeschafft. 296

Zum anderen: „(5) [Das Genie] supplants the divine Father“..297 Die Gründe dafür bringt David Wellbery wie folgt auf den Punkt:

The discourse on genius is an assault on Christianity.

This it must be. The Christian God, who created man in His image, thereby condemned mankind to imitation. (I will return to this point in Chapter 8, in connection with the ode ,Prometheus.). If the genius occupies the origin, then he can achieve this position only by appropriating for himself the attribute of divinity. Only through this ultimate mimesis can the law of mimesis be overcome $[\ldots] . .298$

Und diese Punkte (1) und (5) zusammenfassend schreibt er:

He must become his own Father [sic], produce himself out of himself, occupy the position of origin in its most radical sense. The genius is the figure of auto-

\footnotetext{
292 Wellbery 1996, S. 156.

293 Kaum zufällig ist dann, noch akzentuierter, in der Ersten Weimarer Gedichtsammlung (1778) „waten!“ das letzte Wort des Gedichtes (Goethe, Werke, 1. Abteilung, Bd. 1, S. 198).

294 Zitiert nach der Ersten Weimarer Gedichtsammlung (1778), Goethe, Werke, 1. Abteilung, Bd. 1, S. 204.

295 Wellbery 1996, S. 292.

296 Damit muss auch bei aller übrigen Zustimmung Wellbery widersprochen werden, der zu diesen Schlussversen schreibt: „The authority of divinity is usurped by the self-positing, autonomous subject, which is to say, by the ,Ich' that, with the last words of the text, designates itself as the paradigm of a godless, hence free, humanity“ (Wellbery 1996, S. 294).

297 Ebd., S. 130, Hervorhebung MG.

298 Ebd., S. 127.
} 
origination, which is to say, the figure of an impossibility. For the young Goethe, the site where this impossibility takes place is art. ${ }^{299}$

Auf die Verschiebung, die jene „impossibility“ lostritt resp. deren Teil sie ist, und die Rolle, die dabei der Kunst resp. dem Kunstwerk zukommt, wird unten zurückgekommen. Hier sei zuerst nochmals an die oben zitierten Stellen bei Jochen Schmidt angeknüpft: Unter Schmidts Formulierung, „alle Prädikate, die bisher dem Göttlichen zugeschrieben wurden [Hervorhebung MG]“, fiele nun aber gerade auch das Prädikat der Ewigkeit, wenngleich er darauf nicht näher eingeht. Dasselbe gilt auch für seine Beobachtung, dass im Zuge der Säkularisierung „[d]as bisher ins Jenseits Projizierte [...] ins Diesseits zurückgeholt [wird]“. ${ }^{300}$ Es ist Schmidt also einerseits sofort zuzustimmen, dass das Schöpferische ein zentrales Attribut des Geniegedankens jener Zeit, und de facto bis heute, ist. Doch ist andererseits gerade dieses Attribut immer auch verbunden mit dem göttlichen Attribut der Ewigkeit, wie im Folgenden weiter $\mathrm{zu}$ zeigen ist. Das Ganze ließe sich, und diesen reziproken Gedankengang verdankt der Verfasser dem Austausch mit Daniel Müller Nielaba, also auch umdrehen:

Gerade um sich das göttliche Attribut der Ewigkeit zu sichern, sind die Genies jener Zeit derart bemüht, in der poetischen Praxis und der wechselseitig damit verknüpften Praxis der Theoretisierung derselben sich schöpferisch als göttlich zu beweisen.

(In diesem Zusammenhang wäre über die vorliegende Arbeit hinaus auch eine Auseinandersetzung mit der These Jan Assmanns gefordert, die vor allem auf das alte Ägypten sich stützend besagt, der Druck zum Neuen sei bereits mit der Schriftlichkeit an sich verbunden.) ${ }^{301}$

\footnotetext{
299 Ebd., S. 130.

300 Schmidt 2004, Bd. 1, S. 6. Wobei Schmidts implizit wertende Formulierung „zurückgeholt [Hervorhebung MG]“ die bis heute anhaltende Wirksamkeit jener im 17. und 18. Jahrhundert immer stärker voranschreitenden Säkularisierung eindrücklich aufzeigt.

301 „Der Barde ist Träger der Überlieferung; seine Kreativität besteht darin, der Überlieferung, die durch ihn hindurchgeht, eine besonders eindrucksvolle, elaborierte Gestalt zu geben. Der Autor dagegen steht der Überlieferung gegenüber und muß sie überbieten. Das ist nicht erst die Erfahrung der Moderne, wie die um 1800 v. Chr. entstandene ,Klage des Chacheperresneb` zeigt: ,O daß ich unbekannte Sätze hätte, seltsame Aussprüche, / neue Rede, die noch nicht vorgekommen ist, / frei von Wiederholungen, / keine überlieferten Sprüche, die die Vorfahren gesagt haben. Der mündliche Barde verkörpert die Tradition; sein Lied ist immer wieder neu, es ,erneuert' sich in jeder neuen Aufführung, auch wenn es traditionell und möglicherweise uralt ist. Vom schriftlichen Autor dagegen erwartet man das Neue. Er kann sich nicht auf die Tradition berufen, sondern muß sie aus Eigenem bereichern; das lateinische Wort auctor heißt ja ,Vermehrer“" (J. Assmann 2003, S. 46).
} 
Es sei sich nun den eng miteinander verknüpften Verschiebungen der göttlichen Attribute des Schöpferischen und der Ewigkeit schrittweise über die Dimension der Zeit genähert: Bereits das vorangegangene Kapitel hat auf die von den aufkommenden Naturwissenschaften mitbewirkte Dynamisierung hingewiesen, die im 18. Jahrhundert in die Naturvorstellung Einzug hält (Stichwort Epigenesis). Jochen Schmidt schreibt aus geistesgeschichtlicher Perspektive dazu, dass die Natur ,in den frühen Phasen der Aufklärung und auch noch bei Lessing [...] ein Analogon rationis" sei. Diese Vorstellung der Natur als „Vernunftnatur" und deren Nachahmung als "nur eine Betonung des Vernunftprinzips“ ändere sich im Sturm und Drang:302

Natur ist primär nicht mehr rationale Struktur, sondern emotionales Leben, nicht Sein, sondern Werden. Der statischen natura naturata wird die dynamische natura naturans vorgezogen. ,Natur' erscheint als generatives Prinzip. In dieser Zeit des Sturms und Drangs, auf dem Höhepunkt der Genie-Bewegung, geht deshalb der Begriff der Natur-Nachahmung in den der Schöpfung über. Denn wenn die natura naturans, das schöpferische Werden, als Wesen der Natur zu verstehen ist, dann heißt Natur-Nachahmung, daß man selbst schöpferisch werden soll. Dieses Naturverständnis trägt entscheidend zur Legitimation der Genie-Ideologie bei. ${ }^{303}$

Wenn nun aber in der Kunst die Natur als eine schaffende Natur nachgeahmt wird, so bedeutet dies nichts anderes, als dass ein jedes Kunstwerk, das nach diesem Prinzip erschaffen wird, die Möglichkeitsbedingungen ebendieses Erschaffens mitabbildet. Oder anders formuliert: Jedes Kunstwerk, dem jene Nachahmung gelingt, ist auch poetologisch. Nun hat sich aber oben gezeigt, dass Poetologie auch als eine Operation zur Ewigkeitsattribuierung von Schriftzeichen zu beobachten ist. Kombiniert man diese beiden Erkenntnisse, so lässt sich in einem ersten Schritt zunächst einmal Folgendes festhalten:

Die Genieästhetik führt zum verstärkten Auftreten der Unteroperation Poetologie resp. generell der Grundoperation Reflexivität.

Und zwar sowohl im Befolgen jener Ästhetik als auch erst recht - da jene zwangsläufig implizit thematisierend und damit allein dadurch schon poetologisch - in der kritischen künstlerischen Auseinandersetzung mit derselben. ${ }^{304}$ Kein Zufall also, um auf die im Kapitel zur Unteroperation Poetologie behandelten literarischen Texte zurückzukommen, dass gerade

302 Vgl. Schmidt 2004, Bd. 1, S. 13.

303 Ebd.

304 Zu Letzterem vgl. die Auseinandersetzung mit Hoffmanns Kater Murr im folgenden Kapitel 3.3.2. 
Lessings Fabel Der Phönix, die zumindest Altes neu zu variieren sucht,, ${ }^{305}$ eine poetologische Fabel ist oder dass Schillers Nänie auch die Vergänglichkeit und Ewigkeit des Gedichtes selbst sowie von zeichenhafter Kunst im Allgemeinen poetologisch mitbehandelt. Gerade Nänie zeigt anhand des Orpheus-Mythos, dass die Übertragung göttlicher Ewigkeit auf ein zeichenhaftes Lied resp. Werk aufgrund ebendieser Zeichenhaftigkeit letztlich scheitern muss. Und doch verabschiedet Nänie das Bestreben Orpheus' nicht, weil es als Lied über Orpheus' Versuch eines Liedes von göttlicher Macht die Vergänglichkeit der genialen Heroen und Schöpfer sowie ihrer Werke, selbst der schönen, ausstellt - und sie gerade dadurch zu verewigen sucht.

Mit all dem stimmt überein, was Wellbery weite Teile seiner Untersuchung zur Genieästhetik zusammenfassend festgestellt hat: In Anlehnung an Niklas Luhmann und Peter Fuchs sieht er nämlich den Geniediskurs der 1770er-Jahre bis ins 19. Jahrhundert hinein gewissermaßen als (negatives) Spiegelbild des sozialen resp. gesellschaftlichen Systems: ${ }^{306}$ „From this perspective, society, in its modern form, appears as the negation of genius, the stifling of genial productivity, and precisely this feature of modernity, according to the discourse

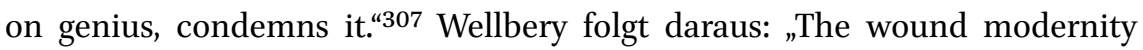
inflicts, in other words, is castration." ${ }^{308}$ Oder etwas weniger ,freudianisch und etwas vorsichtiger ausgedrückt: Die Wunde, welche die Moderne dem (männlichen?) Subjekt zufügt, ist die Furcht vor dem Verlust der eigenen Schöpfungsmacht. Um sich - weiterhin nach Wellbery - dennoch als genialer Vater seiner selbst ermächtigen zu können, müsse das Genie einerseits jenen Teil der sozialen Realität, den es ex negativo spiegle, die Depotenzierung also, ausblenden und andererseits das Feminine marginalisieren. ${ }^{309}$ Nun scheint aber gerade jene oben u. a. anhand der Enden von Wandrers Sturmlied und Prometheus erwähnte Erfahrung des Genies, letztlich doch nicht im absoluten Sinne den Platz des Schöpfer-Vaters einnehmen zu können, sich mit einer Aufwertung des mütterlichen Prinzips zu verschränken, die eine solche Marginalisierung des Weiblichen unterläuft:

The love-based model of art, like that of self-fathering genius, is a model of artistic self-generation, the difference being that the autonomous paternal instance is replaced by the maternal gift and the reciprocity of the specular regard.

305 Zum rationalistischen Naturbegriff der Frühaufklärung bis noch zu Lessing siehe Kapitel 3.2.1; resp. vgl. Schmidt 2004, S. 13 .

306 Vgl. Wellbery 1996, S. $156 \mathrm{f}$.

307 Ebd., S. 156.

308 Ebd., S. 157 .

309 Vgl. ebd. 
In fact, what we have here is an endless circularity and exchange: recalling the event that gave birth to him as artistic subject (the Mother's [sic] primordial donation of desire), the artist recreates or reenacts that event with his charged instrument and thereby constitutes the Mother as she constitutes him. The artistic act simulates an erotic union with the Mother, whose issue is the artist reborn as erotic-artistic subject, and so on endlessly. ${ }^{310}$

Im vorliegenden Rahmen kann und soll nicht über diese These Wellberys geurteilt werden. Seine titelgebenden Beobachtungen zur Spiegelung - es sei hier auch nochmals an das Kapitel zur Höhlenszene in Novalis' Heinrich von Ofterdingen erinnert - als zentralem Prinzip der Kunst der Moderne und des Geniediskurses wären jedoch in Kombination mit den hier dargelegten Ergebnissen zur Ewigkeitsattribuierung von Schriftzeichen weiterzudenken. Denn dass nicht nur das Attribut des Schöpferischen, sondern mindestens damit verschränkt und ebenso dominant auch das Attribut ewiger Dauer für die Genieästhetik konstitutiv ist, zeigt die vorliegende Arbeit. Und so erscheint jene von Wellbery beobachtete Verschränkung der väterlichen und mütterlichen Schöpfungsprinzipien auch als ein Versuch, die beiden von Diotima ${ }^{311}$ formulierten Möglichkeiten, Unsterblichkeit $\mathrm{zu}$ erlangen, miteinander $\mathrm{zu}$ kombinieren ...! 312

In einem zweiten Schritt ist daran zu erinnern, dass aber gerade das Schöpferische der Natur ursprünglich Gott attribuiert und von dort erst auf dessen Schöpfung, die Natur, übertragen wurde - ebenso wie die übrigen Attribute Gottes, also auch dessen Ewigkeit. Es lässt sich somit sagen:

Im Modus der Reflexivität verschränken sich Genieästhetik und Ewigkeitsattribuierung von Schriftzeichen resp. von Kunst im Allgemeinen.

Dies war der Übertragungsbewegung des göttlichen Attributs des Schöpferischen folgend festzustellen; es lässt sich aber auch beobachten, wenn die Übertragungsbewegung des göttlichen Attributs der Ewigkeit nachvollzogen wird: Denn ähnlich wie das Attribut des Schöpferischen erfährt auch das der Ewigkeit eine Verzeitlichung. Dies klingt paradoxal, ist aber wie folgt gemeint: Ruhte sowohl die Natur und damit auch die sie gemäß dem Mimesisgebot nachahmende Kunst in der platonisch-christlichen Tradition in der Stabilität der Ewigkeit des Seins resp. Gottes, überträgt sich dieses Attribut der Ewigkeit nun immer weiter bis hin auf das Kunstwerk. Dabei wird eine Dynamik

310 Ebd., S. 177, vgl. auch S. 183 .

311 Vgl. dazu die Einleitung der vorliegenden Arbeit.

312 Eine Kombination, die kaum zufällig auch im 21. Jahrhundert von gewissen (ebenso wenig zufällig oft sich selbst als ,Genies' inszenierenden und inszenierten) KI-Forschern erträumt wird. 
freigesetzt - und da kommt die Verschränkung mit der Übertragung des Schöpferischen ins Spiel -, die, paradoxal gesprochen, den Modus jener Ewigkeit affiziert:

Ewigkeit im Modus der stabilen Dauerhaftigkeit scheint dem modernen Menschen zu entgleiten in Richtung eines unendlichen Prozesses, eines Modus, der-im Gegensatz zu ersterem - mittels Zeichen wenigstens potenziell eingeholt werden kann.

Oder anders formuliert: Durch den Verlust Gottes und der von ihm garantierten Ewigkeit ist man bestrebt, zumindest Letztere mit größter intellektueller Anstrengung wieder einzuholen, und zwar indem man sie - auch das ein Paradoxon und deshalb letztlich zum Scheitern verurteilt mittels zeichenhafter (Kunst-)Werke schöpferisch herzustellen sucht. Natürlich fand, wie u. a. in der Einführung dargelegt, Ewigkeitsattribuierung von Schriftzeichen und auch von (zeichenhaften) Kunstwerken schon vor dem Aufkommen des Geniegedankens statt, aber jene soeben aufgezeigten Verschiebungen von Schöpferischem und Ewigkeit sowie die Verschränkung derselben miteinander erklären wesentlich die im 18. Jahrhundert stattfindende Akzentuierung von Ewigkeitsattribuierung. Da der Versuch, sich als Genie selbst als den absoluten Ursprung zu setzen, aber letztlich ein paradoxaler ist, ist das Genie dazu getrieben, sich ständig als schöpferisch zu erweisen, soll sein - gemessen am absoluten Anspruch unausweichliches - Scheitern abgewendet werden.

Und genau aus diesem Versuch, sich selbst dauerhaft als Genie zu versichern, resultiert der implizite Zwang zu entweder endlosem Erschaffen - das freilich spätestens mit dem Tod des Genies enden wird - oder, als einzige (scheinbar) übrig bleibende Rettung, der Zwang zum Erschaffen von Ewigem, zum Erschaffen eines ewigen Werkes. ${ }^{313}$

In diesem Sinne wäre Wellberys Aussage, „[t] who was or the figure who will be; his place is not in the present", ${ }^{\prime \prime} 314 \mathrm{zu}$ ergänzen: Das Genie wäre die Figur, deren Werk „will be“ forever.

Nun lässt sich im Umfeld der Geniedebatte aber nicht nur eine Verschiebung der Ewigkeit Gottes beobachten, sondern, gewissermaßen als weitere Facette desselben Prozesses, auch eine Verschiebung der ewig gültigen poetischen Regeln der antiken Autoritäten, insbesondere Aristoteles'. Dabei vollzieht sich letztere bemerkenswerterweise in denselben Übertragungsschritten wie erstere: Sucht man zunächst, wie die Modernes in ihrer Querelle mit den Anciens im Frankreich des späten 17. Jahrhunderts und noch im Falle Lessings,

313 Vgl. dazu auch das historisch-kontextualisierende Kapitel II.3.

314 Wellbery 1996, S. 129. 
die Antike mit der Natur gleichzusetzen und damit die antiken Regeln letztlich als Abbild der ewig gültigen Regeln der Natur zu sehen, ${ }^{315}$ so vollzieht Herder in seinem berühmten Shakespeare-Aufsatz vor dem Hintergrund der zeitgenössischen Dynamisierung der Natur ${ }^{316}$ eine Historisierung poetischkünstlerischer Normen. Die zeitlose Gültigkeit von antiken (Kunst-)Regeln und Vorbildern verschiebt sich also - wie die Ewigkeit Gottes und mit deren Verschiebung verknüpft und sie legitimierend - zunächst auf die Natur, ${ }^{317}$ dann auf das geniale Individuum und von dort auf das Kunstwerk. Damit sei nun auch übergeleitet zu jenem berühmten, in der vorliegenden Arbeit bereits mehrfach erwähnten Aufsatz Herders.

3.3.2 Exemplarische Textstellen bei Herder, Goethe und

E. T. A. Hoffmann

Herder: Shakespeare $(1773)^{318}$

Die Ausgabe der „Bibliothek deutscher Klassiker“ vermerkt im Kommentar zu Herders Aufsatz: „Herders Shakespeare-Aufsatz von 1773 galt seit jeher als Meilenstein in der Geschichte der Literaturtheorie. Der Versuch historischgenetischen Verstehens stellt gegenüber der normativen aufklärerischen Ästhetik eine neuartige Methode dar."319 Und auch Jochen Schmidt stellt mit Bezug auf die im 18. Jahrhundert stattfindende Auseinandersetzung mit Shakespeare, der gemeinsam mit Pindar für den Inbegriff des Genies schlechthin stand, fest:

315 Schmidt 2004, Bd. 1, S. 14-17, und zu Lessing S. 69-95 sowie insbesondere S. 166 f. (im Zusammenhang mit Shakespeare): „Aber aufs Ganze gesehen ist das Nachahmungsdenken, allgemeiner gesprochen: das Bedürfnis, sich an Autoritäten zu orientieren, immer noch so stark, dass man eines neuen ,Musters' und einer neuen Autorität bedarf. Ja, Lessing verbindet diese Autorität noch mit der zur Natur umgedeuteten Über-Autorität der Antike.“

316 Siehe oben Kapitel 3.2.1. Bei Herder heißt es dann: „Wie sich Alles in der Welt ändert: so musste sich auch die Natur ändern [...]" (Herder, Werke, Bd. 2, S. 503).

317 Vgl. dazu auch A. Assmann 1999, S. 137-145; und Nate 2018; sowie Neumann 2018.

318 Die Ergebnisse dieses Unterkapitels zu Herders Shakespeare-Aufsatz wurden zusammen mit einem Ausblick auf Ewigkeitsattribuierungen im 21. Jahrhundert bereits in einem Vortrag an der Asiatischen Germanistik Tagung (AGT) „Germanistik in Zeiten des grossen Wandels“ 2016 in Seoul (Südkorea) vorgestellt. Um der wissenschaftlichen Redlichkeit willen sei vermerkt, dass dieser Vortrag allenfalls noch im damals angekündigten, aber nach dem besten Wissen des Verfassers bis heute nicht erschienenen Tagungsband publiziert werden könnte.

319 Herder, Werke, Bd. 2, S. 1169 . 
Und im selben Maße, wie sich Geniebegriff und Naturbegriff bis zum Sturm und Drang irrationalistisch aufluden, ${ }^{320}$ wandelte sich das Bild Shakespeares. Herders großer Shakespeare-Aufsatz ist der Höhepunkt, die Summe alles Früheren und zugleich die Erweiterung in die Dimension des Geschichtlichen. ${ }^{321}$

Herders Aufsatz mag hier also in seiner Schlüsselstellung innerhalb der Shakespeare- resp. Geniedebatte als ein hervorragendes Exempel dienen, die oben genannten Verschiebungen der Schöpfungsmacht und der Ewigkeit Gottes noch etwas genauer am Text nachzuvollziehen.

Auf Herders neue, historisch-relativierende Perspektive auf das Genie wurde soeben hingewiesen; ${ }^{322}$ die über die beiden Entwürfe bis hin zur dritten, publizierten Fassung des Aufsatzes sich schrittweise vollziehende zunehmende Gleichsetzung Shakespeares mit Gott - bei gleichzeitiger, dazu etwas widersprüchlicherer, bescheidenerer und theodizeehafter Rolle Shakespeares „als Mittler[s] zwischen Gott und den Menschen“ - ist schon hinlänglich bekannt. ${ }^{323}$ Zusammen ergeben diese beiden Säulen von Herders Aufsatz auf den ersten Blick das, was Schmidt wie folgt auf den Punkt bringt:

\begin{abstract}
Also ist er [Shakespeare, MG] als Genie-Paradigma nicht zeitlos gültig, sowenig wie die Griechen. ,Trauriger und wichtiger', sagt Herder am Ende seiner Abhandlung, ,wird der Gedanke, daß auch dieser große Schöpfer von Geschichte und Weltseele immer mehr veralte!' Das Genie verliert prinzipiell die Aura der zeitlosen Natur. Mit der Vorstellung genialen Schöpfertums kann sich nicht mehr der Nimbus der absoluten Autorität verbinden. Diese Rückführung des Genies, die ganz am Ende des Shakespeare-Aufsatzes noch mehr betont wird, deutet schon auf die alsbald noch weitergehenden Rücknahmen voraus, auf jenes Bewußtsein der Endlichkeit und Begrenztheit, das der Klassik präludiert. ${ }^{324}$
\end{abstract}

Doch dass das Genie in Herders Aufsatz „prinzipiell die Aura der zeitlosen Natur“ - deren Zeitlosigkeit von der Ewigkeit Gottes her übertragen worden war - verliere, da muss Schmidt widersprochen werden: Es verliert sie nicht im umfassenden Sinne, sondern sie verschiebt sich - und zwar auf das Kunstwerk, wie schon im Kapitel zur Autonomieästhetik u. a. auch anhand der Kalligone

320 Auch hier vereinfacht Schmidt: Etwa bei Goethe und Lenz lädt sich die Natur nicht „irrationalistisch“, sondern spinozistisch auf, woraus sich erneut eine hochrationalistische Spiegelfigur ergibt, nämlich die Auseinandersetzung damit, wie sich in einer solchen Welt das Göttliche im eigenen schöpferischen ,Wesen` äußere.

321 Vgl. Schmidt 2004, Bd. 1, S. 150-178.

322 Zum Aufsatz insgesamt, zu seiner Entstehungsgeschichte, Rezeption etc. vgl. auch zusammenfassend u. a. den Kommentar der Klassikerausgabe (Herder, Werke, Bd. 2, S. 11061111 und 1158-1170); und Schmidt 2004, Bd. 1, vor allem S. 168-175 und 178.

323 Vgl. etwa Herder, Werke, Bd. 2, S. 1166 f.

324 Schmidt 2004, Bd. 1, S. 171. 
aufgezeigt wurde. ${ }^{325}$ Dies belegt denn auch der von Schmidt herangezogene letzte Abschnitt von Herders Shakespeare-Aufsatz eindrücklich:

Trauriger und wichtiger wird der Gedanke, daß auch dieser große Schöpfer [Shakespeare, MG] von Geschichte und Weltseele immer mehr veralte! daß da Worte und Sitten und Gattungen der Zeitalter, wie ein Herbst von Blättern welken und absinken, wir schon jetzt aus diesen großen Trümmern der Ritternatur so weit heraus sind, daß selbst G a r rik, ${ }^{326}$ derWiedererwecker und Schutzengel auf seinem [Shakespeares, MG] Grabe, so viel ändern, auslassen, verstümmeln muß, und bald vielleicht, da sich alles so sehr verwischt und anders wohin neiget, auch sein Drama der lebendigen Vorstellung ganz unfähig werden, und eine Trümmer von Kolossus, von Pyramide sein wird, die Jeder anstaunet und keiner begreift. Glücklich, daß ich noch im Ablaufe der Zeit lebte, wo ich ihn begreifen konnte, und wo du, mein Freund, der du dich bei diesem Lesen erkennest und fühlst, und den ich vor seinem heiligen Bilde mehr als Einmal umarmet, wo du noch den süßen und deiner würdigen Traum haben kannst, sein Denkmal aus unsern Ritterzeiten in unsrer Sprache, unserm so weit abgearteten Vaterlande herzustellen. Ich beneide dir den Traum, und dein edles Deutsches Würken laß nicht nach, bis der Kranz dort oben hange. Und solltest du alsdenn auch später sehen, wie unter deinem Gebäude der Boden wankt, und der Pöbel umher still steht und gafft, oder höhnt, und die daurende [sic] Pyramide nicht alten aegyptischen Geist wieder aufzuwecken vermag. - Dein Werk wird bleiben, und ein treuer Nachkomme dein Grab suchen, und mit andächtiger Hand dir schreiben, was das Leben fast aller Würdigen der Welt gewesen: voluit! quiescit! ${ }^{327}$

Mit seinen zahlreichen Anspielungen - und im unteren Teil mit der Referenz an Goethe (ab „du, mein Freund“), der im Begriff ist, zum neuen Genie-Exempel zu werden - ist der letzte Abschnitt äußerst dicht. ${ }^{328}$ Was aber den gesamten Abschnitt durchzieht, ist zum einen die Klage um die Vergänglichkeit des Genies Shakespeare, der Genies, der Menschen im Allgemeinen - und damit auch Herders selbst; und zum anderen die Übertragung der ewigen Dauer des Genies auf die Dauer des Werkes des Genies, an der Herder gegenüber der eigenen zuvor entfalteten Argumentation inkonsequent und ihr direkt widersprechend festhält und die im letzten Satz in das prophetisch-hoffnungsvolle „dein Werk wird bleiben“ mündet.

\footnotetext{
325 Vgl. zu dieser Verschiebung etwa auch Neumann 2018; und Nate 2018.

326 Zeitgenössischer englischer Schauspieler, er "griff erstmals auf die Urtexte Shakespeares zurück“. Vgl. Herder, Werke, Bd. 2, S. 1193.

327 Herder, Werke, Bd. 2, S. 520 f.

328 Vgl. dazu auch die Stellenkommentare in Herder, Werke, Bd. 2, S. 1192 f. Und erneut versteht es sich, dass im vorliegenden Rahmen nicht in aller Ausführlichkeit auf diesen Abschnitt eingegangen werden kann.
} 
Diese beiden Grundthemen werden bereits zu Beginn des letzten Abschnittes eingebracht, und zwar in der implizit zitierten Blätterallegorie resp. -similitudo Homers, die Herder nach eigener Aussage als Schulknabe einst zu Tränen gerührt habe: ${ }^{329}$ Wo die „Blätter“ in der Ilias noch als Metapher für das Menschenleben standen, verwendet sie nun Herder in ihrer habitualisierten Metaphorik der Schriftblätter. Es zeigen sich dabei an Herder und seinem genialen Aufsatz selbst die Eigendynamik der metonymischen Übertragung der Attribute Gottes und die damit verknüpfte Tragik des modernen Menschen, ja nicht zuletzt die Tragik des Genies selbst: Gewissermaßen inmitten der Flut ${ }^{330}$ jener Übertragung, die er mit seiner genialen Historisierung des Genies selbst wieder in Bewegung gebracht hat, nach dem letzten, „Dauer“ gewährenden Strohhalm greifend, ruft Herder nicht denjenigen an, der sie einst gewährte: Gott, sondern alles andere, das sonst noch die Aura der Ewigkeit umgibt: das alte Genie Homer sowie das neue: Goethe; im Falle von Letzterem zugleich die (freundschaftliche) Liebe; und eben und vor allem die im Paradigma des Monumentalen angesiedelten ${ }^{331}$ (ewigen) Werke, angefangen mit dem Verweis auf die Allegorie Homers, weiter über den (Helios-)Koloss ${ }^{332}$ - vielleicht sogar auch symbolisch dafür, dass selbst Götter sterben können - und hin zur

329 Der Kommentar der Klassikerausgabe dazu ist sehr aufschlussreich und zitiert neben Herders Erinnerung zugleich auch die Originalstelle aus der Ilias nach der zeitgenössischen Übersetzung von Voss: „Herder übernahm dieses Bild aus der Ilias Vi 146149:,Gleichwie Blätter im Walde, so sind die Geschlechter der Menschen, / Siehe, die einen verweht der Wind, und andere wieder / Treibt das knospende Holz hervor zur Stunde des Frühlings: / So der Menschen Geschlecht, dies wächst, und jenes verschwindet.' (J. H. Voss) Vgl. dazu Herders Brief an Caroline vom 20./23. 10. 1771 [also ausgerechnet im kronenlichtenden Herbst, MG]: ,Aber es ist so traurig, daß ich alles gelben u. falben u. fallen u. wintern sehe! ein Geschlecht von Blättern, das so wenig aufersteht, als wir Menschen, wenn wir abfallen. Für mich hat kein Bild u. kein Lied u. Gleichniß von Jugend auf mehr Eindruck gemacht, als dies: $u$. ich erinnere mich, als ich zum erstenmal ganz jung in Homer das Gleichniß von einem Früling [sic] von Blätter laß, daß so auch ein Geschlecht Menschen von der Erde verschwindet; mir, was einem Schulknaben selten zu kommen pflegt, die Thränen ausbrachen.' [zitiert nach der Edition von Herders Briefen von Dobbek und Arnold 1984-1988, Bd. 2, Nr. 31, S. 87, MG]“ (Herder, Werke, Bd. 2, S. 1192 f.).

Herder adaptiert die Allegorie Homers sogar zweimal in seinem Aufsatz, die zweite Stelle findet sich unter: Herder, Werke, Bd. 2, S. 509 .

33 D Die Metapher der ,Flut' ist hier nicht zufällig gewählt: Zur wohl auf Horaz' Pindar-Lob zurückgehenden Strommetapher im Zusammenhang mit der Genieästhetik bei Herder, Goethe, Hölderlin u. a. vgl. Schmidt 2004, Bd. 1, S. 182-184; und natürlich das Kapitel III.1.1 zum Zauberlehrling.

331 Wobei natürlich auch der berühmte Vers Horaz' mitschwingt: Exegi monumentum aëre perennius (vgl. die Einführung).

332 Der zwar zerstört ist, aber noch immer erinnert wird. 
Pyramide sowie von ihr, die als Ganzes selbst schon Grabmal, Grabzeichen ist, bis zur Grabinschrift. Zur Grabinschrift, die in ihrer paradoxalen doppelten Funktion nicht nur verewigt, sondern letztlich trotz aller Bemühungen auch auf den verweist, der dazu überhaupt Anlass gibt: den Tod. Ein letzter Abschnitt also, durchdrungen von Homers Bild der Vergänglichkeit der Menschen. Eine Vergänglichkeit, der das moderne Denken, an dem Herder so wesentlichen Anteil hatte, ausgelieferter ist denn je. Und so vermag dieser letzte Abschnitt, in dem Herders eigenes Ringen damit so deutlich wird, uns heutige Leser selbst wiederum in die Situation jenes Schulknaben zu bringen.

Zwei Punkte bleiben dem noch hinzuzufügen:

1. Gerade die Grabinschrift am Ende des Aufsatzes unterläuft die in der Klage formulierte Vergänglichkeit des Genies in doppelter Hinsicht:

Einerseits schreibt Herder dem „treue[n] Nachkomme[n]“ implizit eben doch die Fähigkeit zu, dass er das Werk, das bleibe, „begreift" resp. umgekehrt, dass ein geniales Werk begreifbar bleibe - zumindest für einen kongenialen geistigen Nachfahren, als den ein paarZeilen zuvor, und im Aufsatz als solchem, sich Herder im Falle Shakespeares selber inszeniert hat; eine Kongenialität, zu der nun der Ausblick auf Goethe eine Analogie bildet. Und Herder geht sogar noch weiter: Nicht nur inszeniert er sich selbst als kongenialer Begreifer Shakespeares, sondern auch Homers, nämlich einerseits über das implizite Blätterzitat und andererseits über das prophetische Sprechen über eine zukünftige Grabinschrift. Letzteres tut genau auch Hektor in der Ilias, ${ }^{333}$ und auch ihm geht es um die Verewigung, zwar nicht eines Dichters, aber eines Heroen, der er selbst ist. So fußt denn die Rührung, die Herder angesichts der Vergänglichkeit Shakespeares und des Menschgeschlechts überkommt, ganz nach Lessings Aristoteles-Übersetzung zwar auf Mitleid, das aber zugleich auch auf der Furcht um sich selbst (und die eigenen Werke) ${ }^{334}$ beruht. $^{335}$

333 „Aber den Toten erstatt ich zurück [...], damit ihn bestatten Achäer im Schmucke des Haupthaars / und ihm ein Mal errichten am Hellespontos, dem breiten. / Und einst wird einer sagen der spätergeborenen Menschen [...]: / ,Das ist das Mal eines Manns, der schon vor Zeiten gestorben, / den nach tapferem Kampf erschlug der strahlende Hektor.' / So wird einer da sagen: mein Ruhm wird niemals vergehen“ (Homer, Ilias 7, 84-91 resp. S. 129). Ähnliches tut bemerkenswerterweise auch E. T. A. Hoffmanns Kater Murr; vgl. Hoffmann, Werke, Bd. 5, S. 38.

334 Fast ist man im Sinne von Platons Diotima (vgl. die Einführung) versucht zu schreiben: ,Furcht um sich selbst und seine Kinder'.

335 Dass die Bereitschaft zur Klage auf Empathie gründe, darauf hat bereits Stefan Börnchen verwiesen, jedoch nicht mit Blick auf Lessing, sondern im Vergleich mit Sternes Tristram Shandy und Thomas Manns Doktor Faustus (vgl. Börnchen 2006, S. 202), wobei einiges darauf hindeutet, dass auch im Doktor Faustus Lessings Ästhetik des Mitleidens, die auf Dauer und Überdauern des Bemitleideten abzielt, entscheidend zum Tragen kommt. 
Andererseits schreibt wiederum jener "treue Nachkomme“ das Werk des Genies fort resp. verweist indexikalisch darauf, indem er eine Grabinschrift verfasst, die seit dem Aufkommen der Schrift wohl die expliziteste Form eines Verewigungsversuchs ist. Der Ort nun, an dem diese Inschrift steht, ist nicht nur das vorgestellte Grab Goethes, sondern auch das Ende von Herders eigenem Aufsatz. Herder vollendet damit (poetisch-)performativ (vgl. die Operation Poetische Performativität) die Stilisierung des eigenen Aufsatzes als selbst ein geniales, unsterbliches Werk und imaginiert damit auch seine eigene Grabinschrift. (Eine Grabinschrift, die, selbstkritisch gesprochen, vom Verfasser der vorliegenden Zeilen soeben ganz im Sinne von Herders Imagination aktualisiert wurde.) Herder kombiniert dabei verschiedene Operationen zur Ewigkeitsattribuierung: Einerseits fällt das quiescit! in seiner Bedeutung von ,er ruht ${ }^{336}$ oder eben auch ,er verstummt(!) ${ }^{‘}$ mit dem Ruhen und Verstummen des Aufsatzes zusammen, während die dritte Person Singular von voluit und quiescit nicht nur auf den direkt angesprochenen Goethe passt, sondern ebenso auf den Verfasser Herder und den Aufsatz selbst (vgl. die Operation Unendliches Verstummen). Andererseits verwischt das Anzitieren der zu Lebzeiten vorgestellten Grabinschrift resp. der Hoffnung auf Verewigung das Ende des Aufsatzes, und zwar hin zur Heroen verewigenden, dies ausgerechnet in jener zitierten Szene poetologisch reflektierenden (vgl. die Grundoperation Reflexivität) und selbst zum Inbegriff des unsterblichen Werkes gewordenen Ilias (vgl. die Operation Unendliche Lektüre). Dass man gerade in diesem Schlüsselaufsatz sowohl des Geniediskurses als auch der aufkommenden Literaturwissenschaft ${ }^{337}$ alle hier behandelten Grundperationen zur Ewigkeitsattribuierung von Schriftzeichen auf engstem Raum und ausgerechnet im letzten Abschnitt antrifft, ist, wenn überhaupt, ein äußerst bemerkenswerter Zufall.

2. Die im Aufsatz gleich zweimal verwendete Blätterallegorie Homers, der Verweis auf Hektors Imagination des eigenen Grabmals, die Pyramiden usw. erinnern hier noch einmal daran, dass das Verhandeln der menschlichen Vergänglichkeit in Schrift und das Ringen dagegen mittels Schrift natürlich kein singuläres Phänomen der Zeit um 1800 ist. Der letzte Abschnitt von Herders Shakespeare-Aufsatz zeigt aber zugleich auch exemplarisch, wie im Zuge der zunehmenden Säkularisierung göttliche Attribute auf das Kunstwerk im Allgemeinen, aber insbesondere und vor allem auf das dichterische, schriftliche Werk übertragen werden - ein Prozess, der in der hier behandelten Zeitspanne zu einer Akzentuierung der Ewigkeitsattribuierung von Schriftzeichen führte.

336 Wie es der Kommentar der Klassikerausgabe übersetzt (Herder, Werke, Bd. 2, S. 1193): "(Lat.) ,Er hat gestrebt! Nun ruht er!" Herkunft des Zitats nicht ermittelt."

337 Vgl. dazu den betreffenden Ausblick im letzten Kapitel des Schlussteils. 
Die Operationen derselben können dabei, auch dies zeigt die Analyse des Shakespeare-Abschnittes erneut, durchaus auch in theoretischen Texten, die jene Übertragung vornehmen, bemüht werden, insbesondere in denjenigen, die sich zugleich selbst als unsterbliches Kunstwerk inszenieren.

\section{Goethe: Zum Schäkespears Tag (1771)}

Goethes anlässlich von Shakespeares (resp. Wilhelms) Namenstag im väterlichen Haus in Frankfurt gehaltene Rede Zum Schäkespears [sic] Tag steigt sogleich in aller Explizitheit mit der Hoffnung auf Verewigung ein: „Mir kommt vor, das sei die edelste von unsern Empfindungen: die Hoffnung, auch dann zu bleiben, wenn das Schicksal uns zur allgemeinen Nonexistenz zurückgeführt zu haben scheint. Dieses Leben, meine Herren, ist für unsre Seele viel zu kurz [...].“338 Der erste Abschnitt schließt sodann nahezu blasphemisch: „[...] und daß keiner sein Ziel erreicht, wornach er so sehnlich ausging; denn wenn es einem auf seinem Gange auch noch so lang glückt, fällt er doch endlich, und oft im Angesicht des gehofften Zwecks, in eine Grube, die ihm Gott weiß

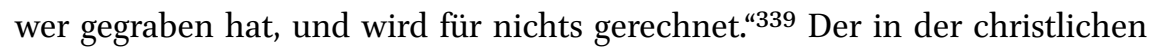
Tradition erlösende und den Weg zur Ewigkeit erst eröffnende Tod wird hier metonymisch als "Grube“ bezeichnet und damit jeder religiösen Übergangskonnotation beraubt, während "Gott" und das von ihm in jener Tradition in Aussicht gestellte ewige Leben völlig ausgeblendet wird. Drastischer noch: Das Wort "Gott" kommt zwar vor, es ist aber, seiner einst heiligen und unaussprechlichen Konnotation beraubt, bloßer sinnentleerter Teil einer Redensart. Und doch ist seine Macht offenbar noch immer so groß, dass Gott trotz allem noch immer wörtlich vorkommt - was der ganzen Rede fast schon etwas unfreiwillig Komisches, geradezu Kindisches verleiht, das auf zukünftige Parodien des Geniekultes vorausweist. Doch es kommt noch besser, denn Goethe führt mit dem zweiten Abschnitt, dessen Anfang zusammen mit dem Ende des ersten bemerkenswerterweise eine die Austauschbarkeit von Anfang und Ende figurierende Anadiplose bildet, ${ }^{340}$ fort: „Für nichts gerechnet! Ich! Da ich mir alles bin, da ich alles nur durch mich kenne! "341 $^{\text {341 }}$

Goethes Rede zum Genie Shakespeare, zum Gedenken von dessen Namen man erinnere sich erneut an das Nachwort Ovids in den Metamorphosen und ebenso daran, dass der Namenstag der Heiligen eine christliche Tradition

\footnotetext{
338 Goethe, Schäkespears Tag, S. 387 .

339 Ebd.

340 Was rückblickend eigentümlich an Goethes 40 resp. 50 Jahre später verfassten Aufsatz Shakespeare und kein Ende erinnert (vgl. das Ende des vorliegenden Unterkapitels).

341 Goethe, Schäkespears Tag, S. 387.
} 
ist - ist also im Grunde eine Rede über das genialisch-göttliche Individuum, „Ich“, und damit insbesondere auch über Goethe selbst. ${ }^{342}$ Diese aufs Ganze gehende Selbstinszenierung als Genie mit Anspruch auf Unsterblichkeit kann (und soll wohl auch) der Nachsatz, der nun bescheiden, jedoch äußerst vage und mit "Weg“ unter Vermeidung jedes direkten Hinweises auf die Religion auf „drüben“ verweist, nicht mehr zurücknehmen: „So ruft jeder, der sich fühlt, und macht große Schritte durch dieses Leben, eine Bereitung für den unendlichen Weg drüben. “343

Die im Zuge der Aufklärung stattfindende zunehmende Abwendung von der Religion und die damit einhergehende Übertragung des göttlichen Attributs der Ewigkeit von Gott und seiner Heiligen Schrift auf den (genialischen) Dichter und dessen Schriften findet also im Beginn von Goethes Rede ein weiteres Exempel: Wie Herder inszeniert sich Goethe im Schreiben über das Genie Shakespeare selber als ein Genie. Im Falle Goethes ist jedoch zusätzlich auf die das Genie charakterisierende, hauptsächlich im zweiten Abschnitt entfaltete Metaphorik des Wanderns hinzuweisen. Der Abschnitt geht nämlich wie folgt weiter:

Freilich, jeder nach seinem Maß. Macht der eine mit dem stärksten Wandertrab sich auf, so hat der andre Siebenmeilenstiefel an, überschreitet ihn, und zwei Schritte des letzten bezeichnen die Tagreise des ersten. Dem sei, wie ihm wolle: dieser emsige Wandrer bleibt unser Freund und unser Geselle, wenn wir die gigantischen Schritte jenes anstaunen und ehren, seinen Fußtapfen folgen, seine Schritte mit den unsrigen abmessen.

Auf die Reise, meine Herren! Die Betrachtung so eines einzigen Tapfs macht unsre Seele feuriger und größer als das Angaffen eines tausendfüßigen königlichen Einzugs.

Wir ehren heute das Andenken des größten Wandrers und tun uns dadurch selbst eine Ehre an. Von Verdiensten, die wir zu schätzen wissen, haben wir den Keim in uns. ${ }^{344}$

Die Metaphorik des Wanderns, „die Hauptchiffre des jungen Goethe für geniale Unruhe“, 345 verweist zum einen auf die metonymische Beziehung zwischen Werk („Fußtapfen“) und Genie („Wandrer“). Zum anderen, und dies gilt es hervorzuheben, bildet sie eine Analogie zur oben wiederholt behandelten

342 Dies geht so weit, dass ohne den Titel zu Beginn der Rede schwer ersichtlich wäre, dass es um eine andere Person, geschweige denn Shakespeare im Besonderen gehen soll.

343 Goethe, Schäkespears Tag, S. 387.

344 Ebd., S. $387 \mathrm{f}$.

345 Schmidt 2004, Bd. 1, S. 168, Anm. 57. Vgl. dazu auch Schmidts ausführliche Analyse von Wandrers Sturmlied; ebd., S. 196-254. 
,wandernden` Übertragung der göttlichen Attribute und vermag diese dadurch poetologisch auszustellen. ${ }^{346}$

Damit lässt sich zwischen Goethes Rede und Herders Shakespeare-Aufsatz eine weitere Parallele feststellen: Beide schreiben nicht nur von der Dauer des Genies und dessen Werken resp. „Fußtapfen“, sondern bei beiden Texten lassen sich auch die in der vorliegenden Arbeit behandelten Operationen zur Ewigkeitsattribuierung von Schriftzeichen beobachten. Im Falle Goethes ist dies nun insbesondere die Operation Poetologie, aber zumindest, und dies ist vor dem Hintergrund des hier besprochenen faszinierend, rückblickend resp. anachronistisch auch die Operation Unendliche Lektüre. Letzteres nämlich im Falle des,Wanderns' des eigenen Schreibens - Goethe kommt in seinem Leben bekanntlich wiederholt auf Shakespeare zurück, nicht zuletzt unter dem be-

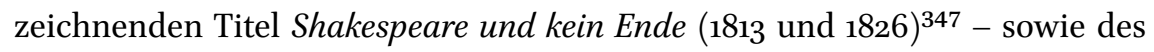
,Wanderns' Goethes als Inbegriff eines Genies, als das er sich bereits in seiner Rede von 1771 inszeniert, ein Wandern etwa zu Herders Aufsatz und über den heutigen Literaturkanon bis in das vorliegende Kapitel hinein.

\section{Noch einmal E. T. A. Hoffmann: Lebensansichten des Katers Murr (1819/21)}

Parallel zum Kult um das Genie kamen erste Parodien dazu auf,, ${ }^{348}$ und auch an direkter, expliziter Kritik mangelte es nicht: Johann Gottfried Herder selbst findet die inflationäre Verwendung des Begriffs Genie bereits in seiner Abhandlung Vom Erkennen und Empfinden der menschlichen Seele (1774; dritte, endgültige Fassung 1776), also nur ein bis fünf Jahre nach seinem oben behandelten Shakespeare-Aufsatz, unerträglich. ${ }^{349}$ Immanuel Kant spricht abwertend von ,Geniemännern', und Goethe und Herder nehmen scheinbar

346 Eine ebenfalls bemerkenswerte Metaphorik schwingt in „feuriger“ mit, nämlich die des promethischen Feuers, das seinerseits wiederum als Metapher für das Leben stehen kann (gerade in Goethes Bearbeitung dieses Mythos; es sei an den kurze Zeit später entstandenen Prometheus erinnert). In der Lektüre eines „Tapfs“ eines Genies flammt also nach Goethe das promethische Feuer auf, ja eine solche Lektüre macht die Seele des Lesers gar „feuriger" und somit lebendiger, als - so suggeriert es die Formulierung „königlichen Einzugs“ - die zeitgenössische politische Situation und deren Rahmenbedingungen es zu tun vermögen.

347 Ebenfalls abgedruckt in Mayers Anthologie: Goethe, Johann Wolfgang: Shakespeare und kein Ende, in: Mayer, Hans (Hg.): Meisterwerke deutscher Literaturkritik. Aufklärung, Klassik, Romantik. Stuttgart 1962, S. 423-436.

348 Etwa der von Friedrich Maximilian von Klinger, Jakob Sarasin und Johann Caspar Lavater ,herausgegebene' Roman Plimplamplasko, der hohe Geist (1780); vgl. Schmidt 2004, Bd. 2, S. 1.

349 Vgl. Schmidt 2004, Bd. 1, S. 144-147. 
„ihren eigenen ursprünglichen Genie-Subjektivismus zurück“. ${ }^{350}$ Doch wie sich im Kapitel zur Autonomieästhetik anhand der Kalligone gezeigt hat, bleibt die enge Verknüpfung von Werk und "Dauer" bei Herder bestehen. Und auch Goethe sucht noch mit Dichtung und Wahrheit (die ersten drei Teile erschienen zwischen 1811 und 1814) in solchem Maße sich selbst als Genie zu verewigen, dass E. T. A. Hoffmanns Parodie des Geniekultes, die Lebens-Ansichten des Katers Murr, in nicht unbedeutendem Maße auf ebendiese Autobiographie Goethes abzielt. Zusätzlich hält Hoffmann dieser mit der fragmentarische[n] Biographie des Kapellmeisters Johannes Kreisler das ,romantische Genie‘ mit seinem noch radikaleren, aber auch in seinen Gefahren reflektierten Subjektivismus entgegen - wobei diese Gefahren des Subjektivismus wiederum mit der in Kapitel 3.1 beobachteten schrecklichen Seite der Spiegelmetapher der Reflexionsphilosophie zusammenhängen. Jochen Schmidt meint zu Hoffmanns Schaffen:

Die skurril artifiziellen Visionen Hoffmanns verraten den Verlust jenes Vertrauens auf die schöpferische Innerlichkeit, das sich noch wenige Jahrzehnte früher am Begriff des Natürlichen orientierte. Hoffmanns surrealistische Phantastik scheint nicht zuletzt so weit zu gehen, um dem Ansturm der Realität überhaupt noch standzuhalten. In schmerzlicher Ironie geriert sie sich schon als abwegig. ${ }^{351}$

Oder auch anders formuliert: Wie kann man um 1820 als Dichter dem trotz allem noch immer vorherrschenden Imperativ ${ }^{352}$ genialen, neuen - und eben auch überdauernden - Schaffens Folge leisten? Hoffmanns Antwort lautet: Indem man diesen Imperativ auf geniale Weise parodiert. Schmidt schreibt dazu zusammenfassend: „Wie kompliziert Hoffmanns Stellung in der Geschichte des Genie-Denkens ist, zeigt auch seine permanente Parodie der Genie-Ideologie inmitten eines Werks, das doch wesentlich von dieser Ideologie geprägt ist.“353 Dies gilt ebenso für die Ewigkeitsattribuierung genialer künstlerischer Schöpfung, die mit dem Geniedenken verknüpft ist: Sie wird bei Hoffmann zum einen konsequenterweise ebenfalls parodiert, wozu nochmals folgende Stelle aus seinem Roman zitiert sei, auf die auch Schmidt verweist, ohne jedoch auf den Aspekt der Unsterblichkeit einzugehen: ${ }^{354}$

350 Schmidt 2004, Bd. 2, S. 1.

351 Vgl. ebd., S. 2.

$35^{2} \mathrm{Zu}$ den „Paradoxien des Genies“ in Hoffmanns Roman vgl. Seidler 2005, insbesondere S. 6 of.

353 Vgl. Schmidt 2004, Bd. 2, S. 3.

354 Ebd., S. 5. Dafür verweist Schmidt auf das Parodieren des Bildungsromans und des „neu[en] Typus von Autobiographie“, der „sein Fundament in einem durch das 
Es ist nehmlich wohl höchst merkwürdig und lehrreich, wenn ein großer Geist in einer Autobiographie über alles, was sich mit ihm in seiner Jugend begab, sollte es auch noch so unbedeutend scheinen, (sich) recht umständlich ausläßt. Kann aber auch wohl einem hohen Genius jemals unbedeutendes begegnen? Alles, was er in seiner Knabenzeit unternahm oder nicht unternahm, ist von der höchsten Wichtigkeit, und verbreitet helles Licht über den tiefern Sinn, über die eigentliche Tendenz seiner unsterblichen Werke. Herrlicher Mut geht in der Brust des strebenden Jünglings, den bange Zweifel quälen, ob die innere Kraft auch wohl genüge, wenn er lieset, daß der große Mann als Knabe auch Soldat spielte, sich in Naschwerk übernahm [...]. „Gerade wie ich, gerade wie ich“, ruft der Jüngling begeistert aus und zweifelt nicht länger, daß auch er ein hoher Genius ist trotz seinem angebeteten Idol. ${ }^{355}$

Zum anderen strebt aber auch Hoffmann mit aller Kunstfertigkeit nach dem „unsterblichen Werke“, wie das Kapitel zu den Lebens-Ansichten des Katers Murr deutlich gezeigt hat. In der zu Beginn des vorliegenden Abschnittes gestellten rhetorischen Frage schwingt nämlich auch die folgende mit: Wie kann man sich als Dichter um 1820 nach all den Genies der vorangegangenen Generationen noch mit einem genialen und damit „unsterblichen Werke“ verewigen?

Im historisch-kontextualisierenden Kapitel zur Grundoperation Unendliche Aktualisation wurde deutlich, dass Jean Paul diese Frage zu beantworten sucht, indem er - in einer gewissen Analogie zu Orpheus - das verewigende Schaffen als ewiges Schaffen quasi wortwörtlich nimmt. Hoffmanns Antwort erfolgt hingegen analog zu seiner soeben dargelegten, indem er dieses Bestreben, das er selbst gerade unternimmt, parodiert und damit gleichzeitig poetologisch reflektiert. Oder anders ausgedrückt: Da sich das Bedürfnis, sich mittels Schrift zu verewigen, selbst als ein äußerst dauerhaftes und wirkmächtiges Bestreben in der Kulturgeschichte des Abendlandes erwiesen hat, kann ein Werk, das jene Ewigkeitsattribuierung genial parodiert und zugleich reflektiert, ${ }^{356}$ darauf hoffen, sich gerade dadurch der Dauer zu versichern. Gleichzeitig vermag die

Genie-Denken erst voll zur Entfaltung gekommenen Glauben an die große künstlerische Individualität [hat], die sich selbst denkwürdig wird und der daher alles berichtenswert erscheint" (ebd., S. 4). Für beides sind die oben angeführten Zeilen eine der zu zitierenden exemplarischen Stellen aus Murrs Autobiographie.

355 Hoffmann, Werke, Bd. 5, S. 38. Hoffmann parodiert in dieser, genial' dichten Stelle somit auch das Paradoxale, das diesem „Idol“ (von griechisch $\varepsilon^{\prime} \delta \omega \lambda$ ov, eigentlich „Bild, Abbild“, speziell „Trugbild“) innewohnt (vgl. dazu auch Schmidt 2004, Bd. 1, S. 166 f.).

356 Womit hier auch eindrücklich das im Kapitel zur Reflexionsphilosophie Behandelte hineinspielt. Dem Prinzip einer genialen Parodie genialer Werke ist nämlich selbst schon die Grundoperation der Reflexivität inhärent. 
fragmentarische Kreisler-Biographie exemplarisch dafür zu stehen, wie in der Romantik, gerade aufgrund der akzentuierten Ewigkeitsattribuierung von Kunst im Zuge des 18. Jahrhunderts, die im vorliegenden Kapitel beobachtete Kunstreligion wieder von der Religion eingeholt wird: „Es ist nur konsequent, dass die Musik, die er [Kreisler, MG] allein als wahren Ausdruck des Innern und der in diesem Innern lebenden romantischen Unendlichkeit gelten lässt, religiöse Musik ist. In typisch romantischer Weise verschmilzt die Kunst mit der Religion“357 - eine Verschmelzung jedoch, so ist zu präzisieren, die bereits nur noch textuell als Dichtung stattfindet ${ }^{358}$ und die nicht mehr hinter die geistesgeschichtlichen Entwicklungen des 18. Jahrhunderts zurückkann.

357 Schmidt 2004, Bd. 2, S. 7. Vgl. dazu auch die historische Problematisierung der Ewigkeitsbehauptung gegenüber Schriftzeichen in der Einführung der vorliegenden Arbeit.

$35^{8}$ Es sei dabei auch an Albrecht Koschorkes Körperströme und Schriftverkehr erinnert, siehe u. a. Kapitel IV.3.1. 
Markus Gut - 978-3-8467-6517-3

Downloaded from Fink.de@4/26/2023 07:48:17AM via free access 


\section{Schlussteil}

\section{Zusammenführung der Ergebnisse}

\subsection{Eine Typologie der Operationen zur Ewigkeitsattribuierung von Schriftzeichen}

Im Folgenden mögen die im Hauptteil gewonnenen Erkenntnisse zusammengeführt, weitergedacht und die dabei erarbeitete Typologie der Operationen zur Ewigkeitsattribuierung von Schriftzeichen tabellarisch aufbereitet werden. Letzteres sei hier sogleich ein erstes Mal vorgenommen:

Grundoperationen zur Ewigkeitsattribuierung von Schriftzeichen
A) Unendliche Aktualisation
B) Autonome Performative
Produktion
C) Reflexivität (autonom und/oder unendlich)

Grund- und Unteroperationen zur Ewigkeitsattribuierung von Schriftzeichen
A) Unendliche Aktualisation
B) Autonome Performative
C) Reflexivität
Produktion
- Unendliche Lektüre
- Poetische
Performativität
- Autoreflexivität
- Unendliches Verstummen
(auton. u./o. unendl.)
- Poetologie
(auton. u./o. unendl.)

Die jeweiligen Grund- und Unteroperationen versuchen zu erreichen

\begin{tabular}{|c|c|c|}
\hline - unbeendbare Lektüre & $\begin{array}{l}\text { - Autonomie des } \\
\text { Verschriftlichten }\end{array}$ & $\begin{array}{l}\text { - Autonomie des } \\
\text { Verschriftlichten } \\
\text { und/oder } \\
\text { - unbeendbare } \\
\text { Lektüre }\end{array}$ \\
\hline
\end{tabular}


In der letzten der drei Tabellen wird deutlich, dass sich die Operationen zur Ewigkeitsattribuierung von Schriftzeichen vielleicht über die drei Grundoperationen hinaus in zwei noch grundlegendere Gruppen einteilen ließen: Die Operationen der ersten Gruppe versuchen eine unbeendbare Lektüre von Schriftzeichen (zuweilen auch ein unbeendbares Weiterschreiben des betreffenden Textes) herbeizuführen; die der zweiten streben nach Autonomie sowohl von Veränderungen der intelligiblen Seite der Zeichen samt ihrer Konnotationen als auch von einem spezifischen Kommunikationszusammenhang resp. vom außertextuellen Kontext überhaupt. Während die Grundoperation Unendliche Aktualisation der ersten und die Grundoperation Autonome Performative Produktion der zweiten Gruppe zugeordnet werden kann, stößt eine übergeordnete Zweiteilung bei der Grundoperation Reflexivität an ihre Grenzen; und dies aus zwei Gründen: Erstens können sowohl die Unteroperation Autoreflexivität als auch die Unteroperation Poetologie jeweils auf Autonomie oder eine unbeendbare Lektüre abzielen, letztlich kommt sogar potenziell immer beides zusammen ${ }^{1}$ zustande (selbst wenn unterschiedliche Akzentuierungen zu beobachten sind). Zweitens wird Autonomie mittels der Grundoperation Autonome Performative Produktion auf eine andere Weise angestrebt als mit der Grundoperation Reflexivität.

Am angemessensten und zugleich heuristisch dienlichsten ist es somit, für das Wie nach wie vor von den drei Grundoperationen auszugehen, die aber hinsichtlich dessen, was sie zu erreichen suchen, grundsätzlich nur auf zweierlei abzielen: Autonomie und/oder unbeendbare Lektüre. Dies gilt es im Folgenden weiter zu ergänzen und zu präzisieren.

Bereits in der Einführung wurde betont, dass die (bewusste oder unbewusste) Verwendung der Operationen zur Ewigkeitsattribuierung von Schriftzeichen immer nur ein Versuch ist, die von den betreffenden Schriftzeichen transportierten Signifikate dauerhaft festzuhalten und damit dasjenige, worauf diese Signifikate verweisen (Gedanken, Dinge, Personen etc. sowie, damit metonymisch verknüpft, oft auch der Verfasser resp. die Verfasserin der betreffenden Schriftzeichen), zu verewigen. Die Aktualisation eines Signifikats ist immer an einen sterblichen Leser, eine sterbliche Leserin gebunden, deren Lektüre damit zwangsläufig endlich sowie Veränderungen der Semantik und des Kommunikationszusammenhanges unterworfen ist. Zudem sind sowohl die Fragestellungen der Leserinnen und Leser an einen Text als auch - nun

1 Aus diesem Grund wurde auch bereits im Hauptteil darauf verzichtet, die Grundoperation Reflexivität sowie ihre Unteroperationen mit den Adjektiven ,autonome‘ oder ,unendliche $\mathrm{zu}$ versehen. Freilich wäre eine Begrifflichkeit wie etwa ,autonome und/oder unendliche Autoreflexivität' präziser, was jedoch einer zu umständlichen Formulierung entspräche. 
auf der Ebene der Signifikanten - die Materialität der Schrift und Schriftträger Veränderungen resp. dem Verfall unterworfen. Aufgrund all dieser Beschränkungen auf den Ebenen der Semiose resp. der Kommunikation, der biologischen Konstitution des Menschen sowie der physikalischen Gesetze ist eine unbeendbare Lektüre letztlich ebenso wenig zu erreichen wie eine absolute Autonomie des Verschriftlichten. Eine Verewigung mittels Schriftzeichen im eigentlichen, absoluten Sinne ist unmöglich. Sie muss immer Versuch bleiben. Damit gelangt man auch hier zur im Hauptteil immer wieder sich implizit aufdrängenden Frage, wozu denn die betreffenden Operationen im Zuge der Lektüre von Texten, die mit ihnen versehen sind, führen, wenn das Ziel der Verewigung letztlich nicht zu erreichen ist.

Zunächst ließe sich als Antwort anfügen, zumindest einige der behandelten Operationen, am deutlichsten die Unteroperation Unendliche Lektüre, würden zu einer potenziell unendlichen Iteration von Schriftzeichen führen. Dabei ergeben sich jedoch zwei Schwierigkeiten: Zum einen wird deutlich, dass sich bloße Iteration als ein zu wenig scharfer Begriff erweist, ist doch etwa eine zweite Lektüre der Lebens-Ansichten des Katers Murr nicht einfach nur die Wiederholung der ersten Lektüre, sondern wird, erstere miteinschließend, eine andere gewesen sein. Zum anderen besitzt ein jedes Schriftzeichen das Potenzial, unendlich oft wiederholt zu werden, dafür braucht es erst einmal keine Operationen zur Ewigkeitsattribuierung, wenngleich gewisse dieser Operationen ganz besonders auf dieses Potenzial abzielen. Diesen beiden Schwierigkeiten lässt sich jedoch begegnen. Für eine präzise Unterscheidung zwischen dem, was die Operationen zur Ewigkeitsattribuierung von Schriftzeichen anstreben, und dem, wozu sie im Rahmen dieser Bestrebungen führen, erweist sich nämlich Derridas Begriff der Iterabilität als äußerst hilfreich:

Meine „schriftliche Kommunikation“ muß, trotz des völligen Verschwindens eines jeden bestimmten Empfängers überhaupt, lesbar bleiben, damit sie als Schrift funktioniert, das heißt lesbar ist. Sie muß in völliger Abwesenheit des Empfängers oder der empirisch feststellbaren Gesamtheit von Empfängern wiederholbar - „iterierbar“ - sein. Diese Iterierbarkeit [besser: Iterabilität, frz. itérabilité, $\mathrm{MG}^{2}$ ] - (iter, „von neuem“, kommt von itara, anders im Sanskrit, und alles Folgende kann als die Ausbeutung jener Logik gelesen werden, welche die Wiederholung mit der Andersheit verbindet) strukturiert das Zeichen der Schrift selbst, welcher Typ von Schrift es im übrigen auch immer sein mag (piktographisch, hieroglyphisch, ideographisch, phonetisch, alphabetisch, um

2 Der Übersetzer übersetzt für den gesamten Aufsatz Derridas itérabilité mit Iterierbarkeit, obwohl Derrida ja genau nicht bloße Wiederholbarkeit meint; in der deutschsprachigen Forschung ist zudem die Übersetzung von itérabilité mit Iterabilität durchaus etabliert; vgl. Wirth 2008, S. 61 f. 
sich dieser alten Kategorien zu bedienen). Eine Schrift, die nicht über den Tod des Empfängers hinaus aus [sic] strukturell lesbar - iterierbar - ist, wäre keine Schrift. ${ }^{3}$

Gemäß Derrida - es wurde bereits wiederholt darauf hingewiesen - ist also die Möglichkeitsbedingung eines jeden Zeichens, und damit auch eines jeden Schriftzeichens, dessen potenziell unendliche Wiederholbarkeit, genauer: dessen Iterabilität, im Zuge derselben ein Zeichen immer wieder (aber im Zuge jeder Lektüre nie ein zweites Mal exakt identisch) aktualisiert worden sein wird.

Gewisse Operationen zur Ewigkeitsattribuierung von Schriftzeichen streben nun an, diese potenziell unendliche Wiederholbarkeit zu forcieren, indem sie die Leser zu zwingen versuchen, jenes Potenzial nicht nur für die jeweilige Lektüre zu nutzen, sondern es in seiner Unendlichkeit auszuschöpfen. Textstellen, welche die übrigen (oder keine) Operationen beinhalten, haben zwar als (Schrift-)Zeichengebilde ebenfalls Iterabilität zur Möglichkeitsbedingung, zielen aber nicht darauf ab, deren unendliches Potenzial auszuschöpfen. Dies lässt sich schließlich wiederum mit den zwei folgenden Befunden präzisieren:

1) Die Operationen, die zu einer forcierten Iterabilität führen, suchen Ewigkeit durch Unendlichkeit zu ersetzen - oder in anderen Worten:Zeitlosigkeit durch die radikalste mögliche Betonung von Zeitlichkeit.

Dies gilt nicht nur für die Operation Unendliche Lektüre, sondern eben auch für die Operation Unendliches Verstummen, die gewissermaßen durch das gegenteilige Extrem, durch den radikalen Einsatz der semiotischen Flüchtigkeit von Schriftzeichen, dasselbe Ziel verfolgt wie erstere. Und es gilt ebenfalls für die Grundoperation Reflexivität, nämlich immer dann, wenn sie nicht nur auf eine möglichst autonome Selbstthematisierung des Textes abzielt, sondern zugleich und vor allem auch eine unendliche Spiegelbewegung fördert.

2) Der erste Befund trifft nicht auf Operationen zu, die zu einer Iterabilität von potenziell autonomer performativer Produktion führen. Denn diese streben keine Ersetzung von Ewigkeit durch Unendlichkeit an, sondern - im Rahmen der oben angeführten semiotischen, biologischen und physikalischen Beschränkungen eine Autonomie des Verschriftlichten von zeitlichen Veränderungen seiner intelligiblen Seite sowie von seinem Kontext.

3 Derrida 1999, S. 333 . 
Letzteres gilt auch für die Grundoperation Reflexivität, sofern diese nicht zugleich zu einer unendlichen Spiegelbewegung führt ${ }^{4}$ resp. genauer: diese nicht (in einem dominanteren Maße) forciert.

Die beiden Grundoperationen Autonome Performative Produktion und Reflexivität führen jedoch diese potenzielle Autonomie auf zwei unterschiedliche Weisen herbei: erstere durch eine performative Herstellung dessen, worauf die Zeichen verweisen; letztere durch den Verweis der jeweiligen Textstelle auf sich selbst und ihre Möglichkeitsbedingungen. Im Zuge dieses Selbstverweises kann dabei auch die Iterabilität der jeweiligen Textstellen resp. gar die Ewigkeitsattribuierung selbst verhandelt und damit erst recht in den Dienst der Ewigkeitsattribuierung gestellt werden, wie etwa die Kapitel zum Heinrich von Ofterdingen, zur Fabel Der Phönix sowie zum Gedicht Nänie gezeigt haben.

Uwe Wirth hat zu Derridas Konzept der Iterabilität geschrieben, diese gründe auf der Kraft zum Bruch mit dem Kontext. ${ }^{5}$ Wirths (und Derridas) Worte aufnehmend ließen sich denn auch die beiden soeben formulierten Befunde mit folgenden Worten zusammenfassen:

Die Operationen zur Ewigkeitsattribuierung von Schriftzeichen suchen - freilich mit unterschiedlicher Gewichtung - die zwei zentralen Konstituenten der Iterabilität auszuschöpfen:zum einen die potenzielle Unendlichkeit, zum anderen die potenzielle Autonomie von zeitlichen Veränderungen.

Auch dies sei wiederum tabellarisch dargestellt:

4 Da eine solche jedoch immer beiden Unteroperationen Autoreflexivität und Poetologie potenziell inhärent ist, sind hier die Grenzen fließend und nicht völlig trennscharf zu bestimmen.

5 Vgl. Wirth 2008, S. 61 f.; Derrida 1999, u. a. S. 339. 
Grund- und Unteroperationen zur Ewigkeitsattribuierung von Schriftzeichen
A) Unendliche
B) Autonome Performative
C) Reflexivität
Aktualisation
Produktion
- Unendliche Lektüre
- Poetische
- Autoreflexivität
Performativität
(auton. u./o. unendl.)
- Unendliches
- Poetologie
Verstummen
(auton. u./o. unendl.)

Die jeweiligen Grund- und Unteroperationen führen zu

$\begin{array}{ccc}- \text { forcierter Iterabilität } & \text { - Iterabilität von potenziell } & \text { - Iterabilität von } \\ & \text { autonomer, performativer } & \text { potenziell autonomer } \\ \text { Produktion } & \text { Reflexivität } \\ & \text { und/oder } \\ & - \text { forcierter Iterabilität }\end{array}$

Eine Kombination von A) mit B) oder mit C) führt zu

$\begin{array}{cc}- \text { forcierter Iterabilität von } & - \text { forcierter Iterabilität } \\ \text { potenziell autonomer, } & \text { von potenziell } \\ \text { performativer Produktion } & \text { autonomer Reflexivität } \\ & \text { und/oder } \\ & -{\text { (forcierter Iterabilität })^{2}}^{\text {(f) }}\end{array}$

Im Hauptteil hat sich gezeigt, dass die einzelnen Operationen oft auch in Kombination miteinander auftreten, wobei jedoch nahezu immer eine Operation dominant ist. Die letzte der drei oben angeführten Tabellen trägt dem Rechnung, indem sie auch darlegt, wozu eine Kombination der Grundoperation Unendliche Aktualisation mit den beiden anderen Grundoperationen führt. Ein Beispiel dafür ist etwa Hölderlins Ode Ermunterung, in der sich gerade in den Eingangsversen eine exemplarische Kombination der Unteroperationen Unendliches Verstummen und Poetische Performativität findet. Ein anderes Beispiel wären die Lebens-Ansichten des Katers Murr, wo - bezeichnend für die Romantik (vgl. das nächste Kapitel) - über den 
gesamten Doppelroman hinweg eine starke Kombination der Grundoperation Unendliche Aktualisation mit der Grundoperation Reflexivität zu beobachten ist.

Natürlich sind auch die Grundoperationen Autonome Performative Produktion und Reflexivität miteinander kombinierbar; in solchen Fällen sind die Begriffe aber schlecht direkt ineinander zu integrieren, weshalb in diesen Fällen jeweils eine schlichte Aufzählung genügen muss: Die untersuchten Textstellen aus Schillers Wallenstein-Trilogie sind ein besonders gutes Beispiel für eine Kombination dieser beiden Grundoperationen, was - bei einer Dominanz der Grundoperation Autonome Performative Produktion - zur Iterabilität der Aktualisation sowohl potenziell autonomer performativer Produktion als auch potenziell autonomer Reflexivität führt. Durch eine derart abstrahierende Beschreibung der betreffenden Textstellen des Wallenstein wird zudem auch besonders deutlich, wie stark in Schillers Trilogie die Bemühungen sind - trotz der inhaltlichen Grundanlage eines auf außerhalb des Textes liegende, historische Begebenheiten referierenden Dramas-, die (semiotische) Autonomie und damit eine möglichst große Zeitenthobenheit des Stückes herbeizuführen.

Eine weitere bemerkenswerte Kombination scheint schließlich - dieses Mal auf der Ebene zweier Unteroperationen - das Fragmentarische zu konstituieren: Denn dieses ist, so ließe sich sagen, eine radikale Ausprägung der Unteroperation Unendliches Verstummen, die gerade aufgrund ihrer Radikalität zugleich eine die fragmentarischen Texte weiterführende, potenziell unendliche Bewegung lostritt, die sich letztlich mit der Unteroperation Unendliche Lektüre überschneidet. Dasselbe gilt in umgekehrter Richtung für die Unteroperation Unendliche Lektüre, die in ihrer extremsten Ausprägung zum Fragmentarischen tendiert. Oder vereinfacht ausgedrückt: Das Fragmentarische ermöglicht gewissermaßen eine Kombination der zueinander komplementären Unteroperationen Unendliches Verstummen und Unendliche Lektüre und ist dadurch das wohl wirksamste mögliche Auftreten der Grundoperation Unendliche Aktualisation.

Zusammenfassend sei zum Schluss noch einmal eine tabellarische Darstellung der Grund- und Unteroperationen angefügt, die zugleich anhand der Hintergrundfarben deutlich macht, worauf die jeweiligen Operationen abzielen. Dunkelgrau steht für die Operationen, welche die potenzielle Unendlichkeit von Iterabilität, Weiß für die, welche die potenzielle Autonomie von Iterabilität auszuschöpfen suchen; Hellgrau hingegen bezeichnet diejenigen Operationen, bei denen beides - jeweils unterschiedlich akzentuiert - der Fall sein kann: 
Operationen zur Ewigkeitsattribuierung in Bezug zur Iterabilität von Schriftzeichen

\begin{tabular}{c|c|c}
\hline $\begin{array}{c}\text { Ausschöpfen } \\
\text { potenzieller Unendlichkeit } \\
\text { der Iterabilität }\end{array}$ & $\begin{array}{c}\text { Ausschöpfen } \\
\text { potenzieller Autonomie } \\
\text { der Iterabilität }\end{array}$ & $\begin{array}{c}\text { Ausschöpfen } \\
\text { von potenziell beidem }\end{array}$ \\
\hline A) Unendliche Aktualisation & $\begin{array}{c}\text { B) Autonome Performative } \\
\text { Produktion }\end{array}$ & C) Reflexivität \\
\hline - Unendliche Lektüre & - Poetische Performativität & - Autoreflexivität \\
- Unendliches Verstummen & & - Poetologie \\
\hline
\end{tabular}
frühen 19.Jahrhunderts

Die wichtigsten geistes- und literaturgeschichtlichen Beobachtungen des Hauptteils seien in diesem Kapitel nicht nur zusammengetragen, sondern, zugleich einen Schritt weiter gehend, jeweils direkt in Bezug zu den zwei oben angeführten zentralen Befunden zur Typologie gestellt:

Befund 1) hat auf rein semiotischer Ebene - und damit grundsätzlich unabhängig von Sprache, Schrift und Jahrhundert, wie etwa die Verweise auf das alte Ägypten oder das antike Griechenland in der Einführung oder Ovids Orpheus und Eurydike im Hauptteil gezeigt haben - im Falle der betreffenden Operationen eine Kompensation von nicht zu erreichender Ewigkeit durch Unendlichkeit festgehalten. Dieser Befund lässt sich nun mit den wichtigsten Ergebnissen der historisch-kontextualisierenden Kapitel des Hauptteils zu folgender These vereinen:

Die semiotische Kompensation von Ewigkeit durch Unendlichkeit findet ab der zweiten Hälfte des 18. Jahrhunderts in verstärktem Maße eine Entsprechung auf geistes- und literaturgeschichtlicher Ebene, was zu einem akzentuierten Auftreten der betreffenden Operationen zur Ewigkeitsattribuierung von Schriftzeichen führt. Dies sind insbesondere die Operationen Unendliche Lektüre und Unendliches Verstummen sowie die Grundoperation Reflexivität (letztere jedoch nur in den Fällen, in denen sie hauptsächlich auf eine unbeendbare Lektüre abzielt).

Geistesgeschichtlicher Hintergrund für diese Entsprechung sind im Zuge der Aufklärung verstärkt und miteinander verschränkt sich vollziehende Entwicklungen, wie etwa die Konstitution des modernen, bürgerlichen ${ }^{6}$ Individuums, die Aufweichung des Mimesisgebotes durch eine Dynamisierung

6 „Bürgerlich“ im Sinne von ,zum (damals entstehenden) Bürgertum gehörig“. 
der Natur, die Aufwertung der schöpferischen Einbildungskraft und deren Ästhetisierung sowie die zunehmende historische Relativierung von Autoritäten und deren Werken, sei es im Bereich der Religion, Wissenschaft oder Literatur. Dies alles führt zu resp. geht einher mit einem Prozess der Säkularisierung, im Zuge desselben wiederum eine Kompensation des Verlustes der Heiligen Schrift und des religiös verbürgten ewigen Lebens nach dem Tode durch eine Heiligung der Schrift als solcher zu beobachten ist. Die Ewigkeit der schriftlichen Werke einzelner Individuen wird dabei nicht bloß in der Weiterführung jahrtausendealter Vorstellungen explizit oder implizit behauptet, sondern vielmehr durch verstärkte Bemühungen der Ewigkeitsattribuierung mit aller intellektuellen Anstrengung angestrebt. ${ }^{7}$ Ewigkeitsbehauptung gegenüber und Attribuierung von Schriftzeichen (und der Kunst im Allgemeinen) aber treiben die Säkularisierung ihrerseits weiter voran, was wiederum zu einer verstärkten Heiligung der Schrift als solcher führt usw. Dabei wird deutlich, dass dieser Wechselwirkung selbst eine unendliche Bewegung eingeschrieben ${ }^{8}$ ist, die letztlich bis heute anhält und in der gegenwärtigen digitalen Revolution neuen Schub erhalten hat. ${ }^{9}$

Entscheidenden Anteil an dieser Wechselwirkung hat insbesondere die in den frühen 1770er-Jahren entstehende (und in Wissenschaft, Kunst, Urheberrecht usw. bis heute nachwirkende) Genieästhetik: In ihr vollzieht sich am explizitesten und radikalsten nicht nur die Übertragung des göttlichen Attributs des Schöpferischen auf den Menschen, sondern auch die Übertragung des göttlichen Attributs der Ewigkeit auf das Individuum und von diesem wiederum weiter auf dessen Werk. Während jene Übertragung des Schöpferischen schon länger Forschungskonsens ist, konnte die vorliegende Arbeit die enge Verschränkung jener Übertragung mit der Übertragung des Attributs der Ewigkeit aufzeigen. Ein Individuum, das sich dauerhaft des Status eines Genies versichern will, ist nämlich einem potenziell unendlichen Schöpfungszwang unterworfen. Oder anders formuliert: Ein Genie muss, um ein solches wortwörtlich zu bleiben, entweder Ewiges erschaffen oder aber ewig erschaffen.

In literaturgeschichtlicher Hinsicht trägt die soeben genannte Wechselwirkung zwischen jener historischen Relativierung sowie dem Verlust der

7 Hierbei ist es höchst bemerkenswert, dass Jan Assmann für eine ähnliche religiöse Krisenzeit in der Spätphase des alten Ägypten eine „Explosion“ der Bemühungen zur Verewigung feststellt. Dies führte zu einer ausgeklügelten Kombination von Schriftzeichen mit Verfahren der Architektur, des Rituals, bildlicher Darstellung und sympathetischer Analogie, um - mit der Begrifflichkeit der vorliegenden Arbeit gesprochen - die effizienteste mögliche Ewigkeitsattribuierung der vermittelten Inhalte zu erreichen (vgl. J. Assmann 1991, S. 73 f.).

8 „Eingeschrieben“ auch und gerade im wortwörtlichen Sinne.

9 Vgl. dazu auch den Ausblick 2.3. 
religiös versicherten Ewigkeit einerseits und der schriftlichen Kompensation derselben andererseits wesentlich zu bekannten ästhetischen Konfigurationen, Experimenten und Auseinandersetzungen bei und gewinnt durch diese - der Verweis auf die Genieästhetik hat es bereits angetönt - zugleich weiter an Dynamik. Eine prägende Rolle kommt dabei ab Mitte der 175oer-Jahre Gotthold Ephraim Lessing zu, dessen Paradigmenwechsel innerhalb der zeitgenössischen Gattung des Trauerspiels nicht nur mit einer Priorisierung der Dauer des Mitleidens gegenüber dem schrecklichen Augenblick einherging, sondern auch zu einer Auflösung der von Aristoteles geforderten Dreieinigkeit von Anfang, Mitte und Ende führte. Eine Auflösung, die sich insofern vollzieht, als dass in Lessings bürgerlichem Trauerspiel das Ende in ein Enden überführt und damit zur Mitte wird.

Dieses Überführen des Endes hin zu einer Mitte ist in seiner Wirkmächtigkeit kaum zu überschätzen, denn es versuchte sich nicht bloß an einer Transformation der Paradegattung der Tragödie, sondern ist damit auch entscheidend an der Auflösung der (vermeintlichen) Einheit der Werke einer jeden Gattung beteiligt. Zusammen mit dem kaum später ${ }^{10}$ einsetzenden Aufgreifen der fragmentarischen Form - durch Hamann, Herder und dann vor allem wieder durch Lessing selbst in den Reimarus-Fragmenten - führt es nämlich in den kommenden Jahrzehnten u. a. über Goethe, Jean Paul und die Frühromantiker zu einer Ästhetik des Fragments, die 65Jahre nach Miss Sara Sampson in E. T. A. Hoffmanns Lebens-Ansichten des Katers Murr sodann einen weiteren Höhepunkt erreicht. In Hoffmanns Doppelroman wird nicht nur auf komplexeste Weise das Ende zur Mitte, sondern auch der Anfang.

Hinsichtlich des Fragmentarischen lassen sich die Beobachtungen des Hauptteils wie folgt zusammenfassen:

Während im Zuge des 18. Jahrhunderts die von Aristoteles geforderte und verbürgte Einheit eines schriftlichen Werkes immer radikaler infrage gestellt und parallel dazu der einst ewige, einheitliche Text der Bibel zusehends als fragmentarische Sammlung von Fragmenten betrachtet wird, entstehen immer mehr und radikalere, künstlich erschaffene Fragmente im Versuch, unendliche Texte zu erschaffen. Die auf diese Weise entstehende Wechselwirkung zwischen Religion, Poetik und schriftstellerischem Schaffen vollzieht sich dabei selbst als potenziell unendlicher Prozess.

Die versuchte Kompensation von Ewigkeit durch Unendlichkeit vollzieht sich sowohl auf der Mikroebene - vgl. etwa die Beobachtungen zu Gedankenstrichen, Absatz und Abschnitt $u$. a. bei Lessing, Jean Paul oder E. T. A. Hoffmann - als auch auf der Makroebene, etwa durch Kreisstrukturen, Rahmenerzählungen, die am Ende nicht mehr geschlossen werden, oder durch 
die entortende Eigendynamik vermeintlich rahmender Vorworte, Nachworte und/oder Autor- und Herausgeberfiktionen. Im Falle der Funktion Herausgeber und insbesondere der Herausgeberfiktion wurde zudem deutlich, wie sehr diese als Garanten der Ewigkeit des von ihnen herausgegebenen Werkes und dessen Autors fungieren. Die Ewigkeitsattribuierung von Schriftzeichen ist denn auch eine wesentliche, wenn nicht gar die entscheidende Konstituente sowohl des fiktiven Herausgebers als auch der Entstehung moderner Autorschaft, die umgekehrt wiederum zur Ewigkeitsattribuierung von Schriftzeichen beitragen. ${ }^{11}$

Befund 2) hat auf semiologischer Ebene die übrigen Operationen zur Ewigkeitsattribuierung einer zweiten Gruppe zugeteilt, da diese nicht zu einer forcierten Iterabilität führen resp. nicht auf Unendlichkeit abzielen, sondern auf eine potenzielle Autonomie des Verschriftlichten von zeitlicher Veränderung der Semantik, des Kommunikationszusammenhangs und des außersprachlichen Kontexts.

Ebenso für diese auf Autonomie abzielende Gruppe von Operationen zur Ewigkeitsattribuierung von Schriftzeichen findet sich im untersuchten Zeitraum eine starke Entsprechung auf kultur- und literaturgeschichtlicher Ebene, was auch in diesem Fall zu einem akzentuierten Auftreten der betreffenden Operationen führt. Dies sind nun insbesondere die Grundoperationen Autonome Performative Produktion und Reflexivität (letztere jedoch nur in den Fällen, in denen sie hauptsächlich auf Autonomie abzielt).

Wichtigster geistes- resp. philosophiegeschichtlicher Hintergrund für diese Entsprechung ist, dass - so die These des entsprechenden Kapitels des Hauptteils - die von Descartes ausgehende Reflexionsphilosophie den durch sie selbst maßgeblich herbeigeführten Verlust einer Ewigkeit des Absoluten wiederzugewinnen sucht.

Sie bedient sich bei diesem Versuch - da mittels des Mediums Sprache angestrebt-Verfahren, die im Bereich der Literaturinsbesondere den Operationen zur Ewigkeitsattribuierung Autoreflexivität und Poetologie resp. der Grundoperation Reflexivität entsprechen und damit viel älter sind als die betreffenden geistesgeschichtlichen Entwicklungen.

Im Anschluss an die semiologischen Befunde zur oben präsentierten Typologie lässt sich nun präzisieren: Wie die Grundoperationen Autonome Performative Produktion sowie Reflexivität (letztere hingegen nicht immer)

11 In diesem Zusammenhang wäre es äußerst spannend, sich umfassender auch mit älteren Formen der Herausgeber- und Autorfiktion auseinanderzusetzen; z. B. unter Einbezug von Texten aus dem alten Ägypten, wo etwa im Papyrus Chester Beatty (13. Jahrhundert v. Chr.) fiktive ,Assertoren' inklusive Rahmenerzählung vorkommen, und zwar in Texten, in denen es auch explizit um Verewigung geht (vgl. J. Assmann 1991, S. 176, Anm. 6). 
auf eine Autonomie des Verschriftlichten zielen, baut die Reflexionsphilosophie auf einem Verfahren auf, das ein autonomes denkendes Ich setzt resp. konstituiert. Die in Kapitel IV.3.1 festgestellte Eigendynamik einer potenziell unendlichen Spiegelung, die der Reflexionsphilosophie inhärent ist und diese zu unterlaufen droht, kann hingegen im Falle der Grundoperation Reflexivität geradezu betont werden, und zwar in den Fällen, in denen sie nicht auf Autonomie, sondern auf Unendlichkeit abzielt. Oder in anderen Worten:

Die eine Ausprägung der Grundoperation Reflexivität entspricht also gewissermaßen der Grundoperation, die der Reflexionsphilosophie innewohnt; die andere Ausprägung hingegen entspricht der der Reflexionsphilosophie inhärenten und diese in ihrer grundlegenden Prämisse bedrohenden Eigendynamik. Die Grundoperation Autonome Performative Produktion wiederum entspricht in ihrem Ziel demjenigen der Grundoperation der Reflexionsphilosophie, sucht es aber auf einem anderen Weg zu erreichen.

Vielleicht könnte man bezüglich Letzterem so weit gehen und sagen: Fichte aber bedient sich eher eines Verfahrens, das der Grundoperation Autonome Performative Produktion sehr nahe kommt, indem er mit dem Ich, das sich selber setzt, das Performativ-Schöpferische - oder plakativer ausgedrückt: das Genie! - und damit letztlich ein ästhetisches Prinzip zur Grundprämisse seines philosophischen Systems erhebt. Ebenso scheint der Ablösung des Mimesisgebotes ein performatives Prinzip inhärent: Wenn die Natur dynamisch schöpferisch ist, so verweist das künstlerische dynamische (Er-)Schaffen nicht nur abbildend auf die Natur, sondern es vollzieht zugleich Natur.

Die soeben unternommene Zusammenführung der wichtigsten semiologischen wie historischen Ergebnisse des Hauptteils macht deutlich, dass verschiedene geistesgeschichtliche Entwicklungen in der zweiten Hälfte des 18. Jahrhunderts einerseits Versuche zur Ewigkeitsattribuierung von Schriftzeichen verstärkt begünstigen resp. geradezu nach sich ziehen und dass andererseits diese geistesgeschichtlichen Entwicklungen selbst eine strukturelle Ähnlichkeit mit den Operationen zur Ewigkeitsattribuierung von Schriftzeichen aufweisen. Gerade diese strukturelle Ähnlichkeit führt dazu, dass für den untersuchten Zeitraum zentrale geistesgeschichtliche Entwicklungen und Versuche zur Ewigkeitsattribuierung von Schriftzeichen (und letztlich von Kunst im Allgemeinen) in eine immer stärkere Wechselwirkung treten, der zum einen selbst eine potenziell unendliche Dynamik innewohnt und die damit zum anderen zugleich ihren eigenen Anfang verwischt. Diese Wechselwirkung - und nicht bloß jene geistesgeschichtlichen Entwicklungen allein - ist sodann wesentliche Ursache für literaturgeschichtliche Experimente und Konfigurationen wie die sogenannten Ästhetiken des Fragments, des Genies oder der Autonomie. Mit der letzteren geht einher, dass die 
„Semiotik der Sinnlichkeit“, die sich im Diskurs der entstehenden Disziplin der Ästhetik „dem ausgehenden [18.] Jahrhundert als übergreifende Problemstellung ${ }^{\text {"12 }}$ darbietet, sich der jahrtausendealten Suche nach dem Zeichen, das sich selber zeigt, ${ }^{13}$ und derselben Hoffnung auf Verewigung und Ewigkeit anschließt, wie sie bereits mit der Semiotik der intelligiblen Zeichen verbunden wurde.

Die vermeintlich klare Trennung zwischen Ursache und Wirkung ist in all diesen Fällen freilich eine heuristische, sind die betreffenden literaturgeschichtlichen Entwicklungen doch immer auch schon Teil jener Wechselwirkung. Damit eröffnet sich hier auch eine neue und die bestehende Forschung ergänzende literaturgeschichtliche Perspektive auf die Zeit um 18oo: Ästhetische Auseinandersetzungen zwischen und innerhalb vermeintlich klar abgrenzbarer literarischer Strömungen wie der Klassik oder der Romantik sowie die isoliertere Stellung einzelner Autoren wie Hölderlin und Jean Paull ${ }^{14}$ lassen sich nun auch auf unterschiedliche Präferenzen der betreffenden literaturgeschichtlichen Konfigurationen sowie der einzelnen Autorinnen und Autoren zurückführen; Präferenzen dazu, welche Operationen primär und in welcher Radikalität zur Ewigkeitsattribuierung eingesetzt werden sollen. ${ }^{15}$ Dies unterstützt auch die Forschung der letzten Jahrzehnte, die zunehmend die Kontinuitäten und Verflechtungen zwischen den literaturgeschichtlichen Konfigurationen jener Zeit von der Aufklärung bis zur Romantik aufzeigt. ${ }^{16}$

Mit all dem geht einher, dass gerade auch hinsichtlich der Analyse sowie einer literatur- und geistesgeschichtlichen (eben nicht starren) Verortung der einzelnen Beispieltexte sich die neue Perspektive auf Operationen zur

\footnotetext{
12 Schneider 1998, S. 12.

13 Vgl. ebd.

14 Oder über den Rahmen der vorliegenden Arbeit hinaus: wohl auch Annette von DrosteHülshoff; vgl. dazu das Unterkapitel 3.4 der Einführung.

15 Um Redundanzen zu vermeiden, sei dies hier nicht noch einmal detailliert ausgeführt; vgl. dazu u. a. die historisch-kontextualisierenden Kapitel II.3.2 und II.3.4; sowie gerade betreffend die Relation zwischen Klassik und Romantik das Ende des Kapitels zum Zauberlehrling; den skizzierten Vergleich von Novalis' Heinrich von Ofterdingen mit Goethes Wilhelm Meister in Kapitel IV.1.1.4; und das Kapitel 2.1 des Ausblicks.

16 Vgl. als ein Beispiel dafür Herbert Uerlings, der ausgehend von Novalis' Auseinandersetzung mit Goethe schreibt: „Es geht bei dem Nachweis solcher poetologischer Entsprechungen, Anverwandlungen und Entgegensetzungen also nicht darum, die Unterschiede zur Weimarer Klassik zu leugnen, sondern - im Gegenzug zu Persen zu betonen, daß die Gemeinsamkeiten zwischen der Frühromantik einerseits und der Weimarer Klassik, Spätaufklärung und Transzendentalphilosophie andererseits größer sind als die zwischen dieser zweiten Gruppe und der, älteren' aufklärerischen Ästhetik und Poetik (wie sie freilich auch in der Berliner Aufklärung noch gepflegt wurden)“, Uerlings 2004, S. 48.
} 
Ewigkeitsattribuierung als außerordentlich gewinnbringend erwiesen hat. Es ergaben sich zahlreiche Ergänzungen bestehender Forschung und neue Interpretationsansätze, die hier alle noch einmal aufzuzählen zu weit führen würde - man halte sich dafür direkt an die betreffenden Kapitel. Zu betonen bleibt aber, dass auch deutlich wurde, welch großes Potenzial diese ergänzende Perspektive für die Auseinandersetzung mit vielen weiteren Texten sowohl aus demselben Zeitraum als auch aus anderen Jahrhunderten besitzt.

\section{Ausblick unter weiterer Anknüpfung an bestehende Forschungsdiskurse}

In der Einführung wurde die Hoffnung geäußert, dass ein Fokus auf Operationen zur Ewigkeitsattribuierung von Schriftzeichen auch neue Anknüpfungsmöglichkeiten an und für bestehende Diskurse schaffen möge, die über das Erarbeiten einer entsprechenden Typologie und deren historische Kontextualisierung hinausreichen. Diese Offenheit war denn auch eine wesentliche Grundhaltung beim Verfassen der vorliegenden Arbeit, der es letztlich nicht um eine isolierte Typologie, sondern um das Potenzial derselben für bereits bestehende Forschungsdiskurse geht. Wegen dieser Grundhaltung und des Umstandes, dass sich daraus im Hauptteil eine die Erwartungen übertreffende Fülle an weiterführenden Anknüpfungsmöglichkeiten aufgetan hat, sei zum Schluss ein etwas ausführlicherer Ausblick erlaubt, ${ }^{17}$ der einige davon noch einmal aufgreift und bündelt. Dabei liegt der Fokus ganz auf Anknüpfungsmöglichkeiten, die über einzelne Texte und Autoren hinausgehen und direkt an einige in der Einführung erwähnte Forschungsdiskurse anschließen. ${ }^{18}$

\subsection{Zur Literatur- und Geistesgeschichte sowie zur Typologie}

Die beobachtete, selbst potenziell unendliche Wechselwirkung zwischen Versuchen zur Ewigkeitsattribuierung von Schriftzeichen und den oben

17 Ebenso wie eingangs zur Widmung würde sich hier auch eine eigene Auseinandersetzung zum „Ausblick“ von wissenschaftlichen Arbeiten anbieten, scheint diesem doch entscheidend die Grundoperation Unendliche Aktualisation inhärent zu sein im Versuch, die Unendlichkeit des wissenschaftlichen Fortschritts und der eigenen Arbeit zu garantieren. Dass für die vorliegende Arbeit ein ausführlicher Ausblick notwendig scheint, wäre somit, selbstkritisch betrachtet, ein weiterer Hinweis auf die Eigendynamik jener Operationen und die Verschiebung göttlicher Attribute auf menschliche, nicht nur literarische, sondern auch wissenschaftliche Werke.

18 Betreffend spezifischere weitere Ansätze zu den einzelnen Beispieltexten halte man sich hingegen direkt an die entsprechenden Kapitel des Hauptteils. 
beschriebenen geistesgeschichtlichen Entwicklungen müsste über den Zeitraum von 1755 bis 1821 hinaus weiterverfolgt werden. Dabei wären $u$. a. folgende Fragen und Hypothesen bedenkenswert:

Inwiefern können die Ergebnisse der vorliegenden Arbeit mit den weiteren noch zu erwartenden Ergebnissen des DFG-Schwerpunktprogramms "Ästhetische Eigenzeiten. Zeit und Darstellung in der polychronen Moderne“ kombiniert und zu weiteren Erkenntnissen geführt werden? ${ }^{19}$ Besonders großes Potenzial hätten hierbei wohl Ansätze, welche die Operationen zur Ewigkeitsattribuierung und die Ergebnisse zu deren akzentuiertem Auftreten in der Zeit um 1800 für die Leitthese des Schwerpunktprogramms, die eine „polychrone Moderne“ postuliert, ${ }^{20}$ fruchtbar zu machen suchen. Etwa dahingehend, dass man sich fragen müsste, ob unterschiedlichen „nachhaltige[n] Kulturen der Eigenzeitlichkeit" ${ }^{\text {"1 }}$ jeweils eine Grund- oder Unteroperation zur Ewigkeitsattribuierung besonders inhärent ist, was sowohl für die vorliegende Arbeit als auch für das Schwerpunktprogramm den Blick für längere historische Linien, Brüche und Konstellationen schärfen dürfte. Ein erster in diese Richtung gehender Versuch wäre die wichtige Ergänzung der von Michael Gamper und Helmut Hühn für das Schwerpunktprogramm getätigten Grundannahme zu Form und Autonomie:

Sie [die Form, MG] verdankt sich ihrerseits aber wiederum selbst in ihren Produktionsprozessen komplexen Zeitlichkeitsstrukturen, und diese ihr als kontinuierliche Transformation mitgegebene Zeitlichkeit prägt auch die Rezeptionsvorgänge. Form kann deshalb nicht, wie in klassizistischen Ästhetiken oft intendiert, als eine Präsenz verstanden werden, die den Stoff der Zeitlichkeit entwindet, sondern als ein Resultat und Ausdruck von Temporalität. ${ }^{22}$

Denn die vorliegende Arbeit hat gezeigt, dass etwa die Autonomieästhetik stark von derjenigen Gruppe der Operationen zur Ewigkeitsattribuierung geprägt ist, die auf Autonomie des Verschriftlichten abzielt, dass aber zugleich insbesondere der zu dieser Gruppe gehörigen Grundoperation der Reflexivität ${ }^{23}$ auch eine potenziell unendliche und damit radikal zeitliche Bewegung inhärent ist. Am Beispiel von Goethes Zauberlehrling ist besonders deutlich geworden, dass sich zumindest die Weimarer Klassik dieser die eigene

\footnotetext{
19 Zu einem ersten Überblick über den Abschluss der ersten Phase des Programms vgl. Bies und Gamper 2019 .

$20 \quad$ Vgl. Gamper und Hühn 2014, S. 21.

21 Ebd.

22 Ebd., S. 16.

23 Und in gewissen Fällen auch der Operation Poetische Performativität, wie das Kapitel zum Zauberlehrling gezeigt hat.
} 
Ästhetik unterlaufenden, verzeitlichenden Operationen bewusst ist, gar damit experimentiert, ${ }^{24}$ sie aber letztlich einzudämmen versucht, während - so eine These des Hauptteils - die Romantik gerade diesen verzeitlichenden Aspekt der Grundoperation Reflexivität begeistert aufgreift, radikal bejaht und bis an die Grenzen des intelligibel Nachvollziehbaren weitertreibt. ${ }^{25}$ Es deutet also alles darauf hin, dass auch die vom DFG-Schwerpunktprogramm untersuchten ,ästhetischen Eigenzeiten' nicht einseitig und zu dichotomisch als Formen der Verzeitlichung „klassizistischen Ästhetiken“, die auf zeitenthobene Autonomie abzielen, gegenübergestellt werden sollten - erste Resultate des Programms selbst scheinen inzwischen ebenfalls in diese Richtung zu weisen.

Mit derselben Differenzierung wären letztlich etwa auch Uwe Wirths Beobachtung zur Verzeitlichung durch die Frühromantiker ${ }^{26}$ oder Dirk Göttsches Untersuchung zum Zeitroman sowie zur literarischen Zeitreflexion zu ergänzen. ${ }^{27}$ In diesem Zusammenhang wäre zudem der in Kapitel II.1.1.3 gestreiften und an die Forschung Claudia Liebrands anknüpfenden ${ }^{28}$ Frage nachzugehen, ob und inwiefern E. T. A. Hoffmann in den Lebens-Ansichten des Katers Murr eine Kombination der bevorzugten Operationen zur Ewigkeitsattribuierung der Weimarer Klassik mit den bevorzugten der Romantik anstrebt. Schließlich würde sich in einem noch umfassenderen Bezug auf Zeit und Zeitlichkeit auch die Frage stellen, ob und inwiefern die Ergebnisse des DFG-Schwerpunktprogramms „Ästhetische Eigenzeiten“ und der vorliegenden Untersuchung mit neueren grundlegenden philosophischen und/oder theologischen Entwürfen zu verknüpfen wären. Man denke dabei u. a. an Michael Theunissens Negative Theologie der Zeit, in der etwa die chiastische Verschränkung des Selbstvollzuges von Individuum und Zeit ${ }^{29}$ an

24 Vgl. dazu auch den dem Programm selbst entstammenden Sammelband Hühn, Oschmann, Schnyder 2018.

25 Vgl. dazu neben den betreffenden Kapiteln des Hauptteils auch Wirth 2008, insbesondere S. 291-295. Ebenfalls, freilich kritisch, zu integrieren wären in einer weiterführenden Untersuchung Paul de Mans Überlegungen zu Allegorie und Symbol (vgl. de Man 1993); vgl. dazu ausführlich Geisenhanslüke 2003, S. 15-17 und 81-94.

26 Vgl. Wirth 2008, S. 292.

27 Vgl. Göttsche 2001, u. a. S. $118 \mathrm{f}$.

28 Vgl. Liebrand 1996, insbesondere S. 194 und in Bezug zur Genie- und Autonomieästhetik zusammenfassend S. $13 \mathrm{f}$.

29 Vgl. Theunissen 1991, S. 303-305, wo es u. a. heißt: „Der Vollzug der Zeit durch menschliche Subjekte ist zugleich deren Selbstvollzug. Hierin erblicke ich eines der tiefsten Geheimnisse humaner Existenz. Das Geheimnisvolle liegt des näheren in der Umkehrbarkeit des Satzes: Der Selbstvollzug endlicher Subjektivität ist ein Vollzug der Zeit. [...] Immerhin lässt sich jetzt erklären, was mit ,Vollzug' gemeint ist. Wir Menschen können uns selbst nicht realisieren, ohne Zeit mitzurealisieren“ (ebd., S. 303 f.). 
die Grundoperation Autonome Performative Produktion erinnert. Bei dieser negativen Theologie der Zeit wäre zudem kritisch zu überprüfen, ob deren vom „Kunstschönen“ inspirierter, zentraler, Dauer implizierender Begriff Verweilen $^{30}$ nicht seinerseits entscheidend auf der Tradition der Ewigkeitsbehauptung gegenüber Kunstwerken beruht.

Hinsichtlich bereits zu Gemeinplätzen gewordener Phrasen wie der ,Zerrissenheit des Menschen ' und der, Fragmentierung des Lebens' in der Moderne ließe sich zudem folgende Hypothese in den Diskurs zu den Merkmalen und Konstituenten der Moderne einbringen: ${ }^{31}$

Gegenüber vergangenen Jahrhunderten häufigere, umfassendere und damit im ästhetischen Diskurs dominanter auftretende Operationen zur Ewigkeitsattribuierung von Schriftzeichen - und wohl auch von anderen Medien als der Schrift - sind eine grundsätzlichere Konstituente der Moderne als die des Fragmentarischen, denn das Fragmentarische ist zugleich Teil und Folge jener akzentuierten Ewigkeitsattribuierung. Oder mit anderen Worten: Das Fragment als vermeintliche Leitmetapher der Moderne ist im Grunde bloß eine Metonymie, die auf die in der Moderne verstärkt auftretenden Versuche zur Ewigkeitsattribuierung verweist, die u. a. das Fragmentarische als Kombination der Operationen Unendliche Lektüre und Unendliches Verstummen ${ }^{32}$ in ihren Dienst zu nehmen suchen.

Wenn es aber um die Frage geht, ob sich für einzelne Operationen zur Ewigkeitsattribuierung von Schriftzeichen größere historische oder gar kulturelle Linien oder Muster beobachten lassen, ist ein Blick vor und hinter den untersuchten Zeitbereich unabdingbar und wohl ausgesprochen ergiebig, wie bereits die Verweise im Hauptteil und in der Einführung - etwa auf die neuere Forschung zu Annette von Droste-Hülshoff, Franz Kafka, Thomas Mann oder Gustave Flaubert und James Joyce ${ }^{33}$ - angedeutet haben. Als ein Beispiel für einen möglichen, generalisierbaren Zusammenhang zwischen einzelnen Operationen zur Ewigkeitsattribuierung von Schriftzeichen und größeren geistesgeschichtlichen Veränderungen sei hier noch einmal kurz an die bis ins 12. Jahrhundert zurückreichende Tageliedlinie angeknüpft, die in den Kapiteln zu Der Spinnerin Nachtlied und der historischen Kontextualisierung insbesondere der Unteroperation Unendliches Verstummen skizziert

30 Ebd., insbesondere S. 286-289.

31 Vgl. dazu A. Assmann 2015, insbesondere S. $5^{2}$ f. inklusive ihres Verweises auf: Funk, Gerald et al. (Hg.): Ästhetik des Ähnlichen. Zur Poetik und Kunstphilosophie der Moderne. Frankfurt am Main 2001.

32 Zu dieser Kombination vgl. die Zusammenführung unter V.1.1.

33 Zu Flaubert und Joyce vgl. Mahler 2011. 
wurde. Ausgehend von dieser Tageliedlinie ließe sich nämlich folgende gewagte Hypothese ableiten:

In Texten (von einzelnen Autoren bis zu ganzen Epochen), für deren kulturhistorischen (oder zuweilen auch bloß autorspezifischen) Kontext eine (religiöse) Ausrichtung auf das Leben nach dem Tod verstärkt feststellbar ist, ist eine ästhetisch besonders produktive, einzelne Werke bis hin zu Gattungen prägende Verwendung der Unteroperation Unendliches Verstummen zu beobachten.

Diese Hypothese wiederum ließe sich ergänzen durch eine zweite, gewissermaßen komplementäre:

Umgekehrt ist in Texten, für deren kulturhistorischen oder autorspezifischen Kontext eine zunehmende Abkehr von einem (religiös begründeten) Leben nach dem Tod feststellbar ist, eher eine verstärkte Verwendung der Unteroperation Unendliche Lektüre festzustellen.

Dies sind freilich Hypothesen, deren Bestätigung oder Verwerfung eine eigene, größere Untersuchung gewidmet werden müsste (zu denken wäre dabei z. B. an den vergleichenden Einbezug einer vertieften Auseinandersetzung mit Texten des Barock). Erste Bestätigungen finden sie einerseits in den ausgehend von Brentanos Der Spinnerin Nachtlied beobachteten Variationen und Adaptionen, die die Tageliedszene vom 12. bis ins 19. Jahrhundert erfahren hat, ${ }^{34}$ und andererseits in den oben genannten literaturgeschichtlichen Entwicklungen der zweiten Hälfte des 18. Jahrhunderts: Es scheint nämlich kein Zufall zu sein, dass ausgerechnet die Romantiker mit ihrer Tendenz zu einer neuen Hinwendung zur Religion - die aber in gewissem Sinne und ganz nach der frühromantischen Dialektik die Abkehr von der Religion miteinschließt sowohl die der Unteroperation Unendliches Verstummen als auch der Grundoperation Reflexivität inhärente potenziell unendliche Bewegung prominent einsetzten, während etwa der Goethe der Weimarer Klassik diesen Operationen resp. Ausprägungen derselben kritischer gegenübersteht. ${ }^{35}$

Ob diese Hypothesen umgekehrt durch den von Michael Neumann beobachteten „radikalisierten Unendlichkeitsbegriff“ vor allem von der Romantik bis zur Avantgarde einen ersten prominenten Widerspruch erfahren oder letztlich doch eher weiter bestätigt werden, ist auf die Schnelle ebenfalls nicht zu beantworten ${ }^{36}$ möglich wäre jedoch auch, dass die akzentuierte Verwendung der Unteroperation Unendliches Verstummen durch die Romantik zu einer Eigendynamik führt, die deren Vorkommen auch in zunehmend säkularisierten Kontexten förderte.

34 Vgl. dazu auch Wolf 2011.

35 Vgl. dazu insbesondere das Kapitel III.1.1 zum Zauberlehrling.

36 Vgl. Neumann 2018. 
Zumindest aber deutet sehr vieles darauf hin, dass in der aktuellen, abendländischen Gegenwart des frühen 21. Jahrhunderts der Prozess der Säkularisierung einerseits einen neuen Höhepunkt erreicht, während andererseits gleichzeitig die Unteroperation Unendliche Lektüre medienübergreifend eine immer dominantere Rolle einzunehmen scheint. ${ }^{37}$ Im Falle von Letzterem wäre etwa zu denken an miteinander verlinkte Texte des World Wide Webs oder, auf der Seite der Schreibenden, an Wikis, während auf dem Buch-, Kino-, TV- und Streamingmarkt die Form der potenziell unendlichen Serie ${ }^{38}$ eine sich immer weiter steigernde (Eigen-)Dynamik erreicht hat. ${ }^{39}$ Viele dieser vermeintlich neuen Ausprägungen sind letztlich digitale Umsetzungen und/ oder Erweiterungen von Verfahren, die im Hauptteil bereits für die Zeit um 18 oo beobachtet wurden. ${ }^{40}$ Oder plakativ gefragt: Sind Big Data und die Vision vom Internet der Dinge letztlich nichts anderes als die radikalstmögliche Unterfütterung aller Lebensbereiche mit der Unteroperation Unendliche Lektüre, nichts anderes als ein weiterer, zeichenhafter Verewigungsversuch?41 All dies führt schließlich zu einer Makroperspektive auf die Geschichte kultureller Semiose und die ihr zugrunde liegenden „Zeichenlogiken“,42 die etwa Aleida Assmann in ihrer Forschung einnimmt: Inwiefern schlagen sich

37 Vgl. dazu auch Brukamp 2011, S. 77-92.

38 Vgl. Fröhlich 2015 .

39 Erste Symptome einer solchen Eigendynamik sind etwa die Potenzierung der Serie, z. B. im Falle der Harry Potter- oder The Hunger Games-Verfilmungen, bei denen der letzte Teil der Serie wiederum in eine Serie von zwei Teilen aufgespalten wurde. Ein grundlegenderes Beispiel wäre die zu beobachtende Tendenz, dass TV- resp. gestreamte Serien klassischen Kinoproduktionen den führenden Rang im Bereich des Mediums Film ablaufen. Natürlich kommt dabei auch ökonomischen Faktoren zentrale Bedeutung zu gerade dem Kapitalismus inhärente, potenziell unendliche Prozesse und Dogmen wie das Zinswesen und Wachstum. Dass aber so etwas wie eine ,Trilogie in vier Filmen' überhaupt erst produziert und vom Publikum akzeptiert wird, lässt sich wohl nicht allein mit wirtschaftlichen Überlegungen seitens der Produzenten begründen.

40 Das Paradebeispiel dafür gibt E. T. A. Hoffmanns Lebens-Ansichten des Katers Murr ab; vgl. dazu die Kapitel II.1.2, II.3 und IV.3.3; sowie Wirth 2002, S. 432. Des Weiteren vgl. Krüger 2004, insbesondere S. 401-413.

41 Zum noch weiter reichenden Glauben an die Möglichkeit des Erlangens von Unsterblichkeit durch die "autonome[] und aktive[] Simulation des Menschen in der Virtualität“ vgl. Krüger 2004, S. 401. Zu beachten wäre bei einer weiterführenden Auseinandersetzung mit diesem Glauben auch Krügers Standpunkt, dass besonders im „anglo-amerikanischen Kontext [...] wir eine Fortschrittsideologie vor[finden], die sich weitgehend innerhalb der Religion versteht" und deren Auswirkungen deshalb mit einer dichotomischen Betrachtungsweise (christliche Heilsgeschichte vs. säkulare Fortschrittsideologie) nicht zufriedenstellend zu erklären seien (ebd., S. 313 f.). Vgl. hierzu des Weiteren Theisohn 2012, u. a. S. 18 f. und 473 . 
allenfalls Veränderungen im semiotischen Paradigma einer Gesellschaft im Auftreten der Operationen zur Ewigkeitsattribuierung von Schriftzeichen nieder - und umgekehrt? Und könnten sich diese Operationen auch auf einer über schriftliche Texte hinausreichenden Makroebene als "Strategien der Dauer “43 erweisen?

Was die Typologie selbst anbelangt, so drängt sich natürlich die Frage auf, ob sich weitere Unter- oder sogar Grundoperationen zur Ewigkeitsattribuierung von Schriftzeichen beobachten ließen. Zudem müsste man vertiefter verfolgen, ob bei den Unteroperationen weitere Binnendifferenzierungen sinnvoll wären. Auf Letztere hat die vorliegende Arbeit absichtlich verzichtet, um für eine erste grundlegende Untersuchung eine zu starke begriffliche Kleinteiligkeit zu vermeiden. Für weiterführende Auseinandersetzungen wäre aber zumindest für die Unteroperation Unendliche Lektüre eine solche Binnendifferenzierung denkbar, dies ließen insbesondere das Kapitel zu den Lebens-Ansichten des Katers Murr und die zum betreffenden Roman bereits bestehende Forschung vermuten. Noch mehr wäre aber eine Erweiterung der Grundoperation Autonome Performative Produktion zu bedenken: Als weitere eigene Unteroperation könnten etwa Verfahren gelten, welche die Materialität der Schrift mit dem Inhalt des Verschriftlichten in Einklang zu bringen suchen. Ein simples Beispiel dafür wäre etwa, das Wort ,rot' anstatt mit blauer mit roter Tinte zu schreiben. Unter eine Variante der Unteroperation Poetische Performativität hingegen könnten Versuche fallen, die über eine ikonische Anordnung der Schriftzeichen - um Charles Sanders Peirces Begrifflichkeit zu benutzen ${ }^{44}$ - die Symbole zugleich zu einem Ikon für den Inhalt ebendieser Symbole werden lassen wollen. Ein Beispiel hierfür wären die Texte der Konkreten Poesie im 20. Jahrhundert, aber auch viel weiter zurückreichende, demselben Prinzip folgende Werke wie etwa der frühmittelalterliche Figurengedichtzyklus De laudibus sanctae crucis (9. Jahrhundert) von Hrabanus Maurus. Beide Ergänzungen zur Autonomen Performativen Produktion führen freilich an die definitorischen Grenzen der in der Typologie versammelten Operationen, die als innersprachliche definiert wurden. ${ }^{45}$ Wiederum tabellarisch dargestellt nähmen sich die möglichen Ergänzungen der Typologie wie folgt aus:

\footnotetext{
43 Vgl. A. Assmann 1999.

44 Vgl. Peirce 1955.

45 Eine weitere Unterteilung wäre auch für die Grundoperation Reflexivität resp. ihre Unteroperationen zu prüfen. Einen möglichen Ansatz dafür böte eventuell Michael Scheffels Typologie der „Formen selbstreflexiven Erzählens“ (vgl. ders. 1997), wobei aber bei einer allfälligen Übertragung aufgrund der unterschiedlichen Perspektiven (Ewigkeitsattribuierung vs. Erzähltheorie) Vorsicht geboten ist.
} 
Ausblick auf mögliche Erweiterungen der Typologie

A) Unendliche Aktualisation

- *Kreisstruktur?

- *Forcierte

Intertextualität?

- Unendliches Verstummen

- *offene

Rahmenhandlung?
B) Autonome Performative Produktion

- Poetische Performativität - Autoreflexivität

- *Ikonisch-Poet.

Performativität?

\author{
- *Materiale \\ Performativität?
}

C) Reflexivität

\author{
Autoreflexivitat
}

Des Weiteren fällt auf, dass die vorliegende Arbeit auch auf semiotischtypologischer Ebene Anknüpfungspunkte zur Forschung Aleida Assmanns aufweist. So besitzen die Operationen Unendliches Verstummen und Poetische Performativität Ähnlichkeiten mit der von ihr mit den Begriffen „Zeichenkraft“ resp. „Zeichenlogiken“ gefassten „Entleerung (asemantisches Zeichen)“ resp. „Vergegenwärtigung (magische Zeichen)“. ${ }^{46}$ Aleida Assmann „folgt dabei zunächst der dreiteiligen Klassifikation von Charles S. Peirce, der die Vielfalt der Zeichen bekanntlich in die Kategorien Index, Ikon und Symbol eingeordnet hat, und möchte sie um drei weitere ergänzen: die performativen, asemantischen und magischen Zeichen“. ${ }^{47}$ Ihre Terminologie ${ }^{48}$ bärge - von

46 Vgl. A. Assmann 2015, S. 53-6o.

47 Ebd., S. 53. Aleida Assmann verwendet hier einen weiten Begriff von ,performativ ${ }^{\star}$ orientiert am späten Austin im Sinne von „Handlungsanweisungen“, was erklärt, weshalb die in der vorliegenden Arbeit vertretene enge Verwendung des Begriffs, performativ' sich stärker mit ihren ,magischen Zeichen' berührt.

48 Assmanns Terminologie mag auf den ersten Blick vielleicht etwas verwirren. Dies aus dem Grund, dass sie Peirces ,Zeichenarten' mit ,Zeichenmodi‘ zu vermischen scheint. Bei näherer Betrachtung wird jedoch deutlich, dass sie - wiederum durchaus kompatibel mit Peirces Zeichentheorie (vgl. Peirce 1955) - wohl Folgendes meint: Die Zeichenart ,Symbol` konstituiert sich zwar grundsätzlich nach der Zeichenlogik „Stellvertretung (Symbolisches Zeichen)“, kann sich aber im Extremfall je auch im Modus von allen anderen fünf Zeichenlogiken konstituieren, also z. B. auch in dem der ikonischen. Dies wiederum sei abhängig von der "Wahrnehmungsperspektive“ (A. Assmann 2015, S. 53), womit sie nach dem Verständnis des Verfassers dem Umstand Rechnung trägt, dass etwa ein indexikalisch gelesenes Symbol in einer, indexikalischen Lektüre' sich als Index konstituiert und nicht (mehr) als Symbol. 
Aleida Assmann bereits angetönt - auch für die Literaturwissenschaft großen analytischen und heuristischen Wert. Dabei wäre zu klären, ob und inwiefern die hier dargelegte, spezifisch auf die Ewigkeitsattribuierung bezogene Typologie, in Kombination etwa mit Assmanns Klassifikationen, nicht auch in einer allgemeinen zeichentheoretischen Typologie aufgehen könnte.

In dieselbe Richtung zielend ist festzuhalten, dass weitere Studien vielversprechend wären, die den Fragen nachgehen, ob, inwiefern und mit welchen allfälligen Ergänzungen die hier erarbeitete Typologie inklusive der historischen Erkenntnisse auch auf andere Medien und Künste ${ }^{49}$ oder gar ein anderes Zeichensystem wie das der Mathematik ${ }^{50}$ übertragbar ist. Diese Fragen der Übertragbarkeit stellen sich natürlich auch dahingehend, ob sich an Texten anderer Schrifttypen, wie etwa der chinesischen Schriftzeichen, zusätzliche Operationen beobachten ließen und ob in anderen Schriftkulturen als der abendländischen ähnliche kulturgeschichtliche Konstellationen zu einem akzentuierten Auftreten derselben Operationen führen oder nicht. Anzunehmen wäre etwa, dass in allen Schriften mit stärkeren ikonischen Aspekten die Unteroperation Unendliches Verstummen weniger stark resp. weniger ästhetisch produktiv vertreten ist, während dafür das Ikonische eine stärkere Gewichtung oder zumindest erweiterte Möglichkeiten der Grundoperation Autonome Performative Produktion nach sich zieht. Und schließlich blieben gerade auch mit Blick auf eine Integration der Typologie in eine allgemeine hermeneutische Theorie (siehe das folgende Kapitel) - die Möglichkeiten und Grenzen einer Übertragbarkeit auf die mündliche Kommunikation zu klären.

\subsection{Zur Hermeneutik}

Dass die Frage, welche Operationen zur Ewigkeitsattribuierung von Schriftzeichen eingesetzt werden, letztlich auch die grundlegend hermeneutische Frage berührt, was denn überhaupt in einem Kommunikationszusammenhang verstanden werden kann, darauf hat die Einführung bereits hingewiesen. Dabei wurde festgestellt, dass (etwas vereinfacht ausgedrückt) die hermeneutische Tradition bis und mit mindestens Hans-Georg Gadamer die Ewigkeitsbehauptung gegenüber Schriftzeichen eher verstärkt hat, als sie kritisch zu hinterfragen. Gleichzeitig bestünde nun aber die Möglichkeit - gewissermaßen

49 Ein Paradebeispiel für das Auftreten der Operationen Unendliche Lektüre und Unendliches Verstummen in einem noch jungen Medium wären etwa die Videospiele resp. Videospielreihen Dark Souls und Bloodborne; vgl. Inderwildi 2017.

50 Man denke etwa an die Mengenlehre, an fraktale Geometrie oder das Halteproblem in der theoretischen Informatik; vgl. dazu auch Neidhart 2008; zu Novalis' „Beschäftigung mit zeitgenössischen Konzepten des Infinitesimalkalküls" und deren Auswirkungen auf sein literarisches und theoretisches Schaffen vgl. Daiber 2001, S. 132-139. 
in der Nachfolge von u. a. Karlheinz Stierle und Jürgen Bolten ${ }^{51}-$, die hier erarbeitete Typologie von Operationen zur Ewigkeitsattribuierung von Schriftzeichen in ein hermeneutisches Modell zu integrieren. Dabei würden sich mindestens zwei grundlegende Herausforderungen stellen:

1. Welche Stellung nehmen innerhalb einer (text-)hermeneutischen Theorie Textstellen ein, denen eine Operation zur Ewigkeitsattribuierung von Schriftzeichen inhärent ist? Es sei hier zumindest einmal die Hypothese gewagt: Solche Textstellen wären wohl die bestmöglichen Ausgangs- und/ oder Referenzpunkte eines jeden hermeneutischen Prozesses, da sie in semiotischer Hinsicht gegenüber den übrigen Textstellen am wenigsten zeit- und kontextabhängig sind. ${ }^{52}$

2. Inwiefern ist der Verstehensprozess selbst ein potenziell unendliches Verfahren, und inwiefern ähnelt und/oder unterscheidet er sich dabei von der Funktionsweise der Operationen zur Ewigkeitsattribuierung von Schriftzeichen? Ähnelt er beispielsweise bloß derjenigen Gruppe der Operationen, die Ewigkeit durch Unendlichkeit zu ersetzen suchen? Und wie steht er im Verhältnis zur anderen Gruppe, die auf Autonomie abzielt?

Die Auseinandersetzung mit diesen beiden Punkten könnte wiederum bereits bei Schleiermacher ansetzen, bei dem es in der postum erschienenen Hermeneutik und Kritik (1838) heißt:

$[18,4]$ Die Aufgabe ist, so gestellt, eine unendliche, weil es ein Unendliches der Vergangenheit und Zukunft ist, was wir in dem Moment der Rede sehen wollen. Daher ist auch diese Kunst [= die Kunst des Verstehens, MG] ebenfalls einer Begeisterung fähig wie jede andere. In dem Maße, als eine Schrift diese Begeisterung nicht erregt, ist sie unbedeutend. - Wie weit man aber und auf welche Seite vorzüglich man mit der Annäherung gehen will, das muß jedenfalls praktisch entschieden werden und gehört höchstens in eine Spezialhermeneutik, nicht in die allgemeine. ${ }^{53}$

$5^{1} \quad$ Vgl. Bolten 1985; und Stierle 1985. Letzterer fasst etwa seine Kritik an Gadamer wie folgt zusammen: „Das Programm einer Hermeneutik von der ,Mitte der Sprache“ aus verwirklicht sich bei Gadamer konsequent unter Verzicht auf jegliche Erkenntnis, die die moderne Sprachwissenschaft, Zeichentheorie und Sprachpsychologie als methodische Disziplinen erbracht hatten" (Stierle 1985, S. 340).

$5^{2}$ Das gilt insbesondere für die Operationen, welche die potenzielle Autonomie der Iterabilität auszuschöpfen suchen. Nicht zufällig war etwa die autoreferenziell-autoreflexive Stelle am Ende der Texte des Steins von Rosette entscheidender Ausgangspunkt für die Entzifferung der Hieroglyphen (vgl. Doblhofer 20oo, S. 56).

Schleiermacher, Hermeneutik und Kritik, S. 94. 
Man könnte nämlich sagen, dass die Operationen zur Ewigkeitsattribuierung von Schriftzeichen "diese Begeisterung“ zu erregen suchen. Und zur Formulierung „wie weit man gehen will“ ließe sich ergänzen: Mindestens diejenigen Operationen, die zu einer forcierten Iterabilität führen, suchen die Rezipienten dazu zu zwingen, so weit wie möglich zu gehen - und zwar wohl auf beiden Seiten. Zudem ist darauf hinzuweisen, dass hier auch bei Schleiermacher eine Verschiebung festzustellen ist, die den literatur- und geistesgeschichtlichen Ergebnissen der vorliegenden Arbeit entspricht: Ein absoluter, ewiger (von Gott und den,Autoritäten' garantierter) Sinn ist unsicher geworden und soll nun durch das Verfahren einer Hermeneutik wenigstens annähernd wieder eingeholt werden - durch ein Verfahren, das in der soeben zitierten Stelle bei Schleiermacher selber als ein unendliches beschrieben wird. Auch dem Beginn der modernen Hermeneutik liegt also ein Verfahren zugrunde, das letztlich selbst einer Operation zur Ewigkeitsattribuierung entspricht, indem es ewig gültigen Sinn durch unendliche Sinnstiftung zu ersetzen sucht. Oder in anderen Worten: Die moderne Hermeneutik sucht die ihr inhärente Ewigkeitsbehauptung, es gäbe über die Zeiten hinweg etwas zu verstehen, nach der Struktur einer selbsterfüllenden Prophezeiung wahr werden zu lassen.

Neben anderen haben Emil Angehrn und Daniel Müller Nielaba rund 200 Jahre nach Schleiermacher die potenzielle Unendlichkeit des Verstehensprozesses ebenfalls zu beschreiben versucht. Angehrn nennt dabei vier „Varianten“: „Die Unendlichkeit kann an der Unausschöpfbarkeit des Sinns, der uneinholbaren Vermitteltheit der Kommunikation, der nie zu vollendenden Reflexion des Subjekts, der Offenheit des Textes festgemacht werden. ${ }^{44}$ Nach einer kurzen Besprechung derselben ${ }^{55}$ folgert er:

Schon der schematische Überblick macht deutlich, daß diese verschiedenen ,Unendlichkeiten“ nicht losgelöst voneinander bestehen, sondern Facetten eines Phänomens, der Offenheit eines Sinngeschehens sind, an welchem Autor, Leser, Text und Verstehensvollzug gleichermaßen teilhaben. Sie bedingen sich gegenseitig, wie [sic] wirken zusammen und gegeneinander, sie verstärken sich, indem sie sich zugleich absorbieren. [...]

Unendlichkeit oszilliert zwischen positiver Transzendenz und unendlichem Regress. Sie kann Überfülle meinen oder Entformung und Leere. Sie kann positiv oder negativ über die bestimmte, begrenzte Form hinausgehen. [...] Hegel nennt dieses Hinausgehen, welches das Endliche mit Mitteln des Endlichen überwinden will und es dadurch nur reproduziert, ${ }^{56}$ die schlechte Un-

54 Angehrn 2004, S. $121 \mathrm{f}$.

55 Vgl. ebd., S. 122-124.

56 Dazu gehörten dann, in der Terminologie der vorliegenden Arbeit, letztlich auch all diejenigen Operationen, die zu einer forcierten Iterabilität führen. 
endlichkeit. ${ }^{57}$ Ein affirmatives Jenseits des Endlichen, wie es in theologischen Kontexten anvisiert ist, klingt in der Unausschöpfbarkeit des Sinns in großen Symbolen, eminenten Texten an. Doch bleibt die Frage, wie die Überfülle gegen die Leere, die Überbestimmtheit von der Unterbestimmtheit abzuheben ist. Der Richtungsstreit der Hermeneutik ist nicht zuletzt einer im Umgang mit dem Unendlichen. ${ }^{58}$

Daniel Müller Nielaba wiederum nimmt eine dezidiert rhetorische Perspektive ein, wenn er schreibt:

Das Verstandene ist hinsichtlich eines zu Verstehenden immer ein Anderes, immer ein diesem Heteronomes: Die Relation von Verstandenem und zu Verstehendem ist mithin nichts anderes als ein rhetorisch bestimmtes Verhältnis, indem sie sich als metonymische Verschiebung erweist. [...] die Aussage also: ,Verstehen ist unmöglich ${ }^{-}$-, implizierte ebenso zwingend, daß es ein Verstehen vor diesem Verstehen gäbe, daß also Verstehen, nach der unhintergehbaren Maßgabe seiner Selbstapplikabilität, stets ein Vor-Verstehen wäre [...]. Verstehen und zu Verstehendes sind in ihrem Zusammenwirken damit weder zu verstehen noch nicht zu verstehen, vielmehr: Ein mögliches und tatsächliches Verstehen des Verstehens erweist sich in aller Konsequenz als das Verschieben oder das Verstellen des Verstehens, als ein unsistierbares Übertragen des Verstehens also. ${ }^{59}$

Verbindet man nun die Beobachtungen zur zitierten Stelle bei Schleiermacher sowie die Überlegungen Angehrns und Müller Nielabas mit den Ergebnissen der vorliegenden Arbeit, so ergeben sich daraus folgende komplementäre Thesen, denen es weiter nachzugehen gälte:

1. Ewigkeit dient als figuraler Bezugspunkt des modernen Verstehens, das sich dadurch zwar nicht der Ewigkeit, aber zumindest einer potenziellen Unendlichkeit zu versichern sucht und sich so selbst als ein unendliches Verfahren in Gang hält. Dies wiederum führt zu einer noch größeren Unerreichbarkeitjenes figuralen Bezugspunktes und immer so fort. Würde dieser Bezugspunkt jedoch erreicht, könnte ewig gültiger Sinn durch dieses Verfahren ein für alle Mal verstanden werden, so wäre das zugleich das Ende dieses Verfahrens und damit das Ende des modernen Verstehens.

2. Dabei wird auf semiotisch-rhetorischer Ebene auch sichtbar, dass umgekehrt Ewigkeitsattribuierung wohl eine entscheidende Konstituente, wenn vielleicht nicht für Figuration im Allgemeinen, so doch für rhetorische

57 Zur, schlechten Unendlichkeit' in der Philosophie des Deutschen Idealismus vgl. ausführlich Unger 2015 .

58 Angehrn 2004, S. 124.

59 Müller Nielaba 2005, S. 4 O. 
Figuren (und wohl auch die Tropen) ${ }^{60}$ ist. Dies gälte komplementär zur ersten These hinsichtlich der potenziell unendlichen Bewegung, die einer jeden Figuration inhärent ist, abervielleicht sogar auch hinsichtlich (gewisser) Verfahren, die auf Autonomie abzielen. Letzteres nämlich wohl immer dann, wenn das Erzielen poetischer Performativität als ein wesentlicher Aspekt der betreffenden rhetorischen Figur ${ }^{61}$ beobachtet werden kann.

\subsection{Zur Literarizität sowie kritische Reflexion auf die vorliegende Arbeit und ihr Fachgebiet}

Auch hinsichtlich der Auseinandersetzung damit, was Literatur von Nichtliteratur unterscheide, bietet die vorliegende Arbeit neue, ergänzende Ansätze an. Vorschnell mag vielleicht jemand einwenden, einige der von ihr angeführten Operationen zur Ewigkeitsattribuierung von Schriftzeichen seien lediglich bereits bekannte Konstituenten von Literarizität. Als Erstes träfe ein solcher Einwand wohl die Grundoperation Reflexivität resp. deren Unteroperationen Autoreflexivität und Poetologie. Für diese - wie für alle anderen Operationen der Typologie - gilt jedoch:

1) Bereits in der Einführung wurde klar festgehalten, dass die vorliegende Arbeit sich mit Operationen zur Ewigkeitsattribuierung von Schriftzeichen befasst. Das schließt nicht aus, dass dieselben Prinzipien, nach denen diese Operationen funktionieren, auch für Verfahren grundlegend sein können, die andere Zwecke verfolgen. So mag z. B. der Verweis einer Textstelle auf sich selbst und ihre Möglichkeitsbedingungen auch primär der Verfremdung der üblichen Verweisstruktur und damit einer Unterbrechung des Leseflusses resp. einer genaueren Lektüre oder einem neuen Blick auf vermeintlich Altbekanntes dienen. Das Wort ,primär wird hier bewusst verwendet, weil selbst in einem solchen Fall nicht bestritten werden kann, dass die betreffende Textstelle zugleich - und unabhängig von der Intention des Verfassers oder der Verfasserin - weniger zeitlichen Veränderungen ihrer intelligiblen Seite sowie ihres Kontextes unterworfen ist und/oder das Potenzial für eine unendliche Lektüre einer unendlichen Spiegelungsbewegung besitzt.

6o Zum figurativen Aspekt der Tropen vgl. Quintilian, Institutio Oratoria, Teil 2, S. 251; resp. den Beginn von Kapitel IV.3.1.1.

61 Dieser Aspekt der These ist auch inspiriert von einer, noch in gemeinsamen Studienzeiten stattgefunden habenden Diskussion mit Kathiana Meyer, die während dieser, Gedanken des Verfassers weiterführend, die Hypothese aufgestellt hatte, rhetorische Figuren seien vielleicht immer performativ. Eine Hypothese, die nun - gestützt auf die in Kapitel III.1 vorgenommene Definiton poetischer Performativität - wiederum weitergedacht und in ihrer etwas zu großen Verallgemeinerung abgeschwächt wurde. 
2) Die Wahl einer anderen Begrifflichkeit für die Operationen Autoreflexivität und Poetologie - und letztlich ebenso aller anderen in der Typologie aufgeführten Operationen - hätte eine solche Überschneidung nur vordergründig vertuscht und damit das Verständnis der hier vorgelegten Typologie letztlich nicht erleichtert. Im Gegenteil vermag gerade die Verwendung bestehender Begriffe darauf aufmerksam zu machen, dass die Ergebnisse der vorliegenden Arbeit das Potenzial besitzen, den Blick von einer bloßen Beschreibung von Konstituenten von Literarizität hin auf eine mögliche Begründung von Literarizität zu richten. In diesem Sinne wäre jener vorschnelle Einwand genau umzudrehen, woraus sich folgende Hypothese ergibt:

Die Versuche zur Ewigkeitsattribuierung von Schriftzeichen sind eine wesentliche Ursache für die Verwendung von innersprachlichen Operationen, die als Konstituenten von Literarizität gelten. Oder einfacher ausgedrückt: Die Ewigkeitsattribuierung von Schriftzeichen ist eine wesentliche Ursache von Literarizität. ${ }^{62}$

In dieselbe Richtung würde ein allfälliger zweiter vorschneller Einwand zielen, nämlich dass die Textbeispiele, mit denen der Hauptteil arbeitet, bereits kanonisierte Klassiker seien und damit hier letztlich eine bloße Weiterführung der Ewigkeitsbehauptung gegenüber denselben fortgeführt werde. Dem wäre aber entgegenzuhalten:

1) Allein schon was die Textauswahl selbst betrifft, so umfasst diese auch Texte, die weniger bekannt sind, wie Der Phönix oder Ermunterung; und in anderen Fällen, etwa des Zauberlehrlings, aber in geringerem Ausmaß auch Der Spinnerin Nachtlied, die zwar zu den kanonischen Texten gehören, ist (nach bestem Wissen des Verfassers) das Ausmaß bisheriger Forschungen entweder ebenfalls äußerst gering oder liegt mehrheitlich Jahrzehnte zurück.

2) In der Einführung wurde deutlich gemacht, dass für die vorliegende Arbeit nicht bloß Texte und Textstellen ausgewählt wurden, für die sich mindestens eine Operation zur Ewigkeitsattribuierung von Schriftzeichen beobachten lässt, sondern auch solche, die einerseits für eine dieser Operationen besondere Exemplarität beanspruchen können und die andererseits im

62 Besonders bemerkenswert ist hierbei, dass zumindest die altägyptische Literatur direkt aus der Tradition der Grabinschriften entstanden zu sein scheint; vgl. J. Assmann 1991, S. 169-199. Dies geht so weit, dass dabei sogar Parallelen zu Uwe Wirths These der "Geburt des Autors aus dem Geist der Herausgeberfiktion“ zu beobachten sind (vgl. J. Assmann 1991, insbesondere S. 176, Anm. 6). J. Assmann formuliert zudem in einem weiteren Schritt die These, seine Feststellung zur altägpytischen Literatur könnte letztlich für die Entstehung von Literatur im Allgemeinen gelten, indem er u. a. beobachtet, dass ganz grundsätzlich "die Analogie zwischen Grab und schriftlichem Kunstwerk enger ist als die zwischen mündlicher und schriftlicher Literatur" (ebd., S. 173). 
Rahmen des zeitgenössischen kulturellen und theoretischen Kontextes explizit oder implizit das Paradigma von Dauer, Vergänglichkeit, Ewigkeit und/ oder Verewigung aufweisen. Bei diesen Auswahlkriterien verwundert es nicht, wenn einige dieser Texte auch in anderer Hinsicht besonders beispielhaft und wirkmächtig waren und so eine gewisse Kanonisierung erfuhren. Zudem ist hier analog zur Frage der Literarizität festzuhalten: Die vorliegende Arbeit schreibt nicht eine unreflektierte Ewigkeitsbehauptung gegenüber gewissen Klassikern fort, sondern sie liefert eine von den ausgewählten Texten selbst her entwickelte, mögliche innersprachliche Begründung dafür, weshalb diese sich auch für die Kanonisierung als ein institutionelles, außersprachliches Verfahren der Verewigung besonders anerboten haben.

Dieser zweite mögliche Einwand würde aber - und dem sei nun zum Schluss begegnet - ein Körnchen Wahrheit beinhalten, das zu einem ganz grundlegenden Problem führt: Jeder Text, der sich mit älteren Texten auseinandersetzt, diese zitiert usw., beteiligt sich an der Überlieferung resp. am Weiterschreiben derselben und bedient sich dabei Verfahren, die oft auch Operationen der Ewigkeitsattribuierung entsprechen. Ein Paradebeispiel dafür wäre in der Tat die vorliegende Arbeit selbst: So schreibt der Verfasser einerseits etwa im Exkurs zu Jean Paul dessen ,erschriebenes Leben' weiter, indem er - die Kernthese von Helmut Pfotenhauers Werkbiographie zitierend über Jean Pauls Schriften schreibt und diesem damit, einen weiteren Abschnitt in [s]einem Leben', wie der Kater Murr sagen würde, hinzufügt. Andererseits betreiben gerade dieses letzte Kapitel des Ausblicks, aber auch einige Stellen der Einführung sowie des Hauptteils, eine Reflexion auf die vorliegende Arbeit und werden dabei Teil einer potenziell unendlich sich weiter potenzierenden Reflexionsbewegung. ${ }^{63}$ Und gerade dadurch, dass der Verfasser die Ewigkeitsbehauptungen und Attribuierungen der eigenen Arbeit und Disziplin zum Schluss noch einmal reflektiert, macht er sich sowohl die Grundoperation Reflexivität als letztlich auch die Operation Poetische Performativität zunutze und vollzieht so eine Ewigkeitsattribuierung der eigenen Arbeit. Der Kreis schließt sich, wie man so schön sagt - womit man jedoch nicht nur bei einer potenziell unendlichen Kreisstruktur, sondern auch schon wieder bei der nächsten Reflexion angelangt wäre usw. ad infinitum.

Was für die vorliegende Arbeit im Besonderen gilt (und was diese deshalb auch besonders transparent zu machen sucht), gilt aber letztlich auch für die

63 Vgl. zu dieser Problematik auch Angehrn 2004, insbesondere S. 123-125; und Martyn 1992, insbesondere S. $666 \mathrm{f}$. 
Philologien im Allgemeinen. ${ }^{64}$ Die Literaturwissenschaft und in Teilen auch die Linguistik stellen nicht nur fortwährend implizite - und zuweilen auch explizite - Ewigkeitsbehauptungen gegenüber Schriftzeichen und Texten auf, sie tun dies auf eine Weise, die diese Behauptungen bis zu einem gewissen Grad wahr werden lässt. Verstärkt wird dieses grundlegende Problem einer selbsterfüllenden Prophezeiung - so haben es die historischen Kapitel des Hauptteils aufgezeigt - durch den Umstand, dass die modernen (in Ansätzen letztlich bis in die sogenannte Renaissance ${ }^{65}$ zurückreichenden $)^{66}$ Philologien im 18. Jahrhundert ausgerechnet in einem Kontext entstanden sind, in dem eine Akzentuierung von Ewigkeitsbehauptungen gegenüber und von Ewigkeitsattribuierungen von Schriftzeichen zu beobachten ist. Mehr noch:

Es deutet vieles darauf hin, dass die modernen Philologien aus ebendieser Akzentuierung heraus entstanden sind, zu der sie zugleich wesentlich beigetragen haben.

Bestes Beispiel dafür ist, so hat sich gezeigt, Herders Shakespeare-Aufsatz, der (im deutschsprachigen Raum) ausgerechnet als der Beginn der modernen historischen Literaturwissenschaft gilt; Ähnliches trifft vielleicht sogar auch auf den von Schillers Wallenstein inspirierten Wilhelm von Humboldt und seinen Einfluss auf die entstehende Sprachwissenschaft zu. ${ }^{67}$

Schließlich erklären diese Beobachtungen vielleicht auch, weshalb es bis zur vorliegenden Arbeit noch zu keiner systematischen Untersuchung der Operationen zur Ewigkeitsattribuierung von Schriftzeichen gekommen ist, sind diese Operationen doch gewissermaßen der blinde Fleck derjenigen Disziplinen, in deren Bereich eine solche Untersuchung fällt. Alle mit Texten arbeitenden Disziplinen, insbesondere aber die philologischen und historischen, haben zwangsläufig Anteil an der (noch ungeschriebenen) Geschichte der Ewigkeitsbehauptung gegenüber und an der Ewigkeitsattribuierung von Schriftzeichen. Ebenso ist anzunehmen, dass es gerade diese Disziplinen wären, die eine solche Geschichte schreiben würden. Verzichteten sie aber umgekehrt auf Verfahren, die sich mit Operationen zur

64 Vgl. dazu auch Markus Rothhaars Ausblick am Ende seines Aufsatzes zur Antinomie der Unendlichkeit bei Kant und Hegel; Rothhaar 2018, S. 167 f.

65 Dabei wäre letztlich auch der (aus dem 19. Jahrhundert stammende) Begriff Renaissance als Ewigkeitsbehauptung zu bezeichnen.

66 Vgl. dazu und zu einem „auratischen Verhältnis zu den Quellen“ A. Assmann 1999, insbesondere S. 120 f.; sowie Nate 2018; zur von der Neuzeit ausgehenden und diese mitkonstituierenden Symbiose zwischen der "ars mantica“ und der "ars poetica“ vgl. Theisohn 2012.

Vgl. das Ende von Kapitel III.1.2.1. 
Ewigkeitsattribuierung überschneiden, so würden sie sich selbst auflösen. Es bleibt ihnen also nur, immer wieder aus verschiedenen Perspektiven auf jenen blinden Fleck hinzuweisen. In diesem Sinne sieht sich die vorliegende Arbeit auch als ein Beitrag dazu, seitens der Philologien die eigenen Ewigkeitsbehauptungen und -attribuierungen transparenter zu machen - im Bewusstsein darum, dass einem solchen Unterfangen unausweichlich erneut eine potenziell unendliche Bewegung inhärent ist. 


\section{Semiotics of Eternalization. English General Survey and Summary}

The aim of this general survey and summary ${ }^{1}$ is to bring the present monograph closer to an anglophone readership. Thus, the focus will be on those aspects and results of this study that go beyond the examined German sources. These aspects are first and foremost theoretical and historical in nature. The following text consists of an abridged version of the German summary, framed by a few translated excerpts from the introduction and the outlook. Complementary footnotes as well as longer definitions of concepts are omitted; see for reference the respective chapters in German. The same is the case for the interpretations of individual literary texts.

\section{Point of Departure}

The aim of the present monograph is to engage the notion present in occidental cultural space, from the point of view of literary studies and semiotics, that characters (i.e. written signs) are able to eternalize thoughts, things, or persons and their deeds, that is to record them for all time. Therefore, our point of departure is a paradoxical one: On the one hand, we find this notion. On the other hand, characters are extremely ephemeral with regard to semiotics: During the course of reading, they will never be able to evoke the exact same signified twice, and will, as soon as they have been read, have been nothing but (for example) mere black ink on white paper. On the level of the physical and biological, it should also be noted that neither the readership nor the material dimension of writing and writing surfaces exist outside of time, but instead are subject to death and decay.

The present work takes on the intellectually productive irritation inherent in every paradox, especially this one. This leads to a first conceptual distinction necessary to avoid later confusion: In the following, rather than address the "notion that characters are able to eternalize thoughts, things, or persons and their deeds", we will instead use the more precise terms eternity-assertion toward characters and eternity-attribution of characters.

1 Editor and translator of the English general survey and summary: Andreas Inderwildi. 
Eternity-assertion toward characters describes all those text passages which, despite the ephemerality mentioned above, assert the power of characters to eternalize thoughts, things, or persons and their deeds. This assertion can be either implicit or explicit, and the distinction is not always a clear one. Eternity-attribution of characters on the other hand describes those attempts which, in a given written utterance, utilize intralinguistic operations in order to 'disable' the semiotic ephemerality of characters and thus record for all time the signifieds of the respective utterance. Thus, in the case of eternityattribution, the above-mentioned ephemerality of characters isn't 'denied' or ignored (as is the case for eternity-assertion), but instead attempts to counteract it as far as possible by engaging with this ephemerality - which, in some cases, is paradoxically accomplished by exploiting ephemerality itself. $^{2}$

The present study intentionally focuses on a time period in which a discursive and historical intensification of the thematization of eternity, ephemerality and (industrial) reproducibility, as well as questions of conditions and possibilities of human understanding, have already been determined by previous research. This study seeks to answer two guiding questions:

1. Which intralinguistic operations can be observed in the attempt to 'disable' the semiotic ephemerality of characters in order to record a given written utterance's signifieds for all time and thus to eternalize thoughts, things, or persons and their deeds by means of characters?

The aim of answering this question lies in developing a typology of such intralinguistic operations of the eternity-attribution of characters. This study does not lay claim to presenting a complete and conclusive typology. However, it does seek to classify and discuss those operations which have seen the most frequent use (at least in the chosen period of around 1800). In order to prevent potential misunderstandings, it is necessary to emphasize that this study's aim is not to search for the 'philosopher's stone', but instead to establish a typology of mere attempts to 'disable' as far as possible the ultimately uncircumventable semiotic ephemerality of characters.

2 At least in the case of more ambitious authors, we can frequently also find passages with eternity-attributions in close proximity to passages with eternity-assertions. In the course of this study's main part, this can be observed again and again. 
2. How can we contextualize, from the point of view of literary studies and intellectual history, intralinguistic operations of the eternity-attribution of characters in the period from 1755 to 1821 ?

The issue at hand is to observe the kind of correlation existing between intralinguistic ${ }^{3}$ operations of the eternity-attribution of characters on the one hand and contemporary intellectual and literary historical contexts and co-texts on the other; and furthermore to determine if a certain accentuated occurrence of individual instances of such operations can be observed, and if yes, for what reasons.

The process of answering these guiding questions mainly takes place through engaging with exemplary literary as well as theoretical texts of the German language area in the period between 1755 and 1821. Even though the close readings of the individual texts may be inspired by deconstructionist methods, they still remain faithful to the fundamentally hermeneutic approach of the present study, which does not refrain from critically questioning deconstructionist eternity-assertions. If the present study was not dedicated to an approach decidedly defined by close readings, it would run the severe risk of engaging in mere eternity-assertion toward characters itself. The reason for focusing mainly on literary texts is that literature is the 'space' in which the possibilities and limits of language and characters are experimented with most intensely - especially in a period in which modern philological disciplines were still nascent.

\section{A Typology of Operations of the Eternity-Attribution of Characters}

The following chapter brings together and elaborates on the literarysemiological findings of the study and processes the resulting typology for operations of the eternity-attribution of characters in the form of the following table.

3 It has now been noted several times that the examined operations are intralinguistic. In the following, the adjective 'intralinguistic' will be omitted for the sake of reader-friendliness. 
Basic operations in the service of the eternity-attribution of characters
A) Endless Actualization
B) Autonomous Performative
Production
C) Reflexivity
(autonomous and/or endless)

Basic and sub-operations in the service of the eternity-attribution of characters
A) Endless Actualization
B) Autonomous Performative
C) Reflexivity
Production
- Endless Reading
- Poetic Performativity
- Autoreflexivity
(auton. and/or endl.)
- Endless Falling Silent
- Poetology
(auton. and/or endl.)

The respective basic and sub-operations attempt to achieve

$\begin{array}{ccc}\text { - interminable reading } & \begin{array}{c}\text { autonomy from temporal } \\ \text { changes in semantics and } \\ \text { context }\end{array} & \begin{array}{c}\text { autonomy from } \\ \text { temporal changes in } \\ \text { semantics and context } \\ \text { and/or }\end{array} \\ & - \text { interminable reading }\end{array}$

Basic operation 'endless actualization': Attempts to bring readers to read and re-read the respective characters or texts an infinite amount of times, for example by means of narrative-compositional circular structures, complex and decisively placed intra- and intertextual references, the confusion of narrative frames (sub-operation: 'endless reading') or the purposeful breaking or interruption of a text in order to render its semiotic ephemerality aesthetically utilizable as well as to provoke continued thinking about and writing in 'continuation' of the original text (sub-operation: 'endless falling silent').

Basic operation 'autonomous performative production': Attempts to make each reading create that which the text refers to in order to imbue it with as much autonomy as possible, for example by interspersing the mentioning of an echo with repetitive figures to such a degree that an echo effect is created through the very act of reading the text. 
Basic operation 'reflexivity': Attempts to either imbue a text with as much autonomy as possible by reference to itself (sub-operation: 'autoreflexivity') or its own conditions of possibility (sub-operation: 'poetology') or to 'force' readers to reproduce the potentially endless movement inherent in every self-reference, for example by describing how a novel's characters discover the 'same' novel of which they are a part and proceed to read about themselves. ${ }^{4}$

Due to the restrictions on the levels of semiosis already mentioned in "point of departure", the biological constitution of humans as well as the material dimension of writing, an interminable reading is ultimately as out of reach as an absolute autonomy from time and context. An eternalization by means of characters in a true and absolute sense is impossible and must always remain a mere attempt. With this we reach a question that imposes itself again and again throughout the study's main part: What kind of effects do the respective operations actually achieve in the course of the reading of texts equipped with those operations?

First, we might suggest the answer that at least some of the operations under discussion, especially the basic operation 'endless actualization', would lead to a potentially endless iteration of characters. This, however, results in two problems: On the one hand, mere iteration turns out to be too vague a term to be of use, since a second reading of, for example, Lebens-Ansichten des Katers Murr is not simply a repetition of the first reading, but will, since it includes the first reading, have been a different one. On the other hand, every character has the potential to be repeated an infinite amount of times; for this, operations of eternity-attribution are not (yet) necessary, even though certain operations try to realize this potential before all else. These problems, however, can be met. For a precise distinction between that which operations of the eternityattribution of characters attempt to achieve and that which is achieved in the course of those attempts, Jacques Derrida's concept of iterability (French 'itérabilité') proves itself to be exceedingly helpful.

According to Derrida, the conditions of possibility of each sign, and as a result also of each character, is its potential to be repeated an infinite amount of times, or more precisely its iterability, in the course of which a sign will have been actualized again and again (never, however, the exact same twice). Certain operations of the eternity-attribution of characters attempt to expedite this potentially endless repeatability by trying to force readers to not only use that potential for the respective reading, but instead to exhaust it in its endlessness. Text passages that contain the other operations, by virtue of being

4 The definitions as seen here have been abbreviated for the sake of an improved understanding of the summary; the full definitions can be found at the beginnings of the respective chapters of the German language main part. 
structures of signs and characters, may also have iterability as their condition of possibility, but do not attempt to exhaust their infinite potential. This can be expressed more precisely through the following two findings:

1) Those operations which lead to a forced iterability attempt to substitute eternity with endlessness, or in other words to replace timelessness with the most radical emphasis on temporality possible. This is true not only for the operation 'endless reading', but also for the operation 'endless falling silent', which, through diametrically opposed means, namely a radical use of characters' semiotic ephemerality, in a sense pursues the same goal as the former. This also holds true for the basic operation 'reflexivity' in all those instances in which it not only pursues a text's autonomous self-thematization, but at the same time also fosters an endless mirroring movement.

2) The first finding does not apply to those operations which lead to an iterability of potentially autonomous performative production, since they do not strive toward a substitution of eternity with endlessness, but rather - in the context of the above-mentioned semiotic, biological and physical restrictions toward an autonomy from temporal changes in semantics and context of that which has been put into writing. The latter is also true for the basic operation 'reflexivity', as long as it does not at the same time lead to, or (more precisely) force, an endless mirroring movement. The basic operations 'autonomous performative production' and 'reflexivity', however, create potential autonomy in two different ways: The former through performatively creating that which the signs refer to, the latter through a respective passage's references both to itself as well as to its own conditions of possibility. In the course of this selfreferencing, the respective passage's iterability itself may be negotiated, as has been shown in the chapters discussing Heinrich von Ofterdingen, Nänie as well as the fable Der Phönix.

Uwe Wirth writes, concerning Derrida's concept of iterability, that the iterability of signs is grounded in their power of breaking with context. ${ }^{5}$ Building on Wirth's (and Derrida's) statements, the findings discussed above may be summarized as follows: The operations of the eternity-attribution of characters attempt (of course with varying emphasis) to exhaust the two central constituents of iterability: potential endlessness on the one hand, and potential autonomy from time and context on the other. This, too, can be illustrated via tables:

5 Cf. Wirth 2oo8, pp. 61-62. 
Basic operations in the service of the eternity-attribution of characters
A) Endless Actualization
B) Autonomous Performative
C) Reflexivity Production
- Endless Reading
- Poetic Performativity
- Autoreflexivity
(auton. and/or endl.)
- Endless Falling Silent
- Poetology
(auton. and/or endl.)

The respective basic and sub-operations result in

\begin{tabular}{|c|c|c|}
\hline - forced iterability & $\begin{array}{l}\text { - iterability of } \\
\text { potentially autonomous } \\
\text { performative production }\end{array}$ & $\begin{array}{l}\text { - iterability of } \\
\text { potentially autonomous } \\
\text { reflexivity } \\
\text { and/or } \\
\text { - forced iterability }\end{array}$ \\
\hline \multicolumn{3}{|c|}{ a combination of $\mathrm{A}$ ) and $\mathrm{B}$ ) or $\mathrm{A}$ ) and $\mathrm{C}$ ) results in } \\
\hline & $\begin{array}{l}\text { - forced iterability of } \\
\text { potentially autonomous } \\
\text { performative production }\end{array}$ & $\begin{array}{l}\text { - forced iterability of } \\
\text { potentially autonomous } \\
\text { reflexivity } \\
\quad \text { and/or } \\
\text { - (forced iterability })^{2}\end{array}$ \\
\hline
\end{tabular}

Finally, another noteworthy combination - this time on the level of two suboperations - seems to constitute the fragmentary: It could be said that the fragmentary is a radical manifestation of the sub-operation 'endless falling silent', which, precisely because of its radicality, also triggers a potentially endless movement which continues the fragmentary texts and which ultimately overlaps with the sub-operation 'endless reading'. The same holds true in the opposite direction for the sub-operation 'endless reading', which in its most extreme manifestation tends toward the fragmentary. Or to put it somewhat more simply: The fragmentary in a sense makes possible a combination of the complementary sub-operations 'endless falling silent' and 'endless reading', 
and as a result may be the most effective feasible manifestation of the basic operation 'endless actualization'.

\section{A 'Localization' of the Operations in the Historical Context of the 18th and early 19th Century}

The most important observations of the main part with regard to intellectual and literary history will now be placed in relation to the two central, abovementioned findings regarding typology:

Finding 1) has, in the case of the operations in question and on a purely semiotic level (and thus fundamentally independent from language, writing and period, as has been shown in the introduction and main part's references to ancient Egypt and Greece), recorded a 'compensation' of unreachable eternity through endlessness. This finding and the results of the historicalcontextualizing chapter can now be merged to create the following thesis:

The semiotic 'compensation' of eternity through endlessness finds, to a large extent, a correspondence on the level of intellectual and literary history, which leads to an accentuated occurrence of the operations of the eternity-attribution of characters in question. This is especially true in the case of the operations 'endless reading' and 'endless falling silent', as well as the basic operation 'reflexivity' in those instances in which it primarily aims for an interminable reading.

The intellectual historical background of this correspondence are developments whose occurrence is intertwined and, in the course of the Enlightenment, intensified. This can be seen, for example, in the constitution of the 'modern' individual, the 'softening' of the mimetic imperative through a dynamization of nature, the elevation of creative imagination and its aestheticization as well as the increasing historical relativization of 'authorities' or their works, be it in the realm of religion, science or literature. All of this leads to or is paralleled by a process of secularization, in the course of which a 'compensation' of the 'loss' of Holy Scripture (as well as the religious promise of eternal life after death) can be observed through a sacralization of writing as such. The eternity of individuals' written works is not only asserted explicitly or implicitly in the continuation of millennia-old notions, but rather is pursued through an increasing intellectual effort with regard to eternity-assertion and -attribution. ${ }^{6}$ Eternity-assertion and -attribution, however, play their

6 It is highly noteworthy that Jan Assmann notes an 'explosion' of eternalization efforts during a 'similar' time of religious crisis in the Late Period of ancient Egypt. This led to a sophisticated combination of characters and procedures of architecture, ritual, pictorial representation 
part in further expediting secularization, which in turn leads to an increased sacralization of writing as such.

Thus, it becomes clear that in this interplay itself an endless movement is inscribed that ultimately persists into the present and gains a new-found momentum in today's 'digital revolution. ${ }^{7}$ The 'aesthetics of genius' emerging in the early 1770s (whose lasting effect can still be felt today in science, art, copyright etc.) especially play a defining part in this interplay: In it is carried out to its most explicit and radical degree not only the transfer of the divine attribute of creativity to the human, but also the transfer of the divine attribute of God's eternity to the individual, and in turn from individuals to their work. Even though this transfer of the creative has found broad scholarly agreement some time ago, the present study has been able to reveal the close entanglement between this transfer and the transfer of the attribute of eternity. An individual which seeks to permanently ensure for itself the status of genius is subject to a potentially endless pressure of creation. Or put differently: A genius must, in order to remain as such, either create something eternal or create eternally.

With regard to literary history, the above-mentioned interplay between this historical relativization and, on the one hand, the 'loss' of the religious promise of eternity and, on the other hand, the written 'compensation' of the same, contributes substantially to known aesthetic configurations, experiments and disputes and through these gathers further momentum - as has already been hinted at by referencing the 'aesthetics of genius'. From the middle of the $1750 \mathrm{OS}$ onward, Gotthold Ephraim Lessing played a defining role in this. Lessing's paradigm change within the contemporary genre of the 'Trauerspiel' (or tragedy) not only corresponded to a prioritization of the duration of compassion toward the terrible moment, but also lead to a dissolution of the 'trinity' of beginning, middle and end postulated by Aristotle; a dissolution which occurs in the sense that, in Lessing's bourgeois 'Trauerspiel', the end is turned into an ongoing ending and thus becomes the middle. The potency of this shift of the end to a 'middle' can hardly be overstated, since not only did it attempt a transformation of the exemplary genre of the tragedy, but was also instrumental in the 'dissolution' of the (seeming) 'unity' of works of every genre. Together with the utilization of the fragmentary form that occurred only slightly later ${ }^{8}$ (through Hamann, Herder and later again especially through

and sympathetic analogy in order to reach - in the terminology of the present study - the most efficient eternity-attribution of the mediated contents (cf. J. Assmann 1991, pp. 73-74).

7 See also the outlook further below.

8 Cf. chapter II.3.4. 
Lessing's 'Reimarus fragments') this shift lead, through Goethe, Jean Paul and the early Romantics among others, to an aesthetic of the fragment in the following decades, which, sixty-five years after Miss Sara Sampson, finally reaches another apex with E. T. A. Hoffmann's Lebens-Ansichten des Katers Murr. In Hoffmann's 'twin novel', the end does not only become the middle, but also the beginning. The attempted 'compensation' of eternity through endlessness is carried out both on the micro level - see for example the observations regarding the use of dashes, breaks and paragraphs in Lessing, Jean Paul or E. T. A. Hoffmann among others - as well as on the macro level, for example by means of circular structures, framing narratives which are left open in the 'end', or framing prefaces, postfaces and authorial or editorial fictions, which develop their own displacing dynamics.

In continuation of Uwe Wirth's research ${ }^{9}$, it also becomes clear with regard to the case of the 'editor's function' and especially of editorial fictions just how much they serve as 'guarantees' of the 'eternity' of the work published 'by them' and of its author. The eternity-attribution of characters, then, is a substantial, if not defining constituent not only of the fictional editor, but also of the genesis of modern authorship, which in turn again contribute to the eternity-attribution of characters. ${ }^{10}$

On the semiological level, finding 2) assigned the remaining operations to a second group, since they do not lead to a forced iterability or strive toward endlessness, but instead aim for a potential autonomy of writing from temporal changes of semantics and of the contexts of communication as well as extralinguistics.

This group of operations of the eternity-attribution of characters aiming for autonomy also displays strong correlations on the level of cultural and literary history in the examined time period, which in this case also leads to an accentuated occurrence of the operations in question. These are especially the basic operation 'autonomous performative production' and the basic operation 'reflexivity' in those cases in which it primarily aims for autonomy.

For this correlation, the most significant background with regard to intellectual history and the history of philosophy is the fact that - so the thesis of the corresponding main part's chapter - the 'Reflexions-Philosophie' (philosophy of reflection) beginning with Descartes attempts to win back the

9 Cf. especially Wirth 2008.

10 In this context it would be very interesting to engage more extensively with older forms of authorial and editorial fictions; for example by including texts from ancient Egypt, where fictional 'assertors' as well as framing narratives appear in the Papyrus 'Chester Beatty' (13th century BCE). These are texts dealing explicitly with eternalization (cf. J. Assmann 1991, p. 176, annotation 6). 
'loss' of eternity of the 'absolute' in which it itself has played a substantial part. In this attempt, it utilizes - since it is attempted through the medium of language - procedures which in the realm of literature correspond particularly to the operations of eternity-attribution 'auto-reflexivity' and 'poetology', or the basic operation 'reflexivity' respectively, and are thus much older than the corresponding developments in intellectual history.

Following the semiological findings one might specify: Just as the basic operations 'autonomous performative production' as well as 'reflexivity' (for the latter, however, it is not always the case) aim for an autonomy of that which has been put into writing, the 'Reflexions-Philosophie' builds on a procedure which constitutes an 'I' that thinks 'autonomously'. It has been observed in chapter IV.3.1. how potentially endless mirroring develops a dynamic of its own that is inherent in the 'Reflexions-Philosophie' and threatens to subvert it. In the case of the basic operation 'reflexivity' on the other hand, this dynamic may be emphasized, namely in those cases in which it aims for endlessness rather than autonomy. Or put differently:

One manifestation of the basic operation 'reflexivity' in a sense corresponds to that 'basic operation' which dwells within the 'Reflexions-Philosophie'; another manifestation, on the other hand, corresponds to that dynamic which is both inherent in the 'Reflexions-Philosophie' and a threat to its fundamental premise. The 'aim' of the basic operation 'autonomous performative production' in turn corresponds to that of the 'basic operation' of the 'Reflexions-Philosophie', but attempts to reach its aim in a different way.

Speaking about the latter, one might go as far as to say: Fichte, however, utilizes a procedure which is very similar to the basic operation 'autonomous performative production' by elevating the performative-creative - or put more boldly: the genius - and thus ultimately an aesthetic principle to the basic premise of his philosophical system through the I that constitutes itself. Likewise, a performative principle seems to be inherent in the dissolution of the mimetic imperative: If nature creates dynamically, the artistic, dynamic act of creation not only refers representatively to nature, but also simultaneously performs nature.

By bringing together the most important semiological and historical results, the main part of this study makes clear that different developments in intellectual history during the latter half of the 18th century display a structural similarity to the operations of the eternity-attribution of characters. This structural similarity is largely responsible for intensifying an interplay which, on the one hand, itself contains a potentially endless dynamic and, on the other hand, simultaneously blurs its own beginning. This interplay - and not 'just' those developments in intellectual history alone - is thus a main cause for 
experiments and configurations in literary history, such as the so-called aesthetics of the fragment, the genius, or autonomy. The latter corresponds to the fact that the semiotics of sensuality, which pose a problem to the emerging discipline of aesthetics at the tail end of the 18 th century ${ }^{11}$, join the millenniaold pursuit of the 'sign that shows itself'12 and the same hope of eternalization and eternity that has already been associated with the 'semiotics of the intelligible sign'.

With this, a new perspective in literary history on the period around 1800 that complements current research emerges: Aesthetic engagements between and within seemingly clearly distinguishable 'currents' such as 'Classicism' or 'Romanticism', as well as the 'isolated' position of individual authors such as Hölderlin and Jean Paul, may now also be traced back to distinct preferences of the 'currents' in question (or configurations in literary history respectively) as well as of the authors in question; various preferences regarding the question which operations should be used for eternity-attribution primarily and to which degree of radicalness. This is complemented by the research of the last few decades, which increasingly reveals the continuities and entanglements between configurations in literary history of that period from the 'Enlightenment' to 'Romanticism'.

\section{Outlook and Critical Reflection}

Of the many possible points of connection which the present monograph attempts to offer, one of each will be discussed for a handful of central topics, namely: a general semiotic typology, the history of cultural semiosis, and hermeneutics in connection with rhetoric.

It is striking that the present study's results on a semiotic, typological level finds common ground with Aleida Assmann's research. The operations 'endless falling silent' and 'poetic performativity', for example, display similarities with her concepts "Zeichenkraft" (power of signs) or "Zeichenlogiken" (logic of signs) respectively, which describe the "Entleerung (asemantische Zeichen)" (evacuation, asemantic signs) or "Vergegenwärtigung (magische Zeichen)" (realization, magic signs) respectively. ${ }^{13}$ Assmann follows Charles S. Peirce's semiotic classification of index, icon and symbol, but also adds her own, namely

\footnotetext{
11 Schneider 1998, p. 12.

12 Cf. ibid.

13 Cf. A. Assmann 2015, pp. 53-6o.
} 
performative, asemantic and magic signs. ${ }^{14}$ As has already been hinted at by Assmann herself, her typology carries great potential for literary studies, both with regard to analysis and heuristics. For this reason, it should conversely be clarified if and to what extent this study's typology, which specifically relates to eternity-attribution, may be merged into a general semiotic typology, especially in combination with Assmann's classification.

From a historical perspective, there is much evidence to suggest that the process of secularization has reached a new apex in the 'occidental' present of the early 21th century, while the sub-operation 'endless reading' seems to come to play an increasingly dominant role regardless of medium..$^{15}$ In the latter case, some examples are the hypertexts of the internet or, from the point of view of those who do the writing, wikis, while the potentially endless serial format ${ }^{16}$ has gained a dynamic of its own within the domains of books, cinema, TV and streaming. Many of these supposedly novel manifestations are ultimately digital translations or extensions of procedures that have already been observed for the period around 1800 in this study. Or to put the question more boldly: Is big data and the vision of the 'internet of things' ultimately exposed as nothing else but the most radical underpinning of all aspects of life through the sub-operation 'endless reading', nothing but yet another symbolic ${ }^{17}$ attempt at eternalization? ${ }^{18}$ All of this finally leads to a macro perspective on the history of cultural semiosis and the 'logic of signs' 19 on which it is based; a perspective which in turn is adopted by Assmann's research: To what extent and in what ways may shifts in a society's semiotic paradigm find expression in the 'manifestation' of operations of the eternity-attribution of characters? And could these operations also reveal themselves as 'strategies of duration' 20 on a macro level that transcends written texts?

With regard to hermeneutics, the following question imposes itself: What position within a hermeneutical theory adopt those text passages which contain an operation of the eternity-attribution of characters? We might put forward the following hypothesis:

\footnotetext{
14 Ibid. p. 53. Aleida Assmann uses 'performative' in the broader sense of 'instructions' (cf. chapter III.1), based on Austin's later writings. This explains why the narrower usage of the term 'performative' used in this study overlaps more with Assmann's 'magic signs'.

15 See also Brukamp 2011, pp. 77-92.

16 Cf. Fröhlich 2015.

17 Symbolic in the sense of 'zeichenhaft', not 'symbolisch'.

18 Cf. Krüger 2004, pp. 313-4 and p. 401.

19 A. Assmann 2015, p. 17.

20 Cf. A. Assmann 1999.
} 
Such text passages may well be the best potential 'points' of departure and/ or reference of any hermeneutical process, since they display, with regard to semiotics, the least dependence on time and context compared to other passages. ${ }^{21}$

If we further connect, with regard to hermeneutics and rhetoric, statements by Friedrich Schleiermacher as well as reflections by Emil Angehrn and Daniel Müller Nielaba ${ }^{22}$ with this study's findings, we additionally arrive at the following, complementary theses that warrant further examination:

1) Eternity serves as figural 'point of reference' of 'modern' understanding and through this attempts to ensure not eternity, but, at the 'least', a potential endlessness and, in doing this, 'propels' itself as an unending procedure. This, in turn, leads to an 'even greater' elusiveness of that figural 'point of reference,' and so on. However, if that point of reference was 'reached', eternally valid meaning would be understood through this procedure once and for all. This would also entail the end of this procedure and thus the end of 'modern understanding.'

2) With that, it also becomes apparent on a semiotic-rhetorical level that, conversely, eternity-attribution may be a defining constituent, perhaps not of figuration in general, but of rhetorical figures (and probably tropes). This would complement the first thesis with regard to the potentially endless movement, which is inherent in every figuration, but perhaps even with regard to (certain) procedures which pursue autonomy. The latter would be the case in those instances in which the achievement of poetic performativity can be observed as a defining aspect of the rhetorical figure in question. The present monograph has tried repeatedly to also address those eternityassertions and -attributions which it itself is subject to. And yet, in doing this, the author 'utilizes' both the basic operation 'reflexivity' and ultimately the operation 'poetic performativity' and thus performs another eternityattribution of his own work - and with this observation, we arrive at the next reflection and so on, ad infinitum.

This holds true especially for this study, but ultimately also for philology in general. ${ }^{23}$ Literary studies and partly also linguistics not only continually make implicit - and occasionally explicit - eternity-assertions toward characters and texts; they also do this in a manner that, to some degree, makes those assertions come true. This basic problem of a 'self-fulfilling prophecy' is only

21 It is not an accident that the auto-referential, auto-reflexive passage at the end of the Rosetta Stone's text was a decisive point of departure for the deciphering of the hieroglyphs! (cf. Doblhofer 200o, S. 56).

22 Cf. chapter 2.2. of the monograph's outlook.

23 See also Markus Rothhaar's outlook at the end of his essay on the antinomy of endlessness in Kant and Hegel, Rothhaar 2018, pp. 167-8. 
exacerbated - as has been shown in the historical chapters of the main part due to the fact that modern disciplines of philology (which, to some extent, can be traced back to the so-called Renaissance $\left.{ }^{24}\right)^{25}$ have emerged in the 18th century, of all things, in a context in which can be observed an accentuation of eternity-assertions and eternity-attributions of characters. Furthermore: Much points to the possibility that modern disciplines of philology originated from precisely that accentuation to which they have at the same time substantially contributed.

The best illustration of this, as has been shown, is Herder's essay on Shakespeare, which is seen in the German language area, of all things, as the beginning of modern historical literary studies - a similar observation may even be made for Wilhelm von Humboldt (who was inspired by Schiller's Wallenstein) and his influence on the nascent discipline of linguistics. ${ }^{26}$

These observations may ultimately also explain why there have been no systematic examinations of operations of the eternity-attribution of characters before the present study, since these operations constitute a 'blind spot' of those disciplines of whose fields of study such an examination ought to be a part. Every discipline that works with texts, especially those that fall within philology and history, must necessarily participate in the (as yet unwritten) history of the eternity-assertions and eternity-attributions of characters. ${ }^{27}$ It must also be assumed that it is precisely those disciplines which would write such a history. If, however, they refrained from procedures which intersect with operations of eternity-attribution, they would abolish themselves. Their 'only' option is to point, again and again and from varying perspectives, toward that 'blind spot'. In that sense, the present study also understands itself as a contribution, on the part of the disciplines of philology, to render more transparent their own eternity-assertions and -attributions - in the 'knowledge' that in such an undertaking is again unavoidably contained another potentially endless movement.

24 The term 'Renaissance' too should ultimately be described as eternity-assertion. It is not an accident that the term was not coined until the 19th century.

25 Cf. for this and regarding an 'auratic relation to the sources' A. Assmann 1999, especially pp. 120-121 as well as Nate 2018.

26 Cf. the end of chapter III.1.2.1.

27 Cf. especially chapter 4 of the introduction. 
Markus Gut - 978-3-8467-6517-3

Downloaded from Fink.de@4/26/2023 07:48:17AM via free access 


\section{Danksagung}

An dieser Stelle sei all jenen ganz herzlich gedankt, die zum Gelingen der vorliegenden Arbeit beigetragen haben. Der erste Dank gebührt dabei den Betreuenden:

Prof. Dr. Daniel Müller Nielaba (Zürich) für die hervorragende fachliche Hauptbetreuung, die umfassenden und genauen kritischen Lektüren sowie für das Unterstützen und Gewähren der kreativen Freiheit, was überhaupt erst den Rahmen zur Planung und Umsetzung dieser Arbeit schuf; und nicht zuletzt für das Wecken der Begeisterung für das Schnittfeld von Literaturwissenschaft und Semiotik in meiner damals ersten universitären Vorlesung überhaupt.

Prof. Dr. Claudia Liebrand (Köln) für ihre sehr vielfältige, vertiefte und äußerst hilfreiche Co-Betreuung, für die wichtige und ergänzende kritische Außenperspektive und ganz besonders für den stets sehr ermutigenden persönlichen Austausch auch über die Arbeit hinaus.

Prof. Dr. Sabine Schneider (Zürich) für die entscheidende Hilfe bei der Komposition der Arbeit und der Eingrenzung des Zeitbereichs sowie für ihre Begleitung der historischen Kapitel; und insbesondere auch für ihre Unterstützung bezüglich der Finanzierung und Publikation.

Besonderer Dank gilt dem Förderungsprogramm „doc.ch“ des Schweizerischen Nationalfonds (SNF), der durch seine Finanzierung von Einzelprojekten und deren Publikation das Entstehen und Erscheinen des vorliegenden Buches erst ermöglicht hat.

Ein großes Dankeschön geht natürlich auch an den Wilhelm Fink Verlag für die Aufnahme dieses Buches in sein Programm; insbesondere schätzte ich die Zusammenarbeit mit Dr. Henning Siekmann und dem Lektor Thorsten Tynior.

Ebenfalls zu Dank verpflichtet bin ich Assist. Prof. Dr. Leif Weatherby für die Betreuung während meines Semesters an der New York University 2015. Für die Ermöglichung dieses Aufenthaltes danke ich der NYU und dem (ehemaligen) Doktoratsprogramm „Deutsche und Nordische Philologie“ der Universität Zürich.

Prof. em. Dr. Horst Sitta danke ich für seine hilfreiche ergänzende Beratung in linguistischen sowie altphilologischen Fragen und die bereichernden, stets motivierenden Gespräche; Prof. Dr. Rüdiger Campe (Yale) und Prof. Dr. Charles de Roche (Zürich) für einzelne Literaturhinweise; Andreas Inderwildi, Dr. Mateusz Cwik und William Cheung für das geduldige Korrekturlesen des ersten Manuskripts, das langjährige Teilen der Freude am Fach und die gemeinsamen Wege an den Universitäten Zürich und New York. Darüber hinaus 
gebührt Andreas Inderwildi zusätzlich besonderer Dank für die Übersetzung der englischen Zusammenfassung.

Dank geht auch an Prof. Dr. Bernhard Schemmel (Bamberg) von der E. T. A. Hoffmann-Gesellschaft und Gerald Raab von der Staatsbibliothek Bamberg für das sehr entgegenkommende Beschaffen einzelner Scans der Erstausgaben der Lebens-Ansichten des Katers Murr.

Last but not least danke ich meinen Eltern Elsbeth und Otto Gut-Stocker für das frühe Wecken der Begeisterung für Geschichte und Geschichten und das Ermöglichen meines Studiums; sowie meinem ganzen Freundeskreis, der wesentlich dafür mitverantwortlich ist, dass ich mich während dieser Jahre in den Kreisen der Unendlichkeit nie verloren habe.

Zürich, Ende September 2019

Markus Gut 


\section{Literaturverzeichnis}

\section{Primärtexte}

Aristoteles: Poetik. Griechisch/Deutsch. Übersetzt und herausgegeben von Manfred Fuhrmann. Stuttgart 2012 (RUB 7828)

Aristoteles: Rhetorik. Übersetzt und herausgegeben von Gernot Krapinger. Stuttgart 2015 (RUB 180o6)

Brentano, Clemens: Sämtliche Werke und Briefe, Bde. 19 und 29. Herausgegeben von Gerhard Kluge, Lieselotte Kinskofer et al. Stuttgart 1987/88

Bonnet, Charles: Betrachtung über die Natur. Übersetzt von Johann Daniel Titius. Leipzig 1772

Deghaye, Pierre: De Paracelse à Thomas Mann. Les avatars de l'hermétisme allemand. Paris 2000 (Bibliothèque de l'hermétisme)

de La Fontaine, Jean: Fables 1668, Bd. 1, Fabel 2 [http://www.lafontaine.net/lesFables; Stand: Juni 2018]

Deutsche Tagelieder von den Anfängen der Überlieferung bis zum 15. Jh. Nach dem Plan Hugo Stopps hrsg. v. Sabine Freund. Heidelberg 1983

Goethe, Johann Wolfgang: Sämtliche Werke. Briefe, Tagebücher und Gespräche. Vierzig Bände. Herausgegeben von Hendrik Birus, Dieter Borchmeyer, Karl Eibl et al. Frankfurt am Main 1985-2013 (Bibliothek deutscher Klassiker)

Goethe, Johann Wolfgang: Gedichte. Studienausgabe. Herausgegeben von Bernd Witte. Stuttgart 2008 (RUB 18519)

Goethe, Johann Wolfgang: Zum Schäkespears Tag, in: Hans Mayer (Hg.): Meisterwerke deutscher Literaturkritik. Aufklärung, Klassik, Romantik. Stuttgart 1962, S. 387-391

Gottsched, Johann Christoph: Versuch einer critischen Dichtkunst. Unveränderter photomechanischer Nachdruck der 4., vermehrten Auflage. Darmstadt 1962

Gottsched, Johann Christoph: Sterbender Cato, in: Joachim Birke (Hg.): Johann Christoph Gottsched: Ausgewählte Werke. Zweiter Band. Sämtliche Dramen. Berlin 1970

Gryphius, Andreas: Catharina von Georgien. Herausgegeben von Alois M. Haas. Stuttgart 2012 (RUB 9751)

Herder, Johann Gottfried: Werke. In zehn Bänden. Herausgegeben von Günter Arnold, Martin Bollacher, Jürgen Brummack et al. Frankfurt am Main 1985-200o (Bibliothek deutscher Klassiker)

Homer: Ilias. Übersetzung, Nachwort und Register von Roland Hampe. Stuttgart 2007 (RUB 249) 
Homer: Odyssee. Übersetzung, Nachwort und Register von Roland Hampe. Stuttgart 2007 (RUB 280)

Hoffmann, E. T. A.: Lebens-Ansichten des Katers Murr. Werke, Bd. 5, 1820-1821. Herausgegeben von Hartmut Steinecke unter Mitarbeit von Gerhard Allroggen. Frankfurt a. M. 1992 (Bibliothek deutscher Klassiker 184)

Hoffmann, E. T. A.: Lebens-Ansichten des Katers Murr nebst fragmentarischer Biographie des Kapellmeisters Johannes Kreisler in zufälligen Makulaturblättern. Herausgegeben von E. T. A. Hoffmann. Erster Band. Berlin [1819] 1820 [Staatsbibliothek Bamberg, Sigle Sel.229-1]

Hoffmann, E. T. A.: Lebens-Ansichten des Katers Murr nebst fragmentarischer Biographie des Kapellmeisters Johannes Kreisler in zufälligen Makulaturblättern. Herausgegeben von E. T. A. Hoffmann. Zweiter Band. Berlin [1821] 1822 [Staatsbibliothek Bamberg, Sigle Sel.229-2]

Hölderlin, Friedrich: Ermunterung, in: D. E. Sattler/Michael Knaupp (Hg.): Friedrich Hölderlin: Sämtliche Werke. Historisch-kritische Ausgabe. Bd. 5, Oden II. Frankfurt am Main 1984, S. 759-769

Horaz: Oden und Epoden. Lateinisch/Deutsch. Übersetzt und herausgegeben von Bernhard Kytzler. Stuttgart 2015 (RUB 9905)

Humboldt, Wilhelm von: Brief von Humboldt an Schiller, Paris, Anfang September 1800, in: Siegfried Seidel (Hg.): Der Briefwechsel zwischen Friedrich Schiller und Wilhelm von Humboldt. Bd. 2. Berlin 1962, S. 189-212

Jean Paul: Auswahl aus des Teufels Papieren. Nebst einem nöthigen Aviso vom Juden Mendel [1789], in: Norbert Miller/Wilhelm Schmidt-Biggemann (Hg.): Jean Paul: Sämtliche Werke. Abteilung II. Jugendwerke und vermischte Schriften. Zweiter Band. München 1976, S. 111-469

Jean Paul: Die Unsichtbare Loge. Eine Biographie. Text der Erstausgabe von 1793 mit den Varianten der Ausgabe von 1826, Erläuterungen, Anmerkungen und Register. Herausgegeben von Klaus Pauler. München 1981

Jean Paul: Hesperus oder 45 Hundsposttage. Eine Biographie. Edition der Druckfassungen von 1895, 1798 und 1819 in synoptischer Darstellung. Text. Herausgegeben von Barbara Hunfeld, in: Helmut Pfotenhauer (Hg.): Jean Paul: Werke. Historischkritische Ausgabe 1,3. Tübingen 2009

Jean Paul: Konjektural-Biographie, in: Eduard Berend (Hg.):Jean Pauls sämtliche Werke. Historisch-kritische Ausgabe 1,7. Weimar 1931

Klopstock, Friedrich Gottlieb: Der Messias. Gesang XX, in: Elisabeth Höpker-Herberg et al. (Hg.): Friedrich Gottlieb Klopstock: Werke und Briefe. Historisch-Kritische Ausgabe. Abteilung Werke: IV 2. Berlin, New York 1974, S. 265-299

Lavater, Johann Caspar: Physiognomische Fragmente, zur Beförderung der Menschenkenntnis und Menschenliebe. Erster Versuch. Leipzig und Winterthur 1775 [www.e-rara.ch; Stand Juni 2018] 
Lessing, Gotthold Ephraim: Werke und Briefe. In zwölf Bänden. Herausgegeben von Wilfried Barner zusammen mit Klaus Bohnen, Gunter E. Grimm et al. Frankfurt am Main 1985-2003 (Bibliothek deutscher Klassiker)

Luther, Martin:Assertio omnium articulorum M. Lutheriper bullam Leonis X. novissimam damnatorum (1521), in: D. Martin Luthers Werke. Kritische Gesamtausgabe [unveränderter photomechanischer Nachdruck 1966]. Weimar 1897, S. 91-151

Luther, Martin: Wahrheitsbekräftigung aller Artikel Martin Luthers, die von der jüngsten Bulle Leos X. verdammt worden sind (1520). Übersetzung von Sibylle Rolf, in: Wilfried Härle (Hg.): Martin Luther. Lateinisch-Deutsche Studienausgabe. Band 1: Der Mensch vor Gott. Leipzig 2006, S. 71-217

Moritz, Karl Philipp: Werke. In zwei Bänden, herausgegeben von Heide Hollmer und Albert Meier, Frankfurt am Main 1997 (Bibliothek deutscher Klassiker)

de La Motte, Houdar: CEuvres de Monsieur Houdar de La Motte, l'un de quarante de l'Académie Françoise. Tome neuvième. Buch 5, Fabel 1. Paris 1754 [google books, Stand: Juni 2018]

Novalis (Friedrich von Hardenberg): Heinrich von Afterdingen. Textkritische Edition herausgegeben von Alexander Knopf. Frankfurt am Main, Basel 2015

Novalis (Friedrich von Hardenberg): Heinrich von Ofterdingen. Ein nachgelassener Roman von Novalis. 2 Theile, in: Kluckhohn, Paul/Samuel, Richard (Hg.): Novalis. Schriften. Das dichterische Werk, Bd. 1. Darmstadt 1977

Ovid: Metamorphosen. Lateinisch/Deutsch. Übersetzt und herausgegeben von Michael von Albrecht. Stuttgart 2012 (RUB 1360)

Papyrus Chester Beatty IV, verso 2.5-2.13, in: Helmut Brunner (Hg.): Altägyptische Weisheit. Lehren für das Leben. Zürich, München 1988, S. 224-226

Pico della Mirandola: De hominis dignitate. Über die Würde des Menschen. Auf der Textgrundlage der Editio princeps herausgegeben und übersetzt von Gerd von der Gönna. Stuttgart ${ }^{3} 2018$ (RUB 9658)

Platon: Phaidros oder Vom Schönen. Übertragen und eingeleitet von Kurt Hildebrandt. Stuttgart 2012 (RUB 5789)

Platon: Symposion. Griechisch/Deutsch. Übersetzt und herausgegeben von Thomas Paulsen und Rudolf Rehn. Stuttgart 2012 (RUB 18435)

Quintilianus, Marcus Fabius: Ausbildung des Redners. [Institutio Oratoria]. Zwölf Bücher. Lateinisch und Deutsch. Herausgegeben und übersetzt von Helmut Rahn. Darmstadt 2015

Schiller, Friedrich: Schillers Werke. Nationalausgabe. Herausgegeben von Julius Petersen, Liselotte Blumenthal, Norbert Oellers et al. Weimar 1940-

Schlegel, Friedrich: Philosophische Lehrjahre 1796-1806. Nebst philosophischen Manuskripten aus den Jahren 1796-1828. Erster Teil, in: Ernst Behler (Hg.): Kritische Friedrich-Schlegel-Ausgabe. München, Paderborn, Wien 1963, Bd. 18 
Schlegel, Friedrich: Lucinde. Studienausgabe. Kritisch herausgegeben und mit BegriffsRepertorium, Bibliographie und Nachwort versehen von Karl Konrad Polheim. Stuttgart 2008 (RUB 320)

Schleiermacher, F. D. E.: Das Leben Jesu [Auszug] (1832), in: Manfred Frank (Hg.): F. D. E. Schleiermacher, Hermeneutik und Kritik. Mit einem Anhang sprachphilosophischer Texte Schleiermachers. Frankfurt am Main 1977 (Suhrkamp-Taschenbuch Wissenschaft 211), S. 387-394

Schleiermacher, F. D. E.: Hermeneutik und Kritik, in: Manfred Frank (Hg.): F. D. E. Schleiermacher, Hermeneutik und Kritik. Mit einem Anhang sprachphilosophischer Texte Schleiermachers. Frankfurt am Main 1977 (Suhrkamp-Taschenbuch Wissenschaft 211), S. 69-306

Sterne, Laurence: Leben und Ansichten von Tristram Shandy, Gentleman. Ins Deutsche übertragen und mit Anmerkungen von Michael Walter. Frankfurt a. M. 2010 (Fischer Klassik)

Tagelieder des deutschen Mittelalters. Mittelhochdeutsch/Neuhochdeutsch. Ausgewählt, übersetzt und kommentiert von Martina Backes. Einleitung von Alois Wolf. Stuttgart 2011 (RUB 8831)

Texte zur Geschichte des deutschen Tageliedes. Hrsg. von Ernst Scheunemann. Ergänzt und hrsg. von Friedrich Ranke. Bern 1947

Zürcher Bibel. Herausgegeben vom Kirchenrat der Evangelisch-reformierten Landeskirche des Kantons Zürich. Zürich 2007

\section{Nachschlagewerke}

Enzyklopädie des Märchens. Handwörterbuch zur historischen und vergleichenden Erzählforschung. Herausgegeben von Rolf Wilhelm Brednich. Band 10. Berlin, New York 2002

Deutsches Wörterbuch, digitalisierte Ausgabe: http://woerterbuchnetz.de/DWB

Historisches Wörterbuch der Philosophie. Herausgegeben von Joachim Ritter, Karlfried Gründer und Gottfried Gabriel. 13 Bände. Basel 1971-2007

Lexer, Matthias: Mittelhochdeutsches Taschenwörterbuch. Mit den Nachträgen von Ulrich Pretzel. 38. unveränderte Auflage. Stuttgart 1992

Lexikon für Theologie und Kirche. Begründet von Michael Buchberger. Dritte, völlig neu bearbeitete Auflage. Herausgegeben von Walter Kasper. 11 Bände. Freiburg, Basel, Rom et al. 1993-2001

Metzler Lexikon literarischer Symbole. Herausgegeben von Günter Butzer und Joachim Jacob, zweite, erweiterte Auflage. Stuttgart 2012

Schweizerdeutsches Wörterbuch, Schweizerisches Idiotikon, digitalisierte Ausgabe: https://www.idiotikon.ch/online-woerterbuch 


\section{Forschungsliteratur}

Abbt, Christine/Kammasch, Tim (Hg.): Punkt, Punkt, Komma, Strich? Geste, Gestalt und Bedeutung philosophischer Zeichensetzung, Bielefeld 2009

Alewyn, Richard: „Clemens Brentano: „Der Spinnerin Lied“', in: ders.: Probleme und Gestalten. Essays. Frankfurt am Main 1974, S. 198-202

Alder, Daniel: Epistemologie der Figur. Stimmlichkeit und poetologische Figuralität in der Lyrik um 180o. Würzburg 2015

Ammon, Frieder von: Ungastliche Gaben: Die „Xenien“ Goethes und Schillers und ihre literarische Rezeption von 1796 bis in die Gegenwart. Tübingen 2005

Angehrn, Emil: Sein Leben schreiben. Wege der Erinnerung. Frankfurt am Main 2017 (Klostermann Rote Reihe 94)

Angehrn, Emil: Wege des Verstehens. Hermeneutik und Geschichtsdenken. Würzburg 2008

Angehrn, Emil: Interpretation und Dekonstruktion. Untersuchungen zur Hermeneutik. Weilerswist 2004

Austin, John L.: Zur Theorie der Sprechakte (How to do things with words). Dt. Bearbeitung von Eike von Savigny. Zweite, bibliographisch ergänzte Auflage. Stuttgart 2002 (RUB 9396)

Austin, John L.: How to do things with words. The William James Lectures delivered at Harvard University in 1955. Oxford 1962

Assmann, Aleida: Im Dickicht der Zeichen. Berlin 2015 (Suhrkamp Taschenbuch Wissenschaft 2079)

Assmann, Aleida: Zeit und Tradition. Kulturelle Strategien der Dauer. Köln, Weimar, Wien 1999

Assmann, Jan: Das kulturelle Gedächtnis. Schrift, Erinnerung und politische Identität in frühen Hochkulturen. München ${ }^{5}{ }_{2005}$

Assmann, Jan: „Jenseits der Stimme, jenseits des Mythos. Über die Veränderung der Welt durch die Schrift“, in: Wilfried Seipel (Hg.): Der Turmbau zu Babel. Ursprung und Vielfalt von Sprache und Schrift. Eine Ausstellung des Kunsthistorischen Museums Wien für die Europäische Kulturhauptstadt Graz 2003. Band IIIA: Schrift. Graz 2003, S. $45^{-49}$

Assmann, Jan: Stein und Zeit. Mensch und Gesellschaft im alten Ägypten. München 1991

Baumann, Gerhart: „Novalis: Dichtung und Enzyklopädie; unendliche Annäherungen“, in: Paola-Ludovika Coriando (Hg.): Vom Rätsel des Begriffs. Festschrift für FriedrichWilhelm von Herrmann zum 65. Geburtstag. Berlin 1999 (Philosophische Schriften, Bd. 36), S. 253-261. Wieder in: Gerhart Baumann: Skizzen. Freiburg im Breisgau 2000 (Rombach Wissenschaften, Litterae 79), S. 25-35 
Behler, Ernst: „Das Fragment“, in: Klaus Weissenberger (Hg.): Prosakunst ohne Erzählen. Die Gattungen der nicht-fiktionalen Kunstprosa. Tübingen 1985 (Konzepte der Sprach- und Literaturwissenschaft 34), S. 125-143

Benthien, Claudia: „Die vanitas der Stimme. Verstummen und Schweigen in bildender Kunst, Literatur, Theater und Ritual“, in: Doris Kolesch/Sybille Krämer (Hg.): Stimme. Annäherung an ein Phänomen. Frankfurt am Main 20o6, S. 237-268

Bernauer, Markus et al. (Hg.): Jean Paul, Dintenuniversum: Schreiben ist Wirklichkeit. Berlin, 2013

Berghahn, Cord-Friedrich: Das Wagnis der Autonomie. Studien zu Karl Philipp Moritz, Wilhelm von Humboldt, Heinrich Gentz, Friedrich Gilly und Ludwig Tieck. Heidelberg 2012

Bies, Michael/Gamper, Michael (Hg.): Ästhetische Eigenzeiten. Bilanz der ersten Projektphase. Hannover 2019 (Ästhetische Eigenzeiten 14)

Blanchot, Maurice: Die Literatur und das Recht auf den Tod. Berlin 1982

Bleumer, Hartmut/Franceschini, Rita/Habscheid, Stephan/Werber, Niels: „Turn, Turn, Turn? Oder: Braucht die Germanistik eine germanistische Wende? Eine Rundfrage zum Jubiläum der Lili“, in: Zeitschrift für Literaturwissenschaft und Linguistik 172, 2013, S. 9-15

Bolten, Jürgen: „Die hermeneutische Spirale. Überlegungen zu einer integrativen Literaturtheorie“, in: Poetica 17, 1985, S. 355-371

Böhl, Meinrad: Dichtung; Bibel. „Neuzeit und Gegenwart (19.-21. Jahrhundert)“, in: ders./Wolfgang Reinhard/ Peter Walter (Hg.): Hermeneutik. Die Geschichte der abendländischen Textauslegung von der Antike bis zur Gegenwart. Dichtung, Bibel, Recht, Geschichte, Philosophie. Wien, Köln, Weimar 2013, S. 25-142 und 209-276

Borchmeyer, Dieter: Macht und Melancholie. Schillers Wallenstein. Frankfurt am Main 1988 (Athenäums Monografien, Literaturwissenschaft 91)

Börnchen, Stefan: Allegorien von Schrift, Stimme und Musik in Thomas Manns „Doktor Faustus“. München 2006

Böttigheimer, Christoph/Dausner, René (Hg.): Unendlichkeit. Transdisziplinäre Annäherungen. Würzburg 2018 (Konzeptionen des Unendlichen - eine europäische Kulturkonstante? Bd. 1)

Brachtendorf, Johannes/Herzberg, Stephan (Hg.): Einheit und Vielheit als metaphysisches Problem. Tübingen 2011 (Collegium Metaphysicum 3)

Brachtendorf, Johannes/Möllenbeck, Thoms/Nickel, Gregor et al. (Hg.): Unendlichkeit. Interdisziplinäre Perspektiven. Tübingen 2008 (Religion und Aufklärung 15)

Braun, Michael: „Hörreste, Sehreste“. Das Literarische Fragment bei Büchner, Kafka, Benn und Celan. Köln, Weimar, Wien 2002

Brügger, Lilo: „Der Zauberlehrling und seine griechische Quelle. Eine vergleichende Interpretation“, in: Goethe. Viermonatsschrift der Goethe-Gesellschaft. Neue Folge des Jahrbuchs 1951, S. 243-258 
Brukamp, Kirsten: „Wege des Weiterwirkens der Toten durch moderne Medien“, in: Dominik Gross/Brigitte Tag/Christoph Schweikardt (Hg.): Who wants to live forever? Postmoderne Formen des Weiterwirkens nach dem Tod. Frankfurt, New York 2011, S. $77-92$

Bunia, Remigius: „Die Stimme der Typographie. Überlegungen zu den Begriffen ,Erzähler‘ und ,Paratext', angestoßen durch die Lebens-Ansichten des Katers Murr von E. T. A. Hoffmann“, in: Poetica: Zeitschrift für Sprach- und Literaturwissenschaft 37,2005 , S. 373-392

Burdorf, Dieter: „Blätter, Rosen, Gärten. Zur Theorie des lyrischen Fragments beim jungen Friedrich Schlegel (1794-1798)“, in: Christian Benne/Ulrich Breuer (Hg.): Antike - Philologie - Romantik. Friedrich Schlegels altertumswissenschaftliche Manuskripte. Paderborn u. a. 2011, S. 101-146

Buser, Marcos: Literaturstudie zum Stand der Markierung von geologischen Tiefenlagern. Studie im Auftrag des Schweizerischen Bundesamtes für Energie (BFE). Bern 2010

Campe, Rüdiger: „Form and Life in the Theory of the Novel“, in: Constellations. An International Journal of Critical and Democratic Theory 11, 2011, S. 53-66

Cassirer, Ernst: „Einleitung und Problemstellung“, in: ders.: Philosophie der symbolischen Formen. Erster Teil. Die Sprache. Text und Anmerkungen bearbeitet von Claus Rosenkranz. Hamburg 2001 (Gesammelte Werke von Ernst Cassirer 11.), S. $1-49$

Christiansen, Annemarie: „Der Zauberlehrling“, in: Karl Hotz (Hg.): Gedichte aus sieben Jahrhunderten. Interpretationen. Bamberg 1987, S. 39-46

Claudel, Anne: Long-term preservation and the concept of oversight, in: Radioactive Waste Management and Constructing Memory for Future Generations. Proceedings of the International Conference and Debate 15-17 September 2014, Verdun, France. NEA No. 7259. OECD 2015, S. 85-88

Conrad, Maren: Aufbrüche der Ordnung, Anfänge der Phantastik: ein Modell zur methodischen Balladenanalyse, entwickelt am Beispiel der phantastischen Kunstballade. Heidelberg 2014

Czezior, Patricia: Der Leser und die Hinterfragung seiner Rolle in E. T. A. Hoffmanns Kater Murr und Karl Immermanns Münchhausen. Eine Analyse im Rahmen des Kommunikationsmodells Autor - Text - Leser. München 2008 (Studien Deutsch 38)

Daiber, Jürgen: Experimentalphysik des Geistes. Novalis und das romantische Experiment. Göttingen 2001

Davies, Steffan: The Wallenstein Figure in German Literature and Historiography 17901920. London 2010 (Bithell Series of Dissertations 36)

De Man, Paul: „Rhetorik der Zeitlichkeit“, in: Christoph Menke (Hg.): Paul de Man. Die Ideologie des Ästhetischen. Aus dem Amerikanischen von Jürgen Blasius. Frankfurt am Main 1993 (edition suhrkamp 1682), S. 83-130 
Derrida, Jacques: Dissemination. Herausgegeben von Peter Engelmann, übersetzt von Hans-Dieter Gondek. Wien 1995

Derrida, Jacques: „Signatur Ereignis Kontext“, in: Randgänge der Philosophie. Herausgegeben von Peter Engelmann. Zweite, überarbeitete Auflage. Wien 1999, S. 325-351 Dilthey, Wilhelm: Der Aufbau der geschichtlichen Welt in den Geisteswissenschaften. Baden-Baden 1981 (Suhrkamp Taschenbuch Wissenschaft 354)

Dilthey, Wilhelm: „Wallenstein“, in: Fritz Heuer/Werner Keller (Hg.): Schillers Wallenstein. Darmstadt 1977 (Wege der Forschung 420), S. 74-103

Doblhofer, Ernst: Die Entzifferung alter Schriften und Sprachen (1957). Neubearbeitete Ausgabe. Stuttgart 2000 (Reclam-Bibliothek 1702)

Doderer, Klaus: Fabeln. Formen, Figuren, Lehren. Zürich 1970

Dorn, Andreas: „Ein Literatenwettstreit und das Ende der Diglossie als sprachgeschichtliche Schwelle. Essayistische Gedanken zur Literatur des Neuen Reiches“, in: Dieter Kessler/Regine Schulz/Martina Ullmann et al. (Hg.): Texte - Theben - Tonfragmente. Festschrift für Günter Burkard. Wiesbaden 2009 (Ägypten und Altes Testament 76), S. $70-82$

Egli, Gustav: E. T. A. Hoffmann. Ewigkeit und Endlichkeit in seinem Werk. Zürich 1927 (Wege zur Dichtung 2)

Eichner, Siglinde: Die Prosafabel Lessings in seiner Theorie und Dichtung. Ein Beitrag zur Ästhetik des 18. Jahrhunderts. Bonn 1974 (Bonner Arbeiten zur Deutschen Literatur 25)

Eire, Carlos: A very brief history of Eternity. Princeton 2010

Engelmann, Peter: „Ausblick: Schreibende Katzen, schreibende Dichter“, in: Kofman, Sarah: Schreiben wie eine Katze. Zu E. T. A. Hoffmanns „Lebens-Ansichten des Katers Murr“. Herausgegeben von dems. Graz, Wien 1985 (Edition Passagen 5), S. 124-142 Enzensberger, Hans Magnus: Brentanos Poetik. München 1961 (Literatur als Kunst) Flaherty, Gloria: „Goethe and Shamanism“, in: Modern Language Notes (MLN) 104.3, 1989, S. 58o-596

Folkmann, Mads Nygaard: Figuration des Übergangs: Zur literarischen Ästhetik bei Novalis. Lang: Frankfurt am Main 2006

Forderer, Christof: „Das Singen der ,Sprachen des Himmels. Überlegungen zu Reden und Schweigen in Hölderlins Gedichten“, in:Zeitschrift für Germanistik, Neue Folge 10, Nr. 3, 200o, S. 536-546

Forschbach, Edgar: „Unendlichkeit und Ewigkeit“, in: Otfried Reinke (Hg.): Ewigkeit? Klärungsversuche aus Natur- und Geisteswissenschaften. Göttingen 2004, S. 52-64

Foucault, Michel: „Die Sprache, unendlich“, in: Daniel Defert et al. (Hg.): Michel Foucault, Schriften zur Literatur. Frankfurt am Main 2003 (Suhrkamp-Taschenbuch Wissenschaft 1675), S. 86-99 
Frank, Manfred: „Einleitung“, in: ders. (Hg.): Schleiermacher. Hermeneutik und Kritik. Mit einem Anhang sprachphilosophischer Texte Schleiermachers. Frankfurt am Main 1977 (Suhrkamp-Taschenbuch Wissenschaft 211), S. 7-67

Frank, Manfred: Das Problem "Zeit" in der deutschen Romantik: Zeitbewusstsein und Bewusstsein von Zeitlichkeit in der frühromantischen Philosophie und in Tiecks Dichtung. Zweite, überarbeitete Auflage. Paderborn, Zürich ${ }^{2} 1990$

Frank, Manfred und Kurz, Gerhard: „Ordo inversus. Zu einer Reflexionsfigur bei Novalis, Hölderlin, Kleist und Kafka“, in: Herbert Anton/Bernhard Gajek/Peter Pfaff (Hg.): Geist und Zeichen. Festschrift für Arthur Henkel. Heidelberg 1977, S. 75-92

Frey, Hans-Jost: Der Unendliche Text. Frankfurt 1990

Frey, Johannes: „Nachwort“, in: ders. (Hg.): Beowulf. Das angelsächsische Heldenlied. Stuttgart 2013, S. 113-128

Fries, Thomas: „Die Leerstelle. Der Zwischenraum“, in: Christine Abbt/Tim Kammasch (Hg.): Punkt, Punkt, Komma, Strich? Geste, Gestalt und Bedeutung philosophischer Zeichensetzung. Bielefeld 2009, S. 165-178

Fröhlich, Vincent: Der Cliffhanger und die serielle Narration. Analyse einer transmedialen Erzähltechnik. Bielefeld 2015

Frühwald, Wolfgang: „Zur Textgestalt; Nachwort“, in: ders. (Hg.): Novalis. Heinrich von Ofterdingen. Ein Roman. Stuttgart 2008 (RUB 8939), S. 219-223, 236-255

Frühwald, Wolfgang: „Kommentar zu ,Der Spinnerin Nachtlied““, in: ders. (Hg.): Gedichte der Romantik. Stuttgart 1995 (RUB 8230), S. 407

Frühwald, Wolfgang: „Die artistische Konstruktion des Volkstones. Zu Clemens Brentanos ,Der Spinnerin Nachtlied“', in: Wulf Segebrecht (Hg.): Gedichte und Interpretationen. Band 3. Klassik und Romantik. Stuttgart 1994 (RUB 7892), S. 268-279

Fuls, Andreas: „Methoden zur Entzifferung von Schriftsystemen“, in: MegaLithos. Zeitschrift für Archäologie, Archäoastronomie und Astronomie, 3/2009, S. 1-7

Gadamer, Hans-Georg: Gesammelte Werke. Bd. 1. Hermeneutik: Wahrheit und Methode. 1. Grundzüge einer philosophischen Hermeneutik. Sechste, durchgesehene Auflage. Tübingen ${ }^{6} 1990$

Gamper, Michael und Hühn, Helmut: Was sind Ästhetische Eigenzeiten? Hannover 2014 (Ästhetische Eigenzeiten. Kleine Reihe 1)

Gehring, Petra: „Die Wiederholungs-Stimme. Über die Strafe der Echo“, in: Doris Kolesch und Sybille Krämer (Hg.): Stimme. Annäherung an ein Phänomen. Frankfurt am Main 2006, S. 85-110

Gelbin, Cathy: „Was Frankenstein's monster Jewish?“, in: Publications of the English Goethe Society 2013, S. 16-25

Geisenhanslüke, Achim: Der Buchstabe des Geistes. Postfigurationen der Allegorie von Bunyan zu Nietzsche. München 2003 
Genz, Julia: „Flüchtig oder Dauerhaft? Materialität und Medialität der Schrift am Beispiel von E. T. A. Hoffmanns Lebens-Ansichten des Katers Murr“, in: ZS für Ästhetik und Allgemeine Kunstwissenschaft 54/1, 2009, S. 27-41

Gold, Helmut: Erkenntnisse unter Tage. Bergbaumotive in der Literatur der Romantik. Opladen 1990

Görnitz, Thomas: „Zeit und Ewigkeit aus der Sicht der Physik“, in: Otfried Reinke (Hg.): Ewigkeit? Klärungsversuche aus Natur- und Geisteswissenschaften. Göttingen 2004, S. 80-101

Göttsche, Dirk: Zeit im Roman. Literarische Zeitreflexion und die Geschichte des Zeitromans im späten 18. und 19. Jahrhundert. München 2001

Graham, Ilse: Schiller's Drama. Talent and Integrity. London 1974

Grimm, Gunter E. (Hg.): Deutsche Balladen. Stuttgart 1988 (Gedichte und Interpretationen RUB 8457)

Gut, Markus: Tolkiens „On Fairy-stories: Eine Poetik der Poetologie“, in: Hither Shore. Interdisciplinary Journal on Modern Fantasy Literature. Jahrbuch der Deutschen Tolkien Gesellschaft 12, 2015, S. 130-143

Gut, Markus: „Zur poetologischen Dimension mittelhochdeutscher Tagelieder“, in: Archiv für das Studium der neueren Sprachen und Literaturen 251:2, 2014, S. 255-282

Hausendorf, Heiko und Kesselheim, Wolfgang: Textlinguistik fürs Examen. Göttingen 2008 (Linguistik fürs Examen, Bd. 5)

Hausner, Renate (Hg.): Owê do tagte ez. Tagelieder und motivverwandte Texte des Mittelalters und der frühen Neuzeit. Göppingen 1983

Haarmann, Harald: Universalgeschichte der Schrift. Zweite, durchgesehene Auflage. Frankfurt am Main, New York ${ }^{2} 1991$

Haarmann, Harald: „Ex occidente lux. Die Anfänge des Schriftgebrauchs in Alteuropa“, in: Wilfried Seipel (Hg.): Der Turmbau zu Babel, Ursprung und Vielfalt von Sprache und Schrift. Eine Ausstellung des Kunsthistorischen Museums Wien für die Europäische Kulturhauptstadt Graz 2003. Band IIIA: Schrift. Graz 2003, S. 39-49

Hamacher, Werner: „Unlesbarkeit“, in: ders. (Hg.): Paul de Man. Allegorien des Lesens. Aus dem Amerikanischen von Werner Hamacher und Peter Krumme. Mit einer Einleitung von Werner Hamacher. Frankfurt am Main 1988, S. 7-26

Hartung, Gerald: „Unendlichkeit oder Maßlosigkeit? Anthropologische Überlegungen“, in: Johannes Brachtendorf/Thomas Möllenbeck/Gregor Nickel et al. (Hg.): Unendlichkeit. Interdisziplinäre Perspektiven. Tübingen 2008 (Religion und Aufklärung 15), S. $113-128$

Haufe, Eberhard: „Die Aufhebung der Zeit im ,Heinrich von Ofterdingen“', in: Joachim Müller (Hg.): Gestaltung, Umgestaltung. Festschrift zum 75. Geburtstag von Hermann August Korff. Leipzig 1957, S. 178-188

Heise, Wolfgang: Die Wirklichkeit des Möglichen. Dichtung und Ästhetik in Deutschland 1750-1850. Berlin, Weimar 1990 
Helmstetter, Rudolf: „Schillers Tode und Unsterblichkeiten“, in: ders./Holt Meyer/ Daniel Müller Nielaba (Hg.): Schiller: Gedenken - Vergessen - Lesen. München 2010, S. $87-122$

Hillebrand, Bruno: Ästhetik des Augenblicks: Der Dichter als Überwinder der Zeit - von Goethe bis heute. Göttingen 1999

Hiller, Stefan: „Frühe schriftartige Erscheinungen auf dem Balkan“, in: Wilfried Seipel (Hg.): Der Turmbau zu Babel, Ursprung und Vielfalt von Sprache und Schrift. Eine Ausstellung des Kunsthistorischen Museums Wien für die Europäische Kulturhauptstadt Graz 2003. Band IIIA: Schrift. Graz 2003, S. 31-37

Hilliard, K. F.: „Nänie‘: Critical Reflections on the Sentimental in Poetry“, in: Yearbook of the English Goethe Society 75, part 1, 2006, S. 3-13

Hilgers, Klaudia: Entelechie, Monade und Metamorphose. Formen der Vervollkommnung im Werk Goethes. München 2002

Hinderer, Walter: Der Mensch in der Geschichte. Ein Versuch über Schillers Wallenstein. Mit einer Bibliographie von Helmut G. Hermann. Königstein 1980 (Athenäum Taschenbücher 2155)

Hoch, Walter: „Das Namenstagsfest in Hoffmanns Kater Murr. Fanal einer Festarabeske zwischen barockem Schein und romantischer Entgrenzung“, in: E. T. A. HoffmannJahrbuch 7, 1999, S. 63-83

Honegger, Thomas: „On the Fringes of Interaction: The Dawn-Song as a ,Linguistic Routine' of Parting“, in: Andreas H. Jucker/Gerd Fritz/Franz Lebsanft (Hg.): Historical Dialogue Analysis. Amsterdam 1999 (Pragmatics \& Beyond New Series 66), S. $189-214$

Hörisch, Jochen: Die fröhliche Wissenschaft der Poesie. Der Universalitätsanspruch von Dichtung in der frühromantischen Poetologie. Frankfurt am Main 1976

Hörisch, Jochen: „Selbstbeziehung und ästhetische Autonomie. Versuch über ein Thema der frühromantischen Poetologie und Musils ,Mann ohne Eigenschaften“", in: Euphorion 69, 1975, S. 350-361

Hühn, Helmut/Oschmann, Dirk/Schnyder, Peter (Hg.): Schillers Zeitbegriffe. Hannover 2018 (Ästhetische Eigenzeiten 12)

Inderwildi, Andreas: „Revolutionen ohne Ende“, in: WASD Bookazine für Gameskultur, 11, 2017, S. 92-97

Inderwildi, Andreas: „Zwischen Ritual, Mythos und Geschichte. Zyklen der Erneuerung und des Niedergangs in Dark Souls“, in: Rudolf T. Inderst/Pascal Wagner/Christof Zurschmitten (Hg.): Prepare to Die. Interdisziplinäre Perspektiven auf Demon's Souls, Dark Souls und Bloodborne. Glückstadt [erscheint im November 2019], S. $113-126$

Ishihara, Aeka: „Der Zauberlehrling in der internationalen Flut. Ein kleiner Beitrag zum Weltliteratur-Konzept Goethes“, in: Neue Beiträge zur Germanistik 7, Nr. 1, 2008, S. $167-181$ 
Ito, Shuichi: „Die poetische Reflexion als unendliche Selbstspiegelung. Zur frühromantischen Semontologie“, in: Takahashi, Teruaki (Hg.): Literarische Problematisierung der ,Moderne؛ Deutsche Aufklärung und Romantik in der japanischen Germanistik. Beiträge der Tateshin-Symposien 1990 und 1991. München 1992, S. $185^{-198}$

Jakobson, Roman: Poetik. Ausgewählte Aufsätze 1921-1971. Herausgegeben von Elmar Holenstein und Tarcisius Schelbert. Frankfurt am Main 2016 (suhrkamp taschenbuch wissenschaft 262)

Johnson, Laurie Ruth: „,Wozu überhaupt ein Anfang?‘ Memory and history in ,Heinrich von Ofterdingen“', in: Colloquia Germanica 31, Heft 1, 1998, S. 21-35

Kaiser, Gerhard: „Wallensteins Lager. Schiller als Dichter und Theoretiker der Komödie (1970)“, in: Fritz Heuer und Werner Keller (Hg.): Schillers Wallenstein. Darmstadt 1977 (Wege der Forschung 420), S. 333-363

Kammasch, Tim: „Der Gedankenstrich. ,stille Ekstase““, in: Christine Abbt/ders. (Hg.): Punkt, Punkt, Komma, Strich? Geste, Gestalt und Bedeutung philosophischer Zeichensetzung. Bielefeld 2009, S. 119-138

Kasperowski, Ira: Mittelalterrezeption im Werk des Novalis. Tübingen 1994 (Hermaea. Germanistische Forschungen. Neue Folge 74)

Kiening, Christian und Stercken, Martina: SchriftRäume. Dimensionen von Schrift zwischen Mittelalter und,Moderne . Zürich 2008 (Medienwandel - Medienwechsel - Medienwissen 4)

Kiening, Christian: Fülle und Mangel. Medialität im Mittelalter. Zürich 2016

Klein, Joachim: „Lyrische Fabel und ästhetisches Paradigma. Zu Inhalt und Organisation von C. Brentanos ,Der Spinnerin Nachtlied“', in: Sprachkunst 5, 1974, S. 17-26

Knopf, Alexander: „Begeisterung der Sprache“. Poesie und Poetik in Novalis’ Heinrich von Afterdingen. Frankfurt am Main, Basel 2015

Kirchberger, Lida: „Der Spinnerin Lied': A Fresh Appraisal“, in: Monatshefte 67, Nr. 4, 1975, S. 417-424

Kittler, Friedrich: „,Heinrich von Ofterdingen“ als Nachrichtenfluss“, in: Gerhard Schulz (Hg.): Novalis. Beiträge zu Werk und Persönlichkeit Friedrich von Hardenbergs. Darmstadt 1986 (Wege der Forschung 248), S. 48o-508

Kofman, Sarah: Schreiben wie eine Katze ... Zu E. T. A. Hoffmanns „Lebens-Ansichten des Katers Murr“. Herausgegeben von Peter Engelmann. Graz, Wien 1985 (Edition Passagen 5)

Koschorke, Albrecht: Körperströme und Schriftverkehr. Mediologie des 18. Jahrhunderts. München 1999

Koschorke, Albrecht: „Alphabetisation und Empfindsamkeit“, in: Hans-Jürgen Schings (Hg.): Der ganze Mensch. Anthropologie und Literatur im 18. Jahrhundert. D FGSymposion 1992. Stuttgart 1994, S. 6o5-628 
Kolesch, Doris und Krämer, Sybille: „Stimmen im Konzert der Disziplinen. Zur Einführung“, in: dies. (Hg.): Stimme. Annäherung an ein Phänomen. Frankfurt am Main 2006, S. 7-15

Krämer, Sybille: Sprache, Sprechakt, Kommunikation. Sprachtheoretische Positionen des 20. Jahrhunderts. Frankfurt am Main 2001 (Suhrkamp Taschenbuch Wissenschaft 1521)

Kropf, David Glenn: Authorship as Alchemy. Subversive Writing in Pushkin, Scott, Hoffmann. Stanford 1994

Krüger, Oliver: Virtualität und Unsterblichkeit. Die Visionen des Posthumanismus. Freiburg im Breisgau 2004 (Rombach Wissenschaften, Litterae 123)

Lamport, F. J.: „Faust-Vorspiel und Wallenstein-Prolog oder Wirklichkeit und Ideal der weimarischen ,Theaterunternehmung“', in: Euphorion 83, 1989, S. 323-336

Lange, Barbara: Die Sprache von Schillers Wallenstein. Berlin, New York 1973 (Quellen und Forschungen zur Sprach- und Kulturgeschichte der germanischen Völker. Neue Folge 54)

Laufhütte, Hartmut:Die deutsche Kunstballade. Grundlegung einer Gattungsgeschichte. Heidelberg 1979

Laussmann, Sabine: Das Gespräch der Zeichen. Studien zur Intertextualität im Werk E. T. A. Hoffmanns. München 1992 (Kulturgeschichtliche Forschungen 15)

Lenz, Hans: Universalgeschichte der Zeit. Zweite überarbeitete Auflage. Wiesbaden ${ }^{2} \mathrm{O} 13$

Leppin, Rena: „Johannes Hadlaubs ,Nachtlied““, in: Jahrbuch der Oswald von Wolkenstein Gesellschaft 3, 1984/85, S. 203-231

Leventhal, Robert: „Körper - Tod - Schrift: Zur rhetorischen Umschreibung bei Lessing“, in: Wolfram Mauser und Günter Sasse (Hg.): Streitkultur. Strategien des Überzeugens im Werk Lessings. Tübingen 1993, S. 312-321

Liebrand, Claudia/Hnilica, Irmtraud/Wortmann, Thomas (Hg.): Redigierte Tradition. Literaturhistorische Positionierungen Annette von Droste-Hülshoffs. Paderborn 2010

Liebrand, Claudia: Aporie des Kunstmythos: die Texte E. T. A. Hoffmanns. Freiburg im Breisgau 1996 (Rombach Wissenschaften, Litterae 42)

Linke, Angelika und Müller Nielaba, Daniel: „Linguistik und Literaturwissenschaft: Reziproke Nutzbarkeiten“, in: Zeitschrift für Literaturwissenschaft und Linguistik (LiLi) 172, 2013, S. 38-43

Louth, Charlie: Hölderlin and the Dynamics of Translation. Oxford 1998

Mahler, Andreas: „Narrative Vexiertexte. Paradigmatisches Erzählen als Schreiben ohne Ende“, in: DVjs 85, Nr. 3, 2011, S. 393-410

Mahr, Johannes: Übergang zum Endlichen. Der Weg des Dichters in Novalis' „Heinrich von Ofterdingen“. München 1970 
Martyn, David: „Dekonstruktion“, in: Helmut Brackert/Jörn Stückrath (Hg.): Literaturwissenschaft. Ein Grundkurs. Hamburg 1992 (Rowohlts Enzyklopädie, Bd. 523), S. $664-677$

Mathy, Dietrich: „Nichts ist dem Geist erreichbarer, als das Unendliche‘, Novalis: Paradoxie als Erkenntnis“, in: Carolina Romahn und Gerold Schipper-Hönicke (Hg.): Das Paradoxe. Literatur zwischen Logik und Rhetorik: Festschrift für Ralph-Rainer Wuthenow zum 70. Geburtstag. Würzburg 1999, S. 26-34

Matsuura, Jun: „Duo Cherubim adversis vultibus. Zur Herausbildung und texthermeneutischen Bedeutung des Grundsatzes Scriptura sui ipsius interpres“, in: Volker Leppin (Hg.): Reformatorische Theologie und Autoritäten. Studien zur Genese des Schriftprinzips beim jungen Luther. Tübingen 2015 (Spätmittelalter, Humanismus, Reformation 85), S. 141-174

McGinn, Collin: „Über die Ewigkeit der Zahlen und natürliche Geheimnisse“, in: Otfried Reinke (Hg.): Ewigkeit? Klärungsversuche aus Natur- und Geisteswissenschaften. Göttingen 2004, S. 80-101

Mecklenburg, Norbert: „Balladen der Klassik“, in: Walter Müller-Seidel (Hg.): Balladenforschung. Königstein 1980 (Neue wissenschaftliche Bibliothek 108), S. 187-203

Menke, Bettine: „Rhetorik der Echo. Echo Trope, Figur des Nachlebens“, in: Doerte Bischoff und Martina Wagner-Egelhaaf (Hg.): Weibliche Rede - Rhetorik der Weiblichkeit. Studien zum Verhältnis von Rhetorik und Geschlechterdifferenz. Freiburg im Breisgau 2003 (Rombach Wissenschaften, Litterae 93), S. 135-159

Menke, Bettine: Prosopopoiia. Stimme und Text bei Brentano, Hoffmann, Kleist und Kafka. München 2000

Menninghaus, Winfried: Unendliche Verdopplung. Die frühromantische Grundlegung der Kunsttheorie im Begriff absoluter Selbstreflexion. Frankfurt am Main 1987

Mertens Fleury, Katharina: „Dîns sanges wort, diu hânt den tag ze fruo uns kunt getân. Zum Verhältnis von Zeit und Begehren im Tagelied“, in: Zeitschrift für deutsches Altertum und deutsche Literatur 147, Heft 2, 2018, S. 181-197

Metz-Becker, Martina: „Es sang vor langen Jahren“, in: Sabine Gruber und Hartwig Schultz (Hg.): Lieb und Leid im leichten Leben: Clemens Brentano: 30 Gedichte 30 Interpretationen. Berlin 2006, S. 47-49

Meyer, Kathiana: Performativität und Metatheatralität in Schillers,Wallenstein'(Arbeitstitel), noch unveröffentlichte Dissertation an der Universität Zürich, Hauptbetreuerin: Prof. Dr. Sabine Schneider

Michel, Sascha: Ordnungen der Kontingenz. Figurationen der Unterbrechung in Erzähldiskursen um 1800 (Wieland - Jean Paul - Brentano). Tübingen 2006 (Hermaea. Neue Folge 112)

Mitropoulou, Eleni: „Defining a communication system for the long term“, in: Radioactive Waste Management and Constructing Memory for Future Generations. Pro- 
ceedings of the International Conference and Debate 15-17 September 2014, Verdun, France. NEA No. 7259. OECD 2015, S. 93-96

Mohr, Wolfgang: „Spiegelungen des Tagelieds“, in: Ursula Hennig und Herbert Koll (Hg.): Festschrift für Helmut De Boor zum 8o. Geburtstag. München 1971

Mostert, Walter: „Scriptura sacra sui ipsius interpres. Bemerkungen zu Luthers Verständnis der Heiligen Schrift“ (1979), in: Pierre Bühler und Gerhard Ebeling (Hg.): Walter Mostert. Glaube und Hermeneutik. Gesammelte Aufsätze, Tübingen 1998, S. 9-41

Mönch, Cornelia: Abschrecken oder Mitleiden. Das deutsche bürgerliche Trauerspiel im 18. Jahrhundert. Versuch einer Typologie. Tübingen 1993 (Studia Augustana 5)

Müller Nielaba, Daniel: „Was heißt Rhetorik der Übertragung?“, in: ders./Yves Schumacher/Christoph Steier (Hg.): Rhetorik der Übertragung. Würzburg 2013, S. $11-18$

Müller Nielaba, Daniel/Schumacher, Yves/Steier Christoph: „Figur/a/tion. Möglichkeiten einer Figurologie im Zeichen E. T. A. Hoffmanns“, in: dies. (Hg.): Figur Figura-Figuration: E. T. A. Hoffmann. Würzburg 2011, S. 7-14

Müller Nielaba, Daniel: „Naenie oder: „Auch' Schiller muss sterben!“, in: Rudolf Helmstetter/Holt Meyer/ders. (Hg.): Schiller: Gedenken - Vergessen - Lesen. München 2010, S. $75^{-86}$

Müller Nielaba, Daniel: „Das doppelte Anführungszeichen. ,Gänsefüsschen‘ oder „Hasenöhrchen'?“, in: Christine Abbt und Tim Kammasch (Hg.): Punkt, Punkt, Komma, Strich? Geste, Gestalt und Bedeutung philosophischer Zeichensetzung. Bielefeld 2009, S. 141-149

Müller Nielaba, Daniel: „Vom Bedeuten des Literarischen: Verstehen, verschoben. Einige Grundsatzüberlegungen und zwei Exkurse zu Schiller und zu Eichendorff“, in: Juerg Albrecht/Jörg Huber/Kornelia Imesch et al. (Hg.): Kultur Nicht Verstehen. Produktives Nichtverstehen und Verstehen als Gestaltung. Zürich, Wien, New York 2005 (Theorie: Gestaltung 4), S. 37-52

Müller Nielaba, Daniel: „Schlafes Bruder zu Wort gekommen: Wie Lessing enden lässt“, in: DVjs 73, 1999, S. 266-288

Müller-Seidel, Walter: „Die Idee des neuen Lebens: Eine Betrachtung über Schillers ,Wallenstein“" (1971), in: Fritz Heuer/Werner Keller (Hg.): Schillers Wallenstein. Darmstadt 1977 (Wege der Forschung 420), S. 364-385

Nate, Richard: „Keine bleibende Stadt? Säkulare Heilsvorstellungen in der englischen Literaturgeschichte“, in: Christoph Böttigheimer/René Dausner (Hg.): Unendlichkeit. Transdisziplinäre Annäherungen. Würzburg 2018 (Konzeptionen des Unendlichen - eine europäische Kulturkonstante? 1), S. 257-273

Nehrlich, Thomas: „Es hat mehr Sinn und Deutung, als du glaubst.“ Zu Funktion und Bedeutung typographischer Textmerkmale in Kleists Prosa. Hildesheim, Zürich, New York 2012 (Germanistische Texte und Studien 88) 
Neidhart, Ludwig: „Mathematische Ergebnisse über Unendlichkeit und ihre Bezüge zu Metaphysik und Theologie“, in: Johannes Brachtendorf/Thomas Möllenbeck/ Gregor Nickel et al. (Hg.): Unendlichkeit. Interdisziplinäre Perspektiven. Tübingen 2008 (Religion und Aufklärung 15), S. 217-232

Neumann, Gerhard: „Schreiben und Edieren“, in: Heinrich Bosse/Ursula Renner (Hg.): Literaturwissenschaft. Einführung in ein Sprachspiel. Zweite Auflage. Freiburg im Breisgau 22010 (Rombach Grundkurs 3), S. 339-364

Neumann, Gerhard: „Der verschleppte Process. Literarisches Schreiben zwischen Schreibstrom und Werkidol“, in: Poetica 14, 1982, S. 92-112

Neumann, Michael: „Unendlich radikal. Zur Ästhetik der „Moderne“, in: Christoph Böttigheimer/René Dausner (Hg.): Unendlichkeit. Transdisziplinäre Annäherungen. Würzburg 2018 (Konzeptionen des Unendlichen - eine europäische Kulturkonstante? 1), S. 211-237

Nilges, Yvonne: „Unendliche Werkheiligkeit? Kunstreligion in Thomas Manns frühen Erzählungen und Fiorenza“, in: Christoph Böttigheimer/René Dausner (Hg.): Unendlichkeit. Transdisziplinäre Annäherungen. Würzburg 2018 (Konzeptionen des Unendlichen - eine europäische Kulturkonstante? 1), S. 239-255

Obermaier, Sabine: Von Nachtigallen und Handwerkern. ,Dichtung über Dichtung' in Minnesang und Sangspruchdichtung. Tübingen 1995 (Hermaea 75)

Oei, Bernd: Hölderlin. Das Eine ist Alles. Baden-Baden 2009

Ostermann, Eberhard: „Der Begriff des Fragments als Leitmetapher in der ästhetischen ,Moderne “', in: Athenäum, Jahrbuch für Romantik 1, 1991, S. 189-205

Peirce, Charles Sanders: Philosophical Writings of Peirce. Selected and Edited, With an Introduction by Justus Buchler. New York 1955

Pfefferkorn, Kristin: Novalis: A Romantic's Theory of Language and Poetry. New Haven, London 1988

Pfotenhauer, Helmut:Jean Paul. Das Leben als Schreiben. Biographie. München 2013

Pichtownikowa, Lidija: Synergie des Fabelstils: Die deutsche Versfabel vom 13.-21. Jahrhundert. Aachen 2008 (Ukrainische Beiträge zur Germanistik 5)

Pikulik, Lothar: „Lessing als Vorläufer des frühromantischen Fragmentarismus“, in: Wolfram Mauser und Günter Sasse (Hg.): Streitkultur. Strategien des Überzeugens im Werk Lessings. Tübingen 1993, S. 428-435

Pott [inzw. Richter], Sandra: Poetiken. Poetologische Lyrik, Poetik und Ästhetik von Novalis bis Rilke. Berlin, New York 2004

Posner, Roland (Hg.): Warnung an die ferne Zukunft: Atommüll als Kommunikationsproblem. München 199o (Raben Streifzüge)

Polaschegg, Andrea: „Ausdruckskunst! Satzzeichen als Indizien des Affekts in Ode und Briefroman des 18. Jahrhunderts“, in: Alexander Nebrig/Carlos Spoerhase (Hg.): Die Poesie der Zeichensetzung. Studien zur Stilistik der Interpunktion. Bern 2012 (Publikationen zur Zeitschrift für Germanistik. Neue Folge 25), S. 157-182 
Reinke, Otfried: Ewigkeit? Klärungsversuche aus Natur- und Geisteswissenschaften. Göttingen 2004

Reinhard, Wolfgang: „Einleitung“, in: Meinrad Böhl/Wolfgang Reinhard/Peter Walter (Hg.): Hermeneutik. Die Geschichte der abendländischen Textauslegung von der Antike bis zur Gegenwart. Dichtung, Bibel, Recht, Geschichte, Philosophie. Wien, Köln, Weimar 2013, S. 11-23

Retsch, Annette: Paratext und Textanfang. Würzburg 2000 (Würzburger Beiträge zur Deutschen Philologie 18)

Ringleben, Joachim: Gott im Wort. Luthers Theologie von der Sprache her. Tübingen 2010 (Hermeneutische Untersuchungen zur Theologie 57)

Rommel, Gabriele: „Magie der Zeichen - Novalis' Idee einer ,Zeichenflächenform(figuren)bedeutungskunst' im Kontext der Freiberger naturwissenschaftlichen Studien“, in: Forschungsstätte für Frühromantik und Novalis-Museum Schloss Oberwiederstedt (Hg.): Novalis. Geheimnisvolle Zeichen. Alchemie, Magie, Mystik und Natur bei Novalis. Berlin 1998, S. 7-16

Rothmann, Kurt: „Anmerkungen“, in: Friedrich Schiller: Wallenstein. Ein dramatisches Gedicht. - Wallensteins Lager. Die Piccolomini. Stuttgart 2009 (RUB 41), S. 140-176

Rothmann, Kurt: „Anmerkungen [2]“, in: Friedrich Schiller: Wallenstein. Ein dramatisches Gedicht. - Wallensteins Tod. Stuttgart 2007 (RUB 42), S. 142-16o

Rothhaar, Markus: „Die Antinomie der Unendlichkeit bei Kant und Hegel“, in: Christoph Böttigheimer und René Dausner (Hg.): Unendlichkeit. Transdisziplinäre Annäherungen. Würzburg 2018 (Konzeptionen des Unendlichen - eine europäische Kulturkonstante? Bd. 1), S. 153-168

Sappler, Paul: Das Königsteiner Liederbuch: Ms. germ. qu. 719 Berlin. München 1970 (Münchener Texte und Untersuchungen zur deutschen Literatur des Mittelalters 29)

Schäfer, Bettina: Ohne Anfang - ohne Ende: arabeske Darstellungsformen in E. T. A. Hoffmanns „Lebens-Ansichten des Katers Murr“. Bielefeld 2001

Schiewer, Gesine Lenore: Cognitio Symbolica: Lamberts Semiotische Wissenschaft und ihre Diskussion bei Herder, Jean Paul und Novalis. Tübingen 1996 (Frühe Neuzeit 22)

Scheffel, Michael: Formen selbstreflexiven Erzählens. Eine Typologie und sechs exemplarische Analysen. Tübingen 1997 (Studien zur deutschen Literatur 145)

Schmaus, Marion: Die poetische Konstruktion des Selbst. Grenzgänge zwischen Frühromantik und ,Moderne': Novalis, Bachmann, Christa Wolf, Foucault. Tübingen 2000

Schmidt, Jochen: Die Geschichte des Geniegedankens in der deutschen Literatur, Philosophie und Politik 1750-1945. Bd. 1: Von der Aufklärung bis zum Idealismus. Bd. 2: Von der Romantik bis zum Ende des Dritten Reichs. Dritte, verbesserte Auflage. Universitätsverlag Winter Heidelberg ${ }^{3} 2004$ (Beiträge zur Neueren Literaturgeschichte 210) 
Schneider, Sabine: „Kunstautonomie als Semiotik des Todes? Digressionen im klassizistischen Diskurs der schönen Menschengestalt bei Karl Philipp Moritz“, in: German Life and Letters 52, Nr. 2, 1999, Special number: The body in German literature around 180o, ed. by Nicholas Saul, S. 166-183

Schneider, Sabine: Die schwierige Sprache des Schönen. Moritz' und Schillers Semiotik der Sinnlichkeit. Würzburg 1998 (Epistemata Reihe Literaturwissenschaft 231)

Schnyder, André: Das geistliche Tagelied des späten Mittelalters und der frühen Neuzeit. Textsammlung, Kommentar und Umrisse einer Gattungsgeschichte. Tübingen 2004 (Bibliotheca Germanica 45)

Schramm, Gabriele: Widmung, Leser und Drama. Untersuchungen zu Form- und Funktionswandel der Buchwidmung im 17. und 18. Jahrhundert. Hamburg 2003 (Studien zur Germanistik 2)

Schreiber, Jens: Das Symptom des Schreibens: Roman und absolutes Buch in der Frühromantik (Novalis/Schlegel). Frankfurt am Main, Bern, New York 1983 (Europäische Hochschulschriften. Reihe I. Deutsche Sprache und Literatur. Bd. 649)

Schrimpf, Hans Joachim: „Nachtrag zu Brentanos ,Der Spinnerin Lied‘. Text und Kontext“, in: Alexander von Bormann (Hg.): Wissen aus Erfahrungen. Werkbegriff und Interpretation heute. Festschrift für Hermann Meyer zum 65. Geburtstag. Tübingen 1976

Schulz, Georg-Michael: Tugend, Gewalt und Tod. Das Trauerspiel der Aufklärung und die Dramaturgie des Pathetischen und des Erhabenen. Tübingen 1988 (Theatron 1)

Seidler, Andreas: „Die Paradoxien des Genies. Varianten ihrer Entfaltung in E. T. A. Hoffmanns Lebens-Ansichten des Katers Murr“, in: E. T. A. Hoffmann-Jahrbuch 13, 2005, S. $59-77$

Seipel, Wilfried (Hg.): Der Turmbau zu Babel, Ursprung und Vielfalt von Sprache und Schrift. Eine Ausstellung des Kunsthistorischen Museums Wien für die Europäische Kulturhauptstadt Graz 2003. Schloss Eggenberg, Graz, 5. April bis 5. Oktober 2003. Band IIIA: Schrift

Singer, Herbert: „Hoffmann. ,Kater Murr“, in: Benno von Wiese (Hg.): Der deutsche Roman vom Barock bis zur Gegenwart. Bd. 1. Düsseldorf 1963, S. 301-328

Stašková, Alice: „Metalepse als translatio bei E. T. A. Hoffmann“, in: Daniel Müller Nielaba/Yves Schumacher/ Christoph Steier (Hg.): Figur - Figura - Figuration: E. T. A. Hoffmann. Würzburg 2011, S. 73-88

Steier, Christoph: Hunger/Schrift. Poetologien des Hungerns von der Goethezeit bis zur Gegenwart. Würzburg 2014

Steinecke, Hartmut: „Kommentar“ [zu den Lebens-Ansichten des Katers Murr], in: E. T. A. Hoffmann: Lebens-Ansichten des Katers Murr. Werke 1820-1821. Herausgegeben von Hartmut Steinecke unter Mitarbeit von Gerhard Allroggen. Frankfurt am Main 1992, S. 887-1051 (Bibliothek Deutscher Klassiker 75) 
Steinecke, Hartmut: Die Kunst der Fantasie. E. T. A. Hoffmanns Leben und Werk. Frankfurt am Main, Leipzig 2004

Steinby, Liisa und Schmidt, Michael (Hg.): Augenblick, Lebenszeit, Geschichte, Ewigkeit. Die Zeit in Goethes Werken. Heidelberg 2017 (Beiträge zur neueren Literaturgeschichte 366 )

Stierle, Karlheinz: „Eine Renaissance der Hermeneutik? Für eine Öffnung des hermeneutischen Zirkels“, in: Poetica 17, 1985, S. 340-354

Strack, Friedrich: „Fermenta cognitionis: Zur romantischen Fragmentkonzeption von Friedrich Schlegel und Novalis“, in: Volker Kapp/Helmuth Kiesel/Klaus Lubbers et al., (Hg.): Subversive Romantik. Berlin 2004, S. 345-364

Svenbro, Jesper: Phrasikleia. Anthropologie des Lesens im alten Griechenland. Stuttgart 2005

Swales, Martin: „Die Reproduktionskraft der Eidexen‘. Überlegungen zum selbstreflexiven Charakter der Lebens-Ansichten des Katers Murr“, in: E. T.-A. HoffmannJahrbuch 1, 1992-1993, S. 48-57

Szondi, Peter: Einführung in die literarische Hermeneutik. Studienausgabe der Vorlesungen. Band 5. Einführung in die literarische Hermeneutik. Herausgegeben von Jean Bollack und Helen Stierlin. Frankfurt am Main 1975 (suhrkamp taschenbuch wissenschaft 124)

Theisohn, Philipp: Die kommende Dichtung. Geschichte des literarischen Orakels 14502050. München 2012

Theunissen, Michael: Negative Theologie der Zeit. Frankfurt am Main 1991 (Suhrkamp Taschenbuch Wissenschaft 938)

Todtenhaupt, Martin: „Zur Siebenzahl als Strukturmerkmal in Goethes Zauberlehrling“, in: Studia Neophilologica: A Journal of Germanic and Romance Languages and Literature 71, Nr. 2, 1999, S. 189-195

Trabant, Jürgen: „Wallenstein und die Sprachen des Neuen Kontinents“, in: Hans Feger/Hans Richard Brittnacher (Hg.): Die Realität der Idealisten. Friedrich Schiller, Wilhelm von Humboldt, Alexandervon Humboldt. Köln, Weimar, Wien 2008, S. 53-67

Trauth, M. Kathleen/Hora, Stephen C./Guzowski, Robert V. (Hg.): Sandia Report. Expert Judgment on Markers to Deter Inadvertent Human Intrusion into the Waste Isolation Pilot Plant. SAND92-1382, UC-721, 1993

Uerlings, Herbert: Friedrich von Hardenberg, genannt Novalis. Werk und Forschung. Stuttgart 1991

Uerlings, Herbert: „Einbildungskraft und Poesie bei Novalis“, in: ders. (Hg.): Novalis. Poesie und Poetik. Tübingen 2004, S. 21-62

Unger, Daniel: Schlechte Unendlichkeit. Zu einer Schlüsselfigur und ihrer Kritik in der Philosophie des Deutschen Idealismus. Freiburg, München 2015 (Beiträge zur Schelling-Forschung 6) 
Van Hove, Erik: „Comments on the Constructing Memory Conference“, in: Radioactive Waste Management and Constructing Memory for Future Generations. Proceedings of the International Conference and Debate 15-17 September 2014, Verdun, France. NEA No. 7259. OECD 2015, S. 105-106

Wagner, Martin: Zeit, Geschichte und Ästhetik im Wallenstein-Prolog, in: Orbis Litterarum 67, Heft 5, 2012, S. 366-386

Wanning Harries, Elizabeth: The Unfinished Manner. Essays on the Fragment in the Later Eighteenth Century. Charlottesville, London 1994

Weigel, Sigrid: Die Stimme als Medium des Nachlebens: Pathosformel, Nachhall, Phantom, kulturwissenschaftliche Perspektiven, in: Doris Kolesch/Sybille Krämer (Hg.): Stimme. Annäherung an ein Phänomen. Frankfurt am Main 20o6, S. 16-39

Weiß, Johannes: Das frühromantische Fragment. Eine Entstehungs- und Wirkungsgeschichte. Paderborn 2015 (Laboratorium Aufklärung 27)

Wellbery, David E.: The Specular Moment. Goethe's Early Lyric and the Beginnings of Romanticism. Stanford California 1996

Wellenberger, Georg: Der Unernst des Unendlichen. Die Poetologie der Romantik und ihre Umsetzung durch E. T. A. Hoffmann. Marburg 1986

Wellmon, Chad: „Touching Books: Diderot, Novalis, and the Encyclopedia of the Future“, in: Representations 114, Heft 1, 2011, S. 65-102

Wieland, Magnus: Vexierzüge.Jean Pauls Digressionspoetik. Hannover 2013

Wiethölter, Waltraud: „Stimme und Schrift: Szenen einer Beziehungsgeschichte“, in: dies./Hans-Georg Pott/Alfred Messerli (Hg.): Stimme und Schrift. Zur Geschichte und Systematik sekundärer Oralität. München 2008, S. 9-53

Wirth, Uwe: Die Geburt des Autors aus dem Geist der Herausgeberfiktion. Editoriale Rahmung im Roman um 180o: Wieland, Goethe, Brentano, Jean Paul, E. T. A. Hoffmann. München 2008 (Trajekte)

Wirth, Uwe: „Spuren am Rande. Zwischen genuiner und degenerierter Indexikalität“, in: Heike Gfereis und Marcel Lepper (Hg.): Deixis. Vom Denken mit dem Zeigefinger. Göttingen 2007 (Marbacher Schriften. Neue Folge 1), S. 181-195

Wirth, Uwe: „Hypertextualität als Gegenstand einer ,intermedialen Literaturwissenschaft“", in: Walter Erhart (Hg.): Grenzen der Germanistik. Rephilologisierung oder Erweiterung? Stuttgart, Weimar 2004 (Germanistische Symposien Berichtsbände 26), S. 410-430

Wirth, Uwe: „Zur Einführung“, in: ders. (Hg.): Performanz. Zwischen Sprachphilosophie und Kulturwissenschaften. Frankfurt am Main 2002 (suhrkamp taschenbuch wissenschaft 1575), S. 9-6o

Wirth, Uwe: „Performative Rahmung, parergonale Indexikalität. Verknüpfendes Schreiben zwischen Herausgeberschaft und Hypertextualität“, in: ders. (Hg.): Performanz. Zwischen Sprachphilosophie und Kulturwissenschaften. Frankfurt am Main 2002 (suhrkamp taschenbuch wissenschaft 1575), S. 4O3-433 
Witte, Bernd: „Anmerkungen. Der Zauberlehrling“, in: ders. (Hg.): Johann Wolfgang Goethe. Gedichte. Studienausgabe. Stuttgart 2008 (RUB 18519), S. 716-717

Wolf, Alois: „Literarhistorische Aspekte der mittelalterlichen Tagelieddichtung“, in: Tagelieder des deutschen Mittelalters. Mittelhochdeutsch/Neuhochdeutsch. Ausgewählt, übersetzt und kommentiert von Martina Backes. Einleitung von Alois Wolf. Stuttgart 2011 (RUB 8831), S. 11-81

Wölfel, Kurt: Jean Paul-Studien. Frankfurt am Main 1989 (suhrkamp taschenbuch wissenschaft 742)

Wortmann, Thomas: Literatur als Prozess. Drostes „Geistliches Jahr“ als Schreibzyklus. Konstanz 2014 